University of Rhode Island

DigitalCommons@URI

Open Access Dissertations

2017

\title{
Tools to Fight the Terrorist Threat
}

Matthew Michael Porter

University of Rhode Island, matt_3xp_75@hotmail.com

Follow this and additional works at: https://digitalcommons.uri.edu/oa_diss

\section{Recommended Citation}

Porter, Matthew Michael, "Tools to Fight the Terrorist Threat" (2017). Open Access Dissertations. Paper 563.

https://digitalcommons.uri.edu/oa_diss/563

This Dissertation is brought to you for free and open access by DigitalCommons@URI. It has been accepted for inclusion in Open Access Dissertations by an authorized administrator of DigitalCommons@URI. For more information, please contact digitalcommons-group@uri.edu. 
TOOLS TO FIGHT THE TERRORIST THREAT

BY

MATTHEW MICHAEL PORTER

A DISSERTATION SUBMITTED IN PARTIAL FULFILLMENT OF THE

REQUIREMENTS FOR THE DEGREE OF

DOCTOR OF PHILOSOPHY

IN

CHEMISTRY

UNIVERSITY OF RHODE ISLAND 
DOCTOR OF PHILOSOPHY DISSERTATION

OF

MATTHEW MICHAEL PORTER

\section{APPROVED:}

Dissertation Committee:

Major Professor Jimmie C. Oxley

Co-Major Professor James L. Smith

Brenton DeBoef

Otto Gregory

Nasser H. Zawia

DEAN OF THE GRADUATE SCHOOL 


\begin{abstract}
Chemical, biological, radiological, nuclear, and explosives (CBRNE) terrorist threats put law enforcement and soldiers at risk both at home and abroad. Law enforcement and soldiers must be provided with tools and knowledge to stay ahead of the capabilities of terrorists. Hexamethylene Triperoxide Diamine (HMTD) is a homemade explosive easily synthesized from hexamine, citric acid, and hydrogen peroxide. Although HMTD is very sensitive and prone to stability problems, it has a history of terrorists use, such as in the London bombing of 2005. Because law enforcement personnel must handle this material with no guarantee of purity nor indication of additives, for the sake of safety, knowledge of the stability and reactivity of HMTD was expanded in order to make handling safer. Differential scanning calorimetry was utilized to screen the compatibility of HMTD with various additives. It was found that water and weak acids, such as citric acid, destabilize HMTD. Gas chromatography / mass spectrometry (GC/MS) was employed to characterize both headspace gases (e.g. trimethylamine and dimethylformamide) and condensed phase decomposition products. Monitoring the decomposition of HMTD at room temperature and with gentle heating $\left(60{ }^{\circ} \mathrm{C}\right)$ under various levels of humidity proved that humidity plays a major role in the kinetics of HMTD decomposition. Liquid chromatography / mass spectrometry was helpful for identification of condensed phase decomposition products and monitoring isotopic labeling studies. Through a labeling study with equimolar ${ }^{15} \mathrm{~N}$ and ${ }^{14} \mathrm{~N}$ hexamine during the synthesis of HMTD, it was found that hexamine dissociates before the formation of HMTD.
\end{abstract}


There is currently a need for specialized pyrotechnic materials to combat the threat of biological weapons. Materials have been characterized and will be chosen based on their potential to produce heat and iodine to kill spore-forming bacteria (e.g. anthrax). One formulation, already proven to kill anthrax simulants, is diiodine pentoxide with aluminum; however, it suffers from poor stability and storage problems. The heat and iodine output from this mixture and candidate replacement mixtures were measured with bomb calorimetry and extraction and analysis of iodine by UV-Vis spectroscopy. Of the mixtures analyzed, calcium iodate and aluminum was found to be the highest producer of iodine gas. The heat output of this mixture and others can be increased by adding more fuel, with the cost of some iodine produced. Products of combustion were analyzed by thermal analysis, XPS, XRD, and LC/MS. Evidence was collected supporting the formation of metal iodides and metal oxides. One key reaction explaining the loss of iodine with increase in aluminum content is the reaction between aluminum and iodine, which forms aluminum triiodide.

As seen in multiple cases, including the Boston Marathon bombing, improvised explosives may be as simple as a fuel/oxidizer (FOX) mixture initiated by a hot wire. The knowledge of which materials or compositions are explosive is incomplete, and tests for explosivity are currently conducted at specific scales. For example, ammonium nitrate is classified as an oxidizer because it does not explode at the pound scale, but can become explosive at a larger scale or with a fuel added. Herein, a bomb calorimeter with a pressure transducer has been studied for its use as a small scale metric $(2 \mathrm{~g})$ for predicting whether fuel/oxidizer mixtures will be explosive at larger scales. These results have been compared with calculated and measured detonation velocities, and 
measured air blast pressures. A positive correlation was observed between heat of burning and detonation velocity, and between heat of burning and air blast TNT equivalence. 


\section{ACKNOWLEDGMENTS}

Thank you Dr. Jimmie Oxley and Dr. Jim Smith for all of the incredible opportunities you have provided which have furthered my education and experience as a scientist. Thank you for welcoming me into such a unique research group, and helping me on path in pursuing my passion for pyrotechnics and explosives. Thank you to my high school and college chemistry teachers David See and Jack Hayes for seeing my potential and encouraging me to be a scientist, when I had no idea what that meant. A big thank you to all of my lab mates. I accredit much of my success to having good help. I've learned that being a successful scientist means surrounding yourself with those you trust to help you reach your goals, while at the same time trying to help those around you reach their goals. Thank you to my wife, Ashley, son, Ethan, and daughter, Josephine. I love all of you so much. You give me the greatest motivation to work and provide as a husband and father. Thank you Mom and Dad for encouraging me to pursue a career that brings me joy. Most importantly, I would not be who I am without God, and His help. For man is born for trouble, as sparks fly upward. But as for me, I would seek God, and I would place my cause before God; Who does great and unsearchable things, wonders without number (Job 5:7-9). The fear of the Lord leads to life so that one may sleep satisfied, untouched by evil (Proverbs 19:23). In this you greatly rejoice, even though now for a little while, if necessary, you have been distressed by various trials so that the proof of your faith, being more precious than gold which is perishable, even though tested by fire, may be found to result in praise and glory and honor at the revelation of Jesus Christ (1 Peter 1:6-7). 


\section{PREFACE}

This dissertation has been prepared in manuscript format in accordance with the guidelines of the Graduate School of the University of Rhode Island. The research contained herein is separated into three manuscripts. The first manuscript, "Synthesis and Degradation of Hexamethylene Triperoxide Diamine (HMTD), " has been published in the journal Propellants, Explosives, Pyrotechnics. The second manuscript, "Potential Biocides: Iodine-Producing Pyrotechnics," has been submitted for publication in the

journal Propellants, Explosives, Pyrotechnics. The third manuscript, "Correlation of Explosive Properties of Fuel/Oxidizer Mixtures," is being prepared for submission to the journal Propellants, Explosives, Pyrotechnics. 


\section{TABLE OF CONTENTS}

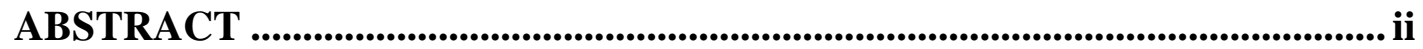

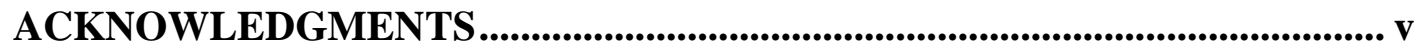

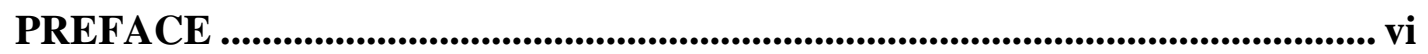

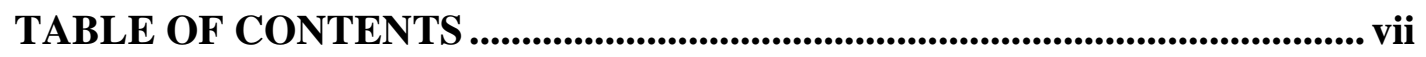

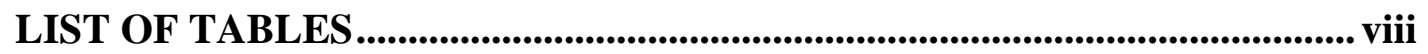

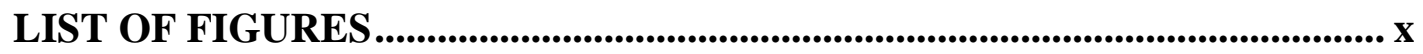

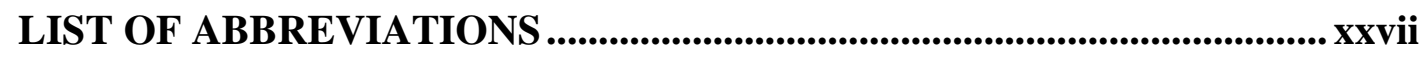

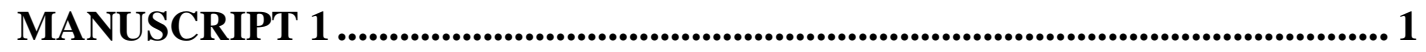

SYNTHESIS AND DEGREDATION OF HEXAMETHYLENE

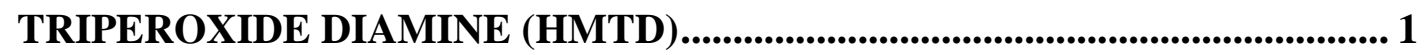

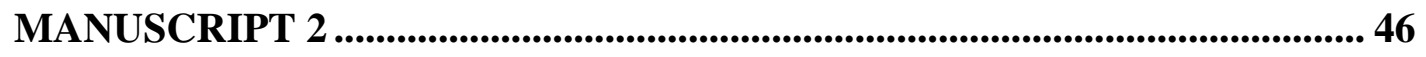

POTENTIAL BIOCIDES: IODINE-PRODUCING PYROTECHNICS ......... 46

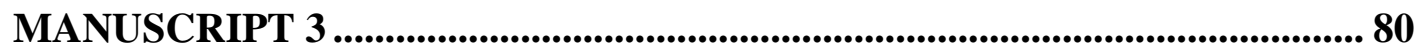

CORRELATION OF EXPLOSIVE PROPERTIES OF

FUEL/OXIDIZER MIXTURES.......................................................................... 80

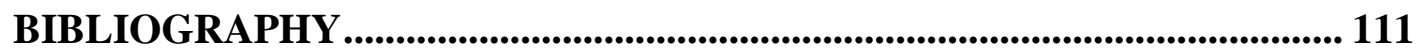

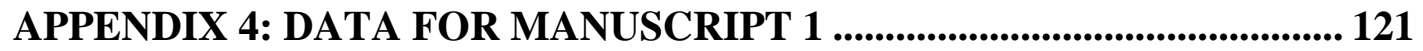

APPENDIX 5: DATA FOR MANUSCRIPT 2 ................................................... 137

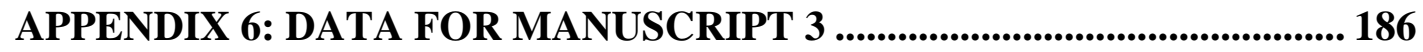




\section{LIST OF TABLES}

Table 1.1. Effect of Solid Additives on HMTD Stability. ....................................... 15

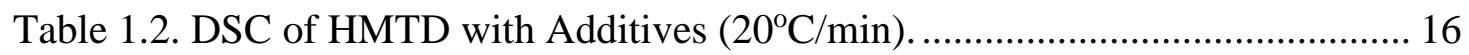

Table 1.3. Decomposition products GC/MS................................................... 21

Table 1.4. Decomposition products LC/MS. ...................................................... 22

Table 1.5. HMTD Reactions with additives with Scaled Yield of 0.5g..................... 24

Table 1.6. Intermediates in the decomposition of gas phase HMTD. Calculations used

PBE0PBE1/cc-pVDZ level of theory. Energy values in kcal/mol, entropy values in

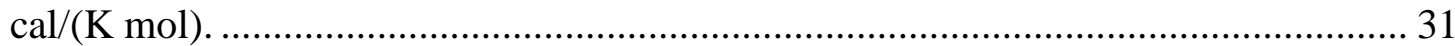

Table 1.7. Intermediates observed along path A during the decomposition of HMTD molecule with a protonated oxygen. The calculations were performed using PBE0PBE1/cc-pVDZ level of theory. Energy values in kcal/mol, entropy values in

$\mathrm{cal} /(\mathrm{K} \mathrm{mol})$

Table 1.8. Structure and properties of intermediates along path B during the decomposition of HMTD molecule with protonated oxygen. Calculations used PBE0PBE1/cc-pVDZ level of theory. Energy values in kcal/mol, entropy values in $\mathrm{cal} /(\mathrm{K} \mathrm{mol})$.

Table 1.9. Intermediates observed in decomposition of gas phase HMTD starting with protonated INT2 (Fig. 8). Calculations used PBE0PBE1/cc-pVDZ. Energy in $\mathrm{kcal} / \mathrm{mol}$, entropy in $\mathrm{cal} / \mathrm{K} \mathrm{mol}$.

Table 1.10. Structure and properties of intermediate species observed during the decomposition of a HMTD-OH- anion calculated using PBE0PBE1/cc-pVDZ level of theory. Energy values in $\mathrm{kcal} / \mathrm{mol}$, entropy values in $\mathrm{cal} /(\mathrm{K} \mathrm{mol})$. 
Table 2.1. Iodine Content of Oxidizers Employed

Table 2.2. Iodate salts with Various Fuels $2 \mathrm{~g}$ in Bomb Calorimeter (515 kPa

Argon)-Heat \& $\mathrm{I}_{2}$ Evolution

Table 2.3. Select Parr Calorimetry Results: Effect of Oxidizer/ Fuel Ratio on Iodine and Heat Production

Table 2.4. XPS on Combustion Products- 2 g Iodates with Al in Bomb Calorimeter

(Argon)

Table 2.5. XPS Elemental Analysis of Combustion products of Iodate Salts with

Aluminum and Standards

Table 2.6. SDT Scans of Various Iodates and Fuels $\left(20^{\circ} \mathrm{C} / \mathrm{min}, 3-5 \mathrm{mg}\right.$ in $\mathrm{N}_{2}$ unless otherwise stated) 67

Table 2.7. SDT Solid Bomb Combustion Products $\left(20^{\circ} \mathrm{C} / \mathrm{min}, 3-5 \mathrm{mg}\right.$ in $\mathrm{N}_{2}$ unless

otherwise stated) 68

Table 2.8. Sensitivity Testing...... 73

Table 2.9. Reactions of Iodine-Containing Salts with $20 \% \mathrm{Al}$ in Argon

(observed dominant products are highlighted) 75

Table 2.10. Thermodynamic Calculations of Oxygen Exchange 76

Table 3.1. Bomb Calorimetry Outputs from Fuel:Oxidizer Mixtures Burned 2g 2859

$\mathrm{kPa}$ argon 95

Table 3.2. Parr Bomb Calorimetry Output for Thermites vs. Gun Propellants 96

Table 3.3. Detonation Testing Summary 100

Table 3.4. Detonation Testing Summary with Analysis 102

Table 5.1. XPS extended table with FWMH for each binding energy 184 ix 


\section{LIST OF FIGURES}

Figure 1.1. HMTD headspace chromatography [trimethylamine (TMA), dimethylformamide (DMF), ethylenimine (EN), methyl formamide (MFM),

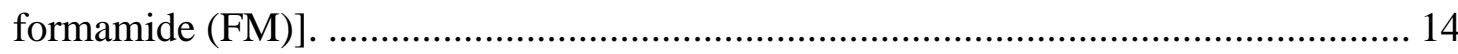

Figure 1.2. Effect of humidity on HMTD. ............................................................ 17

Figure 1.3. Effect of humidity on crude and recrystallized HMTD............................ 18

Figure 1.4. Proposed hexamine decomposition. ………………................................ 23

Figure 1.5. Formation of HMTD from completely dissociated hexamine.................... 25

Figure 1.6. Formation of HMTD from intact hexamine............................................ 27

Figure 1.7. Mass spectrum of HMTD formed from a mixture of N-14 and N-15

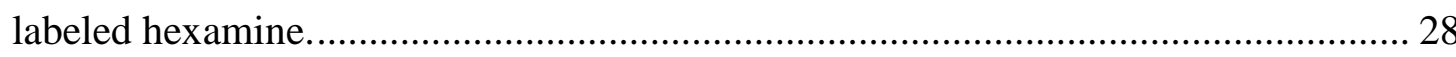

Figure 1.8. Decomposition route of an isolated HMTD molecule. Energy barriers and energies of intermediates for a gas phase molecule are without parenthesis while values of solvated molecule (in water) are in parenthesis............................................ 30

Figure 1.9. The next steps in the decomposition of an isolated HMTD molecule.

Energy barriers and energies of intermediates for a gas phase molecule are without parenthesis while values of solvated molecule (in water) are in parenthesis............... 32

Figure 1.10. Scheme showing all the possible initial decomposition steps of HMTD molecule in different environments. ........................................................................ 34

Figure 1.11. Initial decomposition steps of a nitrogen protonated HMTD molecule. . 39 Figure 2.1. Iodine \& heat release from various iodine species burned (closed-bomb) with aluminum. 
Figure 2.2. Iodine $\&$ heat release from various iodine species burned (closed-bomb) with boron carbide. Diiodine pentoxide did not burn with boron carbide under argon.

Figure 2.3. Freshly made (left) and aged 3 days at ambient pyrotechnic mixtures. .... 55 Figure 2.4. SDT of Dried Methanol Extract of $60 / 40 \mathrm{Ca}\left(\mathrm{IO}_{3}\right)_{2} / \mathrm{Al}$ combustion products (left) and 50/50 $\mathrm{CaI}_{2} / \mathrm{Al}_{2} \mathrm{I}_{6}$ (right). 57

Figure 2.5. XRD of combustion products of $80 / 20 \mathrm{Ca}\left(\mathrm{IO}_{3}\right)_{2} / \mathrm{Al}$ (left) and 60/40

$\mathrm{Ca}\left(\mathrm{IO}_{3}\right)_{2} / \mathrm{Al}$ (right) 69

Figure 2.6. LC/MS of the Methanol Extract of $60 / 40 \mathrm{Ca}\left(\mathrm{IO}_{3}\right)_{2} / \mathrm{Al}$ Combustion products. 70

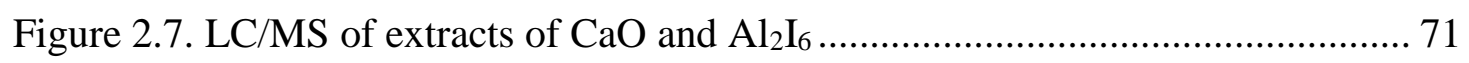

Figure 2.8. LC/MS of the $\mathrm{H}_{2} \mathrm{O}$ Extract of $60 / 40 \mathrm{I}_{2} \mathrm{O}_{5} / \mathrm{Al}$ Combustion products.......... 72

Figure 3.1. Schematic of Protocol for Parr Bomb Calorimetry Tests ........................ 85

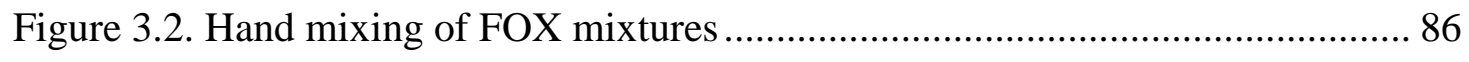

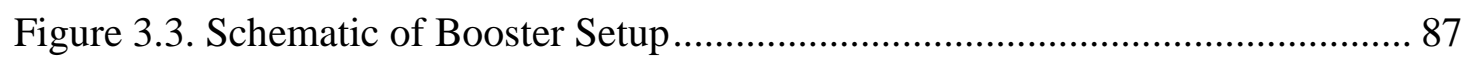

Figure 3.4. Photo Showing Preparation of Booster and Assembled Test Device....... 87

Figure 3.5. Illustration of how detonation front was determined to calculate detonation

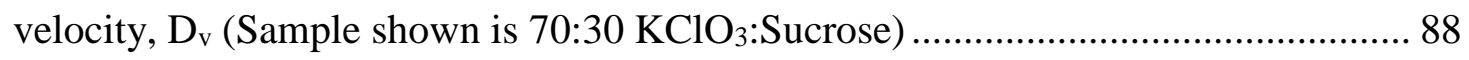

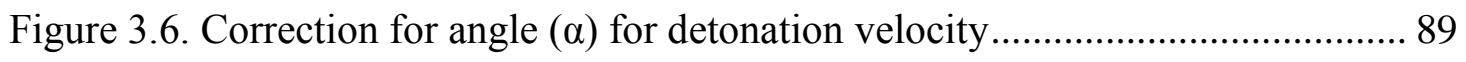

Figure 3.7. Detonation front tracking of rotation corrected Y' points. The slope of the

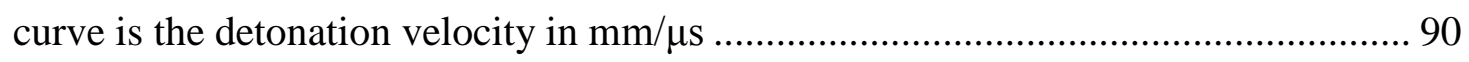

Figure 3.8. Overall Test Arena Setup............................................................. 91 
Figure 3.9. Continuous pressure vs. time: fuel:oxidizer mixtures \& propellants from $2 \mathrm{~g}$ $2859 \mathrm{kPa}$ argon 93

Figure 3.10. Continuous pressure vs time curves of fuel:oxidizer mixtures from $2 \mathrm{~g}$ $2859 \mathrm{kPa}$ argon. In parentheses the result of the large scale test $(\mathrm{D}=$ Detonation; NO $=$ No Detonation). The ammonium nitrate:sugar mixture is so slow that it has its own time axis (above plot) 94 Figure 3.11. One frame from video of each FOX mixture tested. Frame was chosen when reaction was about $75 \%$ along the 24 inch pipe in order to allow the detonation front (samples 5 to 16) to be clearly separated from the booster cloud. (D=Detonation,

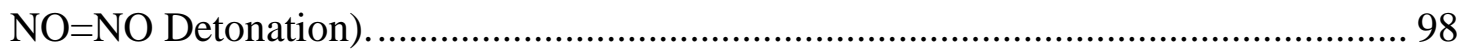

Figure 3.12. Comparison of detonation of $\mathrm{KNO}_{3}$ :Sucrose mix spiked with $\mathrm{KClO}_{3}$ to $\mathrm{KNO}_{3}$ mixes which failed to detonate. ( $\mathrm{KNO}_{3}$ :Al transited to a burn.)

Figure 3.13. Detonation tests showing three steady detonations (left three) and one which failed to propagate (right). 100

Figure 3.14. Heat of Detonation from Parr Bomb Calorimeter vs Calculated by

Cheetah. (Error bars in heat are too small to be seen; Table 1 shows relative standard deviation.) 103

Figure 3.15. Observed Detonation Velocities $(\mathrm{km} / \mathrm{s})$ vs Cheetah Calculation Thereof (X failed to detonate). 104

Figure 3.16. Heat of Reaction measured by calorimetry vs. Detonation Velocity. (Error bars in heat are too small to be seen; Table 1 shows relative standard deviation.)... 105 
Figure 3.17. Air Blast TNT equivalence large scale vs. heat from bomb calorimetry. (Error bars in heat are too small to be seen; Table 1 shows relative standard deviation.)

Figure 3.18. Pressure vs. time curves of fuel:oxidizer mixes from Figures $9 \& 10$.

Ultimate outcome at the 5 to $6 \mathrm{~kg}$ scale is shown by color - red for FOX which detonated; blue for FOX which did not detonate. The ammonium nitrate:sugar mixture is so slow that it has its own time axis (above plot). 108

Figure 4.1. Mass spectrum of HMTD from GC/MS ................................................. 121

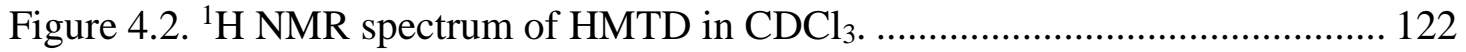

Figure 4.3. IR Spectrum of crude and recrystallized HMTD ................................... 122

Figure 4.4. DSC thermogram of recrystallized HMTD with and without water. ...... 123

Figure 4.5. DSC thermogram of crude HMTD with and without water. 124

Figure 4.6. GC/MS mass spectrum of HMTD extracted during synthesis in the presence of ${ }^{13} \mathrm{C}$ formaldehyde. 125

Figure 4.7. GC/MS mass spectrum of hexamine extracted during HMTD synthesis in the presence of ${ }^{13} \mathrm{C}$ formaldehyde. 126 Figure 4.8. LC/MS mass spectrum of HMTD extracted during synthesis in the presence of ${ }^{13} \mathrm{C}$ formaldehyde. 126 Figure 4.9. LC/MS mass spectrum of hexamine extracted during HMTD synthesis in the presence of ${ }^{13} \mathrm{C}$ formaldehyde.

Figure 4.10. GC/MS mass spectrum of HMTD recovered after synthesis in the presence of ${ }^{15} \mathrm{~N}$ ammonium sulfate. 
Figure 4.11. LC/MS mass spectrum of HMTD recovered after synthesis in the presence of ${ }^{15} \mathrm{~N}$ ammonium sulfate.

Figure 4.12. ${ }^{1} \mathrm{H}$ NMR spectrum of ${ }^{15} \mathrm{~N}$ hexamine in $\mathrm{CDCl}_{3}$.

Figure 4.13. GC/MS Mass Spectrum of $1: 1{ }^{14} \mathrm{~N}:{ }^{15} \mathrm{~N}$ hexamine extracted during synthesis of HMTD.

Figure 4.14. LC/MS Mass Spectrum of $1: 1^{14} \mathrm{~N}:{ }^{15} \mathrm{~N}$ hexamine extracted during synthesis of HMTD.

Figure 4.15. GC/MS mass spectrum of HMTD extracted during synthesis with 1:1

${ }^{14} \mathrm{~N}:{ }^{15} \mathrm{~N}$ hexamine.

Figure 4.16. GC/MS of Hexamine formed after 6 days when HMTD is decomposed in the presence of $15 \mathrm{~N}$ Ammonium Sulfate at $60{ }^{\circ} \mathrm{C}$ and $75 \% \mathrm{RH}$. 133

Figure 4.17. LC/MS of Hexamine formed after 6 days when HMTD is decomposed in the presence of $15 \mathrm{~N}$ Ammonium Sulfate at $60{ }^{\circ} \mathrm{C}$ and $75 \% \mathrm{RH}$. 134

Figure 4.18. ${ }^{1} \mathrm{H}$ NMR of $\mathrm{D}_{2} \mathrm{O}$ in outside vial after 5 days during decomposition of HMTD at $60{ }^{\circ} \mathrm{C} 100 \%$ RD. 135

Figure 4.19. ${ }^{13} \mathrm{C}$ NMR of $\mathrm{D}_{2} \mathrm{O}$ in outside vial after 5 days during decomposition of HMTD at $60{ }^{\circ} \mathrm{C} 100 \% \mathrm{RD}$. 136

Figure 5.1. $\mathrm{I}_{2} \mathrm{O}_{5}$ fresh 137

Figure 5.2. $\mathrm{I}_{2} \mathrm{O}_{5}$ after 3 days $75 \% \mathrm{RH}$ at $60{ }^{\circ} \mathrm{C}$ 137

Figure 5.3. $\mathrm{I}_{2} \mathrm{O}_{5}$ after 14 days $75 \% \mathrm{RH}$ at $60{ }^{\circ} \mathrm{C}$ 138

Figure 5.4. 80/20 $\mathrm{I}_{2} \mathrm{O}_{5} / \mathrm{Al}$ fresh mixture 138

Figure 5.5. 80/20 $\mathrm{I}_{2} \mathrm{O}_{5} / \mathrm{Al}$ after 3 days $75 \% \mathrm{RH}$ at $60{ }^{\circ} \mathrm{C}$ (does not burn) 139

Figure 5.6. 80/20 $\mathrm{I}_{2} \mathrm{O}_{5} / \mathrm{Al}$ after 14 days $75 \% \mathrm{RH}$ at $60{ }^{\circ} \mathrm{C}$ (does not burn) 139 xiv 


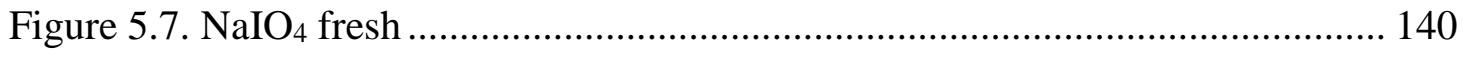

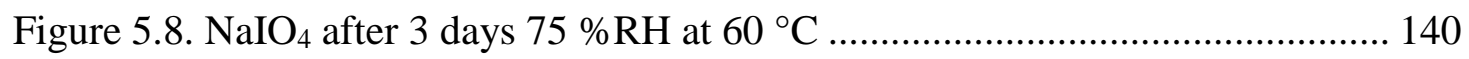

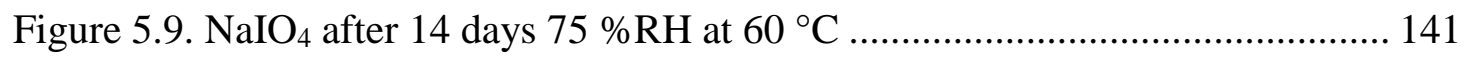

Figure 5.10. 80/10/10 $\mathrm{NaIO}_{4} / \mathrm{B}_{4} \mathrm{C} / \mathrm{Al}$ fresh mixture.............................................. 141

Figure 5.11. 80/10/10 $\mathrm{NaIO}_{4} / \mathrm{B}_{4} \mathrm{C} / \mathrm{Al}$ after 3 days $75 \% \mathrm{RH}$ at $60{ }^{\circ} \mathrm{C} \ldots \ldots \ldots \ldots \ldots \ldots \ldots \ldots . . . .142$

Figure 5.12. 80/10/10 $\mathrm{NaIO}_{4} / \mathrm{B}_{4} \mathrm{C} / \mathrm{Al}$ after 2 weeks $75 \% \mathrm{RH}$ at $60{ }^{\circ} \mathrm{C}$ (burns slower,

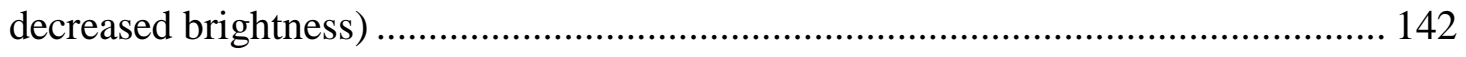

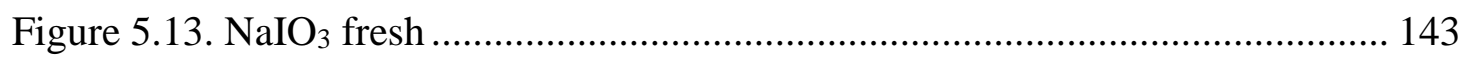

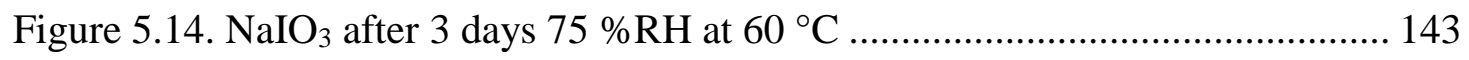

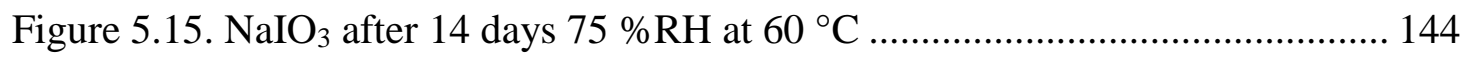

Figure 5.16. 80/10/10 $\mathrm{NaIO}_{3} / \mathrm{B}_{4} \mathrm{C} / \mathrm{Al}$ fresh mixture............................................ 144

Figure 5.17. 80/10/10 $\mathrm{NaIO}_{3} / \mathrm{B}_{4} \mathrm{C} / \mathrm{Al}$ after 3 days $75 \% \mathrm{RH}$ at $60{ }^{\circ} \mathrm{C} \ldots \ldots \ldots \ldots \ldots \ldots \ldots \ldots . . . . . . . . . .145$

Figure 5.18. 80/10/10 $\mathrm{NaIO}_{3} / \mathrm{B}_{4} \mathrm{C} / \mathrm{Al}$ after 2 weeks $75 \% \mathrm{RH}$ at $60{ }^{\circ} \mathrm{C}$ (burns slower,

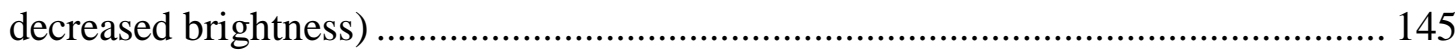

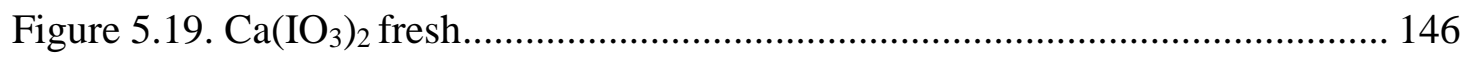

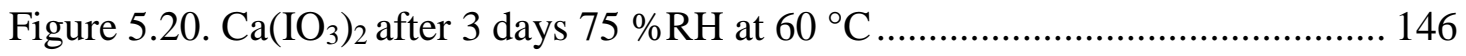

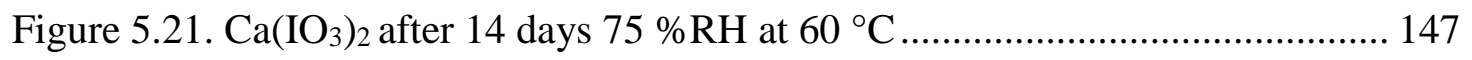

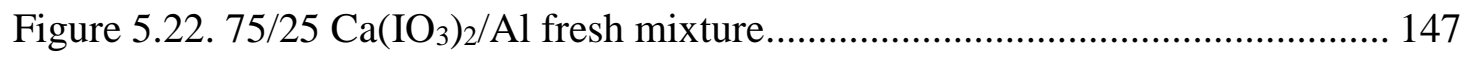

Figure 5.23. 75/25 $\mathrm{Ca}\left(\mathrm{IO}_{3}\right)_{2} / \mathrm{Al}$ after 3 days $75 \% \mathrm{RH}$ at $60{ }^{\circ} \mathrm{C} \ldots \ldots \ldots \ldots \ldots \ldots \ldots \ldots \ldots \ldots . . . . . . . . . . . . . .148$

Figure 5.24. 75/25 $\mathrm{Ca}\left(\mathrm{IO}_{3}\right)_{2} / \mathrm{Al}$ after 14 days $75 \% \mathrm{RH}$ at $60{ }^{\circ} \mathrm{C}$ (burns with a bright

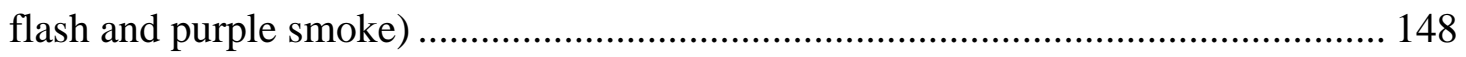

Figure 5.25. $\mathrm{I}_{2} \mathrm{O}_{5}$ fresh (blue) and after 3 days $75 \% \mathrm{RH}$ at $60{ }^{\circ} \mathrm{C}$ (red)................... 149

Figure 5.26. 80/20 $\mathrm{I}_{2} \mathrm{O}_{5} / \mathrm{Al}$ fresh (blue) and after 3 days $75 \% \mathrm{RH}$ at $60{ }^{\circ} \mathrm{C}$ (red) ..... 149 
Figure 5.27. $\mathrm{NaIO}_{4}$ fresh (blue) and after 3 days $75 \% \mathrm{RH}$ at $60{ }^{\circ} \mathrm{C}$ (red) ........ 150

Figure 5.28. 80/10/10 $\mathrm{NaIO}_{4} / \mathrm{B}_{4} \mathrm{C} / \mathrm{Al}$ fresh (blue) and after 3 days $75 \% \mathrm{RH}$ at $60{ }^{\circ} \mathrm{C}$ (red) 150

Figure 5.29. $\mathrm{NaIO}_{3}$ fresh (blue) and after 3 days $75 \% \mathrm{RH}$ at $60{ }^{\circ} \mathrm{C}$ (red) 151

Figure 5.30. 80/10/10 $\mathrm{NaIO}_{3} / \mathrm{B}_{4} \mathrm{C} / \mathrm{Al}$ fresh (blue) and after 3 days $75 \% \mathrm{RH}$ at $60{ }^{\circ} \mathrm{C}$ (red) 151

Figure 5.31. $\mathrm{Ca}\left(\mathrm{IO}_{3}\right)_{2}$ fresh (blue) and after 3 days $75 \% \mathrm{RH}$ at $60{ }^{\circ} \mathrm{C}$ (red) 152

Figure 5.32. 75/25 $\mathrm{Ca}\left(\mathrm{IO}_{3}\right)_{2} / \mathrm{Al}$ fresh (blue) and after 3 days $75 \% \mathrm{RH}$ at $60{ }^{\circ} \mathrm{C}$ (red)

Figure 5.33. 0.5 M KI extraction of $80 / 20 \mathrm{Bi}\left(\mathrm{IO}_{3}\right)_{3} / \mathrm{Al}$ combustion products compared to a $\mathrm{BiI}_{3}$ standard and a standard curve made with $\mathrm{KI}$ and $\mathrm{I}_{2}\left(\mathrm{KI}_{3}\right)$ 153

Figure 5.34. 0.5 M KI extraction of $60 / 40 \mathrm{Bi}\left(\mathrm{IO}_{3}\right)_{3} / \mathrm{Al}$ combustion products compared

to a $\mathrm{BiI}_{3}$ standard and a standard curve made with $\mathrm{KI}$ and $\mathrm{I}_{2}\left(\mathrm{KI}_{3}\right)$.......... 153

Figure 5.35. 80/20 $\mathrm{NaIO}_{3} / \mathrm{Al}$ 154

Figure 5.36. 80/20 $\mathrm{NaIO}_{3} / \mathrm{B}_{4} \mathrm{C}$ 154

Figure 5.37. 80/20 $\mathrm{NaIO}_{4} / \mathrm{Al}$ 155

Figure 5.38. 80/20 $\mathrm{NaIO}_{4} / \mathrm{B}_{4} \mathrm{C}$ 155

Figure 5.39. 80/20 $\mathrm{KIO}_{3} / \mathrm{Al}$ 156

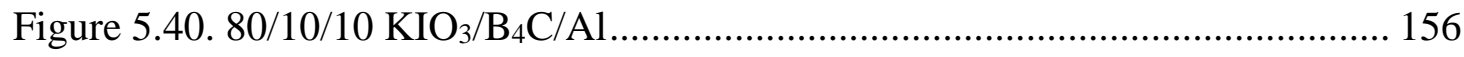

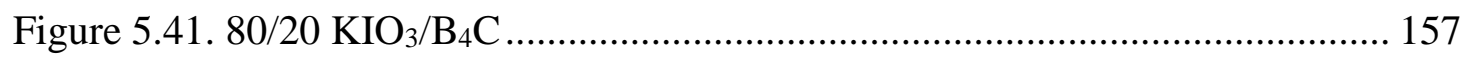

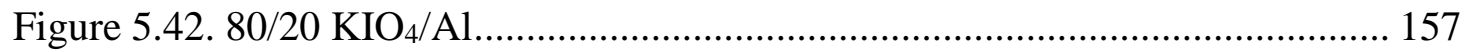

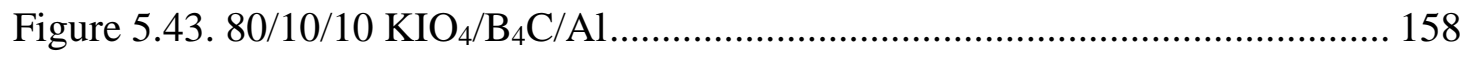

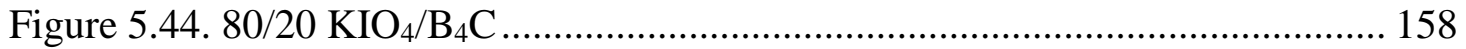

$\mathrm{xvi}$ 


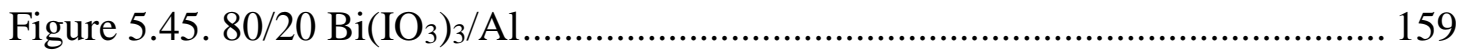

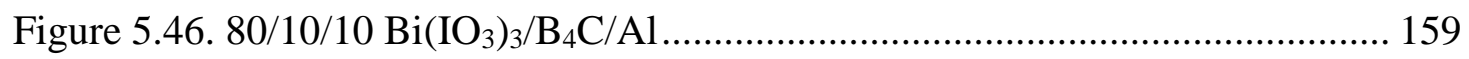

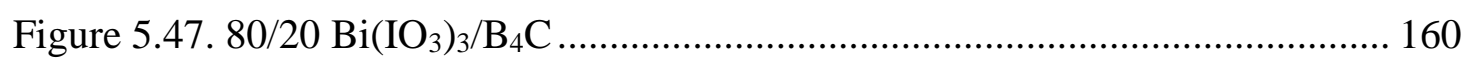

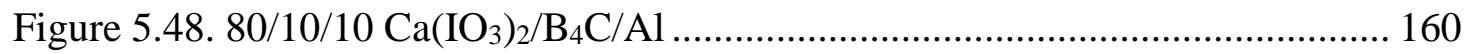

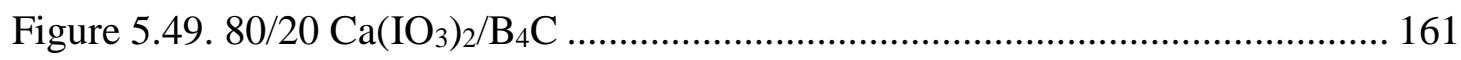

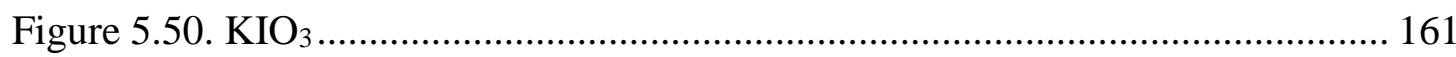

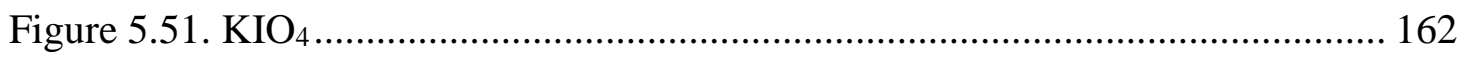

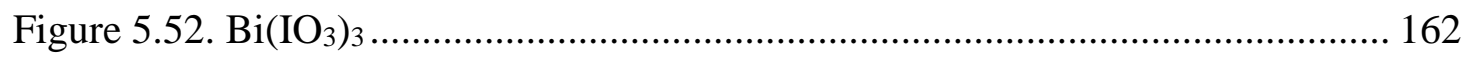

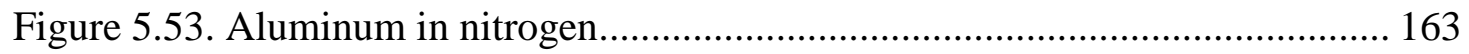

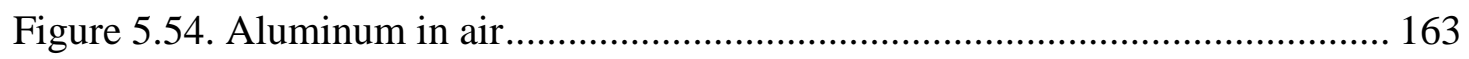

Figure 5.55. 50/50 Aluminum/iodine run in nitrogen ........................................... 164

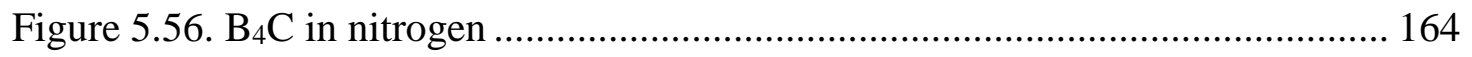

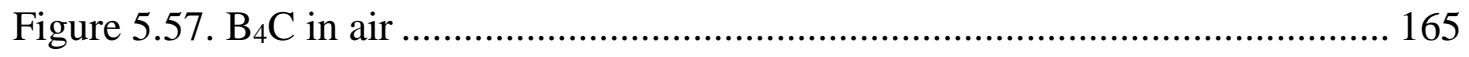

Figure 5.58. 50/50 B4C/iodine run in nitrogen.................................................. 165

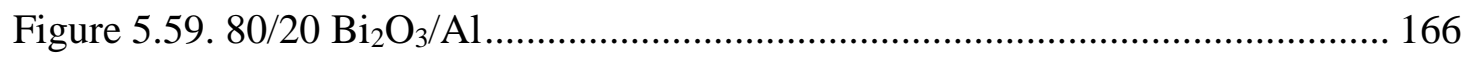

Figure 5.60. 80/20 Ca( $\left(\mathrm{IO}_{3}\right)_{2} / \mathrm{Al}$ combustion products........................................... 166

Figure 5.61. 60/40 $\mathrm{Ca}\left(\mathrm{IO}_{3}\right)_{2} / \mathrm{Al}$ combustion products........................................... 167

Figure 5.62. 80/20 $\mathrm{NaIO}_{3} / \mathrm{Al}$ combustion products ............................................... 167

Figure 5.63. 60/40 $\mathrm{NaIO}_{3} / \mathrm{Al}$ combustion products ............................................... 168

Figure 5.64. 80/20 $\mathrm{KIO}_{3} / \mathrm{Al}$ combustion products ………...................................... 168

Figure 5.65. 60/40 $\mathrm{KIO}_{3} / \mathrm{Al}$ combustion products ................................................. 169

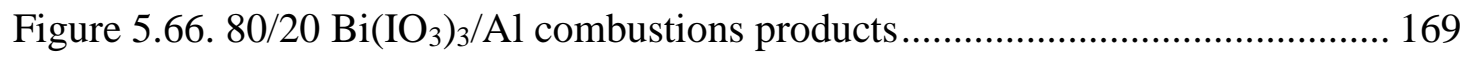

Figure 5.67. $60 / 40 \mathrm{Bi}\left(\mathrm{IO}_{3}\right)_{3} / \mathrm{Al}$ combustion products ............................................ 170 
Figure 5.68. 80/20 $\mathrm{I}_{2} \mathrm{O}_{5} / \mathrm{Al}$ combustion products 170

Figure 5.69. 60/40 $\mathrm{I}_{2} \mathrm{O}_{5} / \mathrm{Al}$ combustion products 171

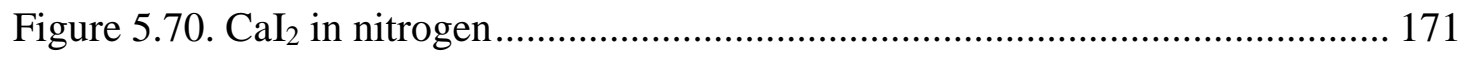

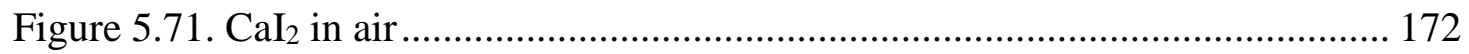

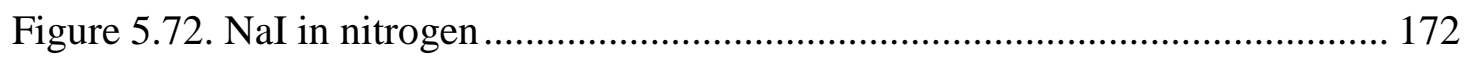

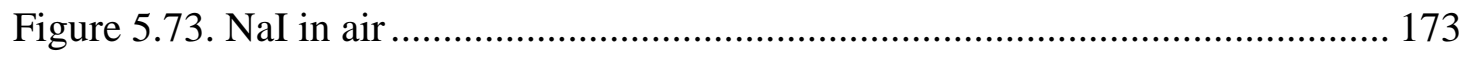

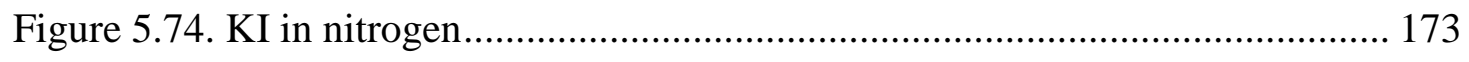

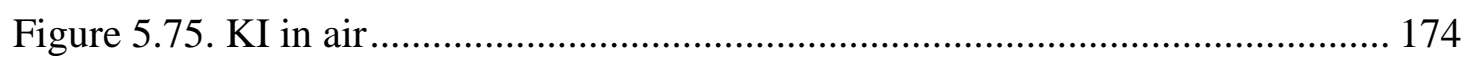

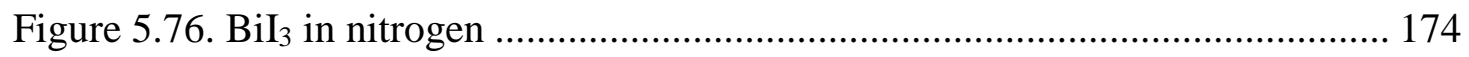

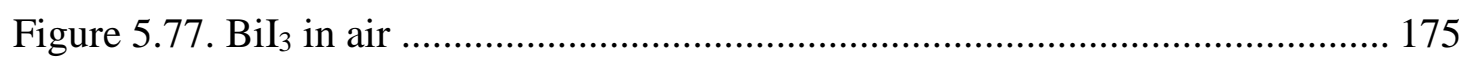

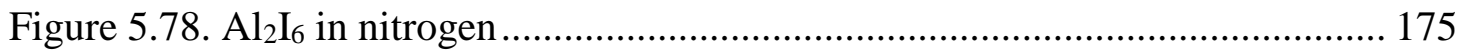

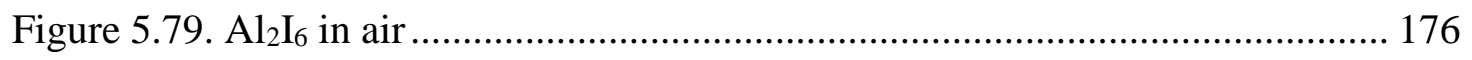

Figure 5.80. 80/20 Ca( $\left(\mathrm{IO}_{3}\right)_{2} / \mathrm{Al}$ combustion products I $3 \mathrm{~d}$ high resolution spectra ... 176

Figure 5.81. 60/40 $\mathrm{Ca}\left(\mathrm{IO}_{3}\right)_{2} / \mathrm{Al}$ combustion products I 3d high resolution spectra ... 177

Figure 5.82. $\mathrm{Ca}\left(\mathrm{IO}_{3}\right)_{2} / \mathrm{Al}$ combustion products $\mathrm{Ca} 2 \mathrm{p}$ high resolution spectra......... 177

Figure 5.83. 80/20 $\mathrm{I}_{2} \mathrm{O}_{5} / \mathrm{Al}$ combustion products $\mathrm{I} 3 \mathrm{~d}$ high resolution spectra ......... 178

Figure 5.84. 60/40 $\mathrm{I}_{2} \mathrm{O}_{5} / \mathrm{Al}$ combustion products I $3 \mathrm{~d}$ high resolution spectra .......... 178

Figure 5.85. 80/20 $\mathrm{Bi}\left(\mathrm{IO}_{3}\right)_{3} / \mathrm{Al}$ combustion products I 3d high resolution spectra.... 179

Figure 5.86. 60/40 $\mathrm{Bi}\left(\mathrm{IO}_{3}\right)_{3} / \mathrm{Al}$ combustion products I 3d high resolution spectra.... 179

Figure 5.87. 80/20 $\mathrm{Bi}\left(\mathrm{IO}_{3}\right)_{3} / \mathrm{Al}$ combustion products $\mathrm{Bi}$ 4f high resolution spectra.. 180

Figure 5.88. 60/40 $\mathrm{Bi}\left(\mathrm{IO}_{3}\right)_{3} / \mathrm{Al}$ combustion products $\mathrm{Bi}$ 4f high resolution spectra.. 180

Figure 5.89. 80/20 $\mathrm{KIO}_{3} / \mathrm{Al}$ combustion products I 3d high resolution spectra ........ 181

Figure 5.90. 60/40 $\mathrm{KIO}_{3} / \mathrm{Al}$ combustion products I 3d high resolution spectra ........ 181 $\mathrm{x}$ viii 
Figure 5.91. 80/20 $\mathrm{NaIO}_{3} / \mathrm{Al}$ combustion products I 3d high resolution spectra....... 182

Figure 5.92. 60/40 $\mathrm{NaIO}_{3} / \mathrm{Al}$ combustion products I 3d high resolution spectra....... 182

Figure 5.93. Aluminum heated in air and nitrogen $\mathrm{Al} 2 \mathrm{p}$ high resolution spectra..... 183

Figure 5.94. Aluminum heated in air and nitrogen $\mathrm{O}$ 1s high resolution spectra ...... 183

Figure 5.95. LCMS - Ca( $\left(\mathrm{IO}_{3}\right)_{2} / \mathrm{Al}$ extracted with $\mathrm{H}_{2} \mathrm{O}$. Blank (top), $\mathrm{Ca}\left(\mathrm{I}_{2}\right)$ in $\mathrm{H}_{2} \mathrm{O}$

(middle top), $\mathrm{CaO}$ added to a solution of $\mathrm{Al}_{2} \mathrm{I}_{6}$ in $\mathrm{H}_{2} \mathrm{O}$ (middle bottom), and 60/40

Calcium Iodate/ $\mathrm{Al}$ combustion products extracted in $\mathrm{H}_{2} \mathrm{O}$ (bottom)...................... 185

Figure 6.1. Pressure vs. Time curve of $\mathrm{Fe}_{3} \mathrm{O}_{4}: \mathrm{Mg}$ 80:20 wt:wt (2 g in $2859 \mathrm{kPa}$ Argon)

Figure 6.2. Pressure vs. Time curve of $\mathrm{Fe}_{3} \mathrm{O}_{4}: \mathrm{Mg}$ 70:30 wt:wt (2 g in 2859 kPa Argon)

Figure 6.3. Pressure vs. Time curve of $\mathrm{Fe}_{3} \mathrm{O}_{4}: \mathrm{Mg}$ 60:40 wt:wt (2 g in $2859 \mathrm{kPa}$ Argon) 188

Figure 6.4. Pressure vs. Time curve of $\mathrm{Bi}_{2} \mathrm{O}_{3}: \mathrm{Al}$ 70:30 wt:wt (2 g in 2859 kPa Argon) 189

Figure 6.5. Pressure vs. Time curve of $\mathrm{Bi}_{2} \mathrm{O}_{3}: \mathrm{Al}$ 90:10 wt:wt (2 g in $2859 \mathrm{kPa}$ Argon)

Figure 6.6. Pressure vs. Time curve of $\mathrm{Bi}_{2} \mathrm{O}_{3}$ :Al 80:20 wt:wt (2 g in 2859 kPa Argon)

191

Figure 6.7. Pressure vs. Time curve of $\mathrm{KNO}_{3}: \mathrm{Nabenzoate}^{70: 30 \mathrm{wt}: \mathrm{wt}}$

(2 $\mathrm{g}$ in $2859 \mathrm{kPa}$ Argon) 192

Figure 6.8. Pressure vs. Time curve of $\mathrm{KClO}_{3}$ :Nabenzoate 70:30 wt:wt

(2 $\mathrm{g}$ in $2859 \mathrm{kPa}$ Argon) 193

xix 
Figure 6.9. Pressure vs. Time curve of $\mathrm{KClO}_{4}$ :Nabenzoate 70:30 wt:wt

(2 $\mathrm{g}$ in $2859 \mathrm{kPa}$ Argon)

194

Figure 6.10. Pressure vs. Time curve of $\mathrm{NH}_{4} \mathrm{ClO}_{4}$ : Nabenzoate 70:30 wt:wt

(2 $\mathrm{g}$ in $2859 \mathrm{kPa}$ Argon)

Figure 6.11. Pressure vs. Time curve of $\mathrm{K}_{2} \mathrm{Cr}_{2} \mathrm{O}_{7}$ :Sucrose 70:30 wt:wt

(2 g in $2859 \mathrm{kPa}$ Argon)

Figure 6.12. Pressure vs. Time curve of $\mathrm{NH}_{4} \mathrm{NO}_{3}$ :Sucrose $70: 30 \mathrm{wt}$ :wt

(2 $\mathrm{g}$ in $2859 \mathrm{kPa}$ Argon)............

Figure 6.13. Pressure vs. Time curve of $\mathrm{KMnO}_{4}$ :Sucrose 70:30 wt:wt

(2 $\mathrm{g}$ in $2859 \mathrm{kPa}$ Argon). 198

Figure 6.14. Pressure vs. Time curve of $\mathrm{KIO}_{3}:$ Sucrose 70:30 wt:wt

(2 $\mathrm{g}$ in $2859 \mathrm{kPa}$ Argon)

Figure 6.15. Pressure vs. Time curve of $\mathrm{KNO}_{2}$ :Sucrose 70:30 wt:wt

(2 $\mathrm{g}$ in $2859 \mathrm{kPa}$ Argon) 200

Figure 6.16. Pressure vs. Time curve of $\mathrm{KNO}_{3}$ :Sucrose 70:30 wt:wt

(2 $\mathrm{g}$ in $2859 \mathrm{kPa}$ Argon)............ 201

Figure 6.17. Pressure vs. Time curve of $\mathrm{KNO}_{3}: \mathrm{KClO}_{3}:$ Sucrose 63:7:30 wt:wt

(2 $\mathrm{g}$ in $2859 \mathrm{kPa}$ Argon) 202

Figure 6.18. Pressure vs. Time curve of $\mathrm{KIO}_{4}:$ Sucrose 70:30 wt:wt

(2 $\mathrm{g}$ in $2859 \mathrm{kPa}$ Argon). 203

Figure 6.19. Pressure vs. Time curve of RDX:KNO $3:$ Sucrose 5:66.5:28.5 wt:wt

( $2 \mathrm{~g}$ in $2859 \mathrm{kPa}$ Argon). 204 
Figure 6.20. Pressure vs. Time curve of $\mathrm{KClO}_{3}: \mathrm{KNO}_{3}:$ Sucrose 17:53:30 wt:wt

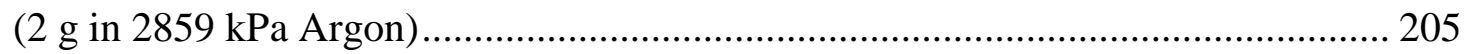

Figure 6.21. Pressure vs. Time curve of RDX:KNO $3:$ Sucrose 10:63:27 wt:wt

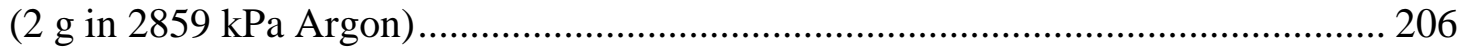

Figure 6.22. Pressure vs. Time curve of $\mathrm{KNO}_{3}: \mathrm{KClO}_{3}:$ Sucrose 35:35:30 wt:wt

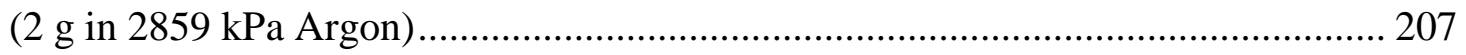

Figure 6.23. Pressure vs. Time curve of $\mathrm{KBrO}_{3}:$ Sucrose 70:30 wt:wt

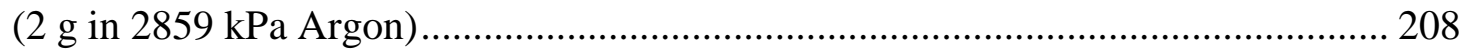

Figure 6.24. Pressure vs. Time curve of $\mathrm{KClO}_{4}$ :Sucrose 70:30 wt:wt

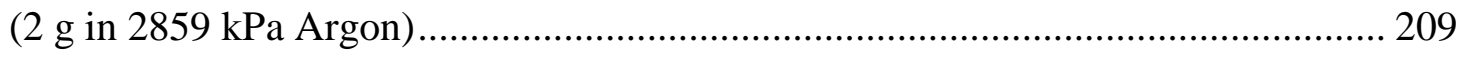

Figure 6.25. Pressure vs. Time curve of $\mathrm{KClO}_{3}:$ Sucrose 70:30 wt:wt

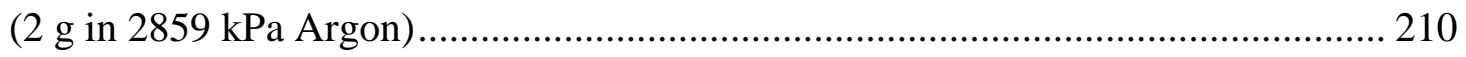

Figure 6.26. Pressure vs. Time curve of RDX:KNO $3:$ Sucrose 50:35:15 wt:wt

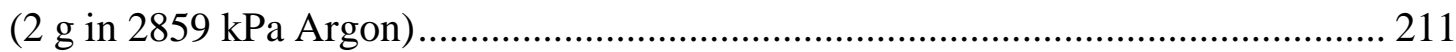

Figure 6.27. Pressure vs. Time curve of $\mathrm{K}_{2} \mathrm{Cr}_{2} \mathrm{O}_{7}$ :Al 70:30 wt:wt

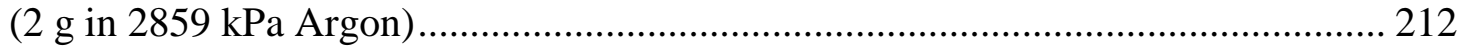

Figure 6.28. Pressure vs. Time curve of $\mathrm{KNO}_{2}: \mathrm{Al} 70: 30 \mathrm{wt}: \mathrm{wt}$

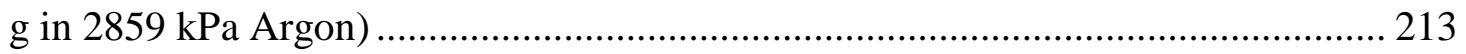

Figure 6.29. Pressure vs. Time curve of $\mathrm{KMnO}_{4}: \mathrm{Al}$ 70:30 wt:wt

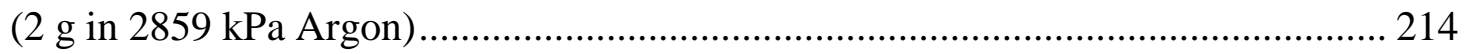

Figure 6.30. Pressure vs. Time curve of $\mathrm{KIO}_{3}: \mathrm{Al}$ 70:30 wt:wt

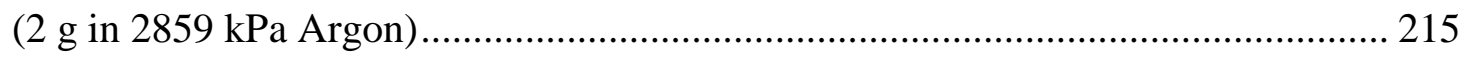

xxi 
Figure 6.31. Pressure vs. Time curve of $\mathrm{KNO}_{3}: \mathrm{Al} 70: 30 \mathrm{wt}: \mathrm{wt}$

( $2 \mathrm{~g}$ in $2859 \mathrm{kPa}$ Argon) 216

Figure 6.32. Pressure vs. Time curve of $\mathrm{KIO}_{4}: \mathrm{Al}$ 70:30 wt:wt

(2 $\mathrm{g}$ in $2859 \mathrm{kPa}$ Argon)

Figure 6.33. Pressure vs. Time curve of $\mathrm{KClO}_{4}$ :Al 80:20 wt:wt

( $2 \mathrm{~g}$ in $2859 \mathrm{kPa}$ Argon) 218

Figure 6.34. Pressure vs. Time curve of $\mathrm{KBrO}_{3}$ :Al 70:30 wt:wt

(2 $\mathrm{g}$ in $2859 \mathrm{kPa}$ Argon) 219

Figure 6.35. Pressure vs. Time curve of $\mathrm{NH}_{4} \mathrm{NO}_{3}$ :Al 70:30 wt:wt

(2 $\mathrm{g}$ in $2859 \mathrm{kPa}$ Argon)..............

Figure 6.36. Pressure vs. Time curve of $\mathrm{KClO}_{4}: \mathrm{Al}$ 50:50 wt:wt

(2 g in $2859 \mathrm{kPa}$ Argon) 221

Figure 6.37. Pressure vs. Time curve of $\mathrm{KClO}_{3}: \mathrm{Al} 70: 30 \mathrm{wt}: \mathrm{wt}$

(2 $\mathrm{g}$ in $2859 \mathrm{kPa}$ Argon) 222

Figure 6.38. Pressure vs. Time curve of $\mathrm{KClO}_{4}: \mathrm{Al}$ 70:30 wt:wt

(2 $\mathrm{g}$ in $2859 \mathrm{kPa}$ Argon) 223

Figure 6.39. Pressure vs. Time curve of $\mathrm{KClO}_{4}: \mathrm{Al}$ 60:40 wt:wt

(2 $\mathrm{g}$ in $2859 \mathrm{kPa}$ Argon) 224

Figure 6.40. Pressure vs. Time curve of $\mathrm{NH}_{4} \mathrm{ClO}_{4}: \mathrm{Al} 70: 30 \mathrm{wt}: \mathrm{wt}$

(2 $\mathrm{g}$ in $2859 \mathrm{kPa}$ Argon) 225

Figure 6.41. Pressure vs. Time curve of 7 mesh granulated Black Powder (2 $\mathrm{g}$ in $2859 \mathrm{kPa}$ Argon). 226

xxii 
Figure 6.42. Pressure vs. Time curve of 20 mesh granulated Black Powder

(2 $\mathrm{g}$ in $2859 \mathrm{kPa}$ Argon)

Figure 6.43. Pressure vs. Time curve of Meal Black Powder

(2 $\mathrm{g}$ in $2859 \mathrm{kPa}$ Argon) 228

Figure 6.44. Pressure vs. Time curve of Pyrodex ( $2 \mathrm{~g}$ in $2859 \mathrm{kPa}$ Argon) 229

Figure 6.45. Pressure vs. Time curve of Red Dot (2 g in $2859 \mathrm{kPa}$ Argon) 230

Figure 6.46. Airblast pressure vs. time curve from large scale testing with the booster

only (sand as the sample)

Figure 6.47. Airblast pressure vs. time curve from large scale testing with TNT as the

sample.

Figure 6.48. Airblast pressure vs. time curve from large scale testing with

$\mathrm{KClO}_{3}:$ Sucrose $70: 30$ wt:wt as the sample

Figure 6.49. Airblast pressure vs. time curve from large scale testing with

$\mathrm{KNO}_{3}:$ Sucrose 70:30 wt:wt as the sample 234

Figure 6.50. Airblast pressure vs. time curve from large scale testing with

$\mathrm{NH}_{4} \mathrm{NO}_{3}:$ Sucrose 70:30 wt:wt as the sample 235

Figure 6.51. Airblast pressure vs. time curve from large scale testing with

$\mathrm{NH}_{4} \mathrm{ClO}_{4}:$ Sucrose 70:30 wt:wt as the sample 236

Figure 6.52. Airblast pressure vs. time curve from large scale testing with

$\mathrm{KClO}_{3}: \mathrm{KNO}_{3}:$ Sucrose 35:35:30 wt:wt as the sample

Figure 6.53. Airblast pressure vs. time curve from large scale testing with

$\mathrm{KMnO}_{4}:$ Sucrose 70:30 wt:wt as the sample. 238

xxiii 
Figure 6.54. Airblast pressure vs. time curve from large scale testing with

$\mathrm{KIO}_{3}:$ Sucrose 70:30 wt:wt as the sample

Figure 6.55. Airblast pressure vs. time curve from large scale testing with

$\mathrm{KClO}_{3}:$ Sucrose 70:30 wt:wt as the sample

Figure 6.56. Airblast pressure vs. time curve from large scale testing with

RDX: $\mathrm{KNO}_{3}:$ Sucrose 50:35:15 wt:wt as the sample.

Figure 6.57. Airblast pressure vs. time curve from large scale testing with

$\mathrm{KNO}_{3}: \mathrm{KClO}_{3}:$ Sucrose 63:7:30 wt:wt as the sample

Figure 6.58. Airblast pressure vs. time curve from large scale testing with

$\mathrm{KNO}_{3}: \mathrm{RDX}:$ Sucrose 66.5:5:28.5 wt:wt as the sample.

Figure 6.59. Airblast pressure vs. time curve from large scale testing with $\mathrm{NH}_{4} \mathrm{NO}_{3}: \mathrm{Al}$

70:30 wt:wt as the sample 244

Figure 6.60. Airblast pressure vs. time curve from large scale testing with $\mathrm{KNO}_{3}: \mathrm{Al}$

70:30 wt:wt as the sample 245

Figure 6.61. Airblast pressure vs. time curve from large scale testing with $\mathrm{NH}_{4} \mathrm{ClO}_{4}: \mathrm{Al}$ 70:30 wt:wt as the sample 246

Figure 6.62. High speed camera record from large scale testing with the booster only and sand as the sample (20161220 shot 1$)$ 247

Figure 6.63 High speed camera record from large scale testing with TNT as the sample

Figure 6.64. High speed camera record from large scale testing with TNT as the sample (20161221 shot 1) 248

xxiv 
Figure 6.65. High speed camera record from large scale testing with $\mathrm{KClO}_{3}$ :Sucrose 70:30 wt:wt as the sample (20170113 shot 1$).$ 249

Figure 6.66. High speed camera record from large scale testing with $\mathrm{KNO}_{3}$ :Sucrose 70:30 wt:wt as the sample (20170113 shot 2) 250

Figure 6.67. High speed camera record from large scale testing with $\mathrm{NH}_{4} \mathrm{NO}_{3}$ :Sucrose 70:30 wt:wt as the sample (20170125 shot 1$)$ 251

Figure 6.68. High speed camera record from large scale testing with $\mathrm{NH}_{4} \mathrm{ClO}_{4}$ :Sucrose 70:30 wt:wt as the sample (20170125 shot 2$)$ 252

Figure 6.69. High speed camera record from large scale testing with

$\mathrm{KNO}_{3}: \mathrm{KClO}_{3}:$ Sucrose 35:35:30 wt:wt as the sample (20170125 shot 3)............. 253

Figure 6.70. High speed camera record from large scale testing with $\mathrm{KMnO}_{4}$ :Sucrose 70:30 wt:wt as the sample (20170206 shot 1) 254

Figure 6.71. High speed camera record from large scale testing with $\mathrm{KIO}_{3}$ :Sucrose 70:30 wt:wt as the sample (20170206 shot 2). 255

Figure 6.72. High speed camera record from large scale testing with $\mathrm{KClO}_{3}$ :Sucrose 70:30 wt:wt as the sample (20170206 shot 3) 256

Figure 6.73. High speed camera record from large scale testing with RDX: $\mathrm{KNO}_{3}:$ Sucrose 50:35:15 wt:wt as the sample (20170206 shot 4) 257

Figure 6.74 High speed camera record from large scale testing with $\mathrm{KNO}_{3}: \mathrm{KClO}_{3}:$ Sucrose 63:7:30 wt:wt as the sample (20170302 shot 1).......... 258

Figure 6.75. High speed camera record from large scale testing with $\mathrm{KNO}_{3}: \mathrm{RDX}:$ Sucrose 66.5:5:28.5 wt:wt as the sample (20170302 shot 2) 259 
Figure 6.76. High speed camera record from large scale testing with $\mathrm{NH}_{4} \mathrm{NO}_{3}: \mathrm{Al}$

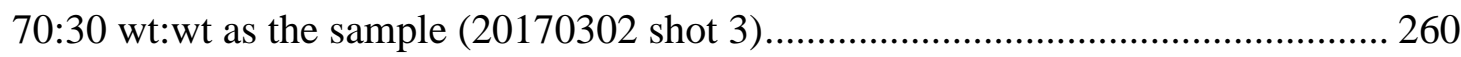

Figure 6.77 High speed camera record from large scale testing with $\mathrm{KNO}_{3}: \mathrm{Al}$ 70:30

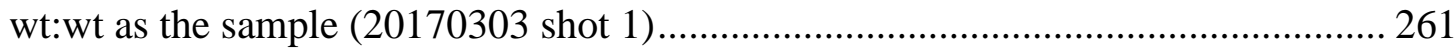

Figure 6.78. High speed camera record from large scale testing with $\mathrm{NH}_{4} \mathrm{ClO}_{4}: \mathrm{Al}$

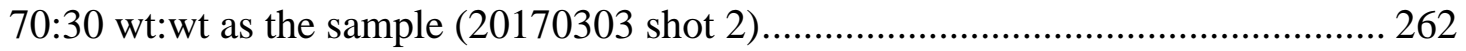




\section{LIST OF ABBREVIATIONS}

ACN - Acetonitrile

BHMP - bis(hydroxymethyl) peroxide

BMAP - bis(methylamine) peroxide

C4 - Military Explosive Composition 4

ESD - Electrostatic Discharge

EN - Ethylenimine

DFT - Density Functional Theory

DMF - Dimethylformamide

DSC - Differential Scanning Calorimetry

EA - Ethyl Acetate

FOX - Fuel/Oxidizer Mixture

FM - Formamide

GC/MS - Gas Chromatography / Mass Spectrometry

HMTD - Hexamethylene Triperoxide Diamine

IR - Infrared Spectroscopy

LC/MS - Liquid Chromatography / Mass Spectrometry

MFM - Methyl formamide

NMR - Nuclear Magnetic Resonance Spectroscopy

PETN - Pentaerythritol Tetranitrate

PVC - Polyvinyl Chloride

RDX - 2,4,6-cyclotrimethylene-1,3,5-trinitramine

RH - Relative Humidity

xxvii 
SDT - Simultaneous Differential Scanning Calorimetry Thermogravimetric Analysis

SPME - Solid Phase Microextraction

TIL - Threshold Initiation Level

TMA - Trimethylamine

TMDD - Tetramethylene Diperoxide Diamine

TMDDD - Tetramethylene Diperoxide Diamine Dialdehyde

UV-Vis - Ultraviolet-Visible Spectroscopy

XPS - X-Ray Photoelectron Spectroscopy

XRD - Powder X-Ray Diffraction 


\title{
MANUSCRIPT 1
}

\section{SYNTHESIS AND DEGREDATION OF HEXAMETHYLENE TRIPEROXIDE DIAMINE (HMTD)}

\author{
by \\ Jimmie C. Oxley ${ }^{[\mathrm{a}]}$; James L. Smith ${ }^{[\mathrm{a}]}$; Matthew Porter ${ }^{[\mathrm{a}]}$; Lindsay McLennan ${ }^{[\mathrm{a}]}$; Kevin \\ Colizza $^{[\mathrm{a}]}$; Yehuda Zeiri ${ }^{[\mathrm{b}, \mathrm{c}]}$; Ronnie Kosloff ${ }^{[\mathrm{d}]}$; and Faina Dubnikova ${ }^{[\mathrm{d}]}$ \\ [a] Department of Chemistry; University of Rhode Island \\ 140 Flagg Rd; Kingston, RI 02881 \\ [b] Biomedical Engineering; Ben-Gurion University \\ Beer-Sheva, 84105, Israel \\ [c] Department of Chemistry; NRCN \\ P.O. Box 9001; Beer-Sheva, 84190, Israel \\ [d] Department of Chemistry; Hebrew University \\ Jerusalem, Israel
}

This manuscript was published in the journal Propellants, Explosives, Pyrotechnics 


\begin{abstract}
The synthesis and decomposition of hexamethylene triperoxide diamine (HMTD) were studied. Mechanisms were proposed based on isotopic labeling and mass spectral interpretation of both condensed phase products and head-space products. Formation of HMTD from hexamine appeared to proceed from dissociated hexamine as evident from scrambling of the ${ }^{15} \mathrm{~N}$ label when synthesis was carried out with equal molar labeled/unlabeled hexamine. Decomposition of HMTD was considered with additives and in the presence and absence of moisture. In addition to mass spectral interpretation, density functional theory (DFT) was used to calculate energy differences of transition states and the entropies of intermediates along different possible decomposition pathways. HMTD is destabilized by water and citric acid making purification following initial synthesis essential in order to avoid unanticipated violent reaction.
\end{abstract}

\title{
1 Introduction
}

HMTD is synthesized from the reaction of hexamine with hydrogen peroxide. The oxidation is catalyzed by acid, usually citric acid. It was discovered in 1885 by Legler using formaldehyde, ammonium sulfate, and hydrogen peroxide [1]. The structure was proposed in 1900 by Baeyer and Villiger [2]. Von Girsewald was the first to use hexamine, citric acid, and hydrogen peroxide [3]. X-ray diffraction showed exactly planar 3-fold coordination about the two bridgehead nitrogen atoms rather than pyramidal structure $[4,5]$. This ring strain in HMTD may account for its low thermal stability and high sensitivity to friction [6,7]. Because there have been several unexpected violent reactions involving HMTD where counterterrorism personnel have 
been injured, we launched a study to better understand its chemistry and, for the purposes of detection, to identify its signature under a variety of conditions.

\section{Experimental Section}

\subsection{Synthesis of HMTD with citric acid}

When HMTD was synthesized simply from ice-cooled hydrogen peroxide $(9.60$ $\mathrm{g}, 50 \mathrm{wt} \%, 141.18 \mathrm{mmol})$ with the slow addition of hexamine $(2.43 \mathrm{~g}, 17.37 \mathrm{mmol})$ and later addition of anhydrous citric acid $(3.66 \mathrm{~g}, 19.03 \mathrm{mmol})$, the reaction was warmed to room temperature, by allowing the ice bath to melt. Under these conditions the reaction mixture stirred 5 to 6 hours before HMTD precipitation was observed [5]. Crude HMTD, vacuum filtered, washed with excess distilled water $(\sim 200 \mathrm{~mL})$ to remove acid and HPLC grade methanol ( 200 mL) to aid drying was gently stirred and left to dry several hours on the vacuum filter. The yield of crude HMTD was $~ 50 \%$, assuming 1:1 molar ratio hexamine:HMTD. Recrystallization was conducted with 70/30 v/v mix of ethyl acetate (EA) /acetonitrile (ACN). Solvent was difficult to remove even after drying under high vacuum for 24 hours. The evidence collected to support that HMTD was synthesized with these conditions included GC/MS (see section 2.12), DSC (see section 2.10), melting point (by Mel-Temp apparatus), LC/MS (see section 2.14), NMR (Bruker $300 \mathrm{MHz},{ }^{1} \mathrm{H}$ NMR [CDCl 3$]$ : 84.80 ), and IR (Thermo Nicolet 6700 FTIR). The evidence gathered to support that HMTD was synthesized under any of the alternate conditions listed below (including labeling studies) included GC/MS, melting point, and LC/MS. Note: HMTD is an extremely sensitive primary explosive; no fritted glass, metal spatulas nor excess force or friction should be applied. 


\subsection{Synthesis of HMTD with other acids or no acid}

Using same amounts of hexamine and hydrogen peroxide as above, but no acid added, precipitation of HMTD was not observed for 7 days at room temperature. After 9 days of stirring, $261 \mathrm{mg}$ HMTD was recovered, 7 \% yield assuming 1:1 molar ratio hexamine:HMTD. Other diprotic and triprotic acids used, in place of citric acid, included sulfuric acid, phosphoric acid, and oxalic acid; like citric acid, they were added in 1.1 to 1 molar ratios hexamine:acid. Monoprotic acids gave poor yields (Table 5) if added in 1.1 to 1 molar ratios. If these (acetic acid, trifluoroacetic acid, formic acid, and nitric acid) were added in a 2.2 to 1 molar ratio hexamine:acid, yields were comparable to those achieved with citric acid.

\subsection{Synthesis of HMTD with formaldehyde $\left({ }^{13} \mathrm{C}\right.$ or $\left.{ }^{12} \mathrm{C}\right)$}

Formaldehyde, up to 6 moles per mole hexamine, appeared to accelerate the reaction and increased the yield to over 100\% based 1 to 1 hexamine:HMTD. For example, HMTD was synthesized by adding hexamine $(0.4499 \mathrm{~g}, 3.22 \mathrm{mmol})$ to a solution of ${ }^{13} \mathrm{C}$ formaldehyde in water $(2.0153 \mathrm{~g}$ of solution, $20 \mathrm{wt} \%, 13.43 \mathrm{mmol})$ in an ice bath. Hydrogen peroxide was then slowly added (1.7871 $\mathrm{g}$ of solution, $50 \mathrm{wt} \%$, $26.28 \mathrm{mmol})$ and later, anhydrous citric acid (0.6817 g, $3.55 \mathrm{mmol})$. HMTD started to precipitate within 2 hours, in contrast to the 5 to 6 hours required without formaldehyde. The reaction was allowed to continue overnight as the ice bath warmed up. Aliquots of the reaction mix were taken every 0.5 hour for 4 hours after the addition of the acid, and the final aliquot was taken 27 hours later. The crude HMTD was vacuum-filtered, washed with distilled water ( $\sim 200 \mathrm{~mL})$ to remove acid and then HPLC grade methanol ( 200 $\mathrm{mL})$ to aid drying (dried several hours by vacuum filtration). 


\subsection{Synthesis of HMTD with ${ }^{15} \mathrm{~N}$ Ammonium Sulfate}

HMTD was synthesized from ice-cooled hydrogen peroxide (2.4082 g, $50 \mathrm{wt} \%$, $35.42 \mathrm{mmol})$ with the slow addition of hexamine $(0.6061 \mathrm{~g}, 4.33 \mathrm{mmol})$ and later addition of anhydrous citric acid $(0.9146 \mathrm{~g}, 4.76 \mathrm{mmol})$. After the citric acid dissolved,

${ }^{15} \mathrm{~N}$ ammonium sulfate was added $(0.2874 \mathrm{~g}, 2.17 \mathrm{mmol})$. After 4 to 5 hours, HMTD began to precipitate from the cold solution. The reaction warmed to room temperature overnight, and crude HMTD was vacuum filtered, washed by gentle agitation with distilled water ( $200 \mathrm{~mL})$ to remove acid then HPLC grade methanol $(\sim 200 \mathrm{~mL})$ to aid drying. It was then left to dry several hours on the vacuum filter. The crude HMTD yield was about $60 \%$ (assuming 1:1 molar ratio hexamine:HMTD).

\subsection{Synthesis of ${ }^{15} \mathrm{~N}$ Hexamine and HMTD Decomposition Products}

Pure ${ }^{15} \mathrm{~N}$ hexamine was synthesized by adding formaldehyde (1.7463 g solution, $37 \mathrm{wt} \%, 21.54 \mathrm{mmol})$ to ${ }^{15} \mathrm{~N}$ ammonium hydroxide (2.3117 g solution, $10.4 \mathrm{wt} \%, 13.36$ mmol) at $40{ }^{\circ} \mathrm{C}$, using a procedure from Nielsen [8]. The reaction mixture was stirred for 2 hours, $2 \mathrm{~mL}$ of methanol was added, and the water/methanol solution was removed by evaporation at $40{ }^{\circ} \mathrm{C}$. The crude hexamine was purified by sublimation at $185-200$ ${ }^{\circ} \mathrm{C}$; a water aspirator was used to maintain the vacuum. The purified hexamine (397.6 $\mathrm{mg}, 2.76 \mathrm{mmol}$ ) had a melting /sublimation point at $265-275{ }^{\circ} \mathrm{C}$ (by Mel-Temp apparatus). GC/MS (gas chromatography with mass spectrometric detection) $(144 \mathrm{~m} / \mathrm{z})$, infrared spectroscopy (IR), and ${ }^{1} \mathrm{H} \mathrm{NMR}\left(\mathrm{CDCl}_{3}\right)$ : $\delta 4.73$, showed good purity. Stirring formaldehyde and formamide at ambient conditions for a day yielded $\mathrm{N}$ (hydroxymethyl)formamide ( $\mathrm{m} / \mathrm{z} 75$, table 3.2) along with hexamine [9]. The synthesis of 1,3,5-triformylhexahydro-s-triazine (m/z 171, table 3.11) was accomplished by 
adding acetic-formic anhydride to hexamethylenetetramine at room temperature, using the method of Gilbert [10]. Tetramethylene diperoxide diamine dialdehyde (TMDDD) was synthesized by the route of Wierzbicki [5]. N,N'-methylenebisformamide (m/z 102, table 3.5) was purchased from Aldrich.

\subsection{Synthesis Conditions of HMTD with a 1-to-1 mix of ${ }^{14} \mathrm{~N}$ and ${ }^{15} \mathrm{~N}$ hexamine}

HMTD was synthesized by adding ${ }^{14} \mathrm{~N}$ hexamine (304.0 mg, $\left.2.17 \mathrm{mmol}\right)$ and ${ }^{15} \mathrm{~N}$ hexamine $(304.0 \mathrm{mg}, 2.11 \mathrm{mmol})$ to hydrogen peroxide (2.4077 $\mathrm{g}$ of solution, 50 wt $\%, 35.41 \mathrm{mmol})$. Anhydrous citric acid was added (0.9154 g, $4.76 \mathrm{mmol})$, and the reaction mixture was allowed to stir overnight as the ice bath warmed up. Aliquots were taken every hour until the HMTD precipitated after 6 hrs. The final aliquot of the reaction mix was taken after $19 \mathrm{hrs}$. The crude HMTD was vacuum-filtered, washed with excess distilled water ( $\sim 200 \mathrm{~mL})$ to remove acid then HPLC grade methanol ( 200 $\mathrm{mL}$ ) to aid drying and left to dry several hours on the vacuum filter.

\subsection{Isothermal Decomposition}

HMTD was aged neat and with additives of interest. Typically samples, about $20 \mathrm{mg}$ total, were heated at $60{ }^{\circ} \mathrm{C}$ or $80{ }^{\circ} \mathrm{C}$ in an oven for varying lengths of time. For testing the compatibility of HMTD with common reagents, liquids $(200 \mu \mathrm{L})$ were added to some samples and solids ( $\sim 3.5 \mathrm{mg}$, i.e. $15 \mathrm{wt} \%)$ were added to other samples. Most samples were stored in open vials which were sealed inside larger $(10 \mathrm{~mL})$ headspace vials (with humidity controlling solution between inner and outer vial) or held in humidity-controlled desiccators. Other samples were sealed directly in $10 \mathrm{~mL}$ headspace vials with no attempt to control humidity. Humidity was controlled with Drierite [considered $0 \%$ relative humidity $(\mathrm{RH})$ ], saturated $\mathrm{MgCl}_{2}$ (considered 30 
$\% \mathrm{RH}$ ), saturated $\mathrm{NaCl}$ (considered $75 \% \mathrm{RH}$ ), and distilled water (considered $100 \% \mathrm{RH}$ )

[11]. At the completion of the aging cycle, vials were opened under $20-40 \mathrm{~mL}$ of acetonitrile. If the HMTD additive was an aqueous solution, magnesium sulfate was added to the sample as a drying agent; if the additive was acidic or basic, sodium bicarbonate was added to neutralize. The acetonitrile solution was sonicated for at least 30 minutes; vortex mixed for 1 minute; and if the solutions were cloudy, syringe filtered into vials for analysis.

\subsection{Decomposition of HMTD with ${ }^{15}$ N Ammonium Sulfate}

${ }^{15} \mathrm{~N}$ ammonium sulfate at $15 \mathrm{wt} \%$ was added to HMTD (20 mg), and the mixture was heated at $80{ }^{\circ} \mathrm{C}$ under dry conditions or at $60{ }^{\circ} \mathrm{C}$ under $75 \% \mathrm{RH}$. After thermolysis, samples were extracted with $30 \mathrm{~mL}$ of acetonitrile and analyzed by GC/MS and on LC/MS (liquid chromatography with mass spectrometric detection) in order to monitor incorporation of ${ }^{15} \mathrm{~N}$ into the condensed-phase decomposition products.

\subsection{Decomposition of HMTD with deuterium oxide high humidity}

HMTD (20mg) was heated at $60^{\circ} \mathrm{C}$ in a small vial which was sealed in a $10 \mathrm{~mL}$ headspace vial with $1 \mathrm{~mL}$ of deuterium oxide $\left(\mathrm{D}_{2} \mathrm{O}\right)$ between the inner and outer vials so that HMTD did not directly make contact. HMTD was decomposed in a similar configuration with a saturated $\mathrm{NaCl} / \mathrm{D}_{2} \mathrm{O}$ solution (analogous to $75 \% \mathrm{RH}$ conditions) between outer and inner vials for 5 days. The $\mathrm{pH}$ of the $\mathrm{D}_{2} \mathrm{O}$ and analogous experiments with water was found to be highly acidic ( $\mathrm{pH}$ of 1$)$. These samples were extracted with $30 \mathrm{~mL}$ of acetonitrile, and run on GC/MS and on LC/MS to track the exchange of deuterium into the condensed phase decomposition products. Headspace analysis was also conducted according to the method described in section 2.13 using SPME. NMR 
$\left({ }^{1} \mathrm{H}\right.$ and $\left.{ }^{13} \mathrm{C}\right)$ of the $\mathrm{D}_{2} \mathrm{O}$ in the vial was used to identify formic acid $(\mathrm{HCOOH}) ;{ }^{1} \mathrm{H}$ $\mathrm{NMR}\left(\mathrm{D}_{2} \mathrm{O}\right) \delta 8.13(\mathrm{~s}, 1 \mathrm{H}) ;{ }^{13} \mathrm{C} \mathrm{NMR} \delta 167.25$.

\subsection{Differential Scanning Calorimeter (DSC)}

DSC samples were prepared by measuring 150 to $200 \mathrm{mg}$ of sample into a glass capillary tube, which was then flame sealed. For samples with an additive, 5 to $30 \mathrm{wt} \%$ additive was gently stirred into a $20 \mathrm{mg}$ HMTD sample, and this mixture was placed in the capillary tube. If additives were liquid, $2 \mathrm{~mL}$ of the liquid was added to $150-200 \mathrm{mg}$ of HMTD, and then sealed in capillary tubes. The sealed micro-ampules were weighed before and after DSC analysis to verify no leakage during testing. Samples were run on a TA Instruments Q100 DSC from 25 to $300^{\circ} \mathrm{C}$ with a ramp rate of $20{ }^{\circ} \mathrm{C} / \mathrm{min}$ under nitrogen flow. Results were processed via TA’s Universal Analysis software.

\subsection{Monitoring Rate of HMTD Formation}

Aliquots $(100 \mu \mathrm{L})$ were removed and diluted with $5 \mathrm{~mL}$ of HPLC grade acetonitrile with sodium bicarbonate and magnesium sulfate added to neutralize acid and dry the solvent, respectively. This mixture was then diluted $1 / 10 \mathrm{v} / \mathrm{v}$ and analyzed by GC/MS.

\subsection{Condensed Phase Analysis - GC/MS}

Analysis of the acetonitrile samples, generated as described above, was accomplished using an Agilent 6890 gas chromatograph with a 5973 Mass Selective Detector (GC/MS) equipped with a Varian VF-200ms column (15m x 0.25mm). Two different GC/MS methods were used, one for quantification of HMTD and one for qualitative analysis of more volatile compounds. Common to both methods were the following: inlet and transfer line temperatures were maintained at $150{ }^{\circ} \mathrm{C}$, the inlet was 
kept in splitless mode; flow rate, constant at $2.5 \mathrm{ml} / \mathrm{min}$, and the post-run oven temperature was always $310^{\circ} \mathrm{C}$ for $3 \mathrm{~min}$. The oven temperature program for the quantification method of HMTD started at $120^{\circ} \mathrm{C}$, and was held for 1 min, ramped 20 ${ }^{\circ} \mathrm{C} / \mathrm{min}$ to $140{ }^{\circ} \mathrm{C}$ and was held for $2 \mathrm{~min}$, and then ramped $10^{\circ} \mathrm{C} / \mathrm{min}$ to $250{ }^{\circ} \mathrm{C}$. The mass spectrometer scan parameters for the quantification of HMTD were from 50-350 $\mathrm{m} / \mathrm{z}$ at a rate of $4.72 \mathrm{scans} / \mathrm{sec}$. The oven temperature program used for qualitative analysis (i.e. product identification) started at $50{ }^{\circ} \mathrm{C}$ and was held for 1 min, ramped 20 ${ }^{\circ} \mathrm{C} / \mathrm{min}$ to $140{ }^{\circ} \mathrm{C}$ and was held for $2 \mathrm{~min}$, then ramped $10{ }^{\circ} \mathrm{C} / \mathrm{min}$ to $250{ }^{\circ} \mathrm{C}$. The mass scan parameters were from $15-450 \mathrm{~m} / \mathrm{z}$ at a rate of $3.35 \mathrm{scans} / \mathrm{sec}$.

\subsection{Headspace Analysis - GC/MS}

Headspace of the HMTD was sampled via gas-tight syringe $(5 \mathrm{~mL}$ or $1 \mathrm{~mL})$ or Solid Phase Microextraction (SPME) fiber (SUPELCO fused silica coated with $65 \mu \mathrm{m}$ of PDMS/DVB). The former was used for permanent gases; the latter for volatile amines. SPME fibers were flushed under helium $45 \mathrm{~min}$ at $250{ }^{\circ} \mathrm{C}$ prior to use. They were exposed to the samples for at least $3 \mathrm{hrs}$ at room temperature and analyzed using a Thermo GC Ultra-ISQ GC/MS equipped with a PoraPlot Amines column (25 m X $0.32 \mathrm{~mm}$ ) and a $2 \mathrm{~m}$ particle trap. Initial oven temperature was $100{ }^{\circ} \mathrm{C}$, with a $20{ }^{\circ} \mathrm{C} / \mathrm{min}$ heating ramp to $220{ }^{\circ} \mathrm{C}$ where it was held 20 minutes. Inlet temperature was $220{ }^{\circ} \mathrm{C}$; and column was used in constant pressure mode (10 psi). MS scans were from 35-200 $\mathrm{m} / \mathrm{z}$ at 5 scans/sec; transfer line and source were at $220{ }^{\circ} \mathrm{C}$. Permanent gases were analyzed with an Agilent 6890 GC with 5973 MS detector with Molsieve 5A Plot column (10 m X $0.32 \mathrm{~mm})$; initial oven temperature was $70{ }^{\circ} \mathrm{C}$ for $1 \mathrm{~min}$, followed by a $50{ }^{\circ} \mathrm{C} / \mathrm{min}$ ramp to $300^{\circ} \mathrm{C}$ and held there for $15 \mathrm{~min}$. Transfer line was set at $300{ }^{\circ} \mathrm{C}$; 
the flow rate, at $2.5 \mathrm{~mL} / \mathrm{min}$. Two injection methods were used. A $5 \mu \mathrm{L}$ injection with 5:1 split ratio was used to detect $\mathrm{O}_{2}$ and $\mathrm{N}_{2}$ signals; a $1 \mathrm{~mL}$ injection with a $1: 1$ split ratio was used for traces of other small molecules. The mass spectrometer scan parameters were from 10 to $100 \mathrm{~m} / \mathrm{z}$ at12.89 scans/sec.

\subsection{Condensed Phase Analysis - LC/MS}

Liquid chromatography / mass spectrometry (LC/MS) analysis was conducted using modified procedures recently published [12]. HMTD samples were typically provided as approximately $1 \mathrm{mg} / \mathrm{mL}$ solutions in acetonitrile. Samples were diluted by placing $10 \mu \mathrm{L}$ of this solution into $1 \mathrm{~mL}$ of $50 / 50(\mathrm{v} / \mathrm{v})$ acetonitrile/water. Injections of $20 \mu \mathrm{L}(\sim 200 \mathrm{ng})$ were made onto the HPLC/MS system. Data collection and analysis was performed with Thermo Xcalibur software version 2.2, SP 1.48. Using a Thermo Electron (Franklin, MA, USA) Exactive Orbitrap mass spectrometer affixed with an atmospheric pressure chemical ionization (APCI) interface, positive ions were produced and introduced into the instrument. Tune conditions were as follows: spray voltage, $5000 \mathrm{~V}$; capillary temperature, $140{ }^{\circ} \mathrm{C}$; sheath gas $\left(\mathrm{N}_{2}\right), 30$; auxiliary gas $\left(\mathrm{N}_{2}\right), 15$; heater temperature $160^{\circ} \mathrm{C}$; capillary voltage, $40 \mathrm{~V}$; tube lens, $160 \mathrm{~V}$; and skimmer, $15 \mathrm{~V}$. Units for sheath and auxiliary gas flow are arbitrary. Liquid chromatography was performed using a Thermo Electron Accela quaternary pump. Sample injections were performed by a CTC Analytics (Zwingen, Switzerland) HTS PAL autosampler.

Due to the highly polar nature of the decomposition products, three methods were employed to identify these compounds. Initial reverse phase chromatography used a Thermo Scientific (Franklin, MA, USA) Hypersil C-18 (2.1 x 100 mm, $5 \mu \mathrm{m})$ column. This method consisted of an initial mobile phase of $95 \%$ solvent B ( $0.1 \%$ acetic acid $)$ 
and $5 \%$ solvent $\mathrm{C}$ (acetonitrile). It was held for 2 minutes and then linearly ramped to $5 \% \mathrm{~B}$ and $95 \% \mathrm{C}$ over 18 minutes. This was held for 2 minutes, returned to initial conditions over 1 minute and the re-equilibrated for 5 minutes. A second HPLC system was developed for optimum analysis of HMTD and hexamine; it employed an Advantage PFP column $(100 \times 2.1 \mathrm{~mm}, 5 \mu \mathrm{m})$ (Analytical Sales \& Service, Pompton Plains). In order to gain some retention of hexamine, neutral $\mathrm{pH}$ conditions were preferable, but this caused broadening of the HMTD peak shape. To remedy this problem, three different mobile phase solvents were used to provide both $\mathrm{pH}$ and solvent strength gradients. Initially, $95 \%$ solvent $\mathrm{A}(10 \mathrm{mM}$ ammonium acetate, $\mathrm{pH} 6.8)$ and $5 \%$ solvent $\mathrm{C}$ (acetonitrile) were held for 3 minutes following injection to retain hexamine. The system was then rapidly ramped to $85 \%$ solvent B (0.1\% acetic acid), $5 \%$ solvent $\mathrm{A}$ and $10 \%$ solvent $\mathrm{C}$ over the next 3 minutes. Organic levels increased slowly for 9 minutes to $35 \% \mathrm{C}, 60 \% \mathrm{~B}$ and $5 \% \mathrm{~A}$, then rapidly for 3 minutes to $90 \%$ $\mathrm{C}$ and $5 \%$ of both $\mathrm{A}$ and $\mathrm{B}$. This was held for 2 minutes before returning to initial conditions and re-equilibrated for 5 minutes prior to the next injection. Although this method revealed HMTD and most of the decomposition products, e.g. hexamine, a substantial number of species were still so polar that they were negligibly retained by this method. A third system employed an aqueous normal phase method using an Analytical Sales and Service Advantage 100 Silica column (150 mm x $2.1 \mathrm{~mm}, 5 \mu \mathrm{m})$. Initial conditions of $95 \%$ solvent $\mathrm{C}$ and $5 \%$ solvent $\mathrm{D}$ (methanol) were held for 2 minutes before ramping to $5 \% \mathrm{C}$ and $95 \% \mathrm{D}$ over 6 minutes. Solvent $\mathrm{C}$ was then replaced with solvent B over 1 minute and then ramped to $60 \%$ B to $40 \%$ D over 10 minutes. After holding this for 2 minutes, it was ramped back to $95 \% \mathrm{D}$ and $5 \% \mathrm{~B}$ 
over 2 minutes then $95 \% \mathrm{D}$ and $5 \% \mathrm{C}$ over 1 minute. Initial conditions were returned over 2 minutes and held for 5 minutes before the next injection. This method required the use of electrospray ionization (ESI); however, this ionization mechanism is not optimal for HMTD detection.

\section{Results and Discussion}

Previously reported were thermal decomposition kinetics of HMTD determined by manometry [Ea $107 \mathrm{~kJ} / \mathrm{mol}$ and $\mathrm{A}=4.21 \times 10^{10} \mathrm{~s}^{-1}$ ] and HMTD fragmentation by electron impact mass spectrometry [13-15]. Here, we examine factors which influence the stability of HMTD. It is the standard protocol of this lab that following synthesis a purification step is performed to promote stability. Unfortunately, HMTD had only limited solubility even in the most polar solvent requiring large volumes of ethyl acetate and acetonitrile for recrystallization which were almost impossible to remove completely from HMTD. For that reason, many of the studies were conducted with both crude and recrystallized HMTD to ensure the presence of trace solvent had not biased results. 


\subsection{HMTD Headspace}

Since HMTD decomposition was readily observed at $60{ }^{\circ} \mathrm{C}$, significant decomposition at ambient temperature was probable. In fact, when HMTD was removed from storage at $-15{ }^{\circ} \mathrm{C}$ (freezer temperature), it developed a noticeable odor after a couple of hours. Headspace samples of both crude and recrystallized HMTD, fresh and aged, were analyzed by GC/MS. When HMTD was heated for a week at 60 ${ }^{\circ} \mathrm{C}$ in $30 \%$ relative humidity, or under a variety of conditions, the predominant decomposition products observed in the headspace were trimethylamine (TMA) and dimethylformamide (DMF) with trace quantities of ethylenimine (EN), methyl formamide (MFM), formamide (FM) and hexamine. When moisture was present 1methyl-1H-1,2,4-triazole and pyrazine were observed. Figure 1 shows that these compounds were found in headspace of HMTD sample stored at room temperature for one year. In addition, while permanent gases, oxygen and nitrogen, were not found, carbon monoxide and carbon dioxide occurred in significant amounts. HMTD was not observed in the headspace by GC/MS under dry, moist, acidic, or basic conditions. Since HMTD could be identified in ACN solutions, either HMTD content in headspace was below the detection limits of our GC/MS system or due to its reactivity, occurrence was not sustainable in the headspace. 


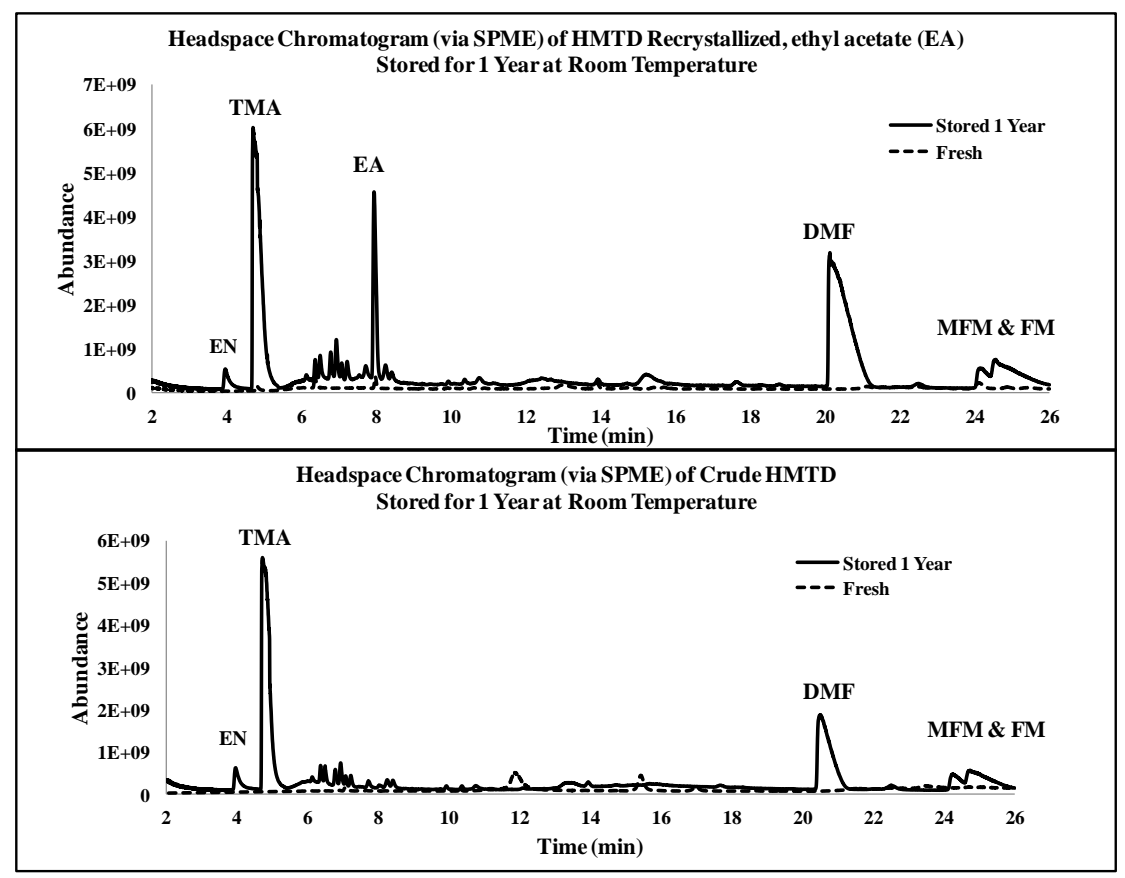

Figure 1.1. HMTD headspace chromatography [trimethylamine (TMA),

dimethylformamide (DMF), ethylenimine (EN), methyl formamide (MFM), formamide (FM)].

\subsection{Effect of Additives on HMTD Decomposition}

The effect of additives on HMTD stability was screened by DSC. A general trend was readily observed: acids lower the temperature at which the exothermic maximum appeared (Table 1). We had previously demonstrated that concentrated mineral acid could be used to destroy HMTD [16]. We and others also observed that aqueous basic solutions rapidly decompose HMTD [17]. To determine the effect of select additives without water, HMTD was held at $60 \mathrm{oC}$ for a week at $30 \% \mathrm{RH}$, and of these additives, only citric acid markedly accelerated HMTD decomposition (Tables 2). The fact that water and citric acid, both used in the synthesis of HMTD, lowered its 
thermal stability markedly emphasizes the need to thoroughly rinse and dry HMTD. Headspace monitoring revealed that water, citric acid or any acidity sped up the production of TMA and DMF in the gas phase.

Table 1.1. Effect of Solid Additives on HMTD Stability.

\begin{tabular}{|l|r|}
\hline \multicolumn{2}{|c|}{$30 \% \mathrm{RH} 60^{\circ} \mathrm{C} 1$ week } \\
\hline $\begin{array}{l}\mathrm{HMTD} \text { Solid } \\
\text { Additive (15\%) }\end{array}$ & $\begin{array}{l}\text { Average \% } \\
\text { Remaining }\end{array}$ \\
\hline None & 87 \\
\hline $\mathrm{NaHCO}_{3}$ & 87 \\
\hline $\mathrm{KH}_{2} \mathrm{PO}_{4}$ & 96 \\
\hline $\mathrm{NaOH} \mathrm{OH}$ \\
\hline $\mathrm{KTButoxide}$ & 80 \\
\hline Citric Acid & 13 \\
\hline
\end{tabular}


Table 1.2. DSC of HMTD with Additives $\left(20^{\circ} \mathrm{C} / \mathrm{min}\right)$.

\begin{tabular}{|c|c|c|c|c|c|}
\hline Material & $\begin{array}{c}\mathrm{pKa} \text { of } \\
\text { Additive }\end{array}$ & $\begin{array}{c}\mathrm{pKb} \text { of } \\
\text { Additive }\end{array}$ & $\begin{array}{c}\text { Onset } \\
\text { Temp. of } \\
\text { Exotherm } \\
\left({ }^{\circ} \mathrm{C}\right)\end{array}$ & $\begin{array}{l}\text { Exotherm } \\
\text { Temp. } \\
\text { Maximum } \\
\left({ }^{\circ} \mathrm{C}\right) \\
\end{array}$ & $\begin{array}{c}\text { Heat } \\
\text { Released } \\
(\mathrm{J} / \mathrm{g}) \\
\end{array}$ \\
\hline $18.2 \mathrm{M} \Omega \mathrm{H} 2 \mathrm{O}$ & 14.00 & 0.00 & & & \\
\hline HMTD Crude & N/A & N/A & 159 & 161 & 2100 \\
\hline HMTD Rec 70/30 EA/CAN & N/A & N/A & 168 & 171 & 3200 \\
\hline \multicolumn{6}{|c|}{ HMTD + Aqueous Solution } \\
\hline HMTD Crude $+2 \mathrm{ul} \mathrm{H} 2 \mathrm{O}$ & N/A & N/A & 136 & 140 & 3100 \\
\hline HMTD Rec 70/30 EA/ACN + 2ul H2O & N/A & N/A & 140 & 143 & 3200 \\
\hline HMTD Crude +2ul pH4 Buffer & N/A & N/A & 126 & 129 & 3700 \\
\hline HMTD Crude $+2 \mathrm{ul} \mathrm{pH7}$ Buffer & N/A & N/A & 134 & 137 & 3300 \\
\hline HMTD Crude $+2 \mathrm{ul}$ pH10 Buffer & N/A & N/A & 137 & 139 & 3100 \\
\hline \multicolumn{6}{|c|}{ HMTD + Solvents } \\
\hline HMTD Crude +2 ul ACN & N/A & N/A & 152 & 178 & 3000 \\
\hline HMTD Crude +2 ul Benzene & N/A & N/A & 166 & 172 & 3200 \\
\hline HMTD Crude + 2ul EtOH & N/A & N/A & 153 & 164 & 2800 \\
\hline HMTD Crude $+2 \mathrm{ul} \mathrm{EtAc}$ & N/A & N/A & 156 & 169 & 2800 \\
\hline \multicolumn{6}{|c|}{ HMTD + Solid Acids } \\
\hline HMTD Crude $+\mathrm{KH}_{2} \mathrm{PO}_{4} 15 \%$ & 7.21 & 6.79 & 163 & 165 & 2100 \\
\hline HMTD Crude + KH Phthalate $15 \%$ & 5.43 & 8.57 & 156 & 157 & 1900 \\
\hline HMTD Crude + Benzoic Acid 15\% & 4.20 & 9.80 & 155 & 160 & 2600 \\
\hline HMTD Crude + Ascorbic Acid $15 \%$ & 4.04 & 9.96 & 146 & 148 & 2000 \\
\hline HMTD Crude + Citric Acid $15 \%$ & 3.13 & 10.87 & 134 & 137 & 2800 \\
\hline HMTD Crude + Sulfanilic Acid 15\% & 3.01 & 10.99 & 122 & 125 & 2400 \\
\hline HMTD Crude + O Phthalic Acid $15 \%$ & 2.94 & 11.06 & 143 & 145 & 2000 \\
\hline \multicolumn{6}{|c|}{ HMTD + Solid Bases } \\
\hline HMTD Crude + Melamine 15\% & 5.00 & 9.00 & 158 & 159 & 2000 \\
\hline HMTD Crude $+\mathrm{NaHCO}_{3} 15 \% *$ & 6.35 & 7.65 & 163 & 164 & 1300 \\
\hline HMTD Crude $+\mathrm{KH}_{2} \mathrm{PO}_{4} 15 \%$ & 7.21 & 6.79 & 163 & 165 & 2100 \\
\hline HMTD Crude + NaOH $15 \%$ & 14.00 & 0.00 & 160 & 161 & 2300 \\
\hline HMTD Crude + $\mathrm{NaOH} 30 \%$ & 14.00 & 0.00 & 162 & 164 & 2100 \\
\hline HMTD Crude + K Tertbutoxide $15 \%$ & 17.00 & -3.00 & 159 & 160 & 2200 \\
\hline
\end{tabular}

$* \mathrm{NaHCO}_{3}$ has an endotherm which lowers the total heat released 


\subsection{Effect of Humidity on HMTD Decomposition}

In 1924, it was reported: “That H.M.T.D. is stable at temperatures up to at least $60{ }^{\circ} \mathrm{C}$; it is not affected by storage under water; but it is slowly affected when subjected to high humidity at maximum summer temperature....It is practically nonhygroscopic"[17]. Since DSC results did not support this statement, samples of crude HMTD were held at $60{ }^{\circ} \mathrm{C}$ with fixed humidity values of $0,30,75$, or $100 \% \mathrm{RH}$ and monitored each week for four weeks (Figure 2). After 2 weeks, the samples of HMTD at high relative humidity (i.e. $75 \% \mathrm{RH}$ and $100 \% \mathrm{RH}$ ) were completely degraded; HMTD was not observed by GC/MS.

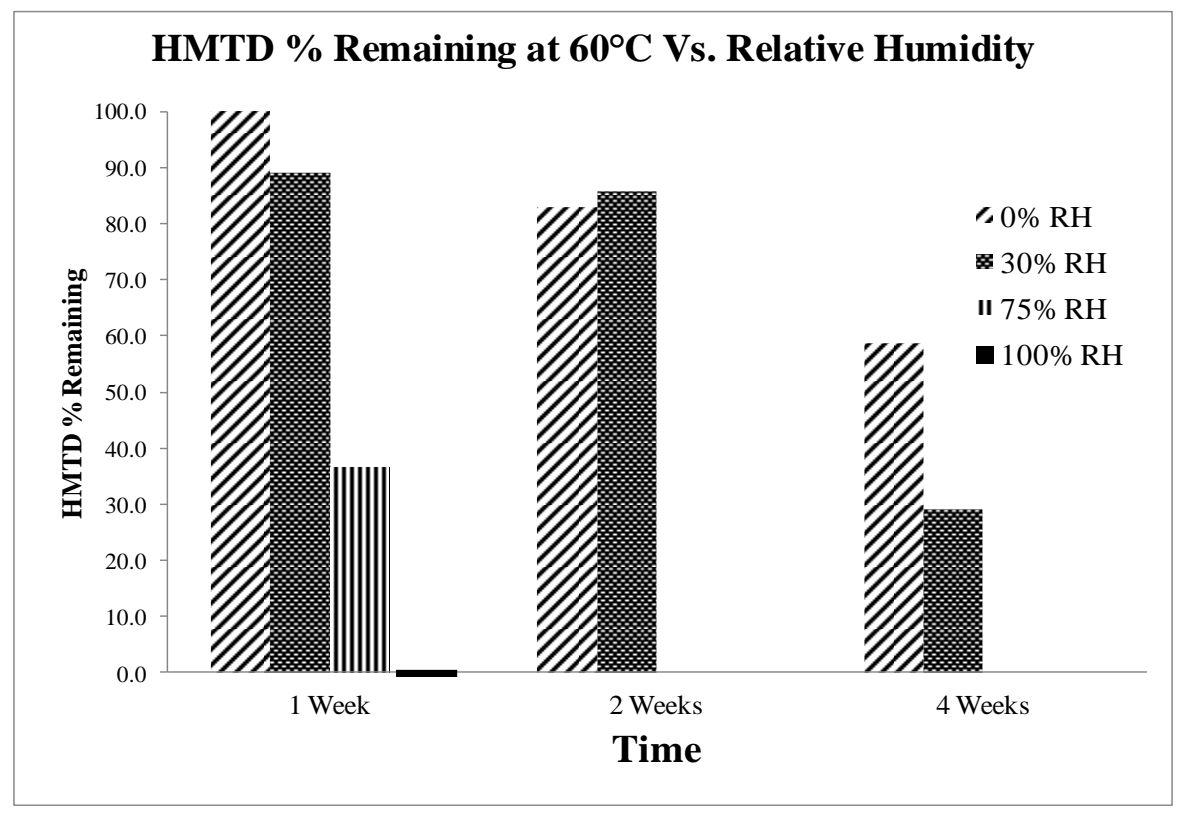

Figure 1.2. Effect of humidity on HMTD.

In Figure 3 the effects of humidity on crude and recrystallized HMTD are particularly informative. Crude and recrystallized HMTD stored dry at $60{ }^{\circ} \mathrm{C}$ undergo only slight decomposition while samples stored at high humidity (i.e. $75 \% \mathrm{RH}$ ) experience significant decomposition. 


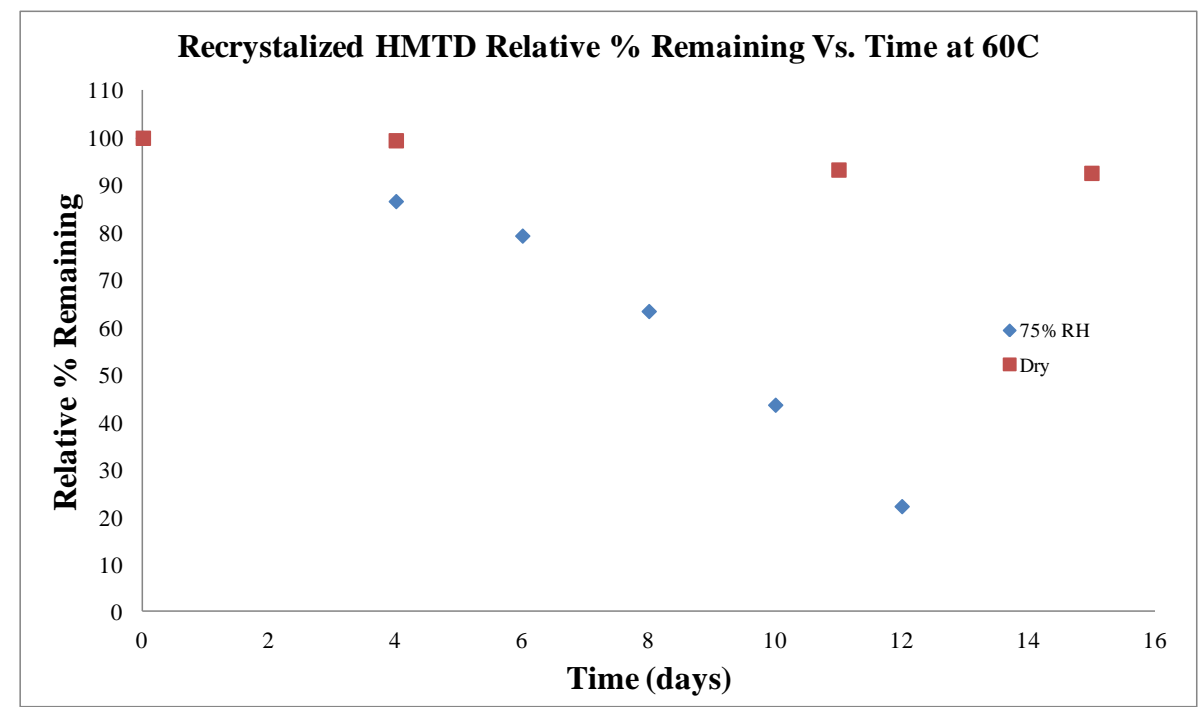

Figure 1.3. Effect of humidity on crude and recrystallized HMTD.

\subsection{Mass Spectral Analysis of Condensed-Phase Synthesis and Decomposition}

\section{Products}

HMTD was heated at $60{ }^{\circ} \mathrm{C}$ under various conditions. Products were examined by GC/MS and LC/MS; and assignments are shown in Table 3 and Table 4, respectively. Assignments are based on comparison with the authentic samples [3.2, 3.5, 3.8, 3.11, 4.2, 4.8, 4.15, 4.22, and HMTD] and on the high resolution mass spectrometric results where compositions could be assigned to within $5 \mathrm{ppm}$ of their calculated mass (Table 4). Examining the HMTD decomposition products, it is tempting to suggest HMTD thermolysis produces a number of small molecular fragments, e.g. $\mathrm{CH}_{2} \mathrm{O}, \mathrm{NH}_{3}, \mathrm{CH}_{2} \mathrm{NH}$ or $\mathrm{CH}(\mathrm{O}) \mathrm{NH}_{2}$ which undergo further reaction, such as an aldehyde-amine condensation. The observed substituted triazine species $(3.10,3.11,3.12)$ and those containing four nitrogens have been reported to be products of hexamethylenetetramine (hexamine) reactions $[8,10,18]$. Indeed, hexamine was found when HMTD was decomposed at $60^{\circ} \mathrm{C}$ with $75 \%$ or $100 \% \mathrm{RH}$ or with added water or acidic buffer. Only tetramethylene 
diperoxide diamine dialdehyde (TMDDD) (4.22), matched to an authentic sample and the mono-aldehyde (3.7) suggested the original HMTD structure; and that HMTD was degraded stepwise.

In examining HMTD decomposition, we speculated the degradation products formed hexamine. Hexamine is made from ammonia and formaldehyde, and the route is via hexahydro-1,3,5-triazine[8,19]. The conversion of hexamine to 2,4,6cyclotrimethylene-1,3,5-trinitramine (RDX) has been the subject of several studies. Thermal degradation of hexamine forms hexahydro-1,3,5-triazine, octahydro-1,3,5,7tetrazocine, and 1,3,5,7-tetrazabicyclo-[3.3.1]-nonane [20]. Bachman found that performing the nitration of hexamine in acetic anhydride with ammonium nitrate allowed two moles of RDX to be produced rather than one via direct nitration [21]. The question was whether the extra RDX came from fragments of hexamine or nitramines $\mathrm{CH}_{2} \mathrm{NNO}_{2}$ or directly from hexamine. On the basis of the observed by-products, Aristoff et al concluded that degradation of hexamine, itself, and not combination of smaller fragments, was the route by which RDX is formed [22]. Gilbert also confirmed this later by showing that RDX can be obtained by the direct nitrolysis of substituted triazine rings [10].

In the synthesis of HMTD from hexamine the question of stoichiometry arises. Under the normal synthetic route as it is describe in equation 1; our yield, based on hexamine, was not more than $60 \%$. However, if excess formaldehyde was added to the reaction mixture, yields of greater than $100 \%$ (based on 1 HMTD to 1 hexamine) were observed, and the reaction rate increases (precipitation of HMTD started to occur in 2 hrs compared to 5-6 hrs without formaldehyde). Equation 2 describes that reaction and 
may also describe what occurs when no extra formaldehyde is added and the reaction must wait for the degradation of part of the hexamine to form formaldehyde (Figure 4). Indeed, hexamine is frequently used as a source of formaldehyde [18,23]. 
Table 1.3. Decomposition products GC/MS.

\begin{tabular}{|c|c|c|c|c|}
\hline \# & $\mathrm{m} / \mathrm{z}$ & Identity & amou & conditions \\
\hline 3.1 & 73 & & L & $\begin{array}{c}\text { DRY (0 \% RH) } \\
\text { \& HUMID ( } \geq 75 \% \text { RH) }\end{array}$ \\
\hline 3.2 & 75 & & L & $\begin{array}{c}\text { MATCHED TO } \\
\text { AUTHENTIC SAMPLE; } \\
\text { MAINLY SEEN IN } \\
\text { HUMID CONDITIONS }\end{array}$ \\
\hline 3.3 & 103 & & M & $\begin{array}{c}\text { MAINLY SEEN IN } \\
\text { HUMID CONDITIONS }\end{array}$ \\
\hline 3.4 & 88 & & S & \\
\hline 3.5 & 84,102 & & L & $\begin{array}{c}\text { MATCHED TO } \\
\text { AUTHENTIC SAMPLE; } \\
\text { DRY CONDIIINNS }\end{array}$ \\
\hline 3.6 & 116 & & $\mathrm{~L}$ & DRY CONDITIONS \\
\hline 3.8 & 178 & & S & $\begin{array}{c}\text { BOTH IN DRY \& HUMID } \\
\text { CONDITIONS }\end{array}$ \\
\hline 3.9 & 140 & & M & $\begin{array}{l}\text { MATCHED TO } \\
\text { AUTHENTIC SAMPLE; } \\
\text { MAINLY SEEN IN } \\
\text { HUMID OR ACIDIC } \\
\text { CONDITIONS }\end{array}$ \\
\hline 3.10 & 208 & & L & \\
\hline 3.11 & 143 & & S & \\
\hline 3.12 & 171 & & L & $\begin{array}{c}\text { MATCHED TO } \\
\text { AUTHENTIC SAMPLE; } \\
\text { MAINLY SEEN IN } \\
\text { HUMID CONDITIONS }\end{array}$ \\
\hline 3.13 & 157 & & S & $\begin{array}{l}\text { MAINLY SEEN IN DRY } \\
\text { CONDITIONS }\end{array}$ \\
\hline
\end{tabular}


Table 1.4. Decomposition products LC/MS.

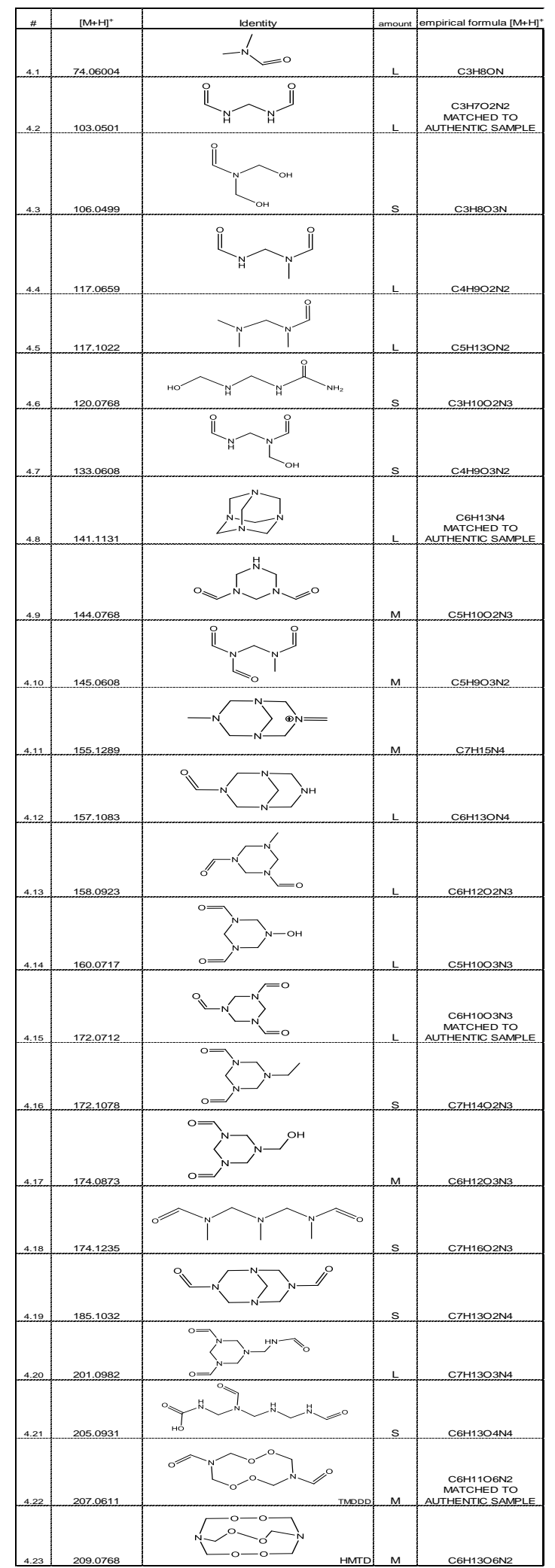




$$
\mathrm{C}_{6} \mathrm{~N}_{4} \mathrm{H}_{12}+3 \mathrm{H}_{2} \mathrm{O}_{2} \rightarrow \mathrm{C}_{6} \mathrm{~N}_{2} \mathrm{H}_{12} \mathrm{O}_{6}+2 \mathrm{NH}_{3}
$$

$\mathrm{C}_{6} \mathrm{~N}_{4} \mathrm{H}_{12}+6 \mathrm{H}_{2} \mathrm{O}_{2}+6 \mathrm{CH}_{2} \mathrm{O} \rightarrow 2 \mathrm{C}_{6} \mathrm{~N}_{2} \mathrm{H}_{12} \mathrm{O}_{6}+6 \mathrm{H}_{2} \mathrm{O}$

$$
\text { 2X( }
$$

Figure 1.4. Proposed hexamine decomposition.

Although not shown in the above reactions, without citric acid formation of HMTD takes days. Furthermore, the reaction is sensitive to the type and amount of acid (Table 5). Diprotic (sulfuric and oxalic) and triprotic (phosphoric) acids could be used as direct replacements for citric acid. Monoprotic acids (acetic acid, trifluoroacetic acid, formic acid, and nitric acid) gave yields comparable to citric acid only if these acids were added in $2.2 \mathrm{~mol}$ acid to $1 \mathrm{~mol}$ hexamine ratio. This aspect of the acid effect merits further examination. 
Table 1.5. HMTD Reactions with additives with Scaled Yield of 0.5g.

\begin{tabular}{|r|c|c|c|c|c|c|}
\hline $\begin{array}{r}\text { HMTD } \\
\text { Reaction \# }\end{array}$ & Additive & $\begin{array}{c}\text { Mol Ratio } \\
\text { of HP } \\
(48.4 \mathrm{wt} \%): \\
\text { Hexamine }\end{array}$ & $\begin{array}{c}\text { Mol Ratio } \\
\text { Acid } \\
\text { (Citric): } \\
\text { Hexamine }\end{array}$ & $\%$ Yield & MP $\left({ }^{\circ} \mathrm{C}\right)$ & $\begin{array}{c}\text { Purity by } \\
\text { GC/MS }\end{array}$ \\
\hline 5 & citric acid & 8 & $1.1: 1$ & 44.5 & $149-150$ & 87.4 \\
\hline 6 & citric acid & 8 & $1.1: 1$ & 40.7 & $144-145$ & 87.1 \\
\hline 17 & citric acid & 8 & $1.1: 1$ & 52.7 & $153-157$ & 95.8 \\
\hline 14 & anhydrous oxalic acid & 8 & $1.1: 1$ & 45.0 & $151-153$ & 94.4 \\
\hline 15 & $85 \%$ o-phosphoric acid & 8 & $1.1: 1$ & 26.9 & $149-150$ & 91.3 \\
\hline 32 & $50 \%$ sulfuric Acid & 8 & $1.1: 1$ & 50.5 & $152-158$ & 98.2 \\
\hline 13 & glacial acetic acid & 8 & $1.1: 1$ & 7.4 & $152-153$ & 94.3 \\
\hline 30 & glacial acetic acid & 8 & $2.2: 1$ & 33.1 & $151-156$ & 100.0 \\
\hline 21 & $88 \%$ formic Acid & 8 & $1.1: 1$ & 6.3 & $154-158$ & 94.5 \\
\hline 25 & $88 \%$ formic Acid & 8 & $2.2: 1$ & 43.5 & $153-154$ & 100.0 \\
\hline 22 & $99 \%$ TFA & 8 & $1.1: 1$ & 3.3 & $155-159$ & 93.3 \\
\hline 26 & $99 \%$ TFA & 8 & $2.2: 1$ & 53.5 & $153-156$ & 99.6 \\
\hline 31 & $70 \%$ nitric Acid & 8 & $2.2: 1$ & 51.1 & $155-157$ & 100.0 \\
\hline Kin. \#2 & no acid & 8 & $0: 1$ & 9.5 & $148-149$ & 89.5 \\
\hline Kin. \#3 & no acid & 8 & $0: 1$ & 7.2 & $152-160$ & 92.4 \\
\hline
\end{tabular}

If HMTD is formed when hexamine breaks into smaller fragments, then it should incorporate carbon and nitrogen from outside sources. When HMTD synthesis was performed with ${ }^{13} \mathrm{C}$ formaldehyde solution, the label appeared in both the HMTD (m/z $209,210,211,212,213)$ and the hexamine $(\mathrm{m} / \mathrm{z} 140,141,142,143,144)$ early in the reaction (42min when precipitation was observed in $2 \mathrm{hr}$ ). A possible explanation is formation of bis(hydroxymethyl) peroxide (BHMP) and its incorporation into HMTD (Figure 5). Incorporation of formaldehyde into the hexamine can be explained by looking at the first two steps of decomposition of hexamine (Figure 4). Excess formaldehyde may push this reaction in the reverse direction. However, HMTD synthesized in the presence of ${ }^{15} \mathrm{~N}$-labeled ammonium sulfate, showed little incorporation based on GC/MS and LC/MS results. 


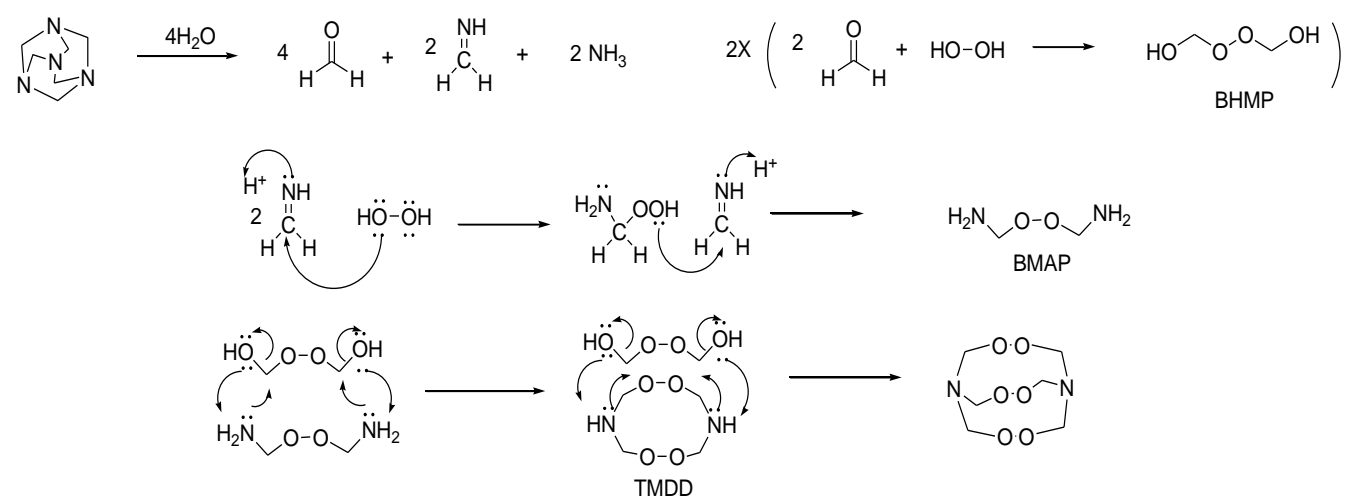

Figure 1.5. Formation of HMTD from completely dissociated hexamine.

In contrast to the lack of ${ }^{15} \mathrm{~N}$ incorporation during HMTD synthesis, it was found that under humid decomposition conditions, the ${ }^{15} \mathrm{~N}$ label was observed in the decomposition products $(4.2,4.12,4.13,4.14,4.15,4.17,4.20)$ as well as in hexamine (single, double, triple and quadruple label). Yet, when the same decomposition conditions were performed dry, no hexamine was formed and the decomposition products 4.2 and 4.14 showed no label incorporation.

In deuterium oxide, HMTD decomposition products trimethylamine, dimethylformamide, hexamine, and triazines showed little incorporation of deuterium ( $\mathrm{m} / \mathrm{z} 157,171$ etc.). This suggested that hydrogen transferred during the decomposition was from the original HMTD molecule.

A mechanism for HMTD formation was proposed on data from isotopic ratio mass spectrometry [24]. Because it required the formation of a triperoxy tertiary amine and protonated methylene imine, we sought alternative proposals. Tentative proposals are illustrated in Figures 5 and 6. In Figure 5 hexamine is broken into small molecules, and from the formaldehyde/hydrogen peroxide reaction bis(hydroxymethyl) peroxide (BHMP) is formed, while from the imine/ hydrogen peroxide reaction bis(methylamine) 
peroxide (BMAP) is formed. The latter reacts with 2 molecules of BHMP, forming tetramethylene diperoxide diamine (TMDD) as an intermediate, to create HMTD. The mechanism in Figure 6 also postulates the formation of BHMP but allows hexamine to remain moderately intact until fairly late in the reaction. Both mechanisms speculate that the reaction proceeds to HMTD faster in the presence of excess formaldehyde because formation does not require initial degradation of hexamine into formaldehyde. The key to both mechanisms is the formation of BHMP, first synthesized in 1914 by Fenton from hydrogen peroxide and formaldehyde and later studied by Satterfield [25]. It is likely this species was generated in situ in the reported syntheses of several caged peroxides having planar bridgehead nitrogen atoms [26]. Once a methylene is lost from hexamine as formaldehyde the resulting octahydro-1,3,5,7-tetrazocine would be subject to rapid ring inversion and isomerization from which BHMP could bridge across two nitrogens. 


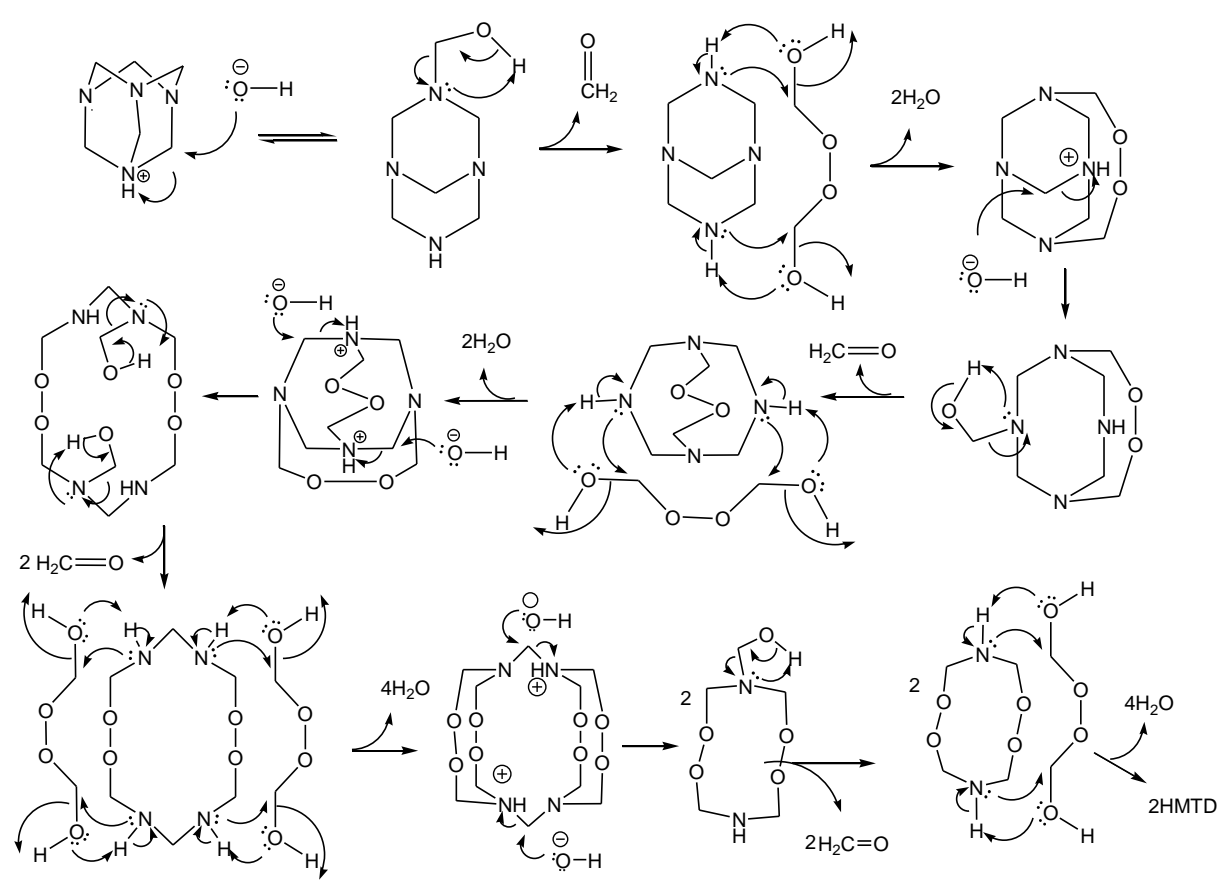

Figure 1.6. Formation of HMTD from intact hexamine. 
To discriminate between the mechanisms proposed in Figures 5 and 6, synthesis of HMTD was done with a 1 to 1 mixture of ${ }^{14} \mathrm{~N}$ hexamine and ${ }^{15} \mathrm{~N}$ hexamine. If the formation of HMTD proceed through the route shown in Figure 5, then complete scrambling of the label would be expected, i.e. the HMTD product should show the unlabeled, single-labeled and double-labeled species $[\mathrm{M}+\mathrm{H}], 209$ to 210 to 211 , in a 1 to 2 to 1 ratio. Indeed that was what was observed (Figure 7).

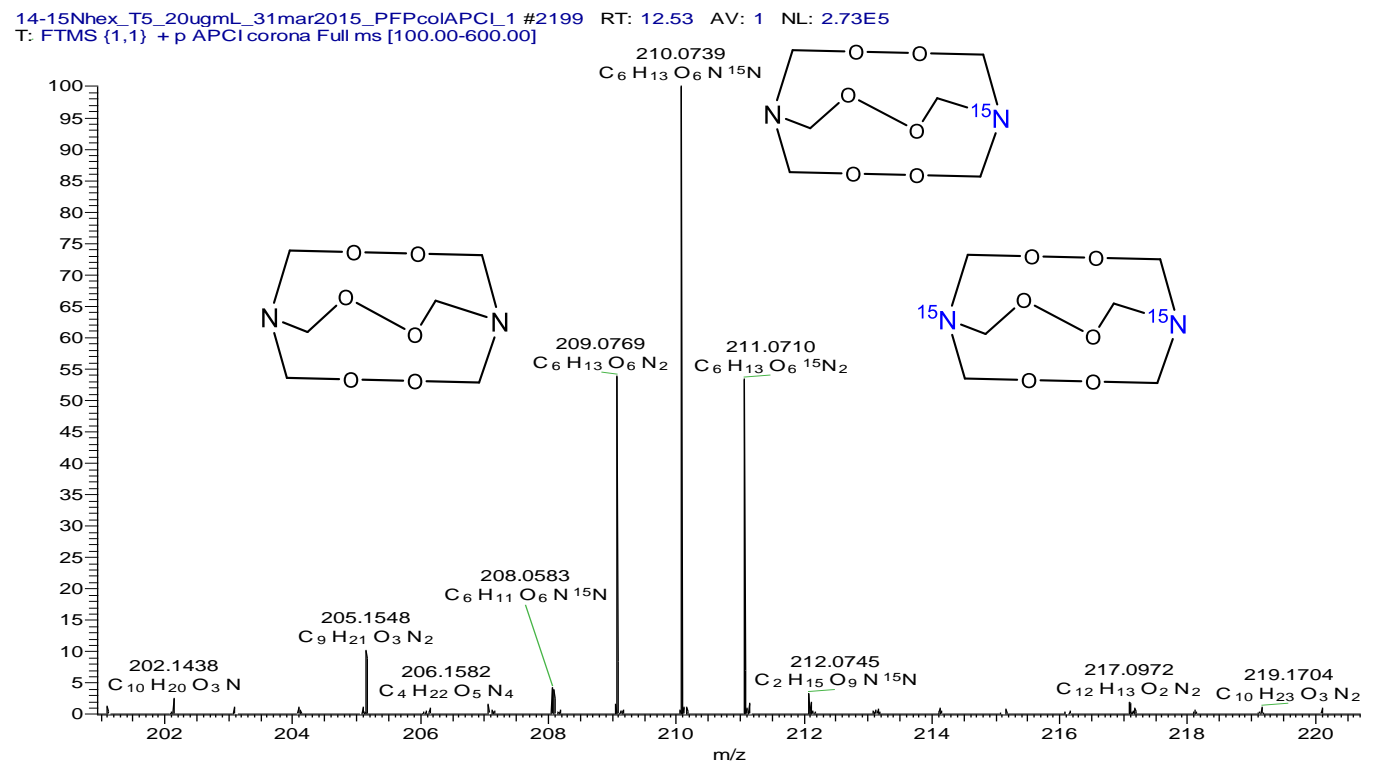

Figure 1.7. Mass spectrum of HMTD formed from a mixture of N-14 and N-15 labeled hexamine.

To shed light on the question of how HMTD decomposes, density functional theory (DFT) calculations were performed. The initial sequence of steps in the decomposition of a single HMTD molecule is described in Figure 8. Energy differences of the transition states and entropies of the various species along the decomposition pathway were calculated relative to the energy of the nearest intermediate or reactant to show energy barrier and entropy change for each decomposition reaction step. The 
calculations were carried out for both gas phase molecule (values without parenthesis) as well as for a solvated molecule in water (values in parenthesis). The structure and properties of the various intermediate species along the decomposition pathway are summarized in Table 6.

1) First step via TS1 consist of $\mathrm{O}-\mathrm{O}$ bond opening together with $\mathrm{H}$-atom transfer from the methylene group $\left(\mathrm{CH}_{2}\right)$ near one of the $\mathrm{O}$-atom to the $\mathrm{O}$-atom farther away. The transition state is an open shell singlet state (bi-radical). This is the rate limiting step in the decomposition process. Following TS hydrogen transfer, $\mathrm{O}-\mathrm{O}$ bond ruptured results in formation of $-\mathrm{OH}$ and $-\mathrm{C}=\mathrm{O}$ groups respectively in INT1.

2) Second step via TS2 is similar to the first step (step 1) and leads to rupture of second $\mathrm{O}-\mathrm{O}$ bond and a second $\mathrm{H}$ transfer to form two new $-\mathrm{OH}$ and $-\mathrm{C}=\mathrm{O}$ groups in INT2.

3) Third step via TS3 involves an $\mathrm{N}-\mathrm{C}$ bond opening concerted with $\mathrm{H}$-atom transfer from $\mathrm{O}$ in $\mathrm{CH}_{2} \mathrm{OH}$ group to $\mathrm{O}$ in $-\mathrm{CH}=\mathrm{O}$ group to yield INT3 and a formaldehyde molecule. 


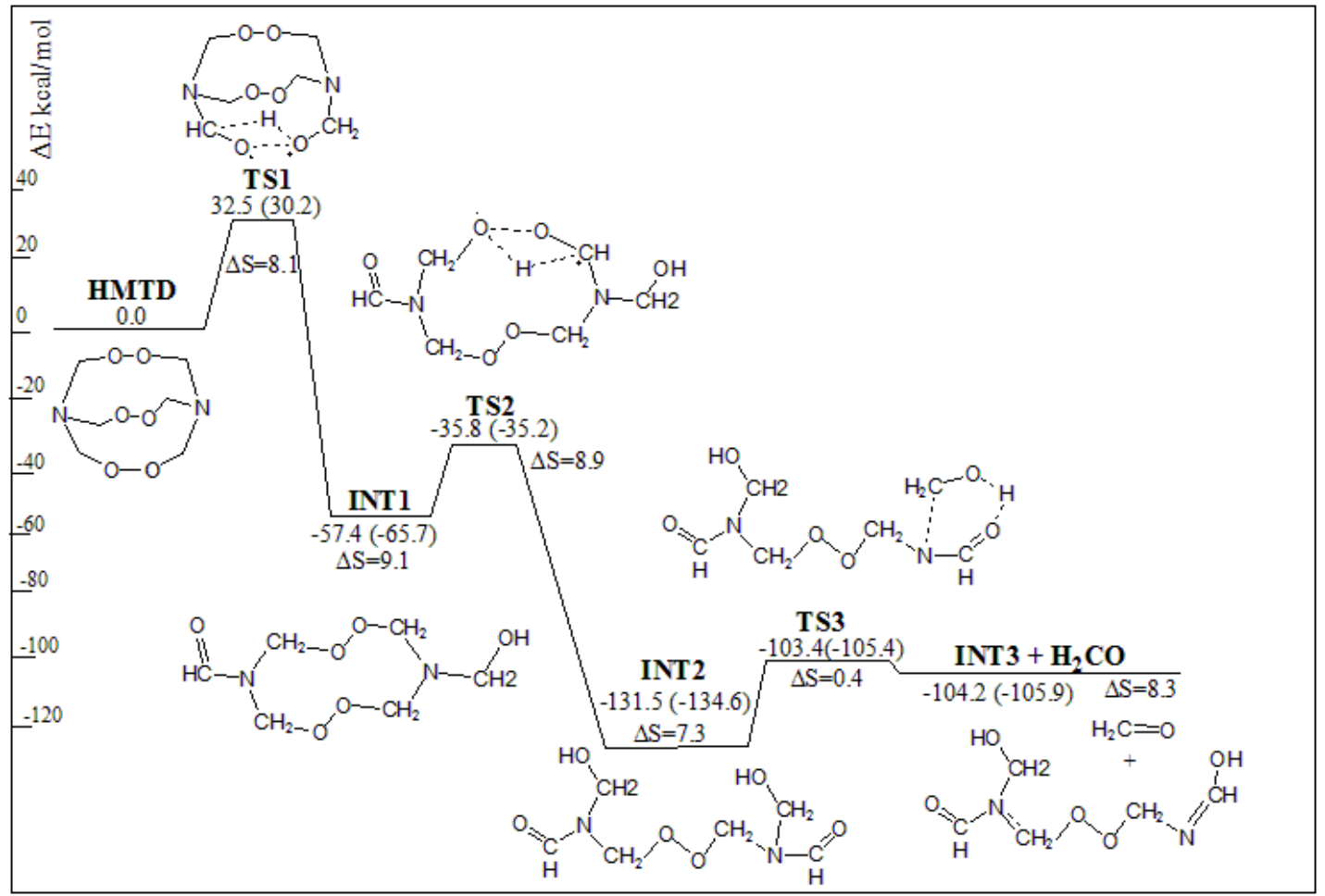

Figure 1.8. Decomposition route of an isolated HMTD molecule. Energy barriers and energies of intermediates for a gas phase molecule are without parenthesis while values of solvated molecule (in water) are in parenthesis. 
Table 1.6. Intermediates in the decomposition of gas phase HMTD. Calculations used PBE0PBE1/cc-pVDZ level of theory. Energy values in $\mathrm{kcal} / \mathrm{mol}$, entropy values in $\mathrm{cal} /(\mathrm{K} \mathrm{mol})$.

\begin{tabular}{|c|c|c|c|c|c|c|}
\hline \# & mass & structure & & name & $\mid \begin{array}{l}\text { Kinetic \& } \\
\text { thermochemical }\end{array}$ & $\begin{array}{l}\text { Reaction step } \\
\text { producing } \\
\text { intermediate }\end{array}$ \\
\hline 1 & 208 & & $\mathrm{C} 6 \mathrm{H} 12 \mathrm{O} 6 \mathrm{~N} 2$ & INT 1 & $\begin{array}{l}\Delta \mathrm{E}^{\#}=32.5(30.2), \\
\Delta \mathrm{S}^{\#}=8.1 \\
\Delta \mathrm{E}_{\text {react }}=-57.4(- \\
65.7), \Delta \mathrm{S}_{\text {react }}=9.1 \\
\begin{array}{l}\text { One O-O bond opening } \\
\text { together with } \mathrm{H}-\text { atom shift } \\
\text { from methylene group to } \\
\text { oxy gen }\end{array}\end{array}$ & HMTD $\rightarrow$ INT 1 \\
\hline 2 & 208 & $\mathrm{H}$ & $\mathrm{C} 6 \mathrm{H} 12 \mathrm{O} 6 \mathrm{~N} 2$ & INT2 & $\begin{array}{l}\Delta \mathrm{E}^{\#}=27.3(26.8), \\
\Delta \mathrm{S}^{\#}=8.9 \\
\Delta \mathrm{E}_{\text {react }}=-68.3(- \\
69.0), \Delta \mathrm{S}_{\text {react }}=7.3 \\
\text { relative INT1 } \\
\Delta \mathrm{E}_{\text {react }}=-131.5(- \\
134.6), \Delta \mathrm{S}_{\text {react }}=16.4 \\
\text { relative HMTD } \\
\text { Second O-O bond opening } \\
\text { together with H-atom shift } \\
\text { from methylene group to } \\
\text { oxy gen }\end{array}$ & INT $1 \rightarrow$ INT 2 \\
\hline 3 & 178 & $\mathrm{C}_{\mathrm{H}}$ & С5H10O5N2 & & $\begin{array}{l}\Delta \mathrm{E}_{\text {react }}=27.2(28.7), \\
\Delta \mathrm{S}_{\text {react }}=8.7 \text { relative } \\
\mathrm{INT} 2 \\
\Delta \mathrm{E}_{\text {react }}=-104.2(- \\
105.9), \Delta \mathrm{S}_{\text {react }}=25.0 \\
\text { relative HMTD }\end{array}$ & $\begin{array}{l}\text { INT 2 } \rightarrow \rightarrow \text { INT3+ } \\
\mathrm{H}_{2} \mathrm{CO}\end{array}$ \\
\hline 4 & 104 & $\mathrm{H}$ & $\begin{array}{l}\text { C3H603N } \\
\text { (radical) }\end{array}$ & INT 4 & $\begin{array}{l}\mathrm{INT} 4+\mathrm{INT} 5 \\
\Delta \mathrm{E}^{\#}=24.8(24.0) \\
\Delta \mathrm{S}^{\#}=3.6 \\
\Delta \mathrm{E}_{\text {react }}=22.1(21.6) \\
\Delta \mathrm{S}_{\text {react }}=10.9 \text { relative } \\
\mathrm{INT3}\end{array}$ & $\begin{array}{l}\text { INT3 } \rightarrow \text { INT 4 + } \\
\text { INT5 }\end{array}$ \\
\hline 5 & 74 & & $\begin{array}{l}\mathrm{C} 2 \mathrm{H} 4 \mathrm{O} 2 \mathrm{~N} \\
\text { (radical) }\end{array}$ & INT 5 & & \\
\hline & 178 & & $\mathrm{C} 5 \mathrm{H} 11 \mathrm{O} 5 \mathrm{~N} 2$ & INT6 & $\begin{array}{l}\Delta \mathrm{E}^{\#}=10.9(11.3), \\
\Delta \mathrm{S}^{\#}=-6.8 \\
\Delta \mathrm{E}_{\text {react }}=0.1(-0.1) \\
\Delta \mathrm{S}_{\text {react }}=-6.6 \text { relative } \\
\mathrm{INT3}\end{array}$ & INT $3 \rightarrow$ INT 6 \\
\hline
\end{tabular}


The following step in this pathway is the decomposition of INT3 into two new species or isomerization into a 7-member ring as shown in Figure 9. The formation of two radials, INT4 and INT5, is favorable according to the entropy changes; however, INT6 formation should be favorable due to a lower energy barrier to overcome.

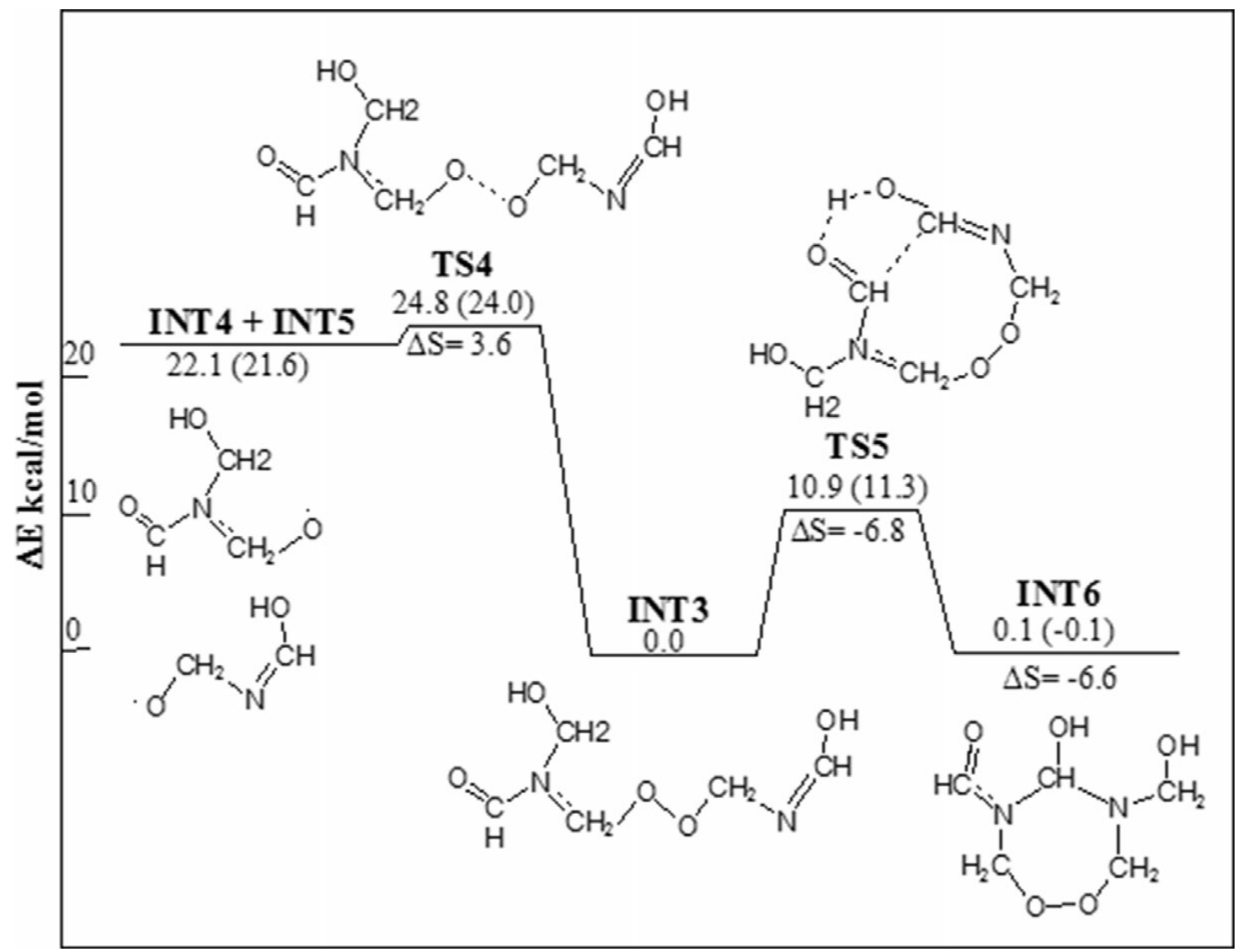

Figure 1.9. The next steps in the decomposition of an isolated HMTD molecule.

Energy barriers and energies of intermediates for a gas phase molecule are without parenthesis while values of solvated molecule (in water) are in parenthesis. 
Next, we considered the decomposition of the HMTD molecule in an acidic environment. A proton can attach to either an oxygen atom or a nitrogen atom. Protonated HMTD forms spontaneously without an appreciable energy barrier. When a proton is attached to one of the nitrogen atoms, the first step in decomposition of the cation will proceed via a $\mathrm{C}-\mathrm{N}$ bond rupture. The energy barrier associated with this event is much higher than that obtained for the first step in the decomposition of a protonated oxygen atom in the HMTD molecule. Moreover, the barrier associated with the O-atom protonation is also smaller than the magnitude of the energy barrier associated with TS1 in Figure 8. A summary of the energy barriers related to the possible initial steps in the different decomposition schemes are shown in Figure 10. In the case of O-atom protonation we revealed two possible decomposition routes that are denoted as Path A and Path B. The intermediates for these two paths are named INTHOA and INTHOB, respectively. The main difference between these two decomposition routes is that Path $\mathrm{A}$ proceeds via $\mathrm{C}-\mathrm{O}$ bond opening while path $\mathrm{B}$ via $\mathrm{O}-\mathrm{O}$ opening. A summary of the structures and properties of all the intermediate species along Path A and Path B are described in Tables 7 and 8, respectively. 


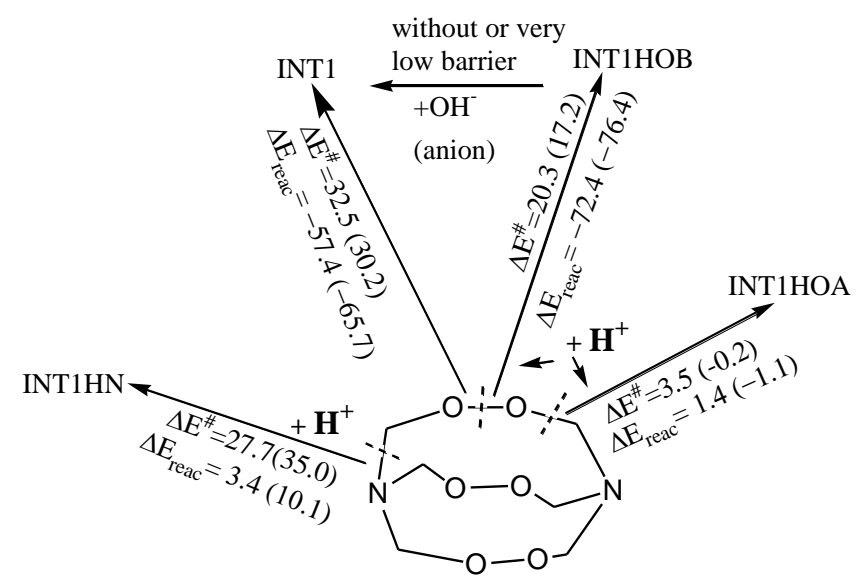

Figure 1.10. Scheme showing all the possible initial decomposition steps of HMTD molecule in different environments. 
Table 1.7. Intermediates observed along path A during the decomposition of HMTD molecule with a protonated oxygen. The calculations were performed using PBE0PBE1/cc-pVDZ level of theory. Energy values in kcal/mol, entropy values in $\mathrm{cal} /(\mathrm{K} \mathrm{mol})$.

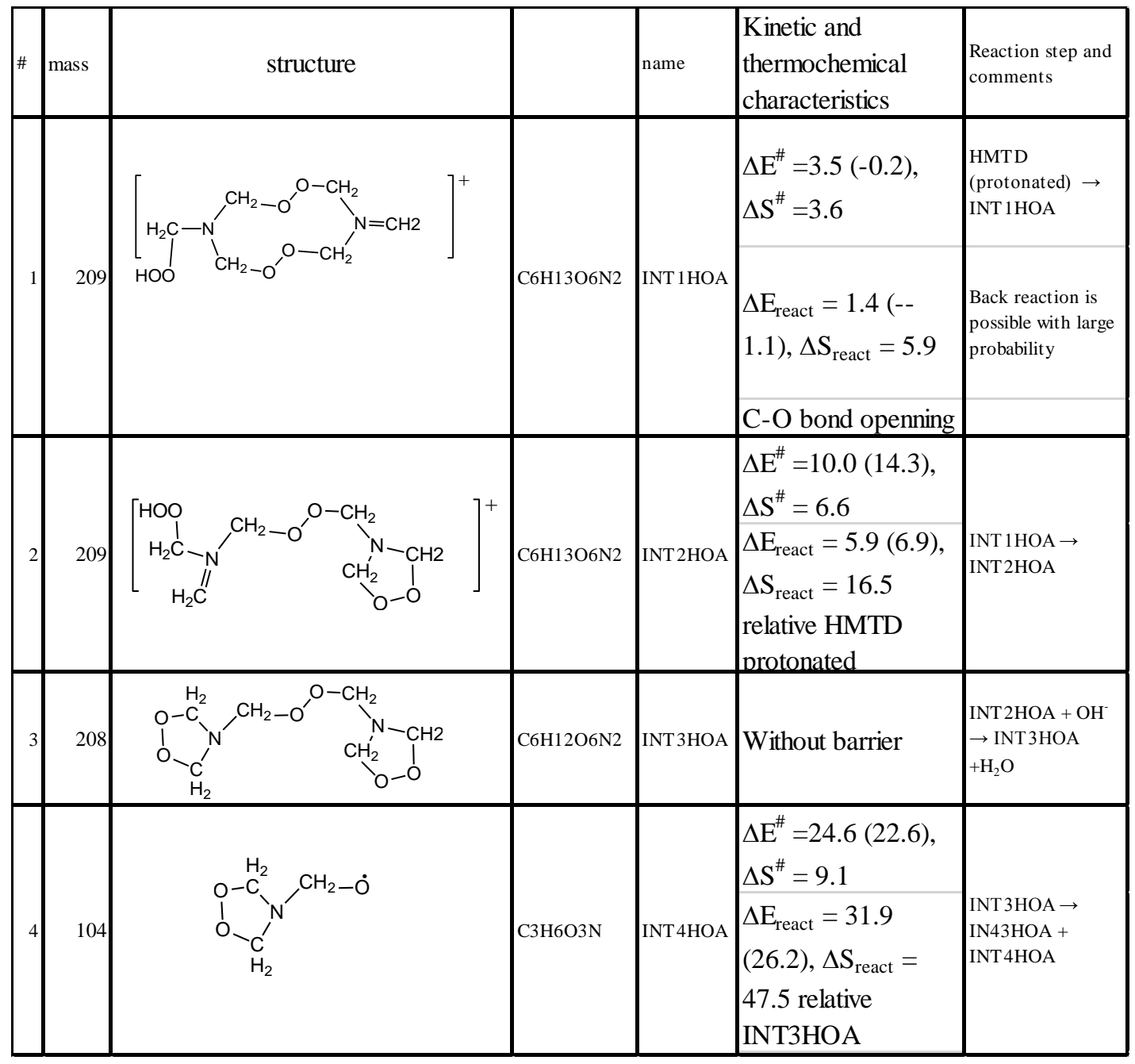


Table 1.8. Structure and properties of intermediates along path B during the decomposition of HMTD molecule with protonated oxygen. Calculations used PBE0PBE1/cc-pVDZ level of theory. Energy values in kcal/mol, entropy values in $\mathrm{cal} /(\mathrm{K} \mathrm{mol})$.

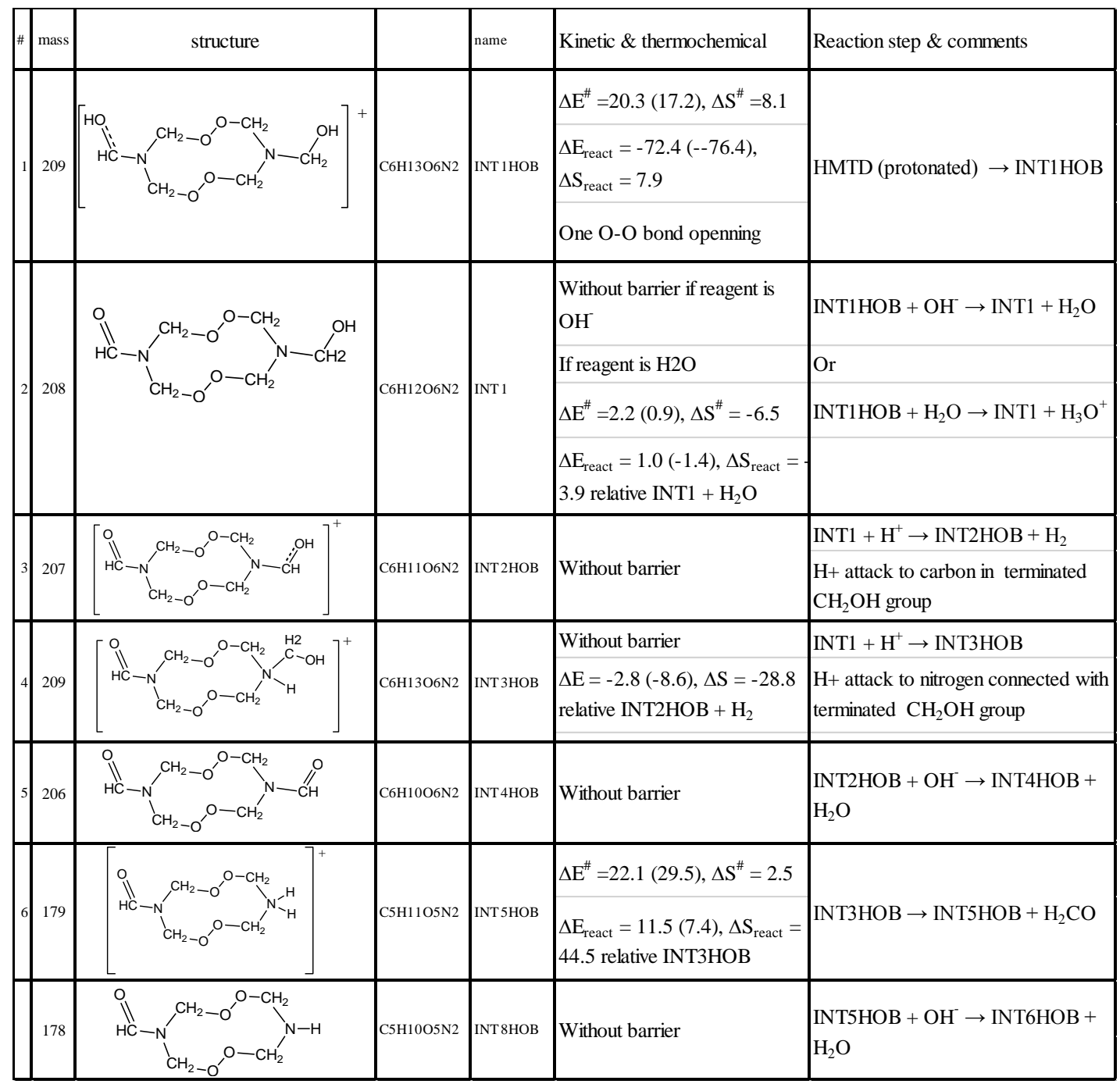

As stated above, protonated HMTD is formed spontaneously without any appreciable energy barrier. The rupture of a $\mathrm{C}-\mathrm{O}$ bond occurs with a minor energy barrier of approximately $3.5 \mathrm{kcal} / \mathrm{mol}$ (Path A). The formation of INT2HOA requires overcoming a slightly larger energy barrier; but this barrier is much smaller than that 
required for HMTD decomposition as a gas phase molecule, TS1. Additional steps in the decomposition of INT2HOA require surmounting a barrier of about $35 \mathrm{kcal} / \mathrm{mol}$. However the presences of anions in the solution suggest another possible pathway. The third intermediate, INT3HOA is formed following the stabilization of INT2HOA by an anion $\left(\mathrm{OH}^{-}\right.$in this case). This neutralization is accompanied by a large energy release. If the $\mathrm{OH}^{-}$is replaced by $\mathrm{H}_{2} \mathrm{O}$, only a very low barrier is observed. The decomposition of INT3HOA requires overcoming a barrier of about $24 \mathrm{kcal} / \mathrm{mol}$ (see Table 7) and it leads to the formation of two 5-member ring radicals.

The structure and characteristics of the intermediate species in Path B of HMTD with protonated oxygen are presented in Table 8 . The most important in this route is the possibility that INT1HOB is neutralized by an anion (several anions were tested, $\mathrm{OH}^{-}, \mathrm{Cl}^{-}, \mathrm{SO}_{4}{ }^{2-}, \mathrm{HSO}_{4}^{-}$) to produce INT1 shown for neutral decomposition in Figure 8 and as entry 2 in Table 8 . This pathway allows one to return to the neutral HMTD decomposition without the necessity to overcome a barrier $32.5(30.5) \mathrm{kcal} / \mathrm{mol}$.

Most neutral intermediates can be protonated without an appreciable energy barrier. The intermediates described in Table 8 suggest the possible intermediates with quite large molar mass similar to those presented in Tables 3 and 4 . All these decomposition steps proceed without barriers or with small energy barriers; hence, most of these species are accessible. The highest barrier is related to the formation of formaldehyde (entry 6, Table 8). We also tested the fate of the relatively stable intermediate INT2 (entry 2, Table 6). The structure and properties of the intermediates observed during the decomposition of its protonated form are presented in Table 9. 
Table 1.9. Intermediates observed in decomposition of gas phase HMTD starting with protonated INT2 (Fig. 8). Calculations used PBEOPBE1/cc-pVDZ. Energy in kcal/mol, entropy in cal/K mol.

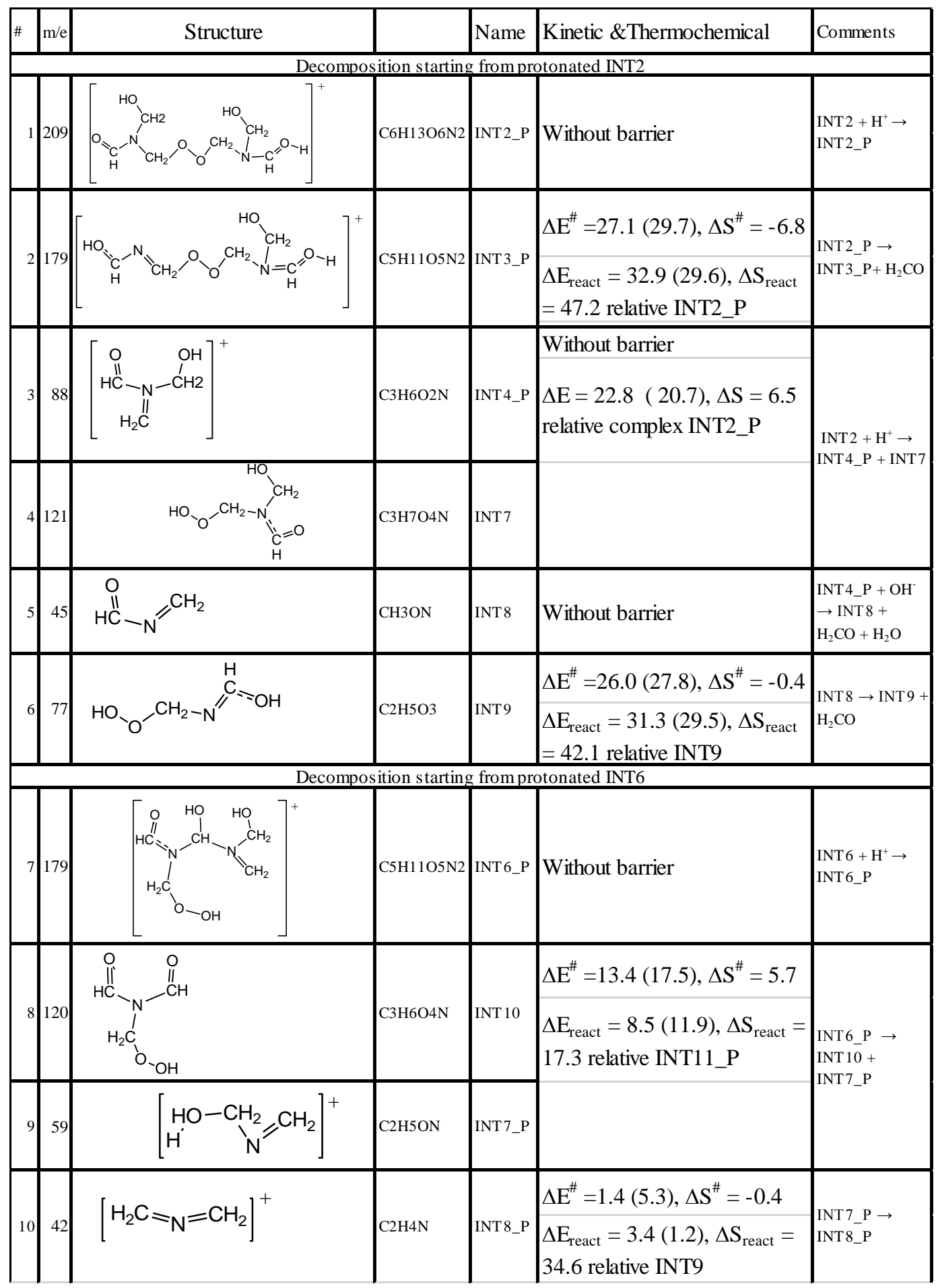


All the decomposition steps that lead to the formation of these intermediates proceed via barriers smaller than $30 \mathrm{kcal} / \mathrm{mol}$. In most cases a much lower barrier or even no barrier is associated with the intermediate. Most of the species listed in Table 9 are rather small and resemble some of the species listed in Tables 3 and 4 . Protonation of a nitrogen in the HMTD molecule as the initial step was also considered. The attachment of a proton to nitrogen is preferred by $2.2 \mathrm{kcal} / \mathrm{mol}$ over its addition to one of the oxygen atoms in the molecule; however, there are only two nitrogen atoms compared to six oxygen atoms in an HMTD molecule. The initial steps in the decomposition of a nitrogen protonated HMTD are shown in Figure 11.

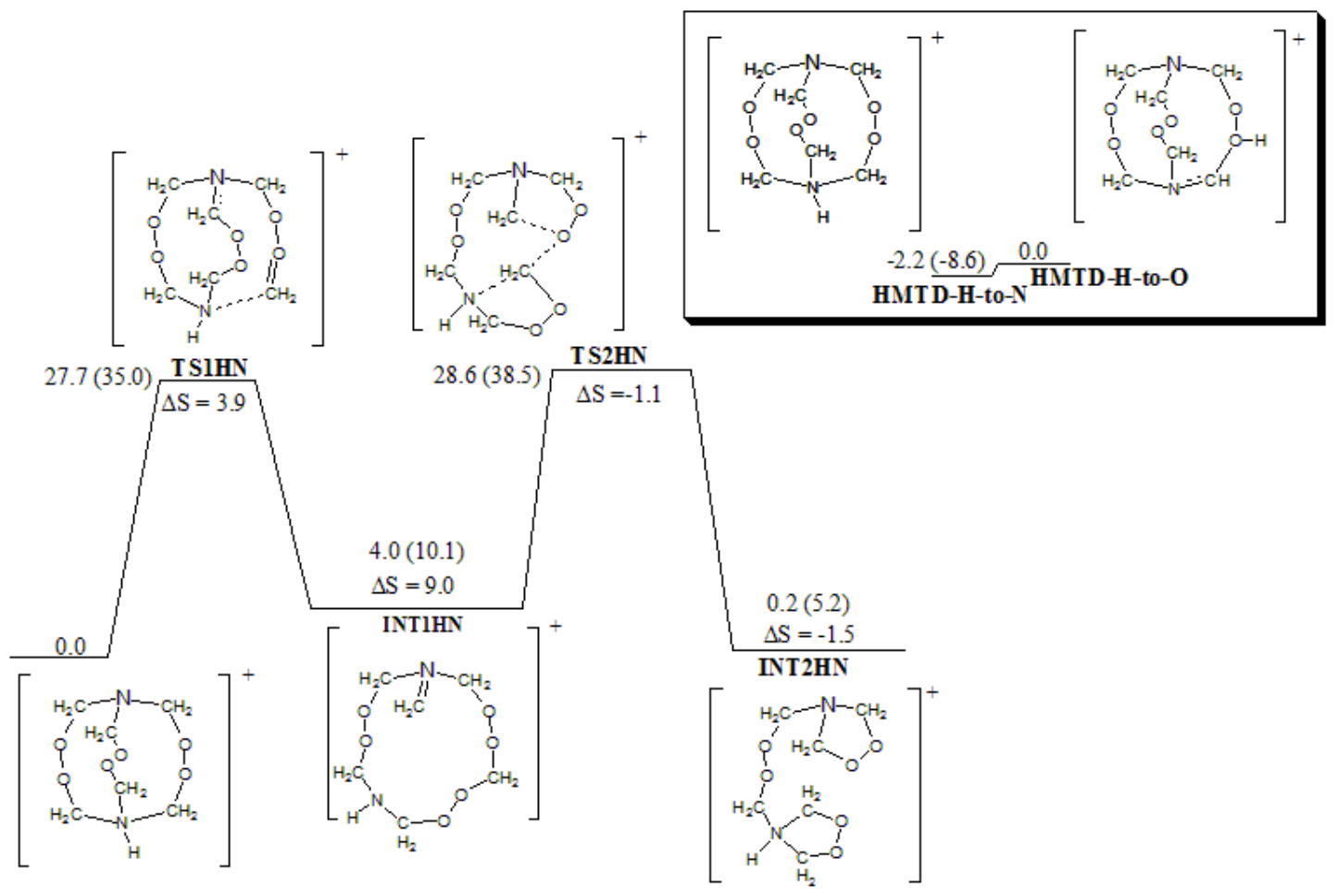

Figure 1.11. Initial decomposition steps of a nitrogen protonated HMTD molecule. 
The first transition state, TS1HN, requires the system to overcome an energy barrier of about $28 \mathrm{kcal} / \mathrm{mol}$ or about $20 \%$ lower than that required to reach TS 1 in gas phase HMTD decomposition. In TS1HN one $\mathrm{C}-\mathrm{N}$ and one $\mathrm{C}-\mathrm{O}$ bonds start to break together with a rearrangement of the molecular structure. Surmounting this energy barrier leads to the formation of a ring shape intermediate that contains three peroxide bonds. A second energy barrier, with similar magnitude to the first one, leads to TS2HN and is followed by ring opening to form INT2HN. This intermediate has two five member rings attached to each $\mathrm{N}$ atom, each ring connected by a $\quad-\mathrm{O}-\mathrm{O}-\mathrm{CH}_{2}-\mathrm{O}-$ O- chain. Further decomposition of INT2HN was examined but did not lead to the formation of stable end products.

We also examined the possible decomposition of HMTD in a basic solution. A sequence of a few steps with relatively low energy barriers separating them (highest is $17 \mathrm{kcal} / \mathrm{mol})$ and formation of an intermediate with large (104 kcal/mol) energy release occurs. During this sequence a few formaldehyde molecules were released together with the formation of different intermediate species. The structure and the properties of the different intermediate species along the decomposition pathway are described in Table 10. Thus, HMTD decomposition is also expected to occur in basic environment as was observed in the experimental part of this study. 
Table 1.10. Structure and properties of intermediate species observed during the decomposition of a HMTD-OH ${ }^{-}$anion calculated using PBE0PBE1/cc-pVDZ level of theory. Energy values in $\mathrm{kcal} / \mathrm{mol}$, entropy values in $\mathrm{cal} /(\mathrm{K} \mathrm{mol})$.

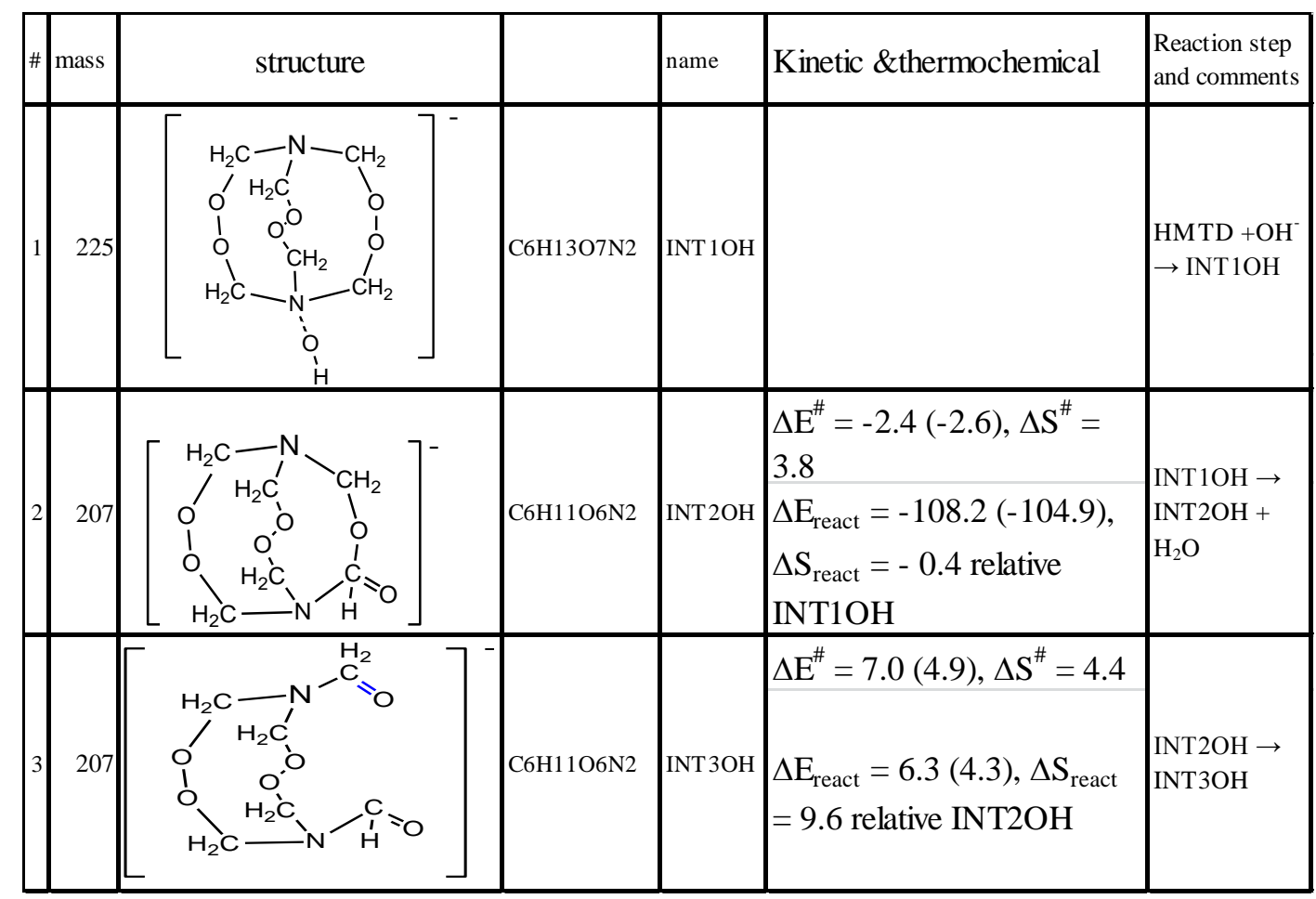

\section{Conclusion}

Since HMTD is destabilized by water and citric acid, it is important to purify it after initial synthesis. It is recommended to rinse with water to remove acid, then with methanol to remove water. Ignoring the degrading effects of water and acid may lead to an unexpected violent reaction during storage and handling. Precautions for storage should be taken to see that HMTD remains dry and cold. Work to elucidate mechanisms of HMTD decomposition continues, but it appears that the headspace of HMTD is mainly trimethylamine (TMA) and dimethylformamide (DMF); these might be used instead of the more hazardous HMTD for canine and other vapor detection modes. It 
was observed that hexamine, substituted triazines, and linear amines are formed in the condensed phase, and the observation of these products is humidity dependant. The mechanism of formation of HMTD was found to proceed through a complete breakdown of hexamine, involving formaldehyde exchange. Positive identification of synthesis intermediates remains as a future work.

Acknowledgements

The authors thank the U.S. Department of Homeland Security and G-38 division of the US Army for funding of this work; however, the views contained herein are those of the authors only.

\section{References}

[1] L. Legler, Ueber Producte der langsamen Verbrennung des Aethyläthers. Berichte, 1885, 183343.

[2] A. Baeyer, V. Villiger, Ueber die Nomenclatur der Superoxyde und die Superoxydeder Aldehyde, Berichte. 1900, 332479.

[3] C. Von Girsewald, Beiträge zur Kenntnis des Wasserstoffperoxyds.

Üfber die Einwirkung des Wasserstoffperoxyds auf Hexamethylentetramin, Berichte. 1912, 45, 2571.

[4] W.P. Schaefer, J.T. Fourkas, B.G. Tiemann, Structure of Hexamethylene Triperoxide Diamine, J. Am. Chem. Soc. 1985, 107, 2461.

[5] A. Wierzbicki, E.A._Salter, E.A Cioffi, E.D. Stevens, Density Functional Theory and X-ray Investigations of P- and M-Hexamethylene Triperoxide Diamine and Its Dialdehyde Derivative, J. Phys. Chem. A, 2001, 105, 8763. 
[6] J.C. Oxley, J.L. Smith, P. Bowden, R. Rettinger, Factors Influencing TATP and DADP Formation: Part I, Propellants, Explosives, Pyrotechnics 2013, 38, 244.

[7] R. Matyas, J. Selesovsky, T. Musil, Decreasing the Friction Sensitivity of TATP, DADP, and HMTD, Central Europ. J Energetic Mat. 2013, 10, 263.

[8] A.T. Nielsen, Structure and Chemistry of the Aldehyde Ammonias. 3.

Formaldehyde-Ammonia Reaction. 1,3,5,-Hexahydrotriazine, J. Org. Chem. 1979, 44, 1678.

[9] N. Subramanian, US Patent US4422982 A 1983.

[10] E.E. Gilbert, J.R. Leccacorvi, M. Warman, The Preparation of RDX from 1,3,5Triacylhexahydro-s-triazines, Ind. Lab. Nitrations, Symp. 1 1976, 22, 327.

[11] A. Wexler, Constant Humidity Solutions, CRC Handbook of Chemistry Physics $85^{\text {th }}$ ed.

[12] K. Colizza, M. Porter, J.L. Smith, J.C. Oxley, Gas Phase Reactions of alcohols with hexamethylene triperoxide diamine (HMTD) under atmospheric pressure chemical ionization conditions, Rapid Commun. Mass Spectrom. 2015, 29, 74. [13] J.C. Oxley, J.L. Smith, H. Chen, E. Cioffi, Decomposition of Multi-Peroxidic Compounds: Part II: Hexamethylene Triperoxide Diamine (HMTD), Thermochemica Acta 2002, 38, 215.

[14] J. Oxley, J. Zhang, J. Smith, E. Cioffi, Mass Spectra of Unlabeled and Isotopically Labeled Hexamethylene Triperoxide Diamine (HMTD), Propellants, Explosives and Pyrotechnics, 2000, 25, 1. 
[15] J.C. Oxley, J.L. Smith, L. Lou, J. Brady, Determining Vapor Pressures of Diacetone Diperoxide (DADP) and Hexamethylene Triperoxide Diamine (HMTD), Propellants Explos. Pyrotech. 2009, 34, 539.

[16] J.C. Oxley, J.L. Smith, J. Brady, F.L.Steinkamp, Factors Influencing Destruction of Triacetone Triperoxide (TATP), Propellants, Explosives, Pyrotechnics, 2014,39, 289.

[17] C.A. Taylor, W. Rinkenbach, H.M.T.D. A New Detonating Explosive" Army Ordnance; J Army Ordnance Assoc. 1924, 5, 436. C.A. Taylor, W. Rinkenbach, Sensitivities of Detonating Compounds to Frictional Impact, Impact, and Heat, J Franklin Institute., 1927, 204, 369.

[18] V.I. Siele, M. Warman, E.E. Gilbert, The Preparation of 3,7-Diacyl-1,3,5,7tetraazabicylco[3.3.1]nonanes, J. Heterocyc. Chem. 1974, 11, 237.

[19] H.H. Richmond, G.S. Myers, G.F. Wright, "The Reaction between Formaldehyde and Ammonia, J. Am. Chem. Soc. 1948, 70, 3659.

[20] L. Stefaniak, T. Urbanski, M. Witanowski, H. Januszewski, NMR

Conformational Study of Cyclic Products from Degadation of

Hexamethylenetetramine Hexahydro-1,3,5-triazines and Octahydro-1,3,5,7-

Tetrazocines, Roczniki Chemii Ann. Soc. Chim. Polonorum 1969, 43, 1687.

[21] W.E. Bachmann, J.C. Sheehan, A New Method of Preparing the High Explosives RDX, J. Am. Chem. Soc. 1949, 71 (5): 1842.

[22] E. Aristoff, J.A. Graham, R.H. Meen, G.S. Myers, G.F. Wright, Nitrolysis of Hexamethylenetetramine, Can J. Res. 1949, 27B, 520. 
[23] J.M. Dreyfors, S.B. Jones, Y. Sayed, Hexamethylenetetramine: A Review, Am. Ind. Hygiene Assoc. J 1989, 50(11), 579.

[24] C.M. Lock, H. Brust, M. van Breukelen, J. Dalmolen, M. Koeberg, D.A. Stoker, Investigation of Isotopic Linkages between Precursor Materials and the Improvised High Explosive Product Hexamethylene Triperoxide Diamine, Analytical Chemistry 2012, 84, 4984.

[25] C.N. Satterfield, L.C. Case, Reaction of Aldehyde and hydrogen peroxide in Aqueous Solution, Ind. And Eng. Chem. 1954, 46 (5), 998. C.N. Satterfield, R.E. Wilson, R.M. LeClair, R. C. Reid, Analysis of Aqueous Mixtures of Hydrogen Peroxide and Aldehydes, Anal. Chem. 1954, 26 (11), 1792.

[26] J.T. Edward, F.L. Chubb, D.F.R. Gilson, R.C. Hynes, F. Sauriol, A. Wiesenthal, Cage Peroxides have Planar Bridgehead Nitrogen Atoms. Can. J. Chem. 1999, 77(5/6) 1057. 


\title{
MANUSCRIPT 2
}

POTENTIAL BIOCIDES: IODINE-PRODUCING PYROTECHNICS

by

\author{
Jimmie C. Oxley; James L. Smith; Matthew Porter; Maxwell J. Yekel; \\ Jeffrey A. Canaria \\ Department of Chemistry \\ University of Rhode Island \\ 140 Flagg Rd \\ Kingston, RI 02881
}

This manuscript was submitted to the journal Propellants, Explosives, Pyrotechnics 


\begin{abstract}
Currently there is a need for specialized pyrotechnic materials to combat the threat of biological weapons. Materials have been characterized based on their potential to produce heat and molecular iodine gas $\left(\mathrm{I}_{2}\right)$ to kill spore-forming bacteria (e.g. anthrax). One formulation, already proven to kill anthrax simulants, is diiodine pentoxide with aluminum; however, it suffers from poor stability and storage problems. The heat and iodine gas output from this mixture and candidate replacement mixtures were measured with bomb calorimetry and extraction and analysis of $\mathrm{I}_{2}$ by UV-Vis. Of the mixtures analyzed, calcium iodate and aluminum was found to be the highest producer of $I_{2}$. The heat output of this mixture and others can be tuned by adding more fuel, with the cost of some iodine. Products of combustion were analyzed by thermal analysis (SDT), XPS, XRD, and LC/MS. Evidence for various metal iodides and metal oxides was collected with these methods.
\end{abstract}

\title{
1 Introduction
}

Previously we examined a series of oxidizers and fuels to determine their potential as explosive threats [1]. In the current work we examine, in detail, performance of oxides of iodine with the goal of determining their effectiveness as biocides. The biological threat of particular concern is spore production by Bacillus anthracis. While kill methods are diverse and not completely understood, it is known that a combination of heat and molecular iodine is effective $[2,3]$. A number of iodate and periodate salts were examined by formulating them with fuels and measuring heat evolution and molecular iodine release. Diiodine pentoxide has been used as a benchmark because it contains the highest weight percentage of iodine. Unfortunately, its long-term stability 
with a favored fuel, aluminum, is poor. Herein we examine the fuels aluminum and boron carbide.

\section{Experimental Section}

\subsection{Calorimetry and Iodine ( $\left.\mathbf{I}_{2}\right)$ Quantification}

The oxidizers $\mathrm{KIO}_{3}, \mathrm{NaIO}_{3}, \mathrm{NaIO}_{4}, \mathrm{KIO}_{4}$ were purchased from Acros; $\mathrm{I}_{2} \mathrm{O}_{5}$, and $\mathrm{Ca}\left(\mathrm{IO}_{3}\right)_{2}$ were purchased from Strem; the aluminum flake $(23 \mu \mathrm{m})$ and boron carbide $(8 \mu \mathrm{m})$ fuels were from Obron and Electron Microscopy Sciences, respectively. The oxidizers were sieved to $100-200$ mesh $(150-75 \mu \mathrm{m}) . \quad \mathrm{Bi}\left(\mathrm{IO}_{3}\right)_{3}$ was synthesized according to Zachariah et al and used as prepared [4]. For preparation of $\mathrm{Bi}\left(\mathrm{IO}_{3}\right)_{3}$, a solution of $\mathrm{Bi}\left(\mathrm{NO}_{3}\right)_{3} \cdot 5 \mathrm{H}_{2} \mathrm{O}(4.85 \mathrm{~g}$ in $80 \mathrm{~mL}, 2 \mathrm{M}$ nitric acid $)$ was added to $\mathrm{HIO}_{3}$ solution (5.28 $\mathrm{mg}$ in $80 \mathrm{~mL} \mathrm{H} \mathrm{H}_{2} \mathrm{O}$ ), then rinsed with $600 \mathrm{~mL} \mathrm{H}{ }_{2} \mathrm{O}$ and $100 \mathrm{~mL}$ of methanol. Product was dried under vacuum overnight. Average particle size was $4 \mu \mathrm{m}$ (Horiba LA950 Particle Size Analyzer, wet mode).

The pyrotechnic mixtures were mixed as dry loose powders using a Resodyne Lab Ram Acoustic Mixer (acceleration 35-40 G). Heat released from the ignition of the pyrotechnic formulations was determined using a Parr 6200 Isoperibol Bomb Calorimeter. The Parr bomb was calibrated (i.e. 10 trials) with benzoic acid ignited with fuse wire and $(9.6232 \mathrm{~J} / \mathrm{cm})$ and cotton string $(167.36 \mathrm{~J})$ in $2515 \mathrm{kPa}$ oxygen $\left(\Delta \mathrm{H}_{\mathrm{comb}}=26434 \mathrm{~J} / \mathrm{g}\right)$. In an oxygen atmosphere, the string is in contact with the fuse wire and sample, and is ignited by the fuse wire to aid the ignition of the sample. The pyrotechnics (2-3 samples under each set of conditions) were loaded in $2 \mathrm{~g}$ samples and ignited with a fuse wire under argon $(515 \mathrm{kPa})$. This slightly elevated pressure was chosen to simplify purging of the Parr 1108 bomb with Argon and to ensure a tight seal. 
Molecular iodine $\left(\mathrm{I}_{2}\right)$ produced from each burn was quantified with ultraviolet-visible (UV-Vis) spectroscopy (Agilent 8453 spectrometer, 190 to $1100 \mathrm{~nm}$, resolution $1 \mathrm{~nm}$, $0.5 \mathrm{~s}$ integration time). Iodine was extracted from the bomb with $100 \mathrm{~mL}$ of an aqueous $0.5 \mathrm{M}$ potassium iodide (KI) solution. The aqueous solution with excess of $\mathrm{I}^{-}$was added to solubilize $\mathrm{I}_{2}$ and transform it to $\mathrm{I}^{3-}$ (absorbance $353 \mathrm{~nm}$ ) [5]. Extracts were diluted with known amounts of $0.025 \mathrm{M} \mathrm{KI}$ for absorbance measurements at $353 \mathrm{~nm}$ to quantify iodine. Control samples were made by pressing solid iodine $(0.8 \mathrm{~g})$ with benzoic acid $(1.2 \mathrm{~g})$. When these control samples were ignited under $350 \mathrm{psi}$ oxygen, iodine recovery was $\sim 97 \%$. For $\mathrm{Bi}\left(\mathrm{IO}_{3}\right)_{3}$ mixtures, an interference in the UV-Vis spectra (Figure S33S34), attributed to a $\mathrm{BiI}_{3}$ and $\mathrm{KI}$ interaction was observed [6]. For these mixtures, iodine standards and sample extractions were conducted with methylene chloride (at 506nm), which did not dissolve $\mathrm{BiI}_{3}$. Control experiments with methylene chloride extractions showed lower recovery $(73 \%)$, which was factored into the recovered iodine from $\mathrm{Bi}\left(\mathrm{IO}_{3}\right)_{3}$ mixtures.

\subsection{Aging Studies}

For aging studies, loose powder pyrotechnic mixtures were aged at $60^{\circ} \mathrm{C}$ and 75\% RH (relative humidity). Time points were at 3 days and 14 days. Fresh samples and aged samples were analyzed by simultaneous differential scanning calorimetry/thermogravimetric analysis (TA Instruments, Q600 SDT, 20C/min, 50 to $1000{ }^{\circ} \mathrm{C}$ ); infrared (IR) spectroscopy (Thermo Nicolet 6700 FR-IR with ATR cell, 32 scans, resolution $4 \mathrm{~cm}^{-1}, 650-4000 \mathrm{~cm}^{-1}$ ); and visual observation. IR was used specifically to detect oxygen-hydrogen bonds, indicating uptake of water. The burn characteristics of fresh and aged samples were also noted. 


\subsection{Simultaneous Differential Scanning Calorimetry Thermogravimetric Analysis (SDT)}

A TA instruments Q600 SDT was used to characterize the original pyrotechnic mixtures, combustion products (from bomb calorimetry, $515 \mathrm{kPa}$ Argon), and standard mixtures. Samples of 3-5 mg were heated in alumina crucibles at a scan rate of 20 ${ }^{\circ} \mathrm{C} / \mathrm{min}$ from 50 to $1000{ }^{\circ} \mathrm{C}$. To remove solid iodine or solvents (in the case of water or methanol extracts for LC/MS) combustion products were dried in a vacuum oven overnight at $50{ }^{\circ} \mathrm{C}$ before the analysis. Unless stated otherwise, samples were run under nitrogen.

\subsection{Titration for Oxide Content}

In the case of $80 / 20 \mathrm{Ca}\left(\mathrm{IO}_{3}\right)_{2} / \mathrm{Al}$ combustion products ( $\mathrm{pH} 11$ when mixed with water), an acid base titration was performed. Hydrochloric acid (30 $\mathrm{mL}$ of $0.100 \mathrm{M})$ was added to $50-150 \mathrm{mg}$ of combustion products and allowed to stir for $20 \mathrm{~min}$. The solution was then back-titrated with $0.100 \mathrm{M}$ sodium hydroxide, with bromothymol blue indicator.

\subsection{X-Ray Photoelectron Spectroscopy (XPS)}

A Thermo Scientific K-Alpha XPS (Aluminum source, $1486.7 \mathrm{eV}$ ) was used to help determine bomb calorimetry combustion products of $\mathrm{NaIO}_{3} / \mathrm{Al}, \mathrm{Bi}\left(\mathrm{IO}_{3}\right)_{3} / \mathrm{Al}$, $\mathrm{KIO}_{3} / \mathrm{Al}, \mathrm{Ca}\left(\mathrm{IO}_{3}\right)_{2} / \mathrm{Al}$, and $\mathrm{I}_{2} \mathrm{O}_{5} / \mathrm{Al}$. The pass energy was $50 \mathrm{eV}$ with a resolution of $\pm 0.05 \mathrm{eV}$. Samples and standards were prepared in a nitrogen glove box (from Genesis). Charge effects were corrected based on the peak signal from the corresponding cation of an appropriate standard (i.e. $\mathrm{KIO}_{3} / \mathrm{Al}$ combustion products were corrected from $\mathrm{K} 2 \mathrm{p} 3 / 2$ from $\mathrm{KI})$. 


\subsection{Liquid Chromatography / Mass Spectrometry (LCMS)}

Water and methanol extracts of bomb calorimetry combustion products of $\mathrm{Ca}\left(\mathrm{IO}_{3}\right)_{2} / \mathrm{Al}$ and $\mathrm{I}_{2} \mathrm{O}_{5} / \mathrm{Al}$ were prepared and infused into a Thermo Exactive Orbitrap Mass spectrometer with an electrospray ionization interface (ESI). This method was modified from a method used to analyze aluminum chloride in ESI negative mode with no additives in water [7]. The tune conditions $(10 \mu \mathrm{l} / \mathrm{min})$ were as follows: spray voltage $1.80 \mathrm{kV}$ (for water extracts) and $2.4 \mathrm{kV}$ (for methanol extracts); capillary temperature at $200{ }^{\circ} \mathrm{C}$; sheath gas $\left(\mathrm{N}_{2}\right)$ at a flow rate of 8; aux gas $\left(\mathrm{N}_{2}\right)$ at a flow rate of 1; capillary voltage at $-10 \mathrm{~V}$; tube lens at $-175 \mathrm{~V}$, and skimmer voltage at $-25 \mathrm{~V}$. The instrument passed the calibration with a mass accuracy of $2 \mathrm{ppm}$. The mass spec scanned from 128.0 to $600.0 \mathrm{~m} / \mathrm{z}$ with 25,000 resolution and a maximum injection time of $50 \mathrm{~ms}$. Solid combustion products were extracted with either water $(60-75 \mathrm{mg}$ in $10 \mathrm{~mL})$ or methanol (500 mg in $25 \mathrm{~mL})$ in falcon tubes by vortex mixing for $2 \mathrm{~min}$, sonicating for $20 \mathrm{~min}$, vortex mixing again for $2 \mathrm{~min}$, then centrifuging for $10 \mathrm{~min}$ at $3.0 \mathrm{G}$. The methanol extract was decanted from the samples, and diluted with 50/50 v/v methanol/water to a concentration of $500-750 \mu \mathrm{g} / \mathrm{ml}$. Standard solutions of calcium iodide, aluminum iodide, and calcium oxide were also prepared the same way (50 mg in $10 \mathrm{~mL}$ of water or $200 \mathrm{mg}$ in $25 \mathrm{~mL}$ of methanol), then diluted to $400 \mu \mathrm{g} / \mathrm{ml}$ with 50/50 methanol/water. 


\subsection{Powder X-Ray Diffraction}

A Rigaku Ultima IV XRD was used (Cu source, $40 \mathrm{kV}, 44 \mathrm{~mA}$ ) to help identify combustion products of the $\mathrm{Ca}\left(\mathrm{IO}_{3}\right)_{2} / \mathrm{Al}$ mixtures. The scan was $0.667 \mathrm{deg} / \mathrm{min}$ from 10 to $110 \mathrm{deg}$ at a sampling width of $0.25 \mathrm{deg}$. Combustion products for $80 / 20$ $\mathrm{Ca}\left(\mathrm{IO}_{3}\right)_{2} / \mathrm{Al}$ and $60 / 40 \mathrm{Ca}\left(\mathrm{IO}_{3}\right)_{2} / \mathrm{Al}$ were handled in a glove box, then run in the instrument with containers of drierite in the analysis chamber that had pre-equilibrated for 1 hour.

\subsection{Friction Testing (BAM method)}

Testing was conducted according to the UN method (on an FS-12A BAM machine from OZM research) where the threshold initiation level (TIL) of a sample (in $\mathrm{N}$ force) is reported where 1 out of 6 samples were a "go" with a snapping sound [8]. A sample size of $10 \mathrm{~mm}^{3}$ was used.

\subsection{Drop-weight impact (Modified BOE method)}

This test was conducted with a BOE machine manufactured by SMS (10 mg sample, $3.63 \mathrm{~kg}$ weight) using the $\mathrm{UN}$ method [8]. $\mathrm{Ca}\left(\mathrm{IO}_{3}\right)_{2} / \mathrm{Al}$ was tested seven times at the highest height of the instrument $(75 \mathrm{~cm}) . \mathrm{A} \mathrm{Dh}_{50}$ number was obtained with an up/down method (14 samples, where $50 \%$ of the samples were a "go") with RDX (class 1, Holston) for comparison. A test was considered a "go" when an explosion or flash occurred.

\subsection{Electrostatic Sensitivity Testing (ARDEC method 1032)}

This test was conducted with a machine manufactured by UTEC Corporation, LLC using ARDEC method 1032 [9]. Testing starting at the $0.25 \mathrm{~J}$ level, and the energy level was stepped down until a TIL energy value was reached with 0 out of 20 samples 
were a "go". A test was considered a "go" when a flash considerably brighter than a blank occurred and the tape holding the sample down split open.

\section{Results and Discussion}

Choice of oxidizers was governed by availability as well as reported iodine production (Table 1). (Iodoform was considered but not examined because it was neither an oxidizer nor a good fuel.)

Table 2.1. Iodine Content of Oxidizers Employed

\begin{tabular}{|l|c|r|r|r|}
\hline $\begin{array}{l}\text { Iodine } \\
\text { Sources }\end{array}$ & $\begin{array}{l}\text { mw } \\
(\mathrm{g} / \mathrm{mol})\end{array}$ & \# I's & $\begin{array}{l}\text { wt \% } \\
\text { iodine }\end{array}$ & $\begin{array}{l}\text { wt\% } \\
\text { oxygen }\end{array}$ \\
\hline $\mathrm{KIO}_{3}$ & 214 & 1 & 59 & 22 \\
\hline $\mathrm{NaIO}_{3}$ & 198 & 1 & 64 & 24 \\
\hline $\mathrm{I}_{2} \mathrm{O}_{5}$ & 334 & 2 & 76 & 24 \\
\hline $\mathrm{Ca}\left(\mathrm{IO}_{3}\right)_{2}$ & 390 & 2 & 65 & 25 \\
\hline $\mathrm{Bi}\left(\mathrm{IO}_{3}\right)_{3}$ & 734 & 3 & 52 & 20 \\
\hline $\mathrm{NaIO}_{4}$ & 214 & 1 & 59 & 30 \\
\hline $\mathrm{KIO}_{4}$ & 230 & 1 & 55 & 28 \\
\hline
\end{tabular}

Because aluminum is often used to create heat-producing pyrotechnic mixtures, oxidizers were initially compared using it as the fuel (Figure 1). Boron carbide was also examined because recent studies reported when it was used in delay mixtures of periodate, iodine production was observed (Figure 2) [10]. 


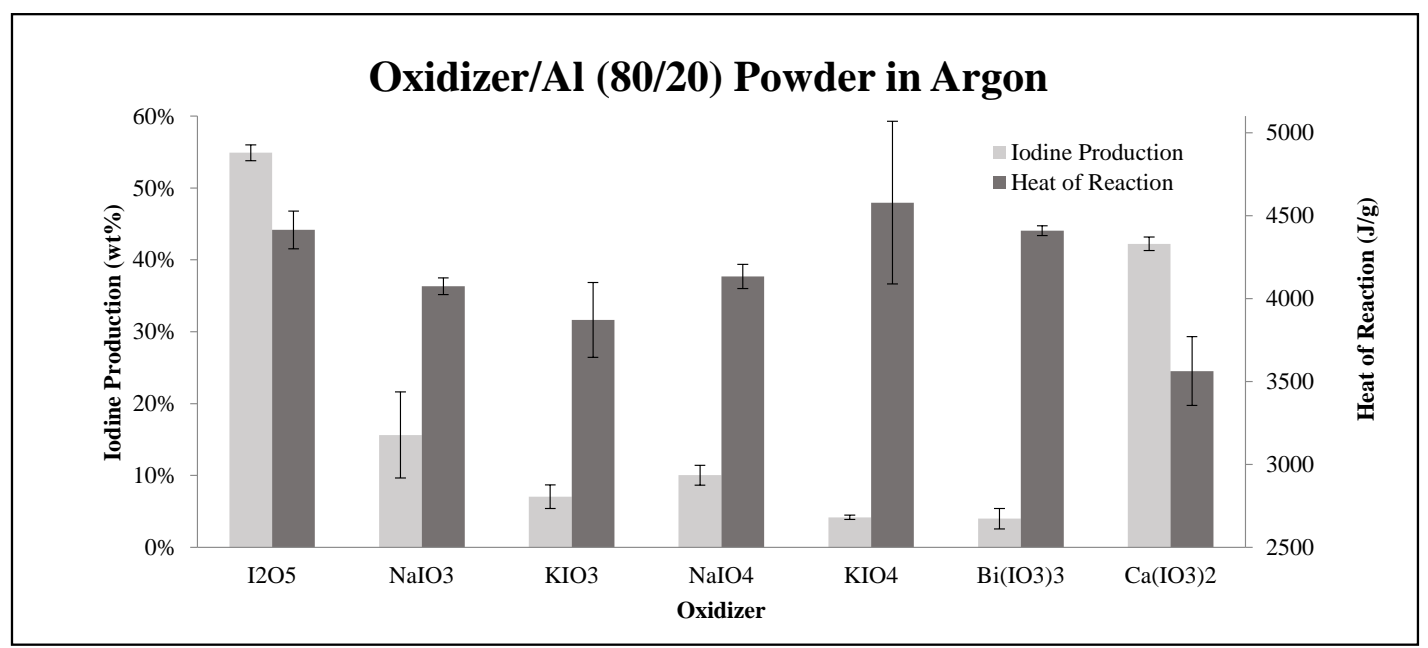

Figure 2.1. Iodine $\&$ heat release from various iodine species burned (closed-bomb) with aluminum.

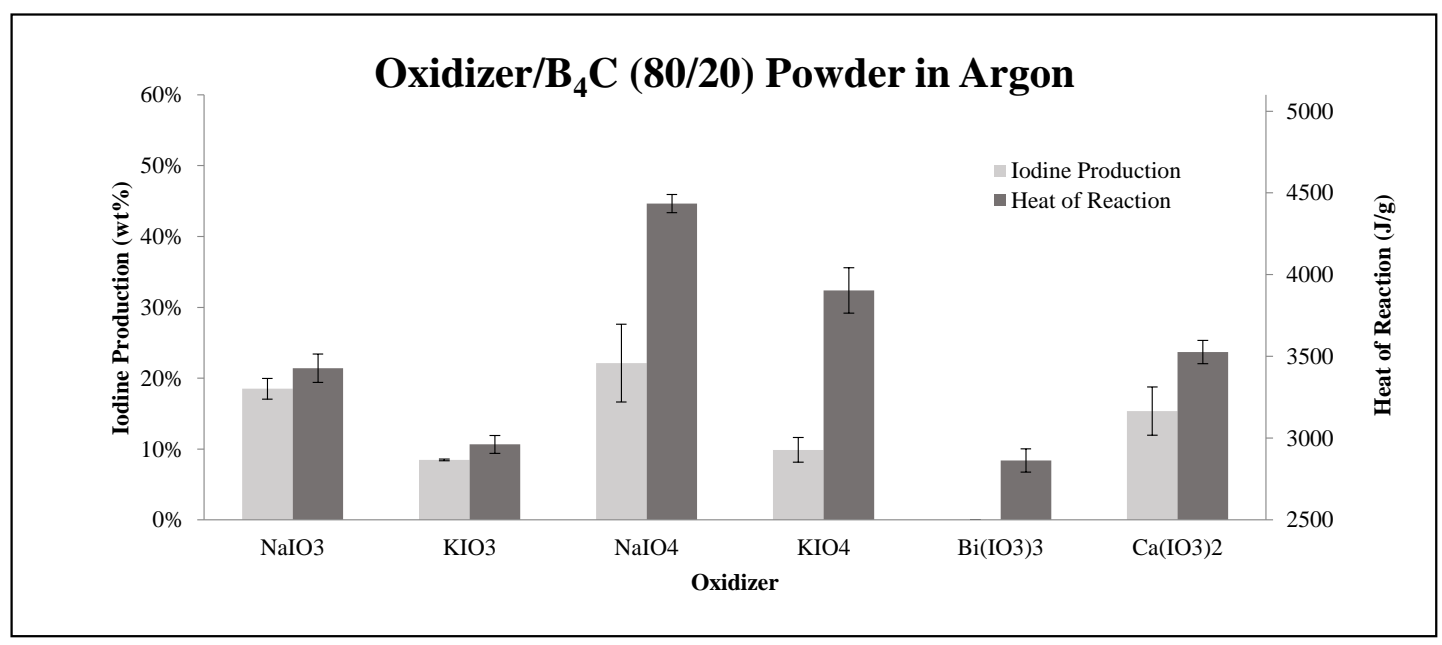

Figure 2.2. Iodine $\&$ heat release from various iodine species burned (closed-bomb) with boron carbide. Diiodine pentoxide did not burn with boron carbide under argon.

As Figure 1 shows, diiodine pentoxide was most effective in both iodine and heat production. However, long term stability was poor. In the presence of moisture this oxide is reportedly converted to iodic acid, also a white solid [11]. The poor stability was exacerbated in the presence of aluminum. After three days, at $60{ }^{\circ} \mathrm{C}$ and $75 \%$ relative humidity, the $80 / 20 \mathrm{I}_{2} \mathrm{O}_{5} / \mathrm{Al}$ mixture turned from a grey powder to a dark brown 
powder (Figure 3). It may be the reaction of aluminum with iodic acid which causes the rapid color change observable in Figure 3. Evidence of the presence of iodic acid can be found in the SDT of $\mathrm{I}_{2} \mathrm{O}_{5}$ aged under the same conditions (Figure $\mathrm{S} 2$; water loss at $112{ }^{\circ} \mathrm{C}$ and $219^{\circ} \mathrm{C}$ ). At the same temperature and humidity, visual observations as well as infrared spectrometry (IR), thermal gravimetric analysis (TGA), and differential scanning calorimetry (DSC) suggested that calcium iodate, sodium iodate, and sodium periodate, (and mixtures with fuel) were stable (Figure S1-S32). All oxidizers alone remained white solids through the aging study. When an original 75/25 calcium iodate/aluminum mixture was allowed to age two weeks under these conditions, no change is observed in its appearance, production of iodine or thermal trace, suggesting acceptable thermal stability (Figure S22-S24).

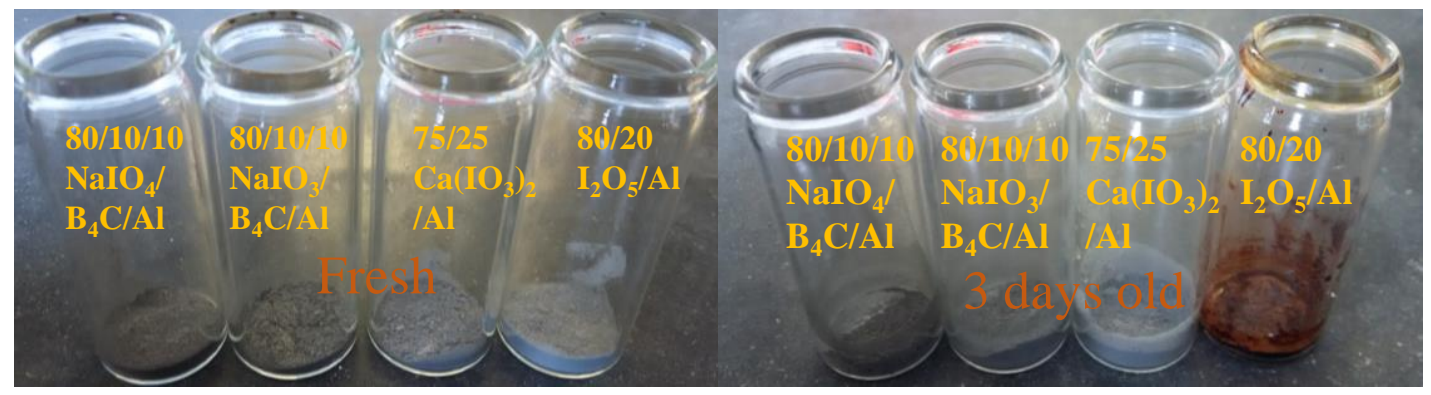

Figure 2.3. Freshly made (left) and aged 3 days at ambient pyrotechnic mixtures.

Even without considering the efficiency of $\mathrm{I}_{2}$ production, it would be difficult for other species to match diiodine pentoxide $\left(\mathrm{I}_{2} \mathrm{O}_{5}\right)$ in terms of iodine formation because they do not contain as much iodine per mass of oxidizer (Table 1). Several overall reactions are possible (eq. 1-3), where $M$ represents the alkali metal cations in this study.

$$
6 \mathrm{MIO}_{3}+10 \mathrm{Al} \rightarrow 5 \mathrm{Al}_{2} \mathrm{O}_{3}+3 \mathrm{M}_{2} \mathrm{O}+3 \mathrm{I}_{2}
$$




$$
\begin{aligned}
& \mathrm{MIO}_{3}+2 \mathrm{Al} \rightarrow \mathrm{Al}_{2} \mathrm{O}_{3}+\mathrm{MI} \\
& 6 \mathrm{MIO}_{3}+2 \mathrm{Al} \rightarrow \mathrm{Al}_{2} \mathrm{I}_{6}+3 \mathrm{M}_{2} \mathrm{O}+15 / 2 \mathrm{O}_{2}
\end{aligned}
$$

The alkali iodates normally decompose to make the iodide salt (eq. 2) and oxygen with perhaps up to $30 \%$ forming the oxide instead (eq. 1) [12]. The addition of a fuel eliminates the free oxygen, but in the case of aluminum fuel, excess aluminum may promote the formation of $\mathrm{Al}_{2} \mathrm{I}_{6}$ [13]. Six oxidizers and $\mathrm{I}_{2} \mathrm{O}_{5}$ were examined with aluminum, boron carbide and a mixture of the two (Table 2). The data reported was obtained in an argon atmosphere in a closed-bomb (Parr); iodine $\left(\mathrm{I}_{2}\right)$ was collected after combustion and usually quantified by UV-Vis spectroscopy. The reported results are averages of at least three tests. Average heat released under argon (across all mixes) was $3975 \mathrm{~J} / \mathrm{g}$; similar to heat released from 80/20 $\mathrm{I}_{2} \mathrm{O}_{5} / \mathrm{Al}(4414 \mathrm{~J} / \mathrm{g})$. Iodine production was more sensitive to the fuel/oxidizer ratio than was heat output (Table 3). Review of the data sorted in Table 3 indicated that as the oxidizer/fuel ratio moved from stoichiometric (roughly 80/20) to a more fuel rich formulation $(60 / 40), \mathrm{I}_{2}$ production decreased and heat generally increased. We attributed this to oxygen deficiency, which caused the fuel to combine with the iodine species (acting as oxidant) preventing the release of molecular iodine. Indeed, preliminary data suggested that both iodine production and heat release are improved by the presence of oxygen. 

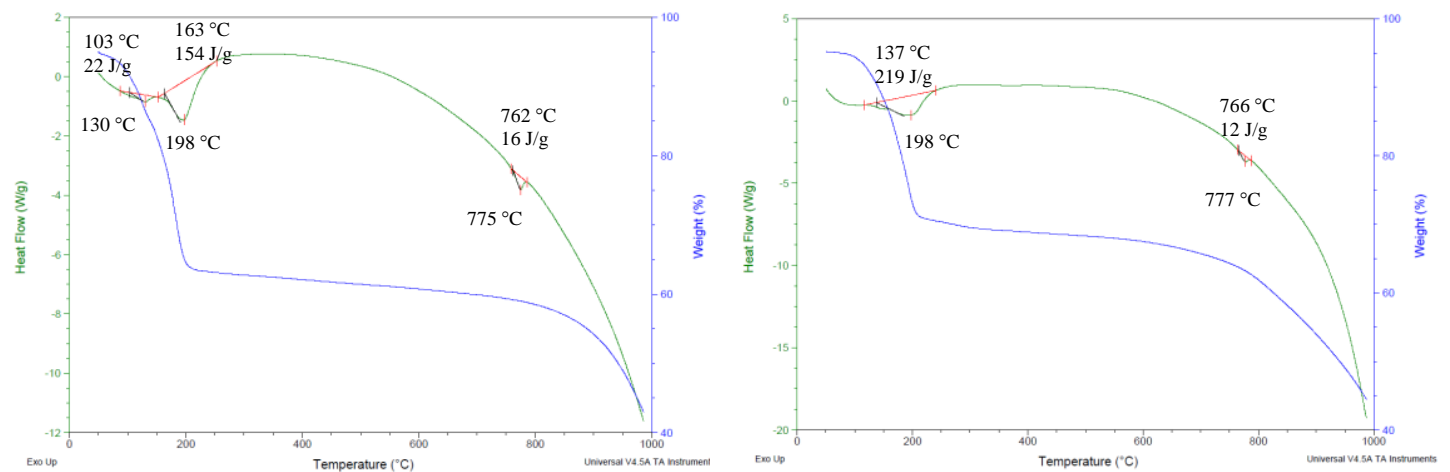

Figure 2.4. SDT of Dried Methanol Extract of $60 / 40 \mathrm{Ca}\left(\mathrm{IO}_{3}\right)_{2} / \mathrm{Al}$ combustion products (left) and 50/50 $\mathrm{CaI}_{2} / \mathrm{Al}_{2} \mathrm{I}_{6}$ (right).

A better understanding of the pyrotechnic reactions, especially knowing why mixes like $\mathrm{Ca}\left(\mathrm{IO}_{3}\right)_{2} / \mathrm{Al}$ favor iodine production over other mixes, required identification of reaction products (by XPS, SDT, XRD, and LC/MS) and ignition mechanisms (by SDT). Measurement of heat evolved and iodine produced was obtained from ignitions in a sealed, Parr bomb calorimeter and extraction of the resulting residue with aqueous KI solution and quantification of iodine by UV-Vis. Other solid products were collected and analyzed by X-ray photoelectron spectroscopy (XPS) and simultaneous thermal gravimetric/differential scanning calorimetry (DSC/SDT). XPS results in Table 4 show electron binding energies of the combustion products, which are consistent with oxidation state assignments of $\mathrm{I}^{-}, \mathrm{O}^{2-}, \mathrm{Al}^{+3}, \mathrm{Ca}^{+2}, \mathrm{~N}^{3-}, \mathrm{Na}^{+}, \mathrm{K}^{+}, \mathrm{Bi}^{+3}$. The resulting elemental analysis is shown in Table 5, noting that all results show more oxygen than anticipated. This is attributed to the presence of moisture or surface oxidation; oxidation of iodides is explained later from SDT experiments (Table 7). The roughly 1:1 match of $\mathrm{Na}$ and $\mathrm{K}$ to I (from mixes 55, 53, and $\mathrm{NaI}$ ) and the roughly 1:3 match for Bi to I (from mix 97) suggest that these cations become incorporated in iodide salts. However, 
for $\mathrm{Ca}\left(\mathrm{IO}_{3}\right)_{2} / \mathrm{Al}$ from mix 60 (which is stoichiometric) there is not sufficient iodide $\left(\mathrm{I}^{-}\right)$ found to support the required 1:2 ratio for $\mathrm{CaI}_{2}$. When the aluminum fuel content was raised from $20 \mathrm{wt} \%$ to $40 \mathrm{wt} \%$, the ratio was consistent with $\mathrm{CaI}_{2}$ production, but this evidence was not supported by DSC/SDT of the fresh combustion products. However, SDT of dried methanol extracts of the combustion products of $60 / 40 \mathrm{Ca}\left(\mathrm{IO}_{3}\right)_{2} / \mathrm{Al} \mathrm{did}$ show both decomposition before endothermic mass loss before $200^{\circ} \mathrm{C}$ and a melt at 774 ${ }^{\circ} \mathrm{C}$, characteristic of the presence of both $\mathrm{Al}_{2} \mathrm{I}_{6}$ and $\mathrm{CaI}_{2}$ respectively. A dried methanol solution of $50 / 50 \mathrm{CaI}_{2} / \mathrm{Al}_{2} \mathrm{I}_{6}$ was very similar (Figure 4); furthermore, it was demonstrated by LC/MS that $\mathrm{CaO}$ (a combustion product) in the presence of $\mathrm{Al}_{2} \mathrm{I}_{6}$ and moisture can be converted to $\mathrm{CaI}_{2}$ vide infra. 
Table 2.2. Iodate salts with Various Fuels $2 \mathrm{~g}$ in Bomb Calorimeter (515 kPa

\section{Argon)—Heat \& $\mathrm{I}_{2}$ Evolution}

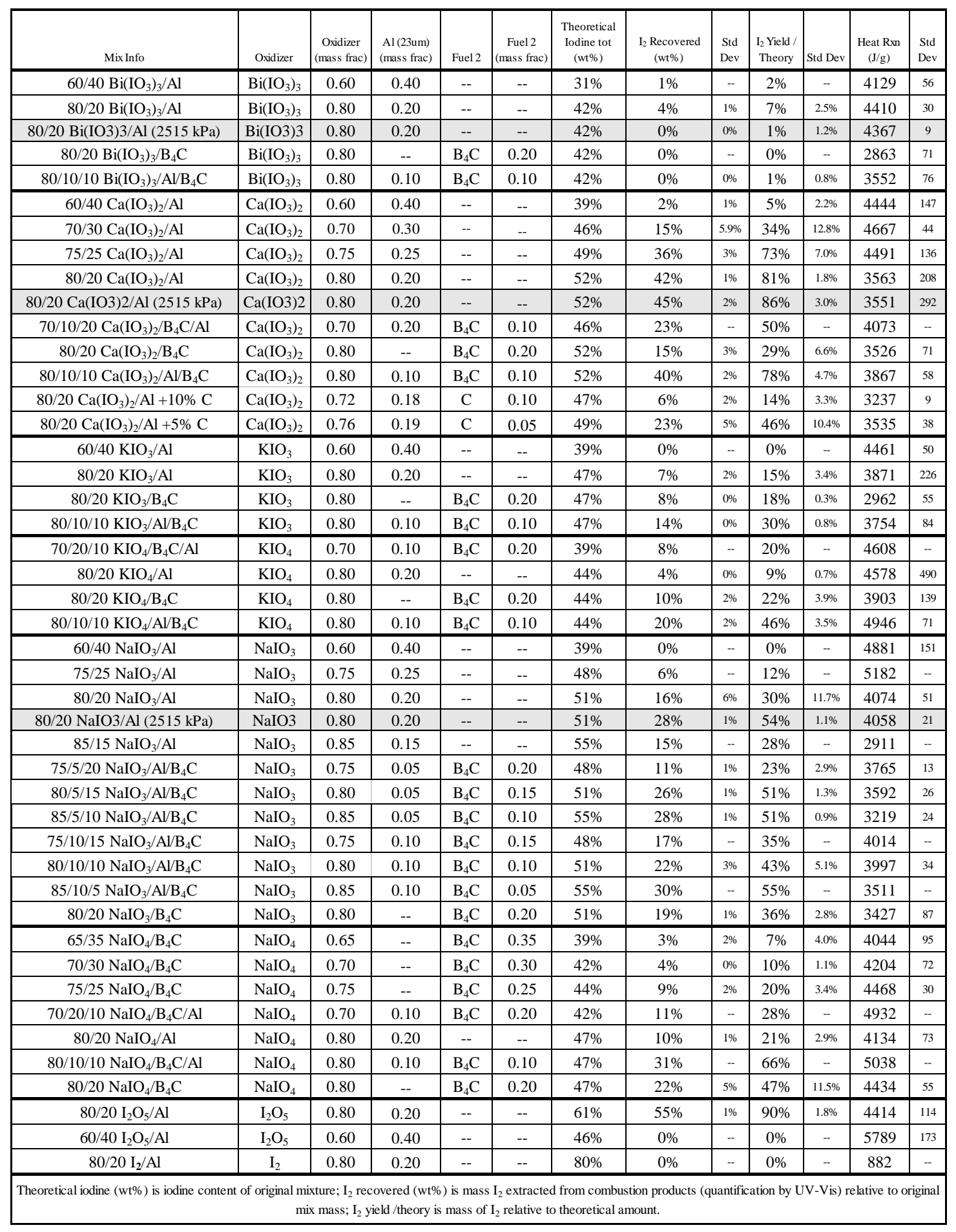


Table 2.3. Select Parr Calorimetry Results: Effect of Oxidizer/ Fuel Ratio on Iodine and Heat Production

\begin{tabular}{|c|c|c|c|c|c|c|c|c|c|c|c|c|}
\hline Mix Info & Oxidizer & \begin{tabular}{|c|}
$\begin{array}{c}\text { Oxidizer } \\
\text { (mass frac) }\end{array}$ \\
\end{tabular} & $\begin{array}{c}\mathrm{Al}(23 u m) \\
\text { mass frac) }\end{array}$ & Fuel 2 & $\begin{array}{c}\text { Fuel 2 } \\
\text { (mass frac) }\end{array}$ & $\begin{array}{c}\text { Theoretical } \\
\text { Iodine tot } \\
\text { (wt } \%)\end{array}$ & \begin{tabular}{c|}
$\%$ \\
$\mathrm{I}_{2} \mathrm{~g} / \mathrm{g}$ mix \\
\end{tabular} & $\begin{array}{l}\text { Std } \\
\text { Dev }\end{array}$ & $\mathrm{I}_{2}$ Yield/Theory & Std Dev & $\begin{array}{c}\text { Heat Rxn } \\
(\mathrm{J} / \mathrm{g})\end{array}$ & $\begin{array}{l}\text { Std } \\
\text { Dev }\end{array}$ \\
\hline $85 / 15 \mathrm{NaIO}_{3} / \mathrm{Al}$ & $\mathrm{NaIO}_{3}$ & 0.85 & 0.15 & -- & -- & $55 \%$ & $15 \%$ & -- & $28 \%$ & -- & 2911 & - \\
\hline $80 / 20 \mathrm{NaIO}_{3} / \mathrm{Al}$ & $\mathrm{NaIO}_{3}$ & 0.80 & 0.20 & -- & -- & $51 \%$ & $16 \%$ & $6.0 \%$ & $30 \%$ & $11.7 \%$ & 4074 & 51 \\
\hline $75 / 25 \mathrm{NaIO}_{3} / \mathrm{Al}$ & $\mathrm{NaIO}_{3}$ & 0.75 & 0.25 & -- & -- & $48 \%$ & $6 \%$ & - & $12 \%$ & - & 5182 & - \\
\hline $60 / 40 \mathrm{NaIO}_{3} / \mathrm{Al}$ & $\mathrm{NaIO}_{3}$ & 0.60 & 0.40 & - & -- & $39 \%$ & $0 \%$ & - & $0 \%$ & - & 4881 & 151 \\
\hline $80 / 20 \mathrm{NaIO}_{4} / \mathrm{B}_{4} \mathrm{C}$ & $\mathrm{NaIO}_{4}$ & 0.80 & -- & $\mathrm{B}_{4} \mathrm{C}$ & 0.20 & $47 \%$ & $22 \%$ & $5.5 \%$ & $47 \%$ & $11.5 \%$ & 4434 & 55 \\
\hline $75 / 25 \mathrm{NaIO}_{4} / \mathrm{B}_{4} \mathrm{C}$ & $\mathrm{NaIO}_{4}$ & 0.75 & -- & $\mathrm{B}_{4} \mathrm{C}$ & 0.25 & $44 \%$ & $9 \%$ & $1.5 \%$ & $20 \%$ & $3.4 \%$ & 4468 & 30 \\
\hline $70 / 30 \mathrm{NaIO}_{4} / \mathrm{B}_{4} \mathrm{C}$ & $\mathrm{NaIO}_{4}$ & 0.70 & -- & $\mathrm{B}_{4} \mathrm{C}$ & 0.30 & $42 \%$ & $4 \%$ & $0.4 \%$ & $10 \%$ & $1.1 \%$ & 4204 & 72 \\
\hline $65 / 35 \mathrm{NaIO}_{4} / \mathrm{B}_{4} \mathrm{C}$ & $\mathrm{NaIO}_{4}$ & 0.65 & -- & $\mathrm{B}_{4} \mathrm{C}$ & 0.35 & $39 \%$ & $3 \%$ & $1.6 \%$ & $7 \%$ & $4.0 \%$ & 4044 & 95 \\
\hline $80 / 20 \mathrm{Ca}\left(\mathrm{IO}_{3}\right)_{2} / \mathrm{Al}$ & $\mathrm{Ca}\left(\mathrm{IO}_{3}\right)_{2}$ & 0.80 & 0.20 & -- & -- & $52 \%$ & $42 \%$ & $0.9 \%$ & $81 \%$ & $1.8 \%$ & 3563 & 208 \\
\hline $75 / 25 \mathrm{Ca}\left(\mathrm{IO}_{3}\right)_{2} / \mathrm{Al}$ & $\mathrm{Ca}\left(\mathrm{IO}_{3}\right)_{2}$ & 0.75 & 0.25 & -- & -- & $49 \%$ & $36 \%$ & $3.4 \%$ & $73 \%$ & $7.0 \%$ & 4491 & 136 \\
\hline $70 / 30 \mathrm{Ca}\left(\mathrm{IO}_{3}\right)_{2} / \mathrm{Al}$ & $\mathrm{Ca}\left(\mathrm{IO}_{3}\right)_{2}$ & 0.70 & 0.30 & -- & -- & $46 \%$ & $15 \%$ & $5.9 \%$ & $34 \%$ & $12.8 \%$ & 4667 & 44 \\
\hline $60 / 40 \mathrm{Ca}\left(\mathrm{IO}_{3}\right)_{2} / \mathrm{Al}$ & $\mathrm{Ca}\left(\mathrm{IO}_{3}\right)_{2}$ & 0.60 & 0.40 & -- & -- & $39 \%$ & $2 \%$ & $0.9 \%$ & $5 \%$ & $2.2 \%$ & 4444 & 147 \\
\hline $85 / 10 / 5 \mathrm{NaIO}_{3} / \mathrm{Al} / \mathrm{B}_{4} \mathrm{C}$ & $\mathrm{NaIO}_{3}$ & 0.85 & 0.10 & $\mathrm{~B}_{4} \mathrm{C}$ & 0.05 & $55 \%$ & $30 \%$ & - & $55 \%$ & - & 3511 & - \\
\hline $85 / 5 / 10 \mathrm{NaIO}_{3} / \mathrm{Al} / \mathrm{B}_{4} \mathrm{C}$ & $\mathrm{NaIO}_{3}$ & 0.85 & 0.05 & $\mathrm{~B}_{4} \mathrm{C}$ & 0.10 & $55 \%$ & $28 \%$ & $0.5 \%$ & $51 \%$ & $0.9 \%$ & 3219 & 24 \\
\hline $80 / 10 / 10 \mathrm{NaIO}_{3} / \mathrm{Al} / \mathrm{B}_{4} \mathrm{C}$ & $\mathrm{NaIO}_{3}$ & 0.80 & 0.10 & $\mathrm{~B}_{4} \mathrm{C}$ & 0.10 & $51 \%$ & $22 \%$ & $2.6 \%$ & $43 \%$ & $5.1 \%$ & 3997 & 34 \\
\hline $80 / 5 / 15 \mathrm{NaIO}_{3} / \mathrm{Al} / \mathrm{B}_{4} \mathrm{C}$ & $\mathrm{NaIO}_{3}$ & 0.80 & 0.05 & $\mathrm{~B}_{4} \mathrm{C}$ & 0.15 & $51 \%$ & $26 \%$ & $0.7 \%$ & $51 \%$ & $1.3 \%$ & 3592 & 26 \\
\hline $75 / 10 / 15 \mathrm{NaIO}_{3} / \mathrm{Al} / \mathrm{B}_{4} \mathrm{C}$ & $\mathrm{NaIO}_{3}$ & 0.75 & 0.10 & $\mathrm{~B}_{4} \mathrm{C}$ & 0.15 & $48 \%$ & $17 \%$ & -- & $35 \%$ & -- & 4014 & -- \\
\hline $75 / 5 / 20 \mathrm{NaIO}_{3} / \mathrm{Al} / \mathrm{B}_{4} \mathrm{C}$ & $\mathrm{NaIO}_{3}$ & 0.75 & 0.05 & $\mathrm{~B}_{4} \mathrm{C}$ & 0.20 & $48 \%$ & $11 \%$ & $1.4 \%$ & $23 \%$ & $2.9 \%$ & 3765 & 13 \\
\hline
\end{tabular}


Table 2.4. XPS on Combustion Products- 2 g Iodates with Al in Bomb Calorimeter

\section{(Argon)}

\begin{tabular}{|c|c|c|c|c|c|c|c|c|c|c|c|c|c|c|c|c|c|}
\hline \multirow{2}{*}{$\begin{array}{l}\text { Combustion } \\
\text { Product }\end{array}$} & \multirow[b]{2}{*}{ Oxidizer } & \multirow[b]{2}{*}{$\%$} & \multirow[b]{2}{*}{$\% \mathrm{Al}$} & \multicolumn{12}{|c|}{ Qualitative Analysis of Peak Binding Energy $(\mathrm{eV})$} & \multirow[b]{2}{*}{ Correction } & \multirow{2}{*}{$\begin{array}{c}\text { Correction } \\
\text { Type }\end{array}$} \\
\hline & & & & $\mathrm{I} 3 \mathrm{~d} 5 / 2$ & $\mathrm{I} 3 \mathrm{~d} 3 / 2$ & O1s & $\mathrm{Al} 2 \mathrm{p}$ & $\mathrm{Al} 2 \mathrm{p}$ & N1s & $\mathrm{Ca} 2 \mathrm{p} 3 / 2$ & $\mathrm{Ca} 2 \mathrm{p} 1 / 2$ & $\mathrm{Na} 1 \mathrm{~s}$ & $\mathrm{~K} 2 \mathrm{p} 3 / 2$ & Bi4f5/2 & Bi4f7/2 & & \\
\hline Mix 60 & $\mathrm{Ca}(\mathrm{IO} 3)_{2}$ & 80 & 20 & 618.6 & 630.0 & 531.0 & 74.0 & & & 347.2 & 350.9 & & & & & -0.91 & $\mathrm{Ca} 2 \mathrm{p} 3 / 2 \mathrm{CaO}$ \\
\hline Mix 78 & $\mathrm{Ca}(\mathrm{IO} 3)_{2}$ & 60 & 40 & 618.7 & 630.2 & 531.5 & 74.2 & & & 347.2 & 350.9 & & & & & -0.91 & $\mathrm{Ca} 2 \mathrm{p} 3 / 2 \mathrm{CaO}$ \\
\hline Mix 95 & I2O5 & 60 & 40 & 619.1 & 630.6 & 532.8 & 75.4 & & & & & & & & & 0.36 & Al2p All3 \\
\hline Mix 97 & $\mathrm{Bi}(\mathrm{IO} 3) 3$ & 80 & 20 & 619.4 & 630.9 & 531.8 & 75.1 & & & & & & & 164.6 & 159.3 & 0.22 & Bi4f5/2 Bil3 \\
\hline Mix 116 & $\mathrm{Bi}(\mathrm{IO} 3)_{3}$ & 60 & 40 & 619.4 & 630.9 & 533.0 & 75.6 & & & & & & & 164.6 & 159.3 & -0.01 & Bi4f5/2 Bil3 \\
\hline Mix 53 & $\mathrm{Na}(\mathrm{IO} 3)$ & 80 & 20 & 619.2 & 630.7 & 531.2 & 73.9 & & & & & 1071.9 & & & & -1.12 & $\mathrm{Na} 1 \mathrm{~s} \mathrm{NaI}$ \\
\hline Mix 114 & $\mathrm{Na}(\mathrm{IO} 3)$ & 60 & 40 & 618.8 & 630.3 & 530.7 & 73.6 & & & & & 1071.9 & & & & -1.48 & $\mathrm{Na} 1 \mathrm{~s} \mathrm{NaI}$ \\
\hline \multicolumn{18}{|l|}{\begin{tabular}{|l|} 
Standards \\
\end{tabular}} \\
\hline $\mathrm{Al}$ & & & & & & 531.3 & 74.0 & 71.3 & & & & & & & & -0.33 & $\mathrm{O} 1 \mathrm{~s} \mathrm{Al} 2 \mathrm{O} 3$ \\
\hline Al heated in Air & & & & & & 531.3 & 74.2 & & & & & & & & & -0.07 & $\mathrm{O} 1 \mathrm{~s} \mathrm{Al} 2 \mathrm{O} 3$ \\
\hline Al heated in N2 & & & & & & 531.3 & 73.7 & & 396.7 & & & & & & & -0.23 & $\mathrm{O} 1 \mathrm{~s} \mathrm{~A} 2 \mathrm{O} 3$ \\
\hline KI & & & & 619.4 & 630.9 & 531.3 & & & & & & & 293.1 & & & & \\
\hline $\mathrm{NaI}$ & & & & 619.1 & 630.6 & 534.9 & & & & & & 1071.9 & & & & & \\
\hline Bil3 & & & & 619.6 & 631.1 & 531.7 & & & & & & & & 164.6 & 159.3 & & \\
\hline $\mathrm{Ca}(\mathrm{IO} 3) 2$ & & & & 624.3 & 635.8 & 531.3 & & & & 347.2 & 351.0 & & & & & -0.46 & $\mathrm{Ca} 2 \mathrm{p} 3 / 2 \mathrm{CaO}$ \\
\hline NaIO3 & & & & 624.9 & 636.4 & 531.4 & & & & & & 1071.9 & & & & 0.19 & $\mathrm{Na} 1 \mathrm{~s} \mathrm{NaI}$ \\
\hline NaIO4 & & & & 625.4 & 636.8 & 531.7 & & & & & & 1071.9 & & & & 0.47 & $\mathrm{Na} 1 \mathrm{~s} \mathrm{NaI}$ \\
\hline KIO3 & & & & 624.2 & 635.7 & 530.8 & & & & & & & 293.1 & & & 0.97 & $\mathrm{~K} 2 \mathrm{p} 3 / 2 \mathrm{KI}$ \\
\hline $\mathrm{Bi}(\mathrm{IO} 3) 3$ & & & & 624.0 & 635.5 & 530.5 & & & & & & & & 164.6 & 159.3 & -0.21 & Bi4f5/2 Bil3 \\
\hline I2O5 & & & & 624.5 & 635.98 & 531.1 & & & & & & & & & & & \\
\hline \multicolumn{2}{|c|}{ Oxidation State } & & & \multicolumn{2}{|c|}{ I } & $\mathrm{O}^{-2}$ & \multicolumn{2}{|c|}{$\overrightarrow{\mathrm{Al}^{+3}}$} & $\mathrm{~N}^{-3}$ & \multicolumn{2}{|c|}{$\mathrm{Ca}^{+2}$} & $\mathrm{Na}^{+}$ & $\mathrm{K}^{+}$ & \multicolumn{2}{|c|}{$\mathrm{Bi}^{+3}$} & & \\
\hline
\end{tabular}


Table 2.5. XPS Elemental Analysis of Combustion products of Iodate Salts with

Aluminum and Standards

\begin{tabular}{|l|l|l|l|l|l|l|l|l|l|l|l|l|}
\hline Combustion & & & \multicolumn{6}{|c|}{ Elemental Analysis (Atomic \%) } \\
\hline Product & Oxidizer & $\%$ & $\% \mathrm{Al}$ & $\mathrm{I}$ & $\mathrm{O}$ & $\mathrm{Al}$ & $\mathrm{N}$ & $\mathrm{Ca}$ & $\mathrm{Na}$ & $\mathrm{K}$ & $\mathrm{Bi}$ & $\mathrm{Sum}$ \\
\hline Mix 60 & $\mathrm{Ca}(\mathrm{IO} 3) 2$ & 80 & 20 & 4 & 60 & 32 & & 3 & & & & 100 \\
\hline Mix 78 & $\mathrm{Ca}(\mathrm{IO} 3) 2$ & 60 & 40 & 15 & 53 & 26 & & 7 & & & & 100 \\
\hline Mix 54 & $\mathrm{I} 2 \mathrm{O} 5$ & 80 & 20 & 2 & 59 & 40 & & & & & & 100 \\
\hline Mix 95 & $\mathrm{I} 2 \mathrm{O} 5$ & 60 & 40 & 8 & 60 & 32 & & & & & & 100 \\
\hline Mix 97 & $\mathrm{Bi}(\mathrm{IO} 3) 3$ & 80 & 20 & 8 & 56 & 34 & & & & & 2 & 100 \\
\hline Mix 116 & $\mathrm{Bi}(\mathrm{IO} 3) 3$ & 60 & 40 & 17 & 58 & 24 & & & & & 2 & 100 \\
\hline Mix 55 & $\mathrm{K}(\mathrm{IO} 3)$ & 80 & 20 & 17 & 40 & 25 & & & & 19 & & 100 \\
\hline Mix 115 & $\mathrm{K}(\mathrm{IO} 3)$ & 60 & 40 & 16 & 42 & 26 & & & & 16 & & 100 \\
\hline Mix 53 & $\mathrm{Na}(\mathrm{IO} 3)$ & 80 & 20 & 17 & 41 & 22 & & & 20 & & & 100 \\
\hline Mix 114 & $\mathrm{Na}(\mathrm{IO} 3)$ & 60 & 40 & 10 & 51 & 31 & & & 8 & & & 100 \\
\hline Standards & & & & & & & & & & & & \\
\hline Bi(IO3)3 & & & & 22 & 68 & & & & & & 10 & 100 \\
\hline Al & & & & & 62 & 38 & 0 & & & & & 100 \\
\hline Al heated in Air & & & & & 62 & 38 & 0 & & & & & 100 \\
\hline Al heated in $\mathrm{N} 2$ & & & & & 36 & 43 & 21 & & & & & 100 \\
\hline Al2O3 & & & & & 63 & 37 & & & & & & 100 \\
\hline CaO & & & & & 74 & & & 26 & & & & 100 \\
\hline CaI2 & & & & 54 & 26 & & & 21 & & & & 100 \\
\hline All3 & & & & 15 & 58 & 27 & & & & & & 100 \\
\hline NaI & & & & 53 & & & & & 47 & & & 100 \\
\hline
\end{tabular}

The SDT allowed observation of heat released or absorbed concomitant with weight loss in the iodine-containing samples during heating as opposed to burning with fuel. Table 6 summarizes the observations when these fresh samples were heated in unsealed SDT pans. Table 7 analyzes the remaining solid products produced from the reactions outlined in Table 6 although the actual residue was collected from the bomb calorimetry experiments (Table 2). Neat $\mathrm{I}_{2} \mathrm{O}_{5}$ decomposed at $\sim 438{ }^{\circ} \mathrm{C}$ and did not appear to react with aluminum (Figure S4). With or without fuel, both sodium and potassium periodate exothermically reduced to the iodate; for $\mathrm{NaIO}_{4}$ at $\sim 312{ }^{\circ} \mathrm{C}$ and for $\mathrm{KIO}_{4}$ at $\sim 350{ }^{\circ} \mathrm{C}$. After that the thermal scans of both salts were identical to those of 
their respective iodates [12]. Sodium iodate melts at $\sim 422{ }^{\circ} \mathrm{C}$ and decomposes to oxygen and the iodide salt $\mathrm{NaI} \sim 600{ }^{\circ} \mathrm{C}$; while potassium iodate undergoes a melt with decomposition to $\mathrm{KI}$ at $\sim 550{ }^{\circ} \mathrm{C}$. These changes are endothermic. If aluminum alone is the fuel, the formation of $\mathrm{NaI}$ occurs $50{ }^{\circ} \mathrm{C}$ earlier at $550{ }^{\circ} \mathrm{C}$, but that of $\mathrm{KI}$ remains at $550{ }^{\circ} \mathrm{C}$ and both decompositions remain endothermic. When boron carbide was present alone or with aluminum, the reaction at $550{ }^{\circ} \mathrm{C}$ for both $\mathrm{NaIO}_{3}$ and $\mathrm{KIO}_{3}$ became extremely exothermic (1700 to $2400 \mathrm{~J} / \mathrm{g}$ ) with sodium salt being more energetic than potassium salt. Evidence for KI formation in these boron carbide mixtures was seen by the presence of its melt at $673{ }^{\circ} \mathrm{C}$ and evaporation at $750{ }^{\circ} \mathrm{C}$. Comparable evidence of $\mathrm{NaI}$ in the boron carbide mixtures was not observed. Boron carbide reacted with the alkali iodates at temperatures (i.e. $\left.\sim 550{ }^{\circ} \mathrm{C}\right)$ much lower than it reacted with air $(\sim 770$ $\left.{ }^{\circ} \mathrm{C}\right)$. However, if aluminum alone was the fuel, then $\mathrm{NaI}$ and $\mathrm{KI}$ melts were observed; the latter, $\mathrm{KI}$ at $\sim 676^{\circ} \mathrm{C}$, separated from the $\mathrm{Al}$ melt. $\mathrm{NaI}$ and $\mathrm{Al}$ both exhibit endotherms near $650{ }^{\circ} \mathrm{C}$. This endotherm was interpreted as the melt of NaI if continued heating resulted in significant weight loss. When Al was heated with no added salt it exhibited a neat melting endotherm at $650{ }^{\circ} \mathrm{C}$, but also an exotherm near $850{ }^{\circ} \mathrm{C}$, which we interpret as the formation of AlN. This exotherm was also observed when Al was the only fuel combined with sodium or potassium iodates/periodates. If aluminum was heated in air, the exotherm is observed much earlier just above $600{ }^{\circ} \mathrm{C}$, and was interpreted as the formation of $\mathrm{Al}_{2} \mathrm{O}_{3}$. For the iodates equation 2 can be broken into several steps where $\mathrm{M}$ is either sodium or potassium cation:

$$
\mathrm{MIO}_{3}+2 \mathrm{Al} \rightarrow \mathrm{MI}+2 \mathrm{Al}+3 / 2 \mathrm{O}_{2} \rightarrow \mathrm{Al}_{2} \mathrm{O}_{3}+\mathrm{MI}
$$


While NaI and KI have been identified from the DSC melt and XPS examination of the combustion products, we know also from the basicity of the combustion products and presence of molecular iodine that equation 1 is also operative $[12,14]$. The sodium and potassium salts show an increase in iodine production when boron carbide, rather than aluminum, was used as the fuel (Figures 12 and 13).

Bismuth triiodate, upon heating, exhibited two modest endotherms at $550{ }^{\circ} \mathrm{C}$ and at $579{ }^{\circ} \mathrm{C}[4,15]$. These are assigned as the stepwise oxidation of bismuth iodate to the oxide $\mathrm{Bi}_{2} \mathrm{O}_{3}$ with release of $\mathrm{I}_{2}$ (eq. 5,6 ). Indeed there was also one small endotherm at $817^{\circ} \mathrm{C}$, the melting point of $\mathrm{Bi}_{2} \mathrm{O}_{3}[16]$.

$$
\begin{aligned}
& 5 \mathrm{Bi}\left(\mathrm{IO}_{3}\right)_{3} \rightarrow \mathrm{Bi}_{5} \mathrm{O}_{7} \mathrm{I}+7 \mathrm{I}_{2}+19 \mathrm{O}_{2} \\
& 2 \mathrm{Bi}_{5} \mathrm{O}_{7} \mathrm{I}+1 / 2 \mathrm{O}_{2} \rightarrow 5 \mathrm{Bi}_{2} \mathrm{O}_{3}+\mathrm{I}_{2}
\end{aligned}
$$

When aluminum was added the two endotherms were visible at slightly lower temperatures, $528{ }^{\circ} \mathrm{C}$ and $566^{\circ} \mathrm{C}$ (accompanied by $\sim 40 \%$ weight loss), and an exotherm near the melting point of aluminum $\left(641^{\circ} \mathrm{C}\right)$ appeared. There is little heat released at this exotherm and almost no weight loss (Table 6). This cannot be explained by a direct reaction of $\mathrm{Bi}_{2} \mathrm{O}_{3}$ with $\mathrm{Al}$. When reagent grade $\mathrm{Bi}_{2} \mathrm{O}_{3}$ and $\mathrm{Al}$ were examined under the same experimental conditions, no reaction was observed until the oxide melted (814 $\left.{ }^{\circ} \mathrm{C}\right)$. The combustion of bismuth triiodate with aluminum in a sealed vessel under argon yielded a black product that exhibited only one endotherm at $\sim 365{ }^{\circ} \mathrm{C}$. This melt as well as its $\mathrm{UV}-\mathrm{V}$ is spectrum confirmed this product as $\mathrm{BiI}_{3}$ (m.p. $390{ }^{\circ} \mathrm{C}$ ) $[6,16]$. Indeed, little molecular iodine was produced if the combustion was in an inert atmosphere. Unlike the alkali iodate salts, less, rather than more, molecular iodine was 
produced when the bismuth or calcium iodates were burned with boron carbide rather than aluminum (Table 2).

Calcium iodate, like the bismuth iodate, exhibited two modest endotherms at $656{ }^{\circ} \mathrm{C}$ and $736{ }^{\circ} \mathrm{C}$. The first endotherm is ascribed to the decomposition of $\mathrm{Ca}\left(\mathrm{IO}_{3}\right)_{2}$ to $\mathrm{Ca}_{5}\left(\mathrm{IO}_{6}\right)_{2}$, iodine and oxygen and the second endotherm to the complete oxidation of the calcium salt to calcium oxide with further generation of iodine and oxygen $[12,17]$. When aluminum is mixed with the calcium iodate, where the decomposition of $\mathrm{Ca}\left(\mathrm{IO}_{3}\right)_{2}$ and melt of aluminum coincide at $650{ }^{\circ} \mathrm{C}$, an exothermic reaction occurs which forms both calcium and aluminum oxide as well as iodine (Table 6). The formation of calcium oxide is claimed based on the basicity of the combustion product (from closed bomb calorimetry in argon) from the $80 / 20 \mathrm{Ca}\left(\mathrm{IO}_{3}\right)_{2} / \mathrm{Al}$ mixture ( $\left.\mathrm{pH} 11\right)$, the ratio of elements in the XPS (Table 5, mix 60); and the fact that when the residue from the combustion was examined by SDT, neither endotherms nor exotherms were observed and weight loss was only $6 \%$. These combustion products were shown by titration to form $11 \%$ $\mathrm{CaO}$ (assuming this is the product). Some XRD peaks characteristic of $\psi-\mathrm{Al}_{2} \mathrm{O}_{3}$ were observed in the $80 / 20 \mathrm{Ca}\left(\mathrm{IO}_{3}\right)_{2} / \mathrm{Al}$ combustion products, but no good matches for a particular iodide (although some peaks match for $\mathrm{CaI}_{2} \bullet 6.5 \mathrm{H}_{2} \mathrm{O}$ ). If aluminum was introduced into the calcium iodate in excess, e.g. $60 / 40 \mathrm{Ca}\left(\mathrm{IO}_{3}\right)_{2} / \mathrm{Al}$, then the DSC/SDT scan of the product mixture showed an endotherm at $652{ }^{\circ} \mathrm{C}$, characteristic of the melt of excess aluminum. XRD peaks of these products match $\gamma-\mathrm{Al}_{2} \mathrm{O}_{3}$ and more closely with $\mathrm{CaI}_{2} \bullet 6.5 \mathrm{H}_{2} \mathrm{O}$ than the products of the $80 / 20 \mathrm{Ca}\left(\mathrm{IO}_{3}\right)_{2} / \mathrm{Al}$ mix (Figure 5). Furthermore, the SDT of the combustion products shows a mass loss of $31 \%$, rather than $6 \%$, and the $\mathrm{pH}$ was $\mathrm{pH} 5$, instead of 11 . These observations along with the great 
reduction in produced $\mathrm{I}_{2}(42 \%$ with $20 \% \mathrm{Al}$ down to $2 \%$ with $40 \% \mathrm{Al}$, see Tables 2 and 3) suggest some formation of $\mathrm{Al}_{2} \mathrm{I}_{6}$, a Lewis acid. The peak binding energies of the iodine signal from XPS suggests that the combustion products from $\mathrm{Ca}\left(\mathrm{IO}_{3}\right)_{2} / \mathrm{Al}$ (both $80 / 20$ and 60/40) as well as other iodate/Al mixtures, contain iodine present as iodide (Table 4). [A similar trend was observed when combustion products from a 60/40 $\mathrm{I}_{2} \mathrm{O}_{5} / \mathrm{Al}$ mixture were analyzed on DSC/SDT, with a mass loss at $300{ }^{\circ} \mathrm{C}$ of $21 \%$. No $\mathrm{I}_{2}$ was observed from the extraction of the mixture with $\mathrm{KI}$ solution (and $\mathrm{pH}$ of the water solution was 4), which also suggests the formation of $\mathrm{Al}_{2} \mathrm{I}_{6}$.] 
Table 2.6. SDT Scans of Various Iodates and Fuels $\left(20^{\circ} \mathrm{C} / \mathrm{min}, 3-5 \mathrm{mg}\right.$ in $\mathrm{N}_{2}$ unless otherwise stated)

\begin{tabular}{|c|c|c|c|c|c|c|c|c|c|c|c|c|c|c|c|c|c|c|c|c|c|}
\hline wt $\% /$ material & ${ }^{\circ} \mathrm{C}$ & $\mathrm{J} / \mathrm{g}$ & $\begin{array}{l}\text { wt } \% \\
\text { loss } \\
\end{array}$ & ${ }^{\circ} \mathrm{C}$ & $\mathrm{J} / \mathrm{g}$ & $\begin{array}{l}\text { wt \% } \\
\text { loss } \\
\end{array}$ & ${ }^{\circ} \mathrm{C}$ & $\mathrm{J} / \mathrm{g}$ & $\begin{array}{l}\text { wt \% } \\
\text { loss } \\
\end{array}$ & ${ }^{\circ} \mathrm{C}$ & $\mathrm{J} / \mathrm{g}$ & $\begin{array}{l}\text { wt \% } \\
\text { loss } \\
\end{array}$ & ${ }^{\circ} \mathrm{C}$ & $\mathrm{J} / \mathrm{g}$ & $\begin{array}{l}\text { wt } \% \\
\text { loss } \\
\end{array}$ & ${ }^{\circ} \mathrm{C}$ & $\mathrm{J} / \mathrm{g}$ & $\begin{array}{l}\text { wt \% } \\
\text { loss } \\
\end{array}$ & ${ }^{\circ} \mathrm{C}$ & $\mathrm{J} / \mathrm{g}$ & $\begin{array}{l}\text { wt \% } \\
\text { loss }\end{array}$ \\
\hline 100 & & & & 425 & 158 & 0 & & & & 601 & 486 & -41 & 654 & 11 & 0 & 883 & 172 & -55 & & & \\
\hline $\mathrm{NaIO}_{3}$ & & & & \multicolumn{2}{|c|}{ melt $\mathrm{NaIO}_{3}$} & & & & & \multicolumn{2}{|c|}{$\rightarrow \mathrm{NaI}+\mathrm{O}_{2}$} & & \multicolumn{2}{|c|}{ melt $\mathrm{NaI}$} & & \multicolumn{2}{|c|}{$\mathrm{NaI}$ Evap } & & & & \\
\hline $80 / 20$ & & & & 422 & 113 & 0 & 555 & 412 & -28 & & & & 657 & 105 & 0 & 722 & 27 & -48 & $\sim 850$ & -710 & 3 \\
\hline $\mathrm{NaIO}_{3} / \mathrm{Al}$ & & & & \multicolumn{3}{|c|}{ melt $\mathrm{NaIO}_{3}$} & \multicolumn{2}{|c|}{$\rightarrow \mathrm{NaI}+\mathrm{O}_{2}$} & & & & & \multicolumn{2}{|c|}{ melt NaI,Al } & & \multicolumn{2}{|c|}{ NaI Evap } & & $\mathrm{Al}$ & IN & \\
\hline $80 / 10 / 10$ & & & & 422 & 81 & 0 & 547 & -2375 & -52 & & & & 653 & 16 & 0 & & & & & & \\
\hline $\mathrm{NaIO}_{3} / \mathrm{Al} / \mathrm{B}_{4} \mathrm{C}$ & & & & melt $\mathrm{Na}$ & $\mathrm{aIO}_{3}$ & & $->\mathrm{Nal}$ & $s+?$ & & & & & melt & & & & & & & & \\
\hline $80 / 20$ & & & & 423 & 121 & 0 & 547 & -2243 & -60 & & & & & & & & & & & & \\
\hline $\mathrm{NaIO}_{3} / \mathrm{B}_{4} \mathrm{C}$ & & & & melt $\mathrm{Na}$ & $\mathrm{aIO}_{3}$ & & $\rightarrow \mathrm{Na}$ & Os $+?$ & & & & & no furthe & peaks & & & & & & & \\
\hline 100 & 312 & -194 & -26 & 425 & 107 & 0 & & & & 604 & 418 & -25 & 656 & 26 & 0 & 800 & & -37 & & & \\
\hline $\mathrm{NaIO}_{4}$ & $\rightarrow \mathrm{NaIO}$ & $\mathrm{O}_{3}+\mathrm{O}_{2}$ & & melt $\mathrm{Na}$ & $\mathrm{aIO}_{3}$ & & & & & $\rightarrow N$ & $\mathrm{aI}+\mathrm{O}_{2}$ & & melt & & & $\mathrm{NaI}$ & Evap & & & & \\
\hline $80 / 20$ & 312 & -167 & -13 & 423 & 60 & 0 & 548 & 208 & -19 & & & & 657 & 78 & 0 & 850 & & -39 & $\sim 860$ & -29 & 1 \\
\hline $\mathrm{NaIO}_{4} / \mathrm{Al}$ & $\rightarrow \mathrm{NaIO}$ & ${ }_{3}+\mathrm{O}_{2}$ & & melt $\mathrm{Na}$ & $\mathrm{aIO}_{3}$ & & $\rightarrow \mathrm{N}$ & $+\mathrm{O}_{2}$ & & & & & melt $N$ & $\mathrm{al}, \mathrm{Al}$ & & $\mathrm{NaI}$ & Evap & & $\mathrm{Al}$ & IN & \\
\hline $80 / 10 / 10$ & 310 & -135 & -13 & 422 & 54 & 0 & 518 & -1643 & -35 & & & & 653 & 21 & 0 & & & & & & \\
\hline $\mathrm{NaIO}_{4} / \mathrm{Al} / \mathrm{B}_{4} \mathrm{C}$ & $\rightarrow \mathrm{NaIO}$ & $\mathrm{O}_{3}+\mathrm{O}_{2}$ & & melt $\mathrm{Na}$ & $\mathrm{aIO}_{3}$ & & $\rightarrow \mathrm{Nal}$ & $\mathrm{s}+?$ & & & & & melt & & & & & & & & \\
\hline $80 / 20$ & 312 & -156 & -15 & 425 & 76 & 0 & 543 & -1727 & -43 & & & & & & & & & & & & \\
\hline $\mathrm{NaIO}_{4} / \mathrm{B}_{4} \mathrm{C}$ & $\rightarrow \mathrm{NaIO}$ & ${ }_{3}+\mathrm{O}_{2}$ & & melt $\mathrm{Na}$ & $\mathrm{aIO}_{3}$ & & $\rightarrow \mathrm{Na}$ & Os $+?$ & & & & & no furth & r peaks & & & & & & & \\
\hline 100 & & & & & & & 553 & 747 & -25 & & & & 676 & 76 & 0 & 847 & 323 & -68 & & & \\
\hline $\mathrm{KIO}_{3}$ & & & & & & & melt KIO & $>\mathrm{KI}+\mathrm{O}_{2}$ & & & & & melt & & & eval & $\mathrm{KI}$ & & & & \\
\hline $80 / 20$ & & & & & & & 551 & 363 & -15 & 654 & 47 & 0 & 676 & 40 & 0 & 850 & & -48 & $\sim 860$ & -59 & 3 \\
\hline $\mathrm{KIO}_{3} / \mathrm{Al}$ & & & & & & & melt KIO & $>\mathrm{KI}+\mathrm{O}_{2}$ & & & melt & & melt & & & eva & $\mathrm{KI}$ & & $\mathrm{Al}$ & $\mathrm{IN}$ & \\
\hline $80 / 10 / 10$ & & & & & & & 570 & -862 & -25 & 653 & 11 & 0 & 672 & 38 & 0 & 850 & & -46 & $\sim 900$ & -87 & 0 \\
\hline $\mathrm{KIO}_{3} / \mathrm{Al} / \mathrm{B}_{4} \mathrm{C}$ & & & & & & & $\rightarrow \mathrm{KB}$ & $s+?$ & & & melt & & melt & & & eval & $\mathrm{KI}$ & & $\mathrm{Al}$ & $\mathrm{IN}$ & \\
\hline $80 / 20$ & & & & & & & 566 & -1106 & -26 & & & & 673 & 23 & 0 & 750 & & -40 & & & \\
\hline $\mathrm{KIO}_{3} / \mathrm{B}_{4} \mathrm{C}$ & & & & & & & $->\mathrm{KB}$ & s + ? & & & & & melt & & & eval & KI & & & & \\
\hline 100 & 354 & -95 & -40 & & & & 548 & 371 & -13 & & & & 675 & 44 & 0 & 813 & 31 & -40 & & & \\
\hline $\mathrm{KIO}_{4}$ & $\rightarrow \mathrm{KIO}_{3}$ & $+\mathrm{O}_{2}$ & & & & & melt KIO & $>\mathrm{KI}+\mathrm{O}_{2}$ & & & & & melt & & & eval & $\mathrm{KI}$ & & & & \\
\hline $80 / 20$ & 354 & -124 & -25 & & & & 552 & 311 & -12 & 655 & 30 & 0 & 677 & 35 & 0 & 862 & 195 & -40 & & & \\
\hline $\mathrm{KIO}_{4} / \mathrm{Al}$ & $\rightarrow \mathrm{KIO}_{3}$ & $+\mathrm{O}_{2}$ & & & & & melt KIO & $>\mathrm{KI}+\mathrm{O}_{2}$ & & & melt & & melt & & & eval & $\mathrm{KI}$ & & & & \\
\hline $80 / 10 / 10$ & 343 & -90 & -21 & & & & 562 & -770 & -19 & 653 & 8 & 0 & 673 & 23 & 0 & 850 & & -31 & $\sim 900$ & -37 & 0 \\
\hline $\mathrm{KIO}_{4} / \mathrm{Al} / \mathrm{B}_{4} \mathrm{C}$ & -> KIO3 & $3+\mathrm{O} 2$ & & & & & $\rightarrow \mathrm{KB}$ & s $+?$ & & & melt & & melt & & & eval & $\mathrm{KI}$ & & $\mathrm{Al}$ & IN & \\
\hline $80 / 20$ & 352 & -84 & -34 & & & & 567 & -738 & -19 & & & & 674 & 18 & 0 & & & & & & \\
\hline $\mathrm{KIO}_{4} / \mathrm{B}_{4} \mathrm{C}$ & -> KIO3 & $+\mathrm{O} 2$ & & & & & $\rightarrow \mathrm{KB}$ & $s+?$ & & & & & melt & & & & & & & & \\
\hline 100 & & & & & & & 550 & 83 & -38 & 579 & 132 & -20 & & & & 818 & 6 & -5 & & & \\
\hline $\mathbf{B i}\left(\mathbf{I O}_{3}\right)_{3}$ & & & & & & & $\rightarrow \mathrm{Bi}_{5} \mathrm{O}_{7}$ & $+\mathrm{I}_{2}+\mathrm{O}_{2}$ & & $\rightarrow \mathrm{Bi}_{2}$ & $\mathrm{O}_{3}+\mathrm{I}_{2}$ & & & & & melt & $\mathrm{Bi}_{2} \mathrm{O}_{3}$ & & & & \\
\hline $80 / 20$ & & & & & & & 528 & 24 & -27 & 566 & 101 & -16 & 641 & -196 & 0 & & & & & & \\
\hline $\mathrm{Bi}\left(\mathrm{IO}_{3}\right)_{3} / \mathrm{Al}$ & & & & & & & $\rightarrow \mathrm{Bi}_{5} \mathrm{O}_{7}$ & $+\mathrm{I}_{2}+\mathrm{O}_{2}$ & & $\rightarrow \mathrm{Bi}_{2}$ & $\mathrm{O}_{3}+\mathrm{I}_{2}$ & & $\mathrm{Al} \rightarrow \mathrm{Al}$ & $\mathrm{O}_{3}+\mathrm{BiI}_{3}$ & & & & & & & \\
\hline $80 / 10 / 10$ & & & & & & & 547 & 49 & -28 & 583 & 31 & -17 & 620 & -90 & 0 & & & & & & \\
\hline $\mathrm{Bi}\left(\mathrm{IO}_{3}\right)_{3} / \mathrm{Al} / \mathrm{B}_{4} \mathrm{C}$ & & & & & & & $\rightarrow \mathrm{Bi}_{5} \mathrm{O}_{7}$ & $+\mathrm{I}_{2}+\mathrm{O}_{2}$ & & $\rightarrow \mathrm{Bi}$ & $\mathrm{O}_{3}+\mathrm{I}_{2}$ & & $\mathrm{Al} \rightarrow \mathrm{Al}_{2}$ & $\mathrm{O}_{3}+\mathrm{BiI}_{3}$ & & & & & & & \\
\hline \begin{tabular}{|l|}
$80 / 20$ \\
\end{tabular} & & & & & & & 547 & 18 & -29 & 582 & -392 & -19 & & & & & & & & & \\
\hline $\mathrm{Bi}\left(\mathrm{IO}_{3}\right)_{3} / \mathrm{B}_{4} \mathrm{C}$ & & & & & & & $\rightarrow \mathrm{Bi}_{5} \mathrm{O}_{7}$ & $+\mathrm{I}_{2}+\mathrm{O}_{2}$ & & $\rightarrow \mathrm{Bi}$ & BOs? & & & & & & & & & & \\
\hline 100 & & & & & & & & & & & & & 656 & 586 & -64 & 736 & 329 & -19 & & & \\
\hline $\mathrm{Ca}\left(\mathrm{IO}_{3}\right)_{2}$ & & & & & & & & & & & & & $->\mathrm{Ca}_{5}(\mathrm{I}$ & $\left.\mathrm{O}_{6}\right)_{2}+\mathrm{I}_{2}+$ & $+\mathrm{O}_{2}$ & $\rightarrow C$ & $\mathrm{aO}+\mathrm{I}_{2}+\mathrm{C}$ & & & & \\
\hline $75 / 25$ & & & & & & & & & & & & & 646 & -842 & -73 & & & & & & \\
\hline $\mathrm{Ca}\left(\mathrm{IO}_{3}\right)_{2} / \mathrm{Al}$ & & & & & & & & & & & & & $\rightarrow \mathrm{CaO}$ & $+\mathrm{Al}_{2} \mathrm{O}_{3}$ & ${ }_{3}+\mathrm{I}_{2}$ & & & & & & \\
\hline $80 / 10 / 10$ & & & & & & & & & & & & & 657 & -572 & -80 & & & & & & \\
\hline $\mathrm{Ca}\left(\mathrm{IO}_{3}\right)_{2} / \mathrm{Al} / \mathrm{B}_{4} \mathrm{C}$ & & & & & & & & & & & & & $\rightarrow \mathrm{CaO}$ & $\mathrm{Al} 2 \mathrm{O} 3$ & $3+12$ & & & & & & \\
\hline $80 / 20$ & & & & & & & & & & & & & 682 & 155 & -51 & 752 & -35 & -14 & & & \\
\hline $\mathrm{Ca}\left(\mathrm{IO}_{3}\right)_{2} / \mathrm{B}_{4} \mathrm{C}$ & & & & & & & & & & & & & $->\mathrm{Ca}_{5}(\mathrm{I}$ & $\left.\mathrm{O}_{6}\right)_{2}+\mathrm{I}_{2}+$ & $+\mathrm{O}_{2}$ & $\rightarrow \mathrm{CaB}$ & & & & & \\
\hline 100 & 200 & & -0.5 & 438 & 640 & -99 & & & & & & & & & & & & & & & \\
\hline $\mathbf{I}_{2} \mathrm{O}_{5}$ & water & loss & & $\rightarrow \mathrm{I}_{2}+$ & & & & & & & & & & & & & & & & & \\
\hline $80 / 20$ & 200 & & -0.7 & 428 & 148 & -76 & & & & 655 & 21 & 0 & & & & & & & & & \\
\hline $\mathrm{I}_{2} \mathrm{O}_{5} / \mathrm{Al}$ & water & loss & & $\rightarrow \mathrm{I}_{2}+$ & & & & & & & melt & & & & & & & & & & \\
\hline $\mathrm{Al}$ in $\mathrm{N}_{2}$ & & & & & & & & & & 657 & 190 & 0 & $\mathrm{Al}$ melt & & & $2 \mathrm{Al}$ & $+\mathrm{N}_{2}>2$ & $2 \mathrm{AlN}$ & 843 & -5989 & 32 \\
\hline $\mathrm{Al}$ in air & & & & & & & & & & 635 & -3902 & $2 \quad 19$ & $\mathrm{Al}+\mathrm{O}_{2}-$ & $\mathrm{Al}_{2} \mathrm{O}_{3}$ & & & & & & & \\
\hline $\mathrm{Al} / \mathrm{I}_{2}(50 / 50)$ & 99 & -46 & -46 & $\mathrm{Al}+\mathrm{I}_{2}-$ & $\rightarrow \mathrm{Al}_{2} \mathrm{I}_{\mathrm{f}}$ & & & & & 656 & 98 & 0 & Al melt & & & & & & & & \\
\hline $\mathrm{B}_{4} \mathrm{C}$ in $\mathrm{N}_{2}$ & & & & & & & & & & & & & & & & no thern & hal event & & & & \\
\hline $\mathrm{B}_{4} \mathrm{C}$ in air & & & & & & & & & & & & & & & & 774 & -10297 & 59 & & & \\
\hline $\mathrm{B}_{4} \mathrm{C} / \mathrm{I}_{2}(50 / 50)$ & 109 & 47 & -53 & $\mathrm{I}_{2} \mathrm{eve}$ & & & & & & & & & & & & & & & & & \\
\hline $\mathrm{Bi}_{2} \mathrm{O}_{3} / \mathrm{Al}(80 / 20)$ & & & & & & & & & & 651 & 28 & 0 & Al melt & & & 732 & 12 & 0 & 813 & -281 & -18 \\
\hline
\end{tabular}


Table 2.7. SDT Solid Bomb Combustion Products $\left(20^{\circ} \mathrm{C} / \mathrm{min}, 3-5 \mathrm{mg}\right.$ in $\mathrm{N}_{2}$ unless otherwise stated)

\begin{tabular}{|c|c|c|c|c|c|c|c|c|c|c|c|c|c|c|c|}
\hline $\mathrm{wt} \%$ & material & ${ }^{\circ} \mathrm{C}$ & $\mathrm{J} / \mathrm{g}$ & $\begin{array}{l}\text { wt } \% \\
\text { loss }\end{array}$ & ${ }^{\circ} \mathrm{C}$ & $\mathrm{J} / \mathrm{g}$ & $\begin{array}{l}\text { wt } \% \\
\text { loss }\end{array}$ & \begin{tabular}{|c|}
${ }^{\circ} \mathrm{C}$ \\
$\mathrm{Al}$ melt \\
\end{tabular} & $\mathrm{J} / \mathrm{g}$ & $\begin{array}{l}\text { wt \% } \\
\text { loss }\end{array}$ & \begin{tabular}{|c|}
${ }^{\circ} \mathrm{C}$ iodide \\
melt
\end{tabular} & $\mathrm{J} / \mathrm{g}$ & \begin{tabular}{|l|} 
wt $\%$ total \\
mass loss
\end{tabular} & XPS & $\mathrm{pH}$ \\
\hline $80 / 20$ & $\mathrm{Ca}\left(\mathrm{IO}_{3}\right)_{2} / \mathrm{Al}$ & & & & & & & & & & $\mathrm{a}$ & & -6 & $\mathrm{Ca}^{2+}, \mathrm{Al}^{3+}, \mathrm{I}, \mathrm{O}^{2-}$ & 11 \\
\hline $60 / 40$ & $\mathrm{Ca}\left(\mathrm{IO}_{3}\right)_{2} / \mathrm{Al}$ & & & & 300 & & -10 & 652 & 48 & 0 & $\mathrm{a}$ & & -31 & $\mathrm{Ca}^{2+}, \mathrm{Al}^{3+}, \mathrm{I}, \mathrm{O}^{2-}$ & 5 \\
\hline 100 & $\mathrm{CaI}_{2}$ in $\mathrm{N} 2$ & 179 & 142 & -7 & $-\mathrm{H}_{2} \mathrm{O}$ & & & & & & 783 & 123 & -38 & & \\
\hline 100 & $\mathrm{CaI}_{2}$ in Air & 177 & 104 & -8 & 520 & -40 & -70 & & & & & & & & \\
\hline $80 / 20$ & $\mathrm{NaIO}_{3} / \mathrm{Al}$ & & & & & & & & & & 653 & 42 & -34 & $\mathrm{Na}^{+}, \mathrm{Al}^{3+}, \mathrm{I}, \mathrm{O}^{2-}$ & 13 \\
\hline $60 / 40$ & $\mathrm{NaIO}_{3} / \mathrm{Al}$ & & & & & & & & & & 656 & 28 & -46 & $\mathrm{Na}^{+}, \mathrm{Al}^{3+}, \mathrm{I}, \mathrm{O}^{2-}$ & 6 \\
\hline 100 & $\mathrm{NaI}$ in $\mathrm{N} 2$ & & & & & & & & & & 657 & 171 & -100 & & \\
\hline 100 & $\mathrm{NaI}$ in Air & & & & & & & & & & 659 & 104 & -93 & & \\
\hline $80 / 20$ & $\mathrm{KIO}_{3} / \mathrm{Al}$ & & & & & & & & & & 681 & 31 & -53 & $\mathrm{~K}^{+}, \mathrm{Al}^{3+}, \mathrm{I}, \mathrm{O}^{2-}$ & 6 \\
\hline $60 / 40$ & $\mathrm{KIO}_{3} / \mathrm{Al}$ & & & & & & & 652 & 14 & 0 & 680 & 28 & -42 & $\mathrm{~K}^{+}, \mathrm{Al}^{3+}, \mathrm{I}, \mathrm{O}^{2-}$ & 6 \\
\hline 100 & $\mathrm{KI}$ in N2 & & & & & & & & & & 681 & 64 & -98 & & \\
\hline 100 & $\mathrm{KI}$ in Air & & & & & & & & & & 682 & 108 & -96 & & \\
\hline $80 / 20$ & $\mathrm{Bi}\left(\mathrm{IO}_{3}\right)_{3} / \mathrm{Al}$ & & & & 365 & 39 & -44 & & & & $\mathrm{~b}$ & & & $\mathrm{Bi}^{3+}, \mathrm{Al}^{3+}, \mathrm{I}, \mathrm{O}^{2-}$ & 4 \\
\hline $60 / 40$ & $\mathrm{Bi}\left(\mathrm{IO}_{3}\right)_{3} / \mathrm{Al}$ & & & & 320 & 8 & -23 & 648 & 10 & 0 & $\mathrm{~b}$ & & & $\mathrm{Bi}^{3+}, \mathrm{Al}^{3+}, \mathrm{I}, \mathrm{O}^{2-}$ & 4 \\
\hline 100 & $\mathrm{BiI}_{3}$ in N2 & & \multicolumn{2}{|c|}{ melt evap $\mathrm{BiI}_{3}$} & 390 & 199 & -100 & & & & & & & & \\
\hline 100 & $\mathrm{BiI}_{3}$ in Air & & \multicolumn{2}{|c|}{ melt evap $\mathrm{BiI}_{3}$} & 379 & 136 & -97 & & & & & & & & \\
\hline $80 / 20$ & $\mathrm{I}_{2} \mathrm{O}_{5} / \mathrm{Al}$ & & & & & & & & & & & & -4 & $\mathrm{Al}^{3+}, \mathrm{I}, \mathrm{O}^{2-}$ & 6 \\
\hline $60 / 40$ & $\mathrm{I}_{2} \mathrm{O}_{5} / \mathrm{Al}$ & & & & 300 & & -21 & 648 & 16 & 0 & $\mathrm{c}$ & & -24 & $\mathrm{Al}^{3+}, \mathrm{I}, \mathrm{O}^{2-}$ & 4 \\
\hline 100 & $\mathrm{Al}_{2} \mathrm{I}_{6}$ in $\mathrm{N} 2$ & 190 & 19 & -18 & 235 & 16 & -58 & 649 & 5 & 0 & & & & & \\
\hline 100 & $\mathrm{Al}_{2} \mathrm{I}_{6}$ in Air & 150 & 84 & -43 & 238 & -524 & -29 & & & & & & & & \\
\hline
\end{tabular}

a. $\mathrm{CaI}_{2}$ melt at $783^{\circ} \mathrm{C}$ was not observed; b. DSC melt \& UV-Vis suggests $\mathrm{BiI}_{3} ;$ c. $\mathrm{Al}_{2} \mathrm{I}_{6}$ observed when aluminum in excess. 

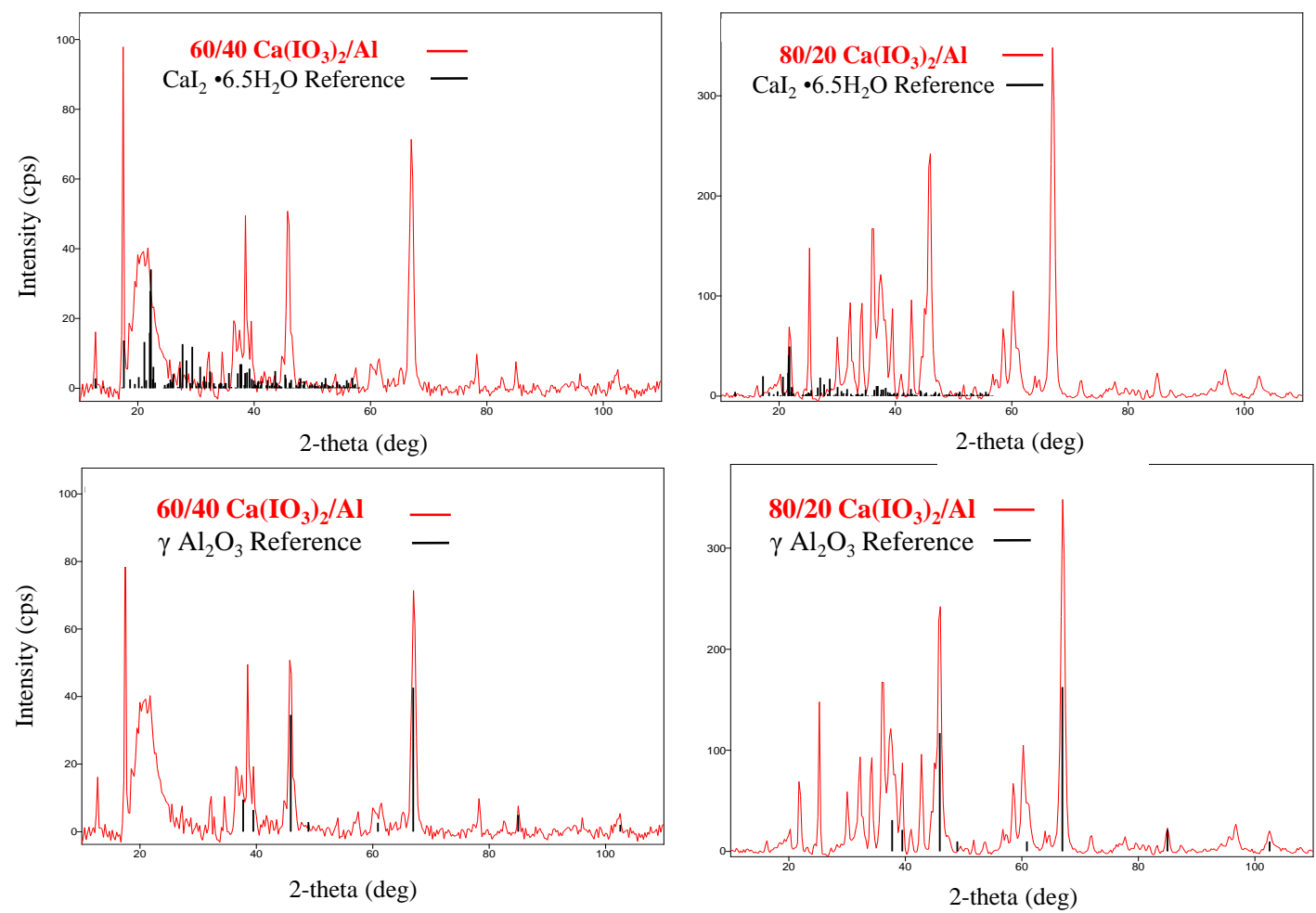

Figure 2.5. XRD of combustion products of $80 / 20 \mathrm{Ca}\left(\mathrm{IO}_{3}\right)_{2} / \mathrm{Al}$ (left) and 60/40

$$
\mathrm{Ca}\left(\mathrm{IO}_{3}\right)_{2} / \mathrm{Al} \text { (right) }
$$

The occurrence of iodides in combustion products of $\mathrm{Ca}\left(\mathrm{IO}_{3}\right)_{2} / \mathrm{Al}$ and $\mathrm{I}_{2} \mathrm{O}_{5} / \mathrm{Al}$, was confirmed by LC/MS of methanol and water extracts. Methanol extracts of 60/40 $\mathrm{Ca}\left(\mathrm{IO}_{3}\right)_{2} / \mathrm{Al}$ combustion products showed peaks consistent with $\mathrm{CaI}_{2}$ (dominant) and $\mathrm{Al}_{2} \mathrm{I}_{6}$ (peaks of which were more prominent in methanol compared to water extracts, Figure S95), where methanol extracts of $80 / 20 \mathrm{Ca}\left(\mathrm{IO}_{3}\right)_{2} / \mathrm{Al}$ combustion products showed peaks consistent with only $\mathrm{CaI}_{2}$ (Figure 6). Similar peaks were observed in a standard methanol solution of $50 / 50 \mathrm{CaI}_{2} / \mathrm{Al}_{2} \mathrm{I}_{6}$. However, adding $\mathrm{CaO}$ to an aqueous or methanol standard solution of $\mathrm{Al}_{2} \mathrm{I}_{6}$ showed a decrease in $\mathrm{Al}_{2} \mathrm{I}_{6}$ signals, and the formation of $\mathrm{CaI}_{2}$, suggesting that moisture might adversely affect the composition of the products if they contained a mixture of $\mathrm{CaO}$ and $\mathrm{Al}_{2} \mathrm{I}_{6}$ (Figure 7), promoting the 
formation of $\mathrm{CaI}_{2}$. LC/MS of the water extract of $60 / 40 \mathrm{I}_{2} \mathrm{O}_{5} / \mathrm{Al}$ combustion products shows peaks consistent with $\mathrm{Al}_{2} \mathrm{I}_{6}$ (Figure 8), but they were not observed in the 80/20 $\mathrm{I}_{2} \mathrm{O}_{5} / \mathrm{Al}$ combustion products. What is also interesting to note, is that the extract of a fresh mixture of $80 / 20 \mathrm{I}_{2} \mathrm{O}_{5} / \mathrm{Al}$ produced LC/MS peaks consistent with known hydration products of $\mathrm{I}_{2} \mathrm{O}_{5}\left(\mathrm{IO}_{3}{ }^{-}\right.$from $\mathrm{HIO}_{3}$, and $\mathrm{I}_{2} \mathrm{O}_{5} \bullet \mathrm{IO}_{3}{ }^{-}$from $\left.\mathrm{I}_{2} \mathrm{O}_{5} \bullet \mathrm{HIO}_{3}\right)$ [11]. The methanol extract of fresh $80 / 20 \mathrm{Ca}\left(\mathrm{IO}_{3}\right)_{2} / \mathrm{Al}$ did not contain any identifiable peaks (Figures 6 and 8).

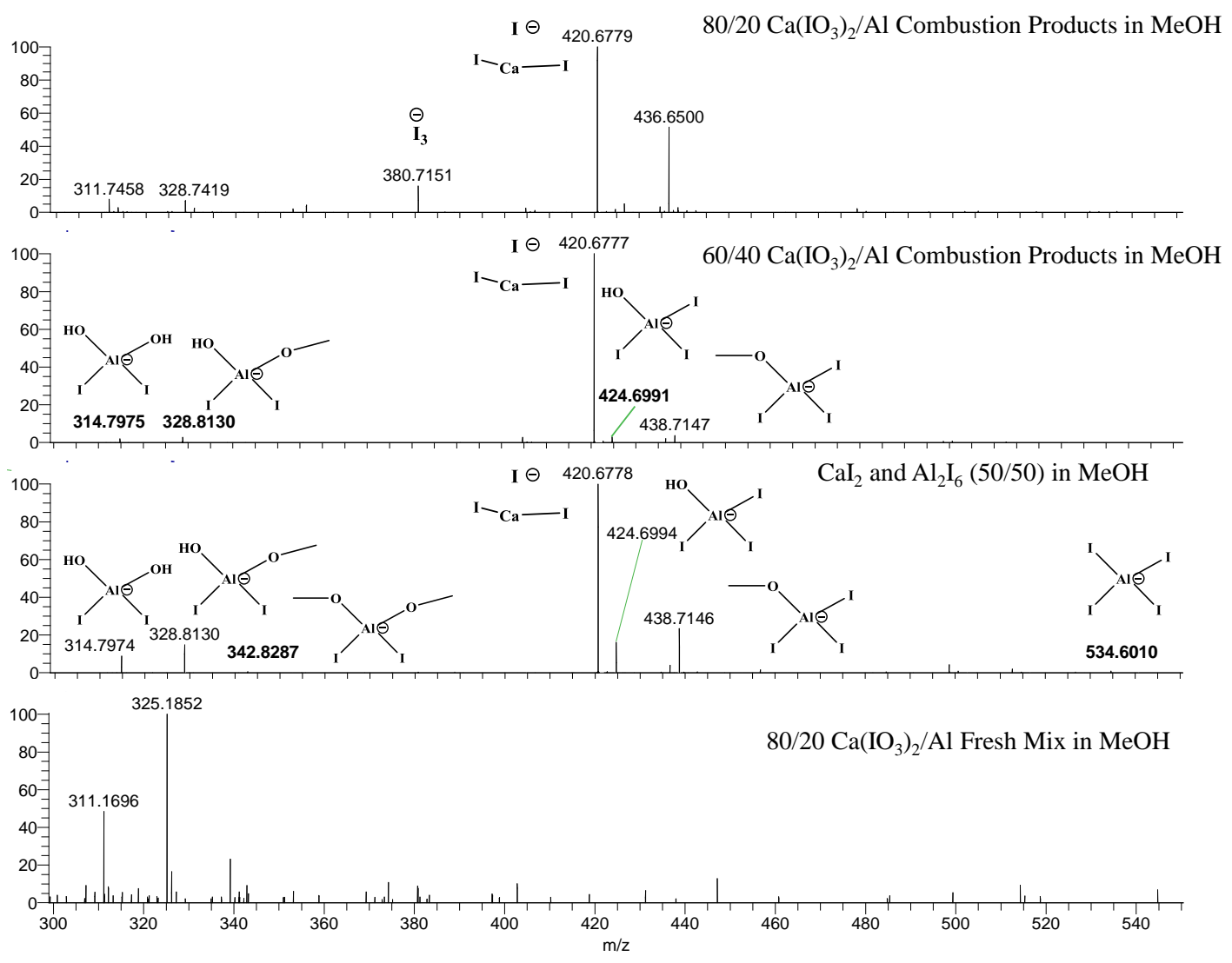

Figure 2.6. $\mathrm{LC} / \mathrm{MS}$ of the Methanol Extract of $60 / 40 \mathrm{Ca}\left(\mathrm{IO}_{3}\right)_{2} / \mathrm{Al}$ Combustion products 


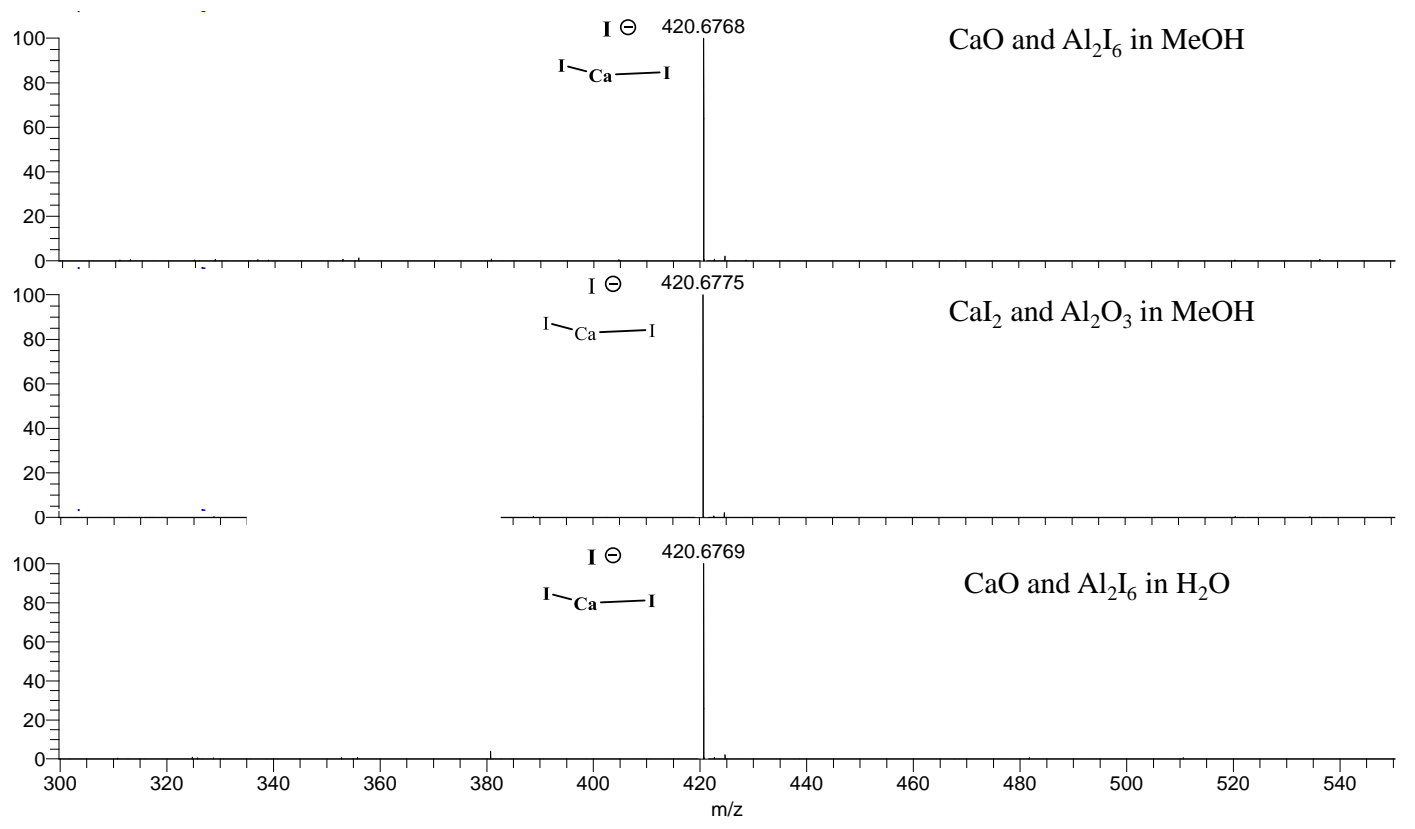

Figure 2.7. LC/MS of extracts of $\mathrm{CaO}$ and $\mathrm{Al}_{2} \mathrm{I}_{6}$ 

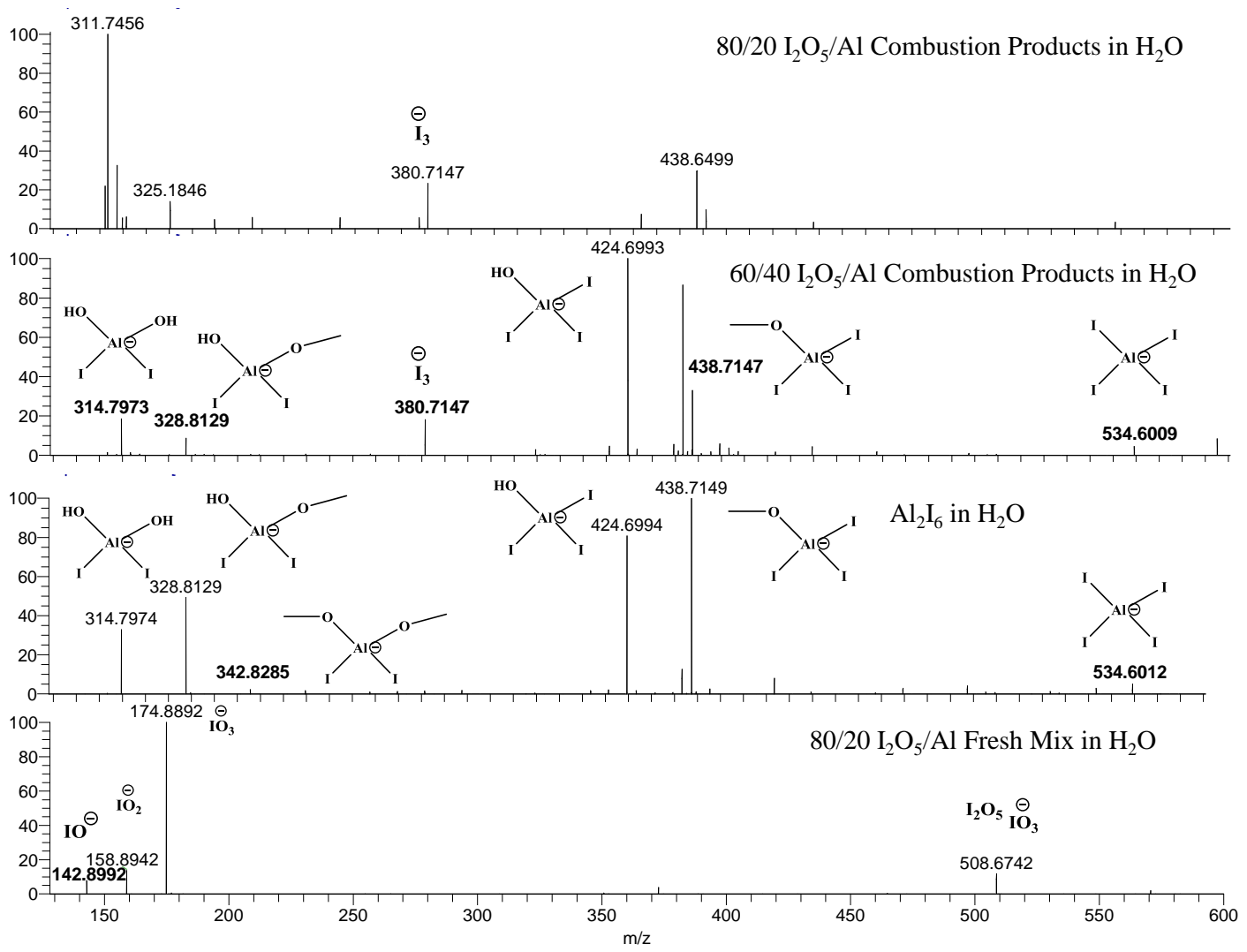

Figure 2.8. LC/MS of the $\mathrm{H}_{2} \mathrm{O}$ Extract of $60 / 40 \mathrm{I}_{2} \mathrm{O}_{5} / \mathrm{Al}$ Combustion products

Impact, friction, and electrostatic discharge (ESD) sensitivity tests were conducted on the mixtures of $\mathrm{Ca}\left(\mathrm{IO}_{3}\right)_{2} / \mathrm{Al}$ because this mixture shows the most promise to be included in final formulations with polymers. Compared with RDX, this mixture is not sensitive to friction or impact, but does have a similar and sometimes more sensitive response than RDX to ESD (Table 8). Adding a binder did not change the impact or friction sensitivity, and seemed to improve the ESD sensitivity. 
Table 2.8. Sensitivity Testing

\begin{tabular}{|l|c|c|c|c|c|c|}
\hline Composition & & $\%$ & $\% \mathrm{Al}$ & $\begin{array}{c}\text { BOE } \\
\text { Impact } \\
\mathrm{H}_{50}(\mathrm{~cm})\end{array}$ & $\begin{array}{c}\text { BAM } \\
\text { Friction TIL } \\
1 / 6(\mathrm{~N})\end{array}$ & $\begin{array}{c}\text { ESD TIL } \\
0 / 20(\mathrm{~J})\end{array}$ \\
\hline \multicolumn{2}{|c|}{$\mathrm{RDX}$} & 100 & 0 & 21.9 & 120 & 0.074 \\
\hline $\begin{array}{l}\mathrm{Ca}\left(\mathrm{IO}_{3}\right)_{2}(-325 m e s h) \\
\mathrm{Al}(23 \mathrm{um} \text { Obron})\end{array}$ & $\mathrm{Ca}\left(\mathrm{IO}_{3}\right)_{2}$ & 75 & 25 & $>75$ & 360 & 0.085 \\
\hline $\begin{array}{l}\mathrm{Ca}\left(\mathrm{IO}_{3}\right)_{2}(-325 m e s h) \\
\mathrm{Al}(23 \mathrm{um} \text { Obron})\end{array}$ & $\mathrm{Ca}\left(\mathrm{IO}_{3}\right)_{2}$ & 90 & 10 & $>75$ & 360 & 0.074 \\
\hline $\begin{array}{l}\mathrm{Ca}\left(\mathrm{IO}_{3}\right)_{2}(-325 m e s h) \\
\mathrm{Al}(23 \text { um Obron})\end{array}$ & $\mathrm{Ca}\left(\mathrm{IO}_{3}\right)_{2}$ & 95 & 5 & $>75$ & $>360$ & 0.045 \\
\hline $\begin{array}{l}\mathrm{Ca}(\mathrm{IO})_{3}(-325 m e s h) \\
\mathrm{Al}(23 \text { um Obron })+ \\
20 \% \text { Polyurethane } \\
\text { Foam (50-100mesh) }\end{array}$ & $\mathrm{Ca}\left(\mathrm{IO}_{3}\right)_{2}$ & 72 & 8 & $>75$ & $>360$ & 0.19 \\
\hline
\end{tabular}

\section{Conclusions}

As a replacement for $\mathrm{I}_{2} \mathrm{O}_{5}$, calcium iodate $\left[\mathrm{Ca}\left(\mathrm{IO}_{3}\right)_{2}\right]$ was unique among the iodine-containing salts examined (sodium, potassium, calcium and bismuth iodates and periodates of the alkali metals). When combusted with aluminum under argon, $\mathrm{Ca}\left(\mathrm{IO}_{3}\right)_{2}$ released the most molecular iodine and trapped the smallest amount of iodine as an iodide salt in an 80/20 mix with aluminum. In this mixture, calcium iodate reacted exothermically but did not release as much heat as some of the other iodate salts. More heat could be obtained by increasing the amount of aluminum, but this would have been at the cost of some molecular iodine. When $60 / 40$ mixtures of $\mathrm{I}_{2} \mathrm{O}_{5} / \mathrm{Al}$ or $\mathrm{Ca}\left(\mathrm{IO}_{3}\right)_{2} / \mathrm{Al}$ were combusted, little or no molecular iodine was recovered. This and other evidence (SDT, XPS, XRD, LC/MS) suggested that with excess aluminum, aluminum triiodide $\left(\mathrm{Al}_{2} \mathrm{I}_{6}\right)$ may have been formed from a reaction of the unburned aluminum and free iodine in this inert atmosphere. It has been reported that the completeness of reaction of a stoichiometric mixture of $\mathrm{I}_{2} \mathrm{O}_{5} / \mathrm{Al}$ is pressure dependent (at pressures less than atmospheric). The reaction forms more $\mathrm{Al}_{2} \mathrm{O}_{3}$ rather than $\mathrm{Al}_{2} \mathrm{I}_{6}$ as atmospheric pressure 
is approached [18]. We have studied $80 / 20 \mathrm{Ca}\left(\mathrm{IO}_{3}\right)_{2} / \mathrm{Al}, \mathrm{Bi}\left(\mathrm{IO}_{3}\right)_{3} / \mathrm{Al}$, and $\mathrm{NaIO} / \mathrm{Al}$ at both $515 \mathrm{kPa}$ (60 psig) and $2515 \mathrm{kPa}$ (350 psig) pressures (Table 2) to determine if the reaction can be driven to produce more molecular iodine. Interestingly, 80/20 $\mathrm{Bi}\left(\mathrm{IO}_{3}\right)_{3} / \mathrm{Al}$ produced very little free iodine (possibly further combination of $\mathrm{Bi}+\mathrm{I}_{2}$ ); $80 / 20 \mathrm{Ca}\left(\mathrm{IO}_{3}\right)_{2} / \mathrm{Al}$ produced slightly more iodine (45\% vs. $\left.42 \%\right)$; and $80 / 20 \mathrm{NaIO}_{3} / \mathrm{Al}$ produced considerably more iodine ( $28 \%$ vs. $16 \%)$. The increase in iodine produced from $80 / 20 \mathrm{NaIO}_{3} / \mathrm{Al}$ would likely be coming from further oxidation of NaI.

Table 9 summarizes the reactions observed with the various iodate and periodate salts. The production of molecular iodine is opposed by both the potential for the original cation $\left(\mathrm{Na}^{+}, \mathrm{K}^{+}, \mathrm{Ca}^{2+}, \mathrm{Bi}^{3+}\right)$ as well as the aluminum to form the iodide salts. Aluminum preferentially forms the oxide if there is sufficient oxygen available in the mixture, but the alkali ions preferentially form the iodide (MI), reducing molecular iodine formation. Calcium and bismuth form oxides, but bismuth oxide undergoes a metathesis reaction with aluminum to form, ultimately, bismuth iodide, which probably forms through elemental bismuth reacting with elemental iodine. In aluminum heavy mixtures, calcium iodate may form calcium iodide and aluminum iodide, although it is difficult to tell the difference between having calcium oxide and aluminum iodide in the products (with post reaction with moisture to form $\mathrm{CaI}_{2} \bullet 6.5 \mathrm{H}_{2} \mathrm{O}$ ), or having a mixture of calcium and aluminum iodides. In general, excess aluminum reduces $\mathrm{I}_{2}$ formation.

The fact that more molecular iodine is released when there is more oxygen available to the fuels indicates that most of the metals would rather be oxides than iodides. This is supported by the Gibbs free energy and enthalpy of oxidation of iodide salts to metal oxides (Table 10). The oxidation of the alkali iodide salts is endothermic, 
with a positive Gibbs free energy suggesting that they are less likely to produce iodine gas than the other iodide salts listed. The oxidation of the alkali earth iodides, aluminum iodide, and bismuth iodide is exothermic, with a negative Gibbs free energy suggesting release of iodine to be more favorable than that of the alkalis. All the iodide salts (KI, $\mathrm{NaI}, \mathrm{CaI}_{2}, \mathrm{BiI}_{3}$, and $\mathrm{Al}_{2} \mathrm{I}_{6}$ ) were run on $\mathrm{SDT}$ under air as well as under nitrogen. Under air, calcium iodide and aluminum iodide produced traces with small exotherms and large mass losses. In contrast, under nitrogen, calcium iodide showed no decomposition as heat flow and mass loss below its melting point, and aluminum iodide produced an endotherm during its melt with some significant mass loss (moderate sublimation). These differences suggest significant oxidation in air for these two salts. The sodium, potassium, and bismuth iodide salts showed little difference between air and nitrogen, with their melts accompanying almost total mass loss, which is presumed to be mostly sublimation (Table 7).

Table 2.9. Reactions of Iodine-Containing Salts with $20 \% \mathrm{Al}$ in Argon (observed dominant products are highlighted)

\begin{tabular}{|c|c|c|c|c|c|c|}
\hline $\mathrm{MIO}_{3}$ & $+\mathrm{Al} \rightarrow$ & $\mathrm{Al}_{2} \mathrm{O}_{3}$ & $\mathrm{Al}_{2} \mathrm{I}_{6}$ & MI & MO & $\mathrm{I}_{2}$ \\
\hline $\mathrm{I}_{2} \mathrm{O}_{5}$ & $+\mathrm{Al} \rightarrow$ & $\mathrm{Al}_{2} \mathrm{O}_{3}$ & & & & $\mathrm{I}_{2}$ \\
\hline $\begin{array}{l}\mathrm{NaIO}_{4} \\
\downarrow\end{array}$ & & & & & & \\
\hline $\mathrm{NaIO}_{3}$ & $+\mathrm{Al} \rightarrow$ & $\mathrm{Al}_{2} \mathrm{O}_{3}$ & & $+\mathrm{NaI}$ & $+\mathrm{Na}_{2} \mathrm{O}$ & $+\mathrm{I}_{2}$ \\
\hline $\begin{array}{l}\mathrm{KIO}_{4} \\
\downarrow\end{array}$ & & & & & & \\
\hline $\mathrm{KIO}_{3}$ & $+\mathrm{Al} \rightarrow$ & $\mathrm{Al}_{2} \mathrm{O}_{3}$ & & $+\mathrm{KI}$ & $+\mathrm{K}_{2} \mathrm{O}$ & $+\mathrm{I}_{2}$ \\
\hline $\mathrm{Ca}\left(\mathrm{IO}_{3}\right)_{2}$ & $+\mathrm{Al} \rightarrow$ & $\mathrm{Al}_{2} \mathrm{O}_{3}$ & & & $+\mathrm{CaO}$ & $+\mathrm{I}_{2}$ \\
\hline $\mathrm{Bi}\left(\mathrm{IO}_{3}\right)_{3}$ & $+\mathrm{Al} \rightarrow$ & $\mathrm{Al}_{2} \mathrm{O}_{3}$ & $+\mathrm{Bi}$ & $+\mathrm{BiI}_{3}$ & $+\mathrm{Bi}_{2} \mathrm{O}_{3}$ & $+\mathrm{I}_{2}$ \\
\hline
\end{tabular}


Table 2.10. Thermodynamic Calculations of Oxygen Exchange

\begin{tabular}{|c|c|c|c|c|c|c|c|c|c|}
\hline & \multicolumn{4}{|c|}{ Potential for Metal Iodide Oxidation to $\mathrm{I}_{2}$} & \multicolumn{5}{|c|}{ Potential for Metal Oxide $\mathrm{O}_{2}$ exchange with Aluminum } \\
\hline & $\begin{array}{c}\Delta \mathrm{G} \\
(\mathrm{Kj} / \mathrm{mol})\end{array}$ & $\begin{array}{c}\Delta \mathrm{S} \\
(\mathrm{j} / \mathrm{mol} / \mathrm{K})\end{array}$ & $\begin{array}{c}\Delta \mathrm{H} \\
(\mathrm{Kj} / \mathrm{mol})\end{array}$ & & & $\begin{array}{c}\Delta \mathrm{G} \\
(\mathrm{Kj} / \mathrm{mol})\end{array}$ & $\begin{array}{c}\Delta \mathrm{S} \\
(\mathrm{j} / \mathrm{mol} / \mathrm{K})\end{array}$ & $\begin{array}{c}\Delta \mathrm{H} \\
(\mathrm{Kj} / \mathrm{mol})\end{array}$ & \\
\hline 2 & MI & + & 0.5 & $\mathrm{O}_{2} \rightarrow 1 \mathrm{I}_{2}(\mathrm{~g})+1 \mathrm{M}_{2} \mathrm{O}$ & 3 & $\mathrm{M}_{2} \mathrm{O}$ & + & 2 & $\mathrm{Al} \rightarrow 1 \mathrm{Al}_{2} \mathrm{O}_{3}+6 \mathrm{M}$ \\
\hline $\mathrm{NaI}$ & 216 & 36 & 224 & & $\mathrm{Na}_{2} \mathrm{O}$ & -456 & 77 & -433 & \\
\hline KI & 347 & 40 & 357 & & $\mathrm{~K}_{2} \mathrm{O}$ & -616 & 100 & -591 & \\
\hline 1 & $\mathrm{MI}_{2}$ & + & 1 & $\mathrm{O}_{2} \rightarrow 1 \mathrm{I}_{2}(\mathrm{~g})+1 \mathrm{MO}$ & 3 & MO & + & 2 & $\mathrm{Al} \rightarrow 1 \mathrm{Al}_{2} \mathrm{O}_{3}+3 \mathrm{M}$ \\
\hline $\mathrm{CaI}_{2}$ & -55 & 54 & -39 & & $\mathrm{CaO}$ & 228 & 5 & 229 & \\
\hline $\mathrm{MgI}_{2}$ & -192 & 55 & -175 & & $\mathrm{MgO}$ & 126 & 11 & 129 & \\
\hline 2 & $\mathrm{MI}_{3}$ & + & 2 & $\mathrm{O}_{2} \rightarrow 3 \mathrm{I}_{2}(\mathrm{~g})+1 \mathrm{M}_{2} \mathrm{O}_{3}$ & 1 & $\mathrm{M}_{2} \mathrm{O}_{3}$ & + & 2 & $\mathrm{Al} \rightarrow 3 \mathrm{Al}_{2} \mathrm{O}_{3}+1 \mathrm{M}$ \\
\hline $\mathrm{BiI}_{3}$ & -85 & & -512 & & $\mathrm{Bi}_{2} \mathrm{O}_{3}$ & -4253 & 1 & -4453 & \\
\hline $\mathrm{AlI}_{3}$ & -923 & 207 & -861 & & & & & & \\
\hline
\end{tabular}

The potential for molecular iodine to be released may depend on the relative oxophilicity of aluminum relative to the cation accompanying the iodate (Table 10). This would especially be important in oxygen deficient situations such as experiments performed under inert atmosphere. With insufficient oxygen the iodide may be formed instead. We believe this to be the case with bismuth iodate, due to the favorable reaction between bismuth oxide and aluminum, which frees up bismuth for a reaction with iodine. Because the reaction of some metal oxides (calcium and magnesium) with aluminum is not as favorable, it is likely that excess aluminum in this case would react with iodine directly in an oxygen deficient environment.

We have noted that use of a combination of boron carbide $\left(\mathrm{B}_{4} \mathrm{C}\right)$ and aluminum as fuels resulted in more iodine formation from the alkali iodates than the use of either fuel alone (Table 2). The exact nature of the reactions have not been ascertained. Boron carbide has been examined by bomb calorimetry, and diboron trioxide and carbon dioxide were formed $[19,20]$.

$$
\mathrm{B}_{4} \mathrm{C}+4 \mathrm{O}_{2} \rightarrow 2 \mathrm{~B}_{2} \mathrm{O}_{3}+\mathrm{CO}_{2}
$$


Furthermore, the combustion products of boron with potassium nitrate and potassium perchlorate under argon were found to be $\mathrm{KB}_{5} \mathrm{O}_{8} \cdot 4 \mathrm{H}_{2} \mathrm{O}$ and $\mathrm{KB}_{5} \mathrm{O}_{6}(\mathrm{OH})_{4} \cdot 2 \mathrm{H}_{2} \mathrm{O}$, respectively [21]. The authors of that article speculate that reaction 8 occurs:

$$
2 \mathrm{KClO}_{4}+2 \mathrm{~B} \rightarrow 2 \mathrm{KBO}_{2}+\mathrm{Cl}_{2}+2 \mathrm{O}_{2}
$$

Using that model we suggest a similar reaction (eq 9). Indeed, over time a boron carbide mixture with sodium iodate evolved molecular iodine at room temperature. Perhaps the reason the combination fuel $\mathrm{Al} / \mathrm{B}_{4} \mathrm{C}$ results in higher amounts of evolved $\mathrm{I}_{2}$ can be attributed to the alkali metal being removed from the competition with aluminum for the freed oxygen. Thus, both the alkali metal and the aluminum are incorporated in a stable species allowing molecular iodine to be evolved.

$$
4 \mathrm{KIO}_{3}+\mathrm{B} 4 \mathrm{C} \rightarrow 4 \mathrm{KBO}_{2}+\mathrm{CO}_{2}+2 \mathrm{I}_{2}+\mathrm{O}_{2}
$$

\section{Acknowledgements}

The authors gratefully acknowledge DTRA for funding this work through grant HDTRA1-14-0027.

\section{References}

[1] Oxley, J.C.; Smith, J.L.; Donnelly, M.; Porter, M. "Fuel-oxidizer mixtures: their stabilities and burn characteristics" J. Therm. Anal. Calorim. 2015, 121, 743-763.

[2] Tennen, R.; Setlow, B.; Davis, K.L.; Loshon, C.A.; Setlow, P. "Mechanisms of killing spores of Bacillus subtilis by iodine, glutaraldehyde, and nitrous acid" J. Appl. Microbiol., 2000, 89, 330-338.

[3] Clark, B.R.; Pantoya, M.L. "The aluminum and iodine pentoxide reaction for the destruction of spore forming bacteria" Phys. Chem. Chem. Phys., 2010, 12, 1265312657. 
[4] Wang, H.; Jian, G.; Zhou, W.; DeLisio, J.B.; Lee, V.T.; Zachariah, M.R. "Metal Iodate-Based Energetic Composites and Their Combustion and Biocidal Performance" ACS Appl. Mater. Interfaces. 2015, 7, 17363-17370.

[5] Burgess, A.E.; Davidson, J.C.; "Kinetics of the Rapid Reaction between Iodine and Ascorbic Acid in Aqueous Solution using UV-Visible Absorbance and Titration by and Iodine Clock" J. Chem. Educ. 2014, 91, 300-304.

[6] Adrian, A.J.; Hume, D.N. “A Spectrophotometric Investigation of Bismuth Iodide Complexes" Inorg. Chem. 1967, 6, 331-339.

[7] Urabe, T.; Tanaka, M.; Kumakura, S.; Tsugoshi, T.; "Study on chemical speciation in aluminum chloride solution by ESI-Q-MS” J. Mass. Spec. 2007, 42, 591-597.

[8] United Nations, "Recommendations on the Transport of Dangerous Goods, Manual of Tests and Criteria," Fifth revised edition, 2009.

[9] MIL-STD-1751A, ARDEC Method 1032.

[10] Poret, J.C.; Shaw, A.P.; Csernica, C.M.; Oyler, K.D.; Vanatta, J.A.; Chen, G. "Versatile Boron Carbide-Based Energetic Time Delay Compositions" ACS Sustainable Chem. Eng., 2013, 1, 1333-1338.

[11] Little, B.K.; Emery, S.B.; Nittinger, J.C.; Fantasia, R.C.; Lindsay, C.M. "Physiochemical Characterization of Iodine(V) Oxide, Part 1: Hydration Rates" Propellants Explos. Pyrotech. 2015, 40, 595-603.

[12] Stern, K.H. "High Temperature Properties and Decomposition of Inorganic Salts Part 4. Oxy-Salts of Halogens" J. Phys. Chem. Ref. Data. 1974, 3, 481-526.

[13] Watt, G.W.; Hall, J.L. “Aluminum Iodide” Inorg. Synth. 1953, 4, 117. 
[14] Erdey, J; Simon, J.; Gal, S. "Thermoanalytical properties of analytical grade reagents-V. Sodium Halates" Talanta. 1968, 15, 653-661.

[15] Bentria, B.; Benbertal, D.; Bagieu-Beucher, M.; Masse, R.; Mosset, Alain “Crystal structure of anhydrous bismuth iodate, $\mathrm{Bi}\left(\mathrm{IO}_{3}\right)_{3}$ " J. Chem. Crystallogr. 2003, 33, 867873.

[16] Lide, D. (editor) "CRC Handbook of Chemistry Physics" $85^{\text {th }}$ ed, CRC Press, 2004. [17] Bousquet, J.; Vermande, P. "Ètude du mécanisme de la décomposition thermique de I'iodate de calcium anhydre" Soc. Chim. Mémoires. 1964, 5, 214-218.

[18] Ivanov, V. G.; Ivanov, G. V.; Lapin, P. V.; Kuznetso, V. P. "Role of Iodation in the Combustion of Metal Oxides with Iodine Pentoxide" Fizika Goreniya 1 Vzryva. 1980, 27, 28-36.

[19] Litz, L.M.; Mercuri, R.A. "Oxidation of Boron Carbide by Air, Water, and AirWater Mixtures at Elevated Temperatures" J. Electrochemical Soc. 1963, 110(8), 921925.

[20] Domalski, E.S.; Armstrong, G.T.; "The Heat of Formation of Boron Carbide" Journal of Research of the National Bureau of Standards - A. Physics and Chemistry. 1968, $72 \mathrm{~A}(2), 133-139$.

[21] Liu, P-J; Liu, L-L; He, G-Q; "Effect of solid oxidizers on the thermal oxidation and combustion performance of amorphous boron." J. Therm. Anal. Calorim. 2016, 124, 1587-1593. 


\title{
MANUSCRIPT 3
}

\section{CORRELATION OF EXPLOSIVE PROPERTIES OF}

\section{FUEL/OXIDIZER MIXTURES}

by

\author{
Jimmie C. Oxley; James L. Smith; Matthew Porter; Ryan Rettinger; \\ Jeffrey A. Canaria \\ Department of Chemistry \\ University of Rhode Island \\ 140 Flagg Rd \\ Kingston, RI 02881
}

This manuscript will be submitted to the journal Propellants, Explosives, Pyrotechnics 


\begin{abstract}
As seen in multiple cases, including the Boston Marathon bombing, improvised explosives may be as simple as a fuel/oxidizer (FOX) mixture initiated by a hot wire. The knowledge of large scale explosive potential of fuel/oxidizer (FOX) mixtures is incomplete. Predicting this explosive potential from small scale test data is desirable. Herein the explosive properties of fuel/oxidizer mixtures (FOX) were measured at both the small scale $(2 \mathrm{~g})$ with bomb calorimetry and large scale $(5 \mathrm{~kg})$ with high speed photography and pressure probe. Properties measured at the small scale such as the energy and pressure of reaction were compared to detonation velocity and air blast TNT equivalence measured at the large scale and predictions by Cheetah thermochemical code.
\end{abstract}




\section{Introduction}

Hundreds of years ago the field of energetic materials began with the creation of a fuel-oxidizer mixture of charcoal, sulfur, and potassium nitrate, which became known as black powder [1]. Within the last century the fuel-oxidizer mixture of ammonium nitrate and fuel oil (ANFO) became popular as a commercial blasting agent [2] and later as a terrorist tool [2,3]. In the intervening period, the discovery of nitration resulted in a number of high-density organic molecules - nitrate esters, nitroarenes, nitramines. Because these molecules have become the basis of military weaponry much effort has been expended in modeling their detonation performance. Fuel/oxidizer (FOX) mixtures, when examined by the same protocols, have been termed "non-ideal" explosives because the models usually over-predict performance. Nevertheless, it has become imperative that we understand FOX mixtures since their ease of creation-simply mixing a fuel and oxidizer together-has made them a common choice in illicit bombing.

We have previously reported a series of 11 oxidizers and 13 fuels examined by differential scanning calorimetry (DSC), simultaneous DSC/TGA (SDT), and by open burn. DSC is usually the first step in evaluating the energy content of an energetic formulation because the technique can use less than a milligram of material. In preparing the fuel/oxidizer DSC samples, great care was taken to make the samples homogeneous. Nevertheless, the DSC traces were difficult to interpret due to the small size of the prepared batches and the presence of multiple thermal events [4]. Herein we report a re-investigation of these and other FOX mixtures using isoperibol calorimetry - a Parr bomb-recording heat release and dynamic pressure rise of 2 gram samples during reaction under argon. Initiation of detonation of select formulations was attempted on 
the pound-scale ( 10 lb FOX with $1 \mathrm{lb}$ C4 Military Explosive), and data was recorded by high-speed photography and pressure transducer.

\section{Experimental Section}

\subsection{Sample Preparation for Bomb Calorimetry with Pressure Transducer, DSC, and SDT}

The fuels chosen were sucrose from Fisher Scientific, $23 \mu \mathrm{m}$ flake coated aluminum powder from Obron, and a $5 \mu \mathrm{m}$ magnesium powder from Firefox. Oxidizers were ground and sieved 100-200 mesh (150-75 $\mu \mathrm{m})$. Sucrose was ground with a small coffee grinder and sieved 100-200 mesh or 150-75 $\mu \mathrm{m}$. Fuel/oxidizer (FOX) mixtures were prepared as dry loose powders placed in plastic pop-top containers, for differential scanning calorimetry (DSC) samples in $500 \mathrm{mg}$ batches and for bomb calorimetry as individual $2 \mathrm{~g}$ samples. Mixing was then conducted with a Resodyn Lab Ram acoustic mixer at 35 - $40 \mathrm{G}$ acceleration for $2 \mathrm{~min}$. Individual DSC samples $\sim 0.25 \mathrm{mg}$ were taken from the $500 \mathrm{mg}$ batch. Sample preparation for SDT was similar, but with sample sizes of 4 to $6 \mathrm{mg}$.

\subsection{Differential Scanning Calorimetry (DSC)}

Samples were flame sealed $(\sim 0.25 \mathrm{mg})$ in glass capillaries (borosilicate, $0.06 \mathrm{in}$. ID, 0.11 in OD) on a metal post cooled by liquid nitrogen to prevent decomposition during sample preparation. Scans were conducted at a ramp rate of $20^{\circ} \mathrm{C} / \mathrm{min}$ on a TA Q100 DSC. The temperature range was usually $30{ }^{\circ} \mathrm{C}$ to $450{ }^{\circ} \mathrm{C}$, and the nitrogen flow rate was set to $50 \mathrm{~mL} / \mathrm{min}$. The temperature was calibrated by running indium with a melting point of $156.6^{\circ} \mathrm{C}$. This technique was chosen for oxidizer / sucrose mixtures 
because exotherms of these mixtures typically fall within the temperature limits of the instrument.

\subsection{Simultaneous DSC/TGA (SDT)}

A TA Q600 simultaneous DSC/TGA was used to run samples of 4-6 mg in open aluminum oxide pans, and scanned at $20^{\circ} \mathrm{C} / \mathrm{min}$ under $100 \mathrm{~mL} / \mathrm{min}$ nitrogen flow. The temperature was calibrated by running Zinc with melting point of $419.5{ }^{\circ} \mathrm{C}$. The temperature range was usually $50{ }^{\circ} \mathrm{C}$ to $1000{ }^{\circ} \mathrm{C}$. Oxidizer / aluminum mixtures were analyzed with this technique due to exotherms appearing at higher temperatures than the DSC limits.

\subsection{Bomb Calorimetry with Pressure Transducer}

Heat output and pressure/time curves were determined using a Parr 6200 calorimeter and Parr 1108 bomb, fitted with a pressure transducer (Parr 6976 pressure recording system, including a 5108A Kistler piezoelectric coupler, and a 211B2 Kistler piezoelectric pressure transducer with a calibrated sensitivity of $1.096 \mathrm{mV} / \mathrm{psi}$ ). The Parr bomb was calibrated (i.e. 10 trials) with benzoic acid ignited with fuse wire $(9.6232$ $\mathrm{J} / \mathrm{cm})$ and cotton string $(167.36 \mathrm{~J})$ in $2515 \mathrm{kPa}$ oxygen $\left(\Delta \mathrm{H}_{\mathrm{comb}}=26434 \mathrm{~J} / \mathrm{g}\right)$. In an oxygen atmosphere, the string was in contact with the fuse wire and sample and was ignited by the fuse wire to aid ignition of the sample. The FOX samples (three to six 2 g samples under each set of conditions) were ignited with a fuse wire under argon (2859 $\mathrm{kPa}, 400 \mathrm{psig}$ ). This pressure represented the maximum initial pressure in which the regulator could handle. It appeared to be a good balance allowing rapid initiation of burn, and minimizing heat losses with the walls of the Parr bomb [5]. With some energetic materials, it has been observed that there is a critical pressure of ignition 
associated with a specified input energy [6,7]. Igniting samples at a higher initial pressure is more likely to overcome the critical pressure of the sample. A National Instruments USB-6210 data acquisition card (maximum sample rate of $250 \mathrm{kS} / \mathrm{s}$ ) and LabView software were used to collect the pressure/time data at a rate of $10 \mathrm{kS} / \mathrm{s}$. This sample collection rate of $100 \mu$ s between pressure points was high enough resolution to result in pressure/time plots that appeared continuous on the ms time-scale (see Figures 9 and 10). Figure 1 outlines the protocol followed.

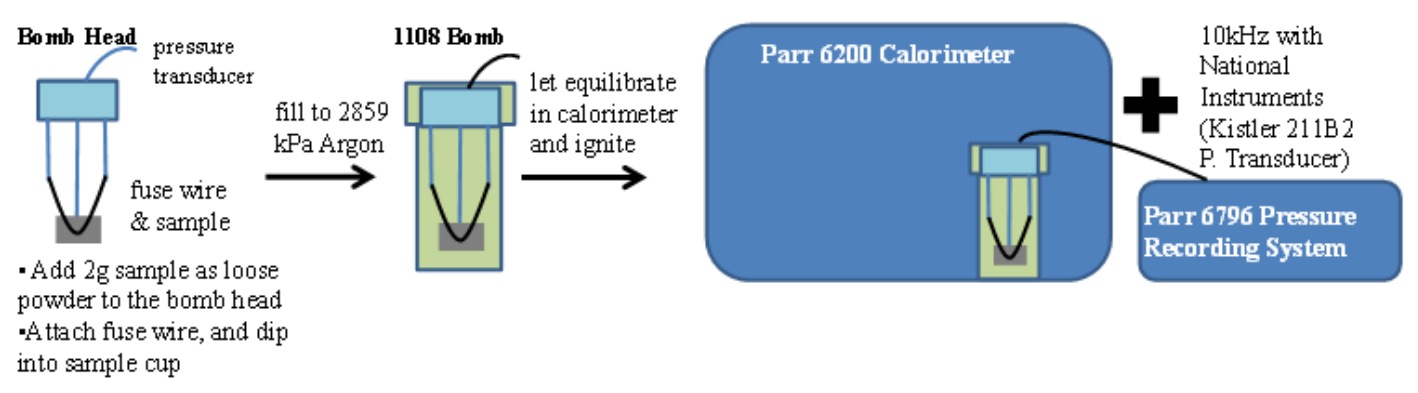

Figure 3.1. Schematic of Protocol for Parr Bomb Calorimetry Tests

\subsection{Sample Preparation for Detonation Diagnostics}

Sucrose and oxidizers were prepared separately by grinding with a Vita-Mix 5000 blender and sieving each to $100-200$ mesh $(150-75 \mu \mathrm{m})$. The aluminum flake $(23 \mu \mathrm{m})$ from Obron was used as received. Fuel/oxidizer samples of approximately $5 \mathrm{~kg}$ were manually mixed in a 37.9 L (10 gal) plastic bag for about 2 minutes (Figure 2). 


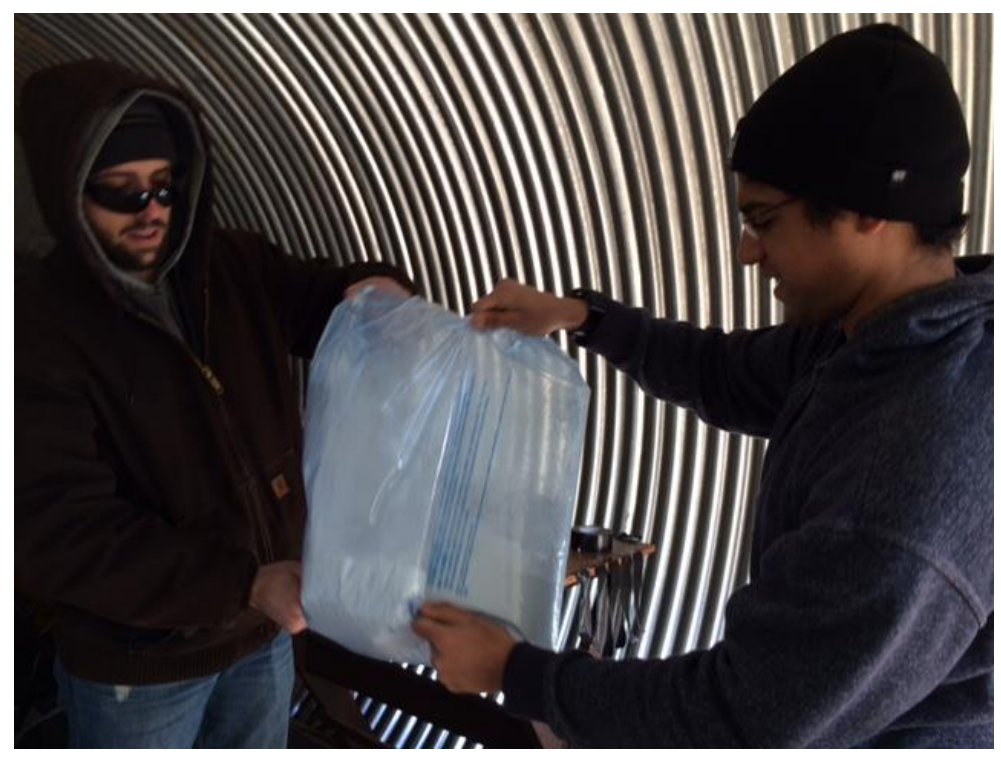

Figure 3.2. Hand mixing of FOX mixtures

For the detonation studies, schedule-40 clear, polyvinyl chloride (PVC) tubes of 4 inch diameter $(10.16 \mathrm{~cm})$ were purchased from McMaster Carr in 8 foot lengths and cut to 24 inches $(60.96 \mathrm{~cm})$ long. PVC booster cups were assembled by gluing a 4 inch PVC sewer and drain endcap to a 4 inch PVC coupler. Into the booster cup were placed two sheets (30 g) of \#2 PETN sheet explosive which had been cut into circle shape to fit tightly into the booster cup. On top of the sheet explosive, C4 (546 g) was packed and then three more circles of the PETN sheet explosive. Booster cups (Figure 3) were taped with duct tape directly to the clear PVC tube so that there was direct contact with the sample mixture. The FOX mixture was added by pouring from the plastic mixing bag, using a kraft paper funnel (Figure 4). The test device was placed in a vertical position (booster end down) on a wooden test stand; the bottom of the test device was $91.4 \mathrm{~cm}$ (36 in) from the ground. The detonator was inserted last before initiation from a blasting machine. 


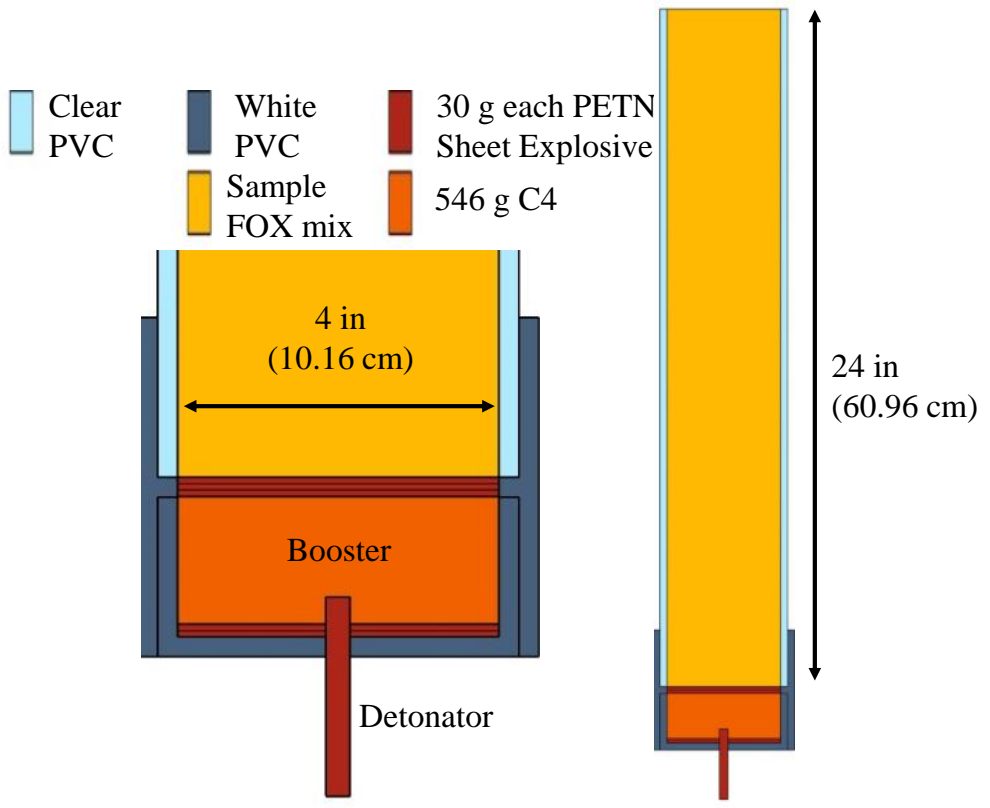

Figure 3.3. Schematic of Booster Setup

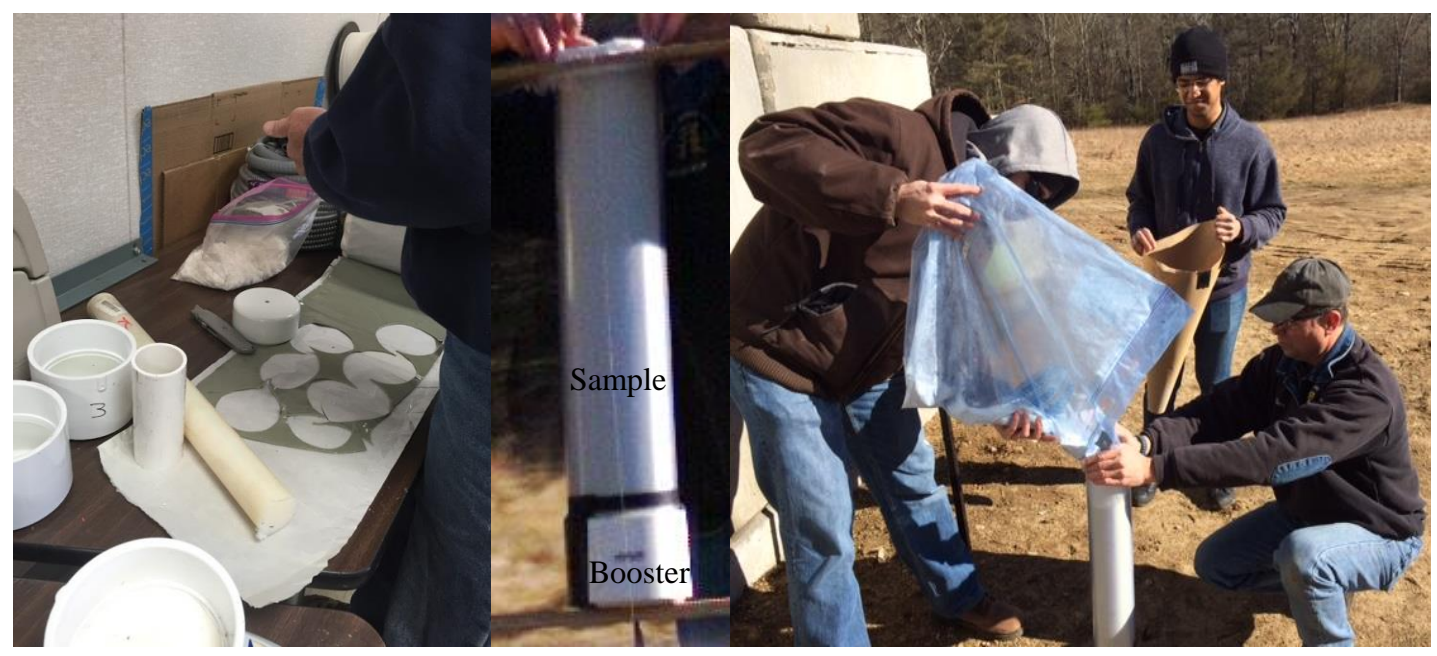

Figure 3.4. Photo Showing Preparation of Booster and Assembled Test Device

\subsection{Detonation Diagnostics}

Detonation velocity was determined visually using a Phantom V7.11 camera with a frame rate of $66,019 \mathrm{fps}$, interframe time of $15.15 \mu \mathrm{s}$, resolution of $160 \mathrm{X} 304$ pixels, exposure of $0.4 \mu \mathrm{s}(0.29 \mu \mathrm{s}$ exposure for aluminum mixtures $), 1 \mathrm{~s}$ of pre-trigger, 
and $1 \mathrm{~s}$ of post-trigger. A twisted pair of duplex wire, taped to the detonator, was used as a falling edge camera trigger (i.e. "make" trigger). Phantom PCC 2.8 software was used to process the camera data, tracking the detonation front and setting the distance scaling calibration for each file to obtain a detonation velocity. The detonation front was assumed to be the forward most position of the emitted band of light, following the contribution of the booster (Figure 5). The initiation of the booster produces a significant fire ball, present even in samples that do not detonate, and is defined herein as the "booster cloud" (Figure 5).

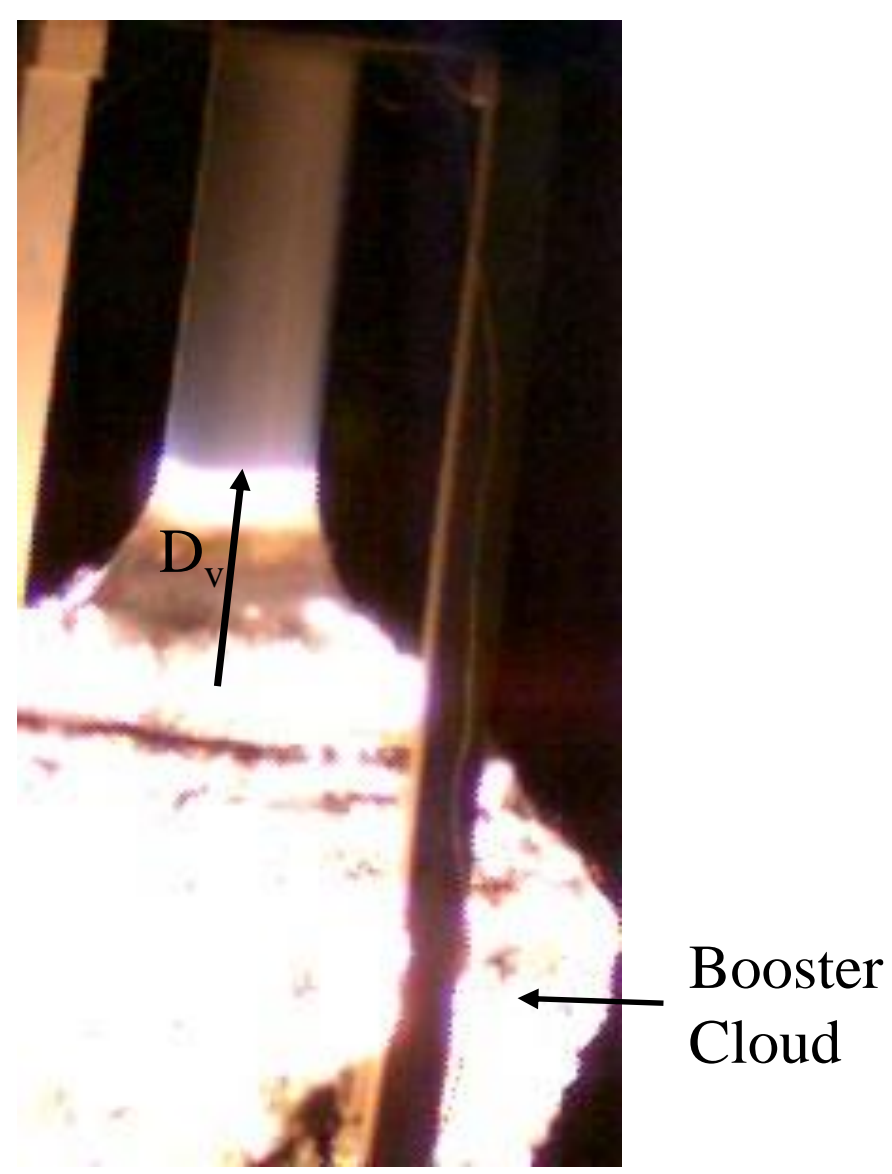

Figure 3.5. Illustration of how detonation front was determined to calculate detonation velocity, $\mathrm{D}_{\mathrm{v}}$ (Sample shown is $70: 30 \mathrm{KClO}_{3}:$ Sucrose) 
After using the Phantom PCC 2.8 software to track the scaled detonation front $(\mathrm{x}, \mathrm{y})$ in time, a correction was made for the angle of incidence (to align the shot to a vertical position). The following equations for rotating the image were used where $\left(\mathrm{X}^{\prime}, \mathrm{Y}^{\prime}\right)$ are the new coordinates:

$$
\begin{aligned}
& X^{\prime}=X \cos (\alpha)-Y \sin (\alpha) \\
& Y^{\prime}=X \sin (\alpha)+Y \cos (\alpha)
\end{aligned}
$$

Where $\alpha$ (Figure 6) is the incident angle from vertical, measured by taking the inverse tangent of two points on the side of the pipe $\left(\mathrm{X}_{1}, \mathrm{Y}_{1}\right)$ and $\left(\mathrm{X}_{2}, \mathrm{Y}_{2}\right)$ :

$$
\alpha=-\tan ^{-1}\left(\frac{X_{2}-X_{1}}{Y_{2}-Y_{1}}\right)
$$

If two points are taken from the calibrated coordinate system (i.e. for 70:30 $\mathrm{KClO}_{3}:$ Sucrose $)$ in $\mathrm{mm}\left(\mathrm{X}_{1}, \mathrm{Y}_{1}\right)=(89,30)$ and $\left(\mathrm{X}_{2}, \mathrm{Y}_{2}\right)=(68,210)$, then $\alpha=0.116 \mathrm{rad}$, and $Y^{\prime}(t)$ can be plotted for each time point (using equation 2) to find the detonation velocity (the slope in Figure 7).

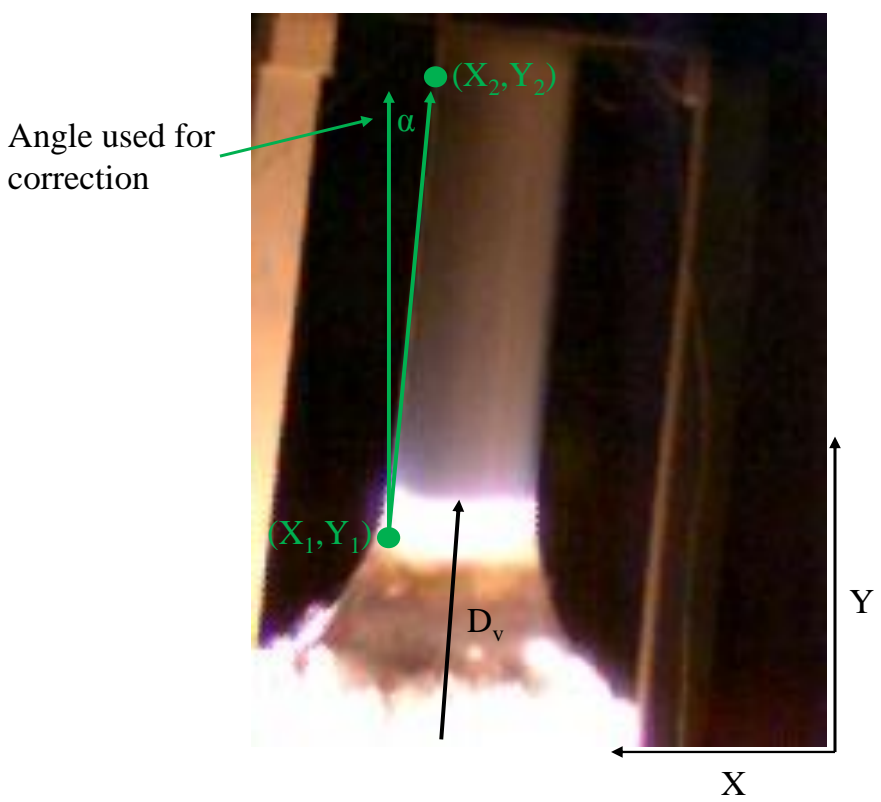

Figure 3.6. Correction for angle ( $\alpha$ ) for detonation velocity 


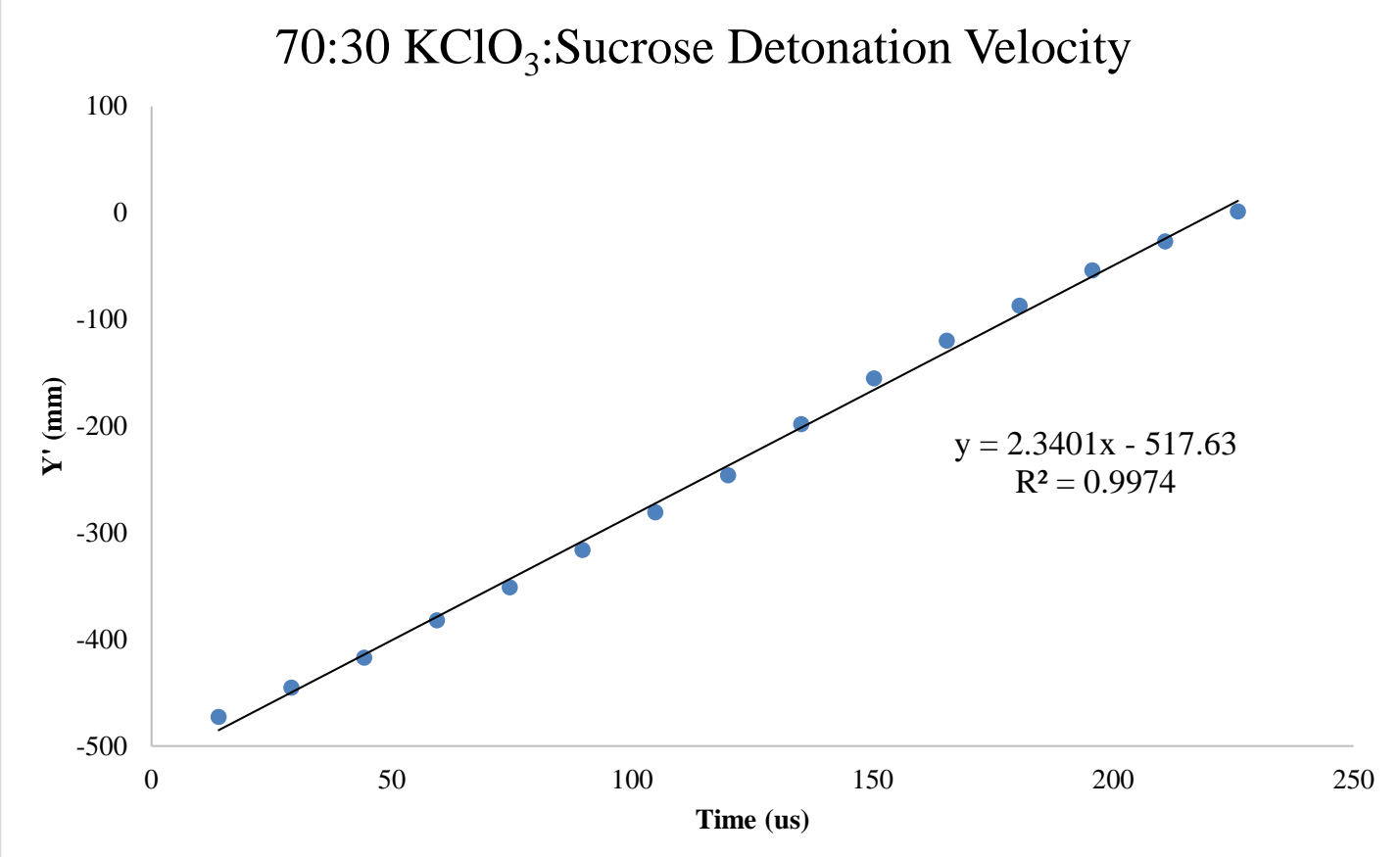

Figure 3.7. Detonation front tracking of rotation corrected Y' points. The slope of the curve is the detonation velocity in $\mathrm{mm} / \mu \mathrm{s}$ The detonation velocity was taken as the slope of the newly rotated points $Y^{\prime}(t)$ distance vs. time curve. The distance vs. time curves were linear $\left(\mathrm{R}^{2}>0.99\right)$ for all of the samples that detonated.

A pencil gauge pressure transducer (Kistler 6233A, 25 psi limit, calibrated sensitivity of $200 \mathrm{mV} / \mathrm{psi}, 5 \mathrm{~V}$ limit) with coupler (Kistler 5134B, $0.05 \mathrm{~Hz}$ high pass filter, gain of 1) measured blast overpressure. Fifty foot coax cables connected the pencil gauge to the coupler, and coupler to a Tektronix oscilloscope. The pencil gauge was mounted $1.29 \mathrm{~m}$ high, positioned $6.096 \mathrm{~m} \mathrm{(20} \mathrm{ft)} \mathrm{from} \mathrm{the} \mathrm{test} \mathrm{device} \mathrm{on} \mathrm{a} \mathrm{wooden}$ stand weighted with sand bags. The Tektronix oscilloscope (model MSO4014B, max bandwidth of $100 \mathrm{MHz}$ ) was set with a typical sampling rate between $5-100 \mathrm{MSa} / \mathrm{s}$; it 
was automatically triggered on the rising edge of the pressure signal. Figure 8 shows the overall test arena setup.

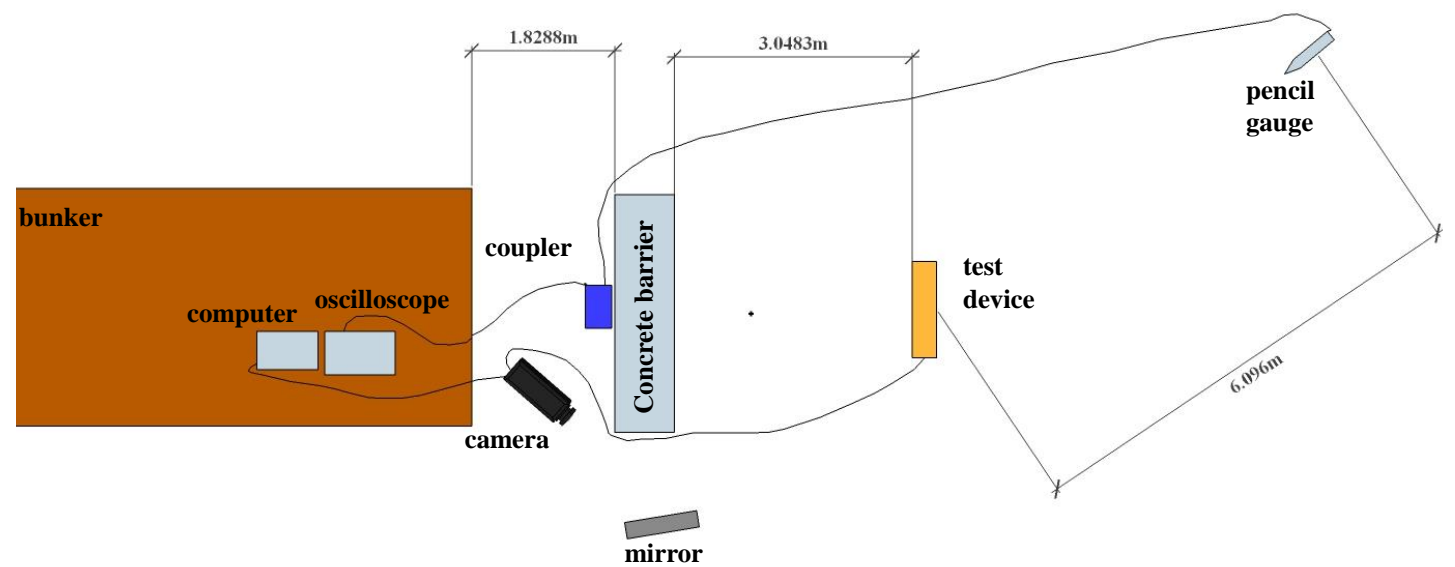

Figure 3.8. Overall Test Arena Setup

\subsection{Predictive Tools}

Cheetah 7.0 from Lawrence Livermore National Laboratory (product library: sandia, jczs revision 1923) was used to predict detonation velocity, detonation pressure, and total energy of reaction. Each mixture was run with Cheetah using the density that was measured for its large scale test [8].

The blast effects calculator (BEC V5.1) was used to obtain air blast TNT equivalence from the measured peak air blast pressures $[9,10,11]$. For each experiment, a goal seek method was used with the empirical fits for pressure (as a function of scaled distance, $\mathrm{m} / \mathrm{kg}^{1 / 3}$ ) to find the total amount of TNT needed to achieve the same peak pressure. However, the booster also has a contribution to the air blast pressure. This contribution must be subtracted in terms of energy or TNT equivalent weight, not in terms of pressure. An experiment with the booster and sand as the sample (no energy contributed from the sand) allowed the TNT equivalent weight of only the booster to be 
calculated with goal seek in the blast effects calculator. The booster TNT equivalent weight from this experiment was subtracted from the total TNT equivalent weight (Table 4) of each test to find the TNT equivalence of the sample (TNT Equivalence = TNT equivalent mass of sample / sample weight).

\section{Results}

\subsection{Parr Bomb Calorimetry}

A Parr bomb calorimeter was used primarily to estimate the energy available from FOX mixtures. Combustion was accomplished under argon gas instead of oxygen gas to determine heat of reaction without excess oxygen (Table 1). The calorimeter had been fitted with a pressure transducer to observe the pressure response as a function of time due to reaction. Closed volume pressure measurement is a common tool for propellant applications. Thus, it was possible to compare the response of a number of common gun propellants (Red Dot, Pyrodex, black powder) to FOX mixtures of interest. (Figure 9). In general the propellants exhibit a larger and faster change in pressure, but the FOX mixtures release more heat. Pressure responses of ammonium nitrate and potassium nitrate with sucrose were significantly delayed compared to other FOX

(Figure 10). It is interesting to note that $\mathrm{KNO}_{3}$ :sucrose burned slower and with slightly less energy than a similar mixture with added $\mathrm{KClO}_{3}\left(63: 7: 30 \mathrm{KNO}_{3}: \mathrm{KClO}_{3}\right.$ :sucrose); $\mathrm{KNO}_{3}$ :sucrose did not detonate on the large scale but mixtures with added $\mathrm{KClO}_{3}$ did. 


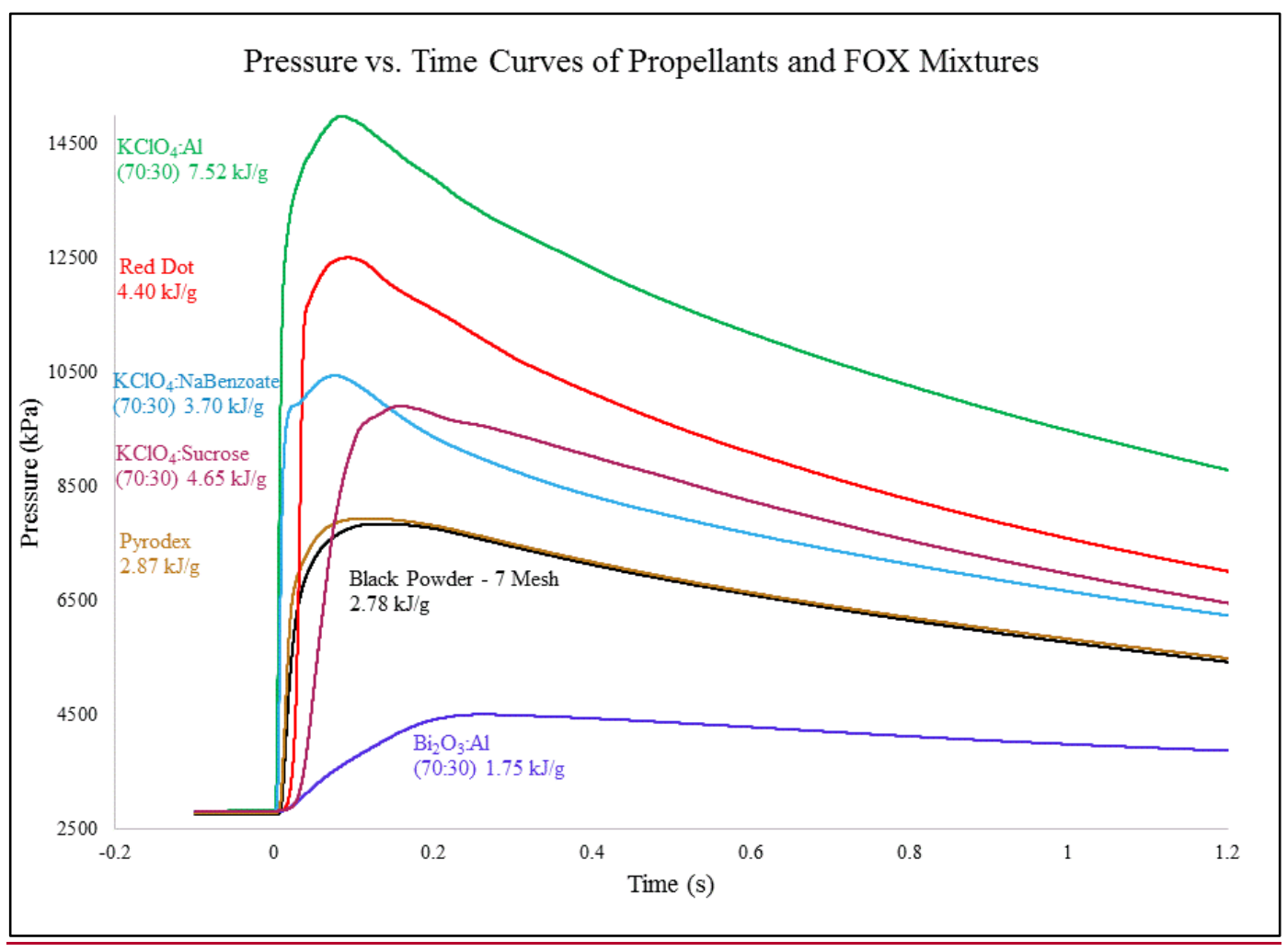

Figure 3.9. Continuous pressure vs. time: fuel:oxidizer mixtures \& propellants from $2 \mathrm{~g}$ $2859 \mathrm{kPa}$ argon 


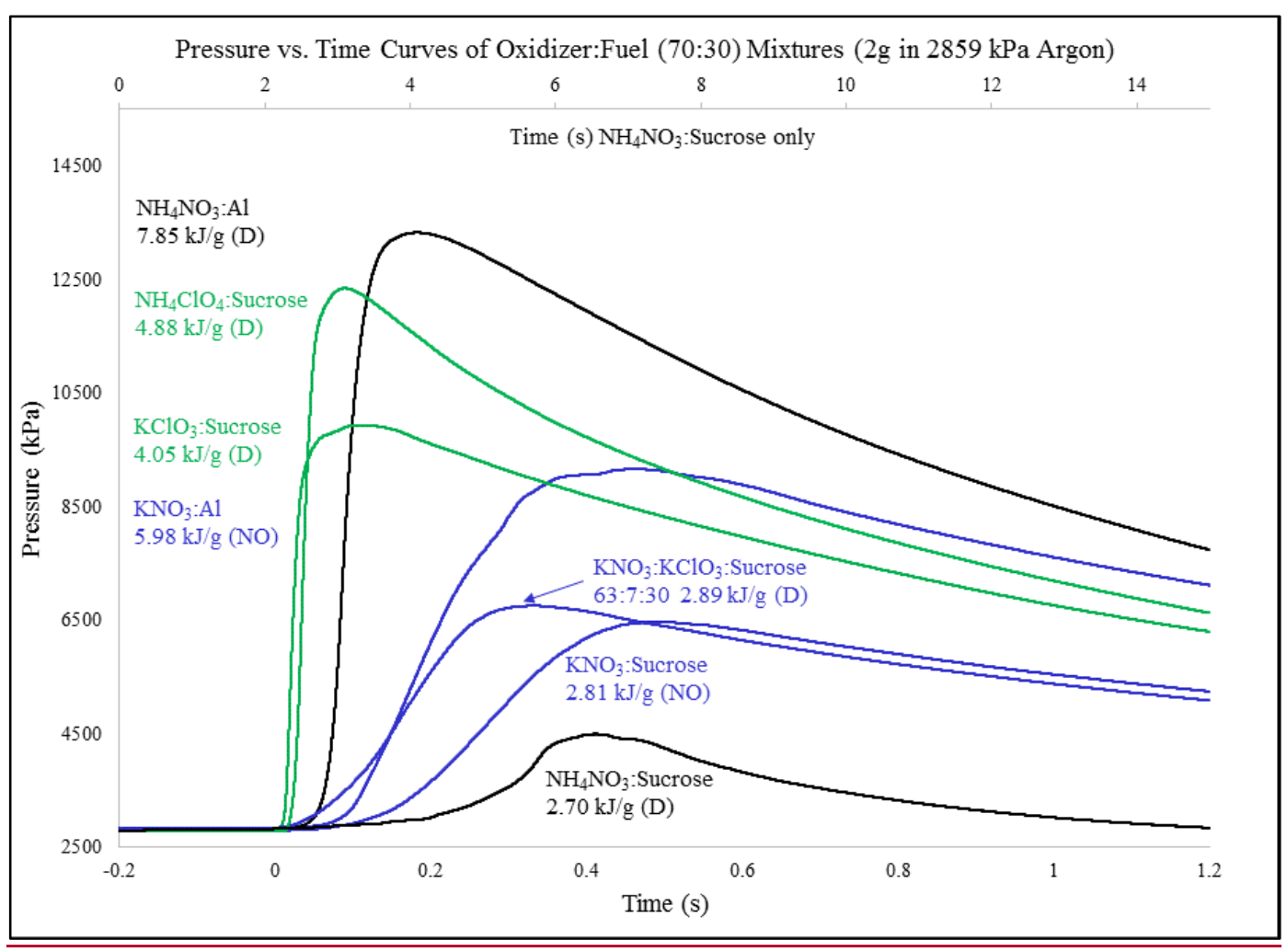

Figure 3.10. Continuous pressure vs time curves of fuel:oxidizer mixtures from $2 \mathrm{~g}$

$2859 \mathrm{kPa}$ argon. In parentheses the result of the large scale test $(\mathrm{D}=$ Detonation; NO $=$ No Detonation). The ammonium nitrate:sugar mixture is so slow that it has its own time axis (above plot). 
Table 3.1. Bomb Calorimetry Outputs from Fuel:Oxidizer Mixtures Burned 2g 2859

$\mathrm{kPa}$ argon

\begin{tabular}{|c|c|c|c|c|c|c|c|c|c|}
\hline Mixture wt,wt & $\begin{array}{c}\Delta \text { Time } \\
(\mathrm{ms})\end{array}$ & RSD & $\begin{array}{c}\Delta \\
\text { Pressure } \\
(\mathrm{kPa})\end{array}$ & RSD & $\begin{array}{l}\Delta \mathrm{P} / \text { Time } \\
(\mathrm{kPa} / \mathrm{ms})\end{array}$ & RSD & $\begin{array}{c}\Delta \mathrm{U} \\
(\mathrm{kJ} / \mathrm{g})\end{array}$ & RSD & $\begin{array}{c}\text { DSC/SDT } \\
80: 20 \\
\text { Ox:Fuel } \\
(\mathrm{kJ} / \mathrm{g})\end{array}$ \\
\hline Oxidizer, Sucrose & & & & & & & & & DSC \\
\hline K2Cr2O7, Sucrose 70,30 & 2084 & $29 \%$ & 776 & $2 \%$ & 0.4 & $29 \%$ & 1.14 & $2 \%$ & 0.10 \\
\hline AN, Sucrose 70,30 & 7687 & $10 \%$ & 1531 & $9 \%$ & 0.2 & $20 \%$ & 2.70 & $1 \%$ & 1.79 \\
\hline KMnO4, Sucrose 70,30 & 641 & $5 \%$ & 1985 & $2 \%$ & 3.1 & $3 \%$ & 2.07 & $0 \%$ & 1.80 \\
\hline KIO3, Sucrose 70,30 & 334 & $13 \%$ & 2514 & $3 \%$ & 7.6 & $15 \%$ & 1.47 & $1 \%$ & 0.84 \\
\hline KNO2, Sucrose 70,30 & 509 & $19 \%$ & 2702 & $3 \%$ & 5.4 & $20 \%$ & 2.61 & $3 \%$ & 1.69 \\
\hline KNO3, Sucrose 70,30 & 509 & $3 \%$ & 3685 & $1 \%$ & 7.2 & $3 \%$ & 2.81 & $1 \%$ & 0.68 \\
\hline $\mathrm{KClO} 3, \mathrm{KNO} 3$, Sucrose 7,63,30 & 332 & $2 \%$ & 3928 & $2 \%$ & 11.8 & $3 \%$ & 2.89 & $2 \%$ & \\
\hline KIO4, Sucrose 70,30 & 183 & $10 \%$ & 3931 & $3 \%$ & 21.6 & $9 \%$ & 2.11 & $0 \%$ & 1.81 \\
\hline RDX, KNO3, Sucrose 5,66.5,28.5 & 479 & $4 \%$ & 4186 & $1 \%$ & 8.8 & $5 \%$ & 2.93 & $2 \%$ & \\
\hline KClO3, KNO3, Sucrose $17,53,30$ & 248 & $13 \%$ & 4369 & $3 \%$ & 17.9 & $17 \%$ & 3.04 & $1 \%$ & \\
\hline RDX, KNO3, Sucrose $10,63,27$ & 401 & $7 \%$ & 4509 & $3 \%$ & 11.3 & $6 \%$ & 3.11 & $1 \%$ & \\
\hline KClO3, KNO3, Sucrose $35,35,30$ & 148 & $12 \%$ & 5580 & $3 \%$ & 38.1 & $10 \%$ & 3.41 & $1 \%$ & \\
\hline KBrO3, Sucrose 70,30 & 78 & $8 \%$ & 5873 & $6 \%$ & 76.0 & $13 \%$ & 2.77 & $2 \%$ & 1.72 \\
\hline KClO4, Sucrose 70,30 & 187 & $15 \%$ & 7060 & $10 \%$ & 38.5 & $21 \%$ & 4.65 & $0 \%$ & 0.87 \\
\hline KClO3, Sucrose 70,30 & 104 & $21 \%$ & 7150 & $7 \%$ & 72.6 & $29 \%$ & 4.05 & $0 \%$ & 2.09 \\
\hline RDX, KNO3, Sucrose 50,35,15 & 212 & $18 \%$ & 7852 & $4 \%$ & 37.8 & $15 \%$ & 4.24 & $1 \%$ & \\
\hline AP,Sucrose 70,30 & 97 & $7 \%$ & 9289 & $4 \%$ & 96.1 & $10 \%$ & 4.88 & $0 \%$ & 1.36 \\
\hline Oxidizer, Al & & & & & & & & & SDT \\
\hline K2Cr2O7, A1 70,30 & 474 & $7 \%$ & 3261 & $6 \%$ & 6.9 & $13 \%$ & 4.18 & $1 \%$ & 0.00 \\
\hline KNO2, Al 70,30 & 696 & $21 \%$ & 4370 & $14 \%$ & 6.5 & $31 \%$ & 5.20 & $8 \%$ & 2.40 \\
\hline KMnO4, Al 70,30 & 254 & $8 \%$ & 5089 & $9 \%$ & 20.1 & $10 \%$ & 5.31 & $2 \%$ & 0.73 \\
\hline KIO3, Al 70,30 & 241 & $38 \%$ & 5682 & $8 \%$ & 26.6 & $46 \%$ & 4.94 & $0 \%$ & 0.49 \\
\hline KNO3, Al 70,30 & 403 & $13 \%$ & 6307 & $1 \%$ & 15.8 & $12 \%$ & 5.98 & $3 \%$ & 1.30 \\
\hline KIO4, A1 70,30 & 153 & $30 \%$ & 8301 & $5 \%$ & 58.6 & $38 \%$ & 6.32 & $1 \%$ & 0.17 \\
\hline $\mathrm{KClO} 4, \mathrm{Al} 80,20$ & 75 & $19 \%$ & 9578 & $5 \%$ & 132.6 & $26 \%$ & 5.11 & $1 \%$ & 0.80 \\
\hline $\mathrm{KBrO} 3, \mathrm{Al} 70,30$ & 105 & $21 \%$ & 10215 & $5 \%$ & 100.1 & $23 \%$ & 6.53 & $1 \%$ & 0.45 \\
\hline $\mathrm{AN}, \mathrm{Al} 70,30$ & 195 & $19 \%$ & 10367 & $4 \%$ & 54.1 & $14 \%$ & 7.85 & $0 \%$ & 0.64 \\
\hline $\mathrm{KClO} 4, \mathrm{Al} 50,50$ & 135 & $17 \%$ & 11045 & $1 \%$ & 84.0 & $19 \%$ & 8.22 & $1 \%$ & \\
\hline $\mathrm{KClO} 3, \mathrm{Al} 70,30$ & 96 & $11 \%$ & 11929 & $5 \%$ & 126.3 & $15 \%$ & 7.18 & $5 \%$ & 1.50 \\
\hline $\mathrm{KClO} 4, \mathrm{Al} 70,30$ & 78 & $18 \%$ & 12272 & $3 \%$ & 161.6 & $20 \%$ & 7.52 & $1 \%$ & \\
\hline KClO4, Al 60,40 & 97 & $19 \%$ & 12727 & $5 \%$ & 136.4 & $22 \%$ & 9.36 & $2 \%$ & \\
\hline $\mathrm{AP}, \mathrm{Al} 70,30$ & 81 & $15 \%$ & 15813 & $4 \%$ & 199.7 & $20 \%$ & 9.36 & $1 \%$ & 1.60 \\
\hline \multicolumn{10}{|l|}{ Oxidizer, Na Benzoate } \\
\hline KNO3, NaBenzoate 70,30 & 471 & $7 \%$ & 3045 & $2 \%$ & 6.5 & $8 \%$ & 2.25 & $2 \%$ & \\
\hline KClO3, NaBenzoate 70,30 & 64 & $6 \%$ & 6815 & $2 \%$ & 105.8 & $4 \%$ & 3.19 & $1 \%$ & \\
\hline KClO4, NaBenzoate 70,30 & 65 & $25 \%$ & 7636 & $2 \%$ & 123.8 & $30 \%$ & 3.70 & $0 \%$ & \\
\hline AP, NaBenzoate 70,30 & 490 & $12 \%$ & 7814 & $1 \%$ & 16.1 & $14 \%$ & 4.13 & $2 \%$ & \\
\hline
\end{tabular}


The change in internal energy of the formulations, as judged by the heat of decomposition measured at the sub-milligram-scale by DSC (far right column, Table 1) and heat of reaction observed in the $2 \mathrm{~g}$ Parr bomb samples (penultimate right column, Table 1), differ. Heat of reaction (i.e. Parr bomb data) is greater than heat of decomposition, particularly when the fuel is aluminum. However, the aluminum/oxidizer formulations were tested in open pans by SDT where there were ample opportunities for sample evaporation/sublimation, thus heat loss.

A comparison of the same oxidizers with different fuels shows the energy input from the choice of fuel is aluminum $>$ sucrose $>$ sodium benzoate (Table 1). Other fuel/oxidizer mixtures were also examined in the Parr bomb (Table 2). In terms of energy output neither the thermites nor the gun propellants released more energy than the examined FOX mixtures.

Table 3.2. Parr Bomb Calorimetry Output for Thermites vs. Gun Propellants

\begin{tabular}{|l|c|c|c|c|c|c|c|c|}
\hline Mixture wt,wt & $\begin{array}{c}\Delta \text { Time } \\
(\mathrm{ms})\end{array}$ & RSD & $\begin{array}{c}\Delta \\
\text { Pressure } \\
(\mathrm{kPa})\end{array}$ & $\mathrm{RSD}$ & $\begin{array}{c}\Delta \mathrm{P} / \mathrm{Time} \\
(\mathrm{kPa} / \mathrm{ms})\end{array}$ & RSD & $\begin{array}{c}\Delta \mathrm{U} \\
(\mathrm{kJ} / \mathrm{g})\end{array}$ & RSD \\
\hline Thermites & & & & & & & & \\
\hline Fe3O4, Mg 80,20 & 1501 & $9 \%$ & 424 & $10 \%$ & 0.3 & $19 \%$ & 2.12 & $0 \%$ \\
\hline Fe3O4, Mg 70,30 & 1322 & $3 \%$ & 970 & $7 \%$ & 0.7 & $9 \%$ & 3.22 & $1 \%$ \\
\hline Fe3O4, Mg 60,40 & 1043 & $17 \%$ & 1539 & $3 \%$ & 1.5 & $16 \%$ & 3.73 & $0 \%$ \\
\hline Bi2O3, Al 70,30 & 288 & $13 \%$ & 1810 & $8 \%$ & 6.3 & $4 \%$ & 1.75 & $1 \%$ \\
\hline Bi2O3, Al 90,10 & 210 & $50 \%$ & 2277 & $12 \%$ & 12.8 & $46 \%$ & 1.61 & $1 \%$ \\
\hline Bi2O3, Al 80,20 & 113 & $6 \%$ & 2704 & $8 \%$ & 23.9 & $13 \%$ & 1.90 & $2 \%$ \\
\hline Gun Propellants & & & & & & & & \\
\hline BP Meal & 183 & $6 \%$ & 4812 & $9 \%$ & 26.4 & $13 \%$ & 2.83 & $1 \%$ \\
\hline BP 07 Mesh & 139 & $9 \%$ & 5000 & $3 \%$ & 36.1 & $6 \%$ & 2.78 & $1 \%$ \\
\hline BP 20 Mesh & 127 & $16 \%$ & 5033 & $3 \%$ & 40.4 & $13 \%$ & 2.79 & $2 \%$ \\
\hline Pyrodex & 116 & $8 \%$ & 5143 & $1 \%$ & 44.6 & $9 \%$ & 2.87 & $1 \%$ \\
\hline Red Dot & 86 & $13 \%$ & 9761 & $3 \%$ & 115.1 & $15 \%$ & 4.40 & $0 \%$ \\
\hline
\end{tabular}




\subsection{Detonation Testing}

Table 3 shows FOX mixtures for which initiation of detonation was attempted. Four of the mixtures failed to propagate detonation although the velocity of the burn front is recorded under the velocity of $\mathrm{km} / \mathrm{s}$. Figure 11 provides screen captures of the reactions observed. The detonation front was taken to be the bright line running ahead of the booster debris cloud (bottom). A detonation rather than a burn was judged by the rapid PVC wall expansion immediately behind the front. Figure 12 shows $\mathrm{KNO}_{3}$ :sucrose as an example of a mixture which failed to support detonation. Figure 12 also shows $\mathrm{KNO}_{3}$ :aluminum as an example of a mixture where the detonation failed and transited to a rapid burn. In this case the mixture is more flammable than detonable. Figure 13 shows an enlarged picture of three FOX mixtures known to be improvised explosive mixtures which detonated $\left(\mathrm{NH}_{4} \mathrm{NO}_{3}:\right.$ Sucrose, $\mathrm{NH}_{4} \mathrm{NO}_{3}: \mathrm{Al}$, and $\mathrm{KClO}_{3}:$ Sucrose) and one more example of one which did not detonate $\left(\mathrm{KMnO}_{4}:\right.$ Sucrose). 


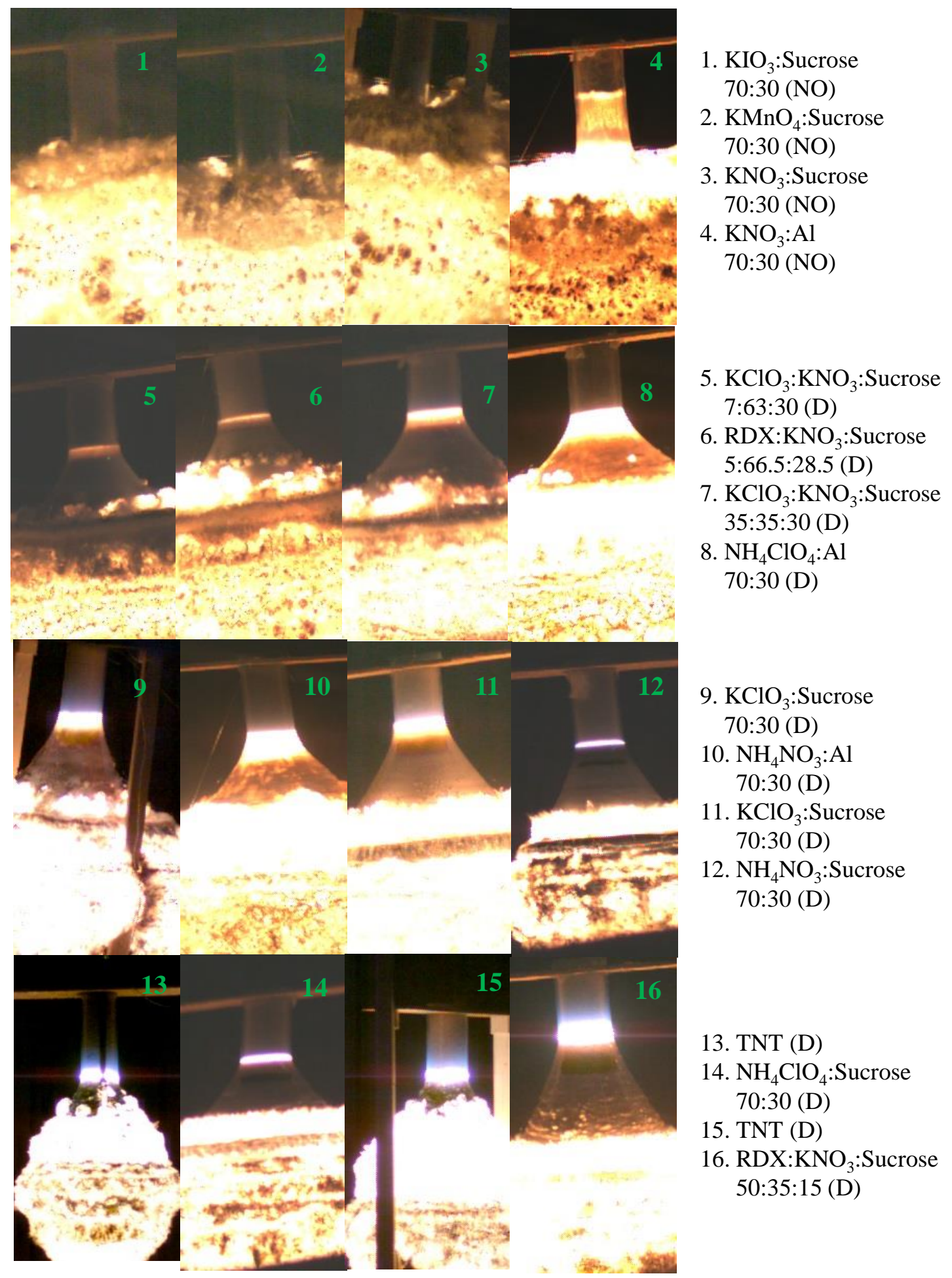

Figure 3.11. One frame from video of each FOX mixture tested. Frame was chosen when reaction was about $75 \%$ along the 24 inch pipe in order to allow the detonation 
front (samples 5 to 16 ) to be clearly separated from the booster cloud. ( $D=$ Detonation, $\mathrm{NO}=\mathrm{NO}$ Detonation).

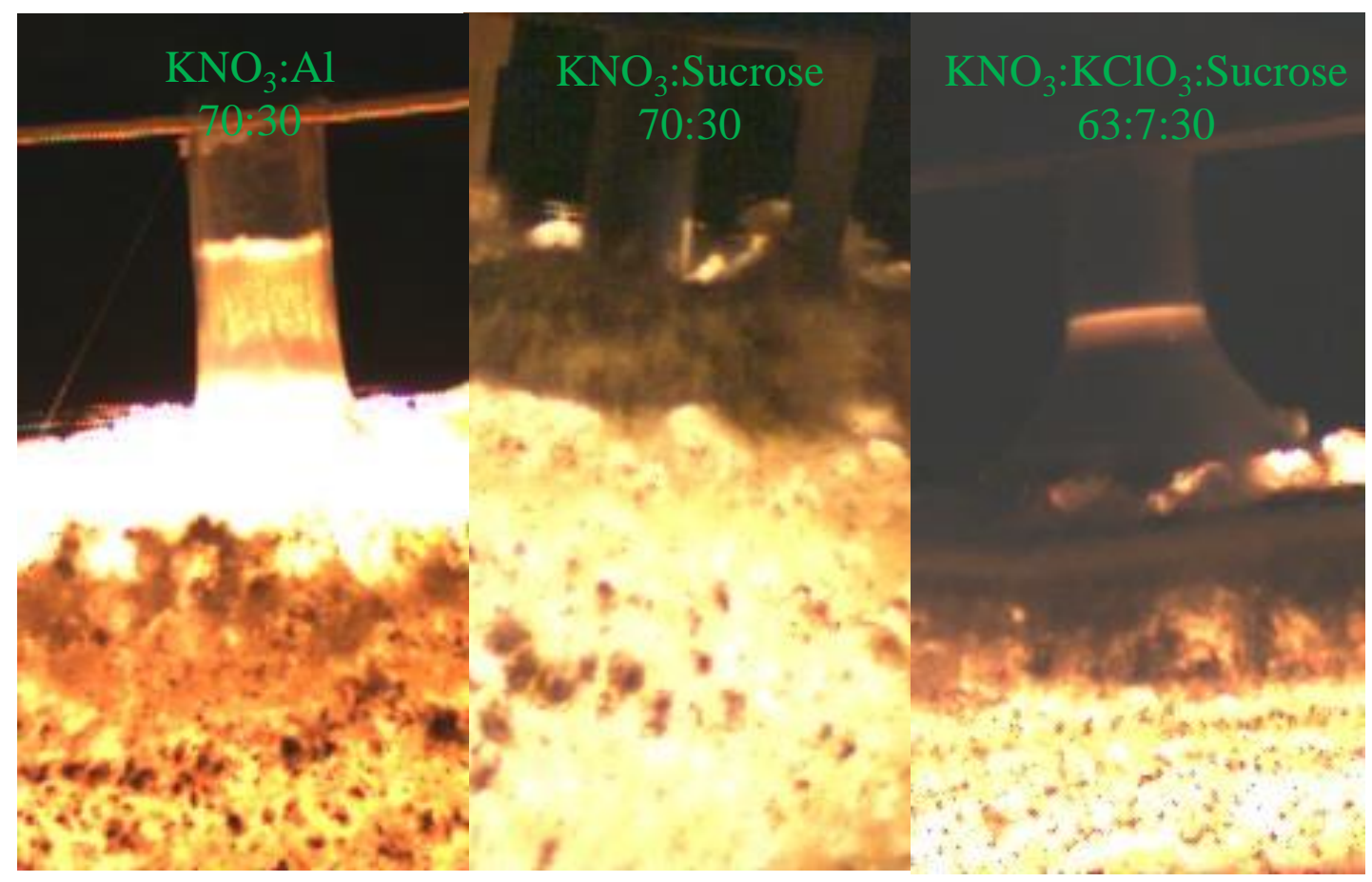

Figure 3.12. Comparison of detonation of $\mathrm{KNO}_{3}$ :Sucrose mix spiked with $\mathrm{KClO}_{3}$ to $\mathrm{KNO}_{3}$ mixes which failed to detonate. ( $\mathrm{KNO}_{3}: \mathrm{Al}$ transited to a burn.) 


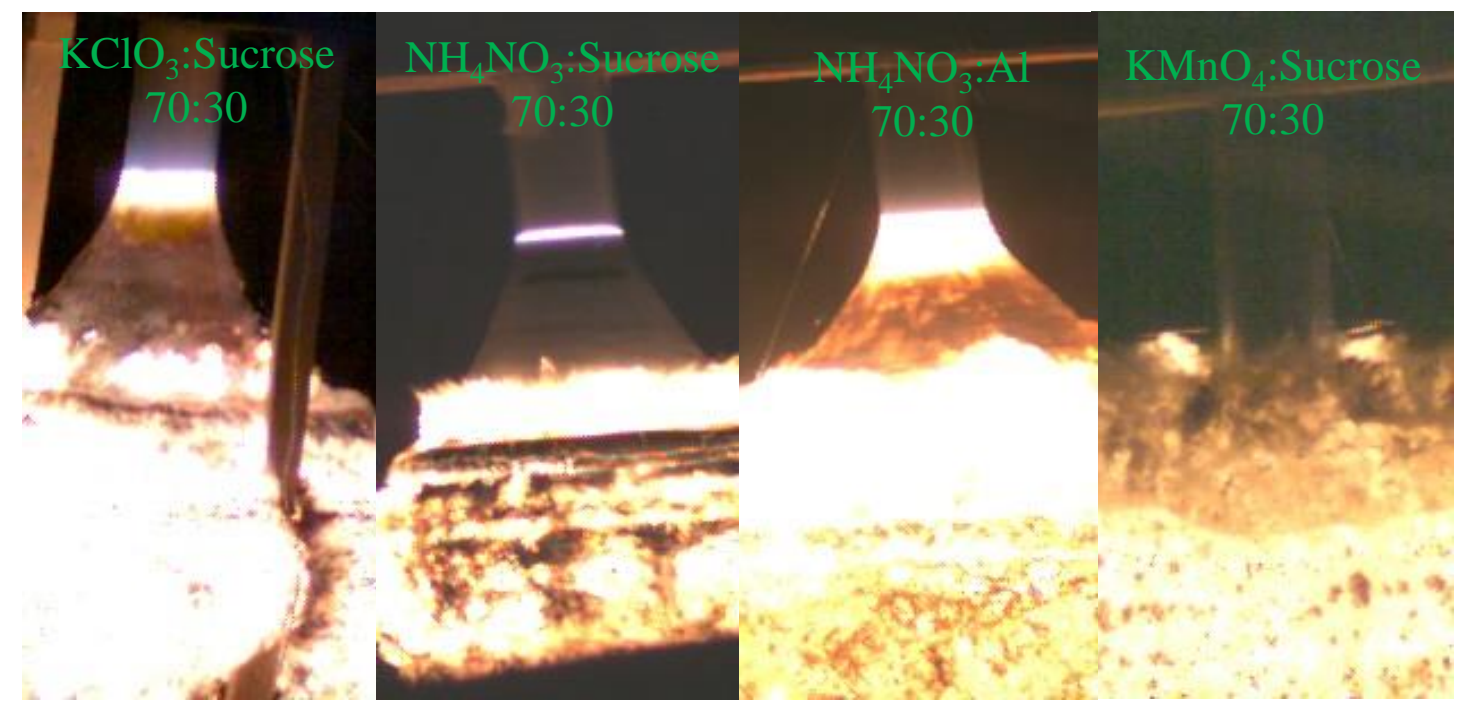

Figure 3.13. Detonation tests showing three steady detonations (left three) and one

which failed to propagate (right).

Table 3.3. Detonation Testing Summary

\begin{tabular}{|c|c|c|c|c|c|c|c|c|c|c|c|}
\hline \multicolumn{2}{|c|}{ Clear PVC pipe Shots (4" Dia x 24" L) } & & \multicolumn{6}{|c|}{ Calorimetry (2g $400 \mathrm{psi} \mathrm{Ar})$} & \multicolumn{3}{|c|}{ Detonation } \\
\hline Mixture & $\begin{array}{c}\text { Mass } \\
(\mathrm{kg})\end{array}$ & $\begin{array}{r}\text { Density } \\
(\mathrm{g} / \mathrm{mL})\end{array}$ & $\begin{array}{l}\text { Heat } \\
(\mathrm{cal} / \mathrm{g})\end{array}$ & $\begin{array}{l}\text { Heat } \\
(\mathrm{kJ} / \mathrm{g})\end{array}$ & $\begin{array}{c}\Delta \mathrm{P} \\
(\mathrm{psi})\end{array}$ & $\begin{array}{c}\Delta \mathrm{P} / \Delta \mathrm{t} \\
(\mathrm{psi} / \mathrm{ms})\end{array}$ & $\begin{array}{c}\Delta \mathrm{P} \\
(\mathrm{kPa})\end{array}$ & $\begin{array}{c}\Delta \mathrm{P} / \Delta \mathrm{t} \\
(\mathrm{kPa} / \\
\mathrm{ms})\end{array}$ & $\begin{array}{c}\text { Phantom } \\
\text { V7.11 Det } \\
\text { Velocity } \\
(\mathrm{km} / \mathrm{s})\end{array}$ & $\begin{array}{c}\text { Peak } \\
\text { Airblast } \\
\Delta \mathrm{P} 20 \mathrm{ft} \\
\text { (psi) }\end{array}$ & $\begin{array}{c}\text { Peak } \\
\text { Airblast } \\
\Delta \mathrm{P} 20 \mathrm{ft} \\
(\mathrm{kPa})\end{array}$ \\
\hline 70:30 KIO3:Sucrose (no Det) & 6.833 & 1.49 & 352 & 1.47 & 365 & 1.11 & 2517 & 7.7 & 0.00 & 7.90 & 54.43 \\
\hline 70:30 KMnO4:Sucrose (no Det) & 5.216 & 1.10 & 494 & 2.07 & 228 & 0.45 & 1572 & 3.1 & 0.00 & 6.47 & 44.57 \\
\hline 70:30 KNO3:Sucrose (no Det) & 4.711 & 0.97 & 672 & 2.81 & 534 & 1.05 & 3682 & 7.2 & 0.67 & 8.20 & 56.54 \\
\hline 70:30 KNO3:Al (no Det) & 3.636 & 0.75 & 1428 & 5.98 & 915 & 2.30 & 6307 & 15.8 & 1.67 & 13.10 & 90.32 \\
\hline 7:63:30 KClO3:KNO3:Sucrose & 4.709 & 0.97 & 692 & 2.89 & 570 & 1.72 & 3928 & 11.8 & 1.71 & 14.54 & 100.25 \\
\hline 5:66.5:28.5 RDX:KNO3:Sucrose & 4.254 & 0.88 & 701 & 2.93 & 607 & 1.27 & 4186 & 8.8 & 1.77 & 12.06 & 83.12 \\
\hline 35:35:30 KClO3:KNO3:Sucrose & 4.768 & 1.01 & 815 & 3.41 & 809 & 5.53 & 5578 & 38.1 & 2.24 & 14.97 & 103.18 \\
\hline 70:30 NH4ClO4:Al & 3.132 & 0.69 & 2238 & 9.36 & 2293 & 28.97 & 15813 & 199.7 & 2.24 & 16.32 & 112.49 \\
\hline 70:30 KClO3:Sucrose & 4.788 & 0.99 & 967 & 4.05 & 1037 & 10.53 & 7150 & 72.6 & 2.34 & 16.70 & 115.14 \\
\hline 70:30 NH4NO3:Al & 3.140 & 0.68 & 1876 & 7.85 & 1504 & 7.85 & 10367 & 54.1 & 2.70 & 18.60 & 128.24 \\
\hline 70:30 KClO3:Sucrose & 5.246 & 1.10 & 967 & 4.05 & 1037 & 10.53 & 7150 & 72.6 & 3.07 & 14.80 & 102.04 \\
\hline 70:30 NH4NO3:Sucrose & 4.121 & 0.87 & 645 & 2.70 & 222 & 0.03 & 1531 & 0.2 & 3.49 & 11.87 & 81.84 \\
\hline Flake TNT & 3.663 & 0.77 & $1093^{*}$ & 4.57 & LLNL & -- & -- & -- & 3.84 & -- & -- \\
\hline 70:30 NH4ClO4:Sucrose & 4.662 & 0.98 & 1167 & 4.88 & 1347 & 13.94 & 9287 & 96.1 & 3.89 & 19.30 & 133.07 \\
\hline Flake TNT & 4.003 & 0.81 & $1093^{*}$ & 4.57 & LLNL & -- & -- & - & 4.50 & 12.73 & 87.76 \\
\hline 50:35:15 RDX:KNO3:Sucrose & 4.986 & 1.05 & 1013 & 4.24 & 1139 & 5.48 & 7853 & 37.7 & 4.80 & 13.50 & 93.08 \\
\hline Booster & -- & -- & -- & -- & -- & -- & -- & -- & -- & 5.57 & 38.40 \\
\hline
\end{tabular}

23" x 4" charge; C4 booster=0.546kg; PETN =0.15 kg; (no Det = no Detonation observed); distance Pressure Trans $20 \mathrm{ft}$

* LLNL Detonation Calorimeter 


\section{Discussion}

FOX mixtures were chosen to examine three issues: 1) relative detonability of oxidizers as judged from small-scale tests; 2) role of the fuel; and 3) importance of small adjustments in energy input to performance. The FOX mixtures in Table 3 are ordered top to bottom by increasing detonation velocity. Among the FOX mixtures studied, chlorate and perchlorate with sucrose had the highest performance although density variations make it difficult to quantify the extent to which they are superior.

Cheetah, a Lawrence Livermore National Laboratory (LLNL) thermochemical code was used to calculate detonation velocity, Chapman-Jouguet (CJ) pressure, and energies of combustion and detonation at the densities used in the field detonation studies (Table 4). For the FOX formulations with aluminum, the calculated energy of combustion was only slightly higher than that of detonation (Cheetah calculations were run assuming all aluminum reacted.) For the FOX mixtures with sucrose fuel, the combustion energy was about $30 \%$ higher than detonation; and for TNT the combustion energy was approximately 4 times as high as the detonation energy. For air blast calculations where TNT equivalence was required, the heat of TNT reaction, rather than combustion, was used. The total heat of detonation calculated from Cheetah correlates linearly with the heat released in the Parr calorimeter (Figure 14). Since it was not feasible to create intact samples of controlled density of the powdery FOX mixtures, it was reassuring that isoperibol bomb calorimetry gave proportional results to detonation calorimetry (heat of detonation of TNT from [12]). 
Table 3.4. Detonation Testing Summary with Analysis

\begin{tabular}{|c|c|c|c|c|c|c|c|c|c|c|c|c|c|c|c|c|c|c|}
\hline \multirow{4}{*}{ 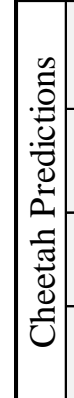 } & 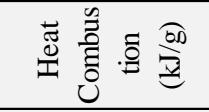 & $\delta$ & 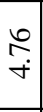 & $\begin{array}{l}\infty \\
\stackrel{\infty}{0} \\
\dot{m}\end{array} \mid$ & $\begin{array}{l}\mathscr{\infty} \\
\stackrel{\sim}{\sim} \\
\end{array}$ & $\left|\begin{array}{c}\hat{\imath} \\
\dot{m}\end{array}\right|$ & $\begin{array}{l} \pm \\
0\end{array}$ & $\begin{array}{l}\text { กิ } \\
+ \\
+\end{array}$ & $\begin{array}{l}\vec{f} \\
\dot{0}\end{array}$ & $\underset{f}{\vec{f}}$ & 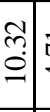 & & & 年 & 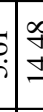 & 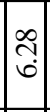 & & \\
\hline & 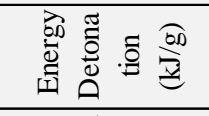 & ले & $\begin{array}{l}\hat{\infty} \\
i \\
i\end{array} \mid$ & $\begin{array}{l}0 \\
0 \\
i\end{array} \mid$ & 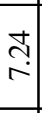 & $\begin{array}{c}\infty \\
\stackrel{\infty}{i} \\
\end{array}$ & $\begin{array}{c}1 \\
\infty \\
i\end{array} \mid$ & $\frac{\Delta}{m}$ & \begin{tabular}{|l}
$\overrightarrow{\hat{N}}$ \\
$\stackrel{0}{\varrho}$
\end{tabular} & nे & & $\begin{array}{l}\vec{b} \\
\dot{m}\end{array}$ & to & & 8 & $\begin{array}{l}\delta \\
\dot{+}\end{array}$ & & \\
\hline & 已 $\begin{array}{l}\overrightarrow{0} \\
\stackrel{0}{0}\end{array}$ & $\begin{array}{l}\infty \\
\infty \\
\dot{m}\end{array}$ & त्ञ & s. & $\begin{array}{c}\infty \\
\vdots \\
0\end{array}$ & $\begin{array}{c}8 \\
\text { i }\end{array}$ & $\stackrel{5}{-6}$ & $\stackrel{\sim}{m}$ & $\stackrel{ }{\stackrel{1}{-}}$ & $\stackrel{\vartheta}{ल}$ & $\begin{array}{l}\text { fa } \\
\text { i }\end{array}$ & 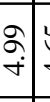 & & $8 \frac{9}{6}$ & 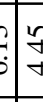 & $\begin{array}{l}\text { సి } \\
0 \\
\end{array}$ & & \\
\hline & $\overrightarrow{\tilde{D}} \overline{\vec{D}}$ & $\stackrel{8}{\circ}$ & $\frac{\mathfrak{Z}}{\mathrm{i}}$ & $\mid \begin{array}{l}\overrightarrow{0} \\
\dot{r} \\
\end{array}$ & $\stackrel{\overbrace{}}{-}$ & \begin{tabular}{|c|}
$\infty$ \\
$\dot{m}$
\end{tabular} & $\begin{array}{l}2 \\
\dot{c} \\
\text { i }\end{array} \mid$ & $\begin{array}{l}\vec{f} \\
\dot{m}\end{array}$ & $\mid$ & $\stackrel{\infty}{\stackrel{\infty}{m}}$ & cho & $\begin{array}{l}\Re \\
\stackrel{+}{+}\end{array}$ & & 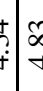 & 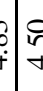 & $\left|\begin{array}{l}\hat{\infty} \\
\dot{f} \\
\dot{f}\end{array}\right|$ & & \\
\hline \multirow{5}{*}{ 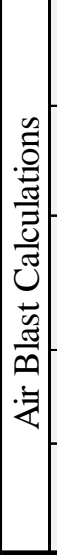 } & 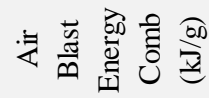 & in & $\stackrel{\sim}{-}$ & 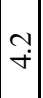 & $\stackrel{n}{=}$ & $\left(\begin{array}{r}n \\
\hdashline\end{array}\right.$ & $\begin{array}{l}0 \\
\stackrel{i}{c}\end{array}$ & $\stackrel{n}{\simeq}$ & ?n & $\infty$ & $\stackrel{\circ}{\infty}$ & ?ֶ. & & 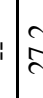 & $\begin{array}{l}c \\
\vdots\end{array}$ & \begin{tabular}{l}
$n$ \\
\hdashline \\
\hdashline
\end{tabular} & & \\
\hline & 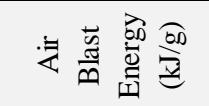 & $\infty$ & 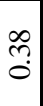 & $\stackrel{?}{-}$ & $\begin{array}{l}\hat{n} \\
\text { n. }\end{array}$ & $\left|\begin{array}{c}\overrightarrow{\hat{N}} \\
\dot{n}\end{array}\right|$ & बे. & 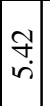 & $\begin{array}{c}0 \\
6 \\
0\end{array} \mid$ & nn & $\stackrel{\infty}{=}$ & $\begin{array}{lll}\mathscr{O} & \\
\dot{+} & & \end{array}$ & & & $\frac{8}{8}$ & $\stackrel{\substack{++}}{+}$ & & \\
\hline & 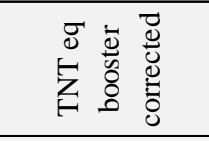 & $\stackrel{\infty}{0}$ & $\begin{array}{l}\infty \\
0 \\
0\end{array}$ & సิे & $\stackrel{\vec{N}}{-}$ & \pm & $\begin{array}{c}\infty \\
0 \\
0\end{array}$ & $\stackrel{2}{=}$ & $=$ & $\stackrel{f}{-}$ & & $\stackrel{8}{\bullet} \mid \vdots$ & & & $g$ & $\begin{array}{l}a \\
0 \\
0\end{array}$ & & \\
\hline & Z & लें & $\hat{n}$ & $\begin{array}{l}8 \\
0 \\
0\end{array}$ & 임. & 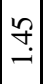 & $\stackrel{\overbrace{}}{-}$ & $\stackrel{\text { n. }}{-}$ & $\left|\begin{array}{l}\infty \\
n \\
i\end{array}\right|$ & I. & $\begin{array}{l}\dot{\theta} \\
\dot{r}\end{array}$ & $\stackrel{t}{-}$ & $\stackrel{2}{2}$ & & i & $\stackrel{\overbrace{}}{-}$ & $\stackrel{\sim}{i}$ & $\begin{array}{l}\text { N } \\
\text { है } \\
\text { हैं }\end{array}$ \\
\hline & 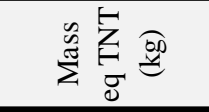 & $\begin{array}{l}\widehat{\sigma} \\
i\end{array}$ & $\bar{\Omega}$ & $\begin{array}{l}i \\
\vdots \\
i\end{array} \mid$ & $\begin{array}{c}\infty \\
\infty \\
n\end{array}$ & $\mid \begin{array}{c}1 \\
\infty \\
0 \\
0\end{array}$ & $\begin{array}{l}\stackrel{2}{\vec{n}} \\
\text { (1) }\end{array}$ & $\stackrel{2}{\sim}$ & $\begin{array}{c}0 \\
\infty \\
\infty\end{array}$ & $\underset{\infty}{m}$ & $\begin{array}{l}\vec{\sigma} \\
\hat{\sigma}\end{array}$ & 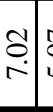 & & $\hat{\delta}$ & $\begin{array}{lll}8 \\
8\end{array}$ & $\frac{ \pm}{6}$ & $\stackrel{\infty}{+}$ & 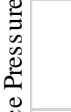 \\
\hline \multirow{5}{*}{ 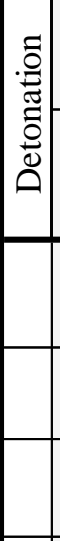 } & 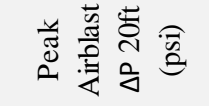 & $\frac{8}{2}$ & f̛ & $\mid \begin{array}{c}\text { ते } \\
\infty \\
\infty\end{array}$ & $\begin{array}{c}\stackrel{ }{2} \\
\stackrel{\leftrightarrow}{2}\end{array}$ & 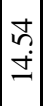 & 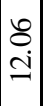 & $\begin{array}{l}\hat{\alpha} \\
\dot{ \pm}\end{array}$ & 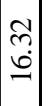 & ? & $\begin{array}{l}8 \\
\infty \\
\infty\end{array}$ & $\begin{array}{l}\stackrel{0}{\infty} \\
\pm \\
\pm\end{array}$ & 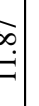 & $\begin{array}{l}0 \\
\tilde{c} \\
0\end{array}$ & 8 & $\left|\begin{array}{l}0 \\
\vdots \\
\hdashline\end{array}\right|$ & in & 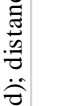 \\
\hline & 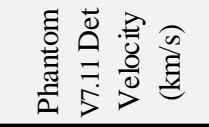 & $\stackrel{8}{0}$ & 8 & \begin{tabular}{|}
1 \\
0 \\
0
\end{tabular} & $\stackrel{0}{-}$ & 둘 & $\stackrel{ }{\stackrel{1}{-}}$ & $\left|\begin{array}{c}\Delta \\
\stackrel{i}{i}\end{array}\right|$ & $\begin{array}{l}\text { ते } \\
\text { in }\end{array}$ & ग্ & $\begin{array}{l}? \\
i \\
i\end{array}$ & $\stackrel{\vec{b}}{\dot{m}}$ & & $\begin{array}{l}0 \\
\vdots \\
ن\end{array}$ & in & $\begin{array}{l}\not \\
\stackrel{+}{+}\end{array}$ & & \\
\hline & 岁产 & $\exists$ & $\stackrel{9}{0}$ & :o & ઼ָ. & $\stackrel{\mathrm{N}}{-}$ & 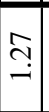 & nิ & $\begin{array}{c}\hat{a} \\
\dot{\alpha} \\
\hat{i}\end{array}$ & กิ & 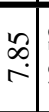 & $\begin{array}{l}n \\
? \\
=\end{array}$ & है & d & & $\left|\begin{array}{c}o \\
\hdashline \\
i\end{array}\right|$ & & 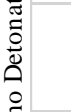 \\
\hline & 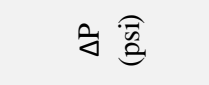 & ¿̊ & జి & 芯 & $\frac{n}{a}$ & in & 8 & ळे & సิ & $\hat{\delta}$ & $\begin{array}{l}+ \\
\\
=\end{array}$ & $\widehat{\tilde{0}}$ & $\mathrm{~s}$ & 㝵 & 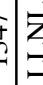 & 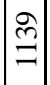 & & $\ddot{\Delta}$ \\
\hline & 营 & $\stackrel{f}{\text { f }}$ & $\mid \begin{array}{l}0 \\
\dot{i}\end{array}$ & $\left|\begin{array}{c}\bar{\infty} \\
i \\
\vec{i}\end{array}\right|$ & $\begin{array}{l}\infty \\
\stackrel{\infty}{ } \\
\end{array}$ & $\left|\begin{array}{l}\stackrel{0}{\circ} \\
i\end{array}\right|$ & $\stackrel{\curvearrowright}{\varsigma}$ & $\begin{array}{l}\vec{f} \\
\dot{m}\end{array}$ & $\mid$ & $\mid \begin{array}{l}0 \\
\dot{f}\end{array}$ & $\stackrel{\leftrightarrow}{\sim}$ & $\begin{array}{l}0 \\
+\end{array}$ & & $\dot{f}$ & : & $\stackrel{\stackrel{\leftrightarrow}{+}}{+}$ & & 豙 \\
\hline \multirow[b]{2}{*}{ 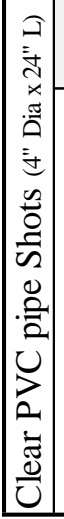 } & 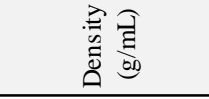 & f) & $\stackrel{0}{=}$ & $\hat{\sigma}$ & $\stackrel{n}{\mathfrak{0}}$ & aे & $\begin{array}{l}\infty \\
\infty \\
\infty \\
\end{array}$ & $\stackrel{\vec{\sigma}}{-}$ & : & ठे & $\stackrel{\infty}{\circ}$ & $\stackrel{2}{-}$ & 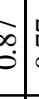 & 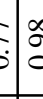 & 0 & 20 & & il \\
\hline & 竞 & 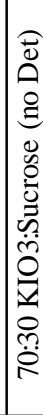 & 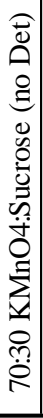 & 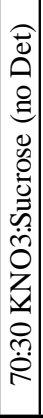 & 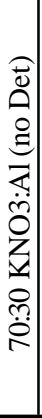 & 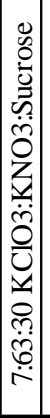 & 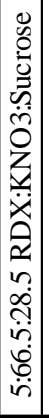 & 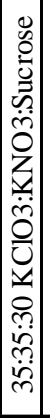 & 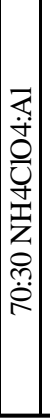 & 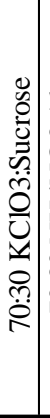 & 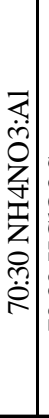 & 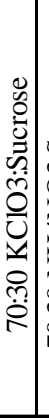 & 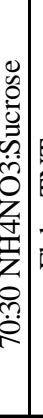 & 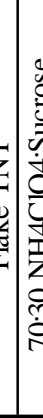 & 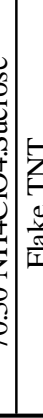 & 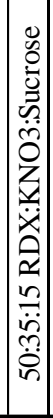 & 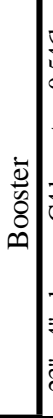 & 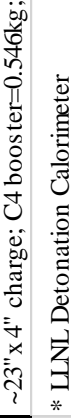 \\
\hline
\end{tabular}




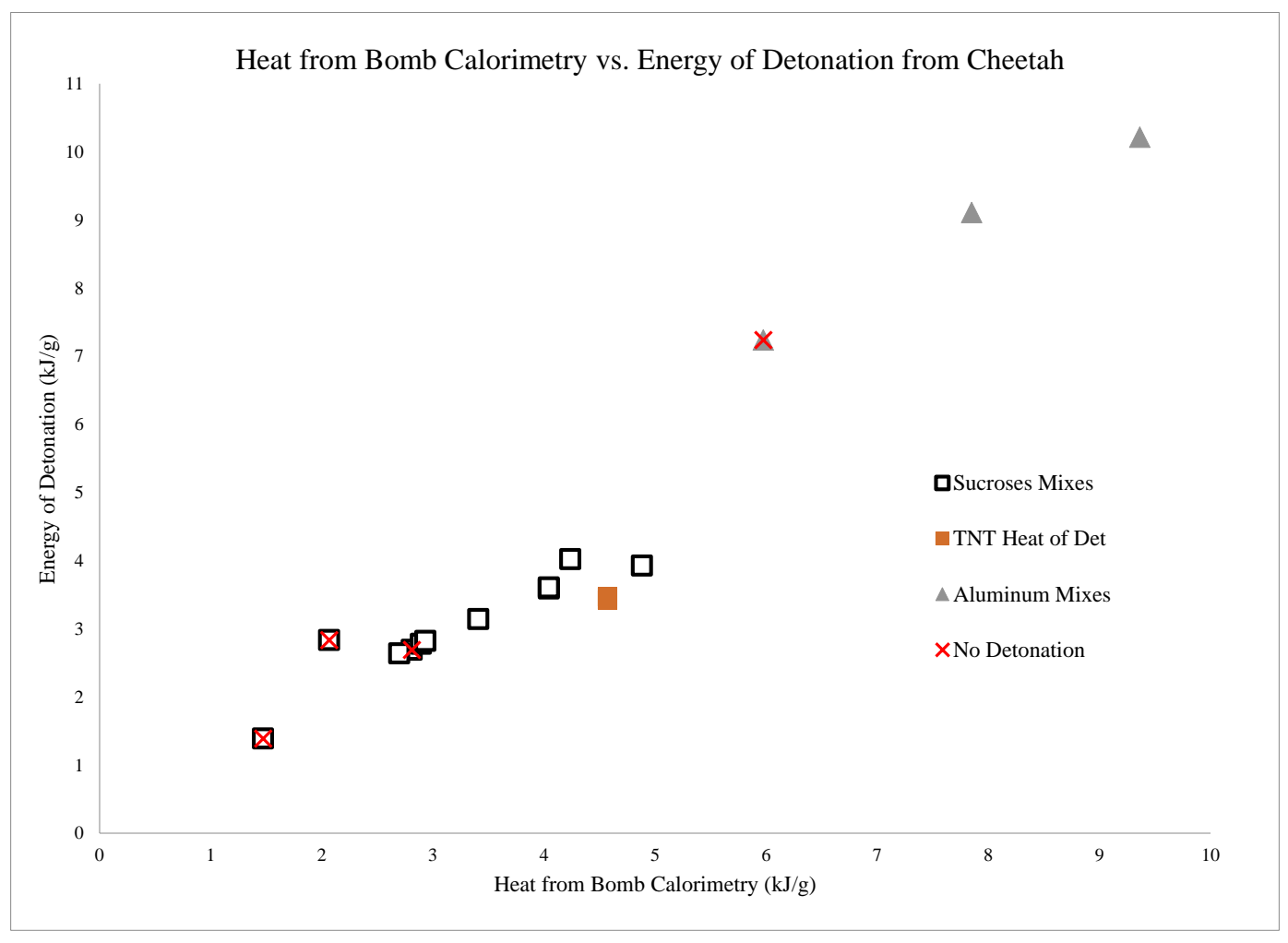

Figure 3.14. Heat of Detonation from Parr Bomb Calorimeter vs Calculated by

Cheetah. (Error bars in heat are too small to be seen; Table 1 shows relative standard deviation.)

Observed detonation velocities tracked with the Cheetah predicted detonation velocities. Figure 15 shows the non-detonations (i.e. potassium nitrate formulations) with an $\mathrm{X}$ and separates the shots done with aluminum fuel from those done with sucrose and from those done with formulations including high explosives (in red, two TNT shots and one that was 50\% RDX). 


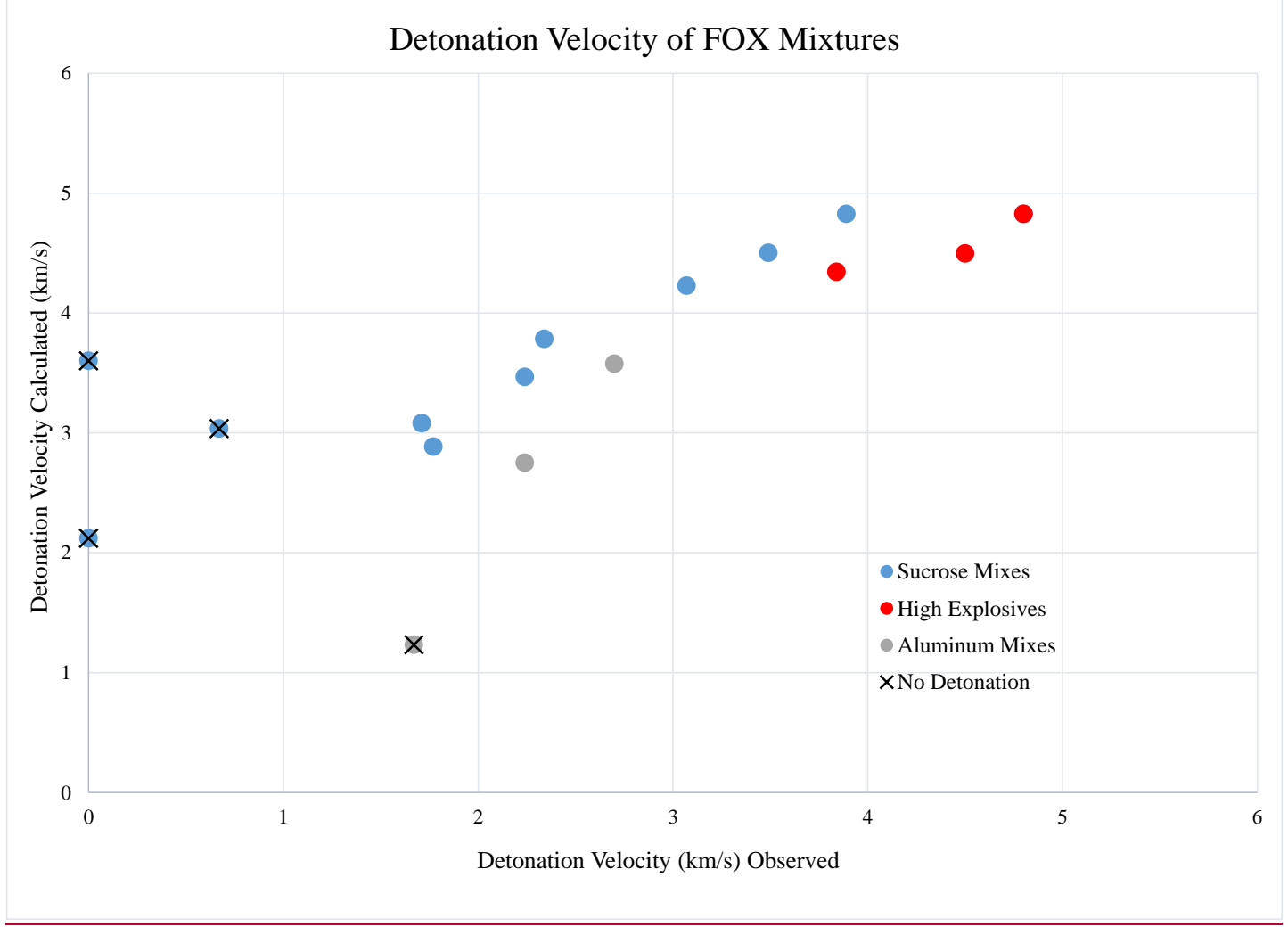

Figure 3.15. Observed Detonation Velocities $(\mathrm{km} / \mathrm{s})$ vs Cheetah Calculation Thereof ( $\mathrm{X}$ failed to detonate).

Since the heat released measured by calorimetry and detonation velocities measured by camera track with Cheetah predictions, it is not surprising that the measured heat of reaction under argon correlated with observed detonation velocities (Figure 16). Interestingly, the outliers (above the line on both the oxidizer/sucrose and oxidizer/aluminum formulations) are the formulations with ammonium nitrate. Part of this is certainly due to the fact that it is difficult for the sucrose formulation to burn under argon, but this does not explain the AN/Al formulation. 


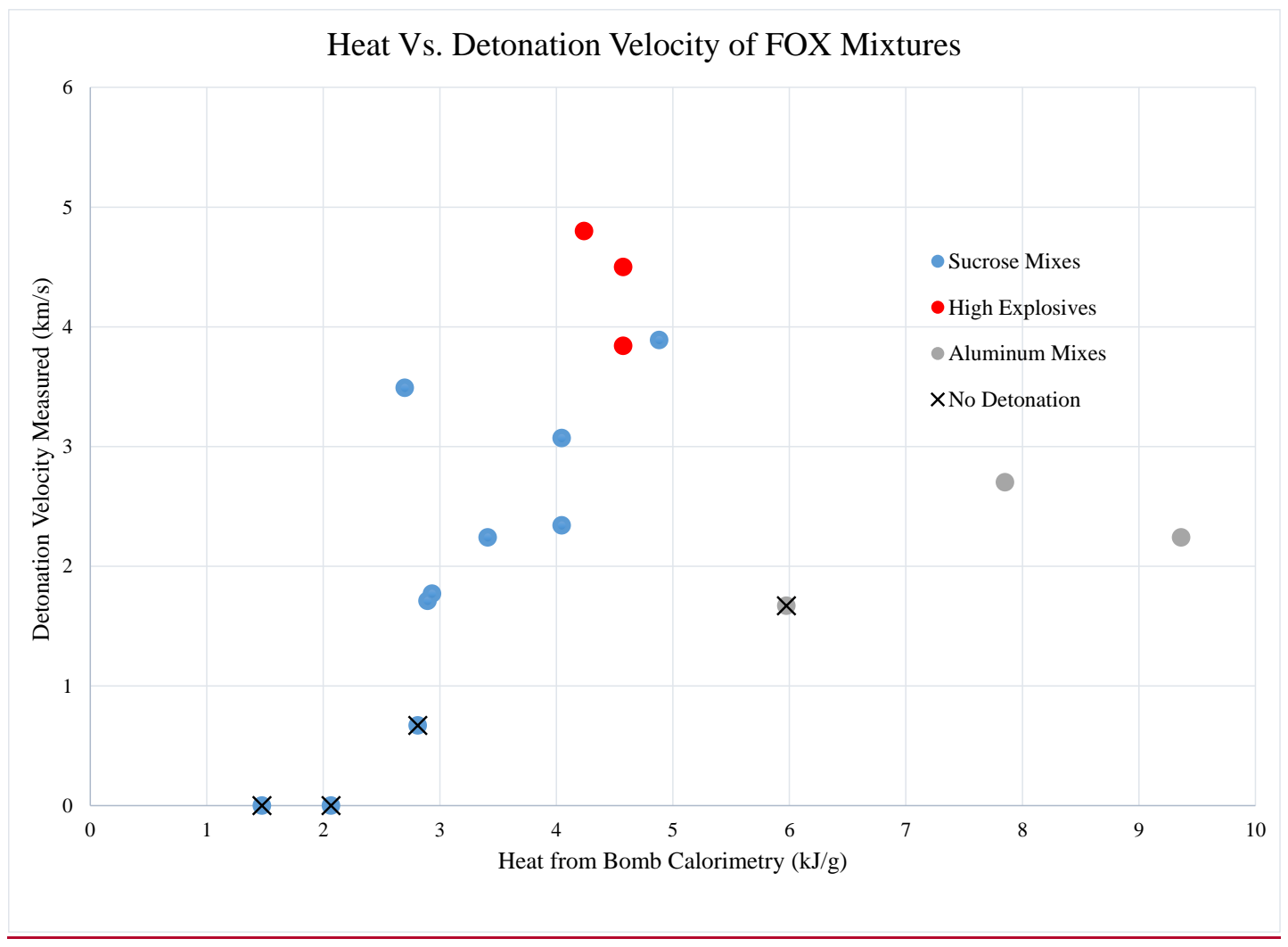

Figure 3.16. Heat of Reaction measured by calorimetry vs. Detonation Velocity. (Error bars in heat are too small to be seen; Table 1 shows relative standard deviation.)

Figure 16 suggests there may be a minimum energy $(\sim 2.8 \mathrm{~kJ} / \mathrm{g})$ needed for detonation. However, the data as well as detonation theory dictates that energy alone does not guarantee detonation. The rate of energy release by the formulation must be fast enough to support detonation. If we make the rather speculative assumption that the rates of all the oxidizer/sucrose reactions are similar because the rate of reaction in these low density powders is diffusion controlled, then we might expect a linear relationship between energy of reaction and detonation velocity.

Figure 16 also shows that the aluminum-fueled oxidizers follow a different trend than the sucrose-fueled formulations. Given the idea of minimum energy, it could be 
speculated that aluminum can provide enough additional energy during its oxidation to push a low-energy formulation to detonation; this was not the case in these studies. Ammonium nitrate and perchlorate sucrose mixtures were detonable; substitution of aluminum for sucrose increased the heat released in the calorimeter, but detonation velocity decreased. We attribute this result to the lower density of the aluminum formulation due to the small aluminum particle size. Not surprisingly the air blast in terms of TNT equivalence increased with the addition of aluminum. It is well known that aluminum does not react rapidly enough to contribute all its energy to the detonation front; hence, the provision in Cheetah to make some of the aluminum content "inert." In fact, air blast in terms of TNT equivalence is proportional to the heat observed in the Parr calorimeter (Figure 17).

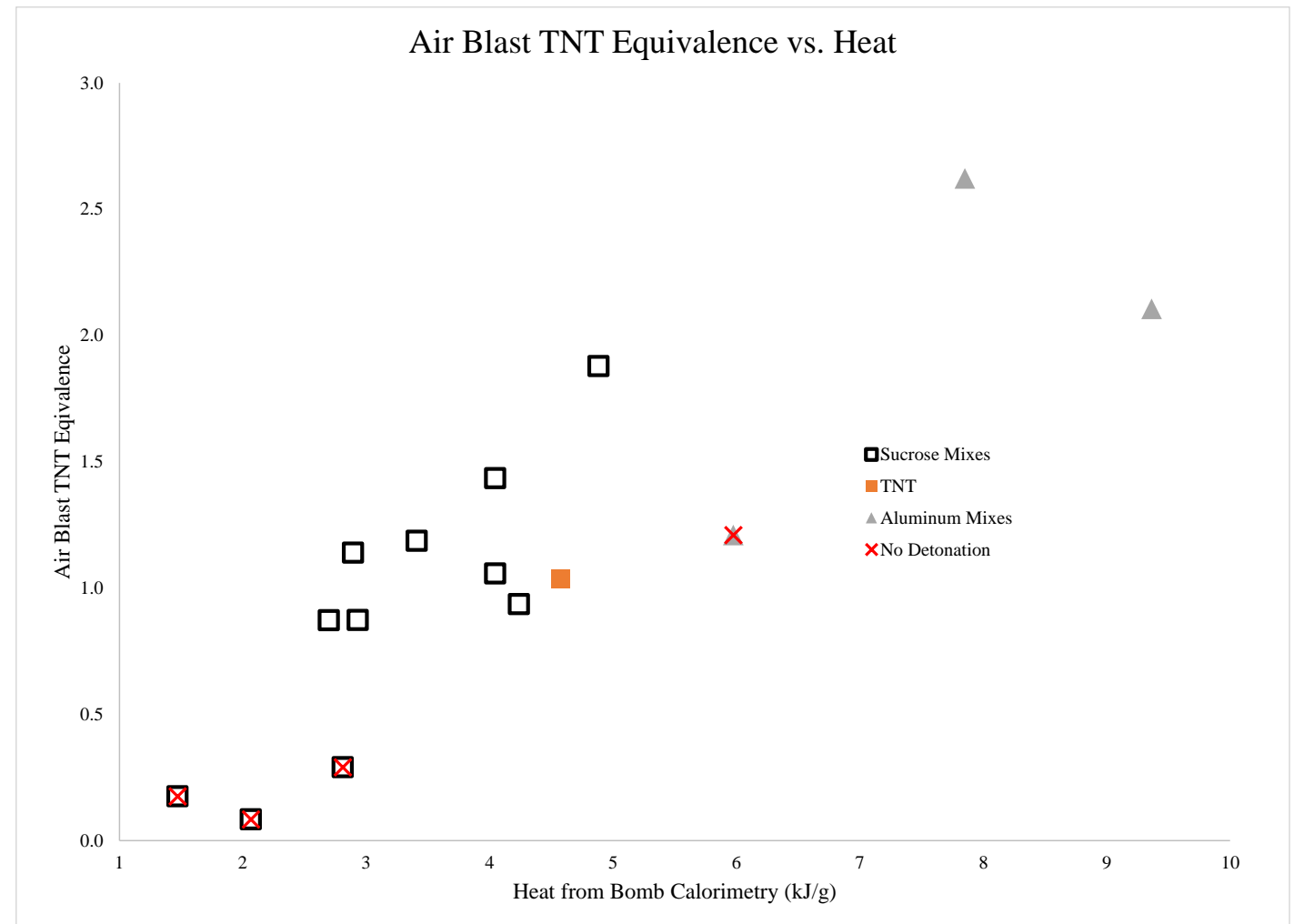


Figure 3.17. Air Blast TNT equivalence large scale vs. heat from bomb calorimetry. (Error bars in heat are too small to be seen; Table 1 shows relative standard deviation.)

\section{Conclusions}

Measurement or calculation (Cheetah) of heat of reaction is a useful first step in determining whether a formulation is potentially detonable. It appears there is some minimum energy which a formulation must possess to be detonable. However, examination of Table 4 clearly shows that some materials with high reaction energy (i.e. $\mathrm{KNO}_{3} / \mathrm{Al}$ ) do not detonate, while others with low reaction energy (i.e. AN/sucrose) do. Clearly any small-scale test or model must take into account the rate of reaction as well as energy. The potassium nitrate/sucrose mixture exhibited low heat release in the Parr bomb, and it did not detonate in the field-scale configuration. The substitution of aluminum for sucrose dramatically increased the energy released (as measured in the calorimeter), but the mixture $\left(\mathrm{KNO}_{3}: \mathrm{Al}\right)$ still did not detonate in field trials. The rate recorded in Table 3 is a burn, as judged by video record and discussed above (Figure 12). The potassium nitrate/sucrose mixture was prodded into detonation by spiking it with $5 \mathrm{wt} \% \mathrm{RDX}$ or $7 \mathrm{wt} \%$ potassium chlorate. Both these chemicals were capable of rapidly adding energy to the mixture. However, the total energy released by these potassium nitrate/sucrose mixture with these additives was only a little over half that of potassium nitrate / aluminum. This observation points to the importance of the rate at which the energy is provided. Figure 18 recasts the Parr data found in Figures 9 and 10 colorizing Parr pressure data to reflect the outcome in the large-scale tests. In general, FOX mixtures, which exhibited a rapid rise to peak pressure, detonated on the large 
scale. Those FOX mixtures, which reached peak pressure more slowly, did not detonate at the large scale, with the exception of ammonium nitrate and sucrose.

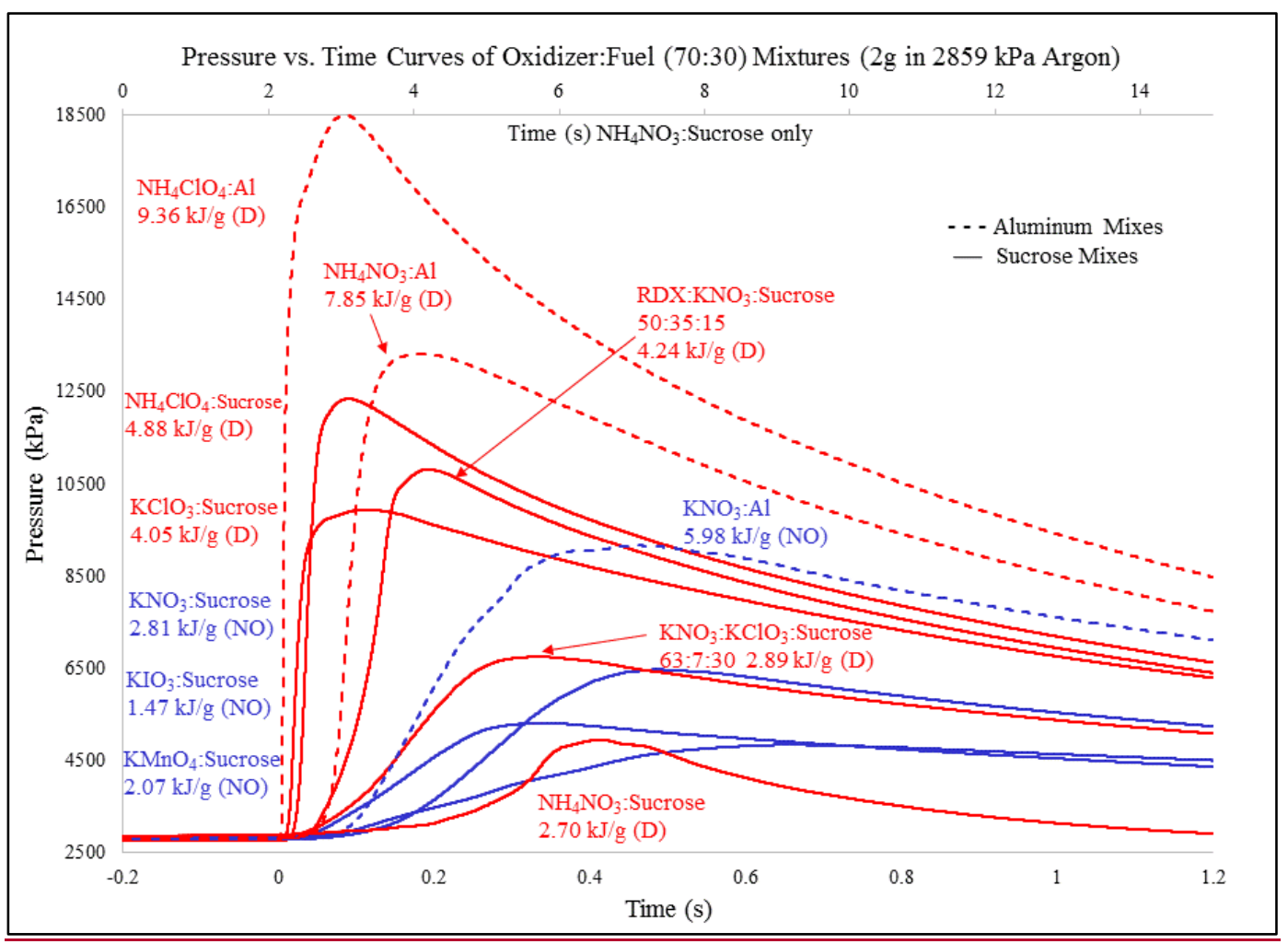

Figure 3.18. Pressure vs. time curves of fuel:oxidizer mixes from Figures $9 \& 10$.

Ultimate outcome at the 5 to $6 \mathrm{~kg}$ scale is shown by color - red for FOX which detonated; blue for FOX which did not detonate. The ammonium nitrate:sugar mixture is so slow that it has its own time axis (above plot).

With aluminum mixtures at the large scale, it has already been mentioned that due to the slowness of the reaction only some fraction of the energy released in the aluminum oxidation can support the detonation front [13]. The rest is manifest in the Taylor wave expansion, i.e. air blast. The fuel/oxidizer mixture has as similar problem with reaction rate. Detonation velocity is strongly dependent on density [14]. FOX mixtures are far from dense, and a significant amount of time must be spent in diffusion 
and compaction of the fuel and oxidizer. High explosives, such as PETN or RDX, have reaction zone lengths of approximately $1-2 \mathrm{~mm}$, reacting rapidly enough so that much of their energy can support the detonation front [15]. This in contrast to a non-ideal explosive, such as ANFO, with a reaction zone length estimated as $8-12 \mathrm{~mm}$ [15]. With these FOX mixtures the fraction of energy released to the front must be significantly less. How much less and the role of compaction in these composite materials will be the subject of a number of future studies.

\section{References}

[1] Davis, T.L. "The Chemistry of Powder and Explosives" 1956. Wiley, New York, NY.

[2] Marshal, M.; Oxley, J. "Aspects of Explosives Detection" 2009. Elsevier B.V., Oxford, UK.

[3] Woodfin, R.L. "Trace Chemical Sensing of Explosives" 2007. John Wiley and Sons, Inc., Hoboken, New Jersey.

[4] Oxley, J.C.; Smith, J.L.; Donnelly, M.; Porter, M. “Fuel-oxidizer mixtures: their stabilities and burn characteristics" J. Therm. Anal. Calorim. 2015, 121, 743-763.

[5] Massey, J.M., Jr. "Measurement of the Impetus, Covolume, and Burning Rate of Solid Propellants" U.S. Naval Weapons Laboratory Dahlgren, Virginia Report AD412685 1963.

[6] Shannon, L.J. "Composite Solid Propellant Ignition Mechanisms" AFOSR Scientific Report AD820453 1967. September.

[7] Barrett, D.H. "Solid Rocket Motor Igniters" NASA Report SP-8051 1971. March.

[8] Cheetah 7.0 [Computer software] Lawrence Livermore National Laboratory. 
[9] Swisdak, M. M., Jr. DDESB Blast Effects Computer V5.0 [Computer software] Explosives Safety Board Department of Defense 2001.

[10] Swisdak, M. M.; Ward, J. M. "DDESB Blast Effects Computer - Version 5.0” Minutes of PARARI 2001 - Australian Safety Seminar 2001. November.

[11] Kingery, C. N.; Bulmash, G. “Airblast Parameters from TNT Spherical Air Bursts and Hemispherical Surface Bursts” ARBRL-TR-02555 1984. April.

[12] Ornellas, D.L. "Calorimetric Determinations of the Heat and Products of Detonation for Explosives: October 1961 to April 1982” Lawrence Livermore National Laboratory. 1982, UCRL-52821.

[13] Cooper, P.W. “Comments on TNT Equivalence” IPS Proceedings. 1994. 20, 215226.

[14] Cooper, P.W. “Explosives Engineering” 1996. Wiley-VCH, New York, NY.

[15] Souers, P.C. “A Library of Prompt Reaction Zone Length Data” Lawrence Livermore National Laboratory. 1998. UCRL-ID-130055 Rev 1. 


\section{BIBLIOGRAPHY}

\section{Manuscript 1}

[1] L. Legler, Ueber Producte der langsamen Verbrennung des Aethyläthers. Berichte, 1885, 183343.

[2] A. Baeyer, V. Villiger, Ueber die Nomenclatur der Superoxyde und die Superoxydeder Aldehyde, Berichte. 1900, 332479.

[3] C. Von Girsewald, Beiträge zur Kenntnis des Wasserstoffperoxyds.

Üfber die Einwirkung des Wasserstoffperoxyds auf Hexamethylentetramin, Berichte. 1912, 45, 2571.

[4] W.P. Schaefer, J.T. Fourkas, B.G. Tiemann, Structure of Hexamethylene Triperoxide Diamine, J. Am. Chem. Soc. 1985, 107, 2461.

[5] A. Wierzbicki, E.A._Salter, E.A Cioffi, E.D. Stevens, Density Functional Theory and X-ray Investigations of P- and M-Hexamethylene Triperoxide Diamine and Its Dialdehyde Derivative, J. Phys. Chem. A, 2001, 105, 8763.

[6] J.C. Oxley, J.L. Smith, P. Bowden, R. Rettinger, Factors Influencing TATP and DADP Formation: Part I, Propellants, Explosives, Pyrotechnics 2013, 38, 244.

[7] R. Matyas, J. Selesovsky, T. Musil, Decreasing the Friction Sensitivity of TATP, DADP, and HMTD, Central Europ. J Energetic Mat. 2013, 10, 263.

[8] A.T. Nielsen, Structure and Chemistry of the Aldehyde Ammonias. 3.

Formaldehyde-Ammonia Reaction. 1,3,5,-Hexahydrotriazine, J. Org. Chem. 1979, 44, 1678.

[9] N. Subramanian, US Patent US4422982 A 1983. 
[10] E.E. Gilbert, J.R. Leccacorvi, M. Warman, The Preparation of RDX from 1,3,5Triacylhexahydro-s-triazines, Ind. Lab. Nitrations, Symp. 1 1976, 22, 327.

[11] A. Wexler, Constant Humidity Solutions, CRC Handbook of Chemistry Physics $85^{\text {th }}$ ed.

[12] K. Colizza, M. Porter, J.L. Smith, J.C. Oxley, Gas Phase Reactions of alcohols with hexamethylene triperoxide diamine (HMTD) under atmospheric pressure chemical ionization conditions, Rapid Commun. Mass Spectrom. 2015, 29, 74.

[13] J.C. Oxley, J.L. Smith, H. Chen, E. Cioffi, Decomposition of Multi-Peroxidic Compounds: Part II: Hexamethylene Triperoxide Diamine (HMTD), Thermochemica Acta 2002, 38, 215.

[14] J. Oxley, J. Zhang, J. Smith, E. Cioffi, Mass Spectra of Unlabeled and Isotopically Labeled Hexamethylene Triperoxide Diamine (HMTD), Propellants, Explosives and Pyrotechnics, 2000, 25, 1.

[15] J.C. Oxley, J.L. Smith, L. Lou, J. Brady, Determining Vapor Pressures of Diacetone Diperoxide (DADP) and Hexamethylene Triperoxide Diamine (HMTD), Propellants Explos. Pyrotech. 2009, 34, 539.

[16] J.C. Oxley, J.L. Smith, J. Brady, F.L.Steinkamp, Factors Influencing Destruction of Triacetone Triperoxide (TATP), Propellants, Explosives, Pyrotechnics, 2014,39, 289.

[17] C.A. Taylor, W. Rinkenbach, H.M.T.D. A New Detonating Explosive” Army Ordnance; J Army Ordnance Assoc. 1924, 5, 436. C.A. Taylor, W. Rinkenbach, Sensitivities of Detonating Compounds to Frictional Impact, Impact, and Heat, J Franklin Institute., 1927, 204, 369. 
[18] V.I. Siele, M. Warman, E.E. Gilbert, The Preparation of 3,7-Diacyl-1,3,5,7tetraazabicylco[3.3.1]nonanes, J. Heterocyc. Chem. 1974, 11, 237.

[19] H.H. Richmond, G.S. Myers, G.F. Wright, "The Reaction between Formaldehyde and Ammonia, J. Am. Chem. Soc. 1948, 70, 3659.

[20] L. Stefaniak, T. Urbanski, M. Witanowski, H. Januszewski, NMR

Conformational Study of Cyclic Products from Degadation of

Hexamethylenetetramine Hexahydro-1,3,5-triazines and Octahydro-1,3,5,7-

Tetrazocines, Roczniki Chemii Ann. Soc. Chim. Polonorum 1969, 43, 1687.

[21] W.E. Bachmann, J.C. Sheehan, A New Method of Preparing the High Explosives RDX, J. Am. Chem. Soc. 1949, 71 (5): 1842.

[22] E. Aristoff, J.A. Graham, R.H. Meen, G.S. Myers, G.F. Wright, Nitrolysis of Hexamethylenetetramine, Can J. Res. 1949, 27B, 520.

[23] J.M. Dreyfors, S.B. Jones, Y. Sayed, Hexamethylenetetramine: A Review, Am. Ind. Hygiene Assoc. J 1989, 50(11), 579.

[24] C.M. Lock, H. Brust, M. van Breukelen, J. Dalmolen, M. Koeberg, D.A. Stoker, Investigation of Isotopic Linkages between Precursor Materials and the Improvised High Explosive Product Hexamethylene Triperoxide Diamine, Analytical Chemistry 2012, 84, 4984.

[25] C.N. Satterfield, L.C. Case, Reaction of Aldehyde and hydrogen peroxide in Aqueous Solution, Ind. And Eng. Chem. 1954, 46 (5), 998. C.N. Satterfield, R.E. Wilson, R.M. LeClair, R. C. Reid, Analysis of Aqueous Mixtures of Hydrogen Peroxide and Aldehydes, Anal. Chem. 1954, 26 (11), 1792. 
[26] J.T. Edward, F.L. Chubb, D.F.R. Gilson, R.C. Hynes, F. Sauriol, A. Wiesenthal, Cage Peroxides have Planar Bridgehead Nitrogen Atoms. Can. J. Chem. 1999, 77(5/6) 1057.

\section{Manuscript 2}

[1] Oxley, J.C.; Smith, J.L.; Donnelly, M.; Porter, M. "Fuel-oxidizer mixtures: their stabilities and burn characteristics" J. Therm. Anal. Calorim. 2015, 121, 743-763.

[2] Tennen, R.; Setlow, B.; Davis, K.L.; Loshon, C.A.; Setlow, P. "Mechanisms of killing spores of Bacillus subtilis by iodine, glutaraldehyde, and nitrous acid" J. Appl. Microbiol., 2000, 89, 330-338.

[3] Clark, B.R.; Pantoya, M.L. "The aluminum and iodine pentoxide reaction for the destruction of spore forming bacteria" Phys. Chem. Chem. Phys., 2010, 12, 1265312657.

[4] Wang, H.; Jian, G.; Zhou, W.; DeLisio, J.B.; Lee, V.T.; Zachariah, M.R. "Metal Iodate-Based Energetic Composites and Their Combustion and Biocidal Performance” ACS Appl. Mater. Interfaces. 2015, 7, 17363-17370.

[5] Burgess, A.E.; Davidson, J.C.; "Kinetics of the Rapid Reaction between Iodine and Ascorbic Acid in Aqueous Solution using UV-Visible Absorbance and Titration by and Iodine Clock” J. Chem. Educ. 2014, 91, 300-304.

[6] Adrian, A.J.; Hume, D.N. “A Spectrophotometric Investigation of Bismuth Iodide Complexes" Inorg. Chem. 1967, 6, 331-339.

[7] Urabe, T.; Tanaka, M.; Kumakura, S.; Tsugoshi, T.; "Study on chemical speciation in aluminum chloride solution by ESI-Q-MS” J. Mass. Spec. 2007, 42, 591-597. 
[8] United Nations, "Recommendations on the Transport of Dangerous Goods, Manual of Tests and Criteria," Fifth revised edition, 2009.

[9] MIL-STD-1751A, ARDEC Method 1032.

[10] Poret, J.C.; Shaw, A.P.; Csernica, C.M.; Oyler, K.D.; Vanatta, J.A.; Chen, G. "Versatile Boron Carbide-Based Energetic Time Delay Compositions" ACS Sustainable Chem. Eng., 2013, 1, 1333-1338.

[11] Little, B.K.; Emery, S.B.; Nittinger, J.C.; Fantasia, R.C.; Lindsay, C.M. "Physiochemical Characterization of Iodine(V) Oxide, Part 1: Hydration Rates" Propellants Explos. Pyrotech. 2015, 40, 595-603.

[12] Stern, K.H. "High Temperature Properties and Decomposition of Inorganic Salts Part 4. Oxy-Salts of Halogens" J. Phys. Chem. Ref. Data. 1974, 3, 481-526.

[13] Watt, G.W.; Hall, J.L. “Aluminum Iodide” Inorg. Synth. 1953, 4, 117.

[14] Erdey, J; Simon, J.; Gal, S. “Thermoanalytical properties of analytical grade reagents-V. Sodium Halates” Talanta. 1968, 15, 653-661.

[15] Bentria, B.; Benbertal, D.; Bagieu-Beucher, M.; Masse, R.; Mosset, Alain “Crystal structure of anhydrous bismuth iodate, $\mathrm{Bi}\left(\mathrm{IO}_{3}\right)_{3}$ ” J. Chem. Crystallogr. 2003, 33, 867873.

[16] Lide, D. (editor) “CRC Handbook of Chemistry Physics” $85^{\text {th }}$ ed, CRC Press, 2004. [17] Bousquet, J.; Vermande, P. "Ètude du mécanisme de la décomposition thermique de I'iodate de calcium anhydre" Soc. Chim. Mémoires. 1964, 5, 214-218.

[18] Ivanov, V. G.; Ivanov, G. V.; Lapin, P. V.; Kuznetso, V. P. "Role of Iodation in the Combustion of Metal Oxides with Iodine Pentoxide" Fizika Goreniya 1 Vzryva. 1980, 27, 28-36. 
[19] Litz, L.M.; Mercuri, R.A. “Oxidation of Boron Carbide by Air, Water, and AirWater Mixtures at Elevated Temperatures" J. Electrochemical Soc. 1963, 110(8), 921925.

[20] Domalski, E.S.; Armstrong, G.T.; "The Heat of Formation of Boron Carbide" Journal of Research of the National Bureau of Standards - A. Physics and Chemistry. 1968, 72A(2), 133-139.

[21] Liu, P-J; Liu, L-L; He, G-Q; "Effect of solid oxidizers on the thermal oxidation and combustion performance of amorphous boron." J. Therm. Anal. Calorim. 2016, 124, 1587-1593.

\section{Manuscript 3}

[1] Davis, T.L. "The Chemistry of Powder and Explosives" 1956. Wiley, New York, NY.

[2] Marshal, M.; Oxley, J. "Aspects of Explosives Detection” 2009. Elsevier B.V., Oxford, UK.

[3] Woodfin, R.L. “Trace Chemical Sensing of Explosives” 2007. John Wiley and Sons, Inc., Hoboken, New Jersey.

[4] Oxley, J.C.; Smith, J.L.; Donnelly, M.; Porter, M. "Fuel-oxidizer mixtures: their stabilities and burn characteristics” J. Therm. Anal. Calorim. 2015, 121, 743-763.

[5] Massey, J.M., Jr. "Measurement of the Impetus, Covolume, and Burning Rate of Solid Propellants" U.S. Naval Weapons Laboratory Dahlgren, Virginia Report AD412685 1963.

[6] Shannon, L.J. “Composite Solid Propellant Ignition Mechanisms” AFOSR Scientific Report AD820453 1967. September. 
[7] Barrett, D.H. “Solid Rocket Motor Igniters” NASA Report SP-8051 1971. March.

[8] Cheetah 7.0 [Computer software] Lawrence Livermore National Laboratory.

[9] Swisdak, M. M., Jr. DDESB Blast Effects Computer V5.0 [Computer software]

Explosives Safety Board Department of Defense 2001.

[10] Swisdak, M. M.; Ward, J. M. "DDESB Blast Effects Computer - Version 5.0”

Minutes of PARARI 2001 - Australian Safety Seminar 2001. November.

[11] Kingery, C. N.; Bulmash, G. “Airblast Parameters from TNT Spherical Air Bursts and Hemispherical Surface Bursts” ARBRL-TR-02555 1984. April.

[12] Ornellas, D.L. "Calorimetric Determinations of the Heat and Products of Detonation for Explosives: October 1961 to April 1982” Lawrence Livermore National Laboratory. 1982, UCRL-52821.

[13] Cooper, P.W. “Comments on TNT Equivalence” IPS Proceedings. 1994. 20, 215226.

Aluminum contributes to air blast TNT Equiv, but not as much to CJ pressure TNT Equiv. TNT equivalence based on CJ pressure is good for destroying metals, brisance. When TNT equivalence is given, it needs to be stated what it is based on, Air Blast, CJ, Trauzl etc. Each TNT equiv. is useful for that specific purpose.

[14] Cooper, P.W. “Explosives Engineering” 1996. Wiley-VCH, New York, NY. [15] Souers, P.C. “A Library of Prompt Reaction Zone Length Data” Lawrence Livermore National Laboratory. 1998. UCRL-ID-130055 Rev 1. 
[16] Gurney, R.W. “The initial velocities of fragments from bombs, shells, and grenades” 1943. BRL Report 405.

[17] Kennedy, J.E. “Gurney Energy of Explosives: Estimation of the Velocity and Impulse Imparted to Driven Metal” Sandia National Labortories. 1970, RR-70-90.

Gurney Energies typically $70 \%$ of heat of Detonation, TNT is $61 \%$ of its heat of detonation.

[18] Kamlet, M.J.; Finger, M. “An Alternative Method for Calculating Gurney Velocities" Combust. Flame. 1979, 34, 213-214.

Gurney energy predicted based on $\sqrt{ }(2 \mathrm{E})=0.887 \varphi^{0.5} \rho_{0}^{0.4}$ and $\varphi=\mathrm{NM} 1 / 2 \mathrm{Q} 1 / 2$ where $\mathrm{N}$ is number of moles of gaseous detonation products per gram of explosive, $\mathrm{M}$ is average molecular weight of gases, and Q is the heat of detonation in calories per gram. [19] Cooper, P.W. "Estimation of the C-J Pressure of Explosives" IPS Proceedings. 1980. $14,569-581$.

[20] Cooper, P.W. "Extending estimation of C-J pressure of explosives to the very low density region" IPS Proceedings. 1992. 18, 187-193.

Estimation of $\mathrm{Cj}$ pressure as a function of the initial density of the explosive and detonation velocity. $\quad P c j=\rho_{0} D^{2}\left(1-0.713 \rho_{0}^{0.07}\right)$ where $D$ is detonation velocity in $\mathrm{mm} / \mathrm{usec}$ and $\rho_{0}$ is the initial density in $\mathrm{g} / \mathrm{cm}^{3}$.

[21] Koch, A. “A Simple Relation between the Detonation Velocity of an explosive and its Gurney Energy" Propellants Explos. Pyrotech. 2002. 27, 365-368.

From shock theory it is known $\mathrm{P}_{\mathrm{CJ}}=\rho_{0} \mathrm{D}^{2} /(\gamma+1)$ and $\rho_{\mathrm{CJ}}=\rho_{0}(\gamma+1) / \gamma(\gamma$ being useful for describing the PV isentrope from the product gases in the Taylor wave). Koch shows 
that by assuming that $\gamma=3$ (good for most explosives), a relationship can be shown between gurney velocity and detonation velocity $\sqrt{ }(2 \mathrm{E})=\mathrm{D} / 3.08$.

[22] Kinney, G.F.; Graham, K.J. “Explosive Shocks in Air” Second Edition 1985.

Spinger Science+Business Media, LLC, New York, NY.

BEC V5.0 fits our data a little better. The BEC V5.0 calculator is headed by Michael Swisdak, and is based on empirical fit parameters from Kingery and Bulmash 1984. Kingery and Bulmash numbers come from measurements taken from 4 events 19591964 from TNT shots of 5, 20, 100, and 500 tons.

[23] Swisdak, M.M., Jr. "Explosion Effects and Properties Part 1 - Explosion Effects in Air" NSWC Technical Report White Oak Laboratory ADA160797 1975. October. On page 95 discusses the difference between cylindrical and spherical charges our tests are about 6/1 L/D and scaled distance of $9 \mathrm{ft} / \mathrm{lb}^{1 / 3}$ (our test $11 \mathrm{lbs}$ at $20 \mathrm{ft}$ ) with a sideon pressure measurement could give up to $20 \%$ more pressure than an equivalent spherical charge.

[24] Kamlet, M.J. and S.J. Jacobs, 1968, “Chemistry of Detonations”, J. Chem Phys, $48,23$.

[25] Son, S.F.; Busse, J.R.; Asay, B.W.; Peterson, P.D.; Mang, J.T.; Bockmon, B.;

Pantoya, M.L. "Propagation Studies of Metastable Intermolecular Composites" IPS Proceedings. 2002. 29, 203-212.

Important to note that the open tray propagation rate of a MoO3/Al thermite $(\mathrm{m} / \mathrm{s})$ was directly proportional to the pressurization rate $\mathrm{dp} / \mathrm{dt}$ of the same mixture inside a closed bomb. The open burn rate and closed volume pressurization rate peaked at the same wt $\%$ aluminum. This shows that $\mathrm{dp} / \mathrm{dt}$ is an important metric for burn rate. 
[26] Massey, J.M., Jr. "Measurement of the Impetus, Covolume, and Burning Rate of Solid Propellants" U.S. Naval Weapons Laboratory Dahlgren, Virginia Report AD412685 1963.

Solid propellants were run for their $\mathrm{P} / \mathrm{t}$ traces. In a simplified equation, it was shown that the $\mathrm{g} / \mathrm{s}$ burn rate, $\mathrm{dC} / \mathrm{dt}=\mathrm{C}_{\mathrm{b}} / \mathrm{P}_{\max } * \mathrm{dP} / \mathrm{dt}$ (where $\mathrm{dC} / \mathrm{dt}$ is the burn rate, $\mathrm{C}_{\mathrm{b}}$ is the total sample mass, and $\mathrm{P}_{\max }$ is the maximum difference in pressure achieved). The assumptions were that heat losses were minimal and high surface area allowed the burn to become complete when peak pressure is reached. If heat losses are large, $\mathrm{P}_{\max }$ may occur before the burn is complete. They ran propellant samples that pass through a 30 mesh sieve to maximize the burn rate and minimize heat losses. Impetus $(\mathrm{F})$ is the ability of the sample to do work based on the volume of the sample, peak pressure reached, and amount of sample. This reference supports what was taught in the Picatinny pyrotechnics class from closed bomb testing. $\mathrm{F}(\mathrm{J} / \mathrm{g})=\mathrm{P}_{\max } * \mathrm{~V} / \mathrm{W}\left(\mathrm{P}_{\max }\right.$ is the maximum difference in pressure in $\mathrm{Pa}, \mathrm{V}$ is the volume of the bomb in $\mathrm{m}^{\wedge} 3$, and $\mathrm{W}$ is the weight of the sample in $\mathrm{g}$ ). 


\section{APPENDIX 4: DATA FOR MANUSCRIPT 1}

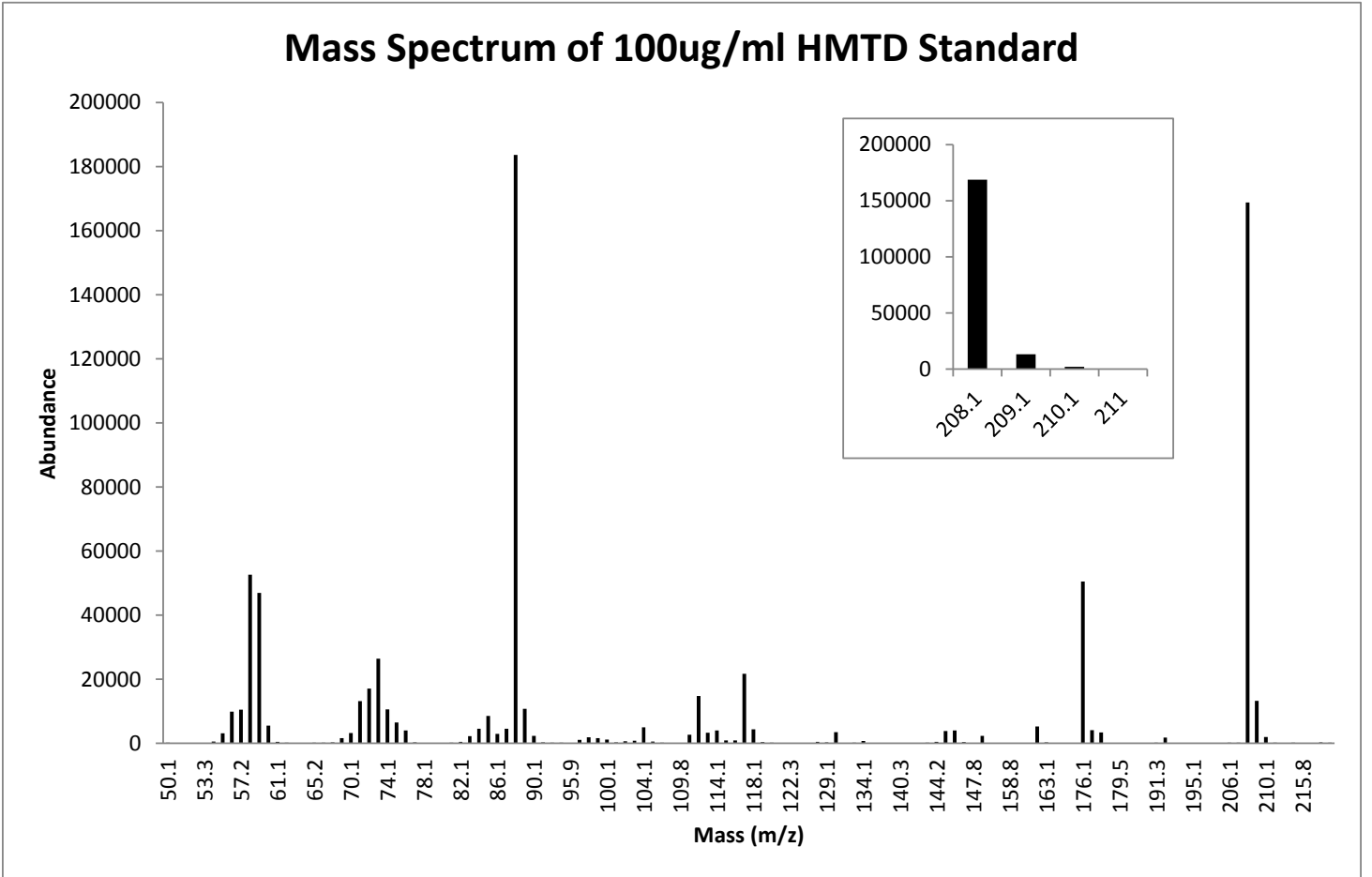

Figure 4.1. Mass spectrum of HMTD from GC/MS 


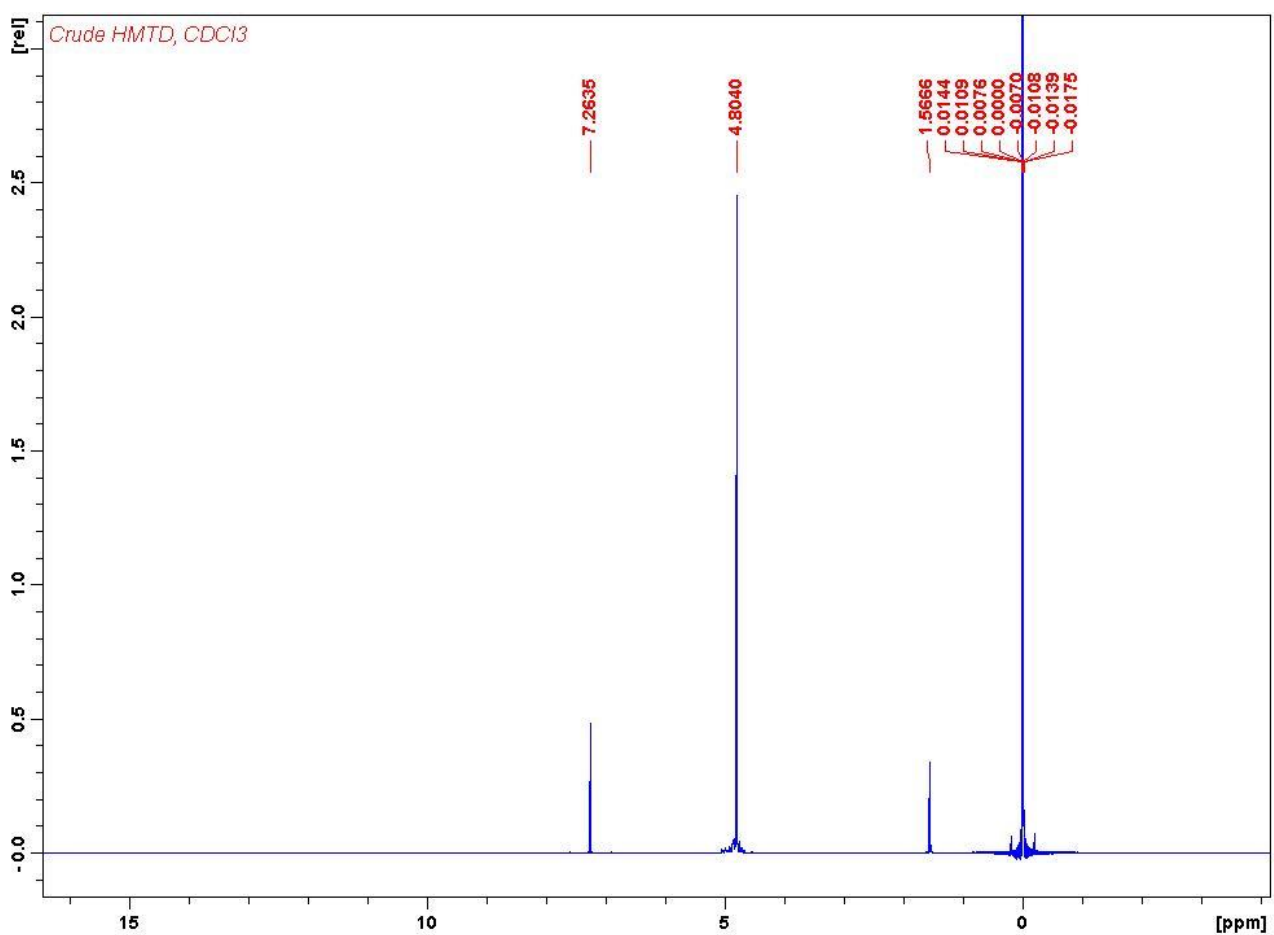

Figure 4.2. ${ }^{1} \mathrm{H}$ NMR spectrum of $\mathrm{HMTD}$ in $\mathrm{CDCl}_{3}$.

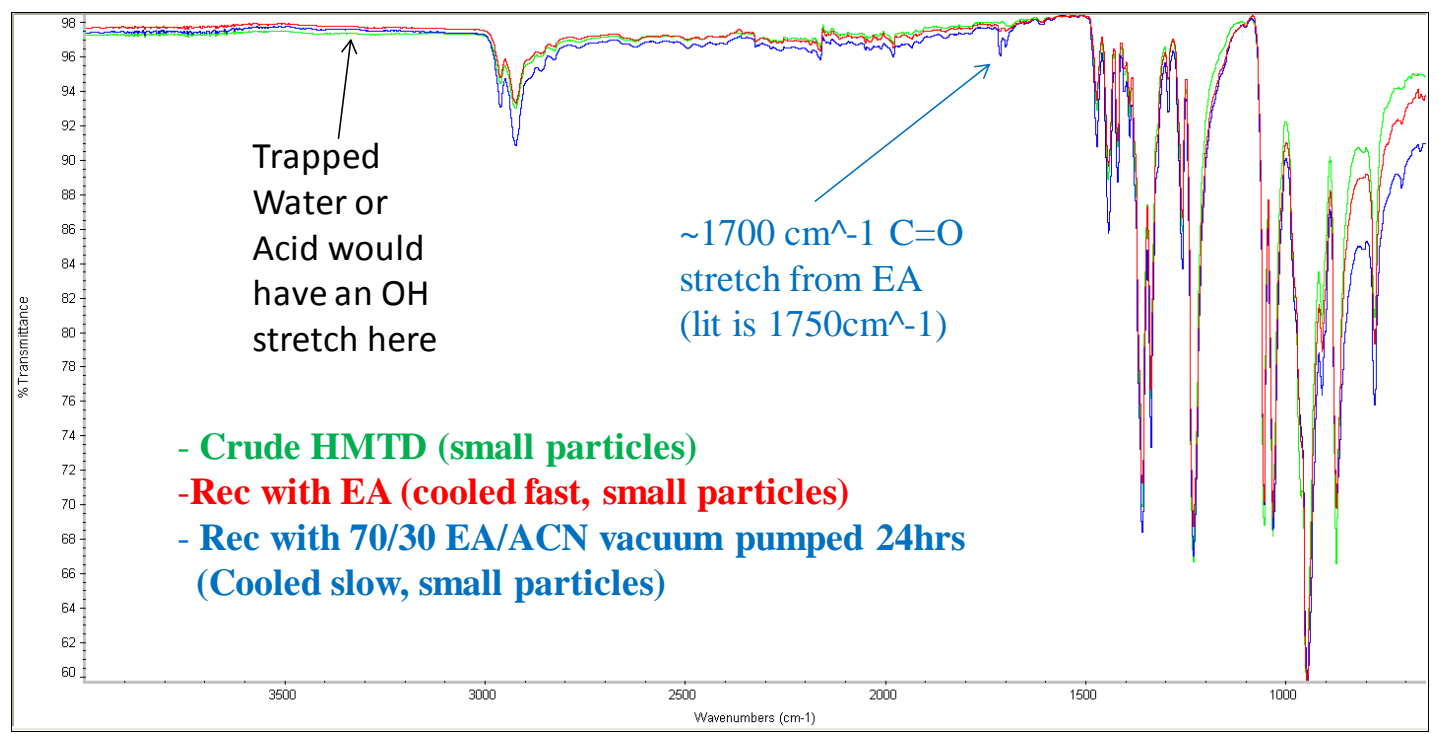

Figure 4.3. IR Spectrum of crude and recrystallized HMTD. 


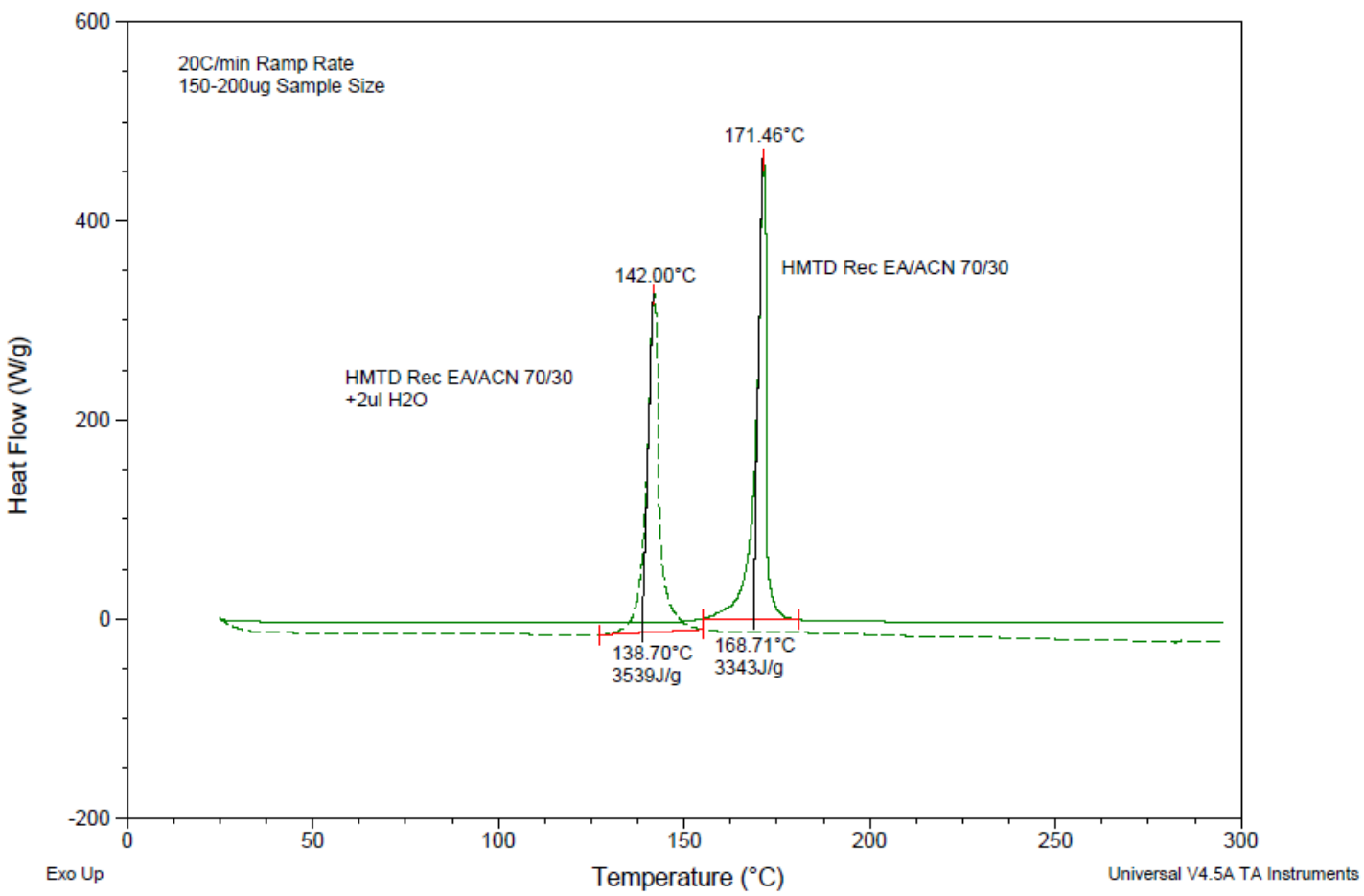

Figure 4.4. DSC thermogram of recrystallized HMTD with and without water. 


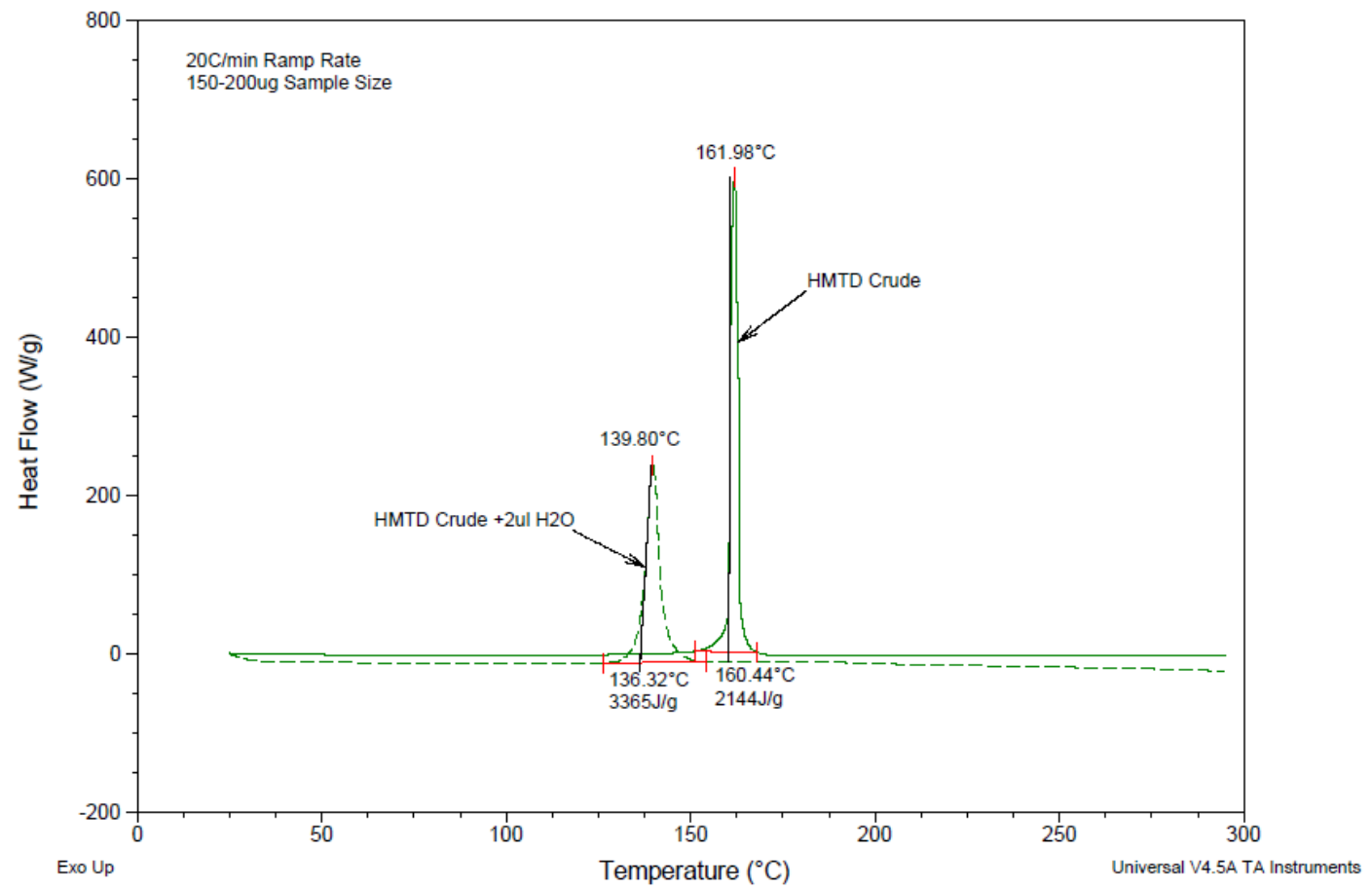

Figure 4.5. DSC thermogram of crude HMTD with and without water. 


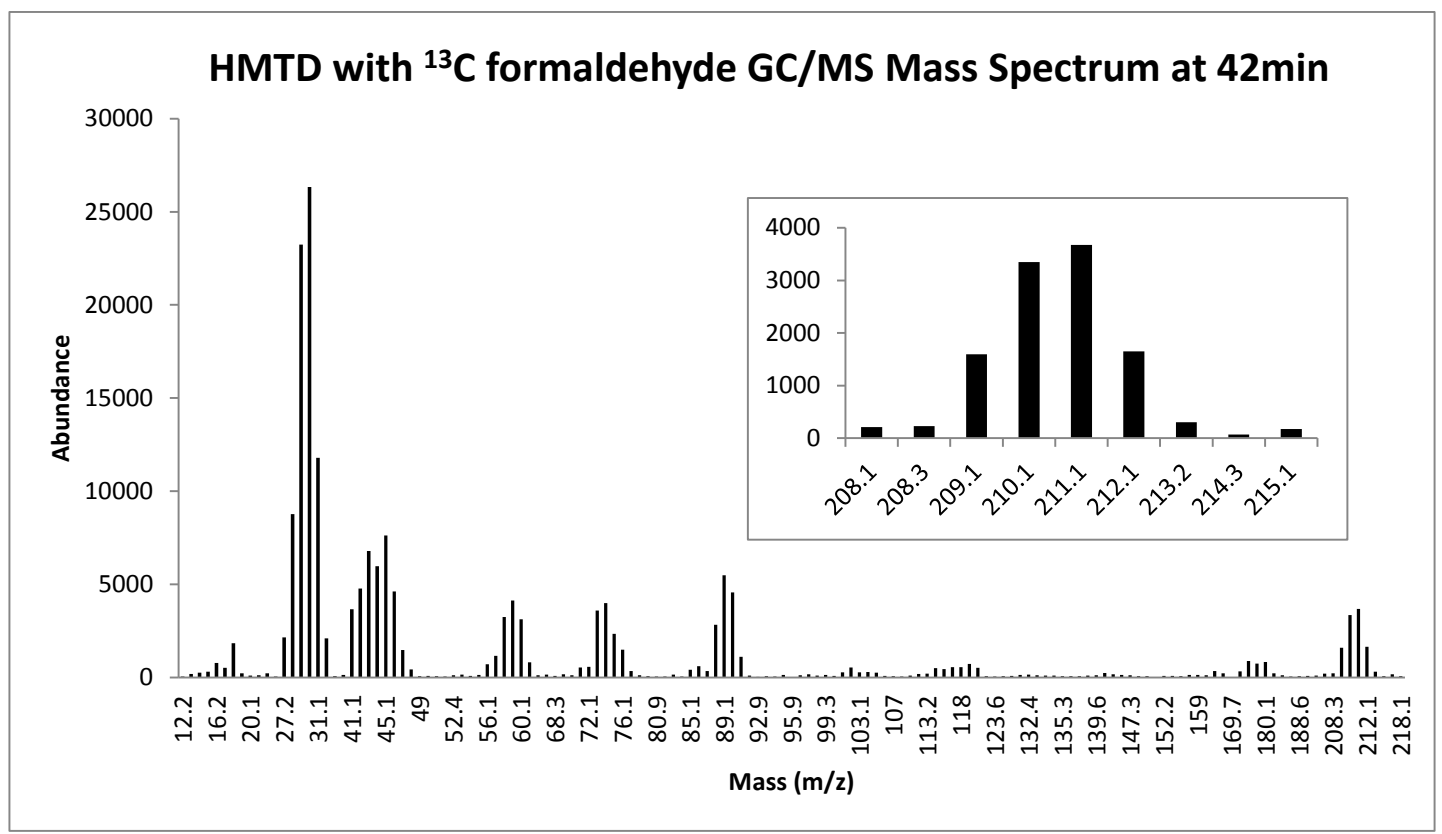

Figure 4.6. GC/MS mass spectrum of HMTD extracted during synthesis in the presence of ${ }^{13} \mathrm{C}$ formaldehyde. 


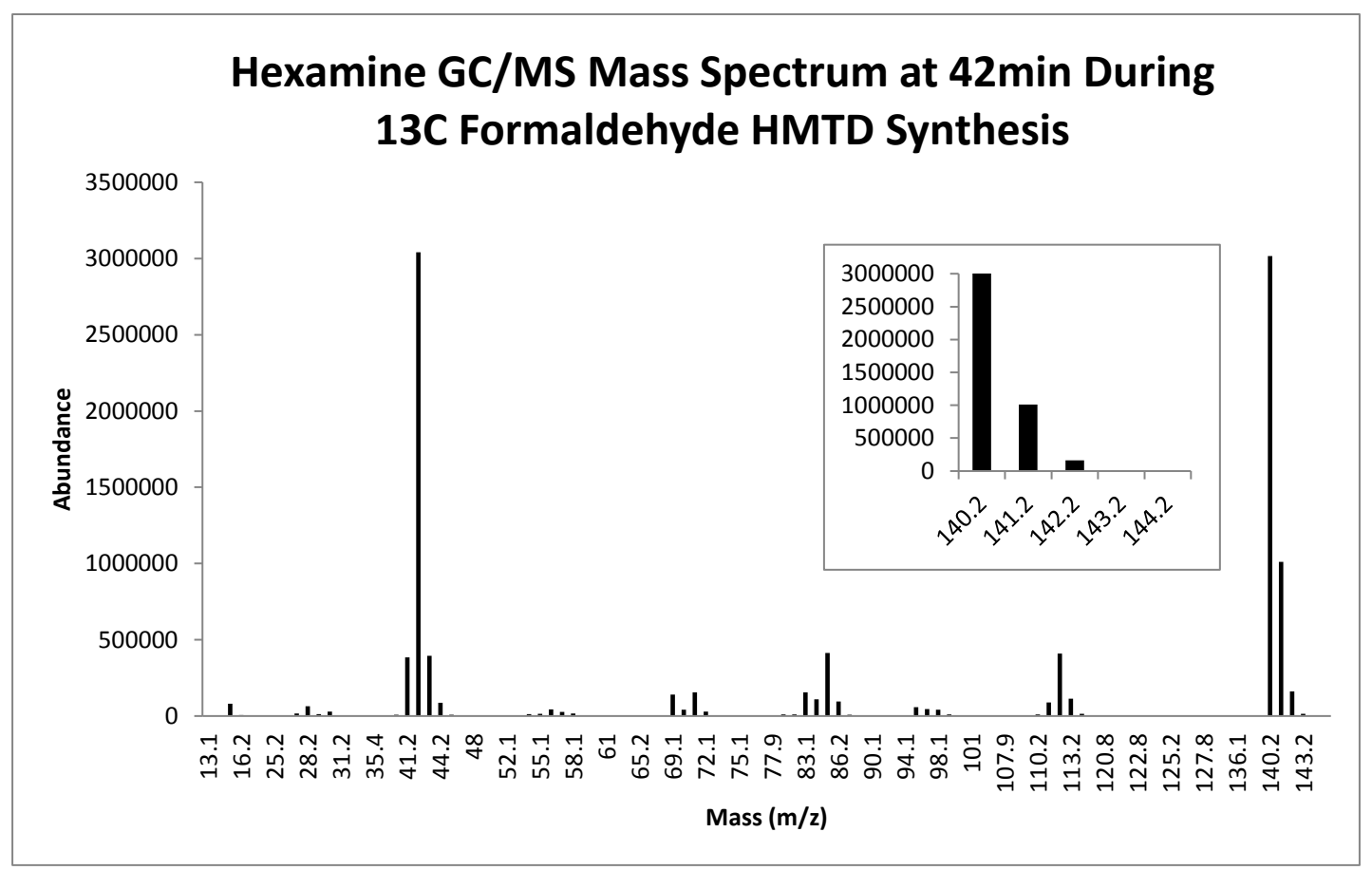

Figure 4.7. GC/MS mass spectrum of hexamine extracted during HMTD synthesis in the presence of ${ }^{13} \mathrm{C}$ formaldehyde.

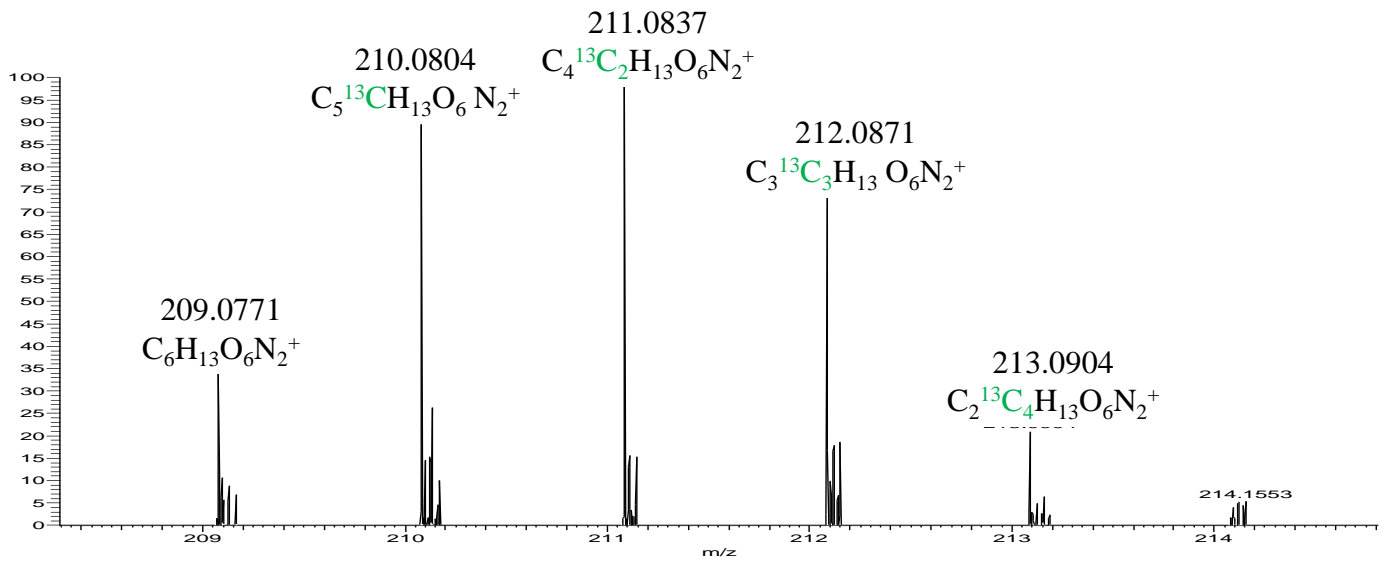

Figure 4.8. LC/MS mass spectrum of HMTD extracted during synthesis in the presence of ${ }^{13} \mathrm{C}$ formaldehyde. 


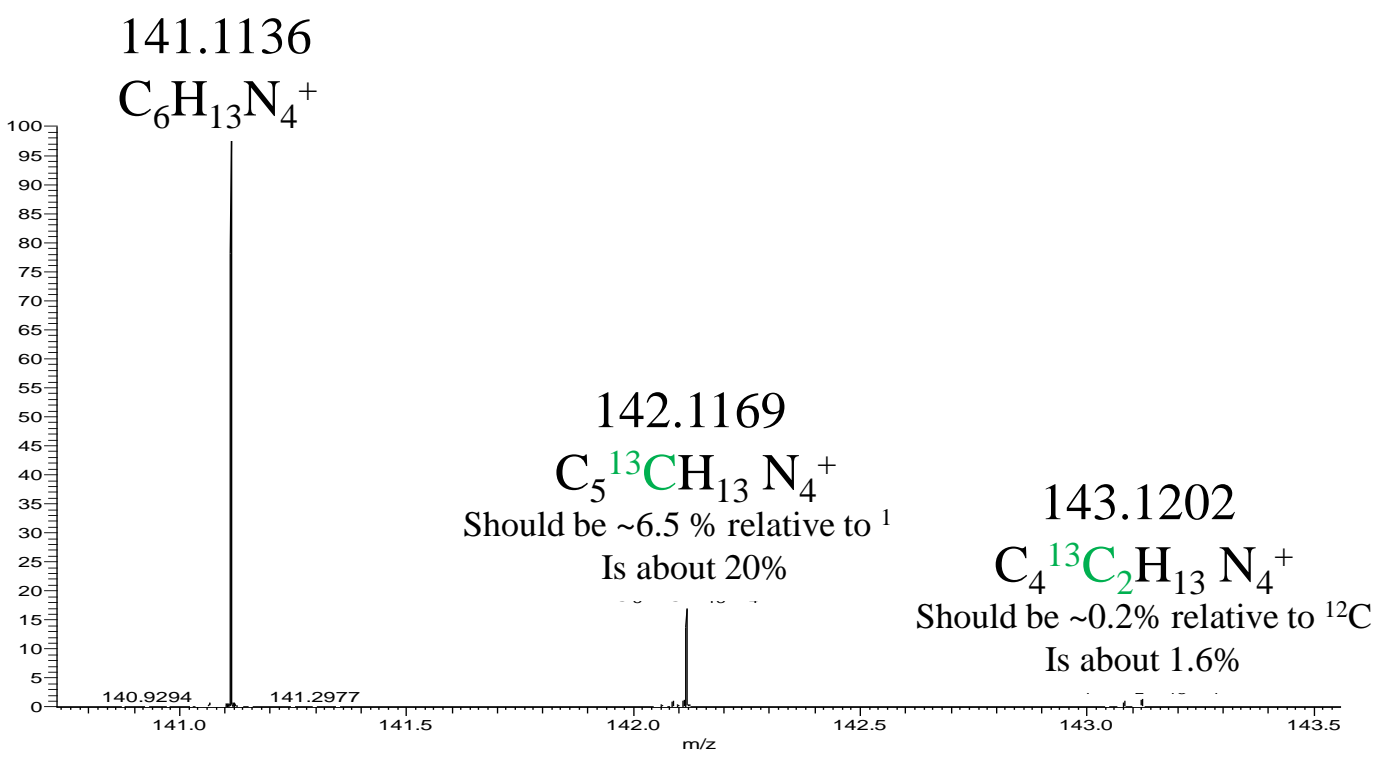

Figure 4.9. LC/MS mass spectrum of hexamine extracted during HMTD synthesis in the presence of ${ }^{13} \mathrm{C}$ formaldehyde. 


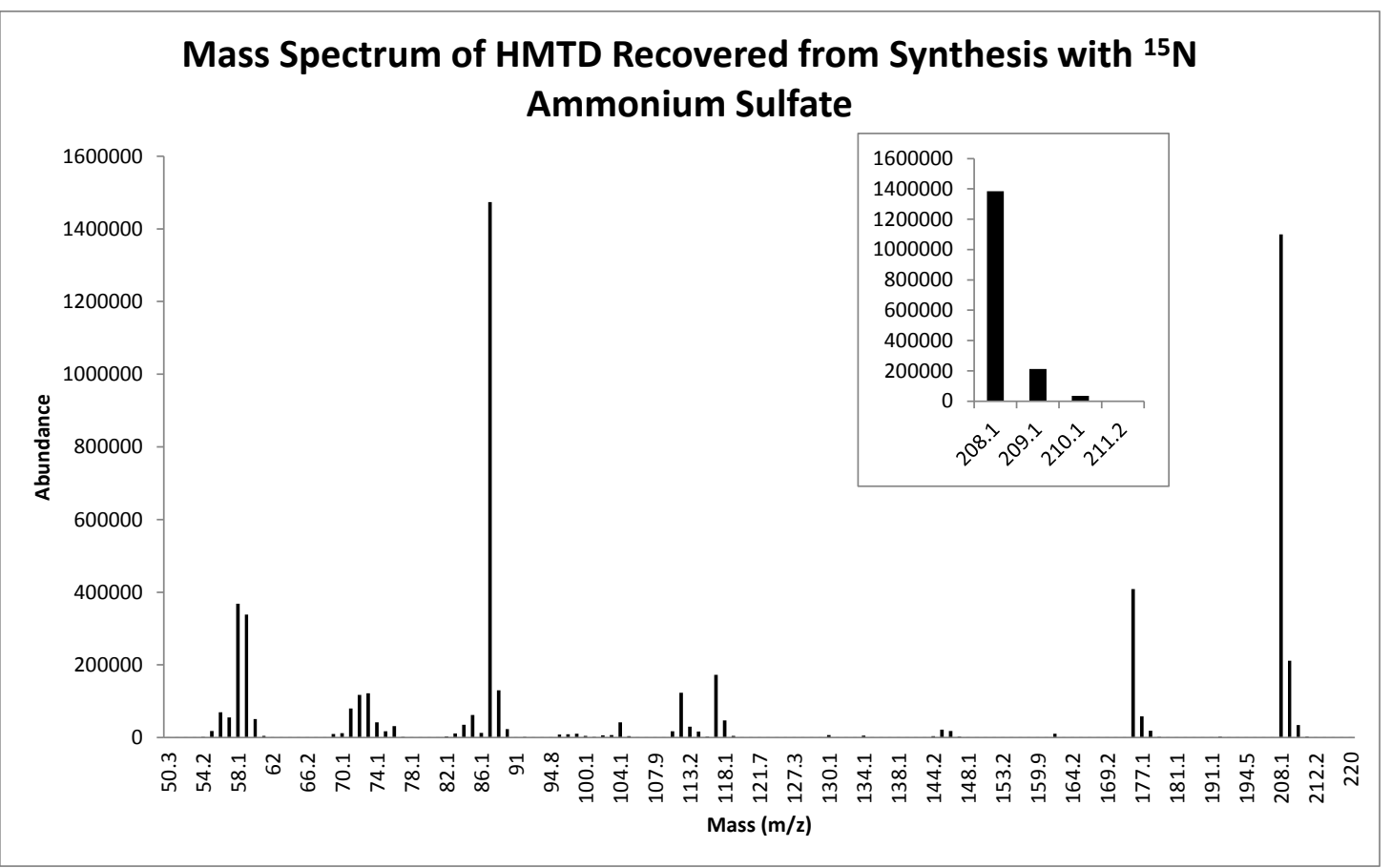

Figure 4.10. GC/MS mass spectrum of HMTD recovered after synthesis in the presence of ${ }^{15} \mathrm{~N}$ ammonium sulfate. 


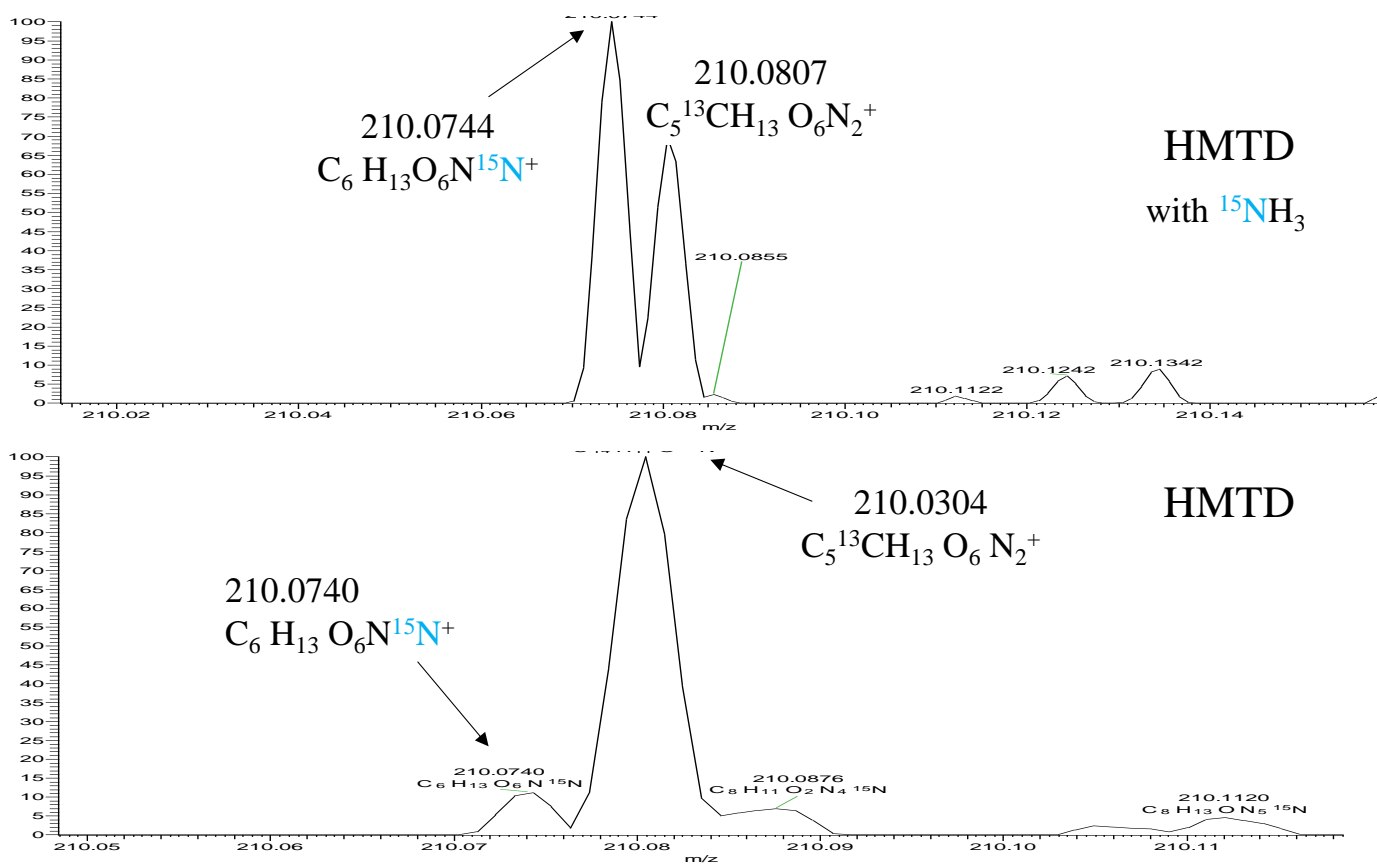

Figure 4.11. LC/MS mass spectrum of HMTD recovered after synthesis in the presence of ${ }^{15} \mathrm{~N}$ ammonium sulfate. 


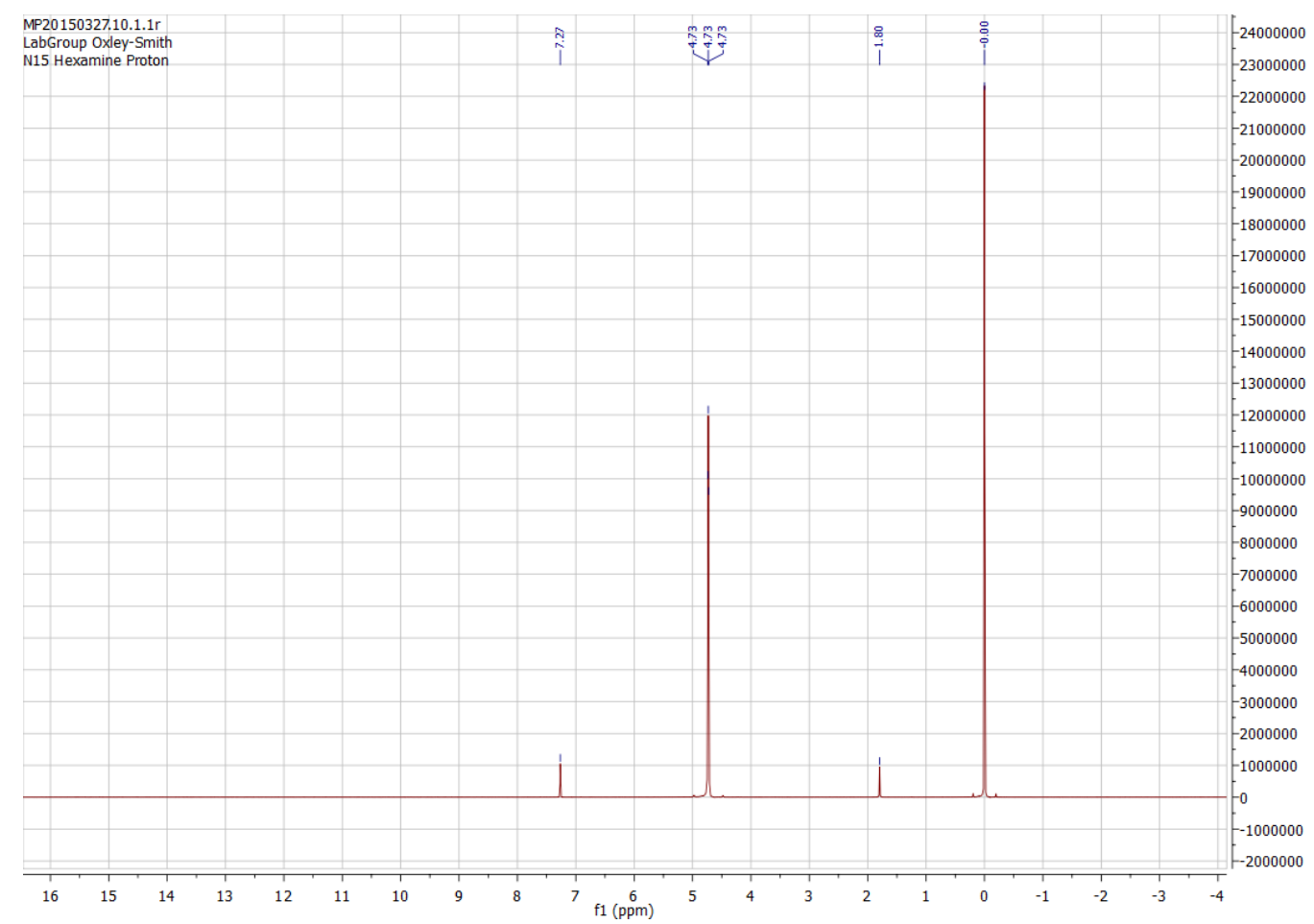

Figure 4.12. ${ }^{1} \mathrm{H}$ NMR spectrum of ${ }^{15} \mathrm{~N}$ hexamine in $\mathrm{CDCl}_{3}$. 


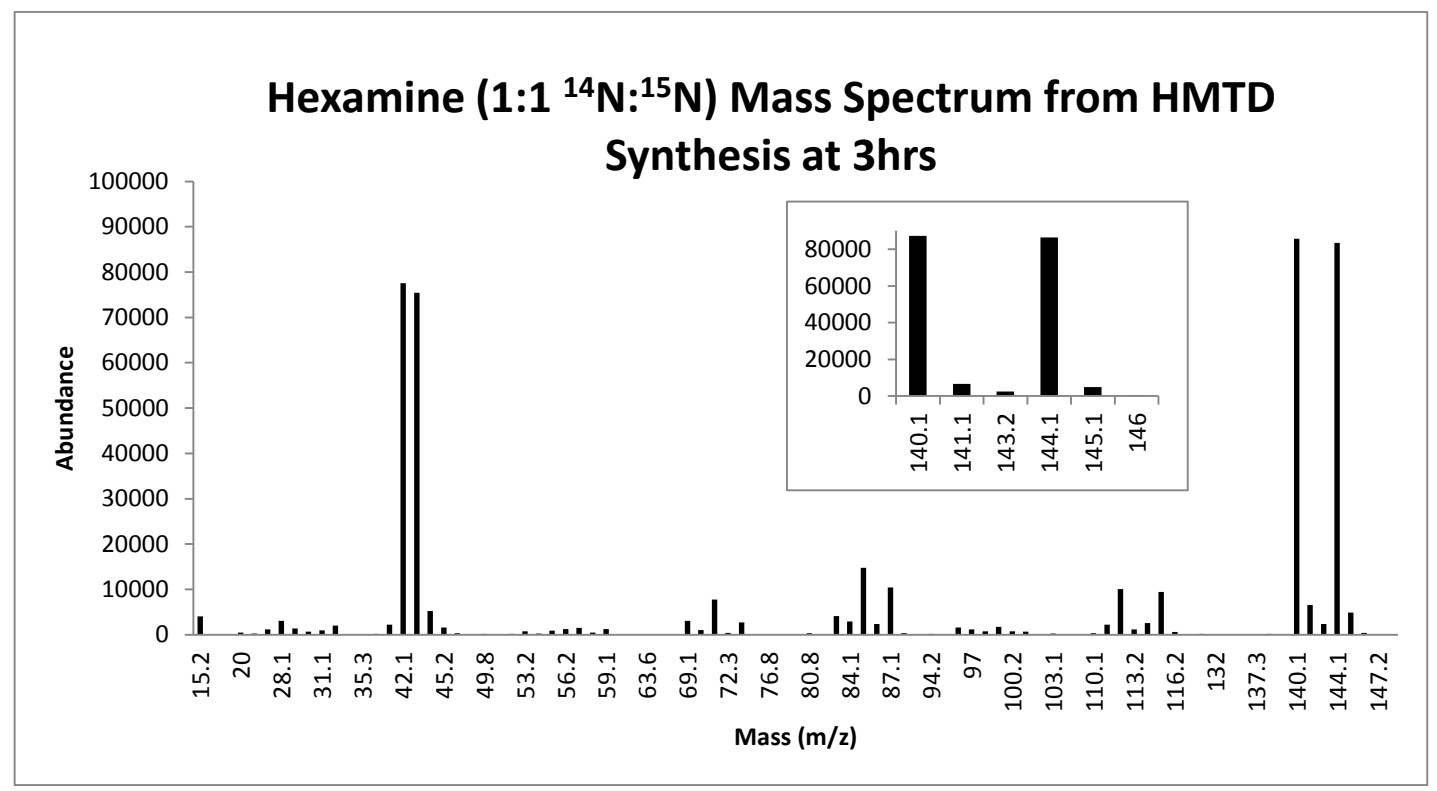

Figure 4.13. GC/MS Mass Spectrum of $1: 1^{14} \mathrm{~N}:{ }^{15} \mathrm{~N}$ hexamine extracted during synthesis of HMTD.

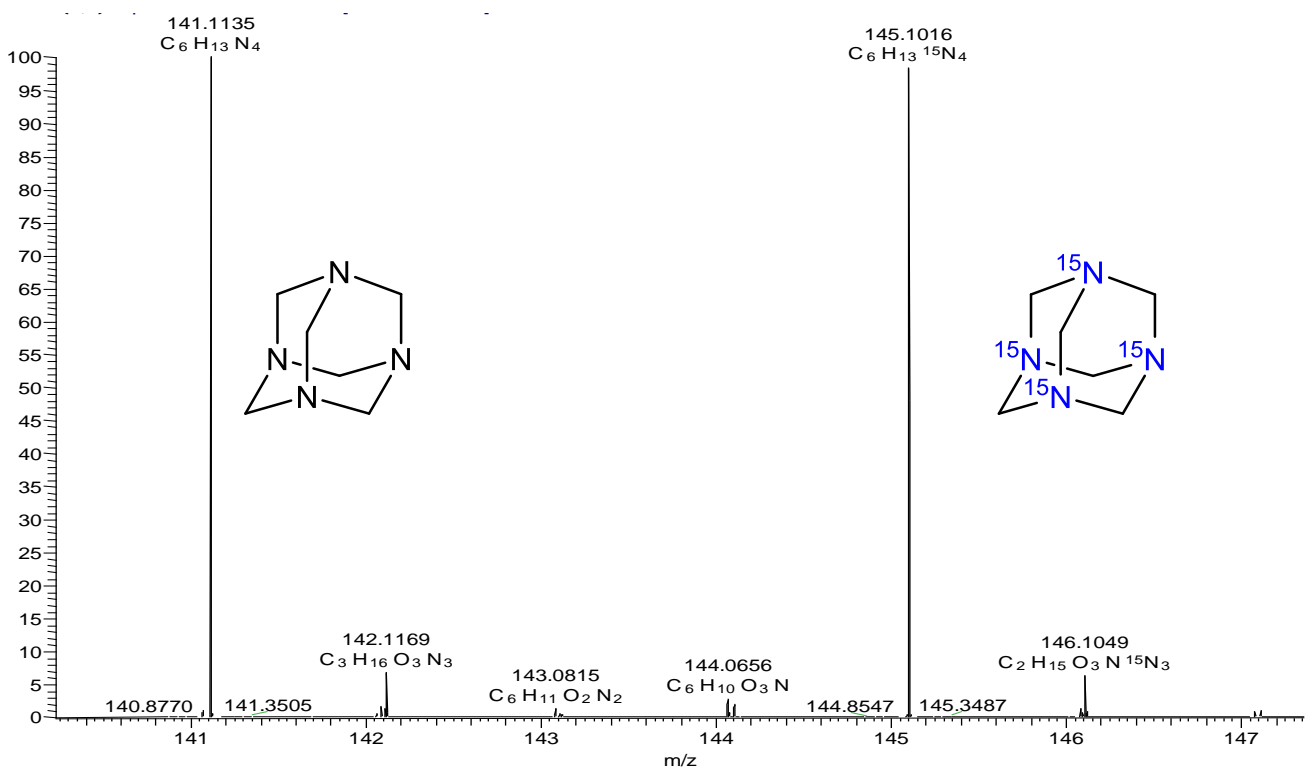

Figure 4.14. LC/MS Mass Spectrum of $1: 1^{14} \mathrm{~N}:{ }^{15} \mathrm{~N}$ hexamine extracted during synthesis of HMTD. 


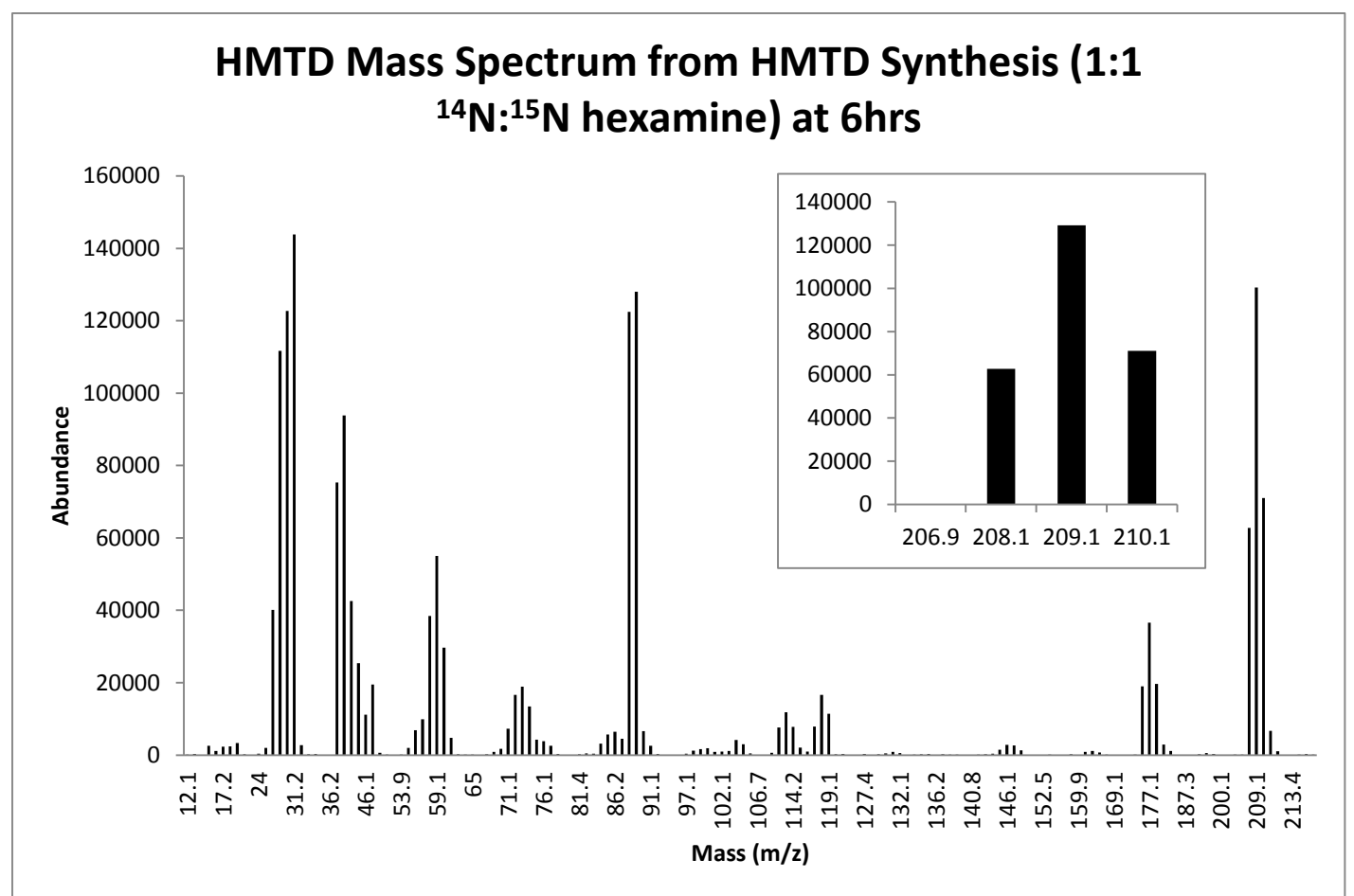

Figure 4.15. GC/MS mass spectrum of HMTD extracted during synthesis with 1:1 ${ }^{14} \mathrm{~N}:{ }^{15} \mathrm{~N}$ hexamine. 


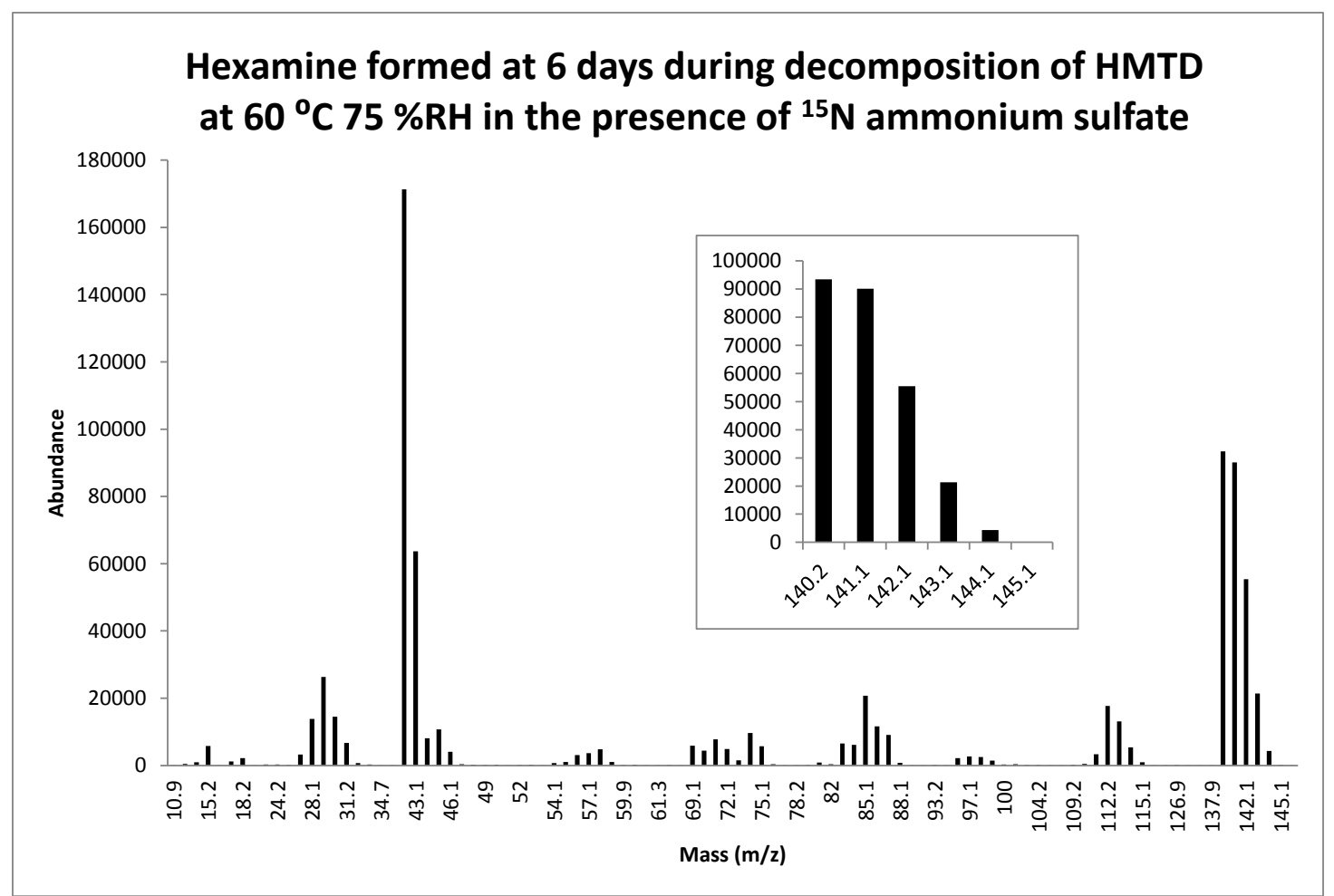

Figure 4.16. GC/MS of Hexamine formed after 6 days when HMTD is decomposed in the presence of $15 \mathrm{~N}$ Ammonium Sulfate at $60{ }^{\circ} \mathrm{C}$ and $75 \% \mathrm{RH}$. 


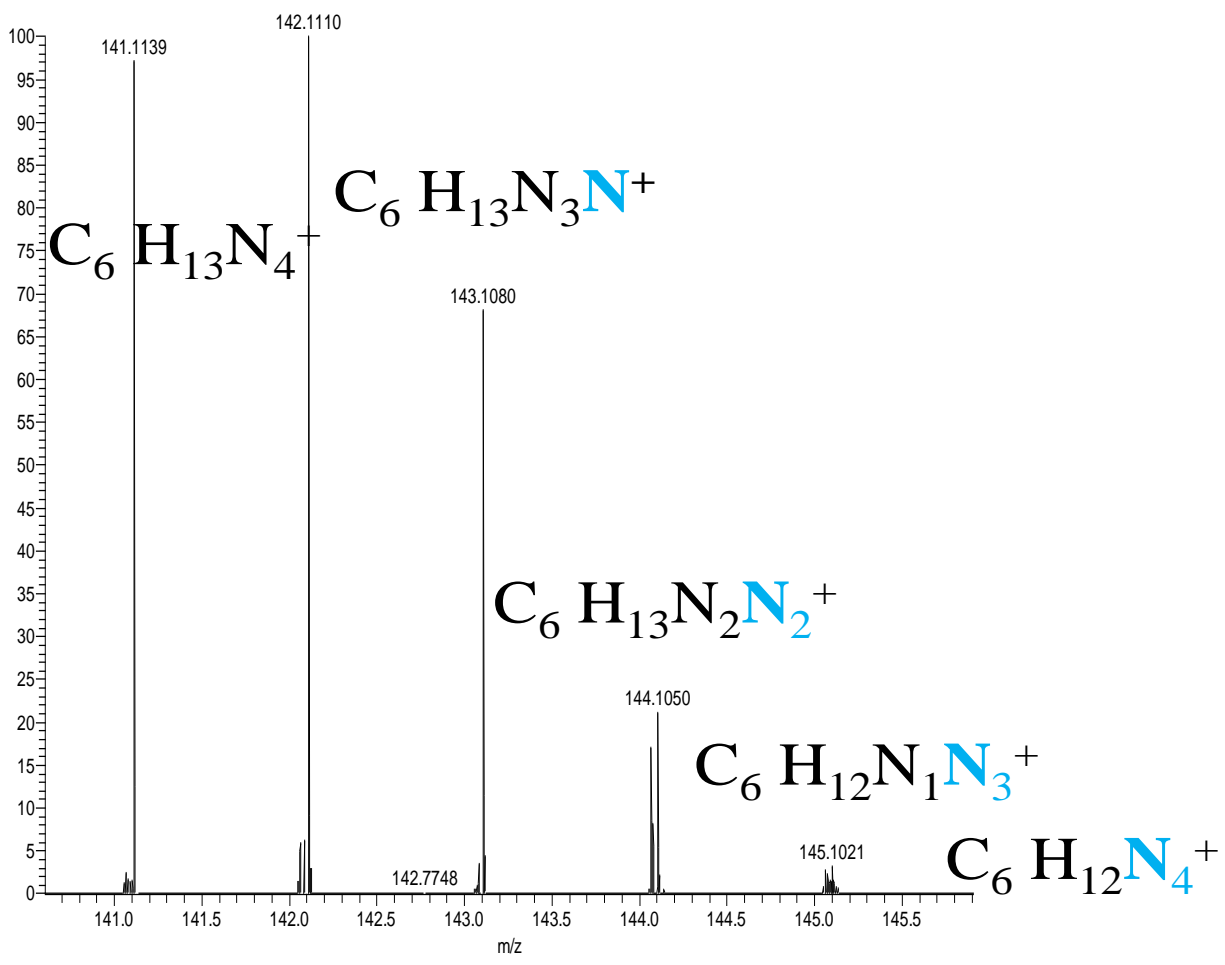

Figure 4.17. LC/MS of Hexamine formed after 6 days when HMTD is decomposed in the presence of $15 \mathrm{~N}$ Ammonium Sulfate at $60^{\circ} \mathrm{C}$ and $75 \% \mathrm{RH}$. 


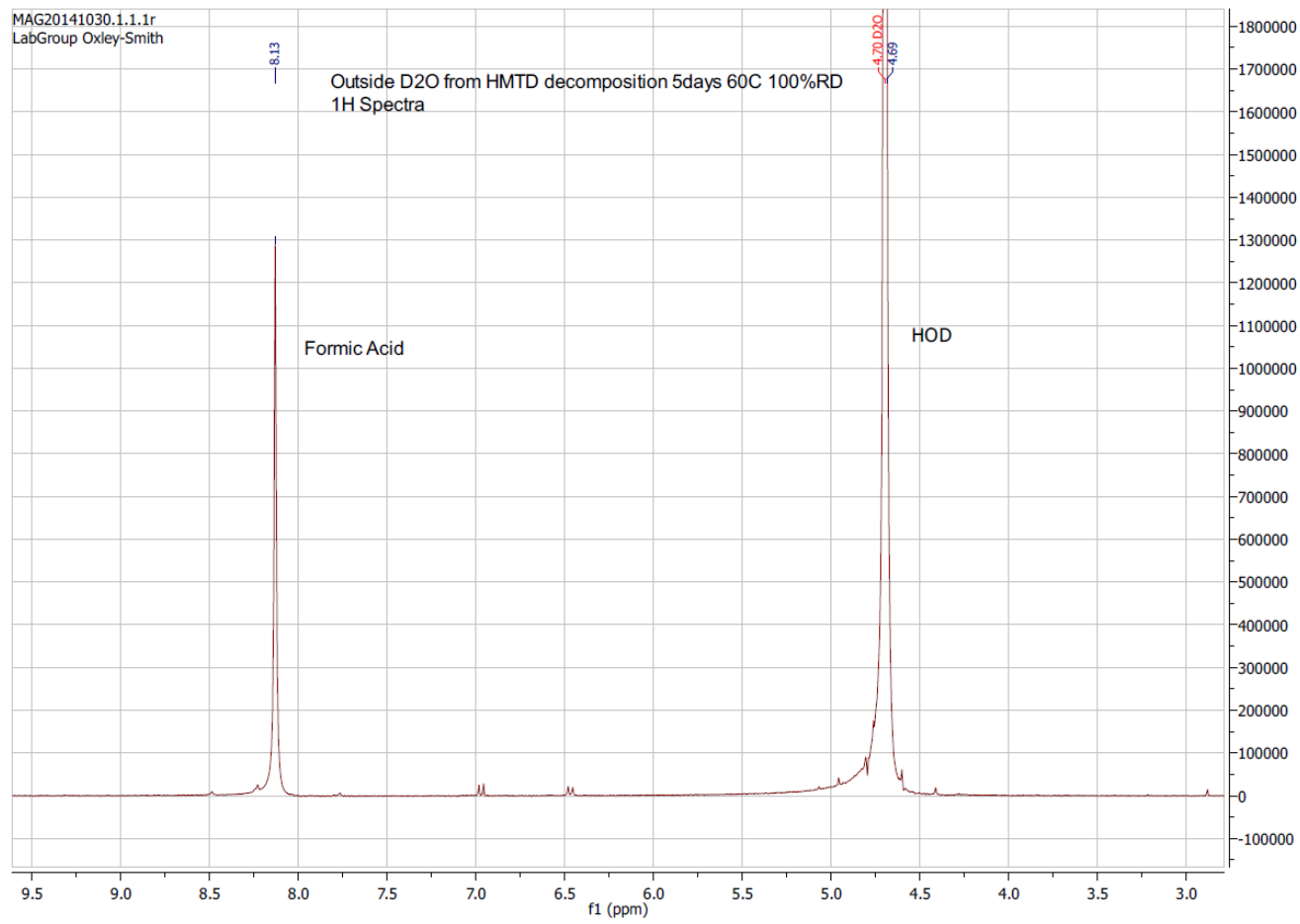

Figure 4.18. ${ }^{1} \mathrm{H}$ NMR of $\mathrm{D}_{2} \mathrm{O}$ in outside vial after 5 days during decomposition of HMTD at $60{ }^{\circ} \mathrm{C} 100 \%$ RD. 


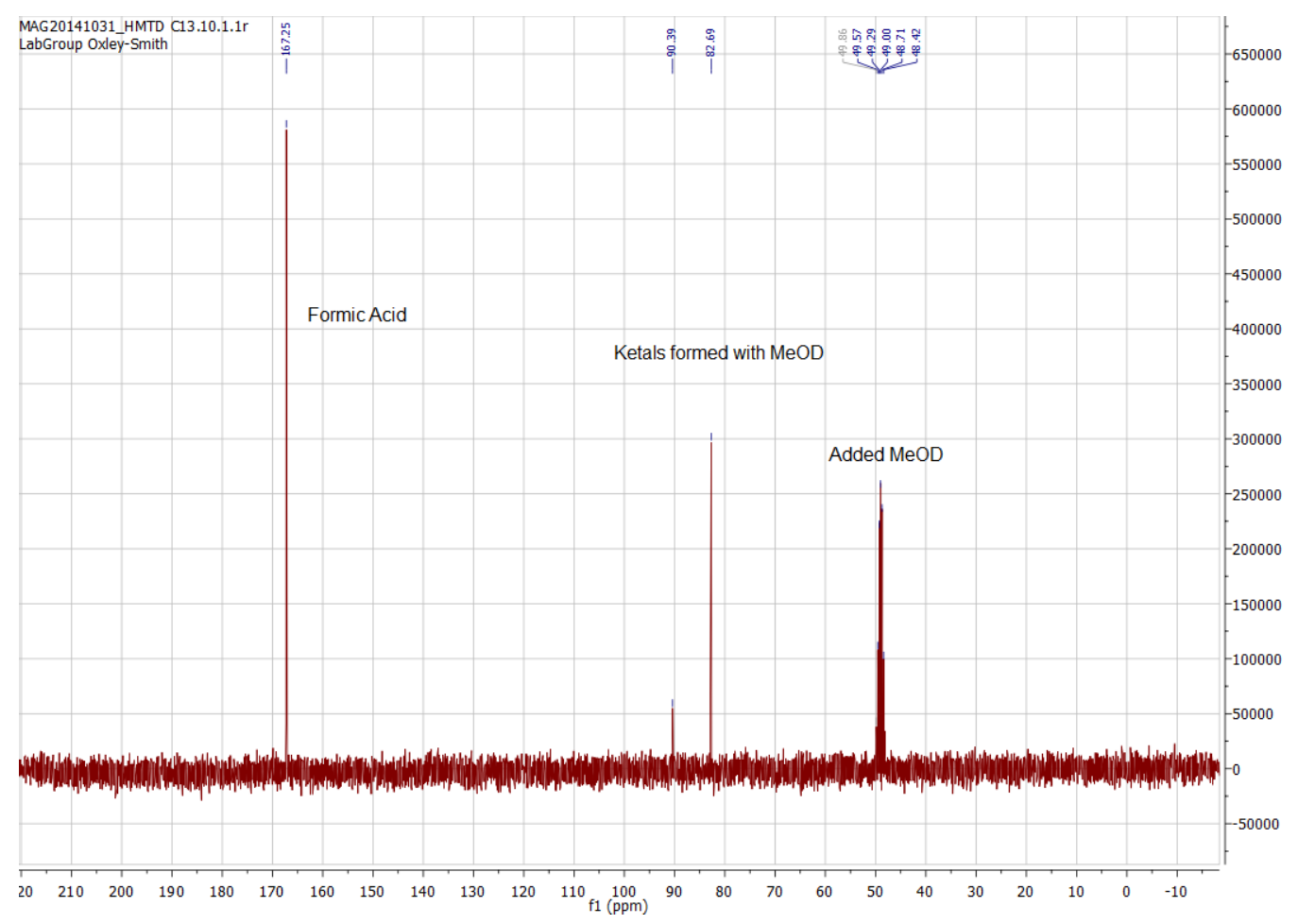

Figure 4.19. ${ }^{13} \mathrm{C}$ NMR of $\mathrm{D}_{2} \mathrm{O}$ in outside vial after 5 days during decomposition of HMTD at $60{ }^{\circ} \mathrm{C} 100 \%$ RD. 


\section{APPENDIX 5: DATA FOR MANUSCRIPT 2}

\section{SDT from Aging Studies}

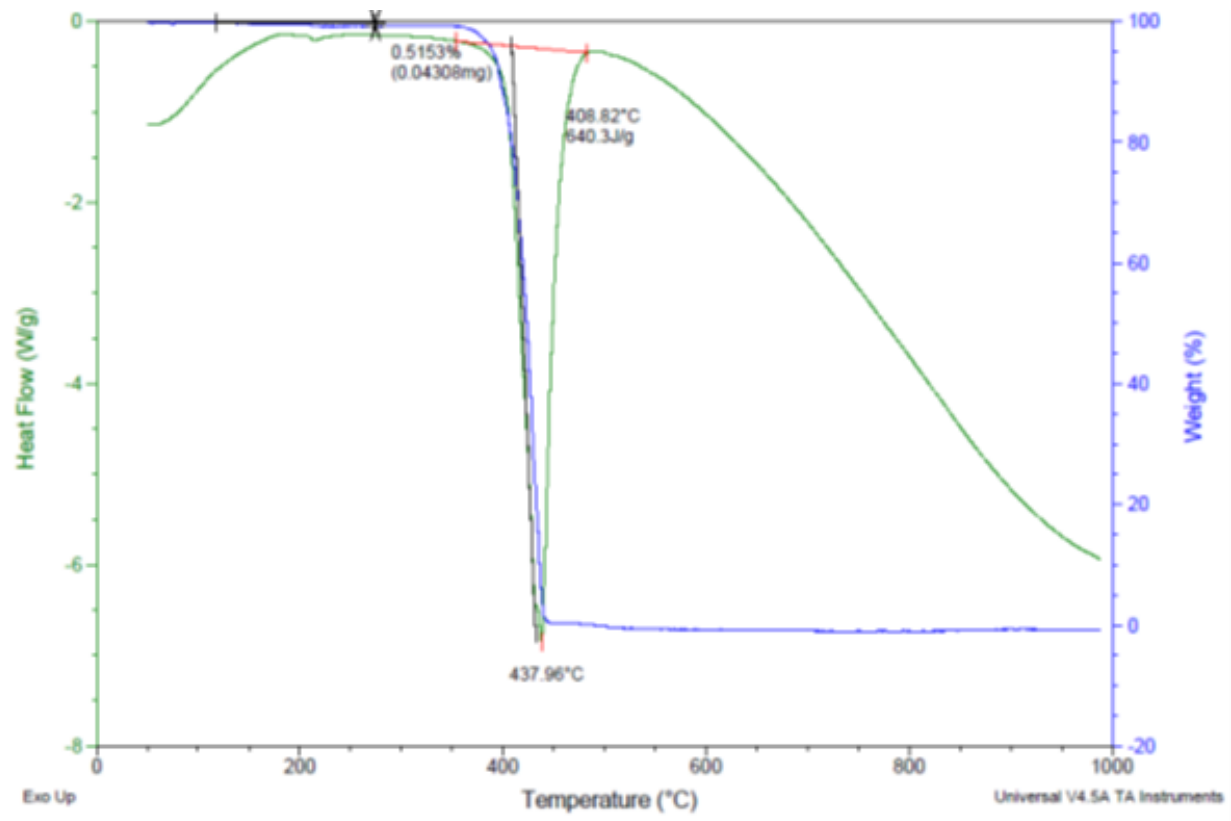

Figure 5.1. $\mathrm{I}_{2} \mathrm{O}_{5}$ fresh

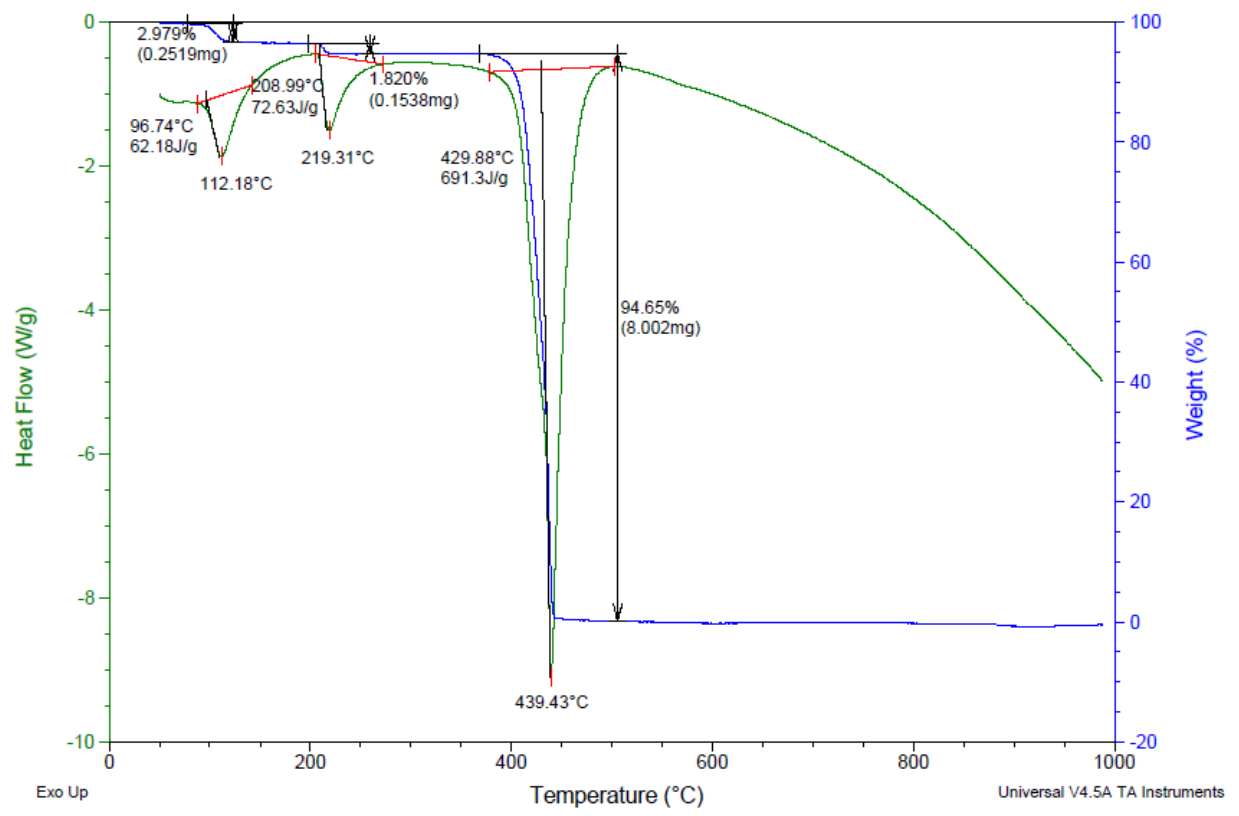

Figure 5.2. $\mathrm{I}_{2} \mathrm{O}_{5}$ after 3 days $75 \% \mathrm{RH}$ at $60{ }^{\circ} \mathrm{C}$ 


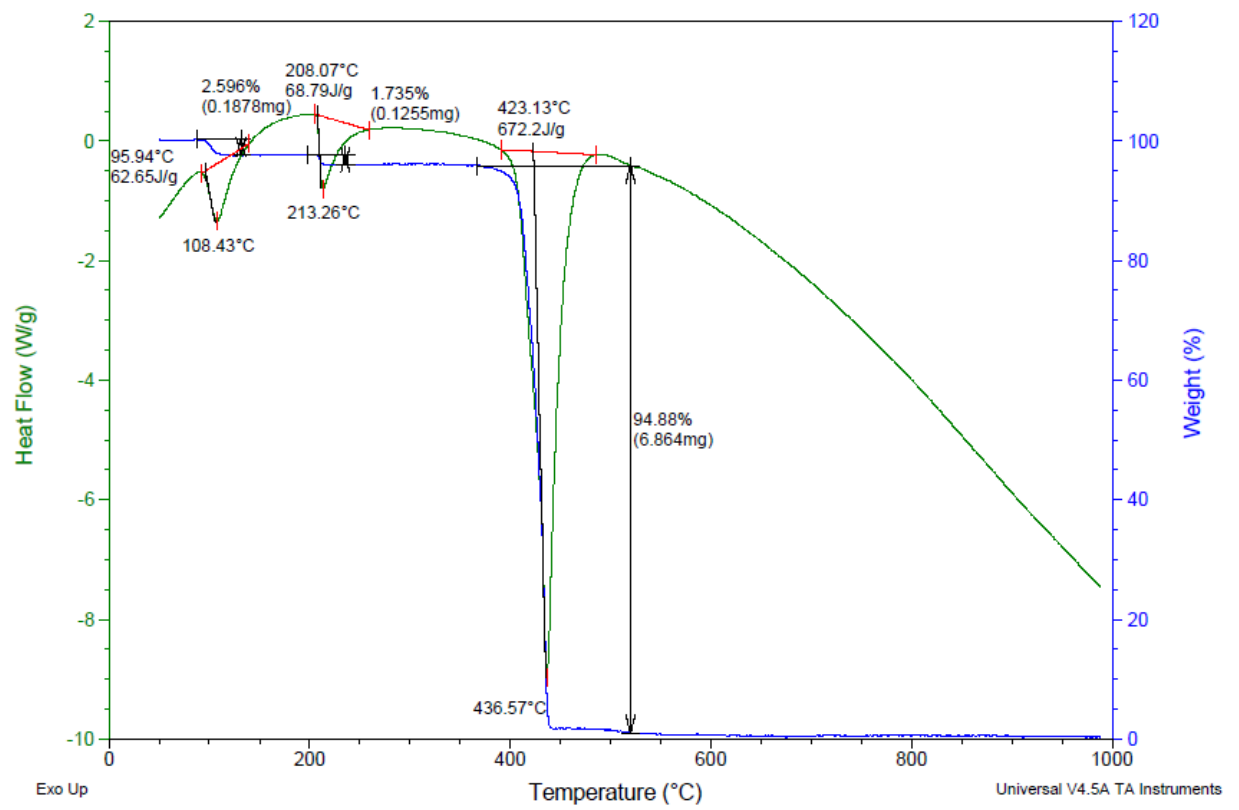

Figure 5.3. $\mathrm{I}_{2} \mathrm{O}_{5}$ after 14 days $75 \% \mathrm{RH}$ at $60{ }^{\circ} \mathrm{C}$

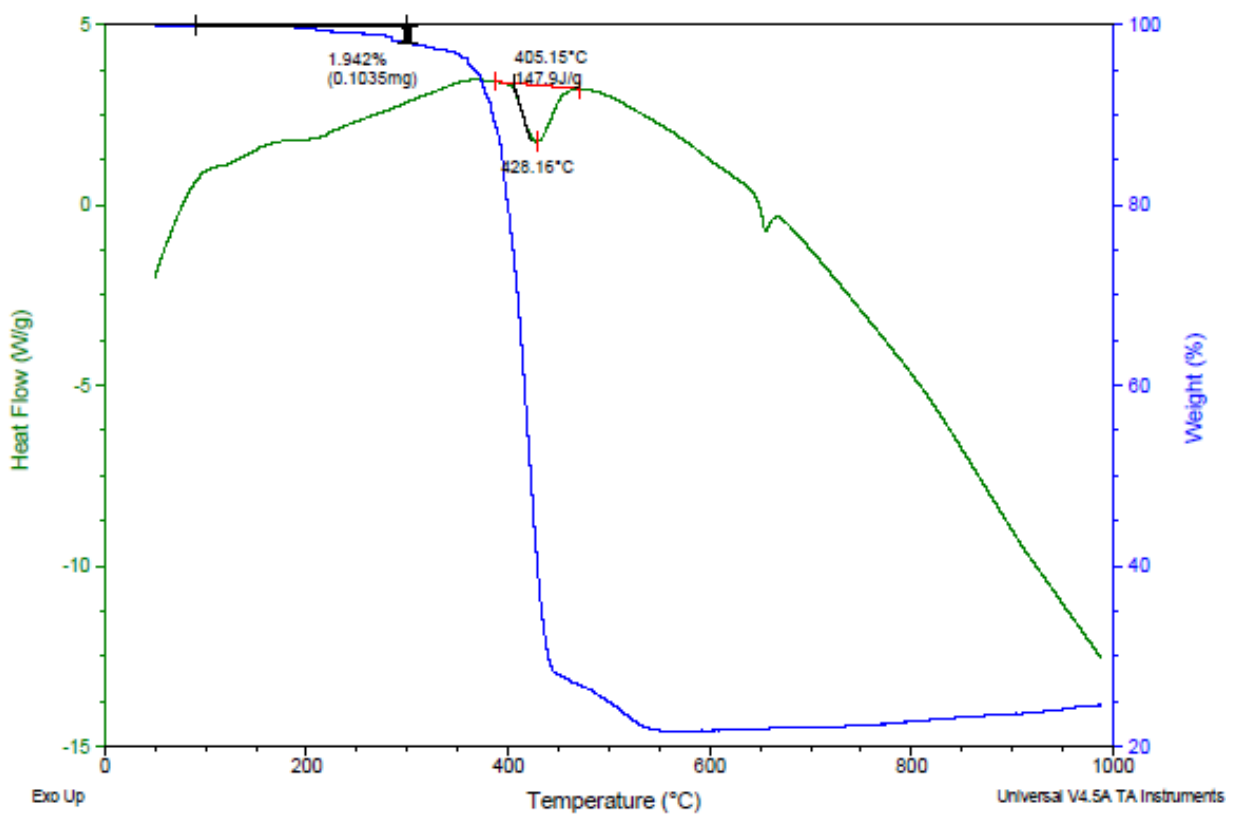

Figure 5.4. 80/20 $\mathrm{I}_{2} \mathrm{O}_{5} / \mathrm{Al}$ fresh mixture 


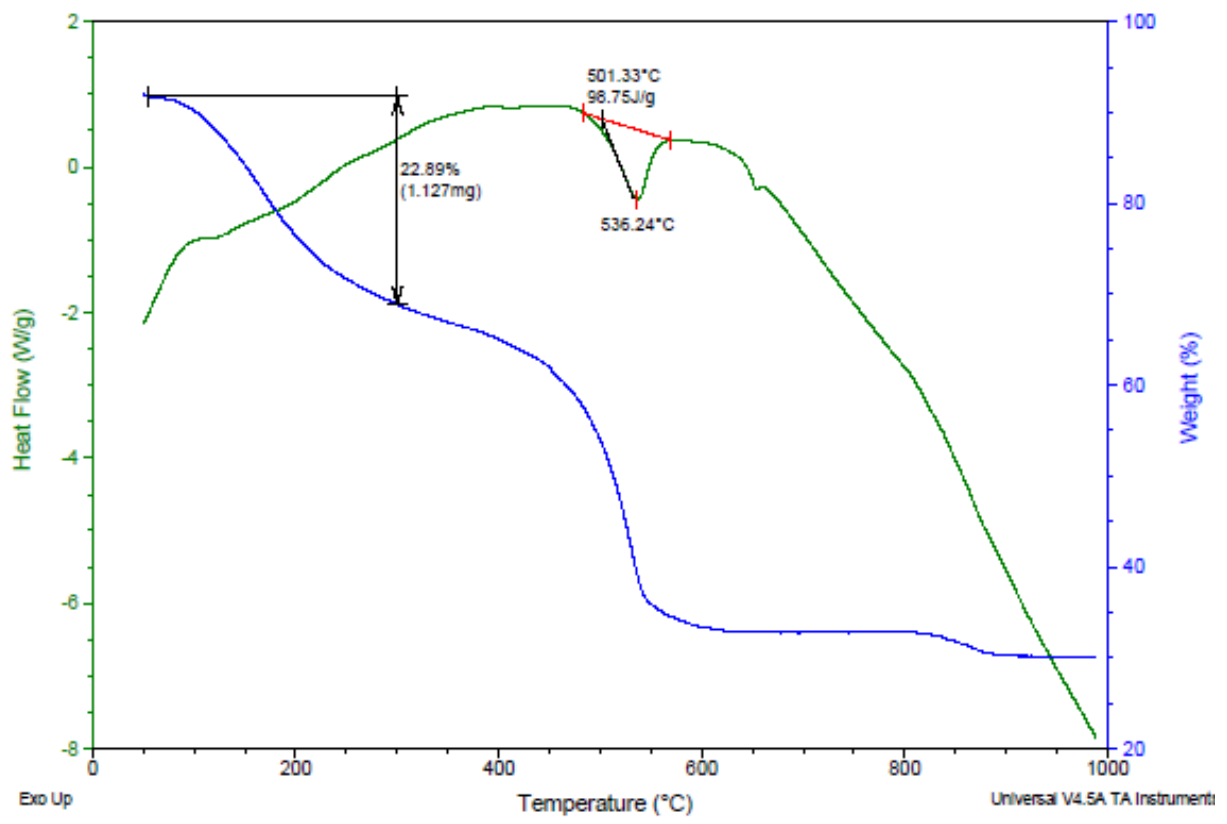

Figure 5.5. 80/20 $\mathrm{I}_{2} \mathrm{O}_{5} / \mathrm{Al}$ after 3 days $75 \% \mathrm{RH}$ at $60{ }^{\circ} \mathrm{C}$ (does not burn)

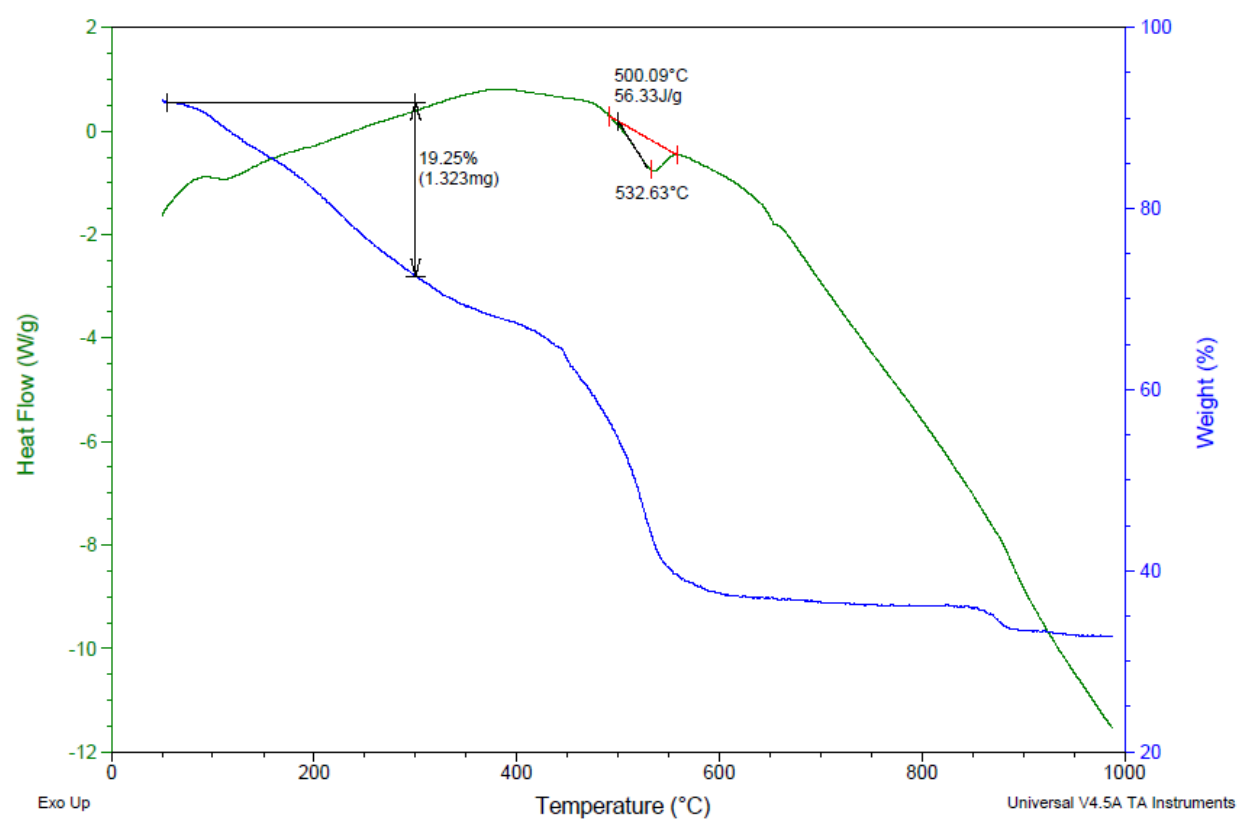

Figure 5.6. 80/20 $\mathrm{I}_{2} \mathrm{O}_{5} / \mathrm{Al}$ after 14 days $75 \% \mathrm{RH}$ at $60{ }^{\circ} \mathrm{C}$ (does not burn) 


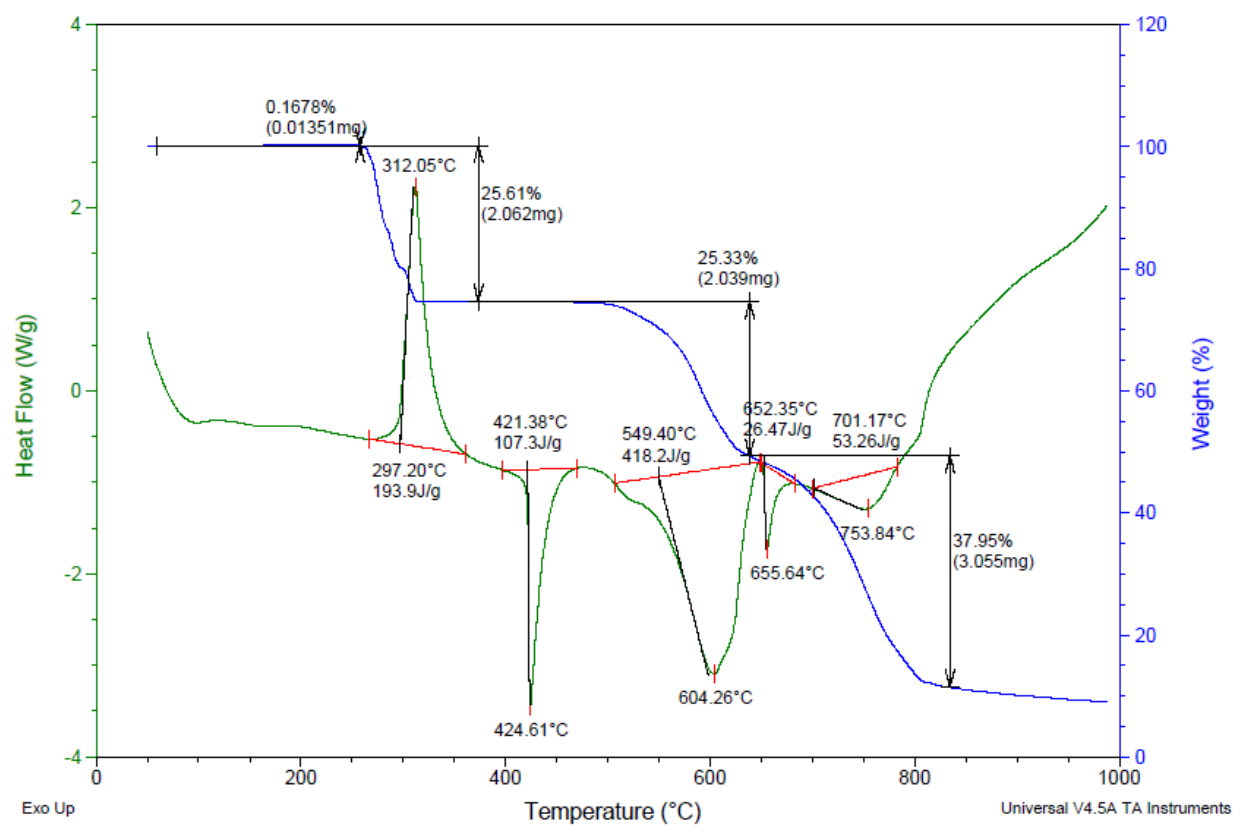

Figure 5.7. $\mathrm{NaIO}_{4}$ fresh

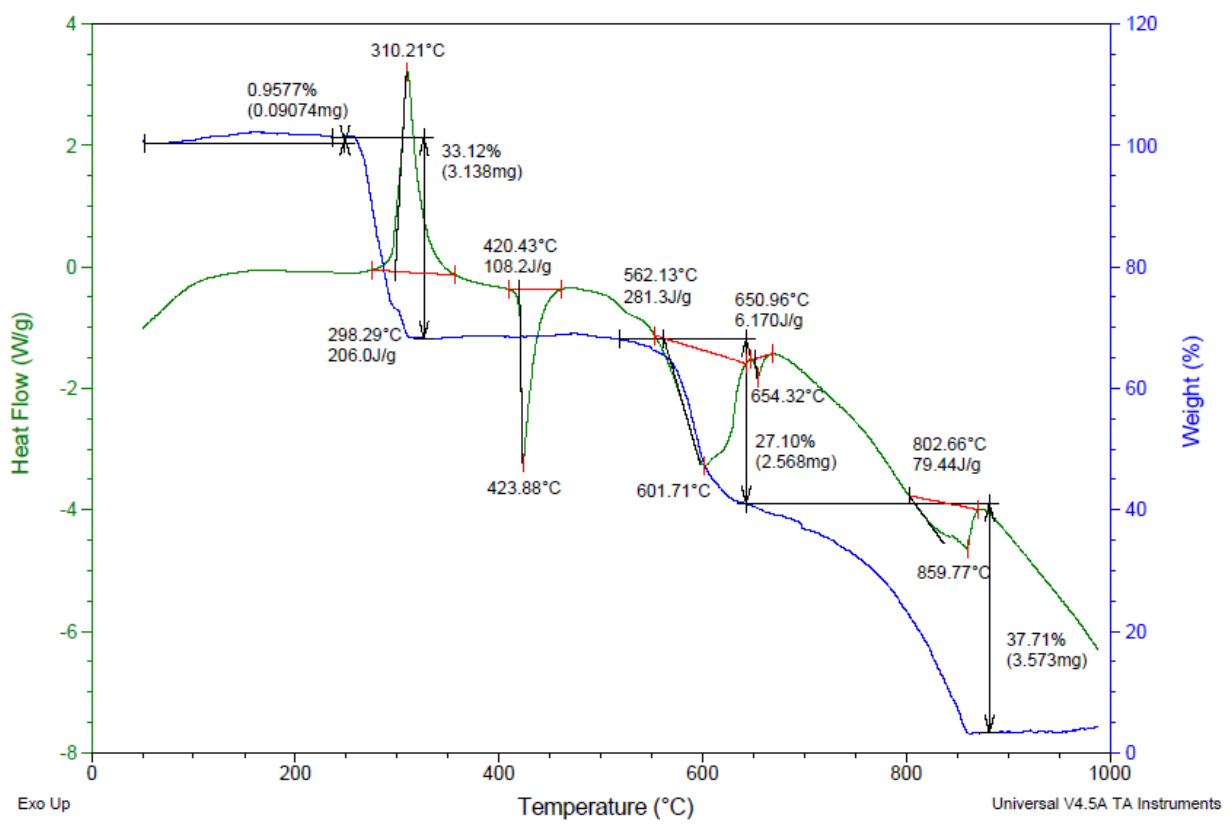

Figure 5.8. $\mathrm{NaIO}_{4}$ after 3 days $75 \% \mathrm{RH}$ at $60{ }^{\circ} \mathrm{C}$ 


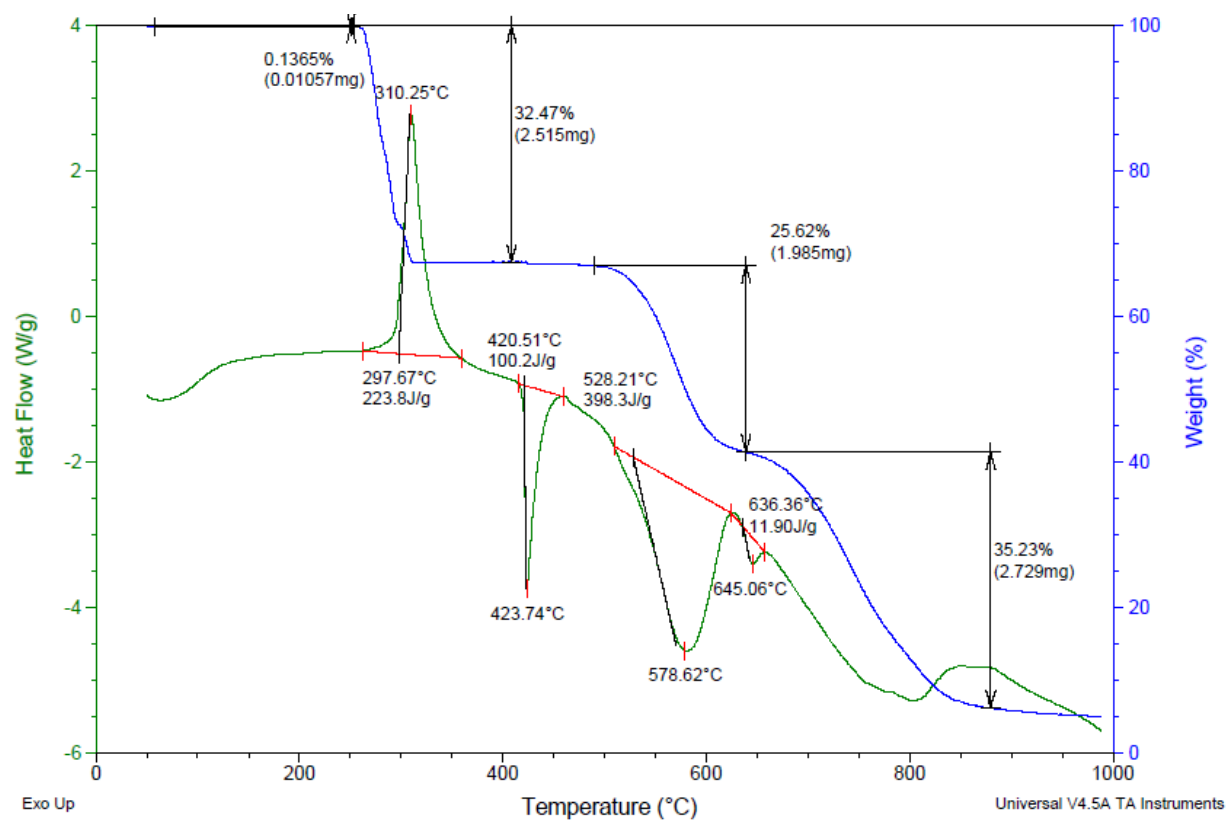

Figure 5.9. $\mathrm{NaIO}_{4}$ after 14 days $75 \% \mathrm{RH}$ at $60{ }^{\circ} \mathrm{C}$

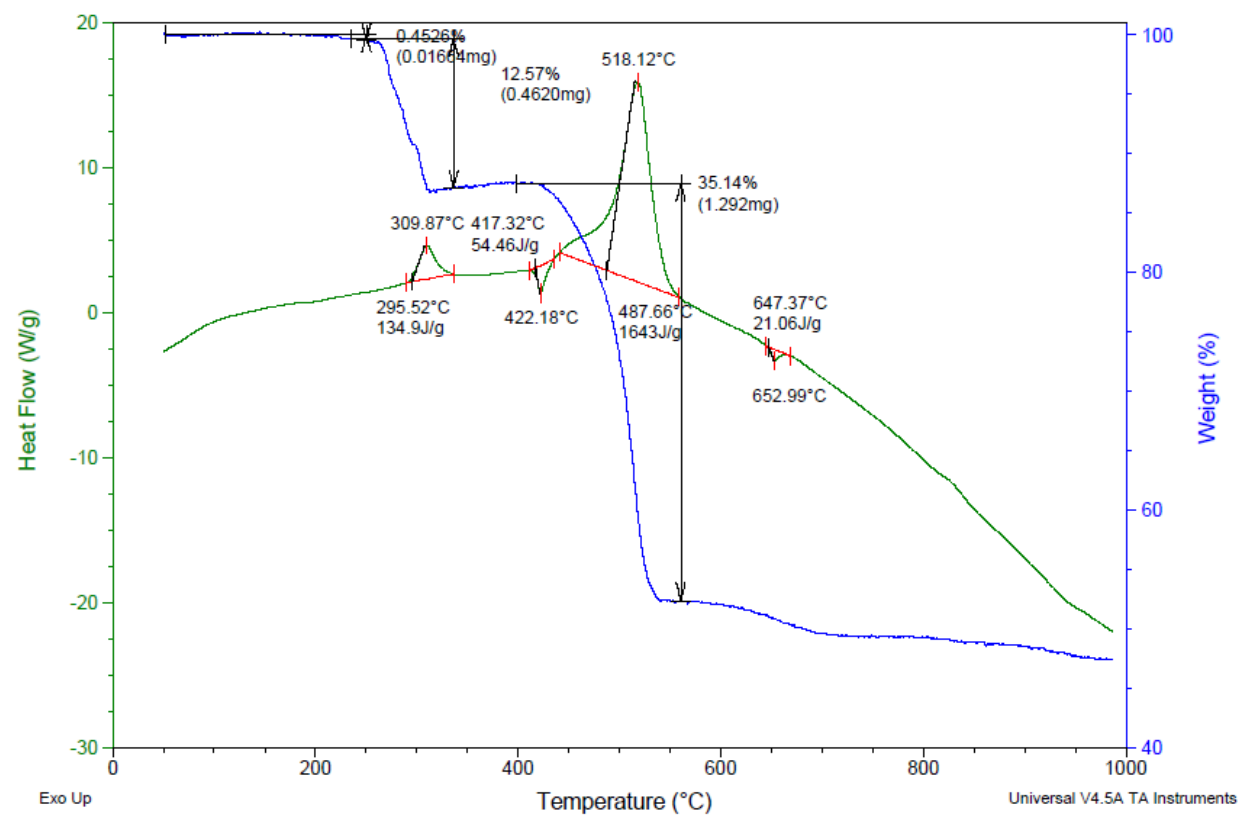

Figure 5.10. 80/10/10 $\mathrm{NaIO}_{4} / \mathrm{B}_{4} \mathrm{C} / \mathrm{Al}$ fresh mixture 


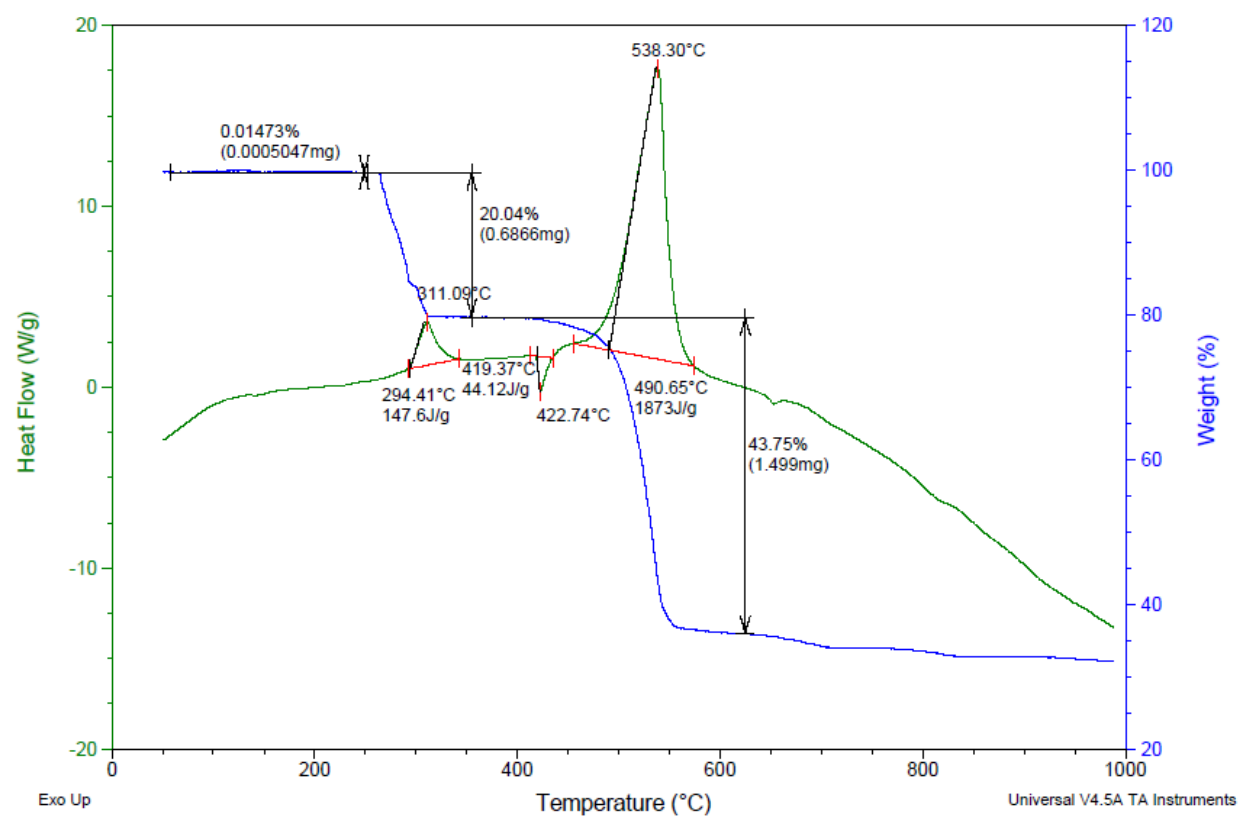

Figure 5.11. 80/10/10 $\mathrm{NaIO}_{4} / \mathrm{B}_{4} \mathrm{C} / \mathrm{Al}$ after 3 days $75 \% \mathrm{RH}$ at $60{ }^{\circ} \mathrm{C}$

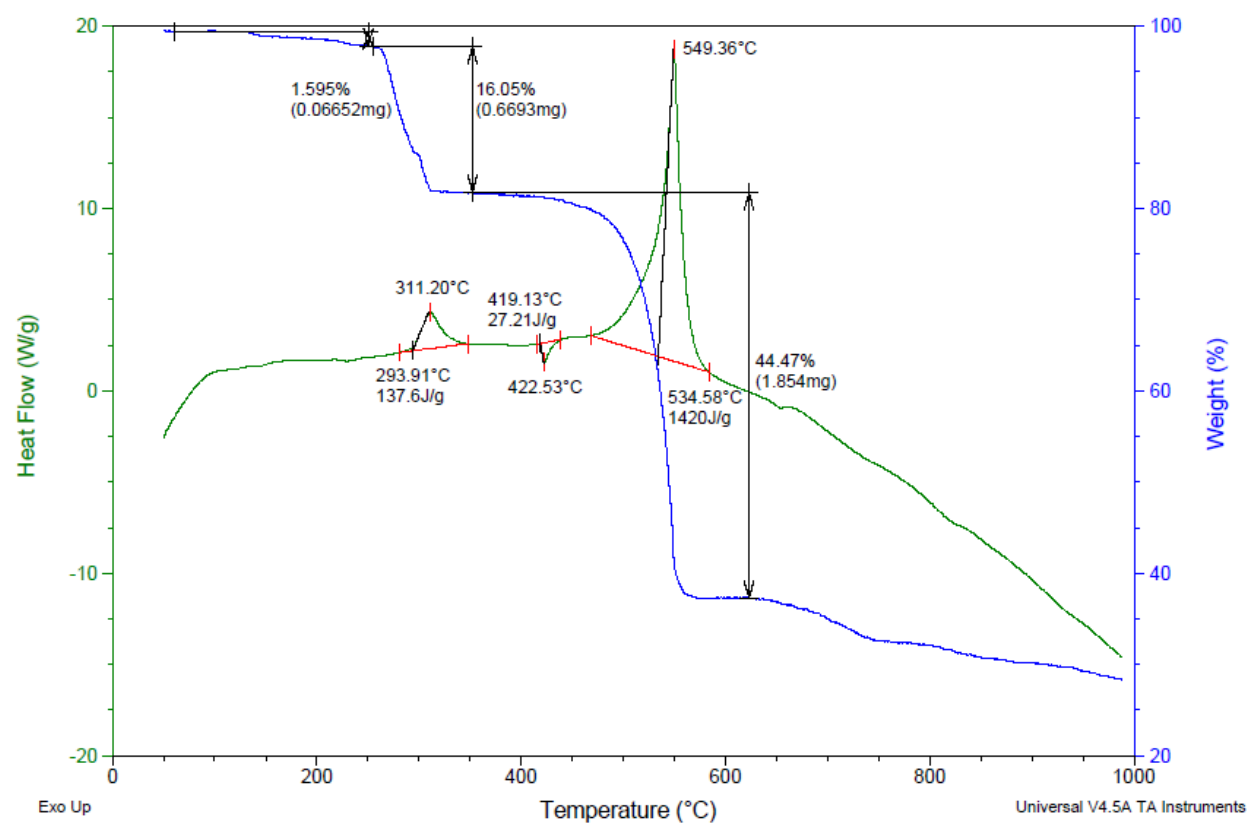

Figure 5.12. 80/10/10 $\mathrm{NaIO}_{4} / \mathrm{B}_{4} \mathrm{C} / \mathrm{Al}$ after 2 weeks $75 \% \mathrm{RH}$ at $60{ }^{\circ} \mathrm{C}$ (burns slower, decreased brightness) 


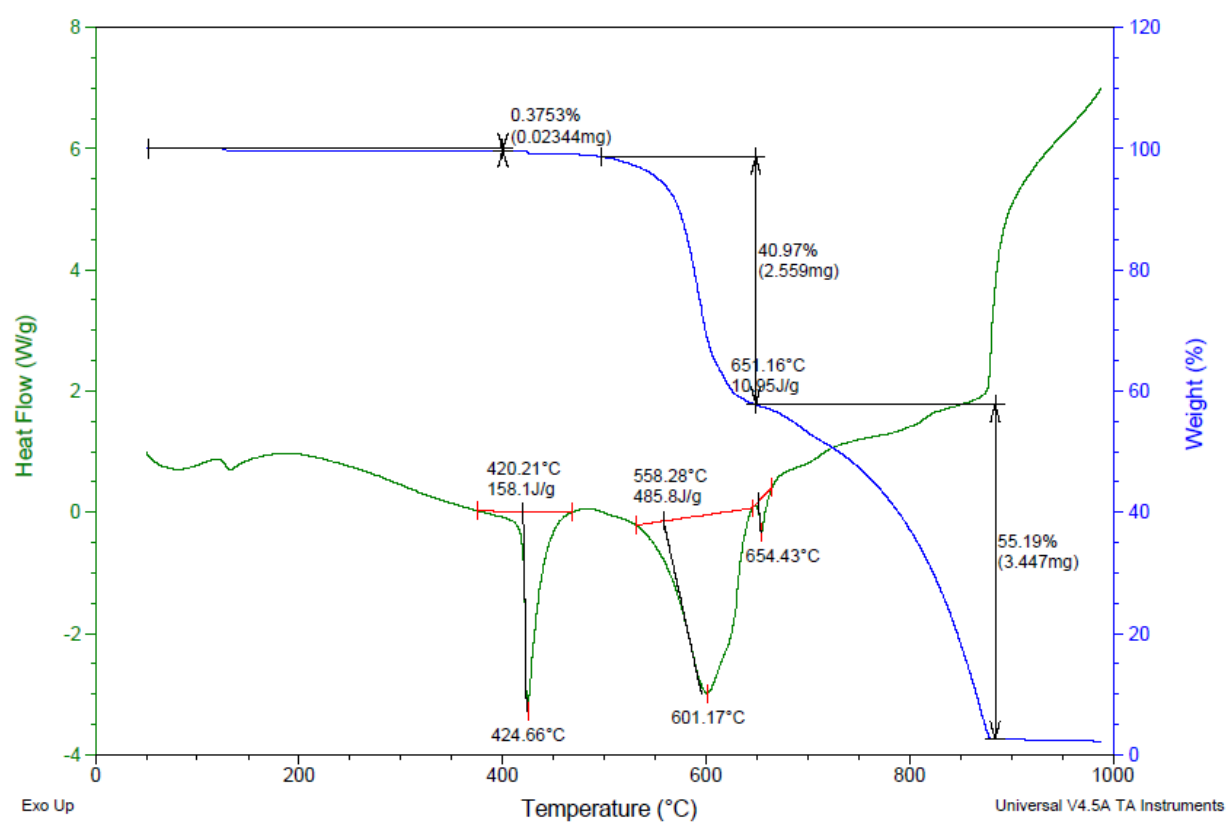

Figure 5.13. $\mathrm{NaIO}_{3}$ fresh

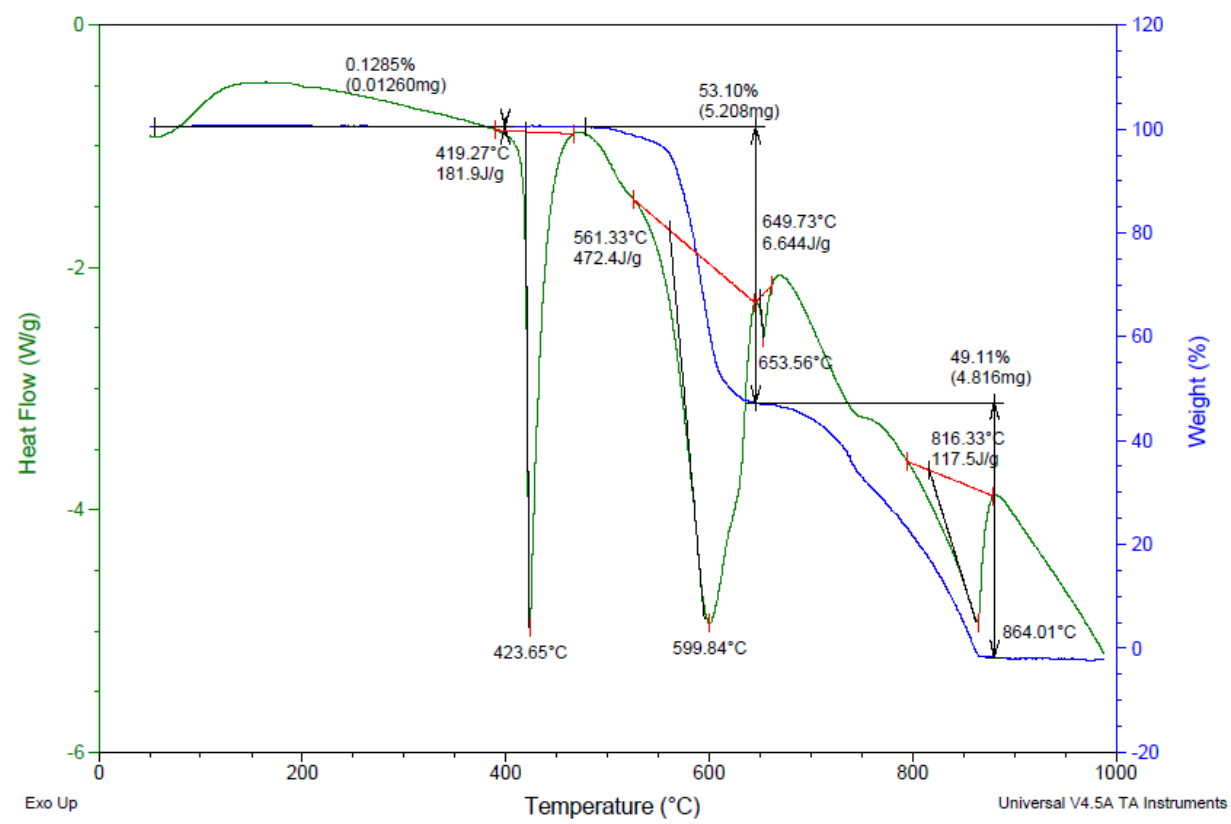

Figure 5.14. $\mathrm{NaIO}_{3}$ after 3 days $75 \% \mathrm{RH}$ at $60{ }^{\circ} \mathrm{C}$ 


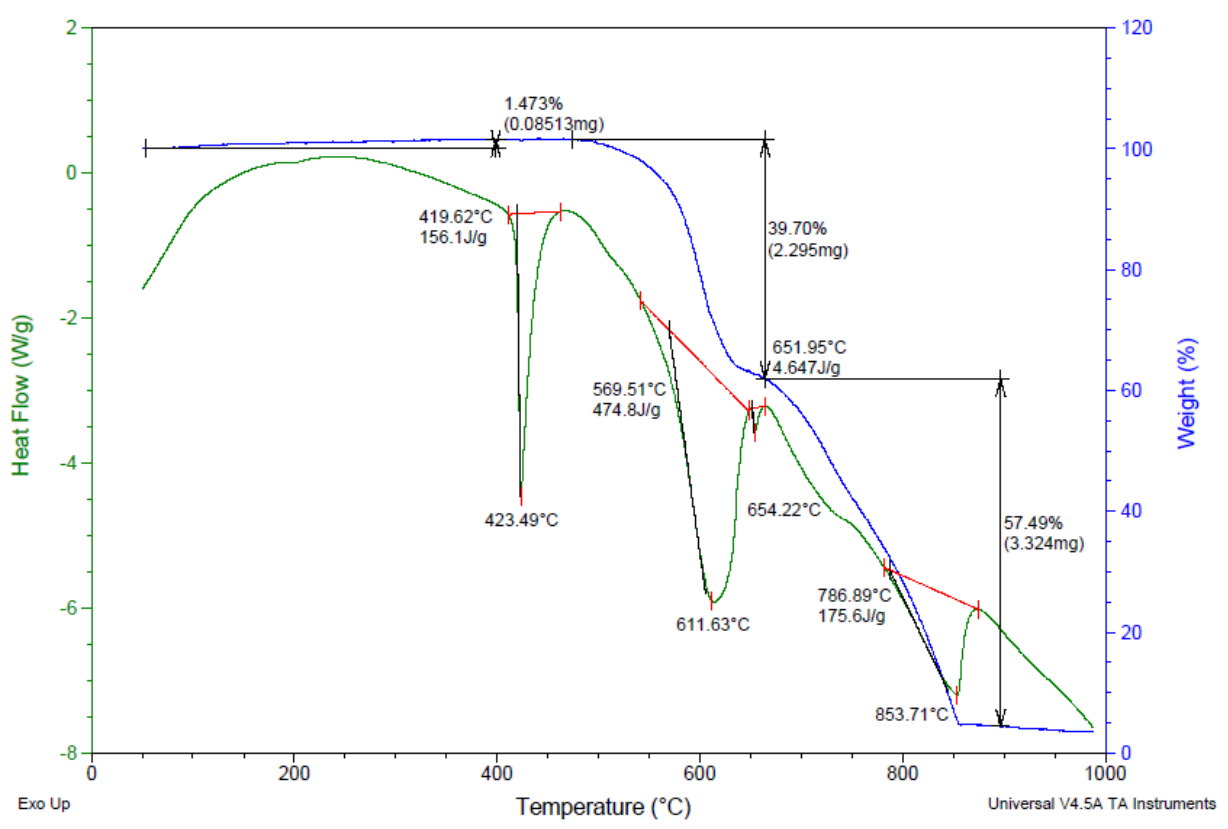

Figure 5.15. $\mathrm{NaIO}_{3}$ after 14 days $75 \% \mathrm{RH}$ at $60{ }^{\circ} \mathrm{C}$

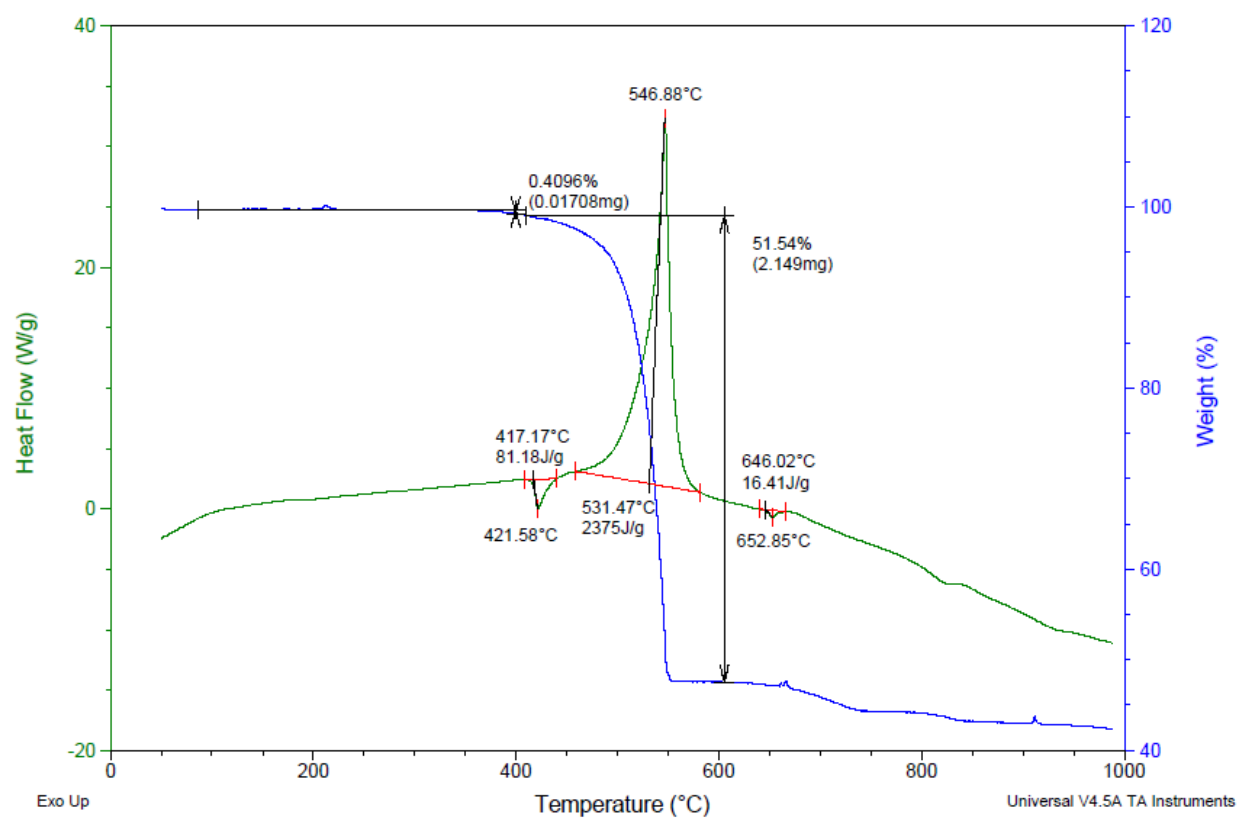

Figure 5.16. 80/10/10 $\mathrm{NaIO}_{3} / \mathrm{B}_{4} \mathrm{C} / \mathrm{Al}$ fresh mixture 


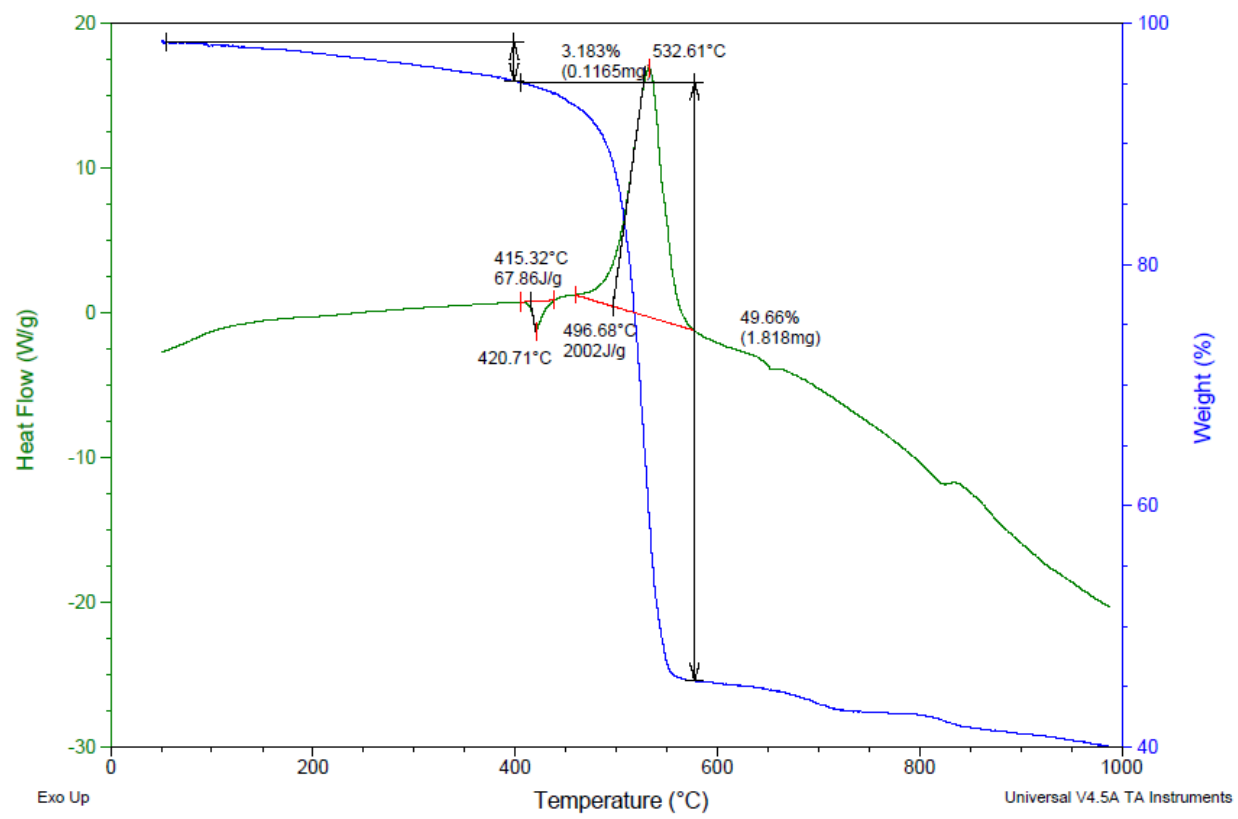

Figure 5.17. 80/10/10 $\mathrm{NaIO}_{3} / \mathrm{B}_{4} \mathrm{C} / \mathrm{Al}$ after 3 days $75 \% \mathrm{RH}$ at $60{ }^{\circ} \mathrm{C}$

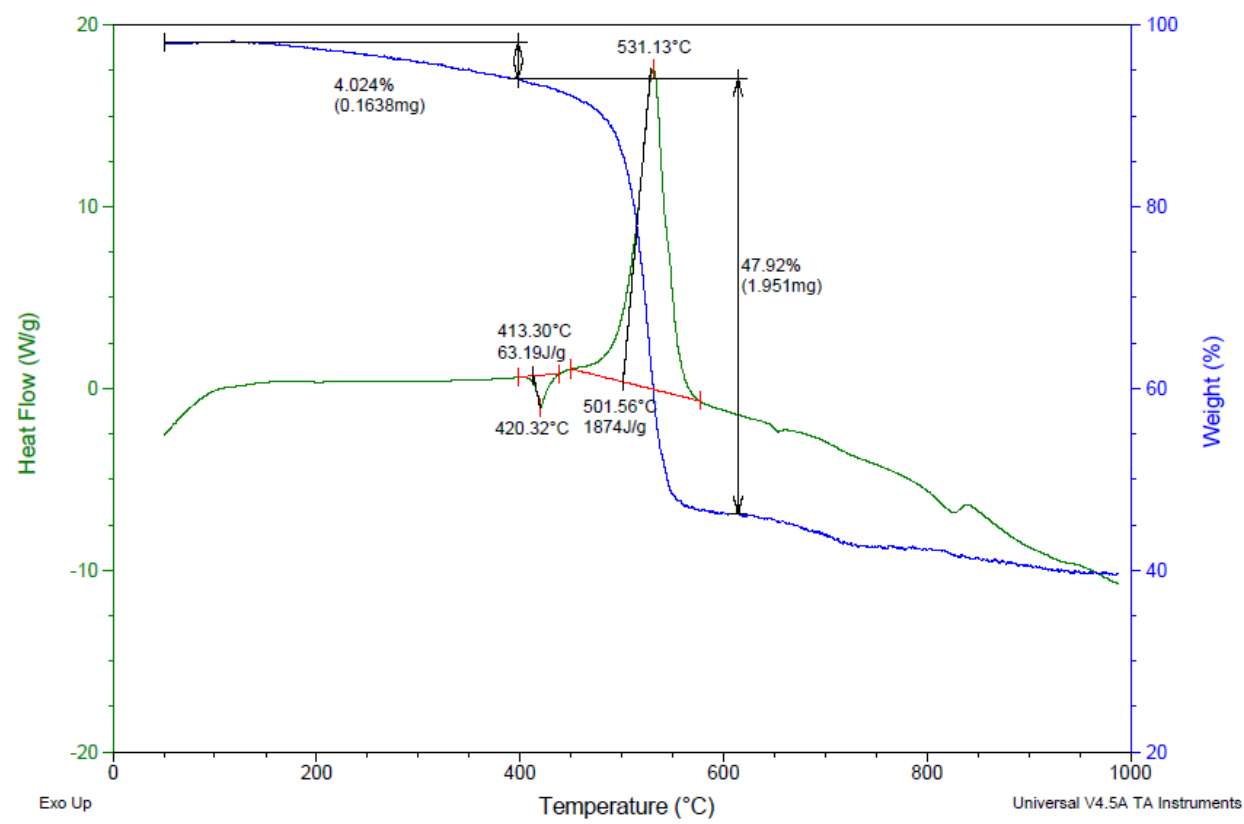

Figure 5.18. 80/10/10 $\mathrm{NaIO}_{3} / \mathrm{B}_{4} \mathrm{C} / \mathrm{Al}$ after 2 weeks $75 \% \mathrm{RH}$ at $60{ }^{\circ} \mathrm{C}$ (burns slower, decreased brightness) 


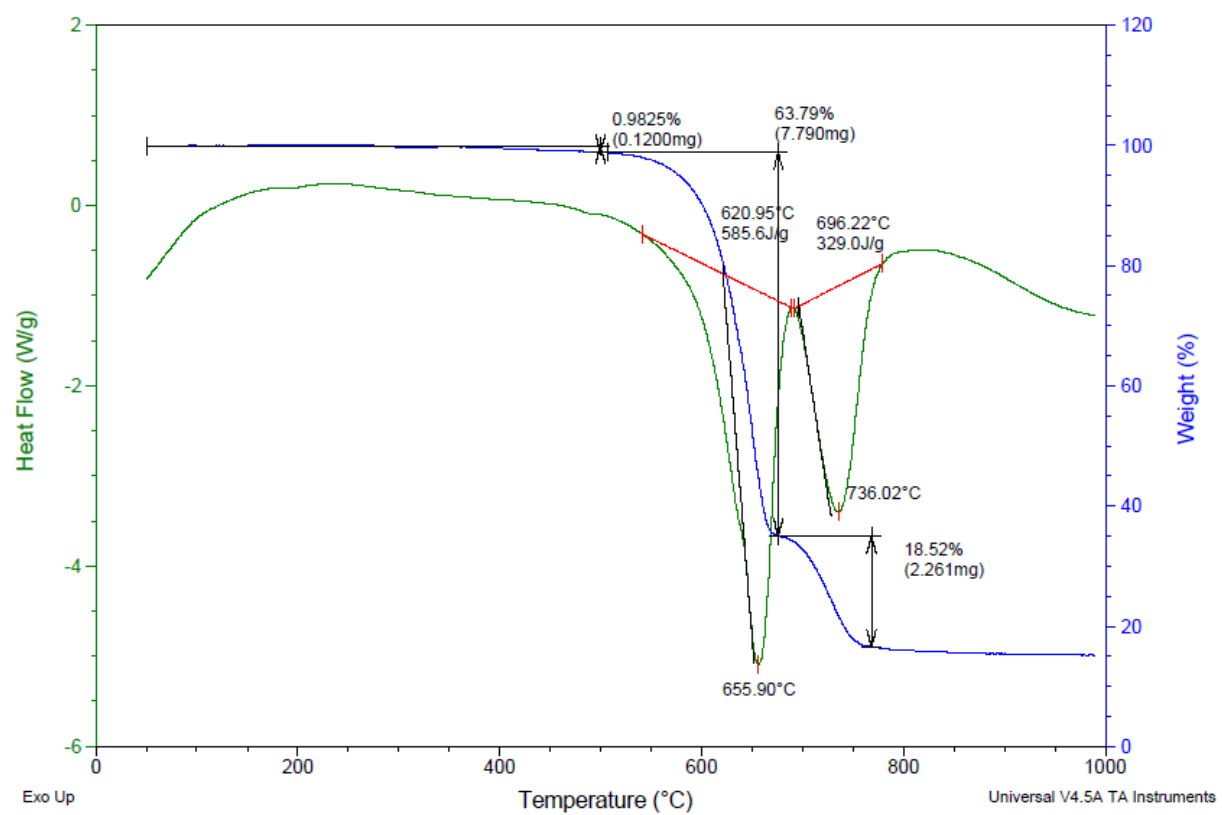

Figure 5.19. $\mathrm{Ca}\left(\mathrm{IO}_{3}\right)_{2}$ fresh

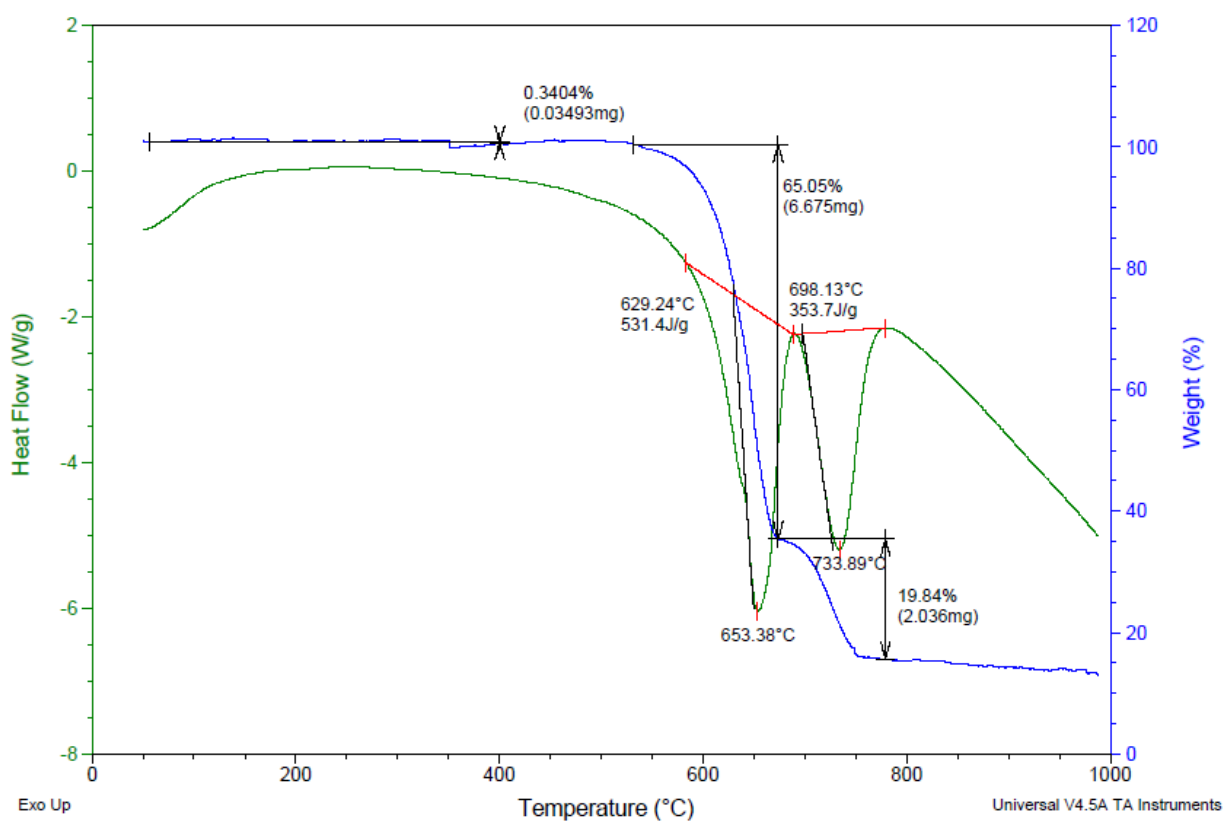

Figure 5.20. $\mathrm{Ca}\left(\mathrm{IO}_{3}\right)_{2}$ after 3 days $75 \% \mathrm{RH}$ at $60{ }^{\circ} \mathrm{C}$ 


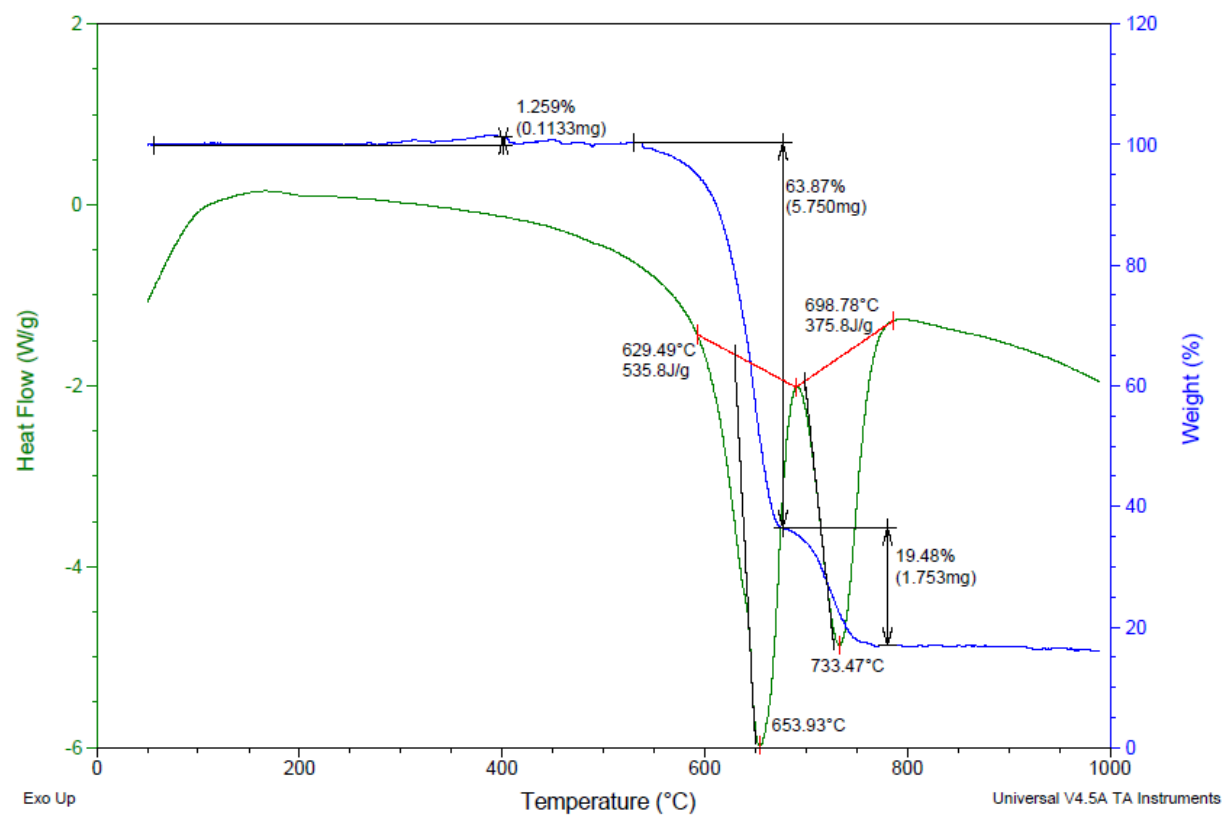

Figure 5.21. $\mathrm{Ca}\left(\mathrm{IO}_{3}\right)_{2}$ after 14 days $75 \% \mathrm{RH}$ at $60{ }^{\circ} \mathrm{C}$

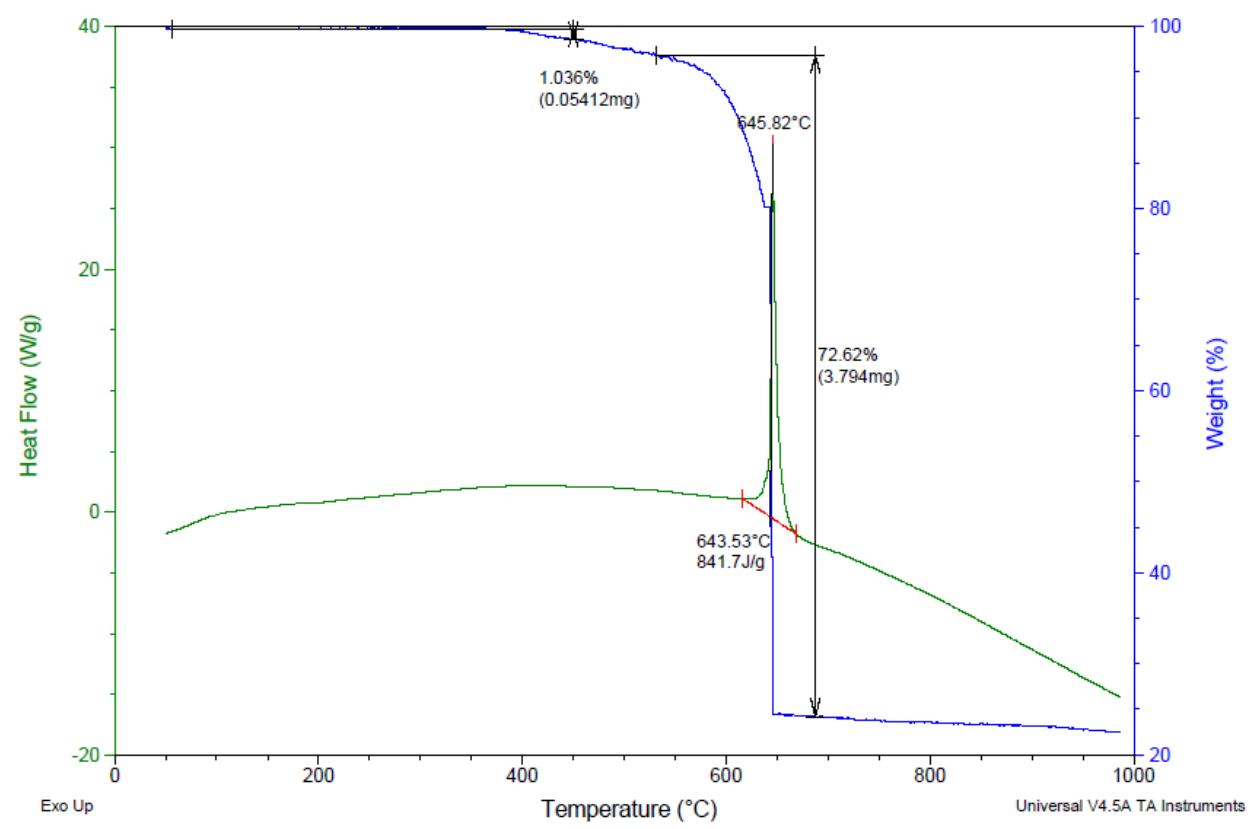

Figure 5.22. 75/25 $\mathrm{Ca}\left(\mathrm{IO}_{3}\right)_{2} / \mathrm{Al}$ fresh mixture 


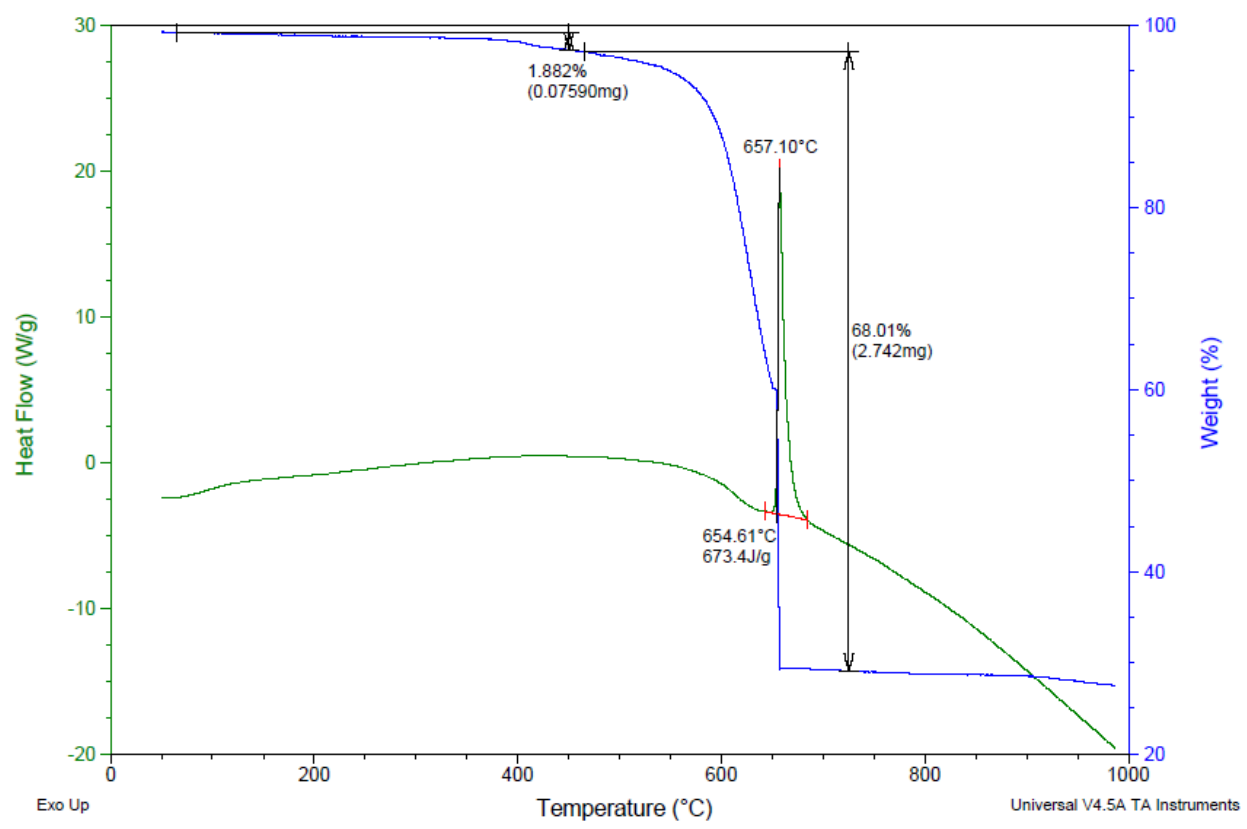

Figure 5.23. $75 / 25 \mathrm{Ca}\left(\mathrm{IO}_{3}\right)_{2} / \mathrm{Al}$ after 3 days $75 \% \mathrm{RH}$ at $60{ }^{\circ} \mathrm{C}$

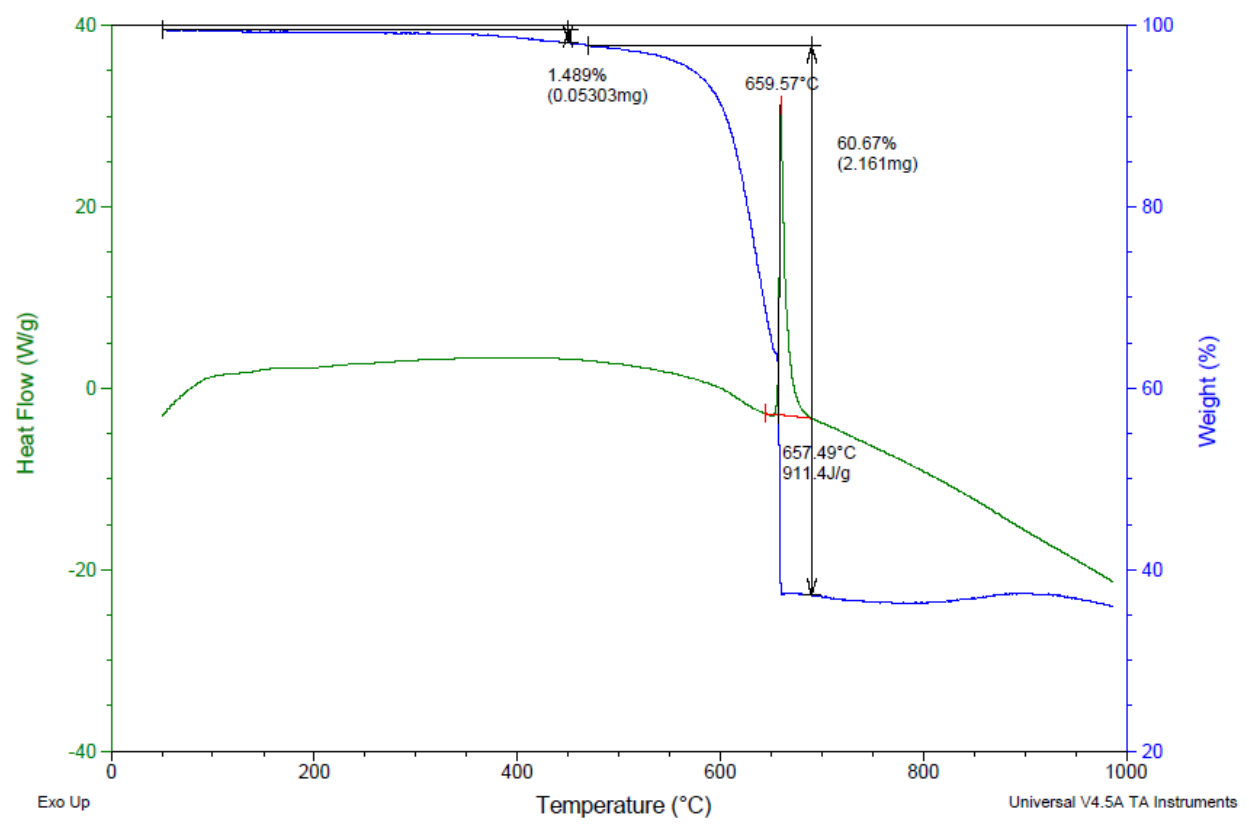

Figure 5.24. 75/25 $\mathrm{Ca}\left(\mathrm{IO}_{3}\right)_{2} / \mathrm{Al}$ after 14 days $75 \% \mathrm{RH}$ at $60{ }^{\circ} \mathrm{C}$ (burns with a bright flash and purple smoke) 


\section{IR from Aging Studies}

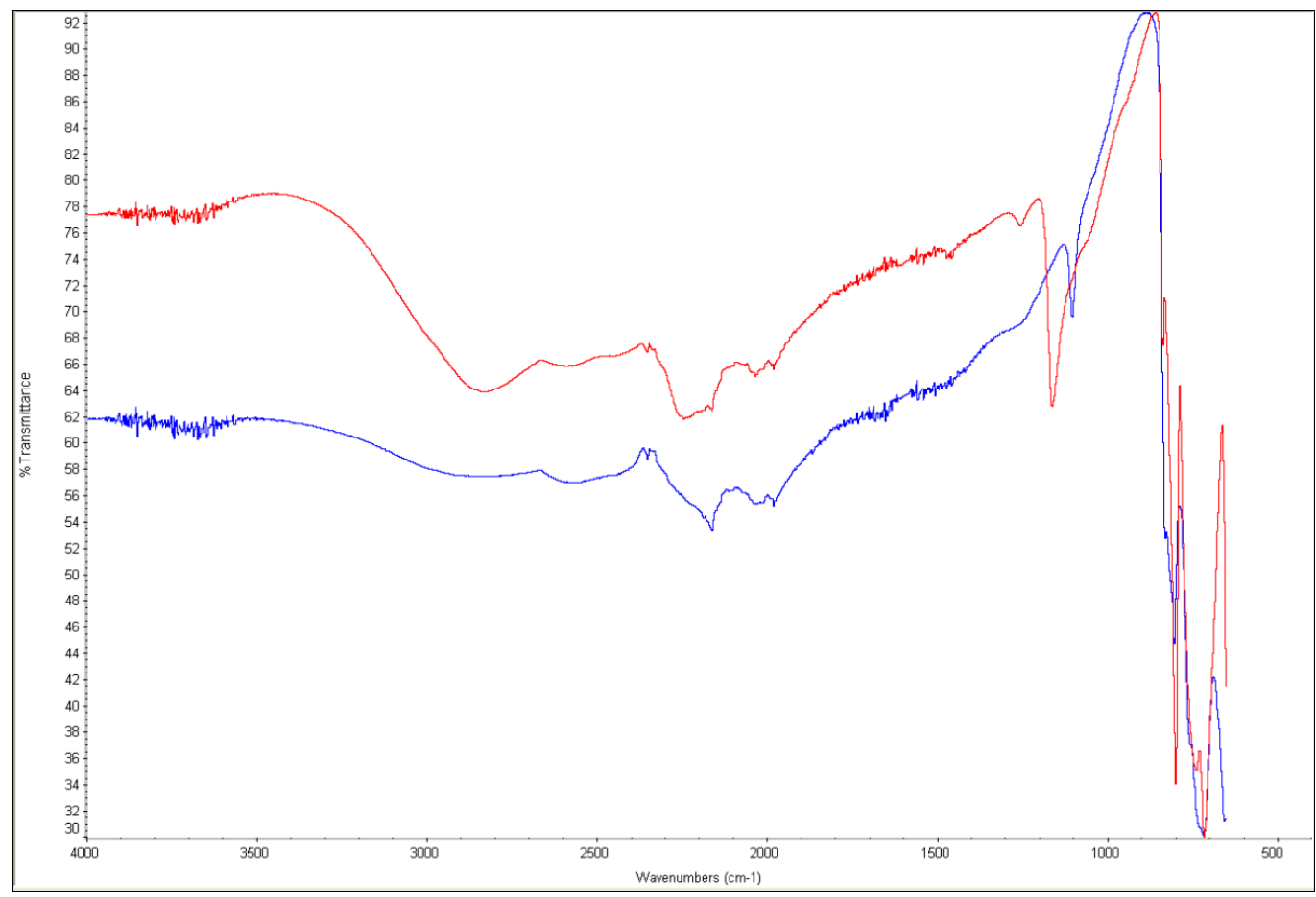

Figure 5.25. $\mathrm{I}_{2} \mathrm{O}_{5}$ fresh (blue) and after 3 days $75 \% \mathrm{RH}$ at $60{ }^{\circ} \mathrm{C}(\mathrm{red})$

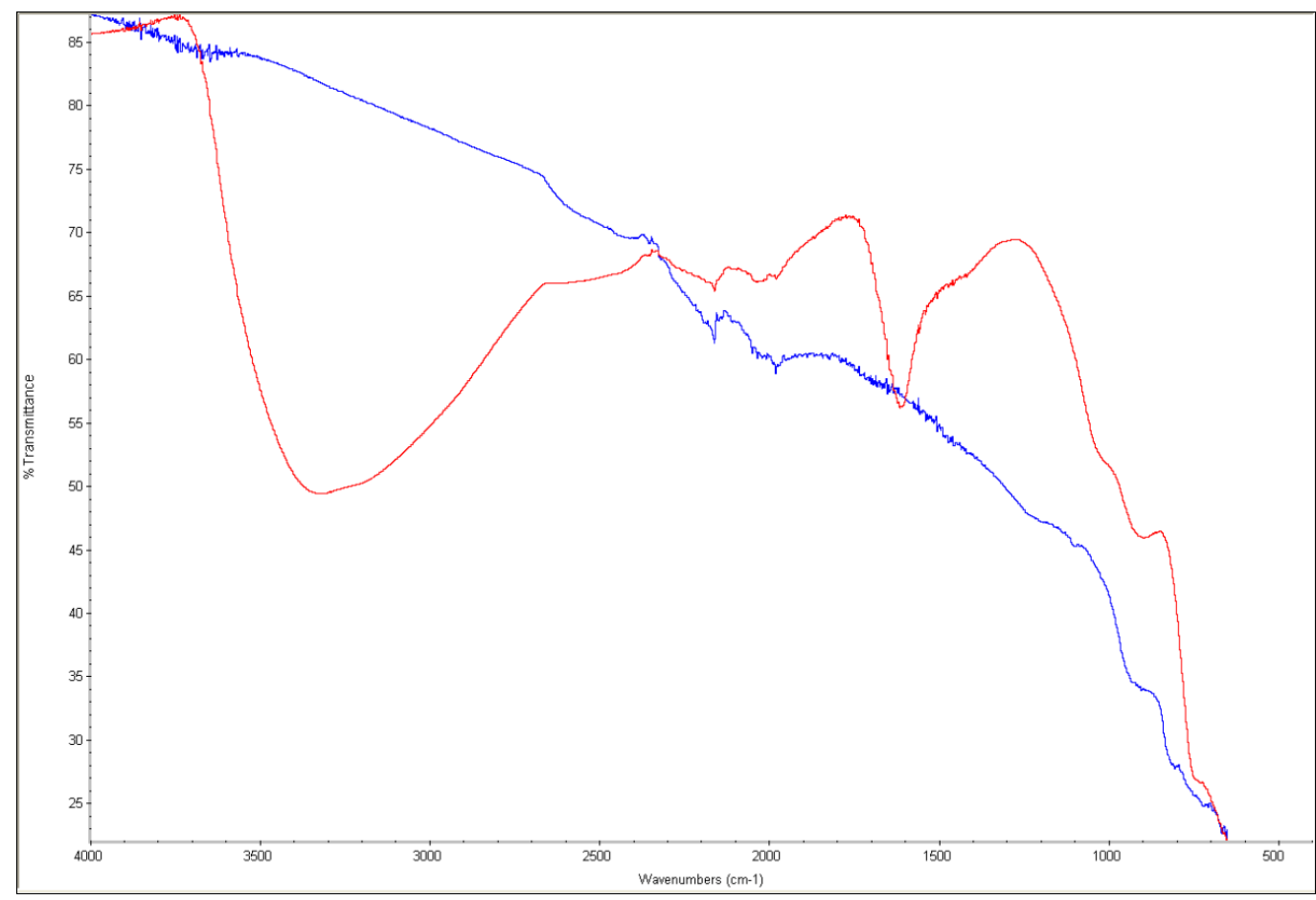

Figure 5.26. 80/20 $\mathrm{I}_{2} \mathrm{O}_{5} / \mathrm{Al}$ fresh (blue) and after 3 days $75 \% \mathrm{RH}$ at $60{ }^{\circ} \mathrm{C}$ (red) 


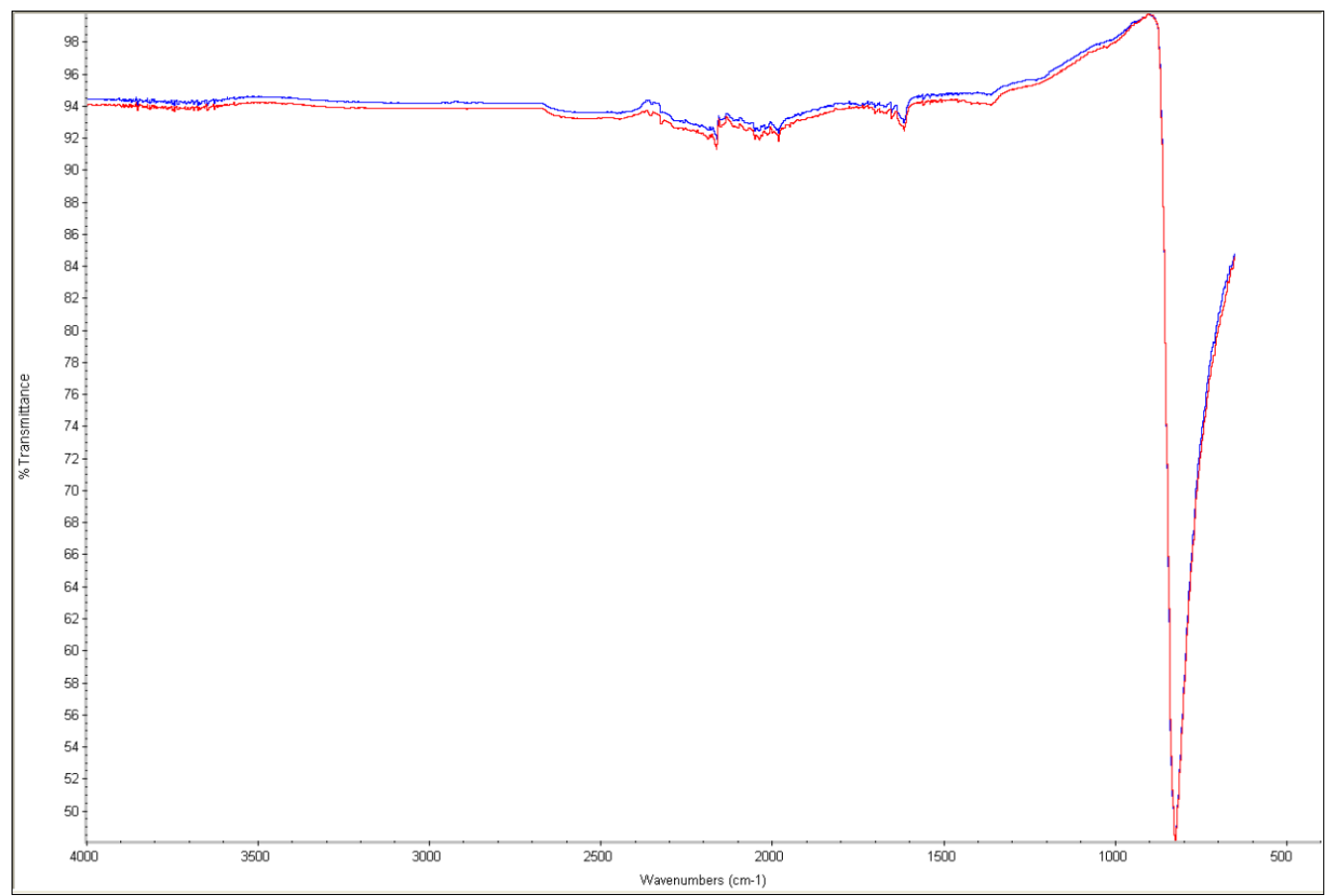

Figure 5.27. $\mathrm{NaIO}_{4}$ fresh (blue) and after 3 days $75 \% \mathrm{RH}$ at $60{ }^{\circ} \mathrm{C}$ (red)

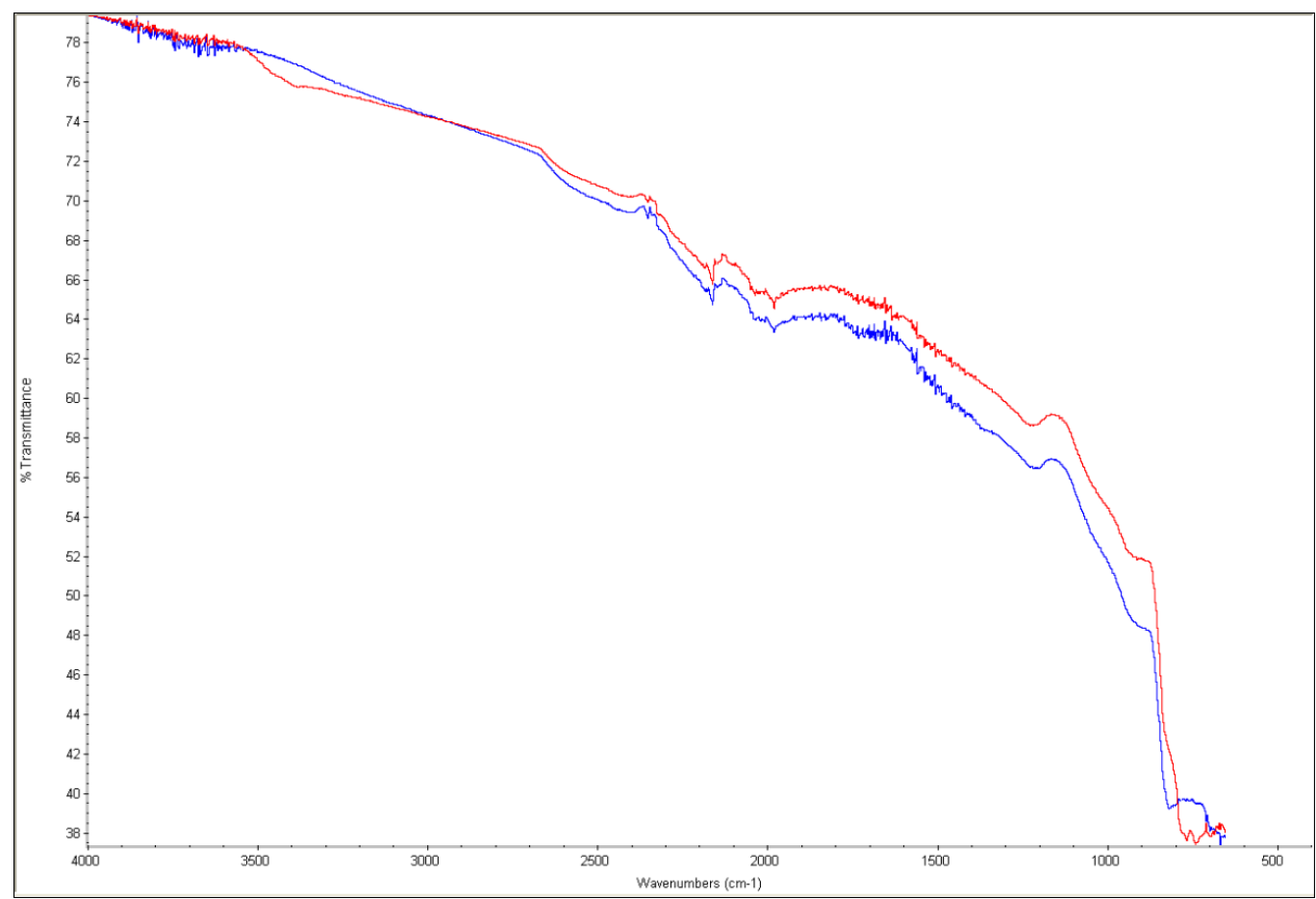

Figure 5.28. 80/10/10 $\mathrm{NaIO}_{4} / \mathrm{B}_{4} \mathrm{C} / \mathrm{Al}$ fresh (blue) and after 3 days $75 \% \mathrm{RH}$ at $60{ }^{\circ} \mathrm{C}$ (red) 


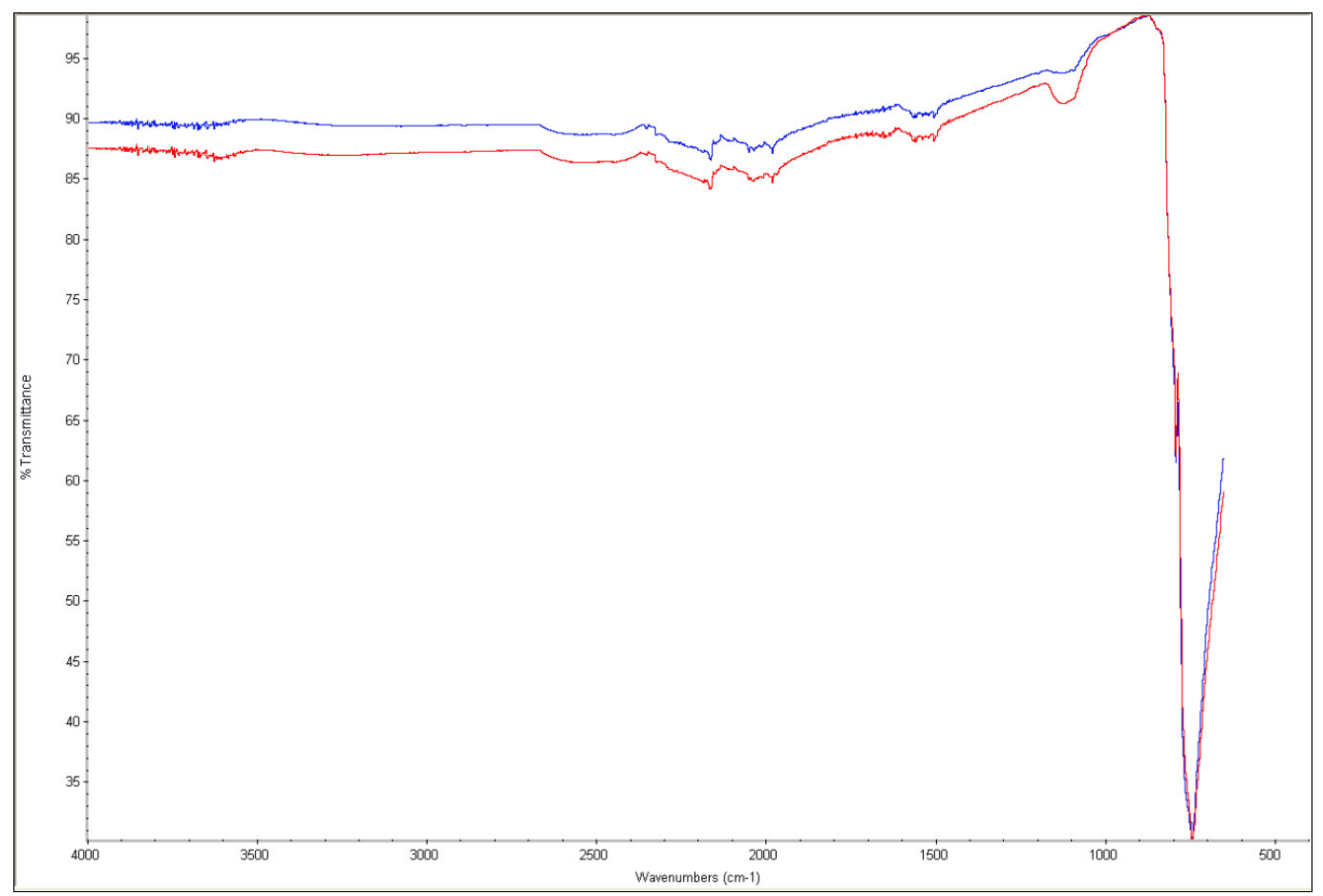

Figure 5.29. $\mathrm{NaIO}_{3}$ fresh (blue) and after 3 days $75 \% \mathrm{RH}$ at $60{ }^{\circ} \mathrm{C}$ (red)

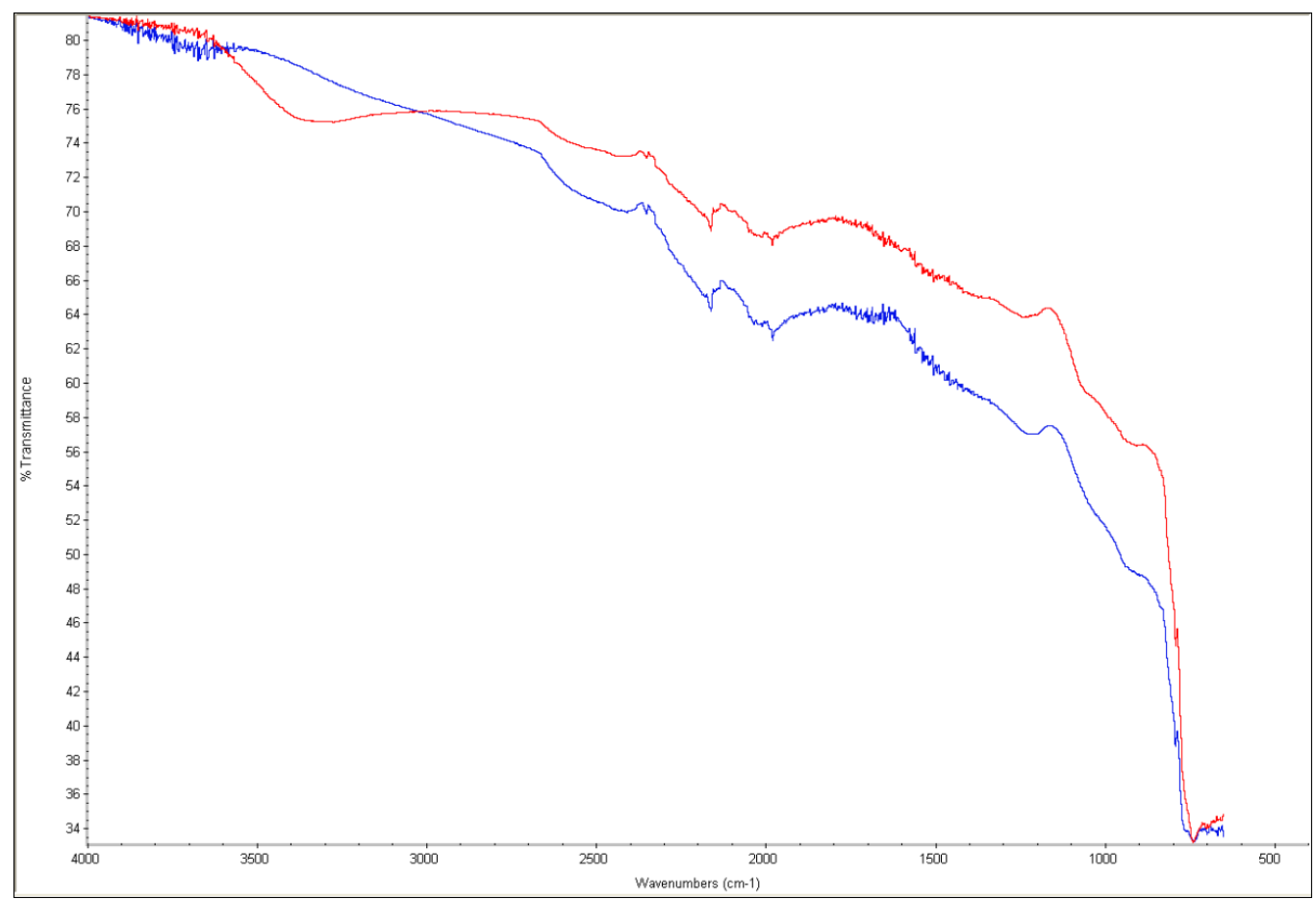

Figure 5.30. 80/10/10 $\mathrm{NaIO}_{3} / \mathrm{B}_{4} \mathrm{C} / \mathrm{Al}$ fresh (blue) and after 3 days $75 \% \mathrm{RH}$ at $60{ }^{\circ} \mathrm{C}$ (red) 


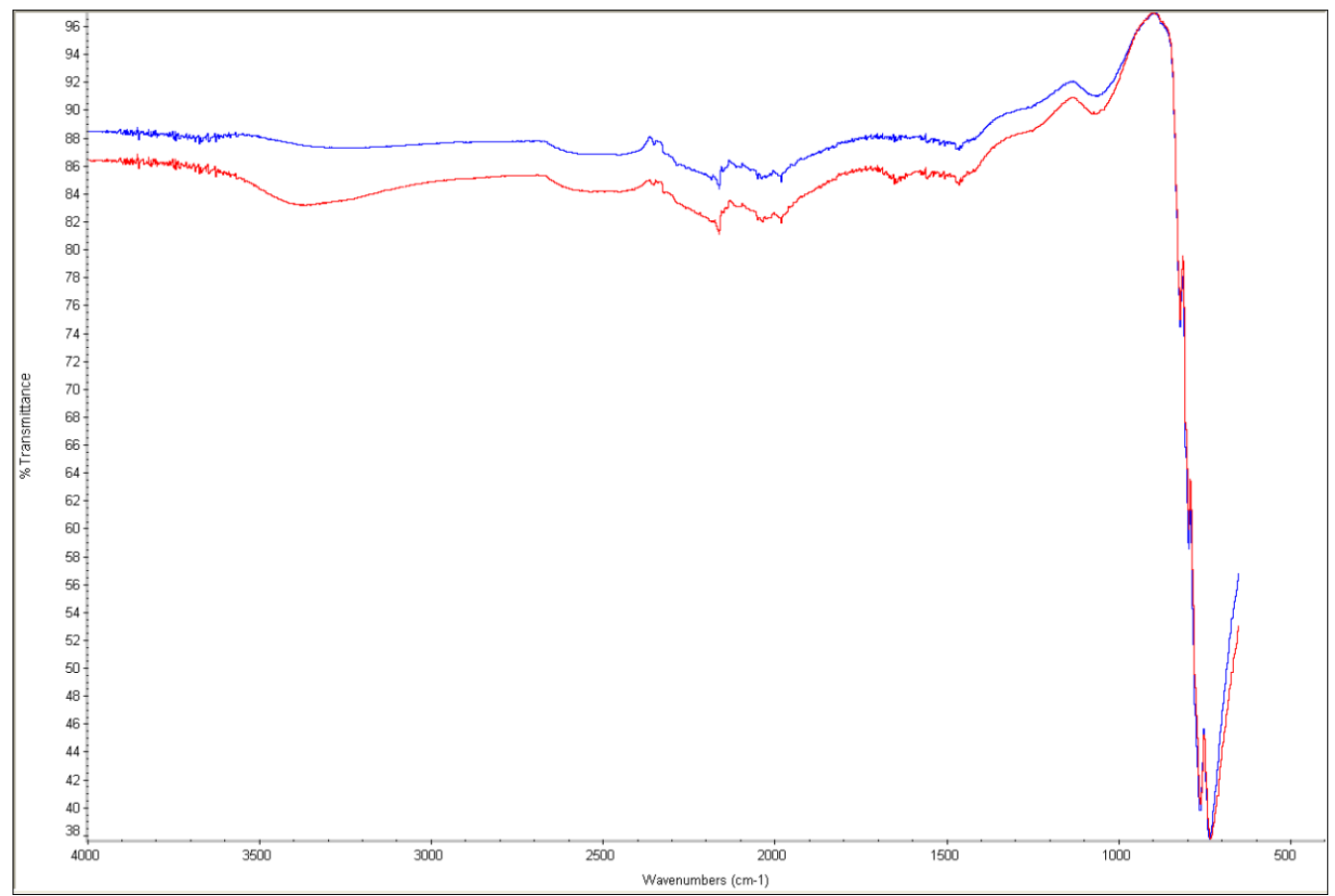

Figure 5.31. $\mathrm{Ca}\left(\mathrm{IO}_{3}\right)_{2}$ fresh (blue) and after 3 days $75 \% \mathrm{RH}$ at $60{ }^{\circ} \mathrm{C}$ (red)

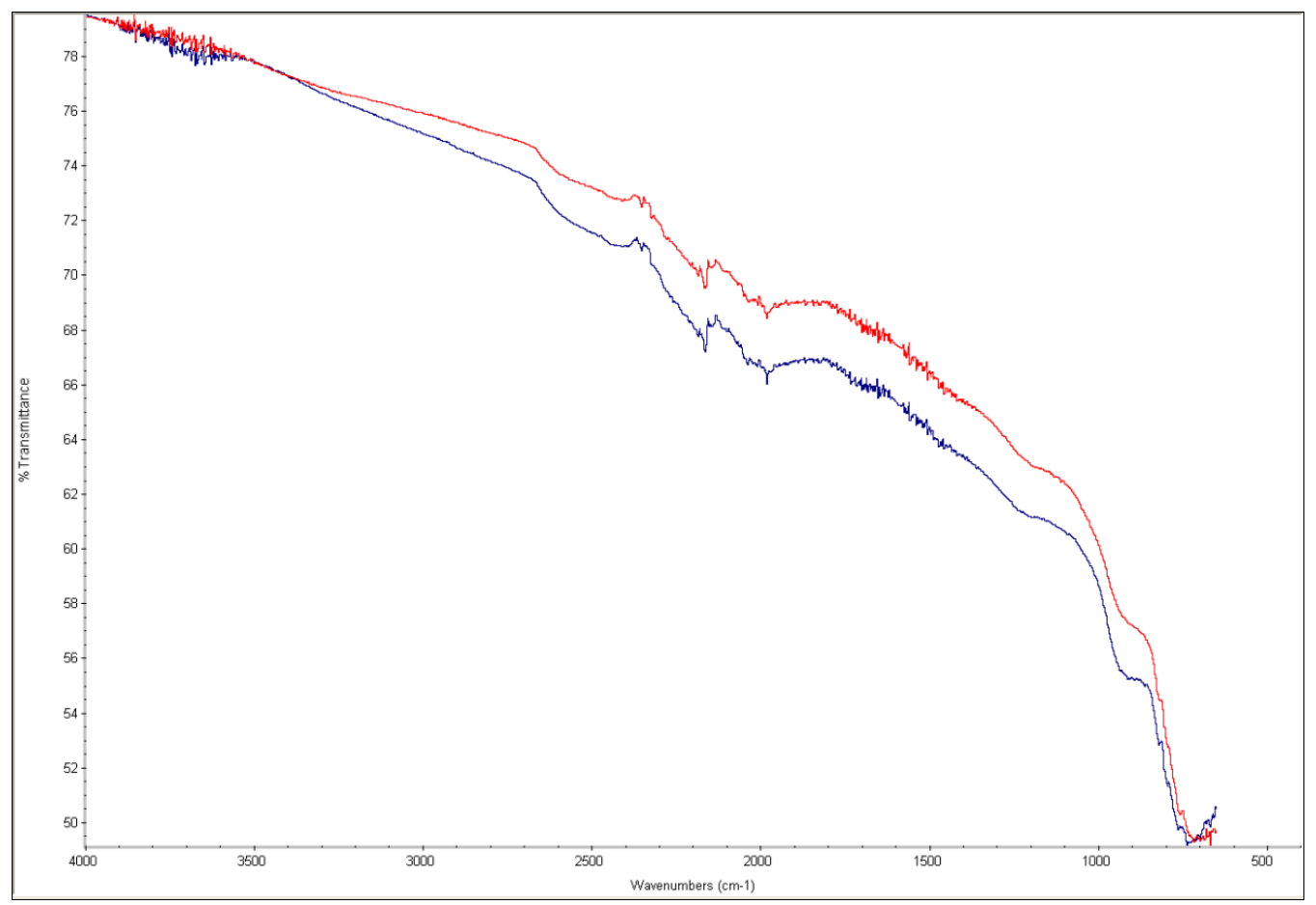

Figure 5.32. 75/25 $\mathrm{Ca}\left(\mathrm{IO}_{3}\right)_{2} / \mathrm{Al}$ fresh (blue) and after 3 days $75 \% \mathrm{RH}$ at $60{ }^{\circ} \mathrm{C}$ (red) 


\section{UV-Vis Data}

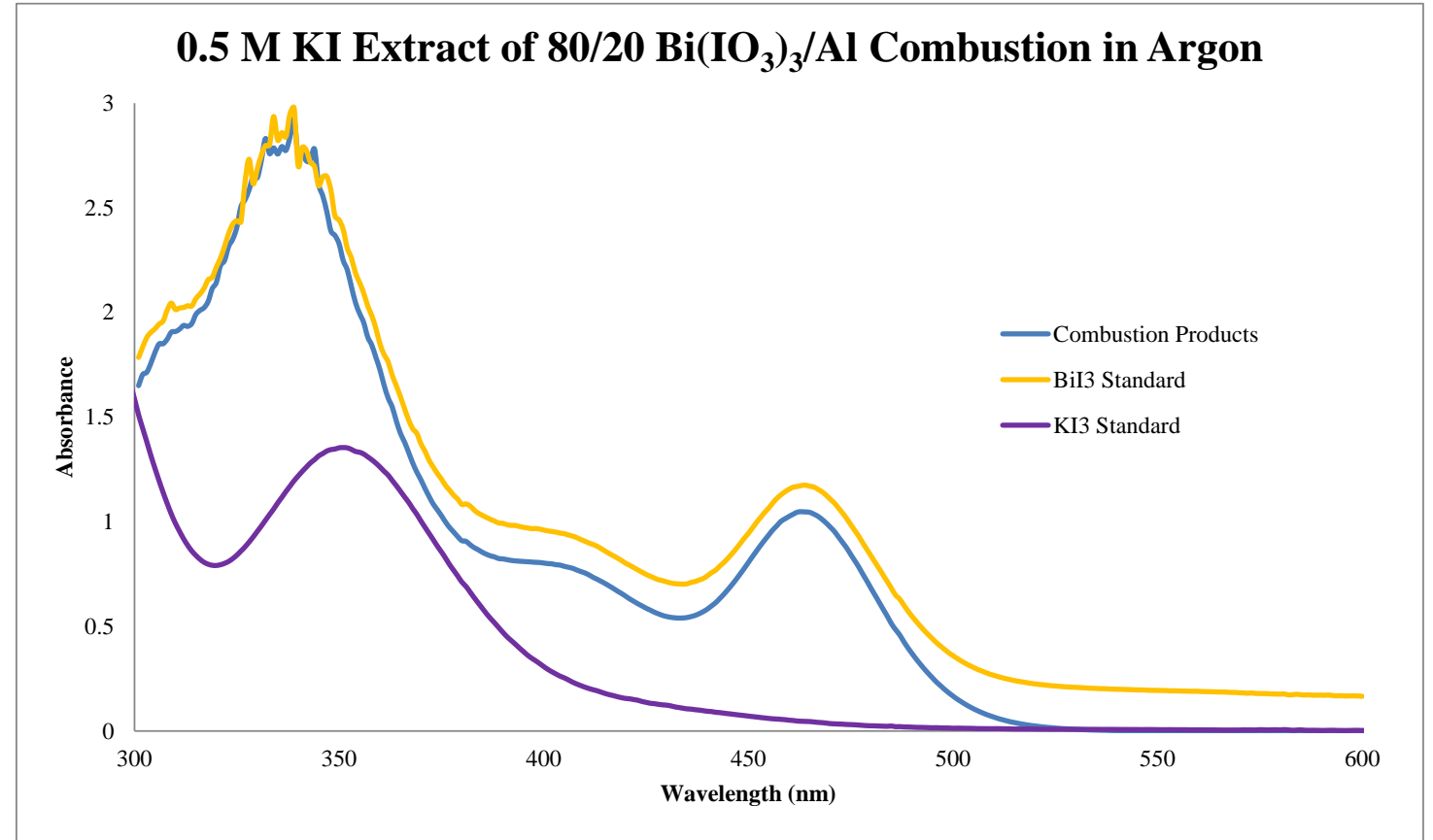

Figure 5.33. 0.5 M KI extraction of $80 / 20 \mathrm{Bi}\left(\mathrm{IO}_{3}\right)_{3} / \mathrm{Al}$ combustion products compared to a $\mathrm{BiI}_{3}$ standard and a standard curve made with $\mathrm{KI}$ and $\mathrm{I}_{2}\left(\mathrm{KI}_{3}\right)$

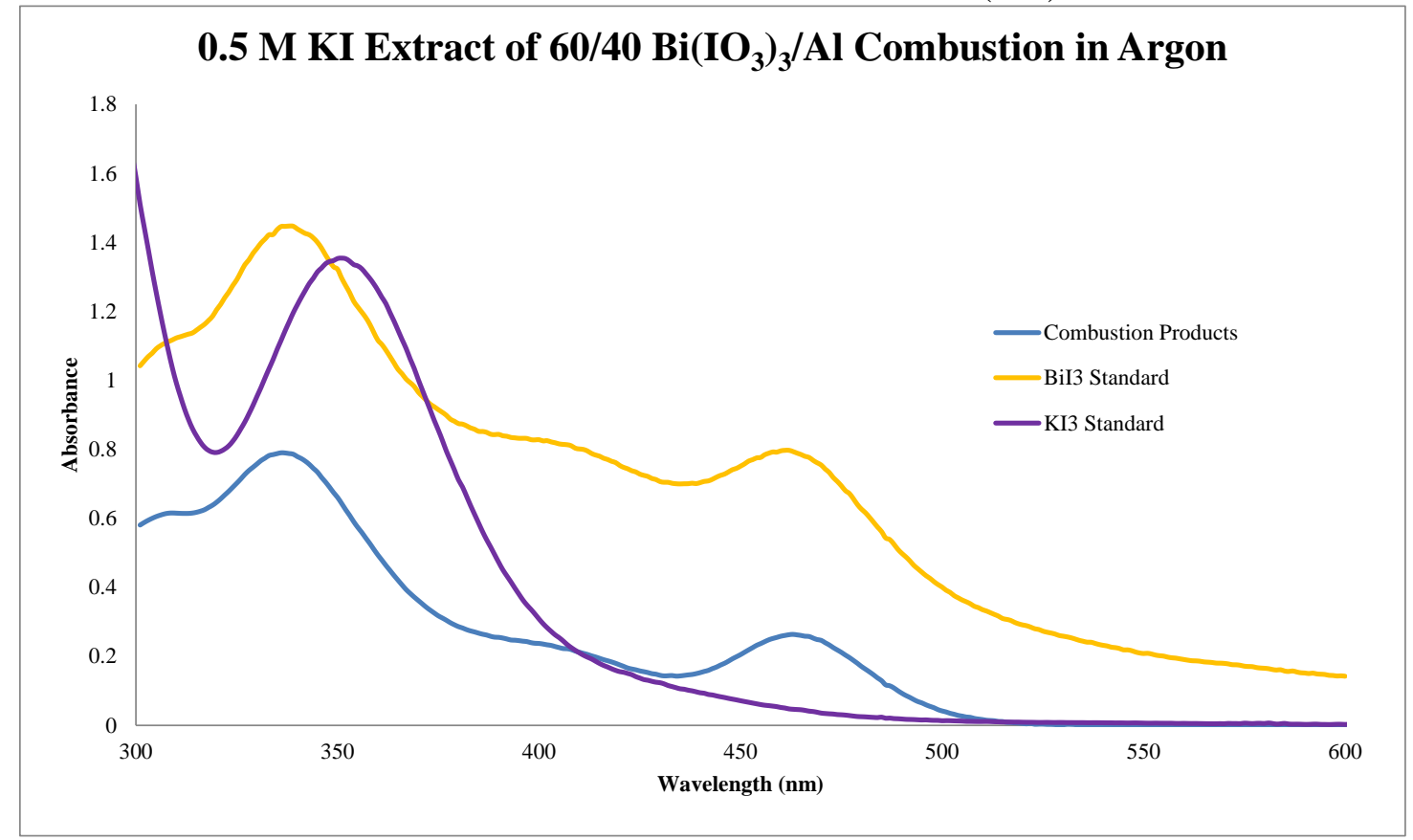

Figure 5.34. 0.5 M KI extraction of $60 / 40 \mathrm{Bi}\left(\mathrm{IO}_{3}\right)_{3} / \mathrm{Al}$ combustion products compared to a $\mathrm{BiI}_{3}$ standard and a standard curve made with $\mathrm{KI}$ and $\mathrm{I}_{2}\left(\mathrm{KI}_{3}\right)$ 


\section{SDT Data of Other Fresh Mixtures}

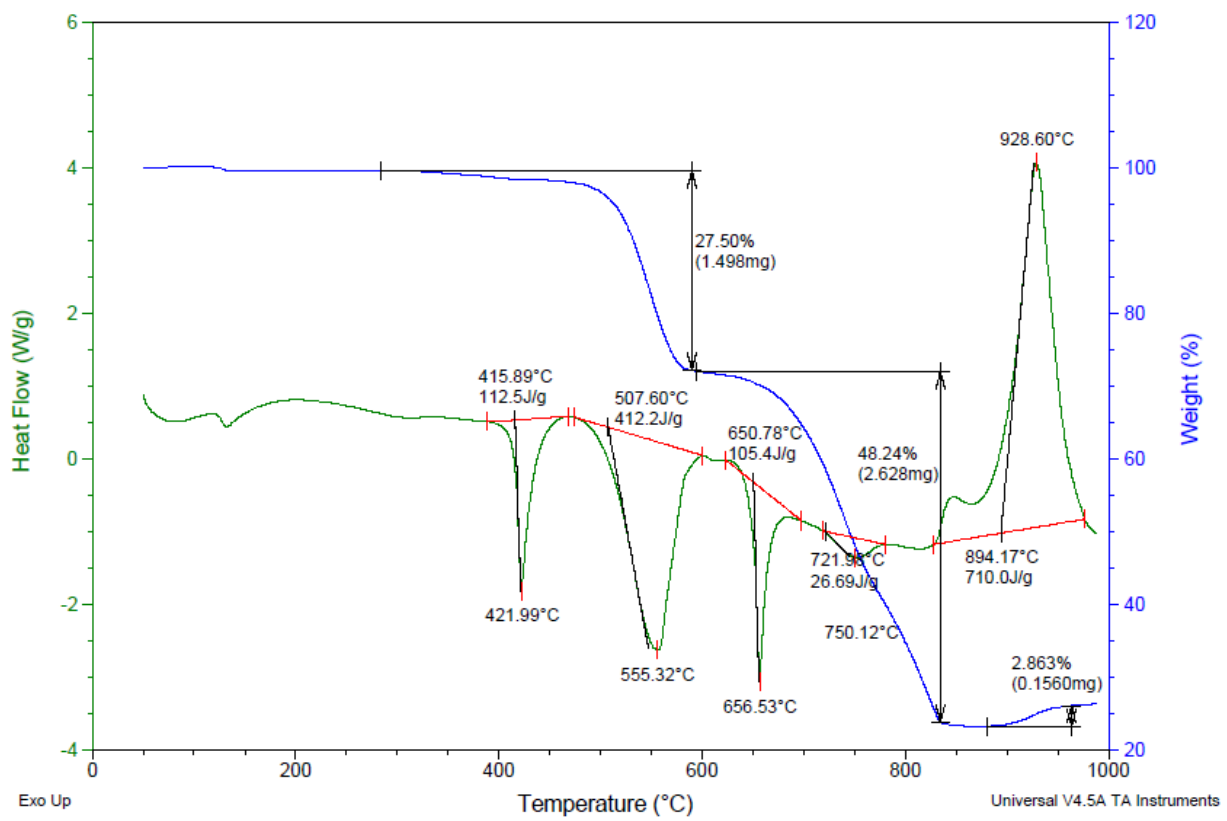

Figure 5.35. 80/20 $\mathrm{NaIO}_{3} / \mathrm{Al}$

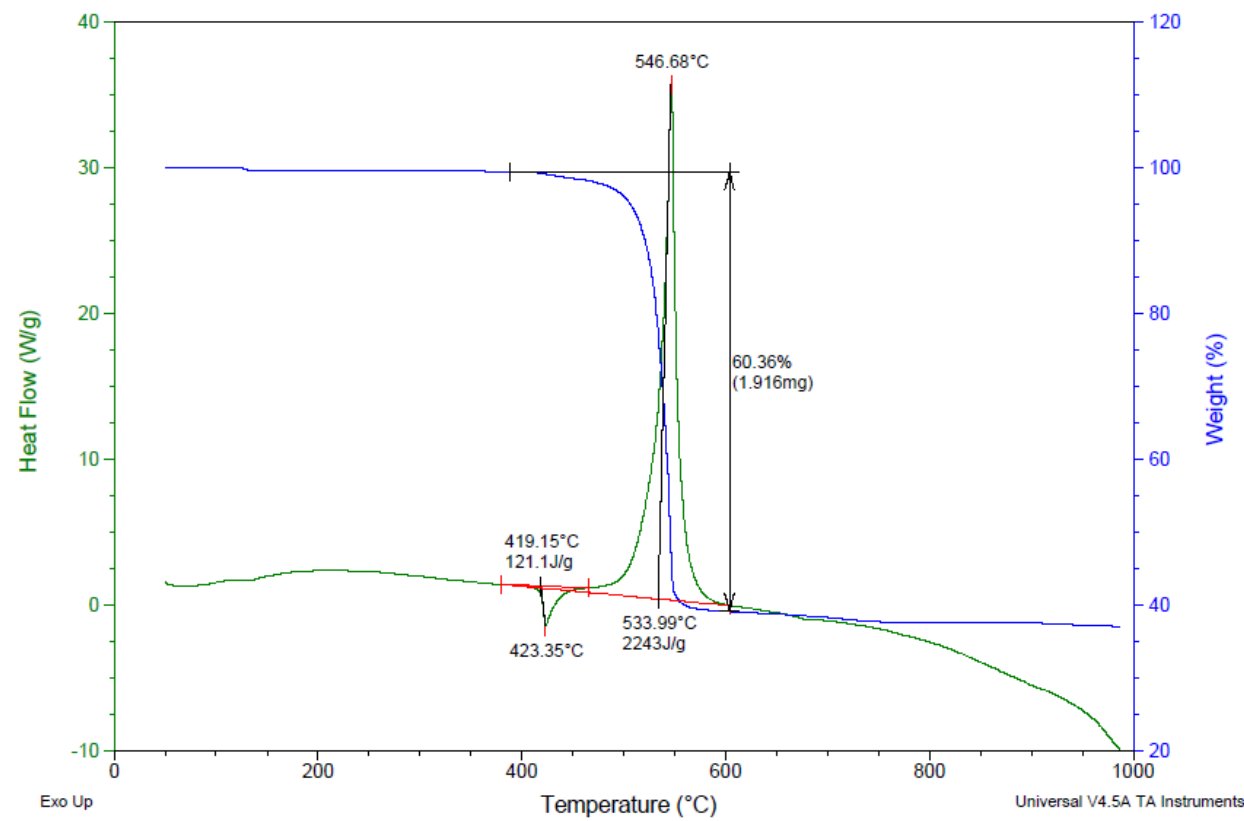

Figure 5.36. $80 / 20 \mathrm{NaIO}_{3} / \mathrm{B}_{4} \mathrm{C}$ 


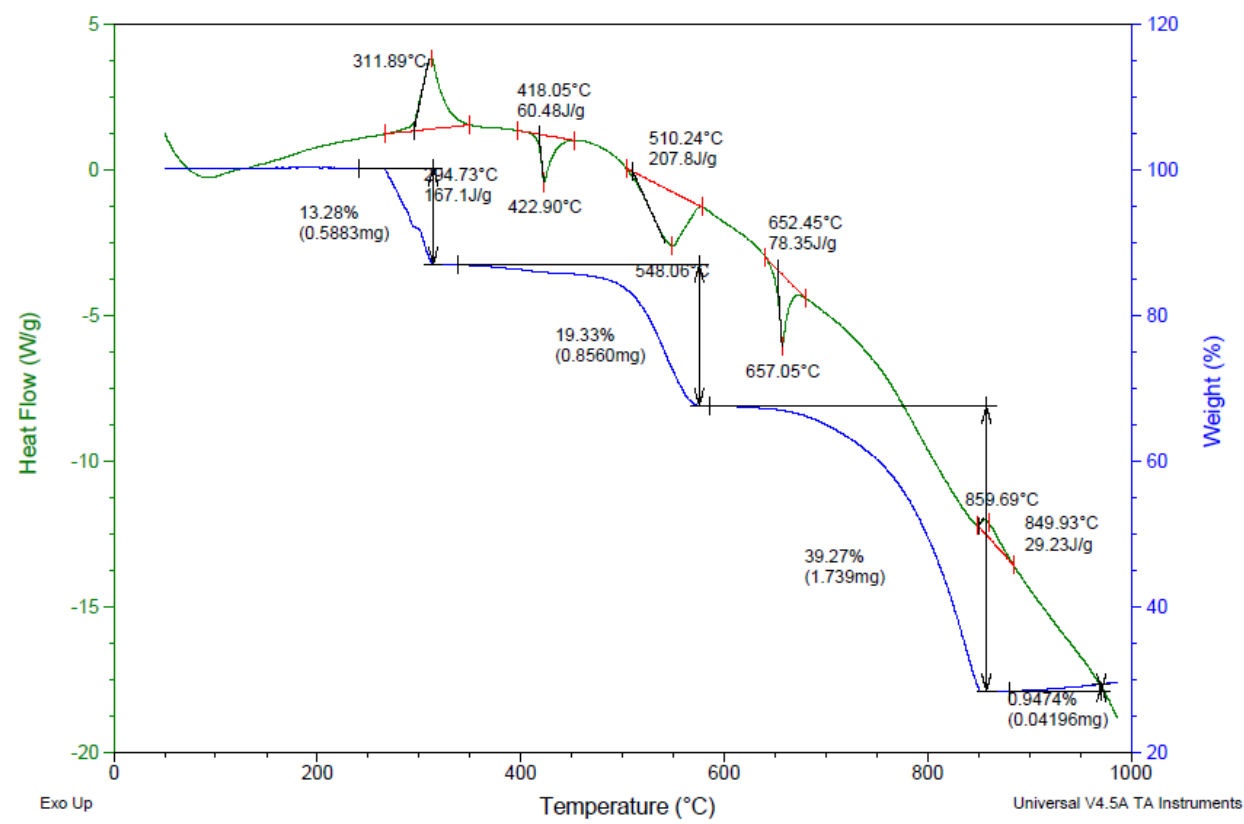

Figure 5.37. 80/20 $\mathrm{NaIO}_{4} / \mathrm{Al}$

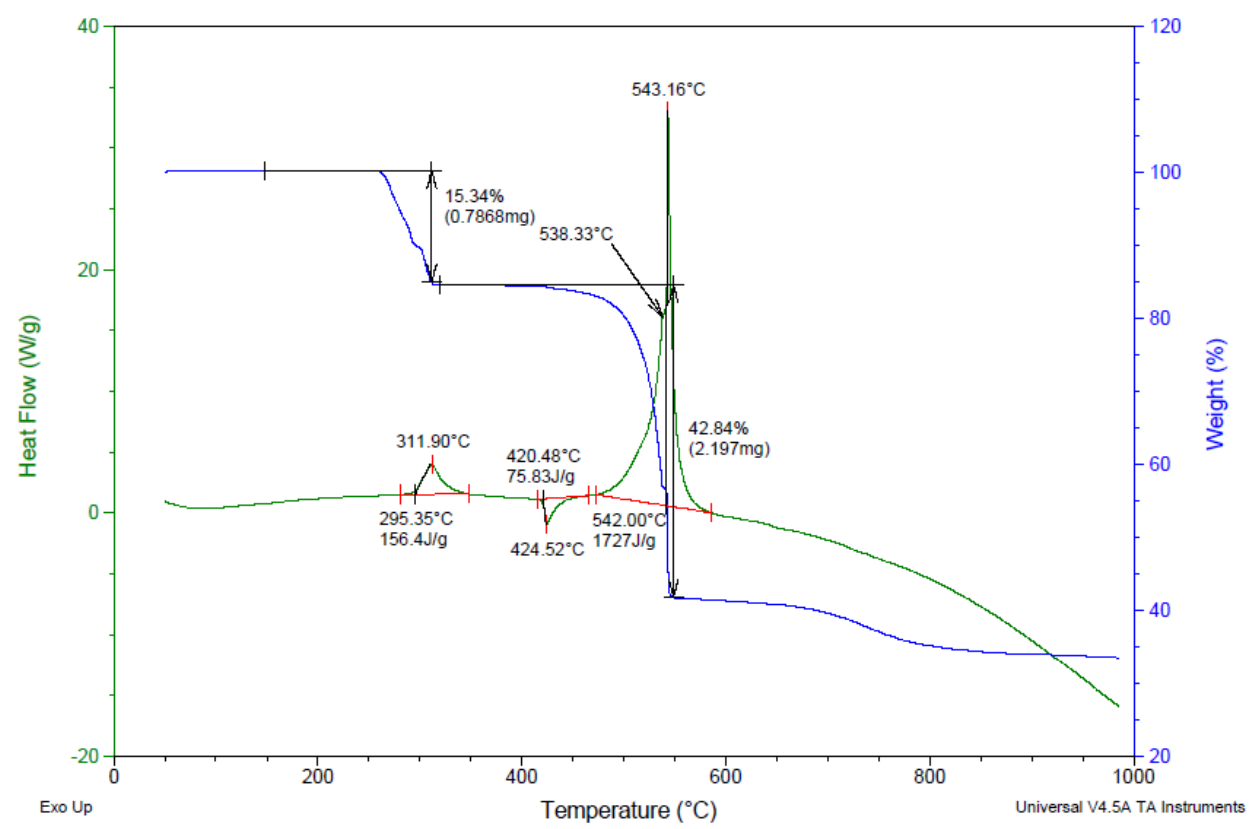

Figure 5.38. 80/20 $\mathrm{NaIO}_{4} / \mathrm{B}_{4} \mathrm{C}$ 


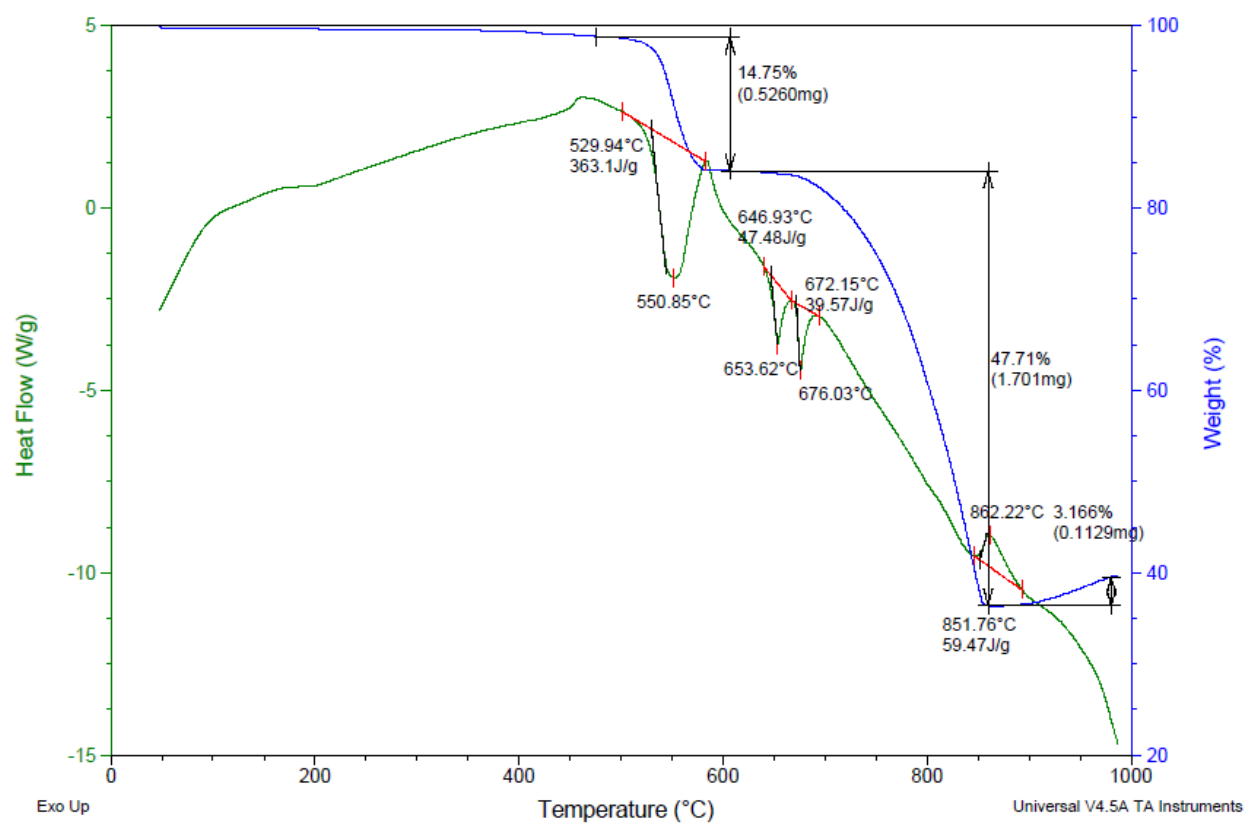

Figure 5.39. 80/20 $\mathrm{KIO}_{3} / \mathrm{Al}$

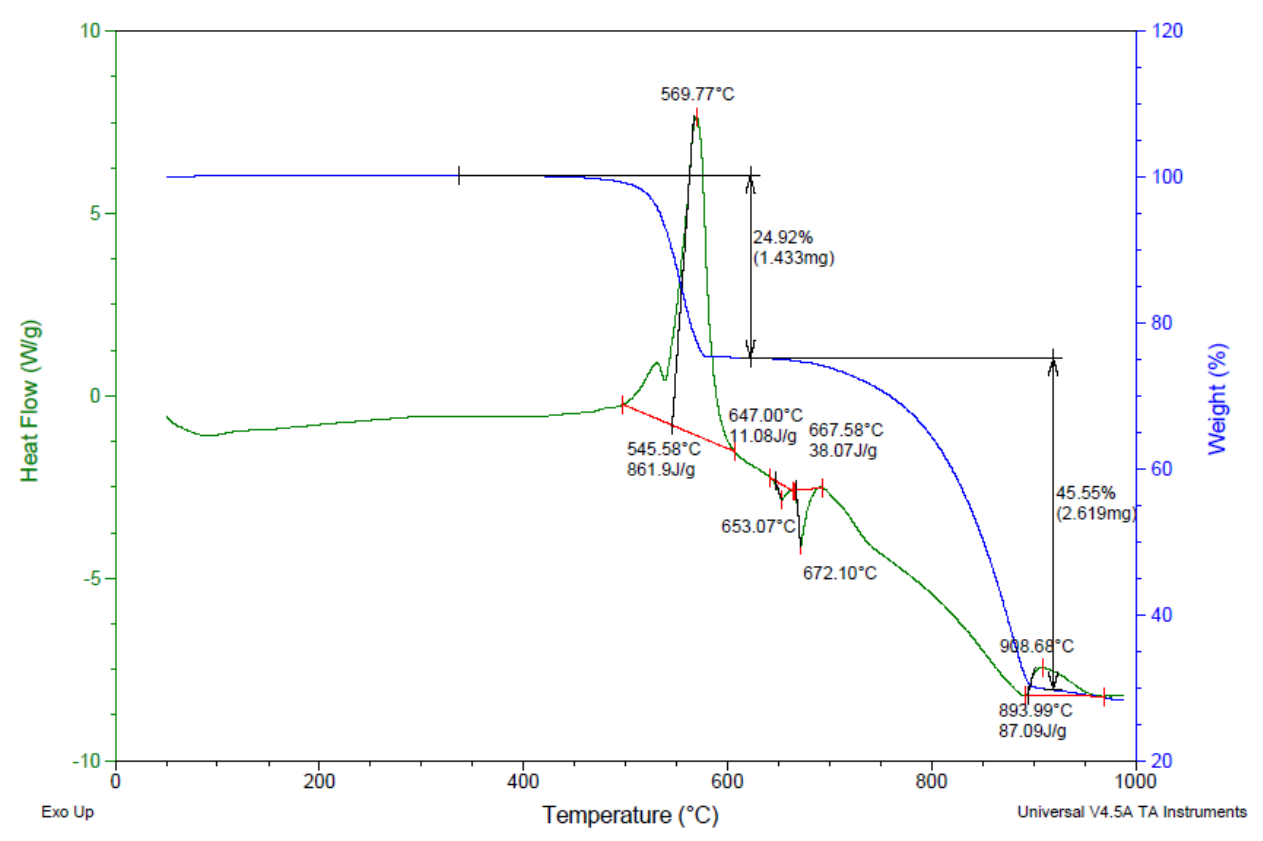

Figure 5.40. 80/10/10 $\mathrm{KIO}_{3} / \mathrm{B}_{4} \mathrm{C} / \mathrm{Al}$ 


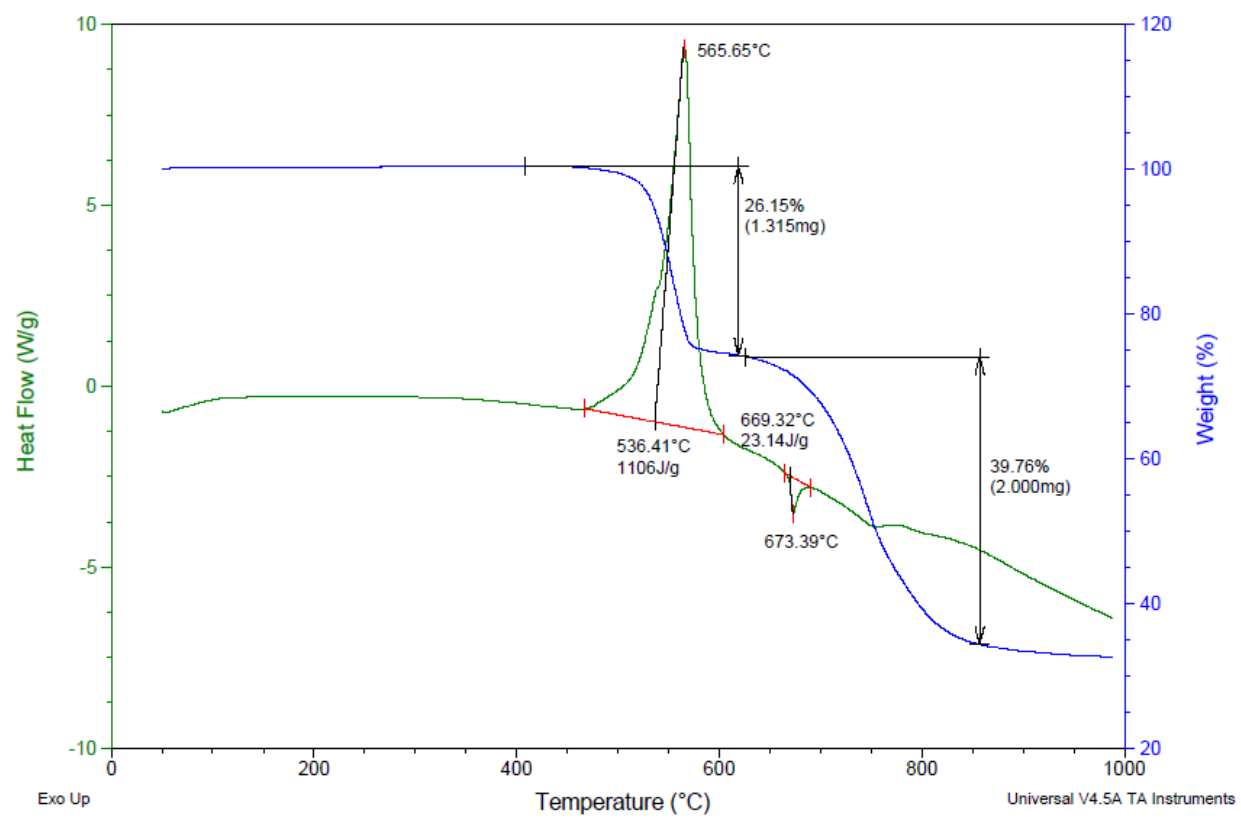

Figure 5.41. 80/20 $\mathrm{KIO}_{3} / \mathrm{B}_{4} \mathrm{C}$

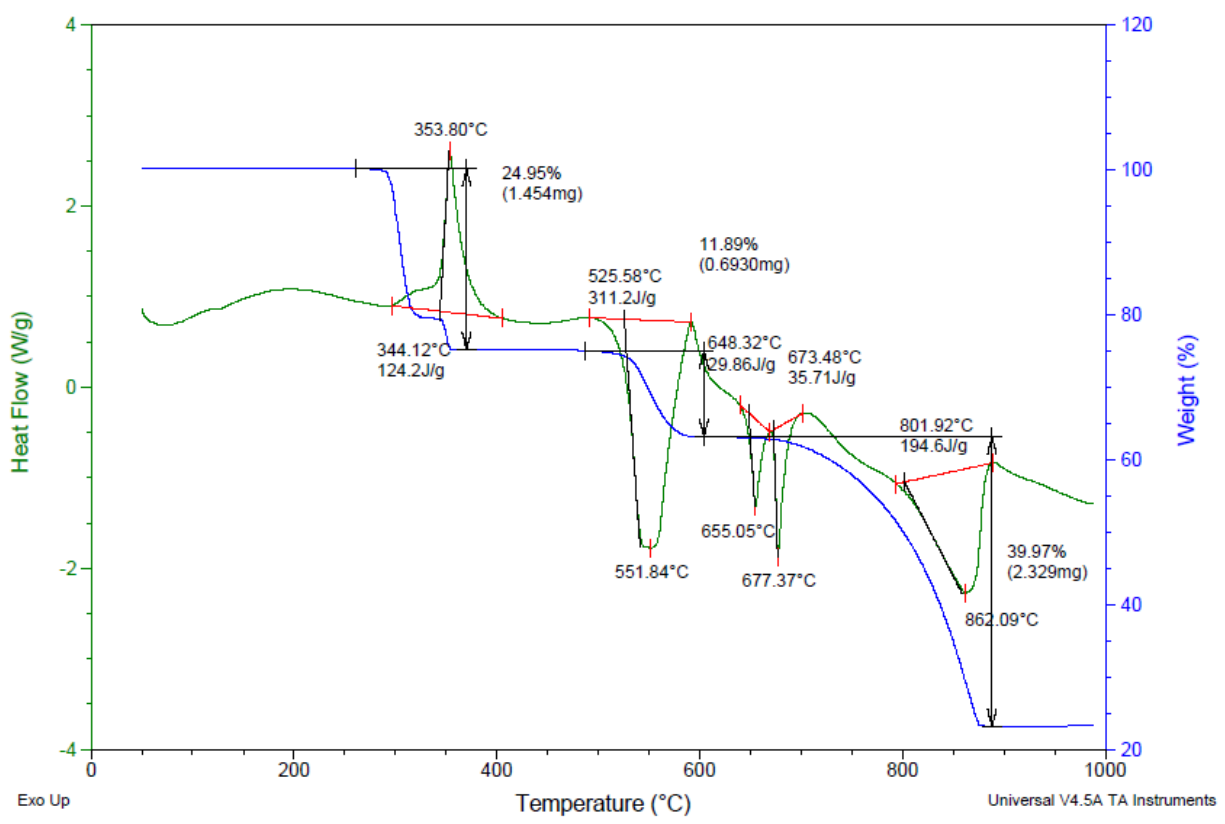

Figure 5.42. 80/20 $\mathrm{KIO}_{4} / \mathrm{Al}$ 


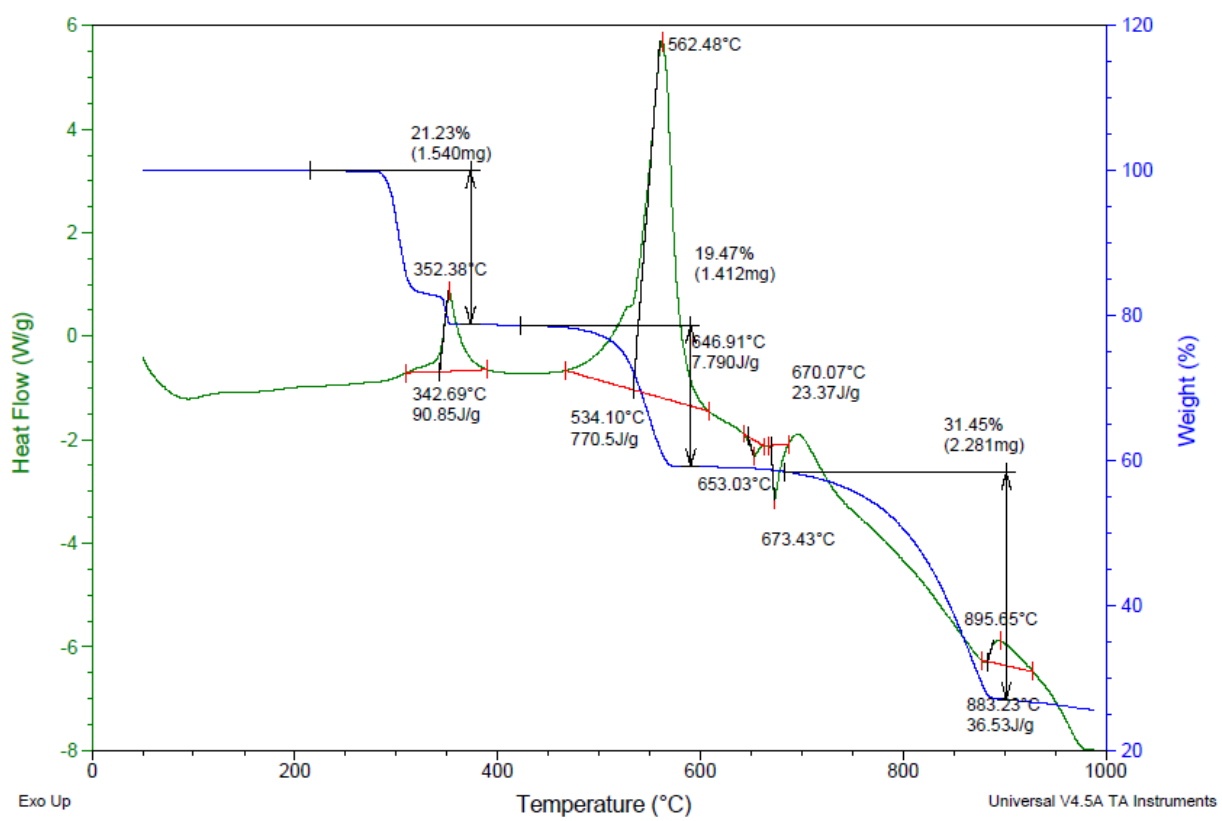

Figure 5.43. 80/10/10 $\mathrm{KIO}_{4} / \mathrm{B}_{4} \mathrm{C} / \mathrm{Al}$

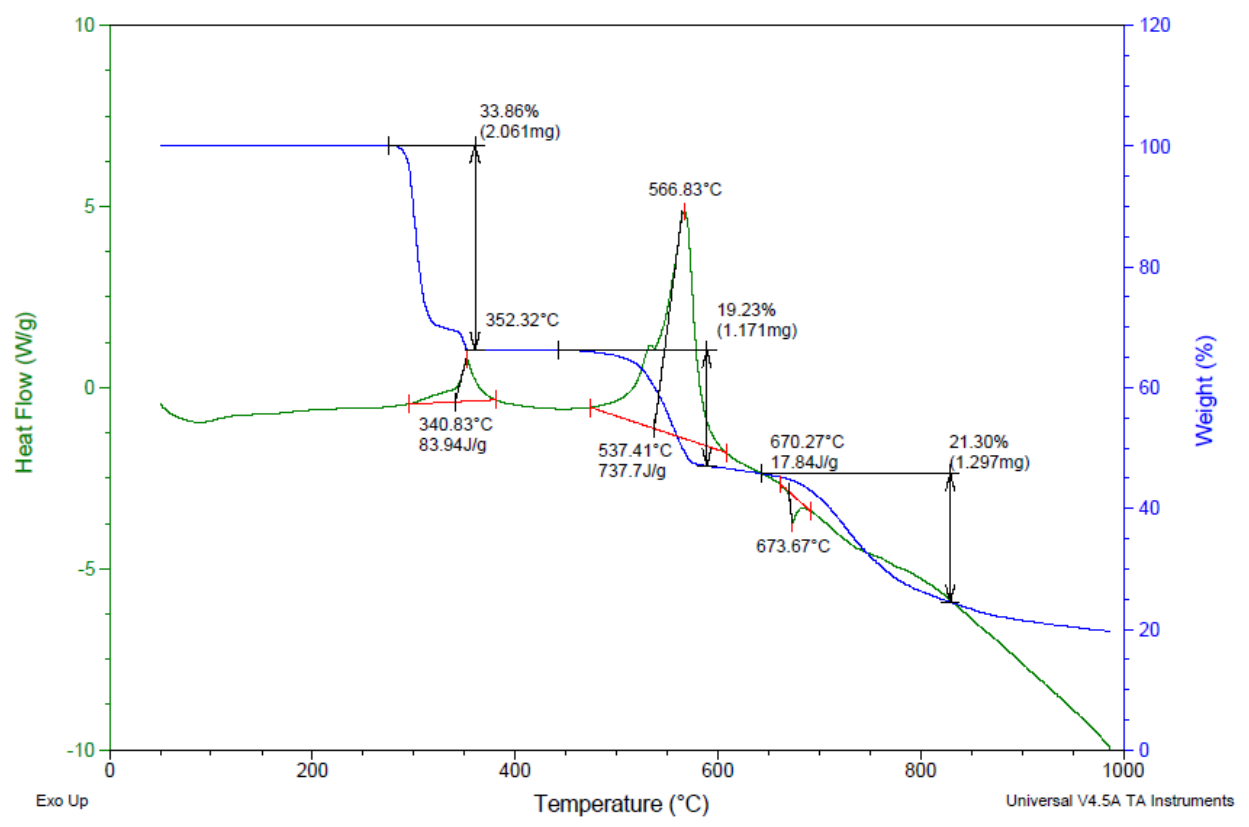

Figure 5.44. 80/20 $\mathrm{KIO}_{4} / \mathrm{B}_{4} \mathrm{C}$ 


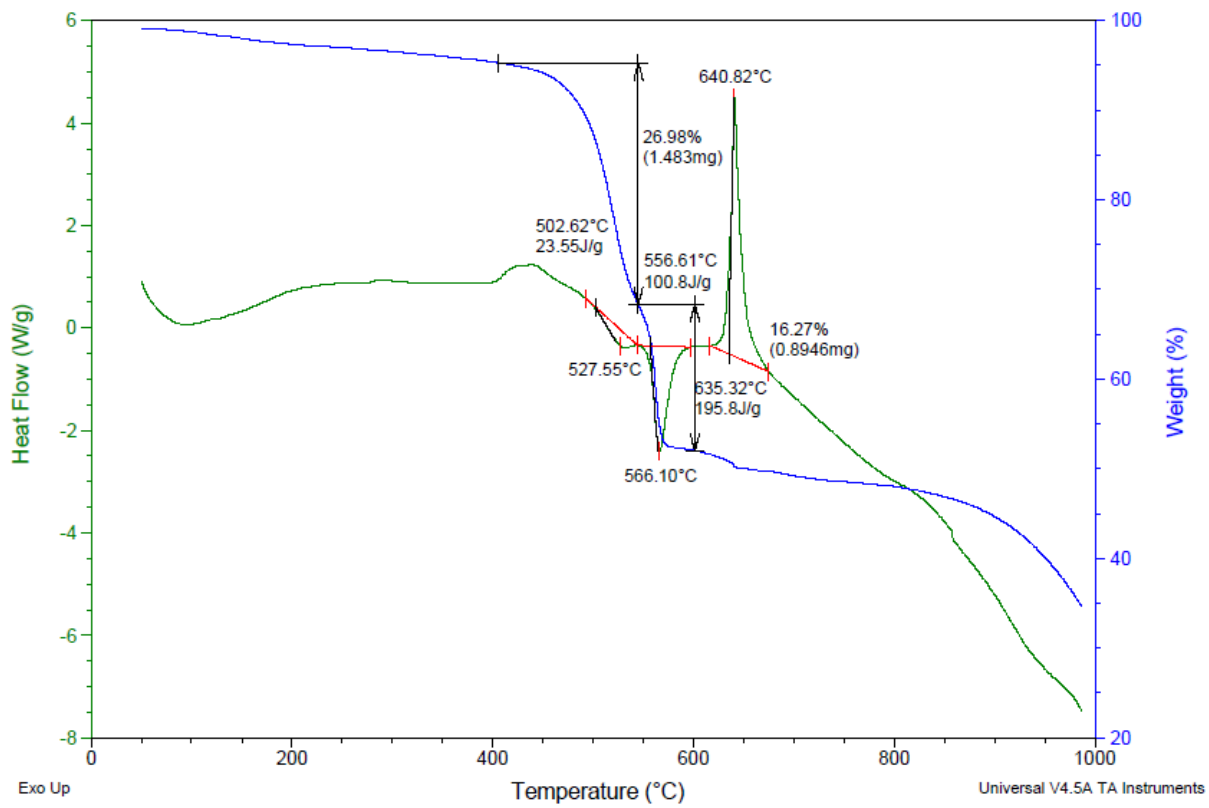

Figure 5.45. 80/20 $\mathrm{Bi}\left(\mathrm{IO}_{3}\right)_{3} / \mathrm{Al}$

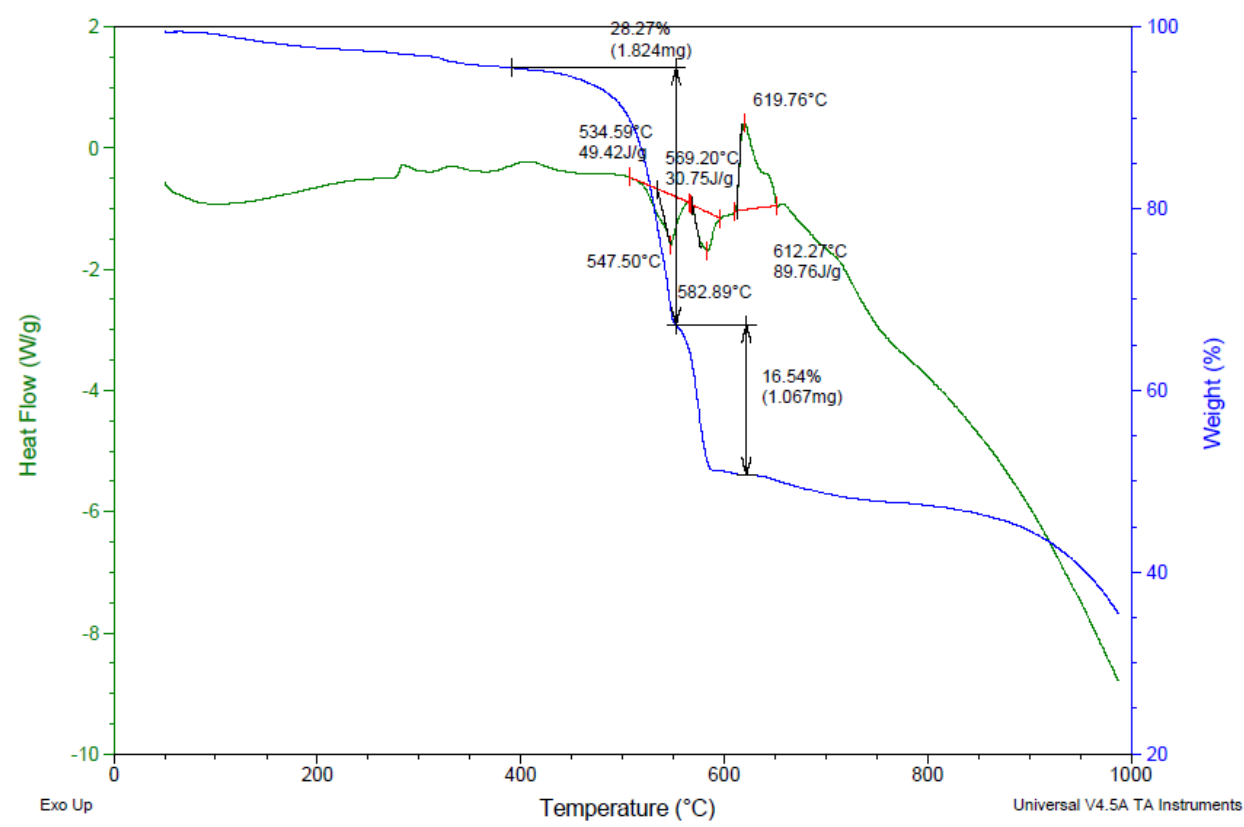

Figure 5.46. 80/10/10 $\mathrm{Bi}\left(\mathrm{IO}_{3}\right)_{3} / \mathrm{B} 4 \mathrm{C} / \mathrm{Al}$ 


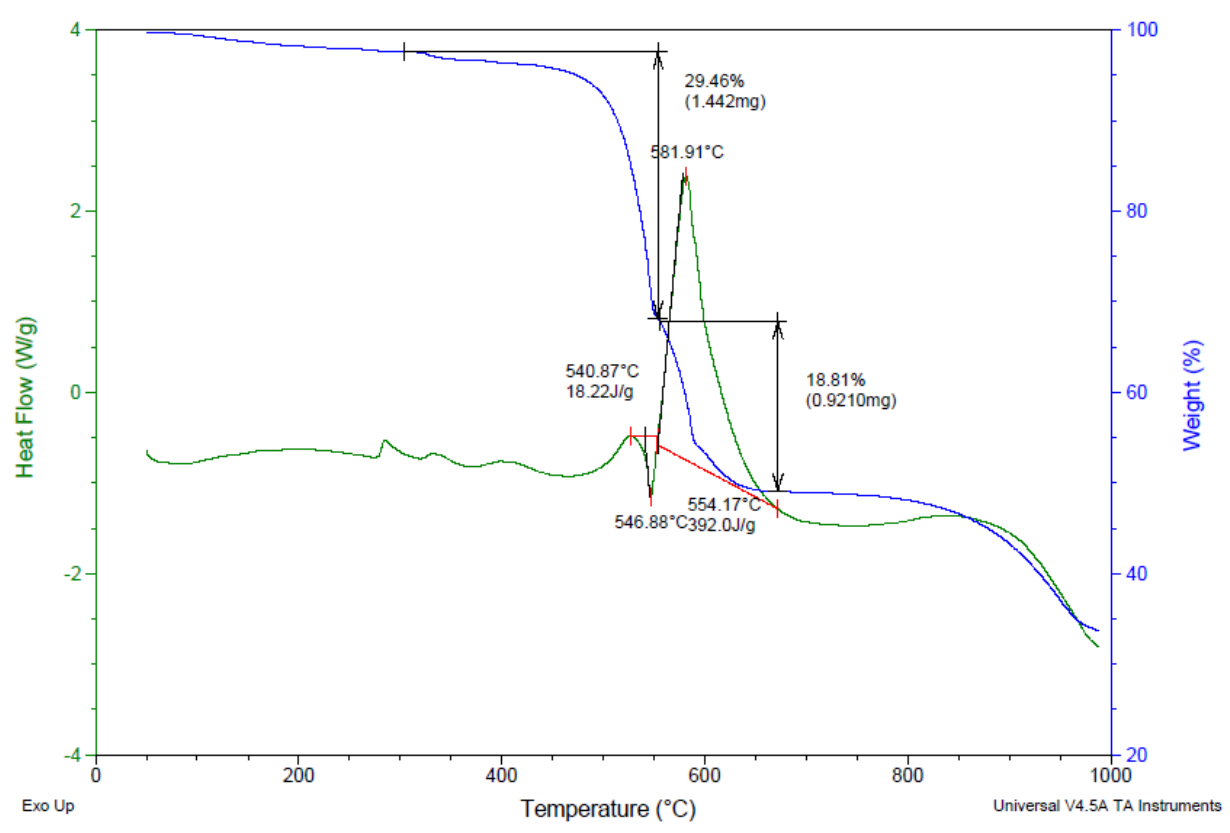

Figure 5.47. 80/20 $\mathrm{Bi}\left(\mathrm{IO}_{3}\right)_{3} / \mathrm{B}_{4} \mathrm{C}$

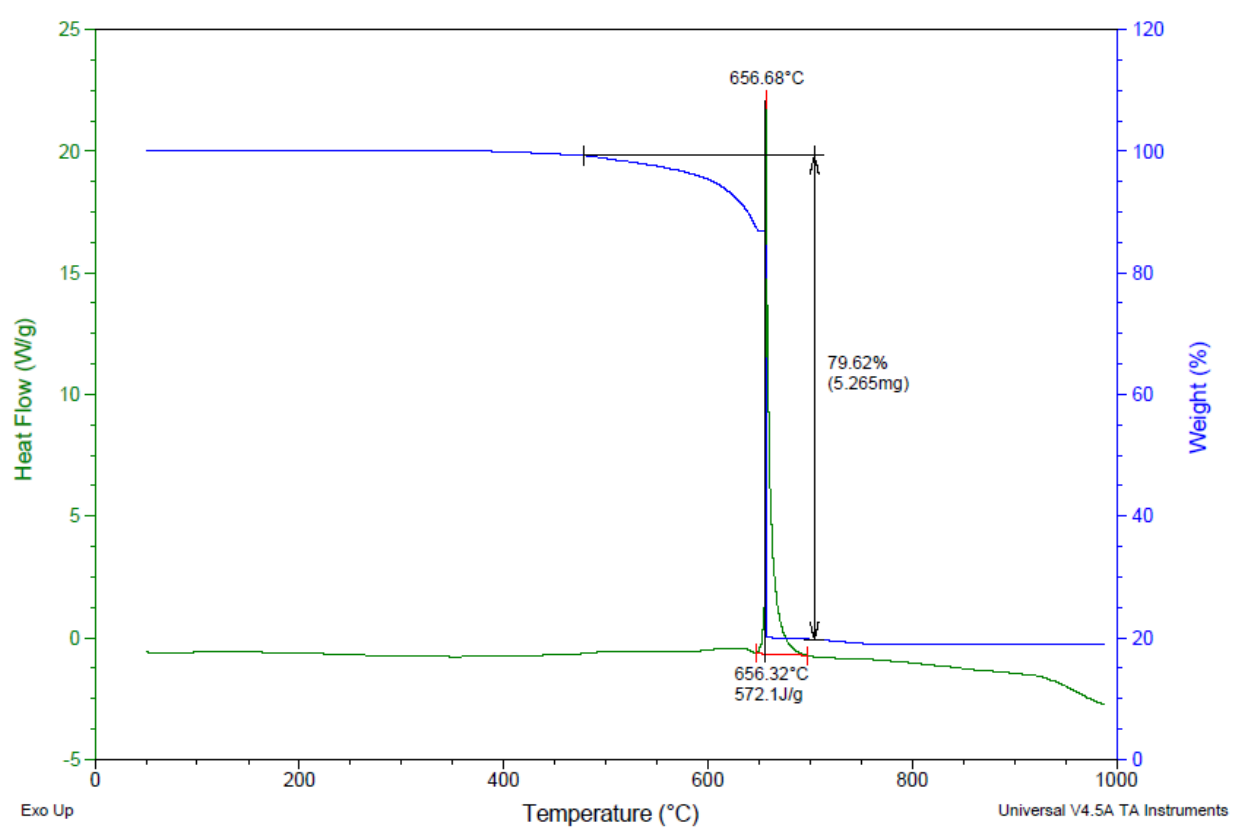

Figure 5.48. 80/10/10 $\mathrm{Ca}\left(\mathrm{IO}_{3}\right)_{2} / \mathrm{B} 4 \mathrm{C} / \mathrm{Al}$ 


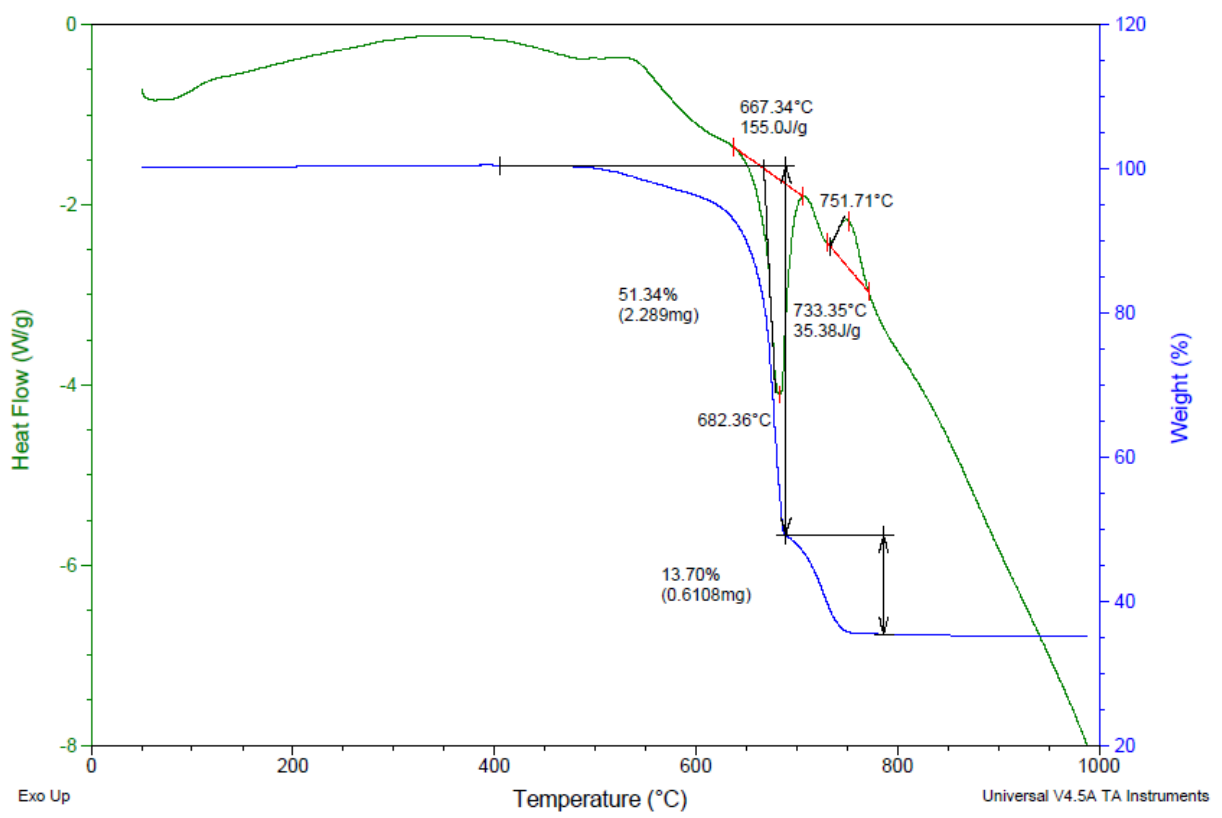

Figure 5.49. 80/20 $\mathrm{Ca}\left(\mathrm{IO}_{3}\right)_{2} / \mathrm{B}_{4} \mathrm{C}$

\section{SDT Data of Other Oxidizers}

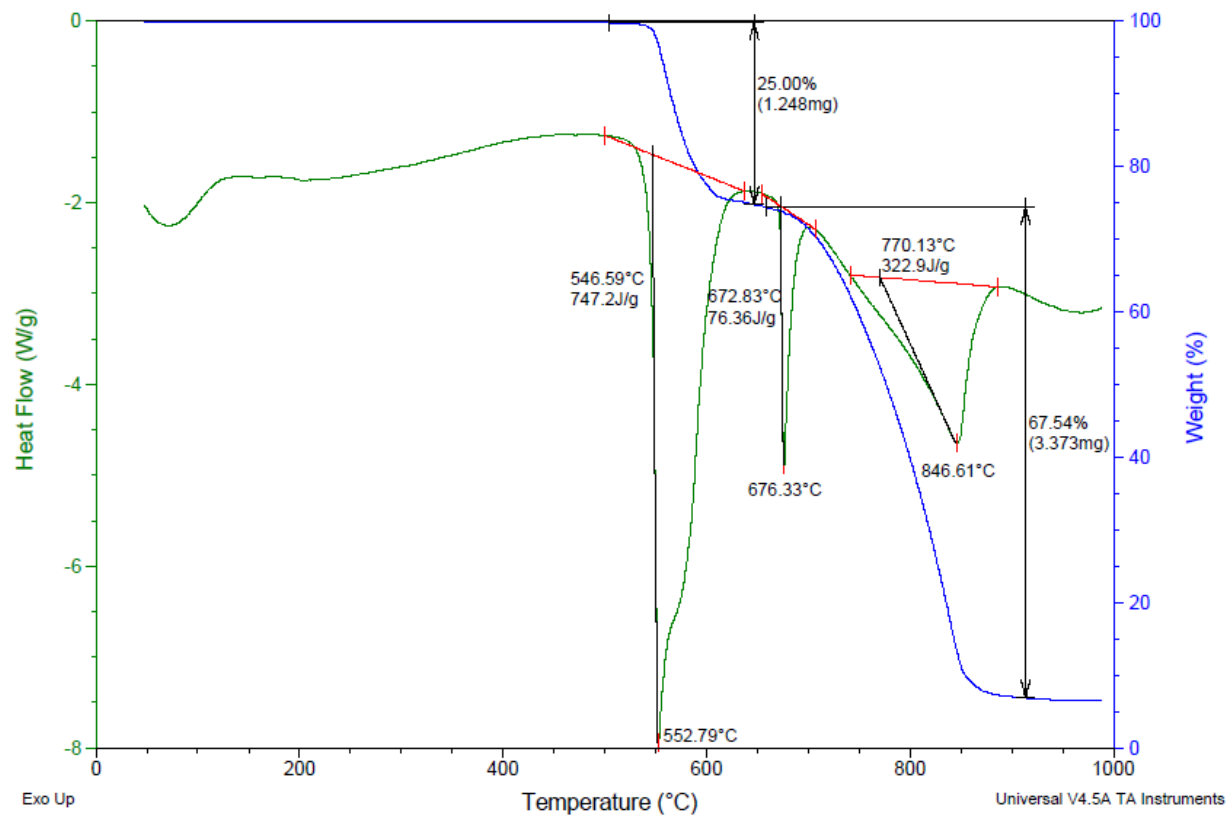

Figure 5.50. $\mathrm{KIO}_{3}$ 


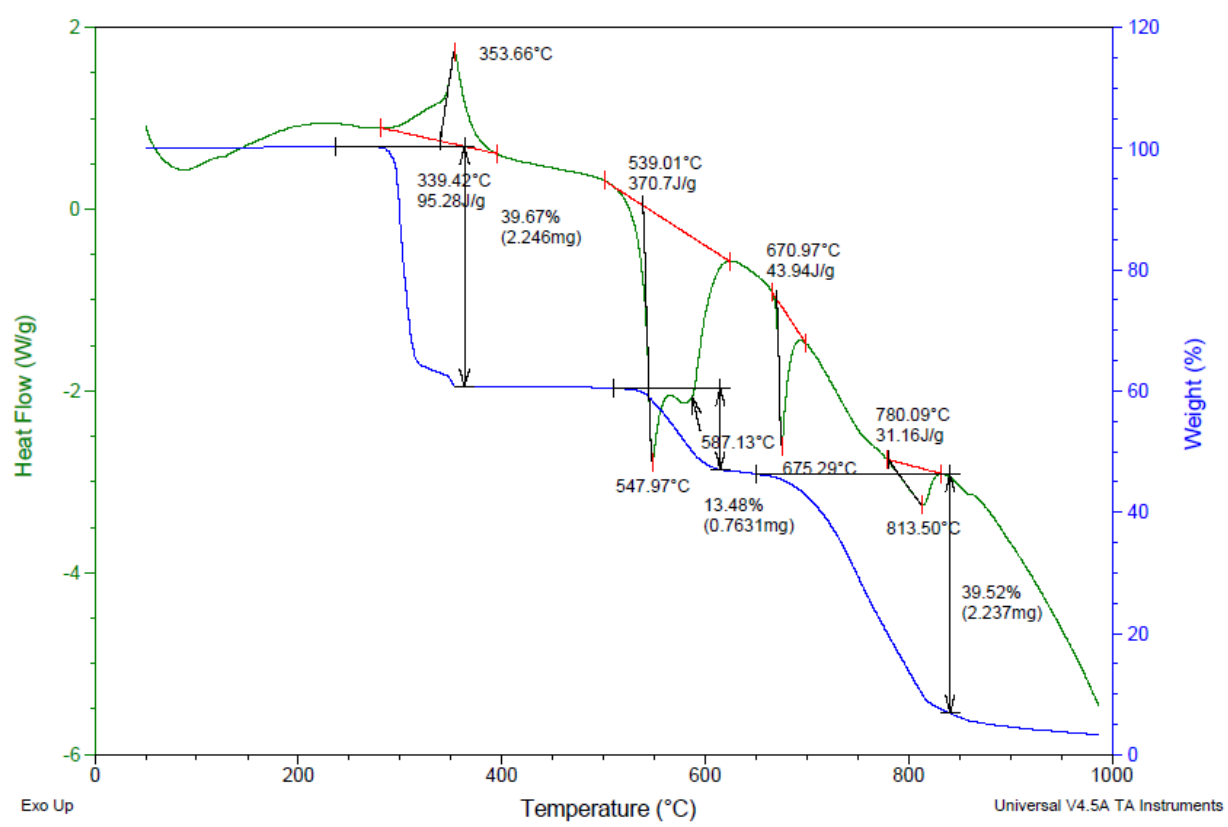

Figure 5.51. $\mathrm{KIO}_{4}$

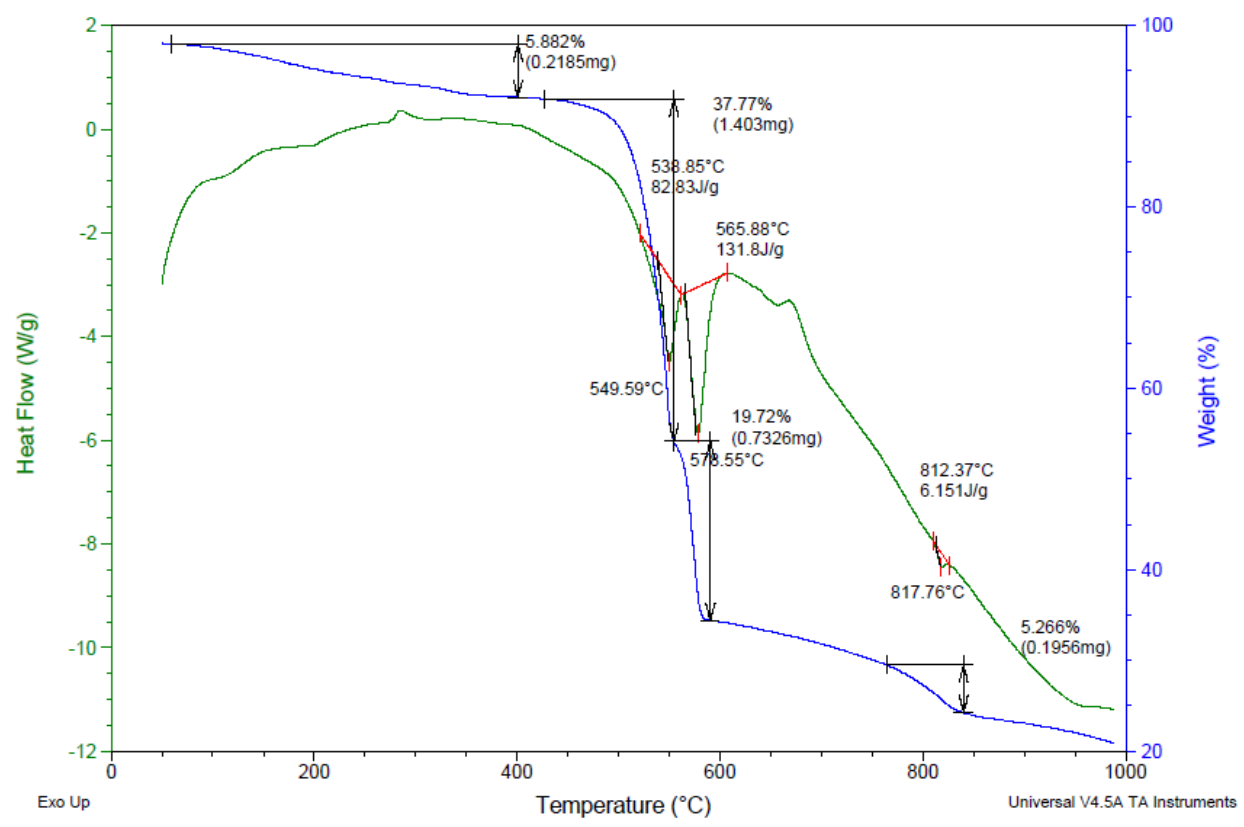

Figure 5.52. $\mathrm{Bi}\left(\mathrm{IO}_{3}\right)_{3}$ 


\section{SDT Data of Fuels}

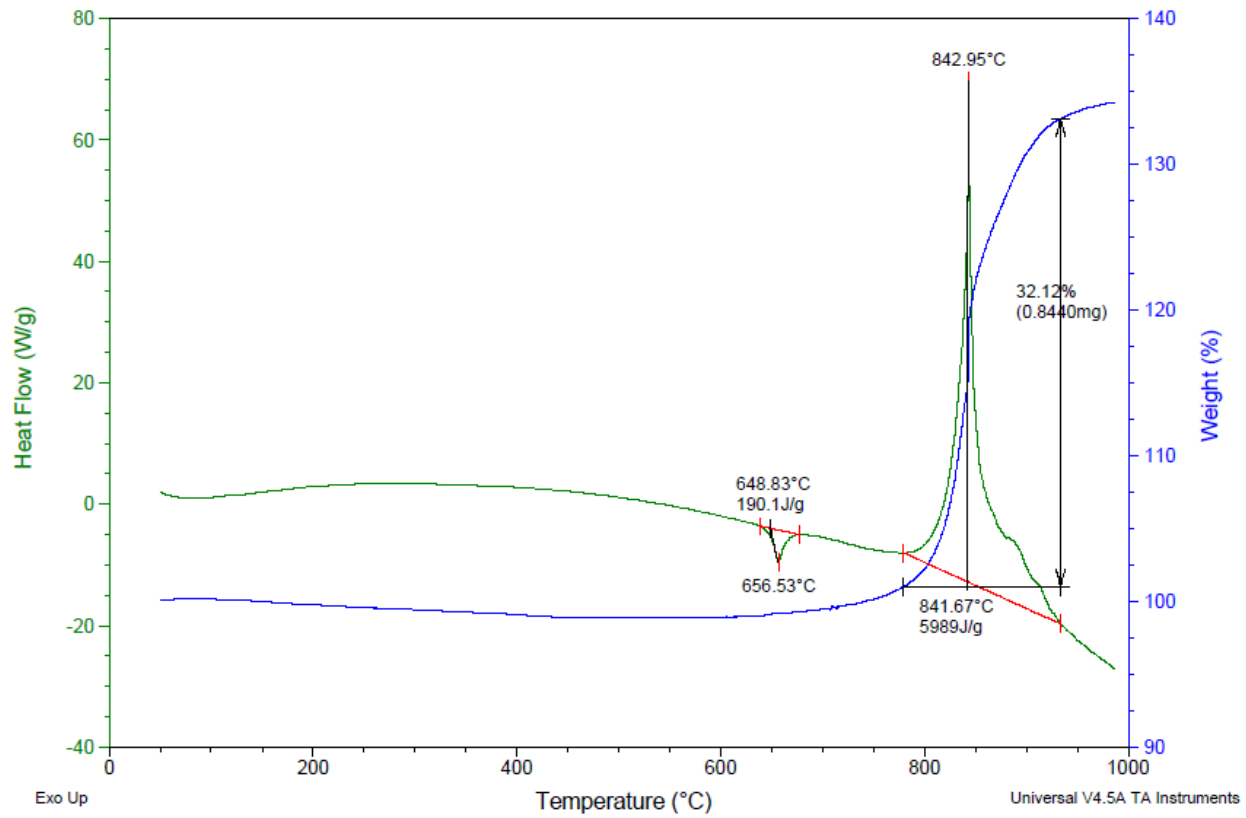

Figure 5.53. Aluminum in nitrogen

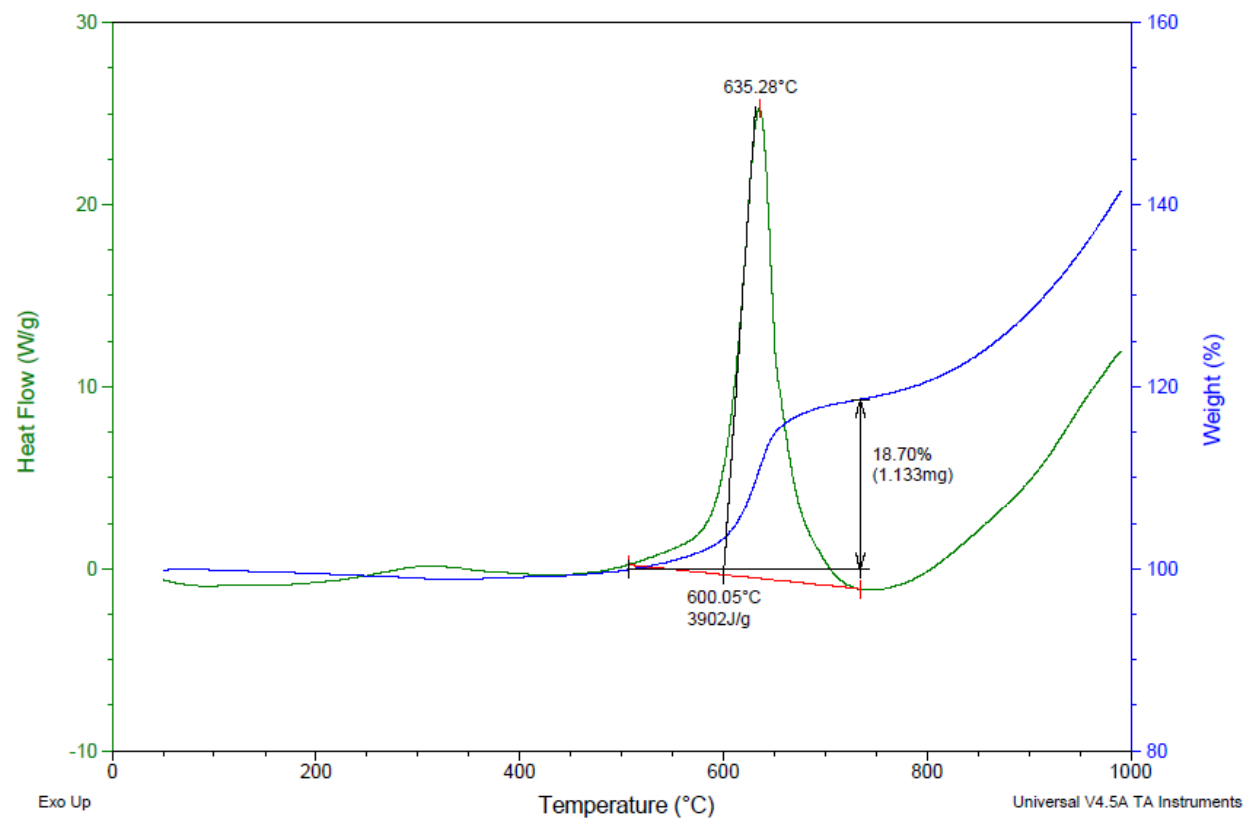

Figure 5.54. Aluminum in air 


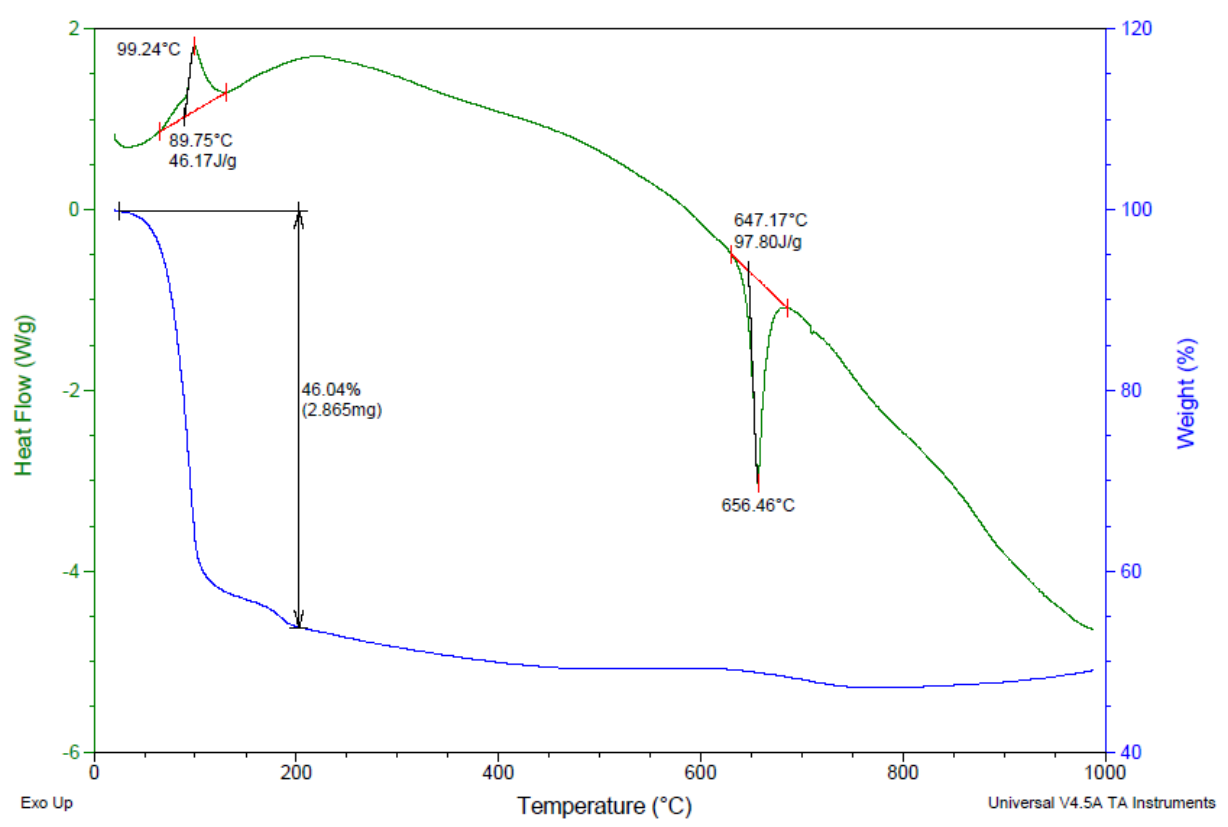

Figure 5.55. 50/50 Aluminum/iodine run in nitrogen

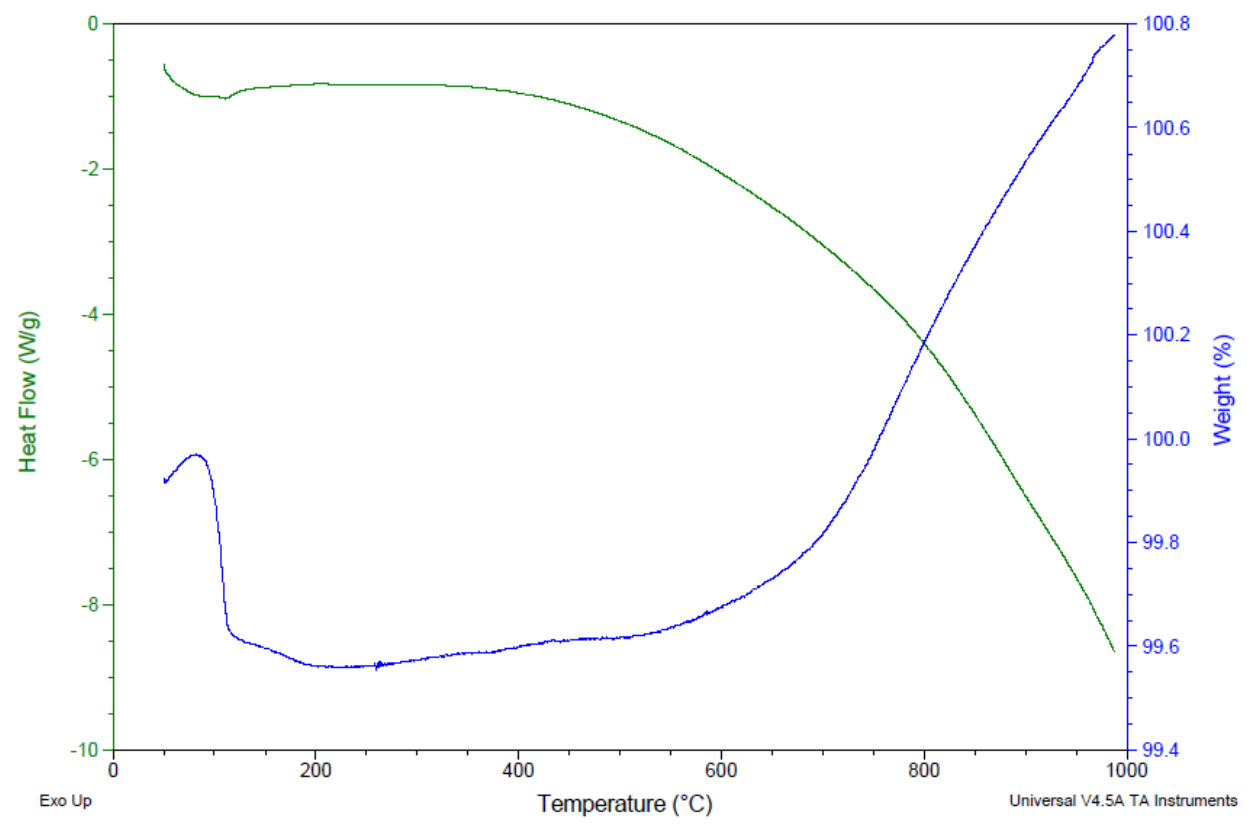

Figure 5.56. $\mathrm{B}_{4} \mathrm{C}$ in nitrogen 


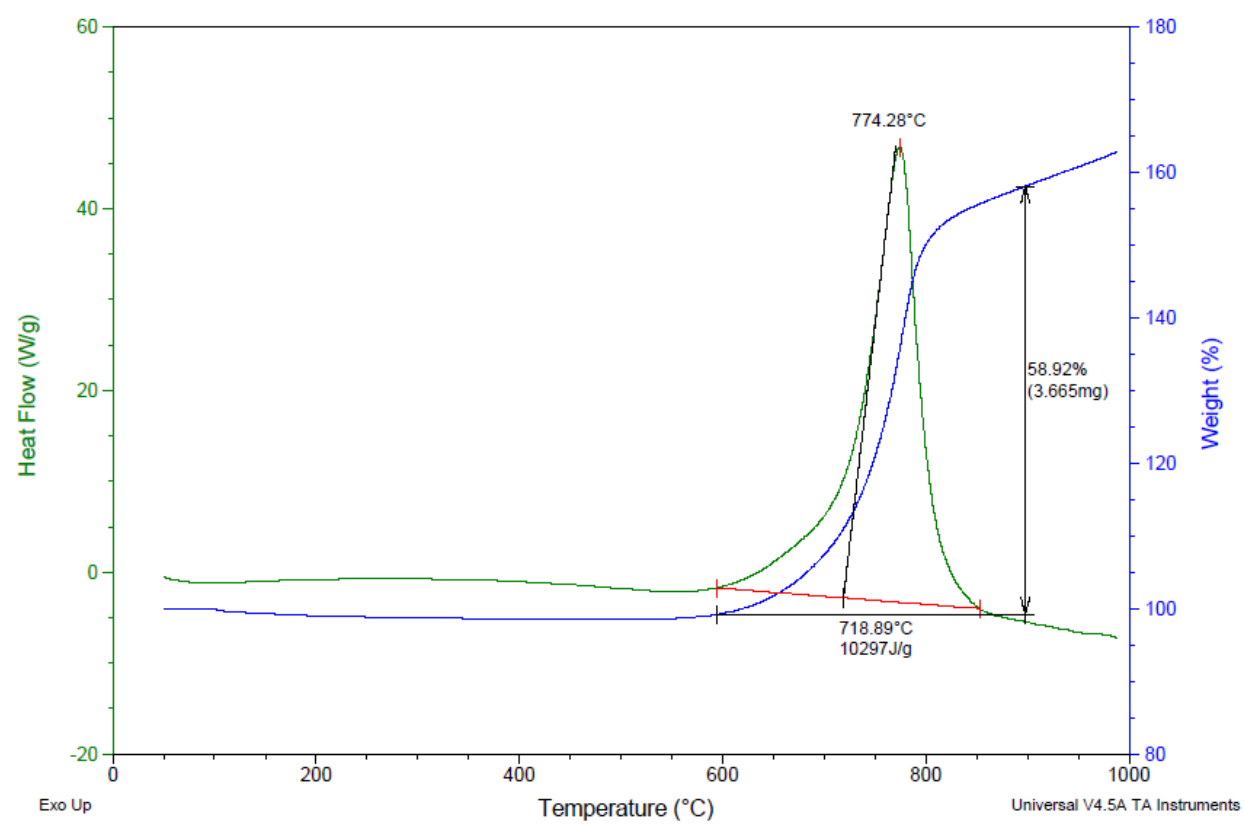

Figure 5.57. $\mathrm{B}_{4} \mathrm{C}$ in air

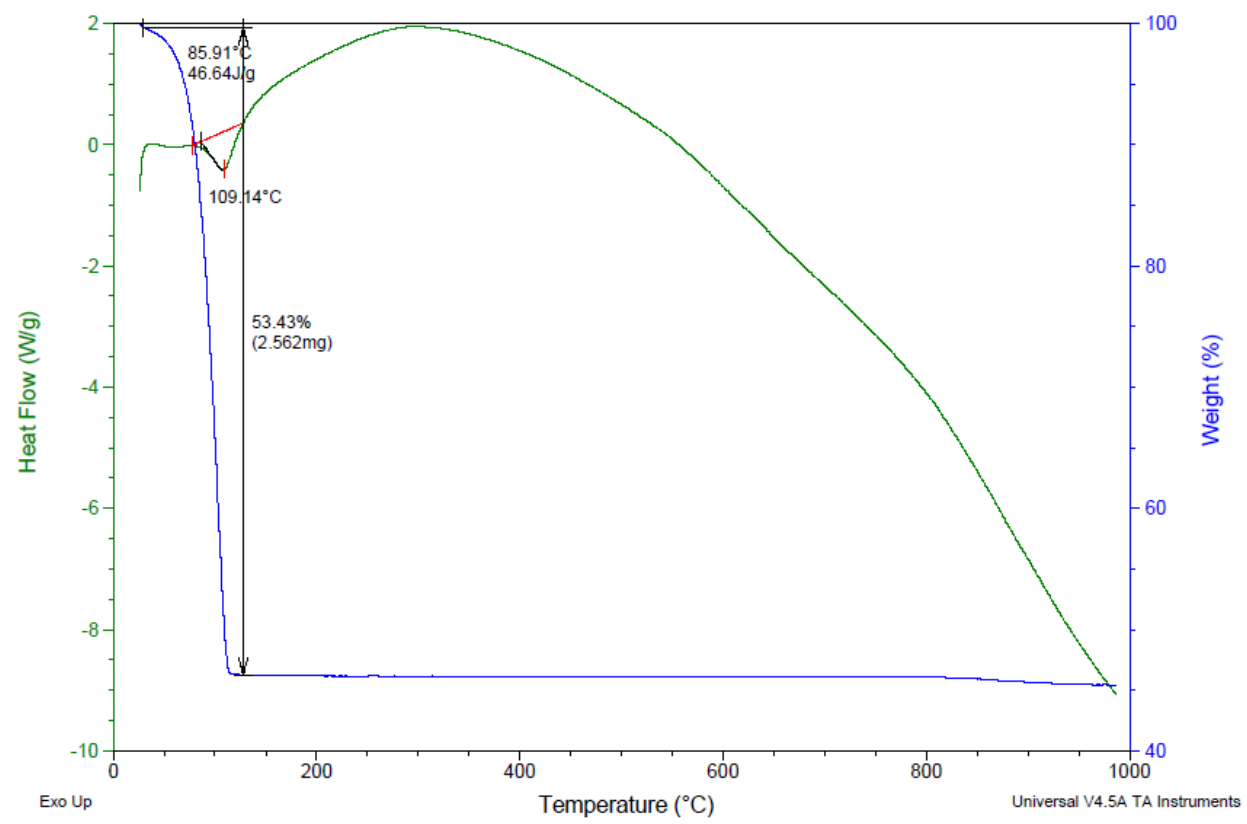

Figure 5.58. 50/50 $\mathrm{B}_{4} \mathrm{C} /$ iodine run in nitrogen 


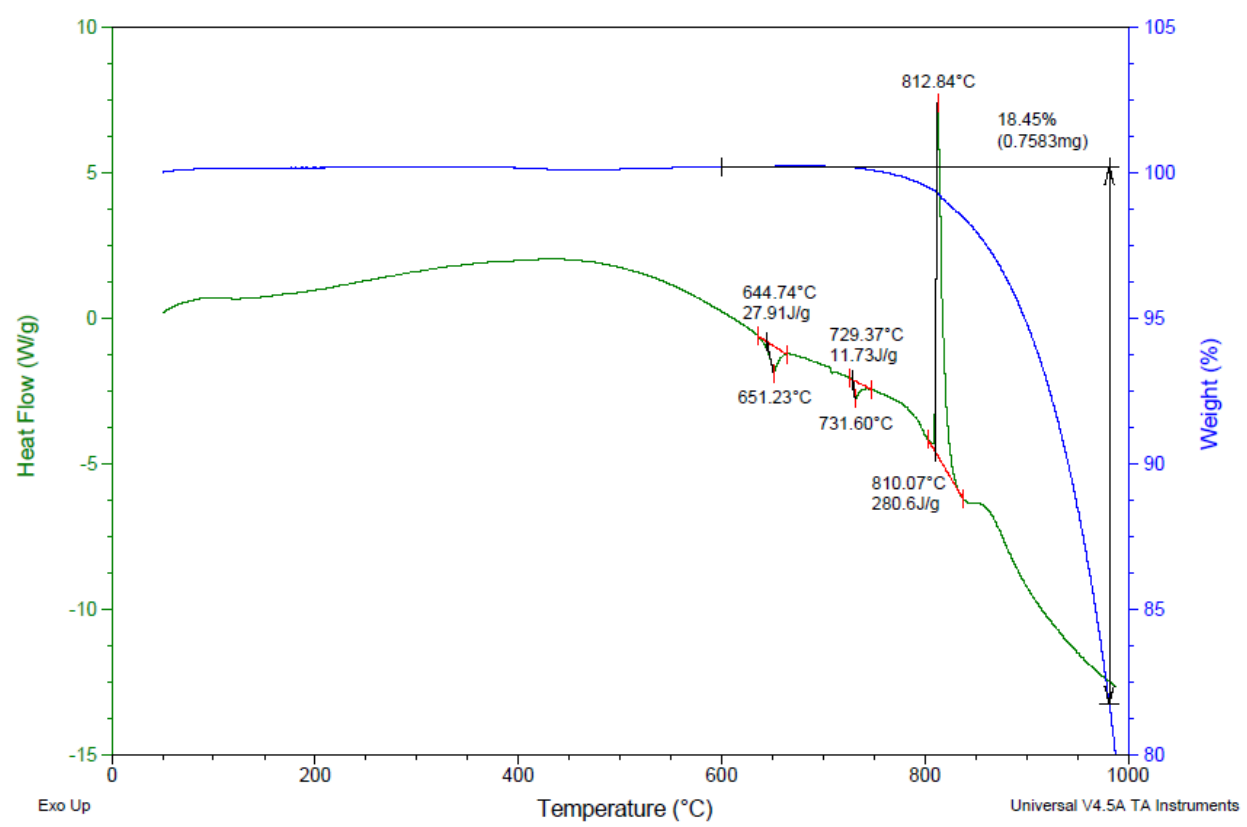

Figure 5.59. $80 / 20 \mathrm{Bi}_{2} \mathrm{O}_{3} / \mathrm{Al}$

\section{SDT Data of Combustion Products}

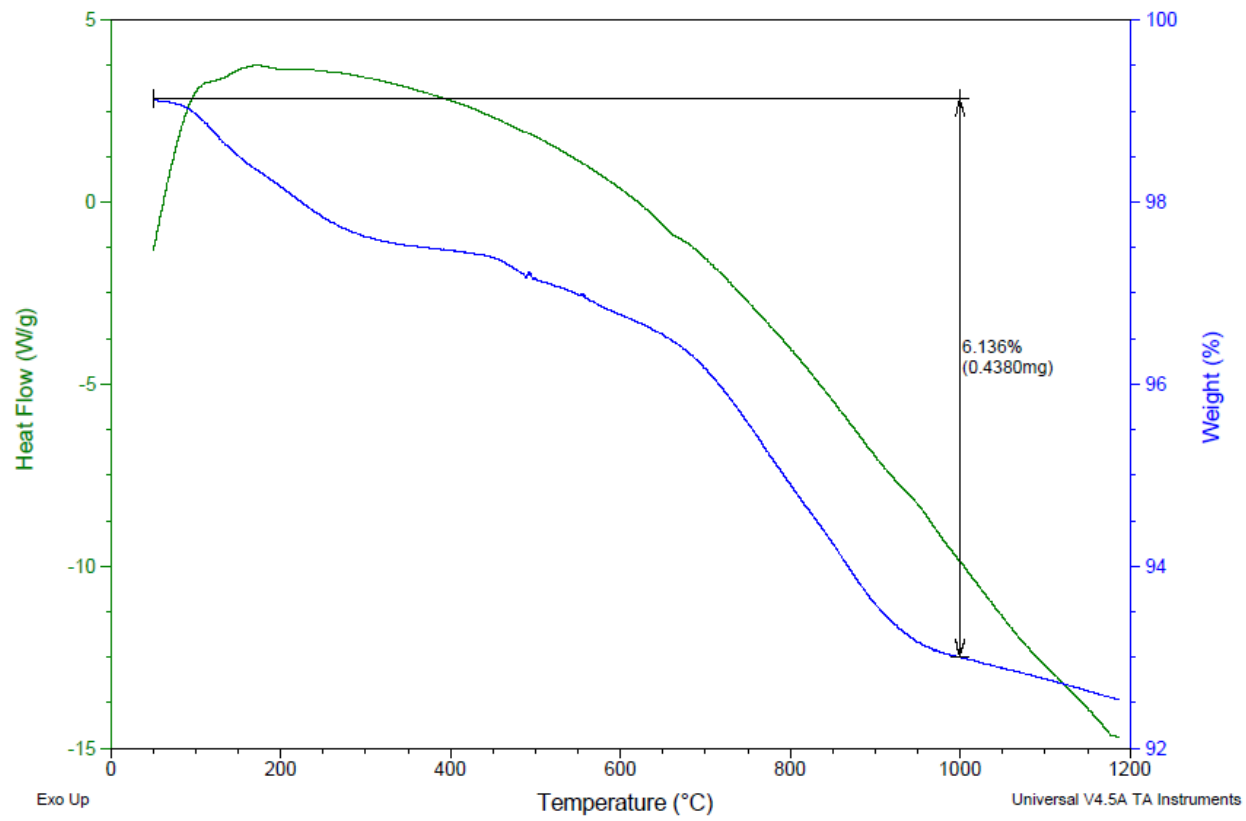

Figure 5.60. 80/20 $\mathrm{Ca}\left(\mathrm{IO}_{3}\right)_{2} / \mathrm{Al}$ combustion products 


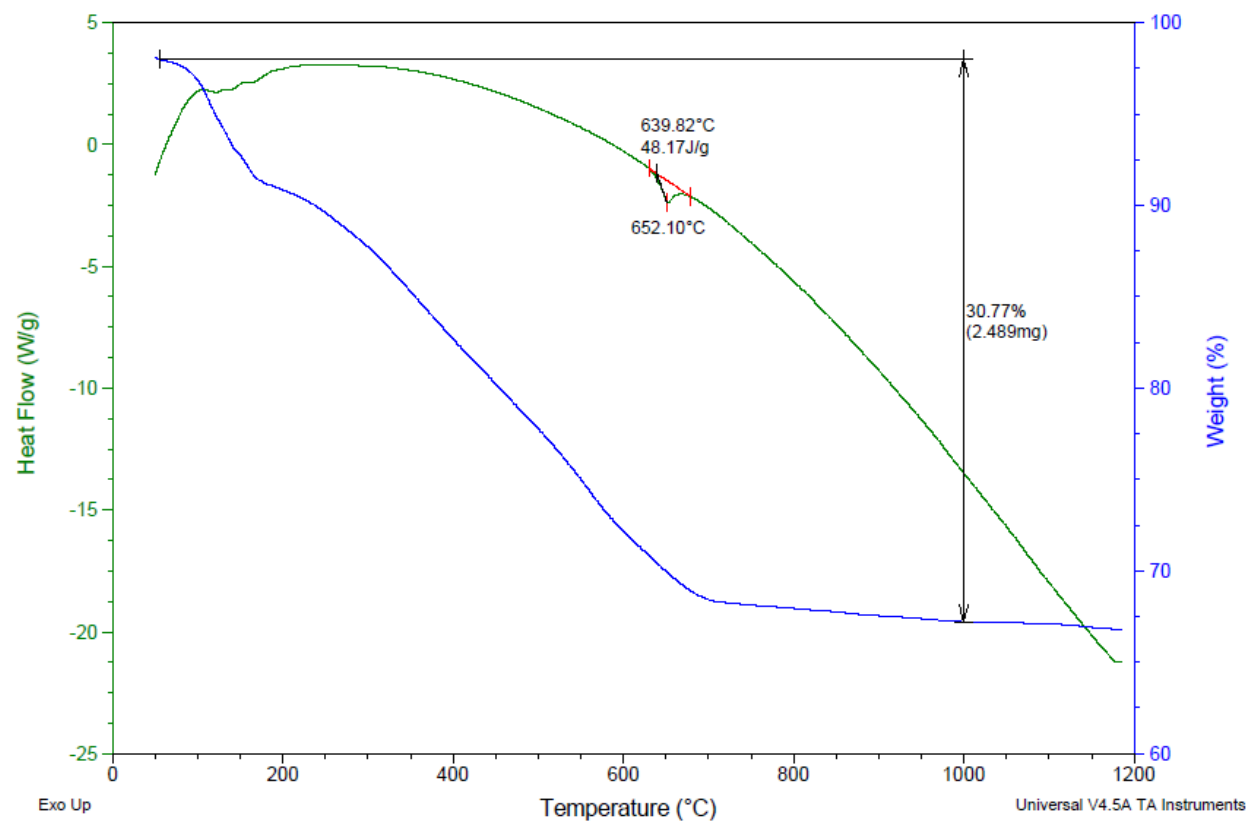

Figure 5.61. 60/40 $\mathrm{Ca}\left(\mathrm{IO}_{3}\right)_{2} / \mathrm{Al}$ combustion products

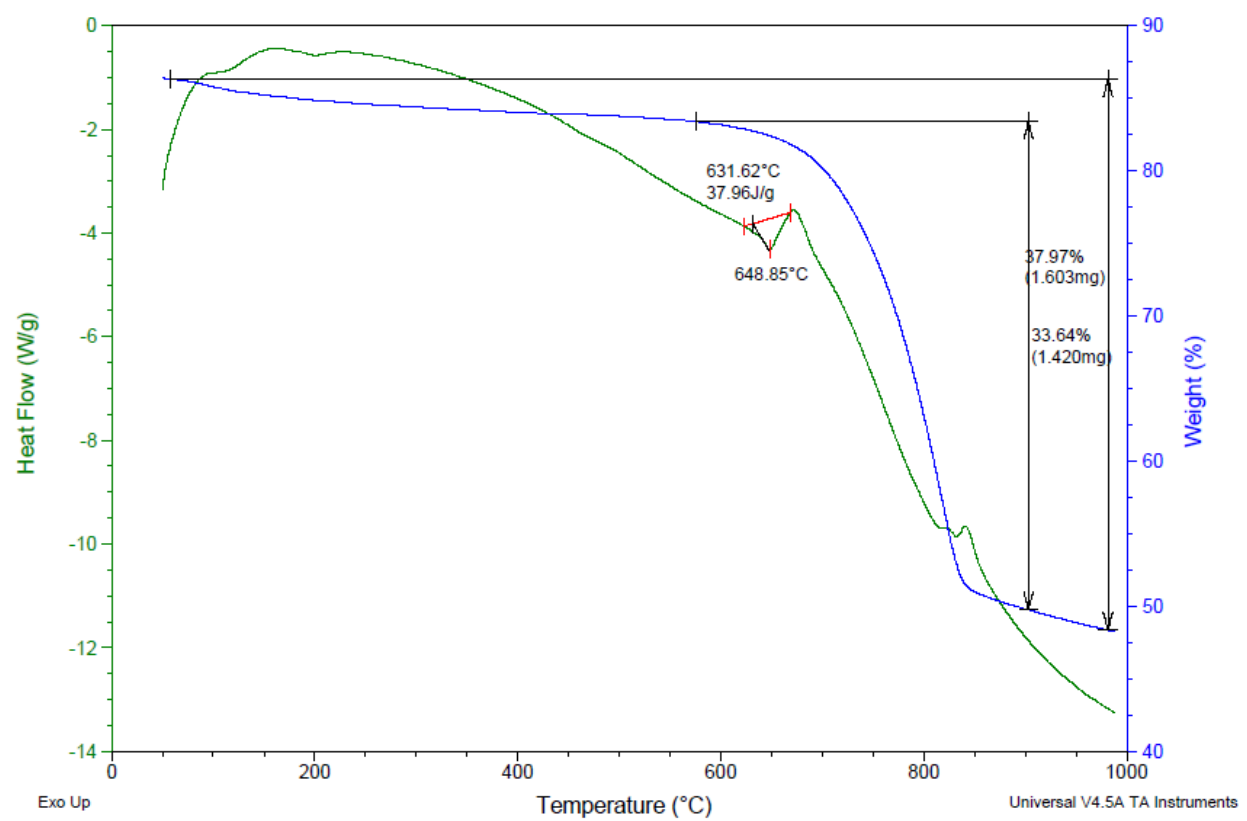

Figure 5.62. 80/20 $\mathrm{NaIO}_{3} / \mathrm{Al}$ combustion products 


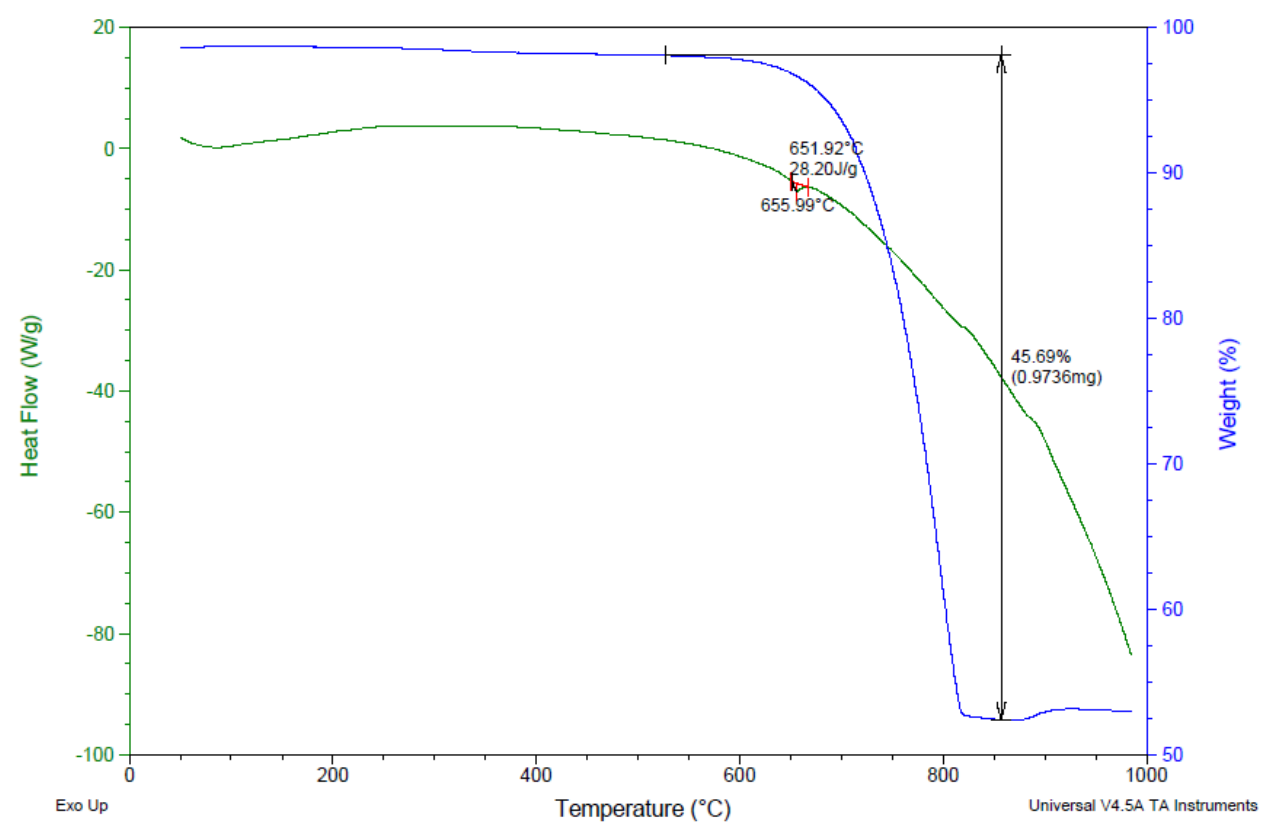

Figure 5.63. 60/40 $\mathrm{NaIO}_{3} / \mathrm{Al}$ combustion products

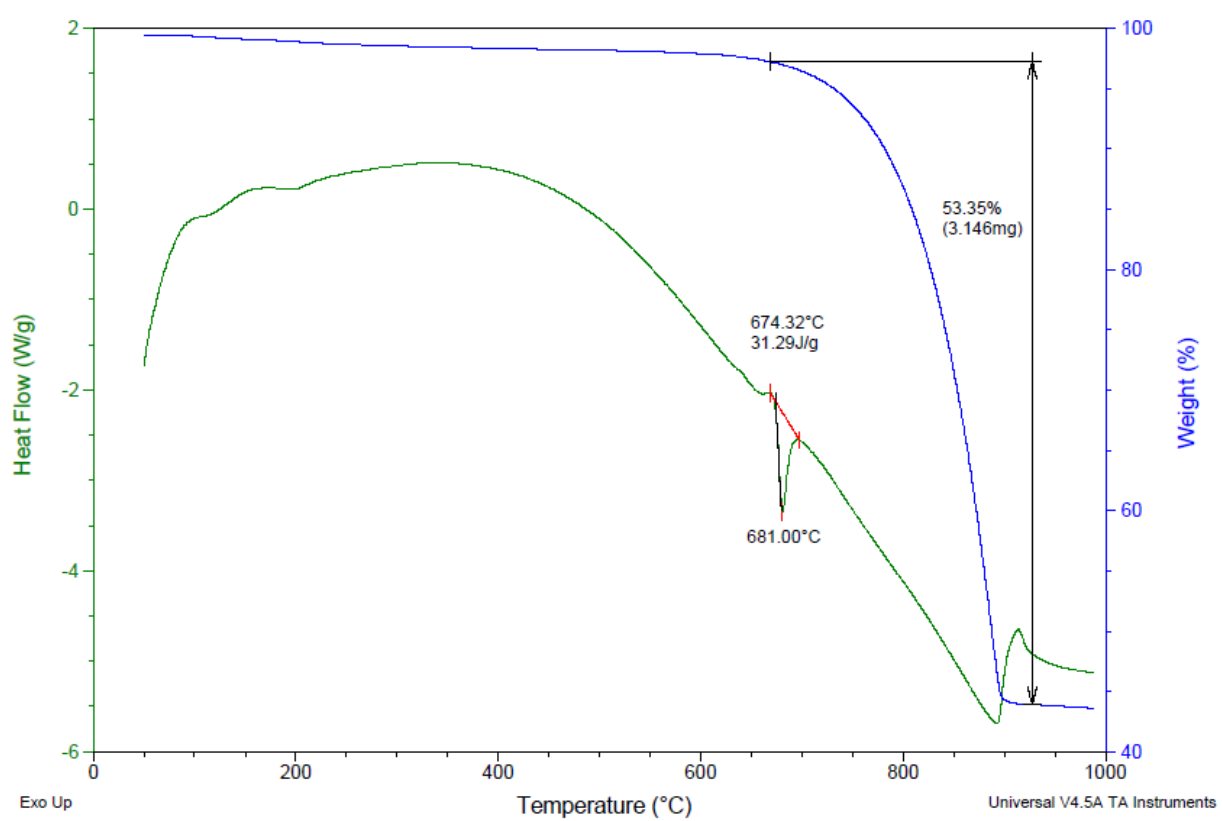

Figure 5.64. 80/20 $\mathrm{KIO}_{3} / \mathrm{Al}$ combustion products 


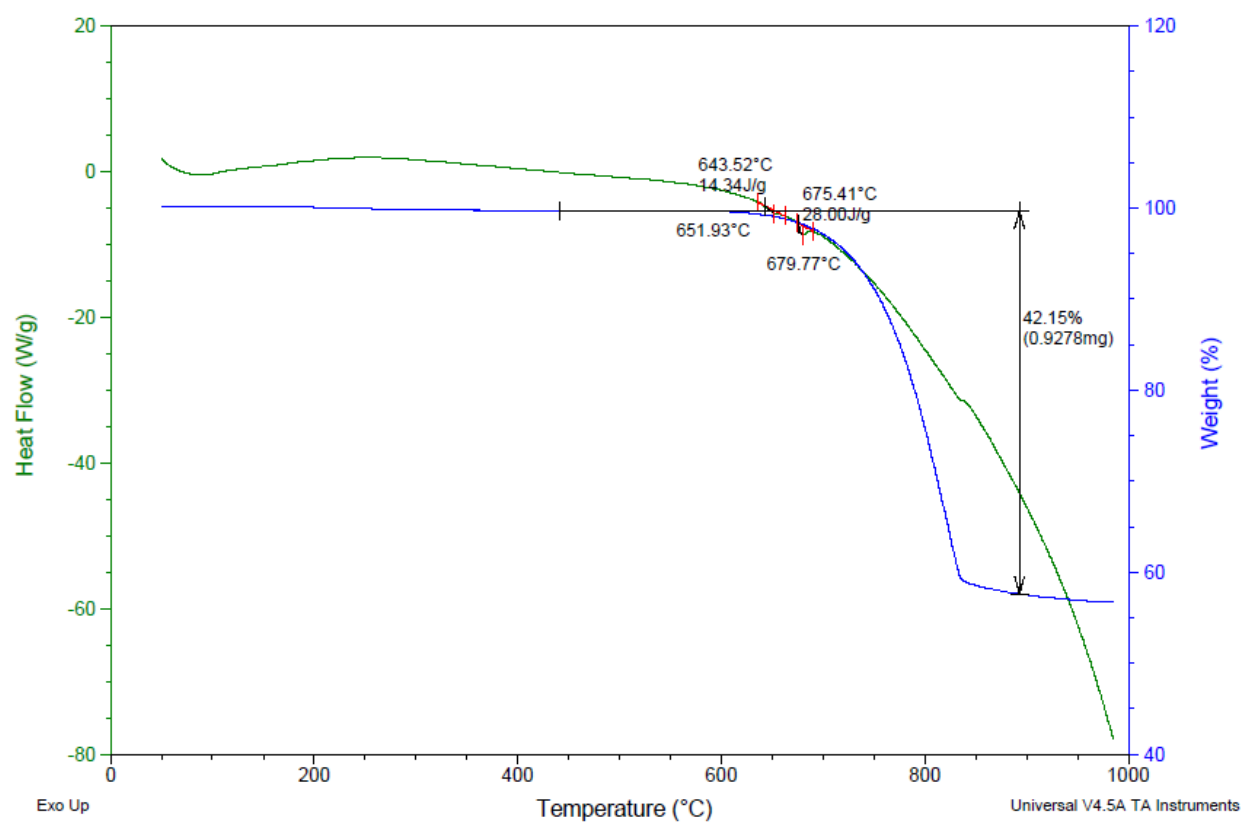

Figure 5.65. 60/40 $\mathrm{KIO}_{3} / \mathrm{Al}$ combustion products

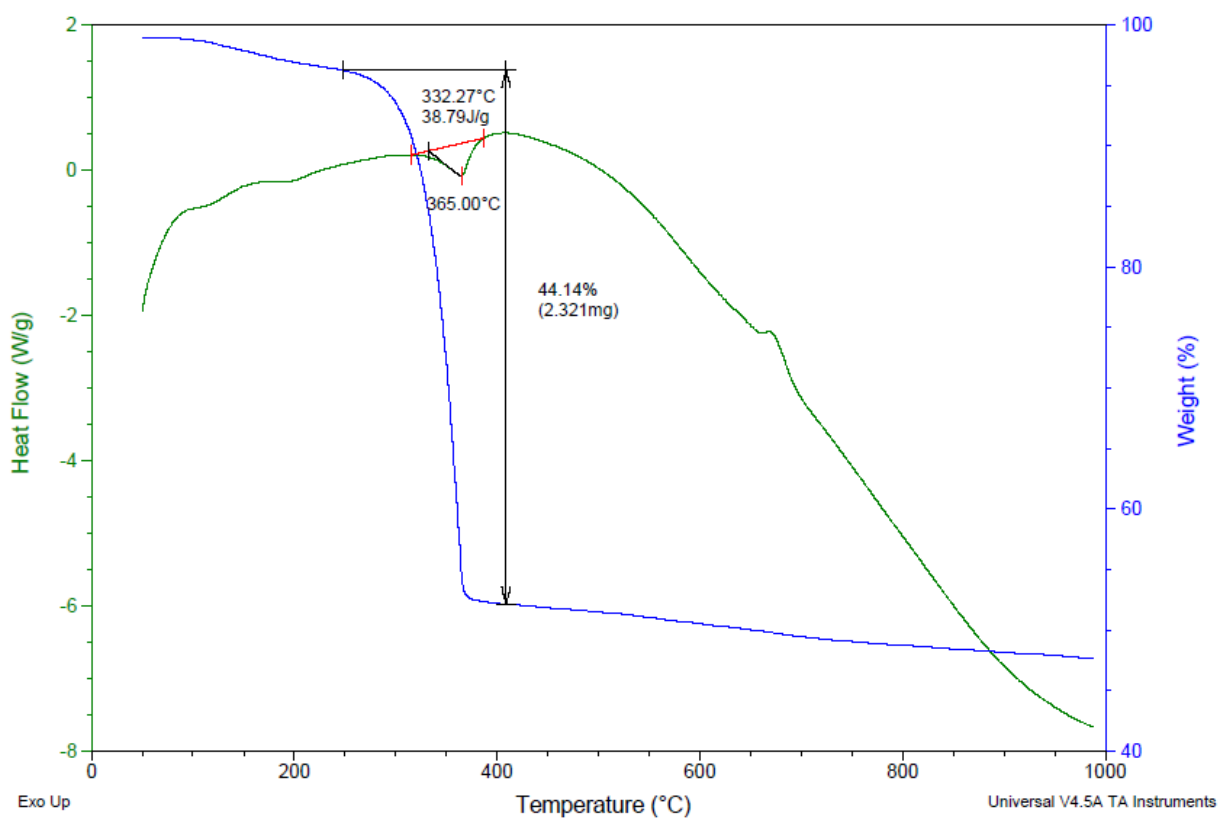

Figure 5.66. $80 / 20 \mathrm{Bi}\left(\mathrm{IO}_{3}\right)_{3} / \mathrm{Al}$ combustions products 


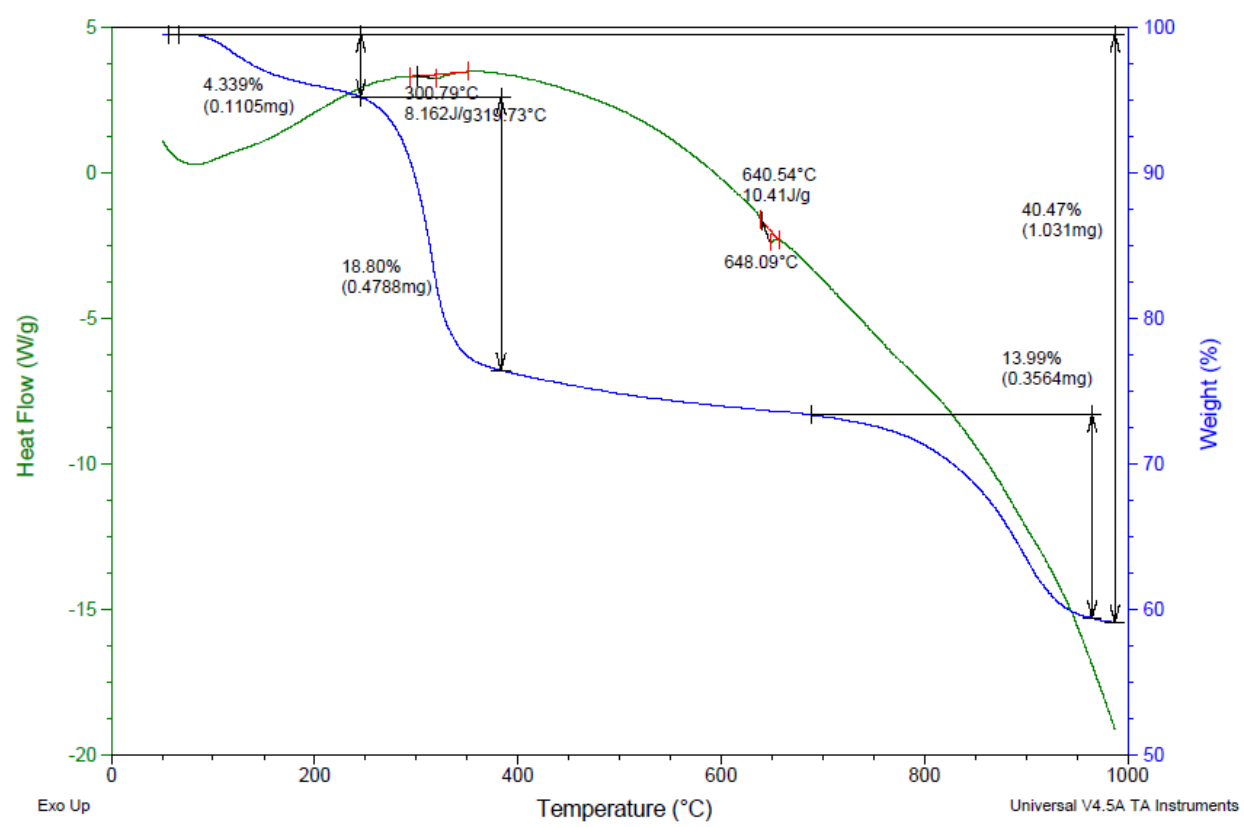

Figure 5.67. $60 / 40 \mathrm{Bi}\left(\mathrm{IO}_{3}\right)_{3} / \mathrm{Al}$ combustion products

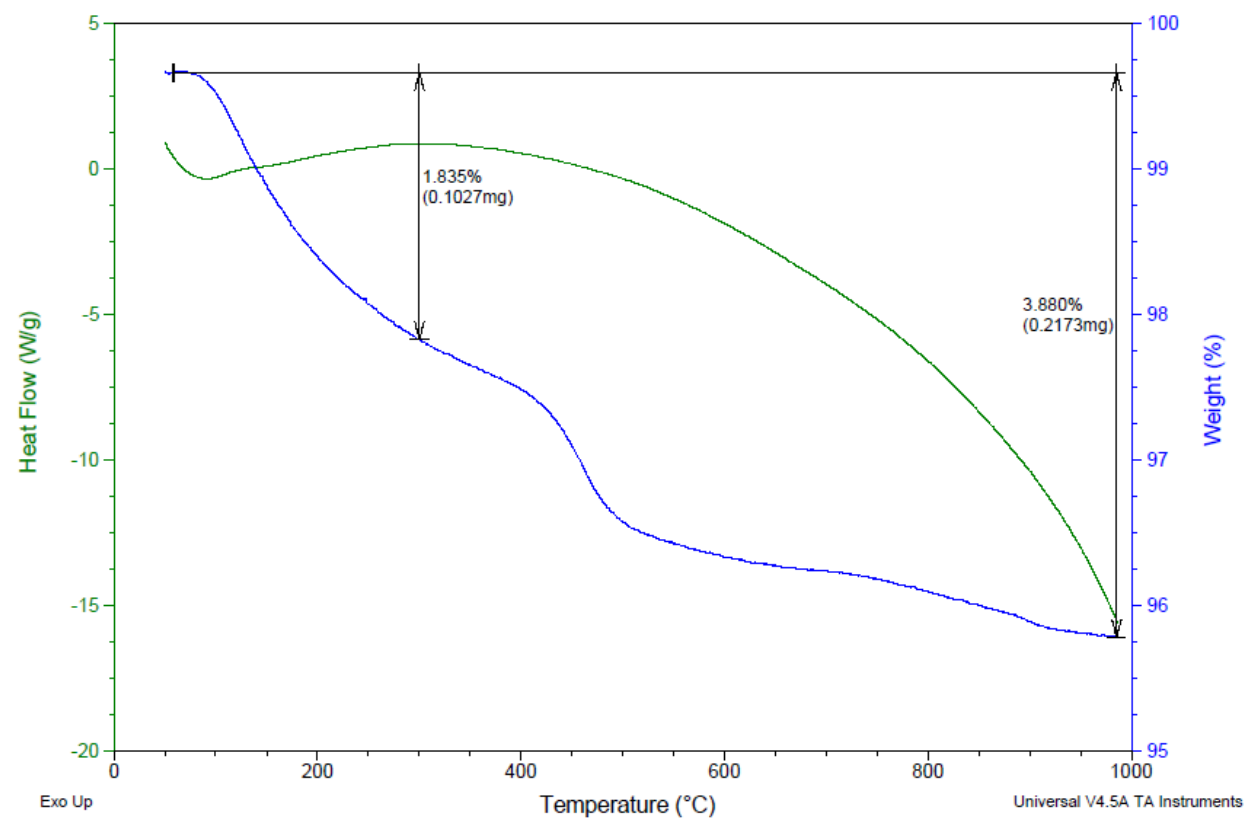

Figure 5.68. 80/20 $\mathrm{I}_{2} \mathrm{O}_{5} / \mathrm{Al}$ combustion products 


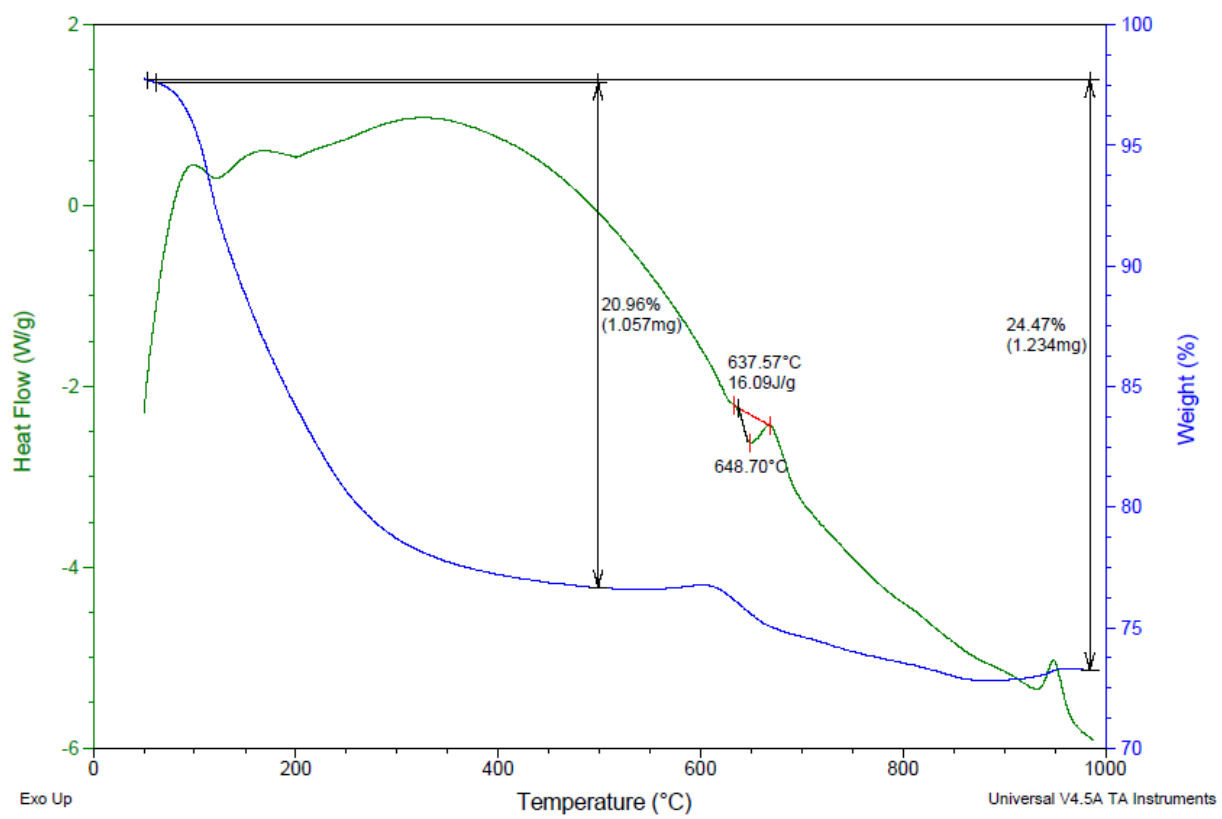

Figure 5.69. 60/40 $\mathrm{I}_{2} \mathrm{O}_{5} / \mathrm{Al}$ combustion products

\section{SDT Data of Iodides}

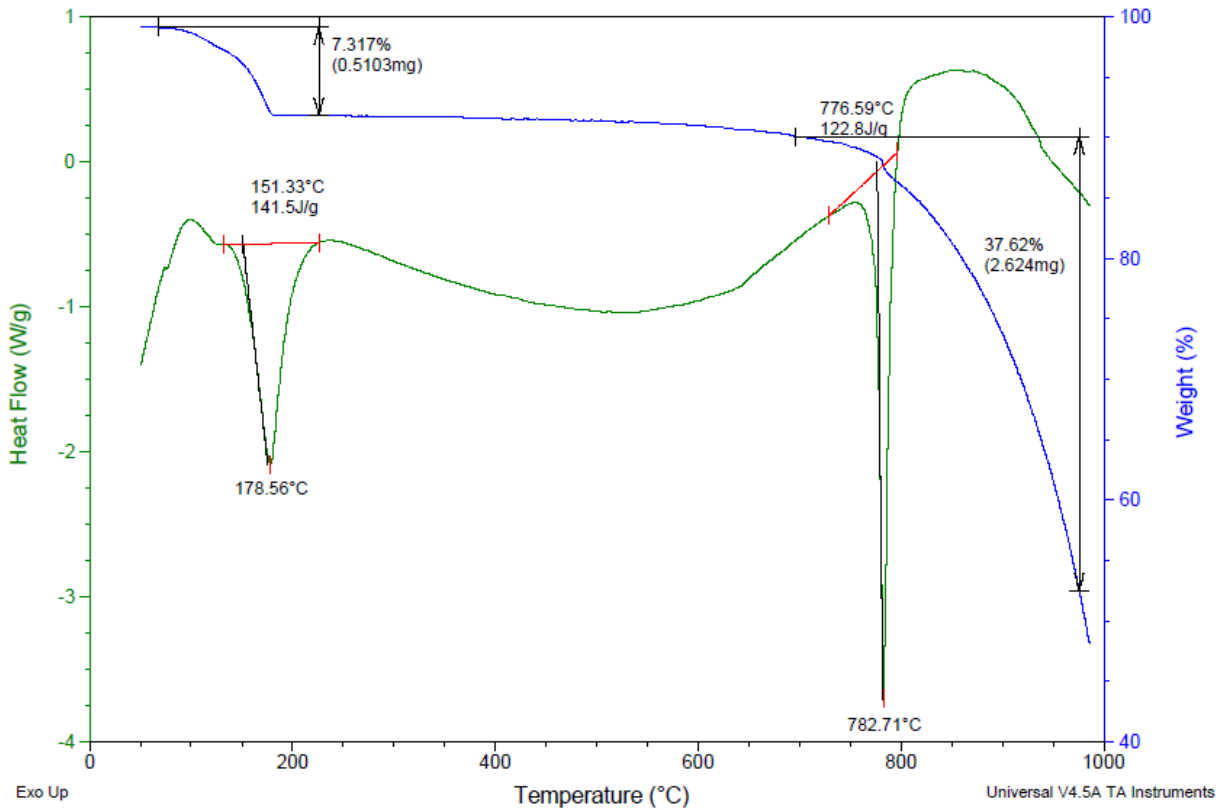

Figure 5.70. $\mathrm{CaI}_{2}$ in nitrogen 


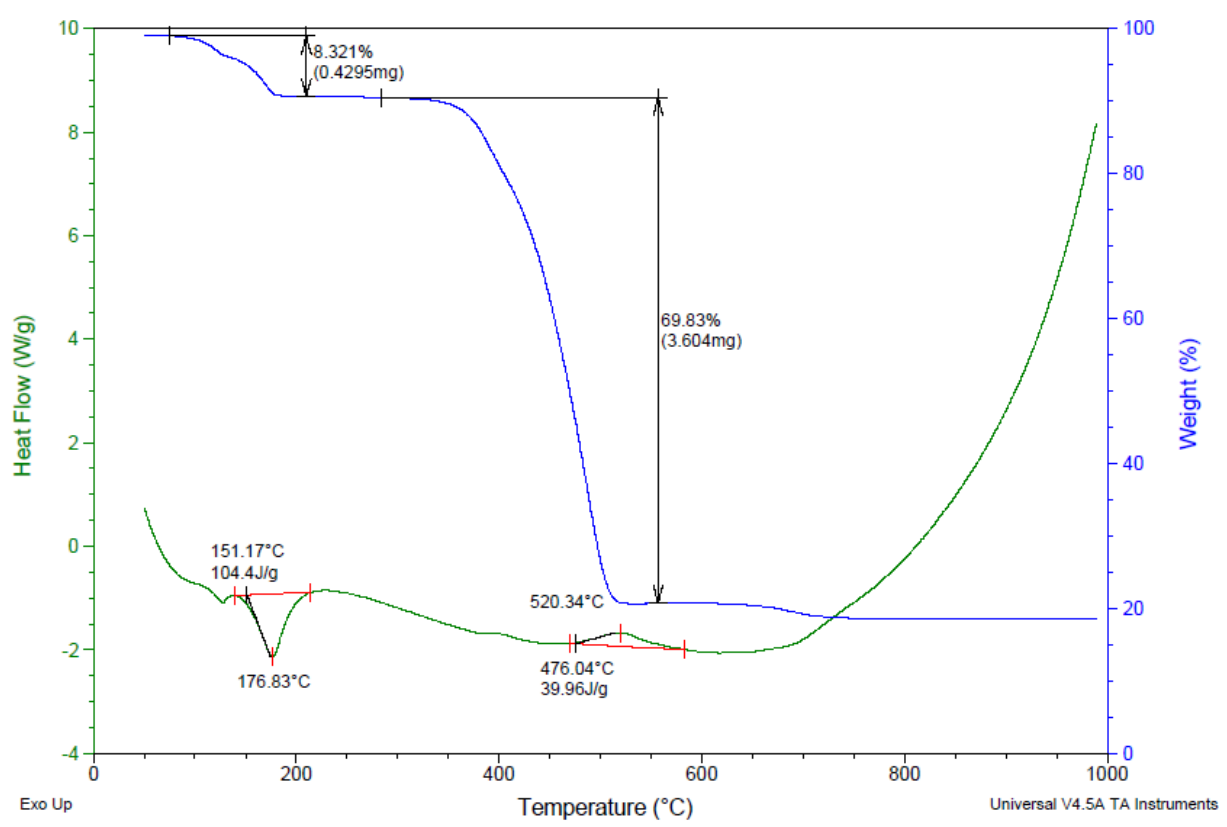

Figure 5.71. $\mathrm{CaI}_{2}$ in air

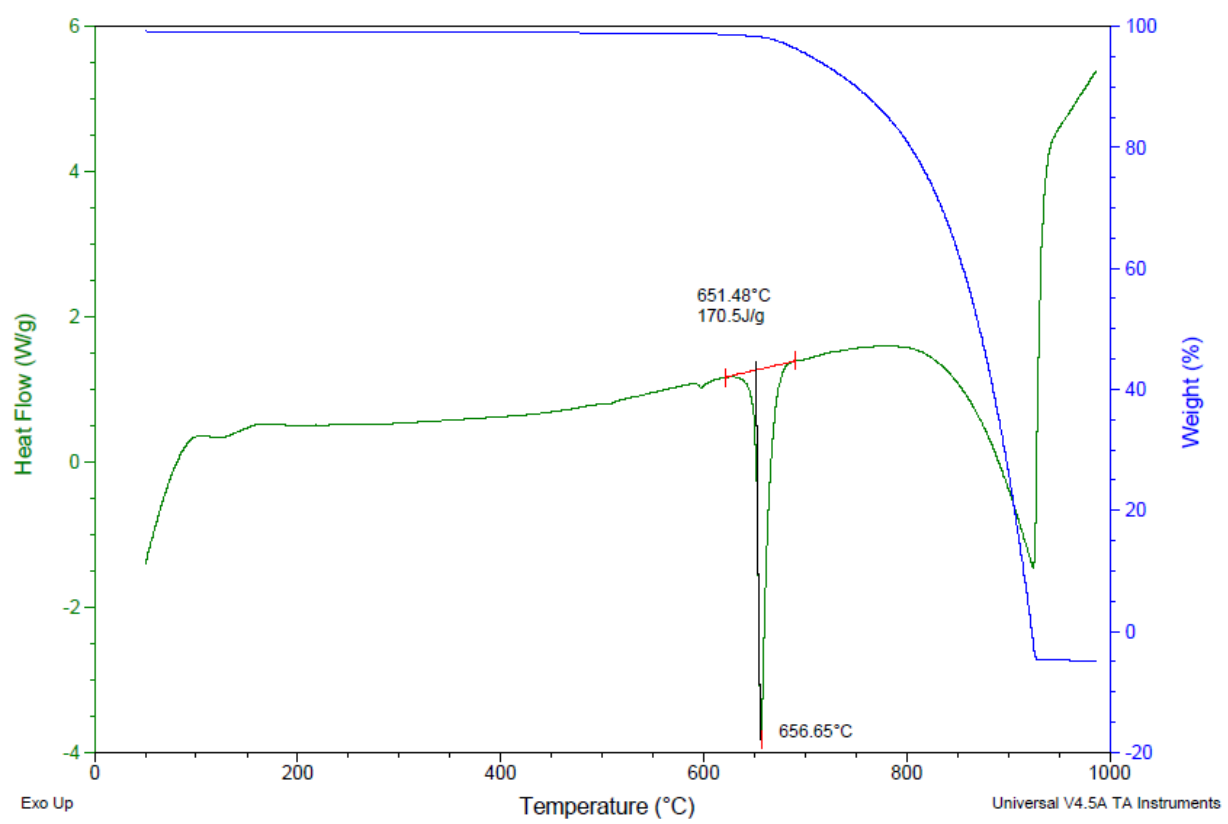

Figure 5.72. NaI in nitrogen 


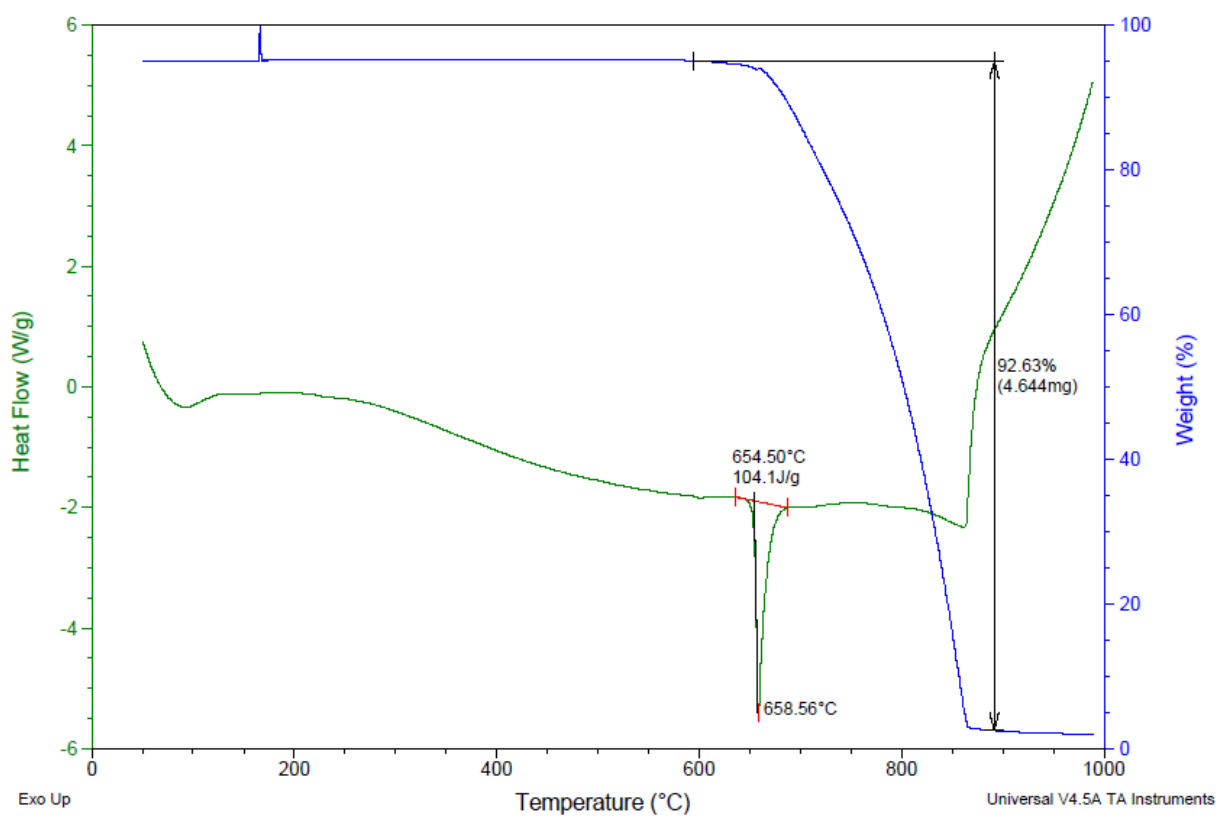

Figure 5.73. $\mathrm{NaI}$ in air

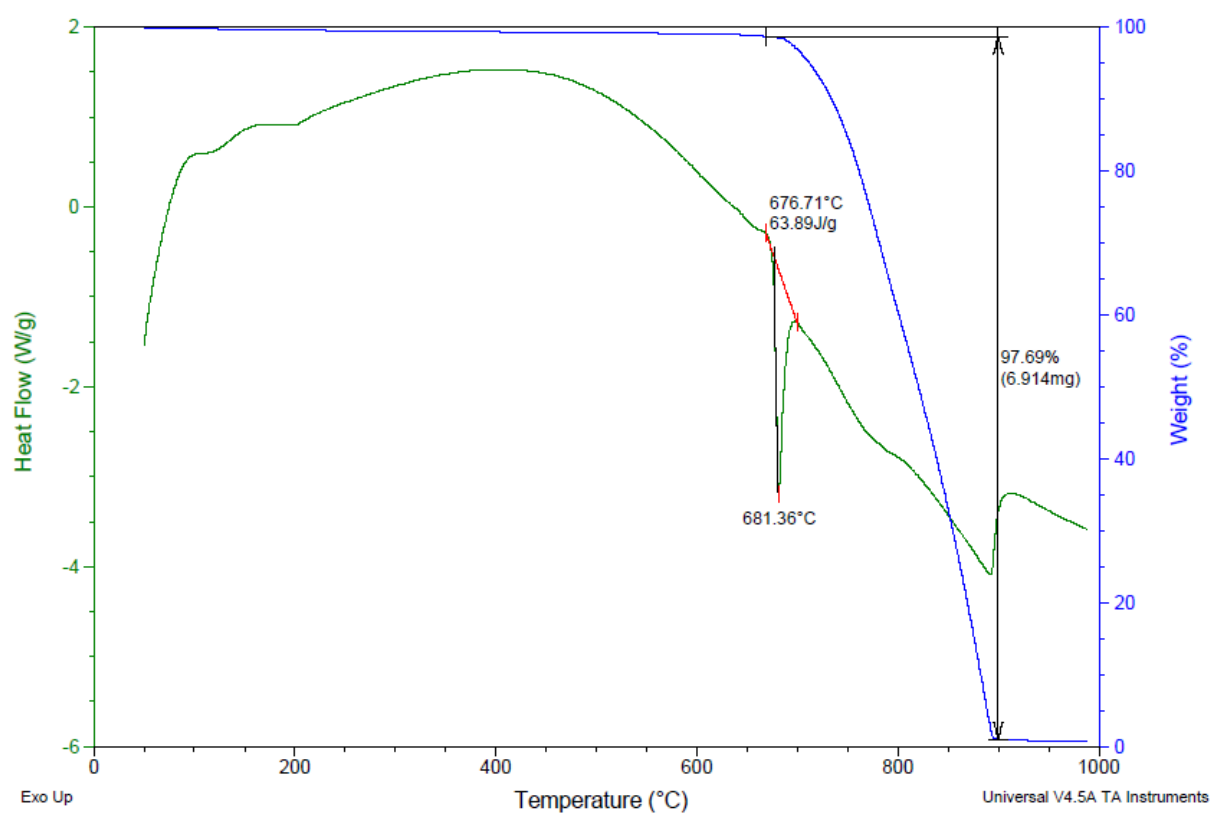

Figure 5.74. KI in nitrogen 


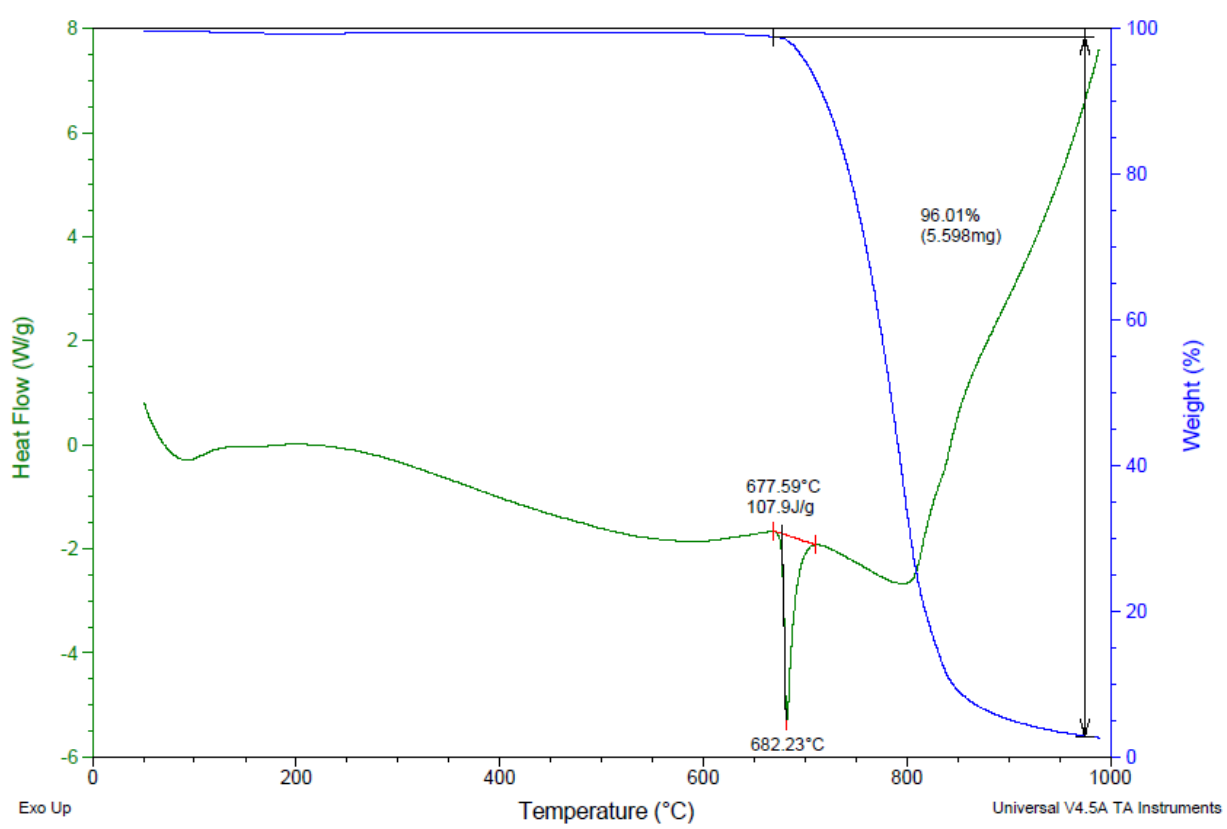

Figure 5.75. KI in air

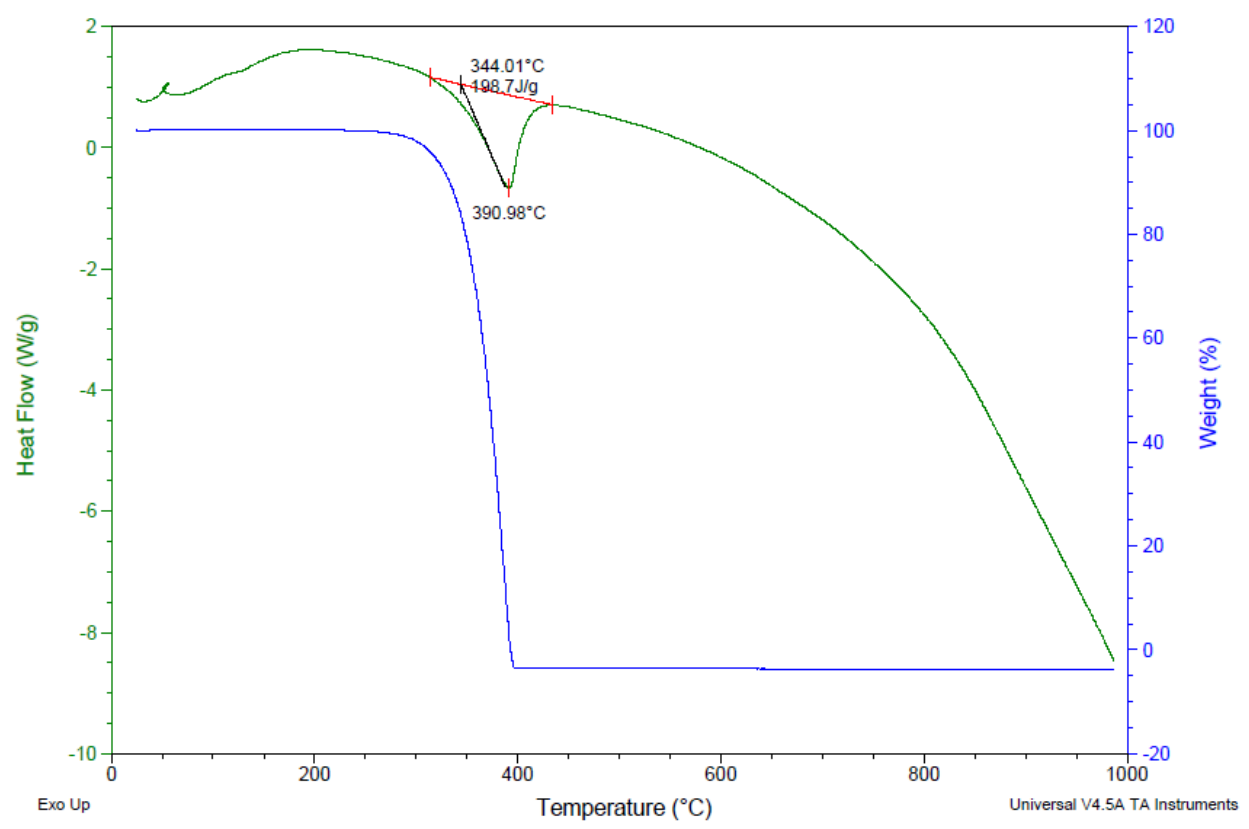

Figure 5.76. $\mathrm{BiI}_{3}$ in nitrogen 


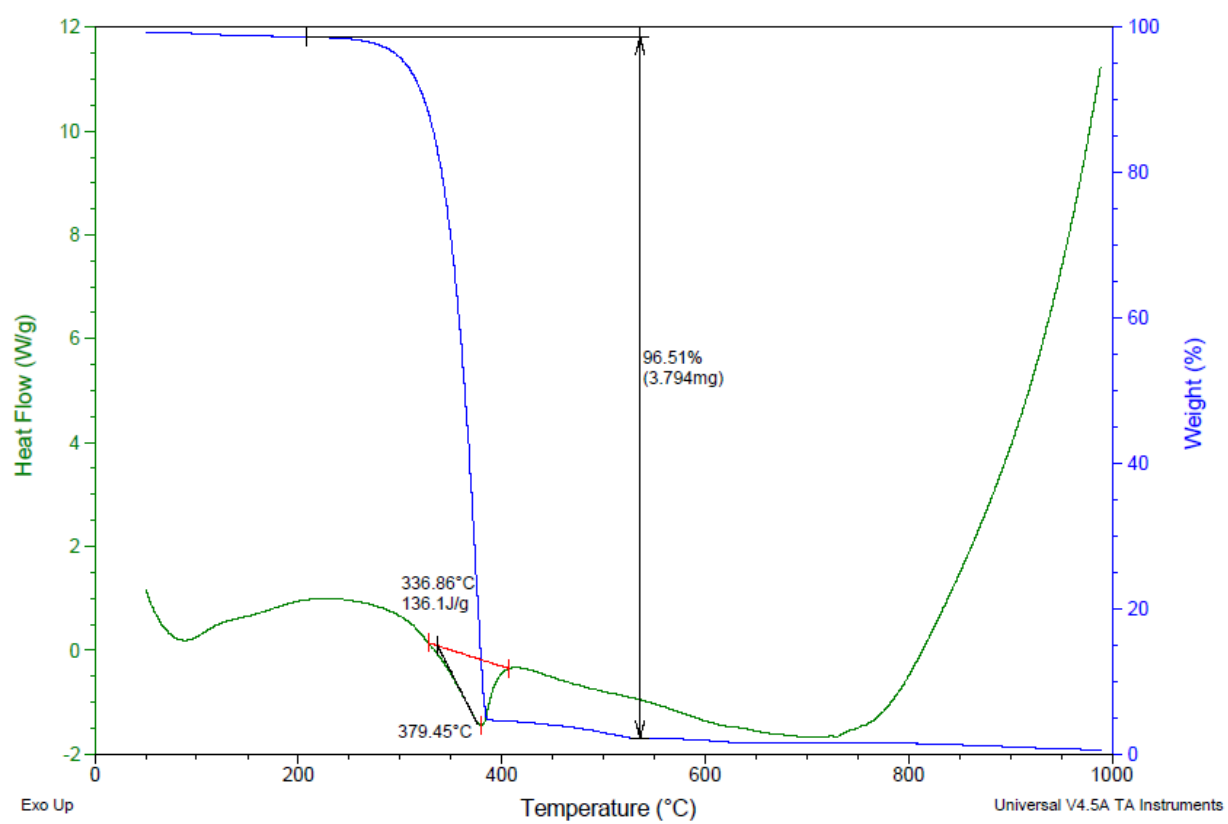

Figure 5.77. $\mathrm{BiI}_{3}$ in air

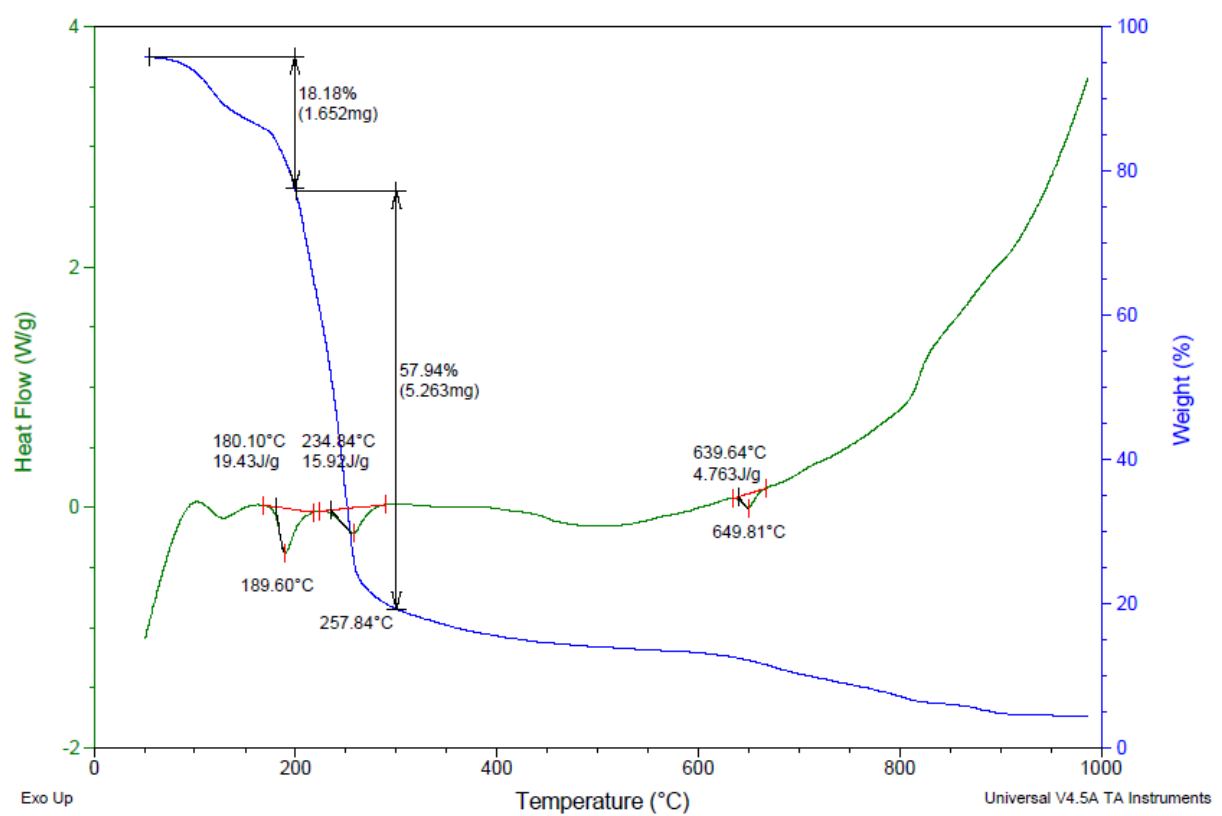

Figure 5.78. $\mathrm{Al}_{2} \mathrm{I}_{6}$ in nitrogen 


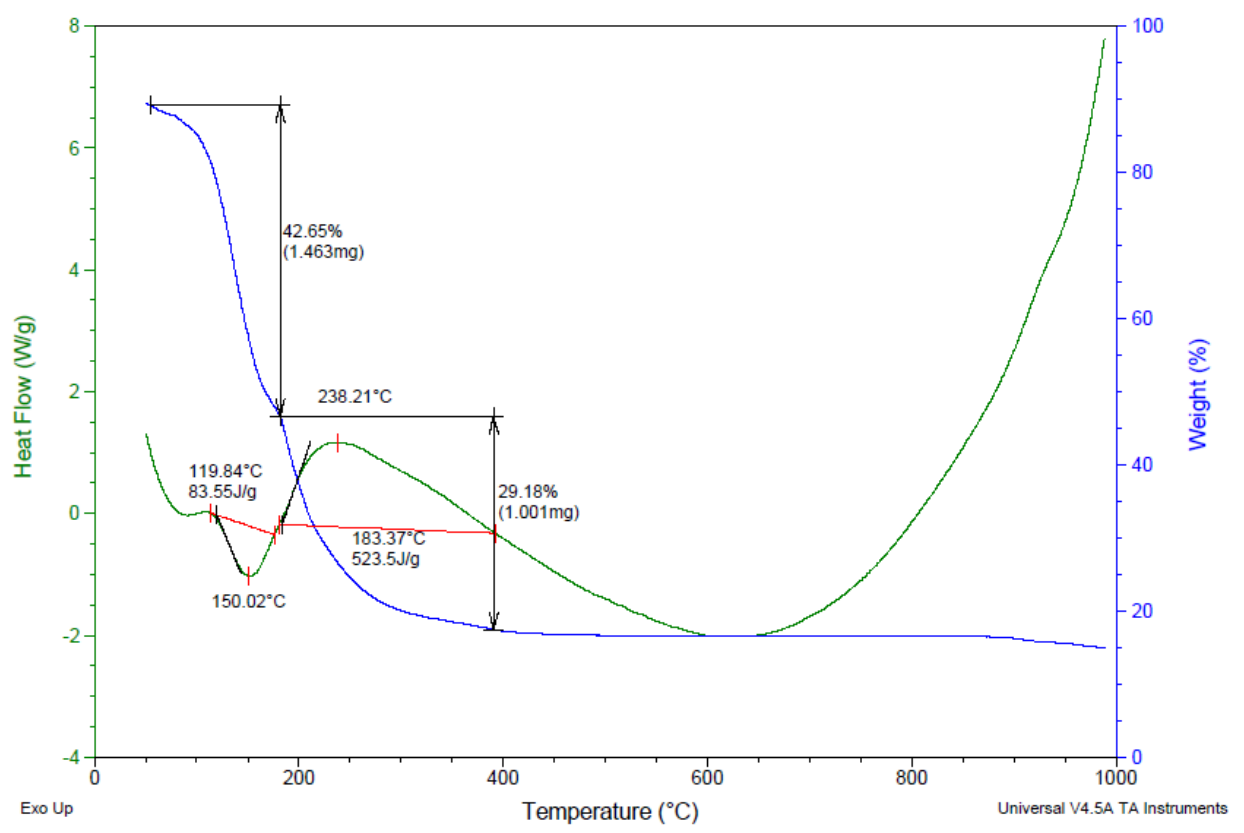

Figure 5.79. $\mathrm{Al}_{2} \mathrm{I}_{6}$ in air

\section{XPS Data}

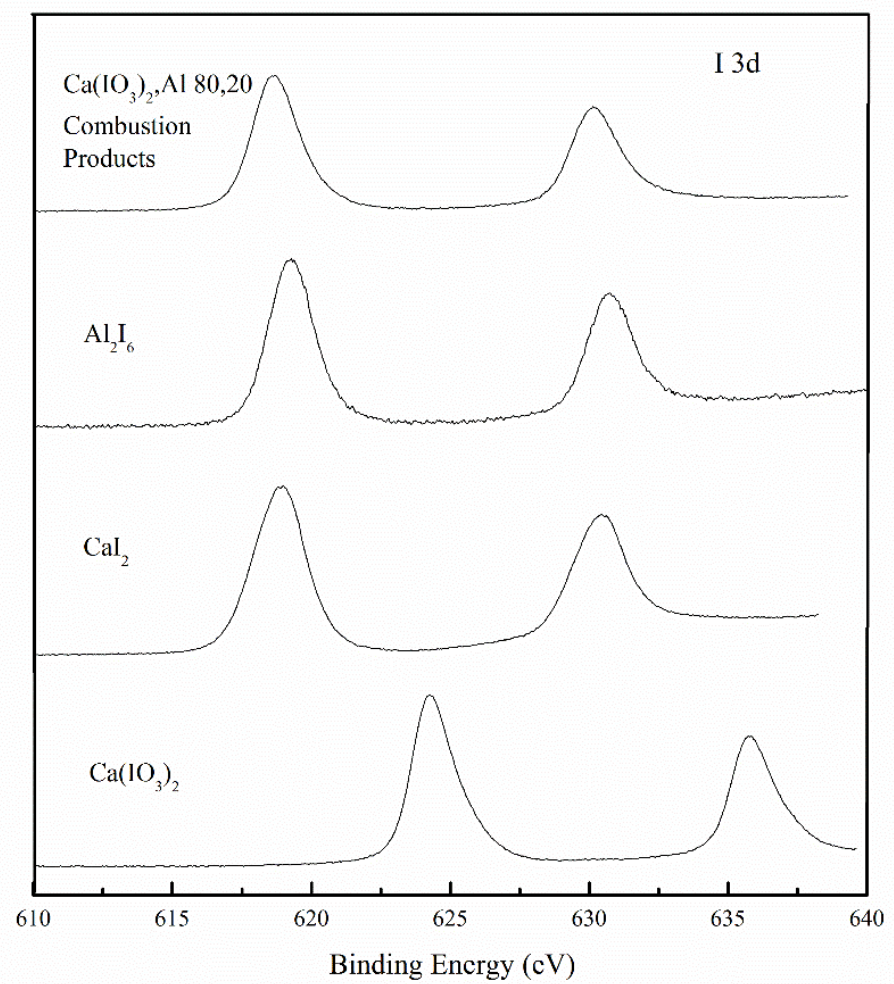

Figure 5.80. 80/20 Ca( $\left(\mathrm{IO}_{3}\right)_{2} / \mathrm{Al}$ combustion products $\mathrm{I} 3 \mathrm{~d}$ high resolution spectra 


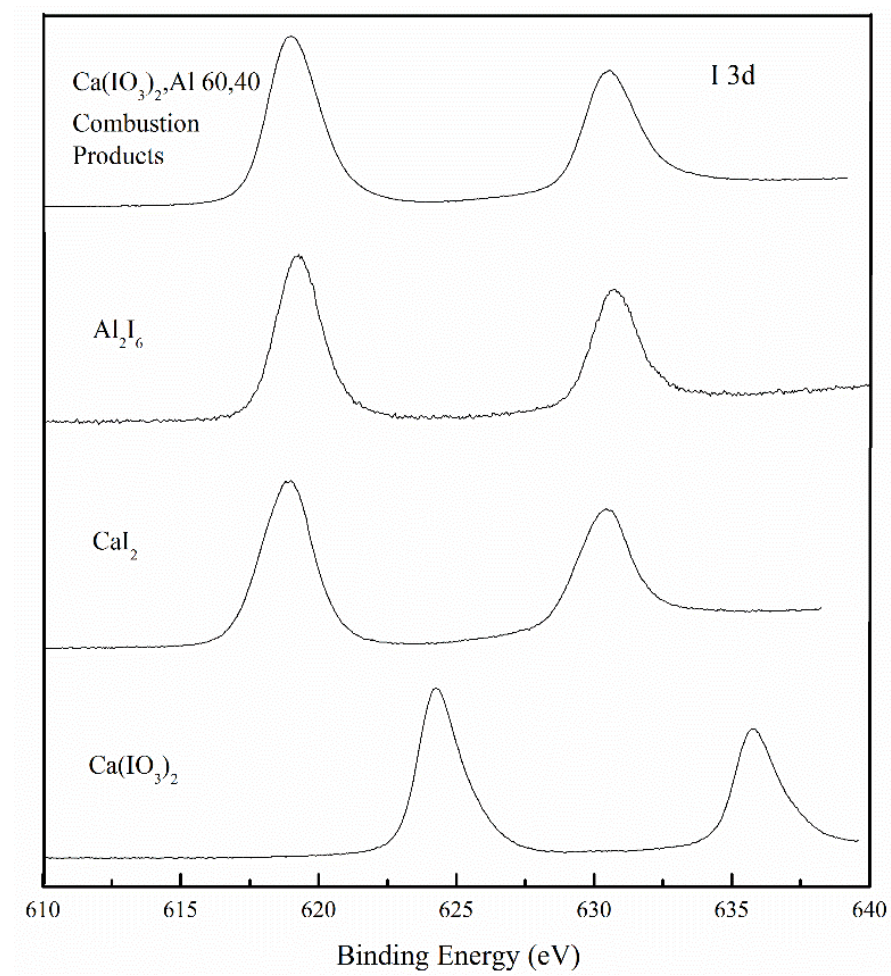

Figure 5.81. 60/40 $\mathrm{Ca}\left(\mathrm{IO}_{3}\right)_{2} / \mathrm{Al}$ combustion products I $3 \mathrm{~d}$ high resolution spectra

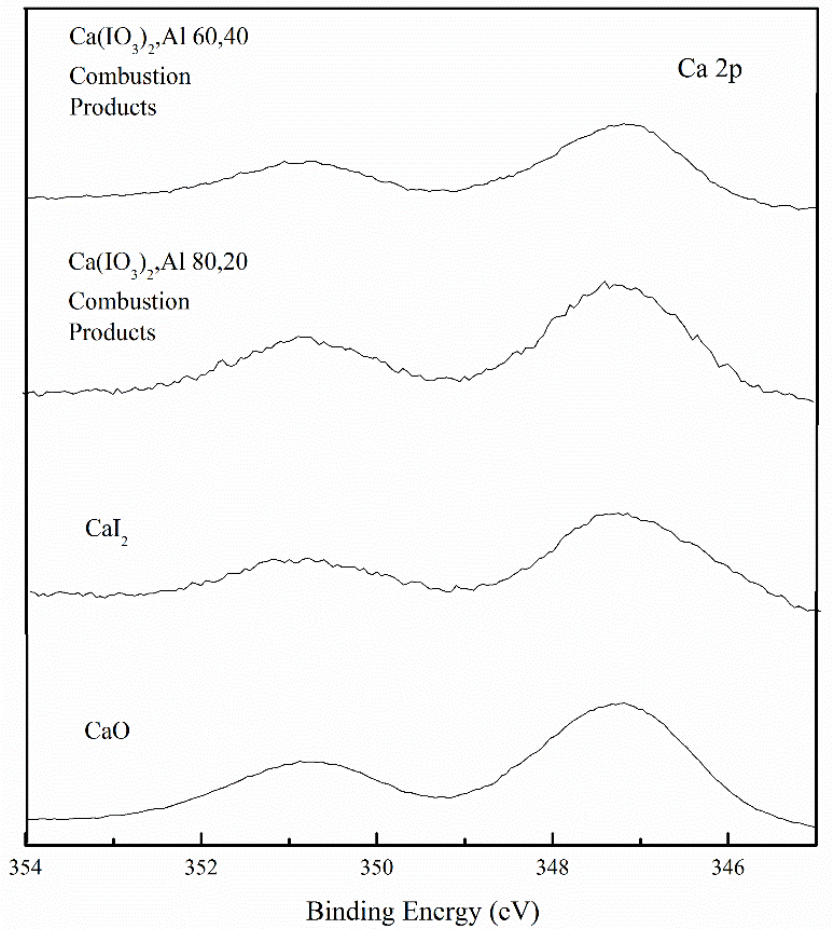

Figure 5.82. $\mathrm{Ca}\left(\mathrm{IO}_{3}\right)_{2} / \mathrm{Al}$ combustion products $\mathrm{Ca} 2 \mathrm{p}$ high resolution spectra 


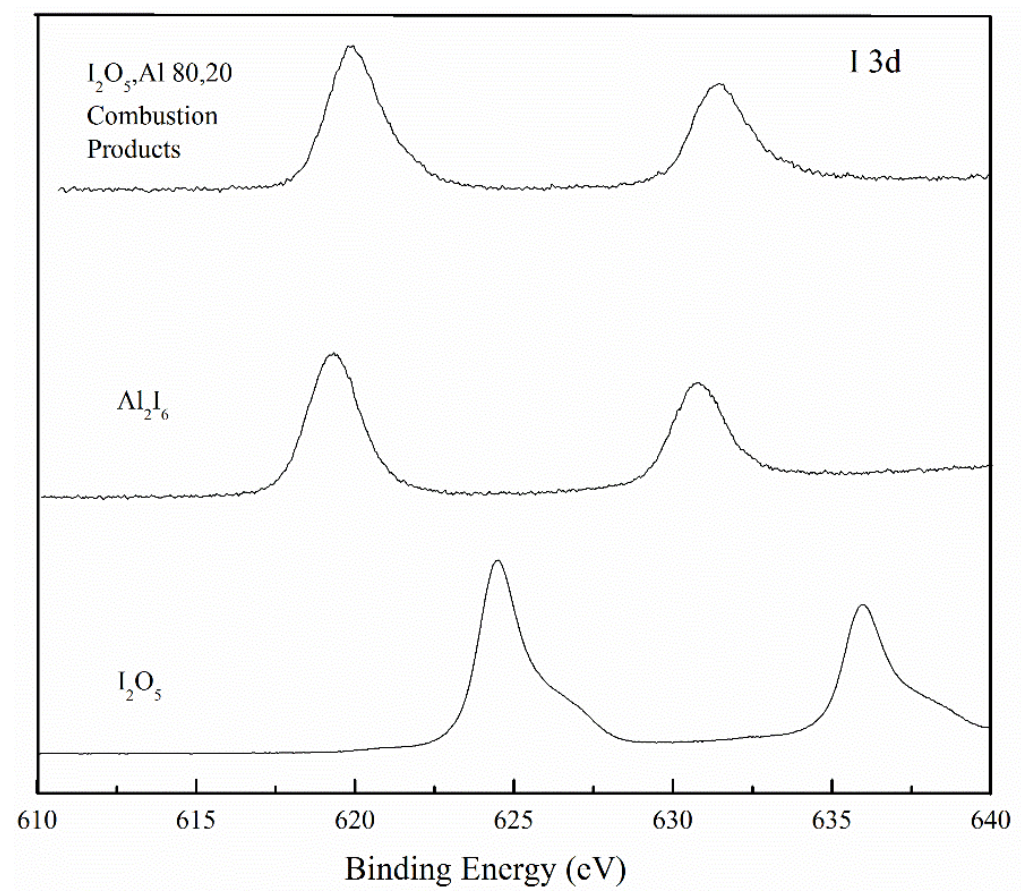

Figure 5.83. 80/20 $\mathrm{I}_{2} \mathrm{O}_{5} / \mathrm{Al}$ combustion products $\mathrm{I} 3 \mathrm{~d}$ high resolution spectra

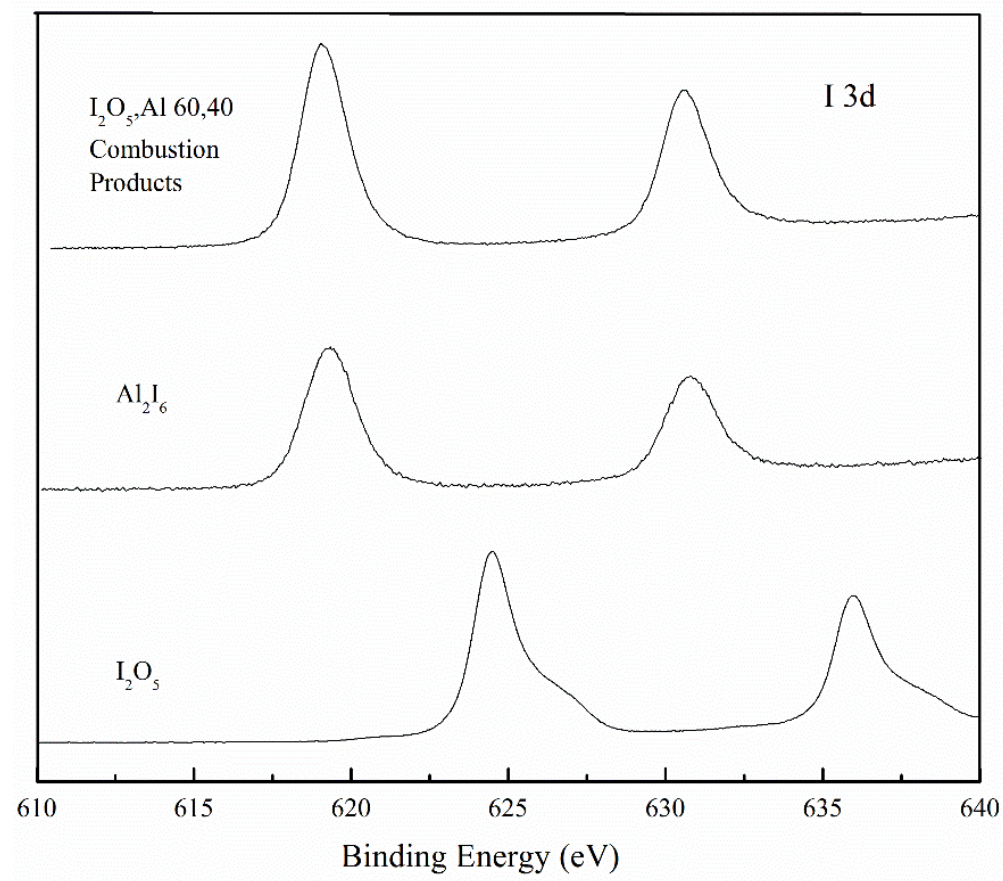

Figure 5.84. 60/40 $\mathrm{I}_{2} \mathrm{O}_{5} / \mathrm{Al}$ combustion products $\mathrm{I} 3 \mathrm{~d}$ high resolution spectra 


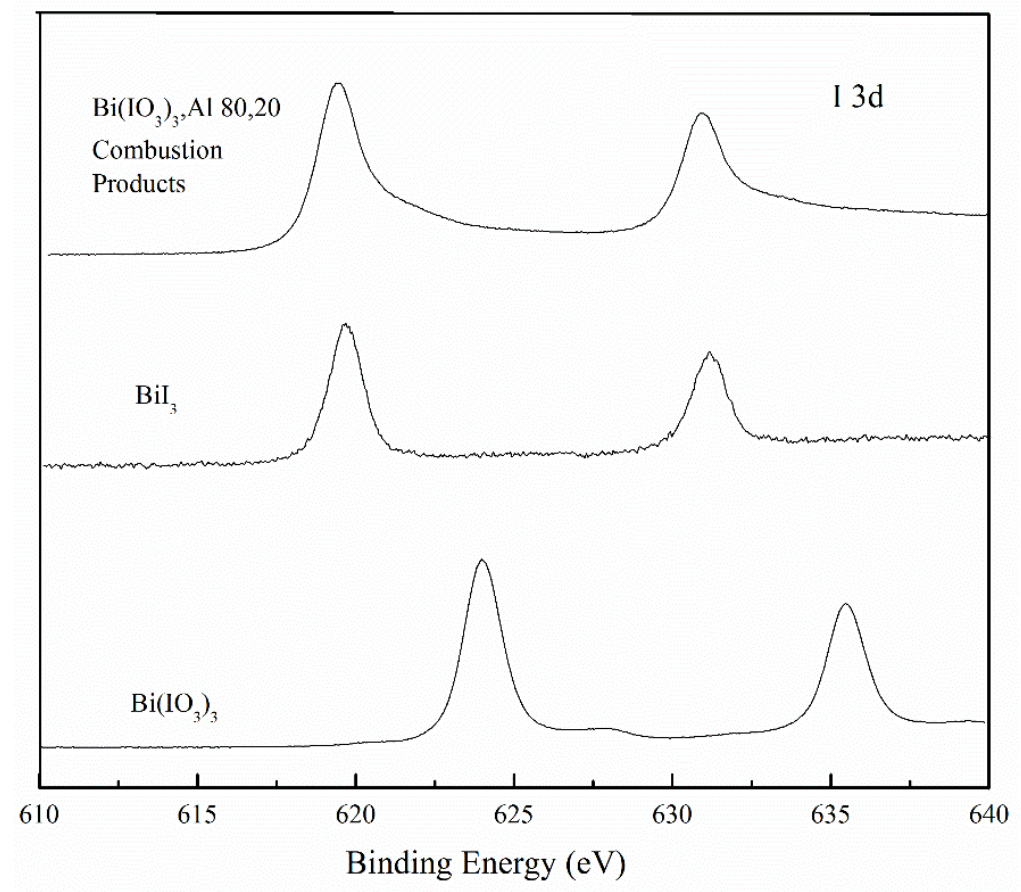

Figure 5.85. 80/20 $\mathrm{Bi}\left(\mathrm{IO}_{3}\right)_{3} / \mathrm{Al}$ combustion products I 3d high resolution spectra

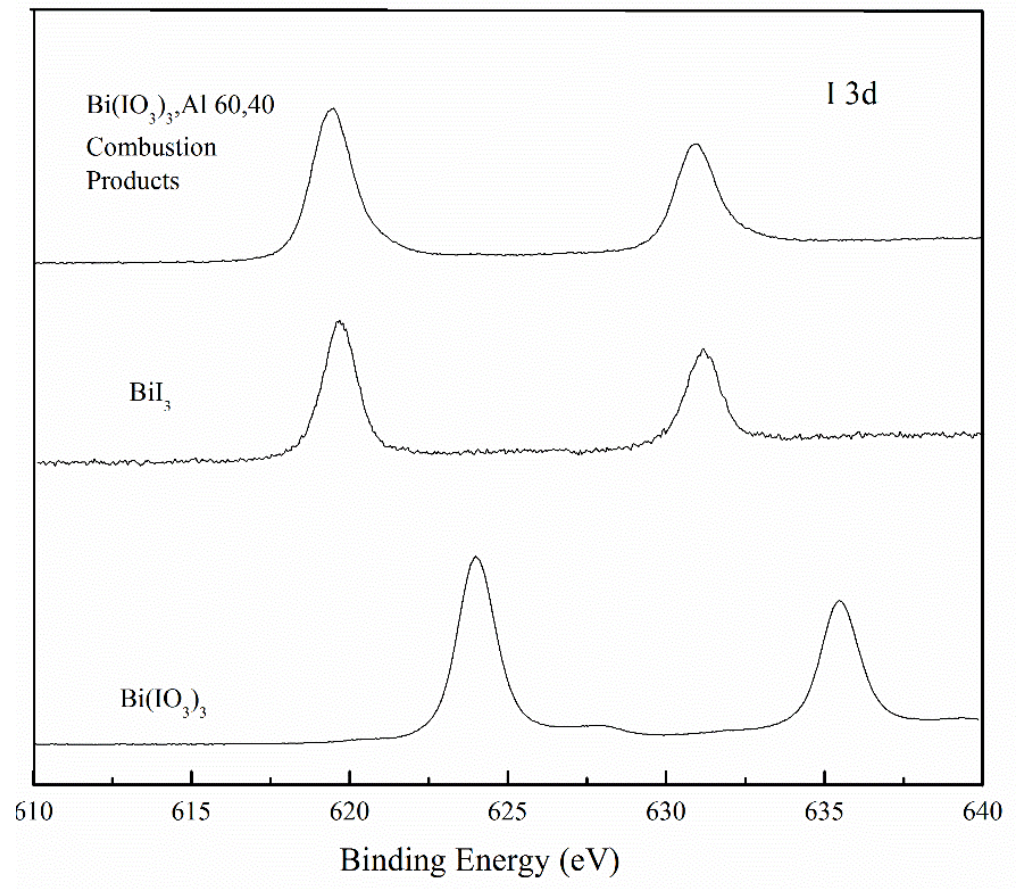

Figure 5.86. 60/40 $\mathrm{Bi}\left(\mathrm{IO}_{3}\right)_{3} / \mathrm{Al}$ combustion products $\mathrm{I} 3 \mathrm{~d}$ high resolution spectra 


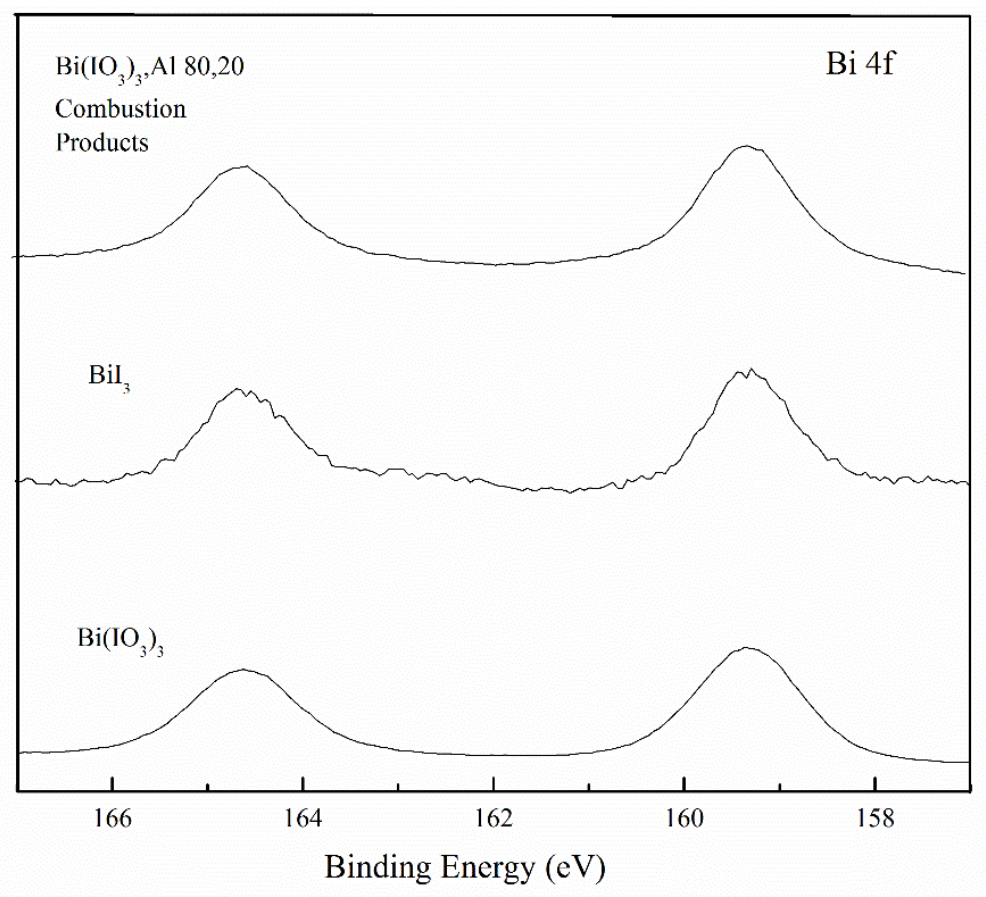

Figure 5.87. 80/20 $\mathrm{Bi}\left(\mathrm{IO}_{3}\right)_{3} / \mathrm{Al}$ combustion products $\mathrm{Bi} 4 \mathrm{f}$ high resolution spectra

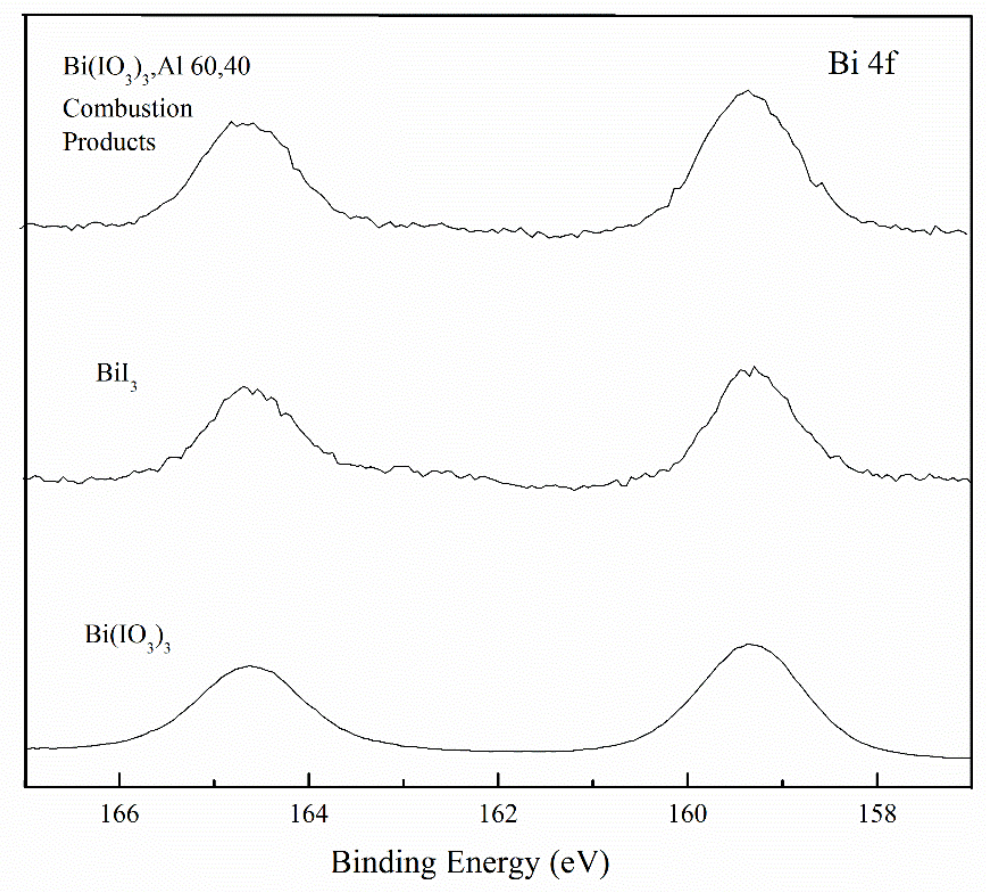

Figure 5.88. 60/40 $\mathrm{Bi}\left(\mathrm{IO}_{3}\right)_{3} / \mathrm{Al}$ combustion products $\mathrm{Bi} 4 \mathrm{f}$ high resolution spectra 


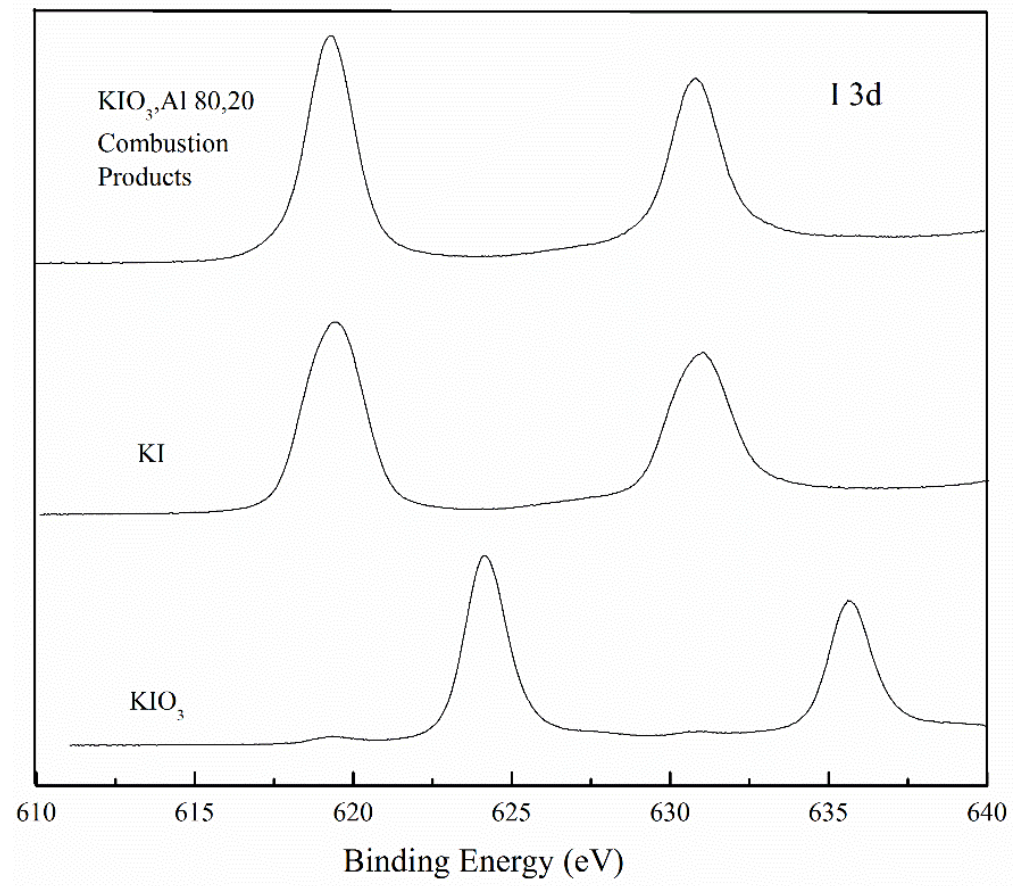

Figure 5.89. 80/20 $\mathrm{KIO}_{3} / \mathrm{Al}$ combustion products I $3 \mathrm{~d}$ high resolution spectra

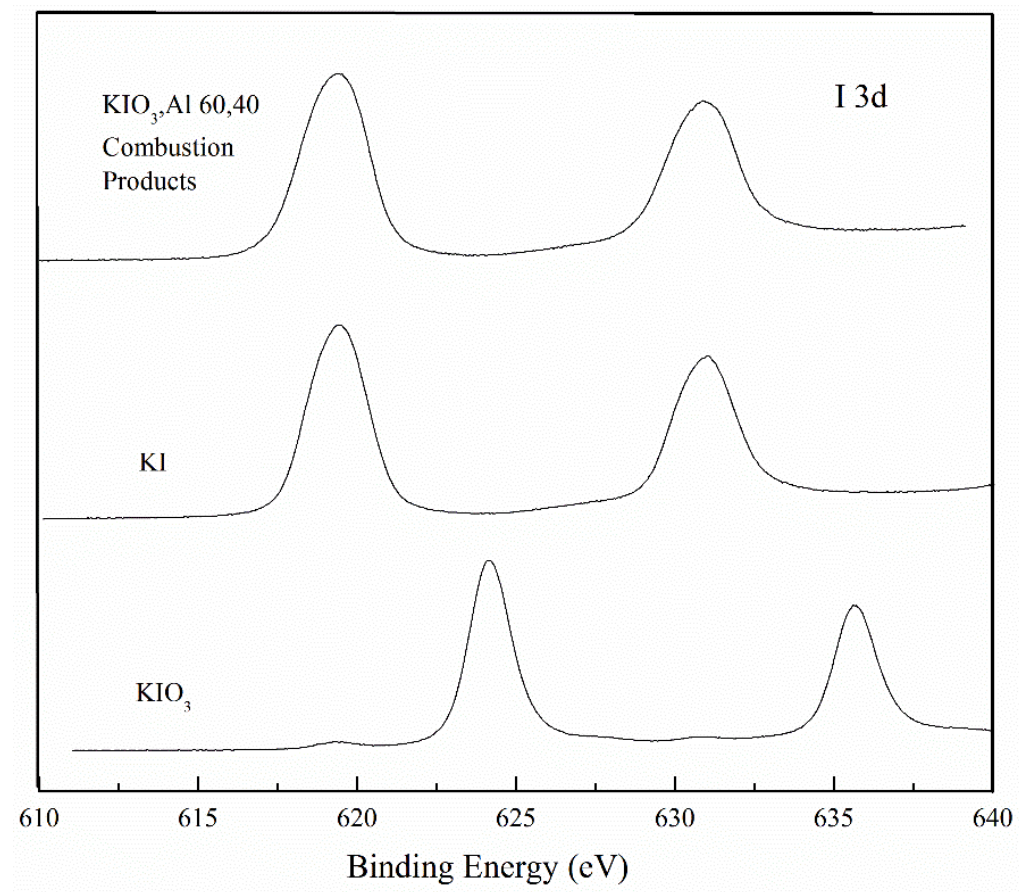

Figure 5.90. 60/40 $\mathrm{KIO}_{3} / \mathrm{Al}$ combustion products $\mathrm{I} 3 \mathrm{~d}$ high resolution spectra 


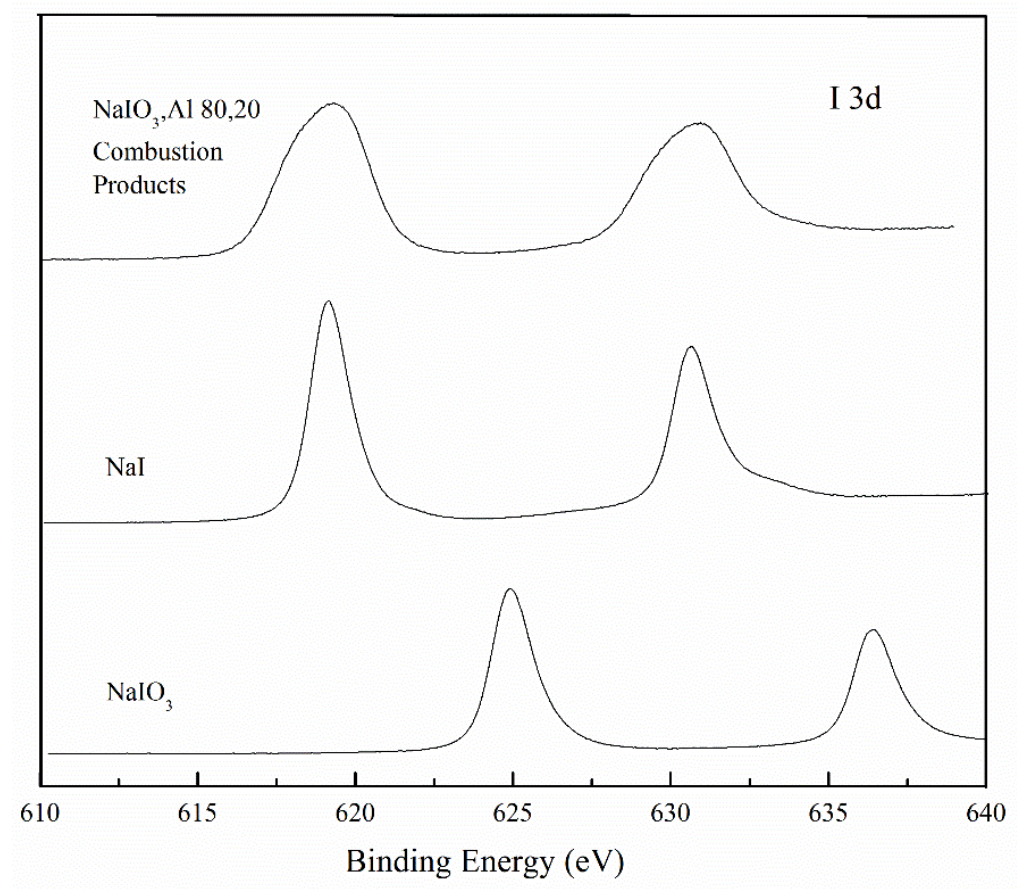

Figure 5.91. 80/20 $\mathrm{NaIO}_{3} / \mathrm{Al}$ combustion products I 3d high resolution spectra

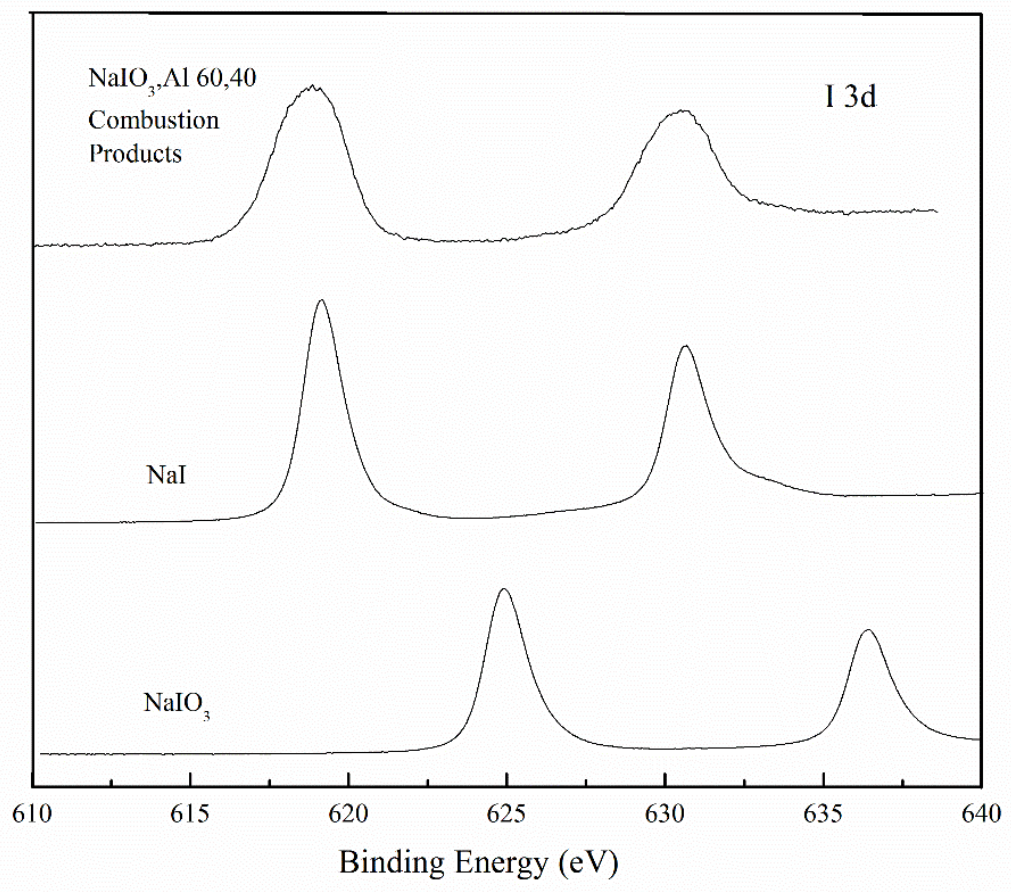

Figure 5.92. 60/40 $\mathrm{NaIO}_{3} / \mathrm{Al}$ combustion products I $3 \mathrm{~d}$ high resolution spectra 


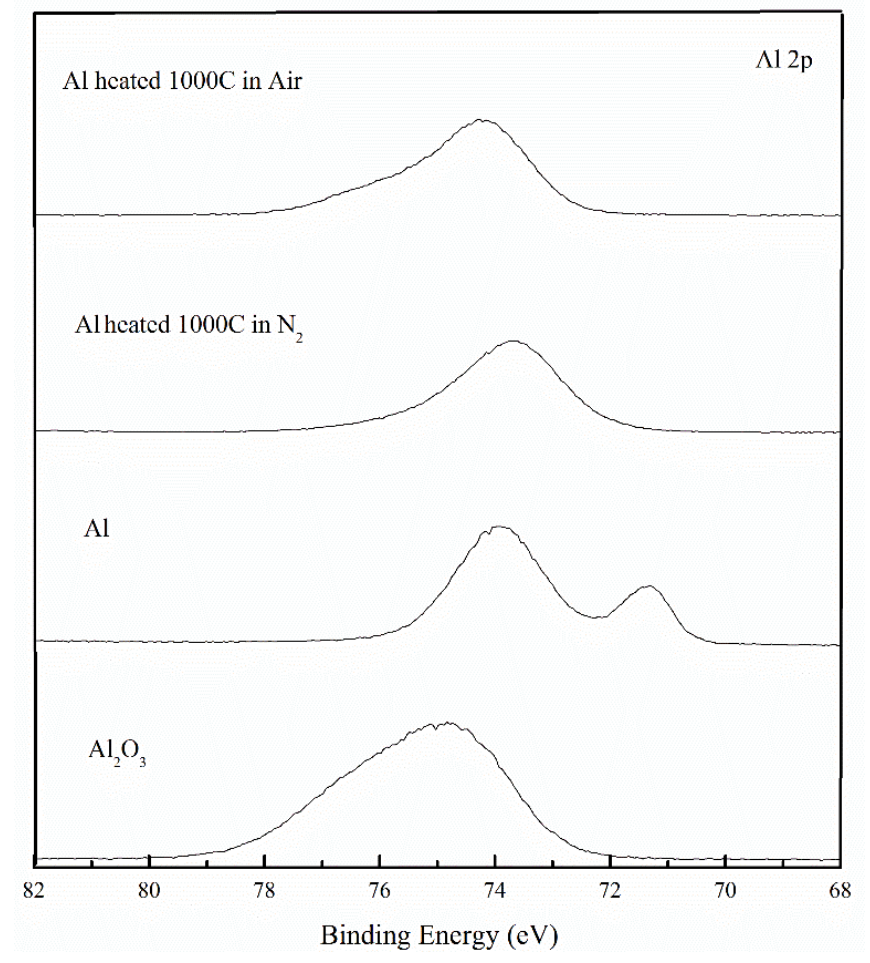

Figure 5.93. Aluminum heated in air and nitrogen $\mathrm{Al} 2 \mathrm{p}$ high resolution spectra

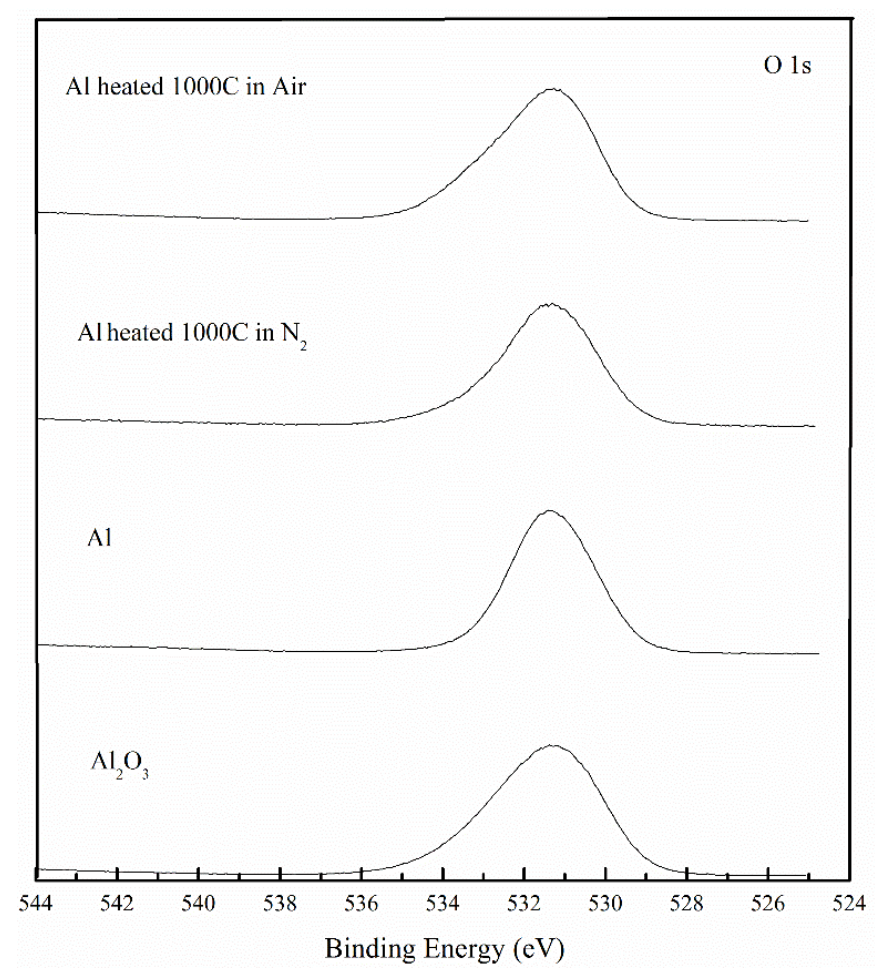

Figure 5.94. Aluminum heated in air and nitrogen $\mathrm{O}$ 1s high resolution spectra 
Table 5.1. XPS extended table with FWMH for each binding energy

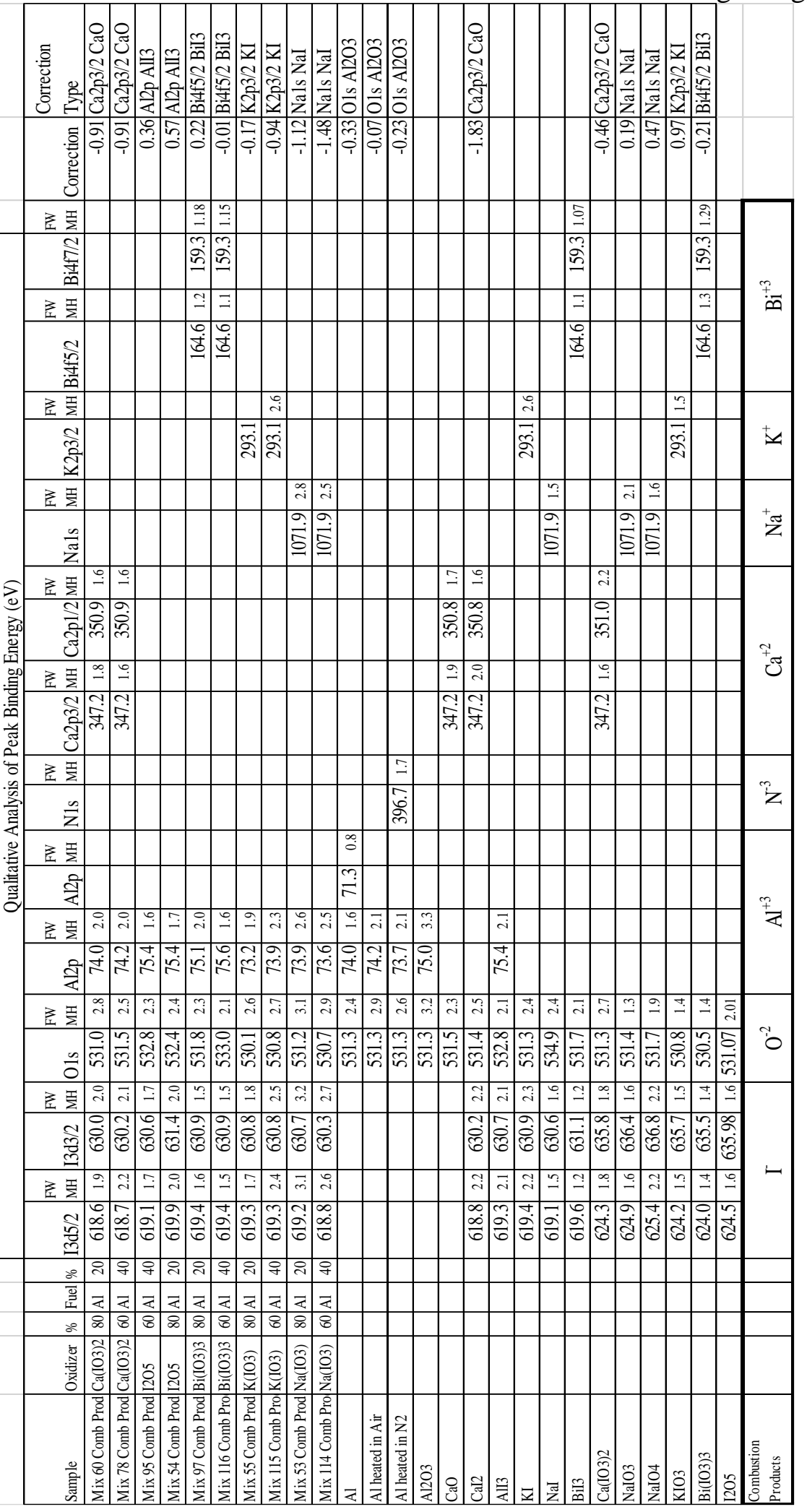




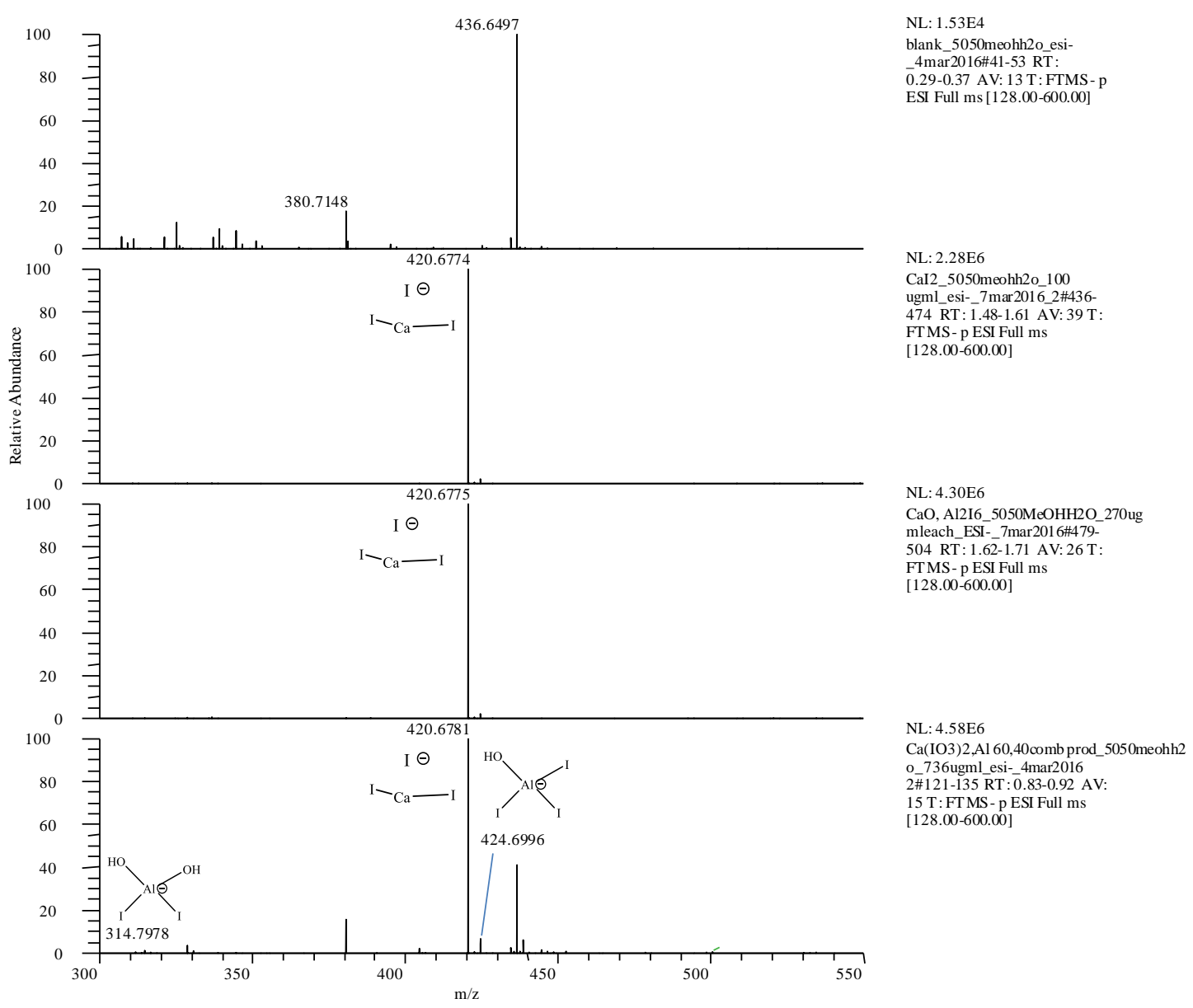

Figure 5.95. LCMS - $\mathrm{Ca}\left(\mathrm{IO}_{3}\right)_{2} / \mathrm{Al}$ extracted with $\mathrm{H}_{2} \mathrm{O}$. Blank (top), $\mathrm{Ca}\left(\mathrm{I}_{2}\right)$ in $\mathrm{H}_{2} \mathrm{O}$ (middle top), $\mathrm{CaO}$ added to a solution of $\mathrm{Al}_{2} \mathrm{I}_{6}$ in $\mathrm{H}_{2} \mathrm{O}$ (middle bottom), and 60/40 Calcium Iodate/Al combustion products extracted in $\mathrm{H}_{2} \mathrm{O}$ (bottom). 


\section{APPENDIX 6: DATA FOR MANUSCRIPT 3}

Pressure vs. Time Curves from Bomb Calorimetry

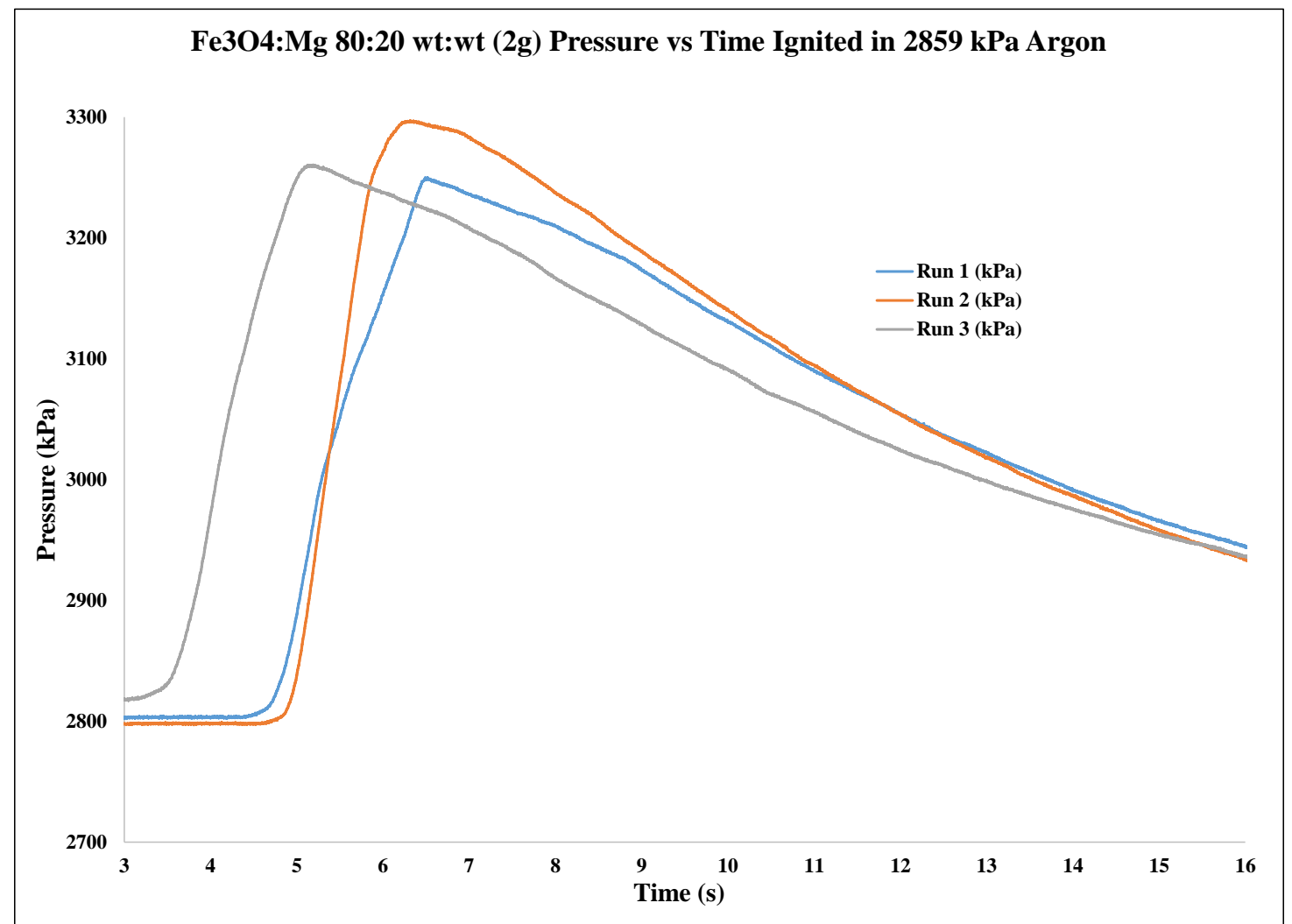

Figure 6.1. Pressure vs. Time curve of $\mathrm{Fe}_{3} \mathrm{O}_{4}: \mathrm{Mg}$ 80:20 wt:wt (2 g in $2859 \mathrm{kPa}$ Argon) 


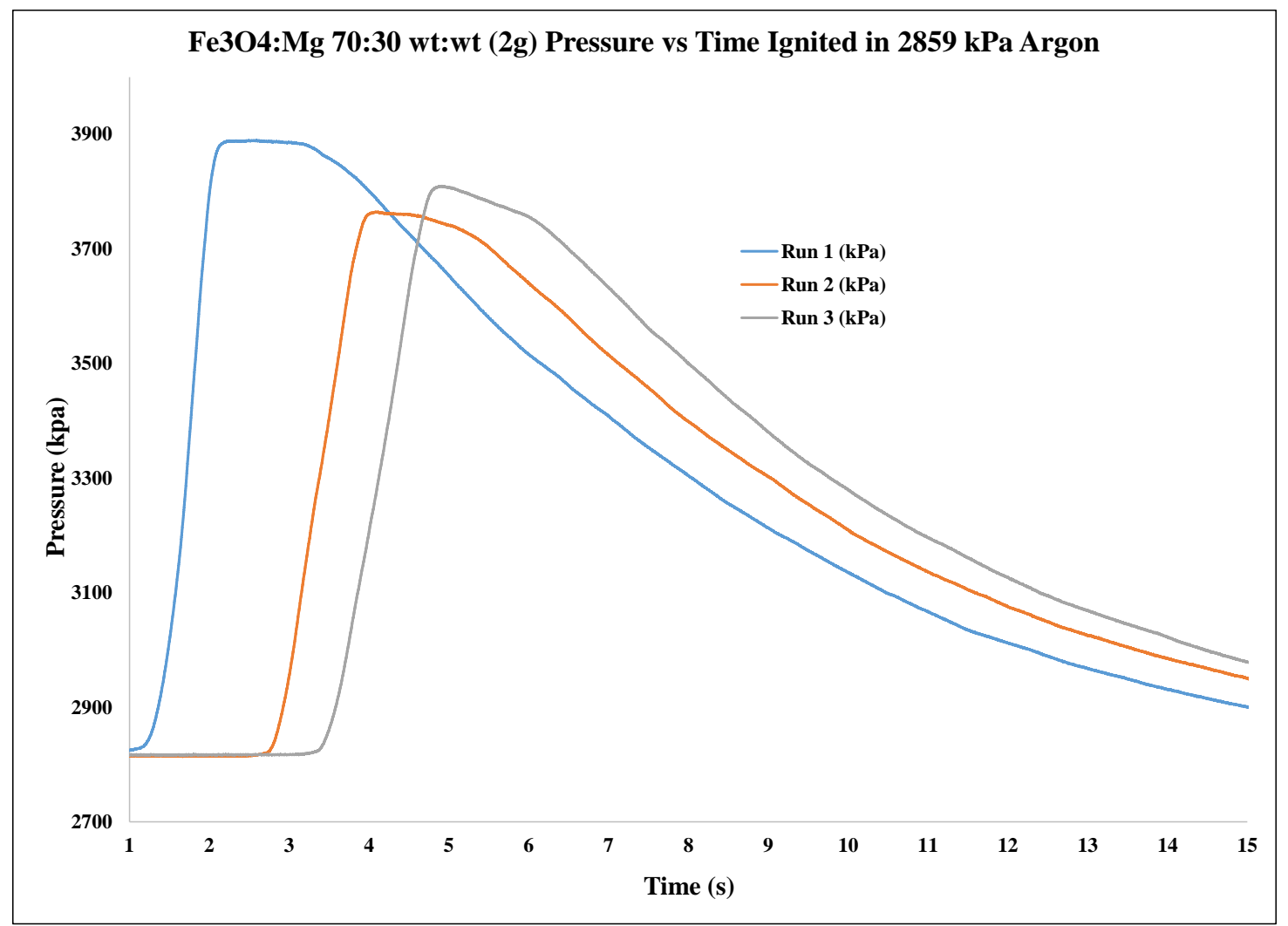

Figure 6.2. Pressure vs. Time curve of $\mathrm{Fe}_{3} \mathrm{O}_{4}: \mathrm{Mg}$ 70:30 wt:wt (2 g in $2859 \mathrm{kPa}$ Argon) 


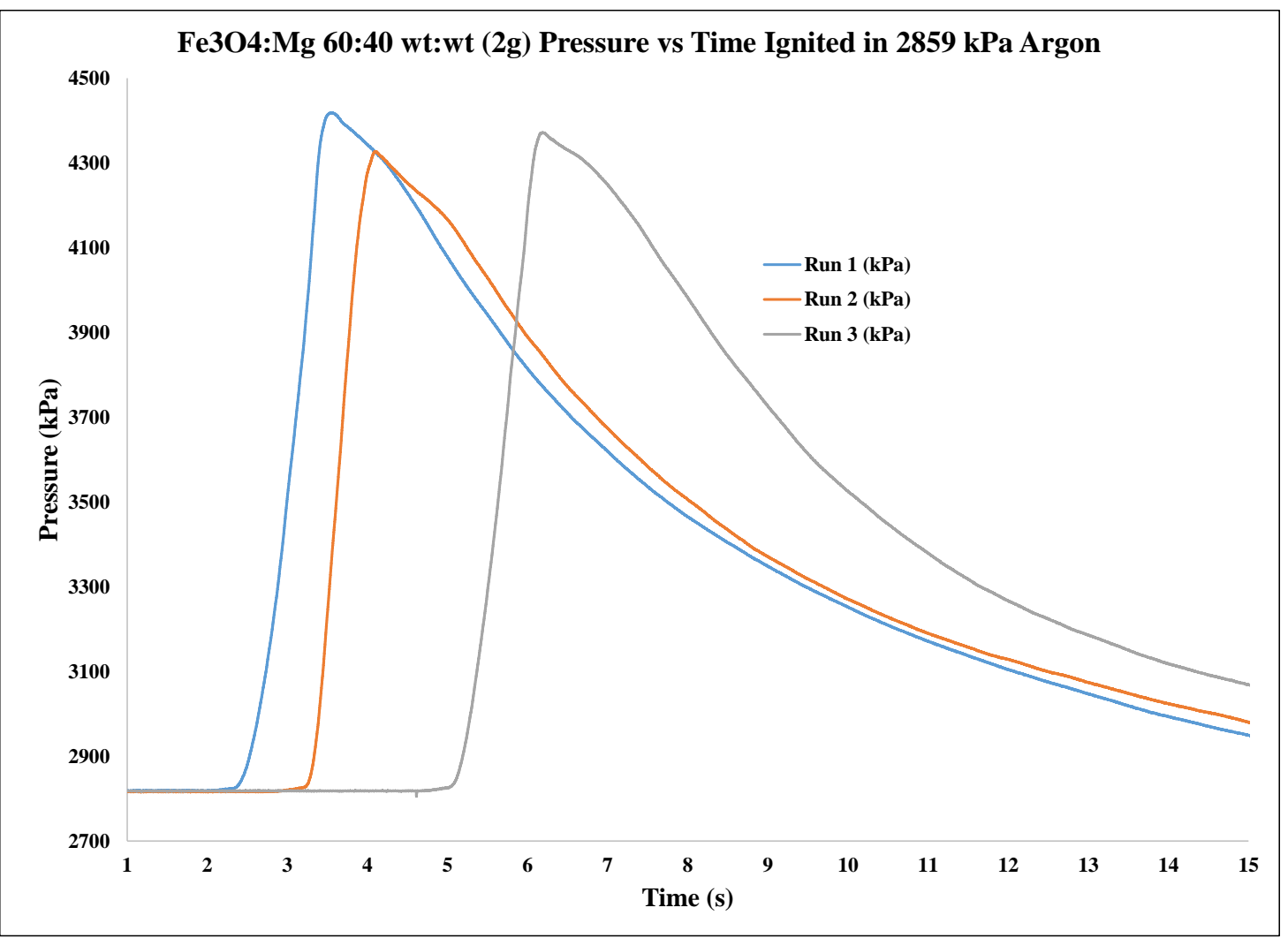

Figure 6.3. Pressure vs. Time curve of $\mathrm{Fe}_{3} \mathrm{O}_{4}: \mathrm{Mg}$ 60:40 wt:wt (2 g in $2859 \mathrm{kPa}$ Argon) 


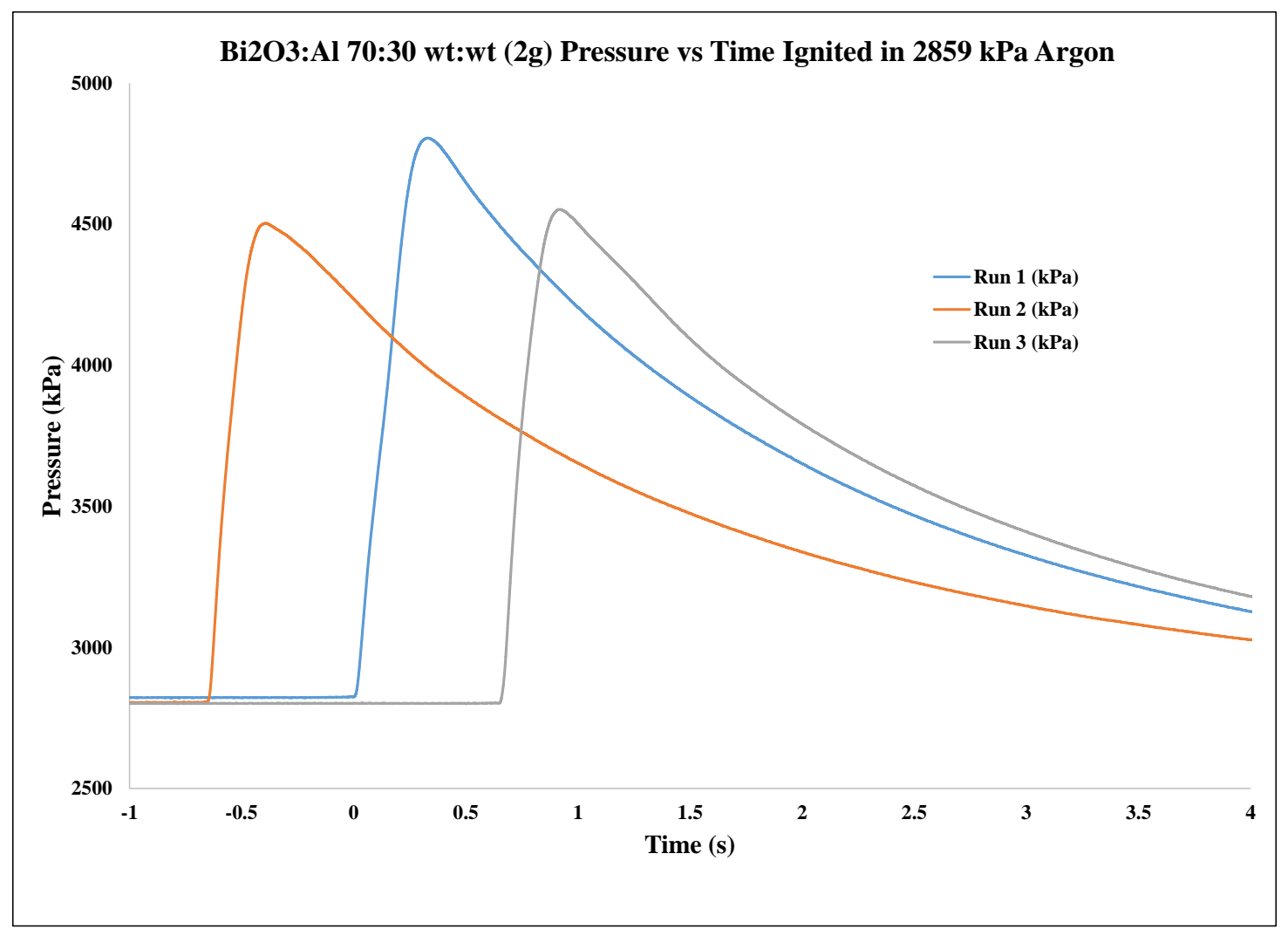

Figure 6.4. Pressure vs. Time curve of $\mathrm{Bi}_{2} \mathrm{O}_{3}: \mathrm{Al}$ 70:30 wt:wt (2 g in $2859 \mathrm{kPa}$ Argon) 


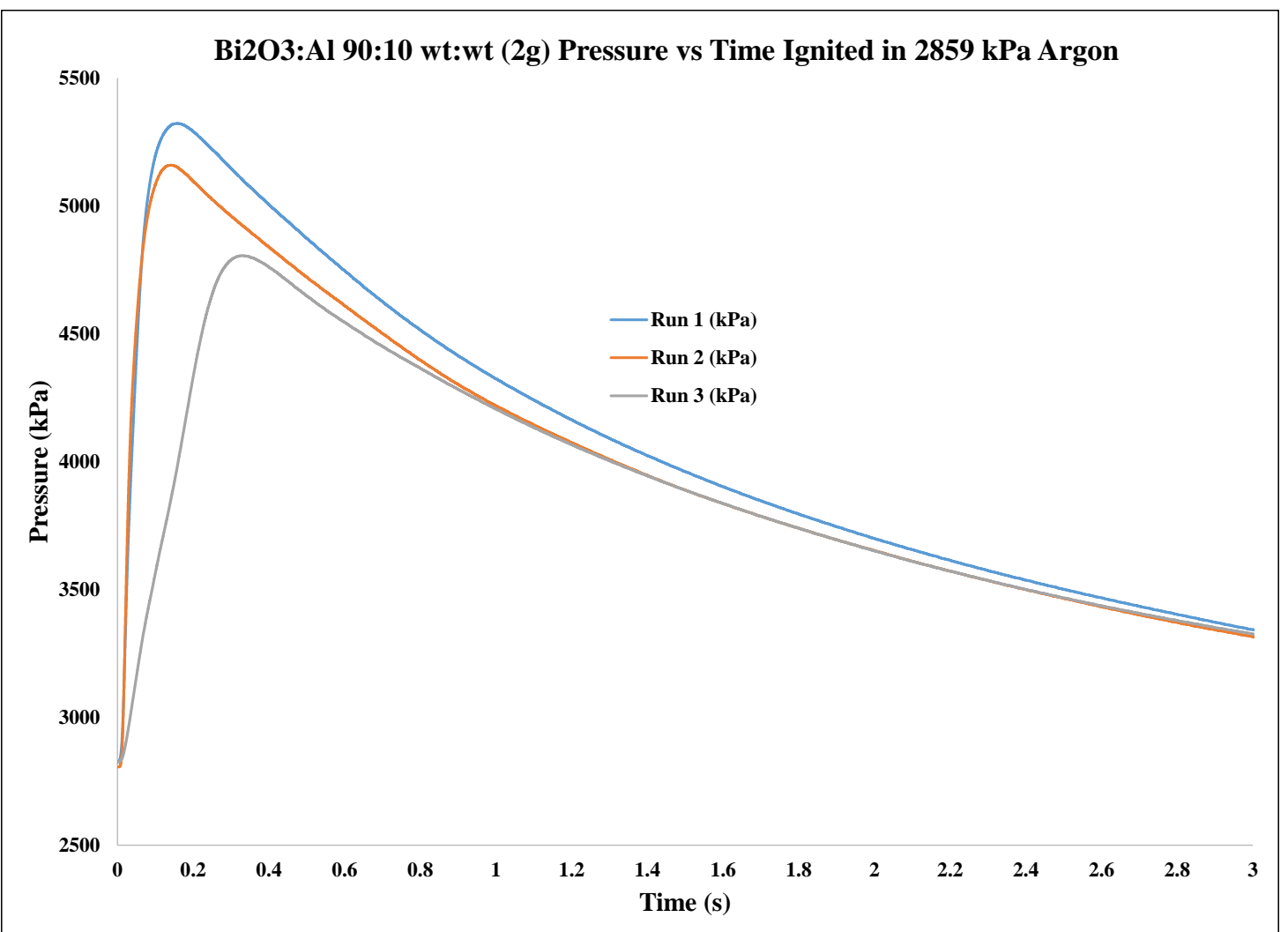

Figure 6.5. Pressure vs. Time curve of $\mathrm{Bi}_{2} \mathrm{O}_{3}: \mathrm{Al}$ 90:10 wt:wt (2 g in $2859 \mathrm{kPa}$ Argon) 


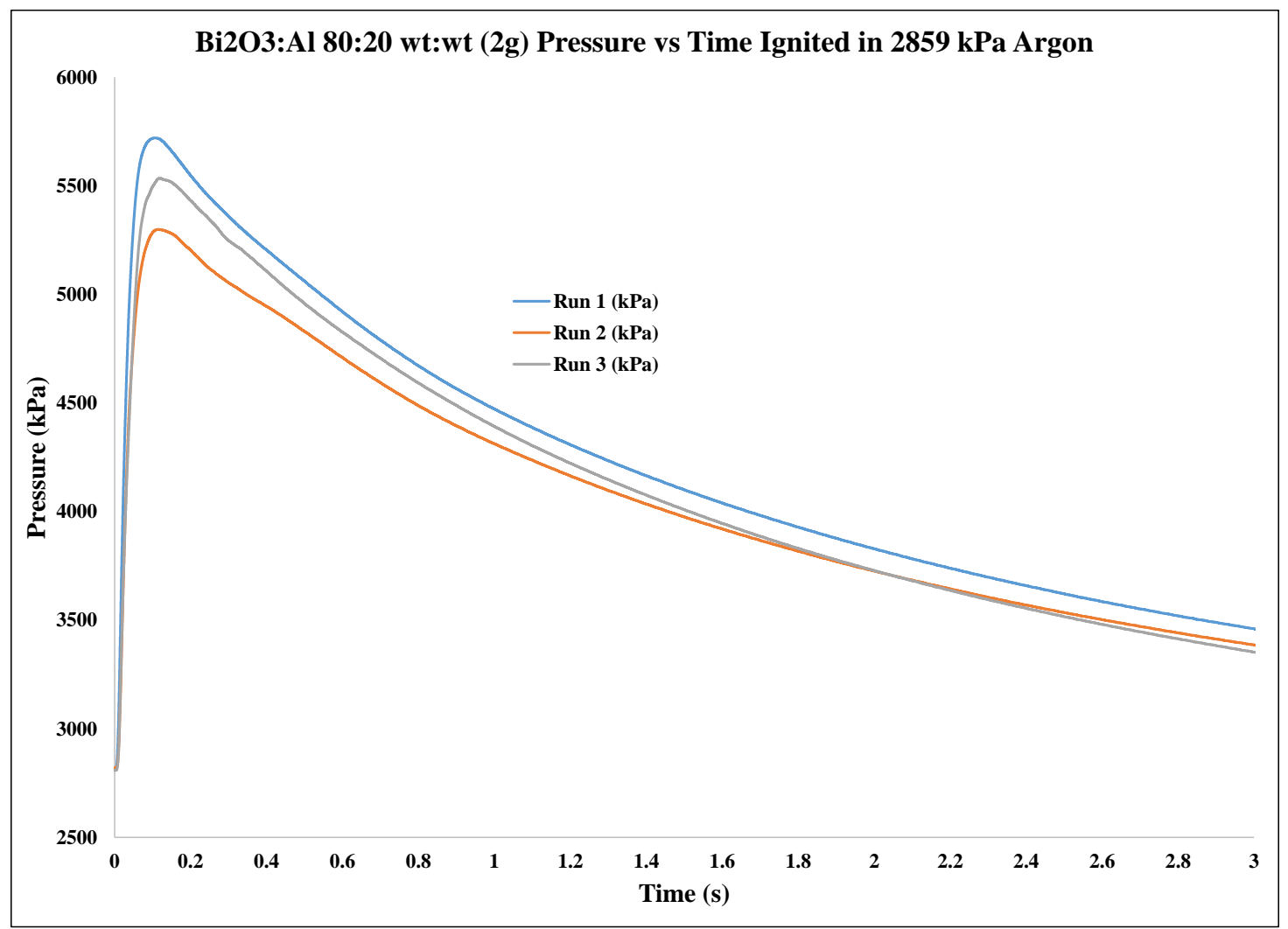

Figure 6.6. Pressure vs. Time curve of $\mathrm{Bi}_{2} \mathrm{O}_{3}$ : $\mathrm{Al}$ 80:20 wt:wt (2 g in 2859 kPa Argon) 


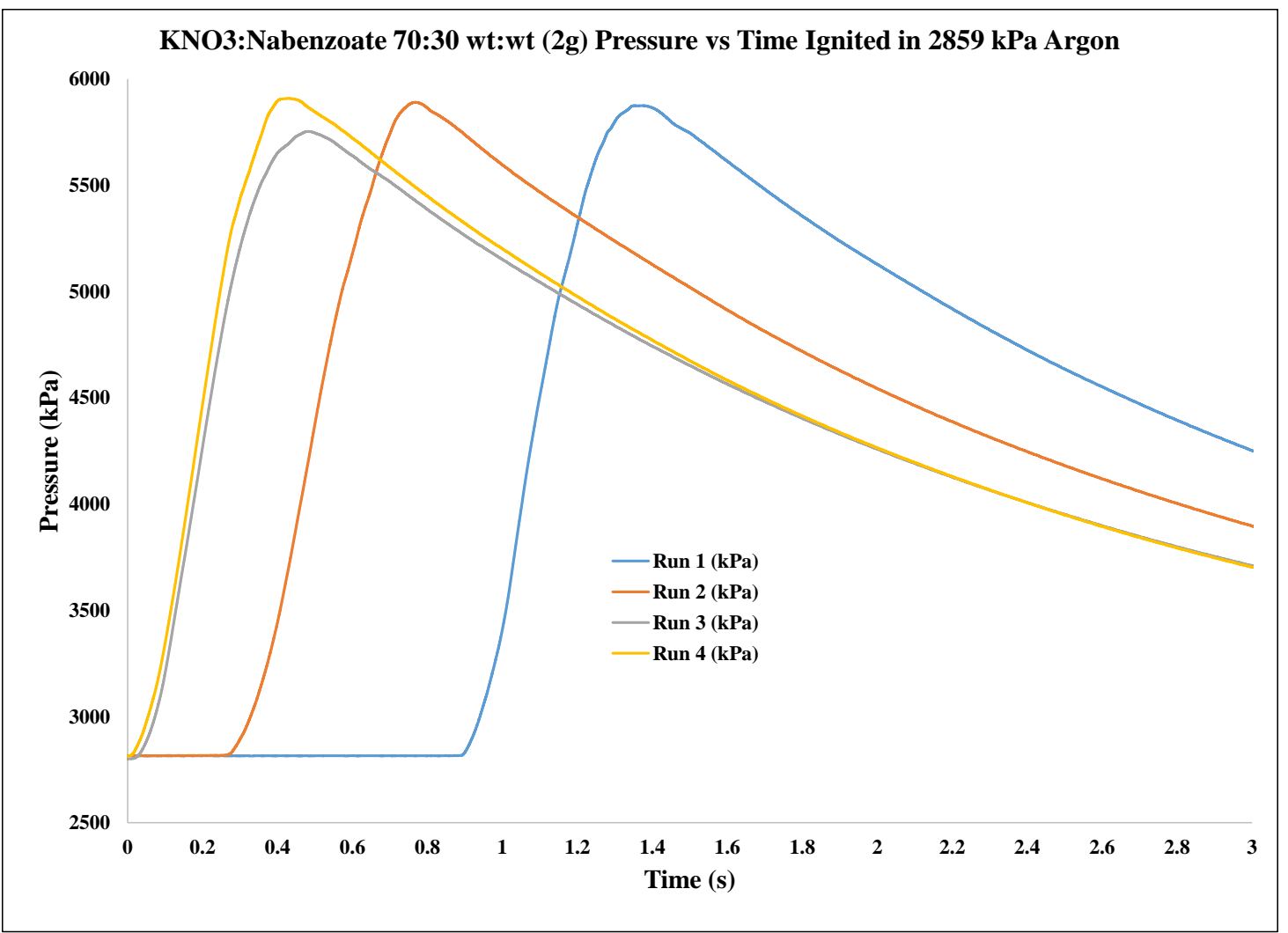

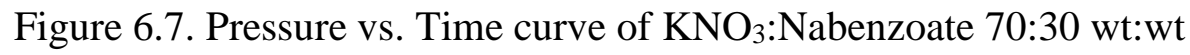
( $2 \mathrm{~g}$ in $2859 \mathrm{kPa}$ Argon) 


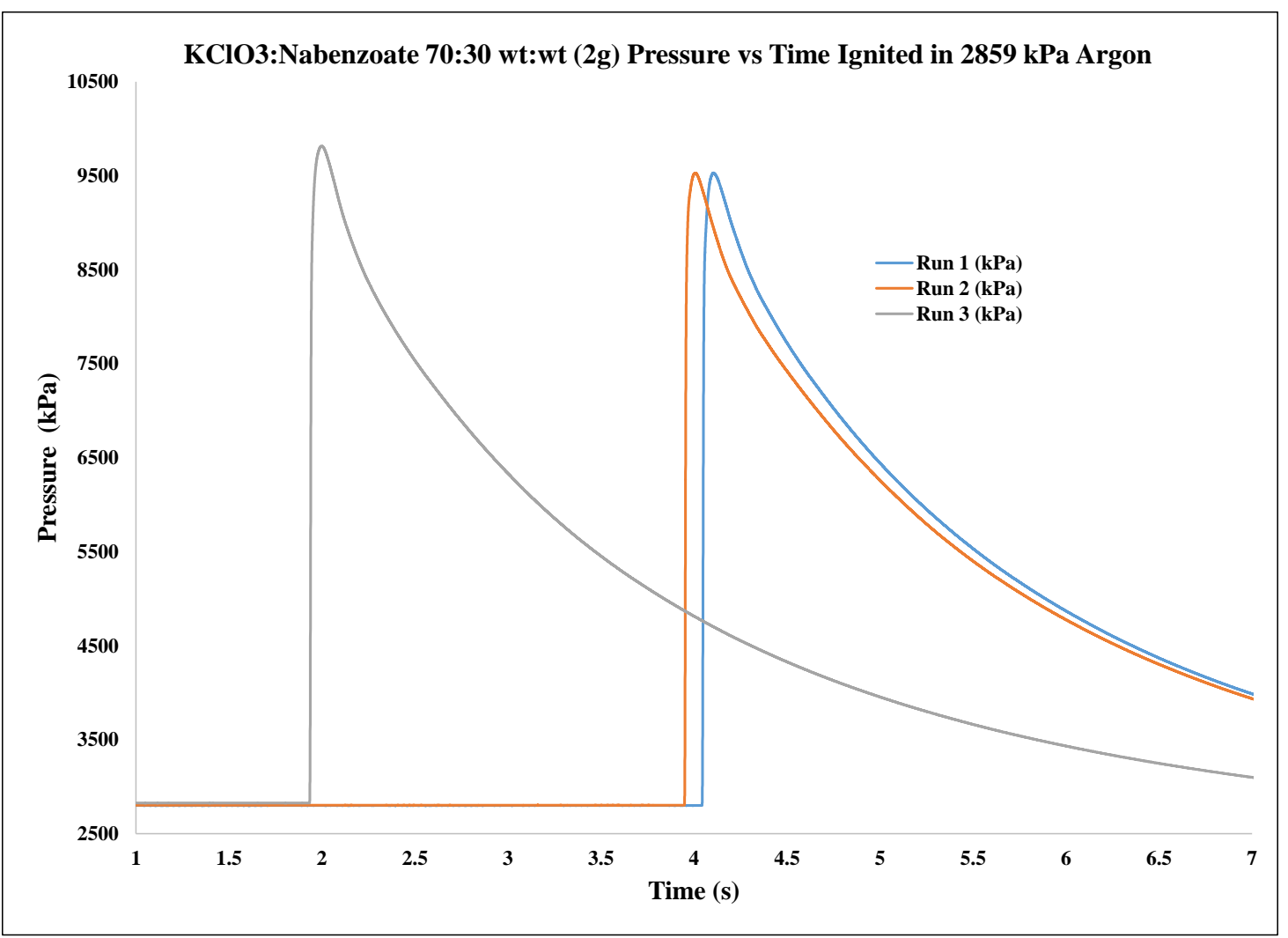

Figure 6.8. Pressure vs. Time curve of $\mathrm{KClO}_{3}:$ Nabenzoate 70:30 wt:wt (2 $\mathrm{g}$ in $2859 \mathrm{kPa}$ Argon) 


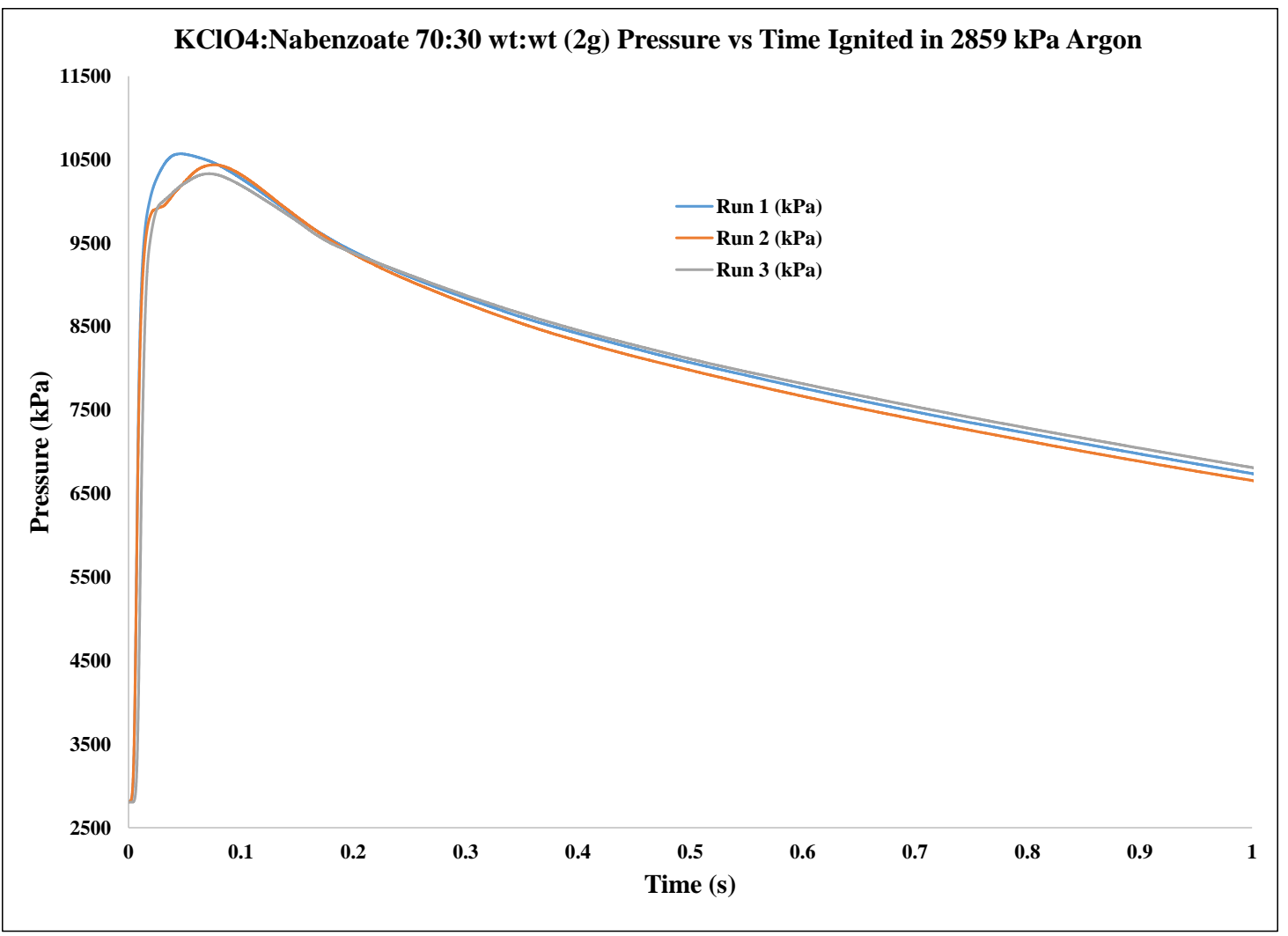

Figure 6.9. Pressure vs. Time curve of $\mathrm{KClO}_{4}$ : Nabenzoate 70:30 wt:wt (2 $\mathrm{g}$ in $2859 \mathrm{kPa}$ Argon) 


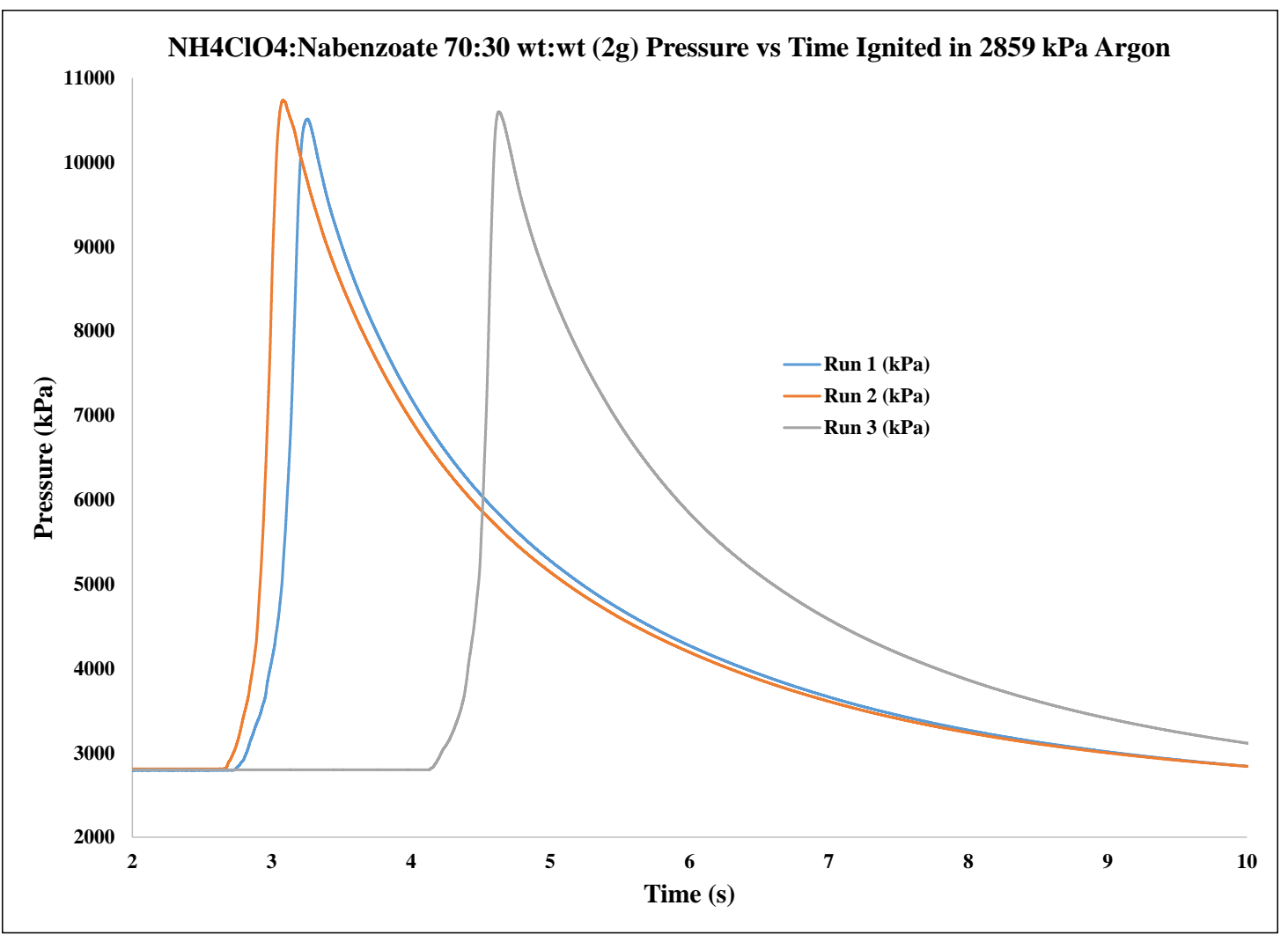

Figure 6.10. Pressure vs. Time curve of $\mathrm{NH}_{4} \mathrm{ClO}_{4}$ : Nabenzoate 70:30 wt:wt (2 $\mathrm{g}$ in $2859 \mathrm{kPa}$ Argon) 


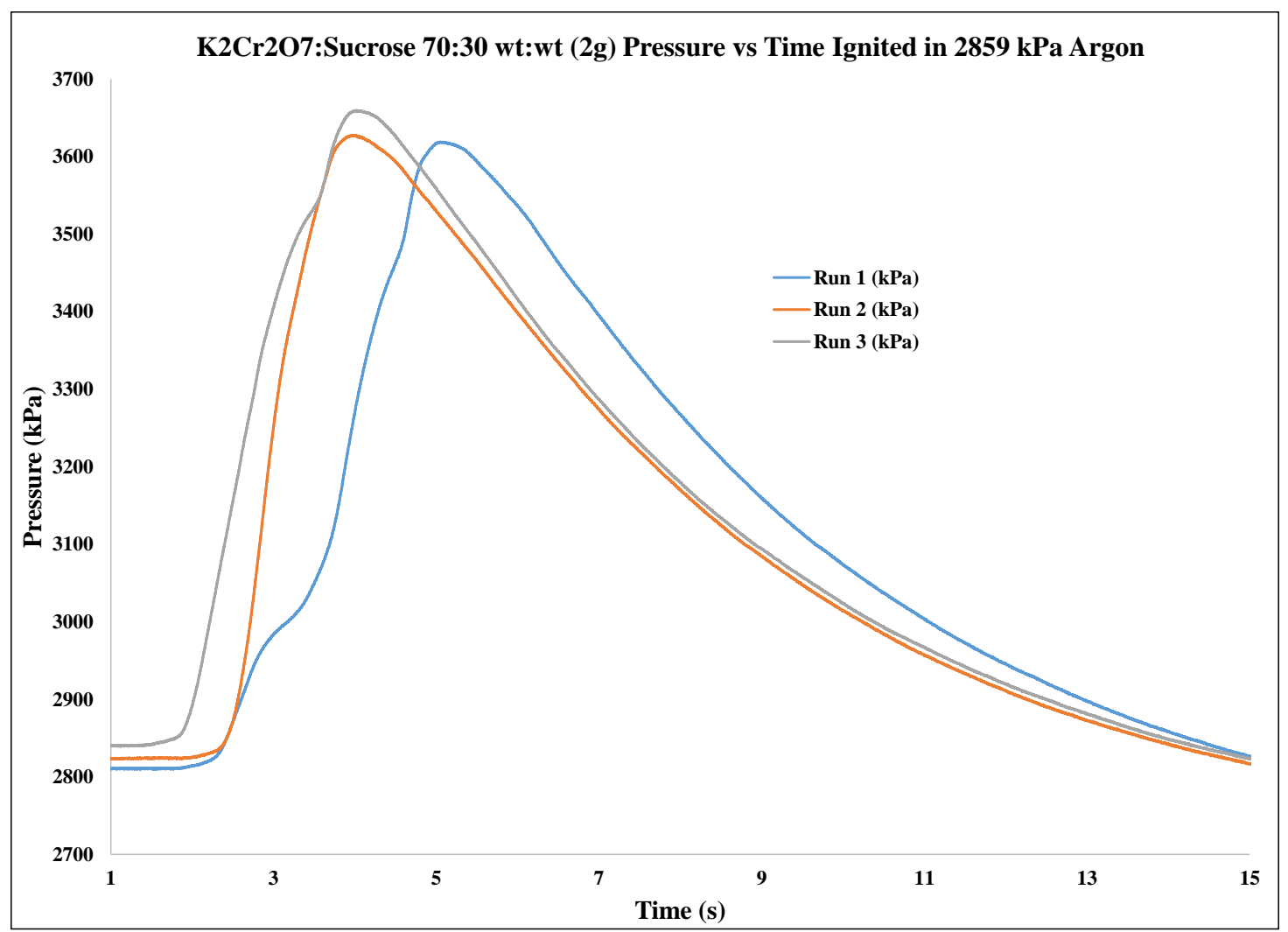

Figure 6.11. Pressure vs. Time curve of $\mathrm{K}_{2} \mathrm{Cr}_{2} \mathrm{O}_{7}$ :Sucrose 70:30 wt:wt (2 $\mathrm{g}$ in $2859 \mathrm{kPa}$ Argon) 


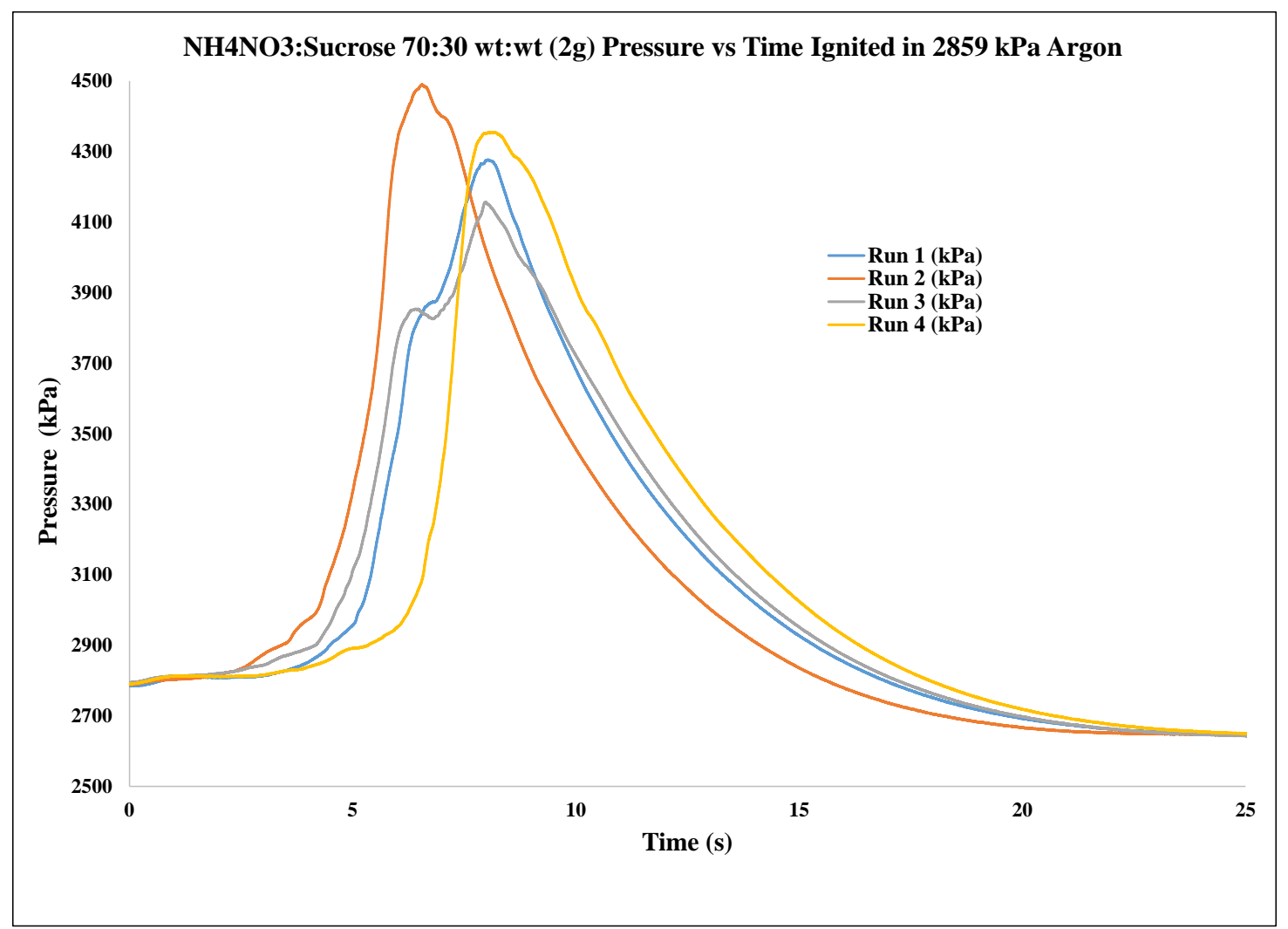

Figure 6.12. Pressure vs. Time curve of $\mathrm{NH}_{4} \mathrm{NO}_{3}$ :Sucrose $70: 30 \mathrm{wt}$ :wt (2 $\mathrm{g}$ in $2859 \mathrm{kPa}$ Argon) 


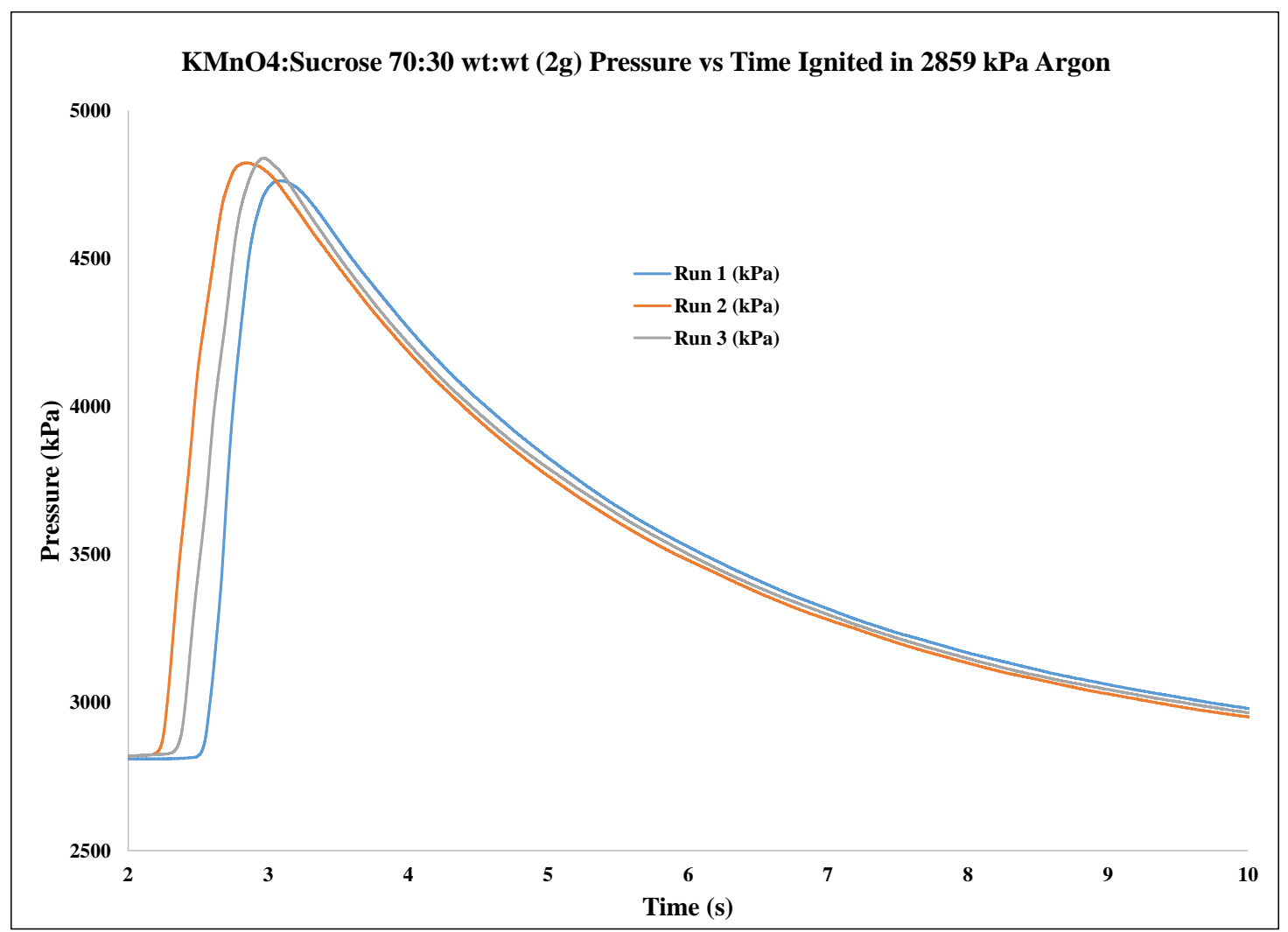

Figure 6.13. Pressure vs. Time curve of $\mathrm{KMnO}_{4}$ :Sucrose 70:30 wt:wt (2 $\mathrm{g}$ in $2859 \mathrm{kPa}$ Argon) 


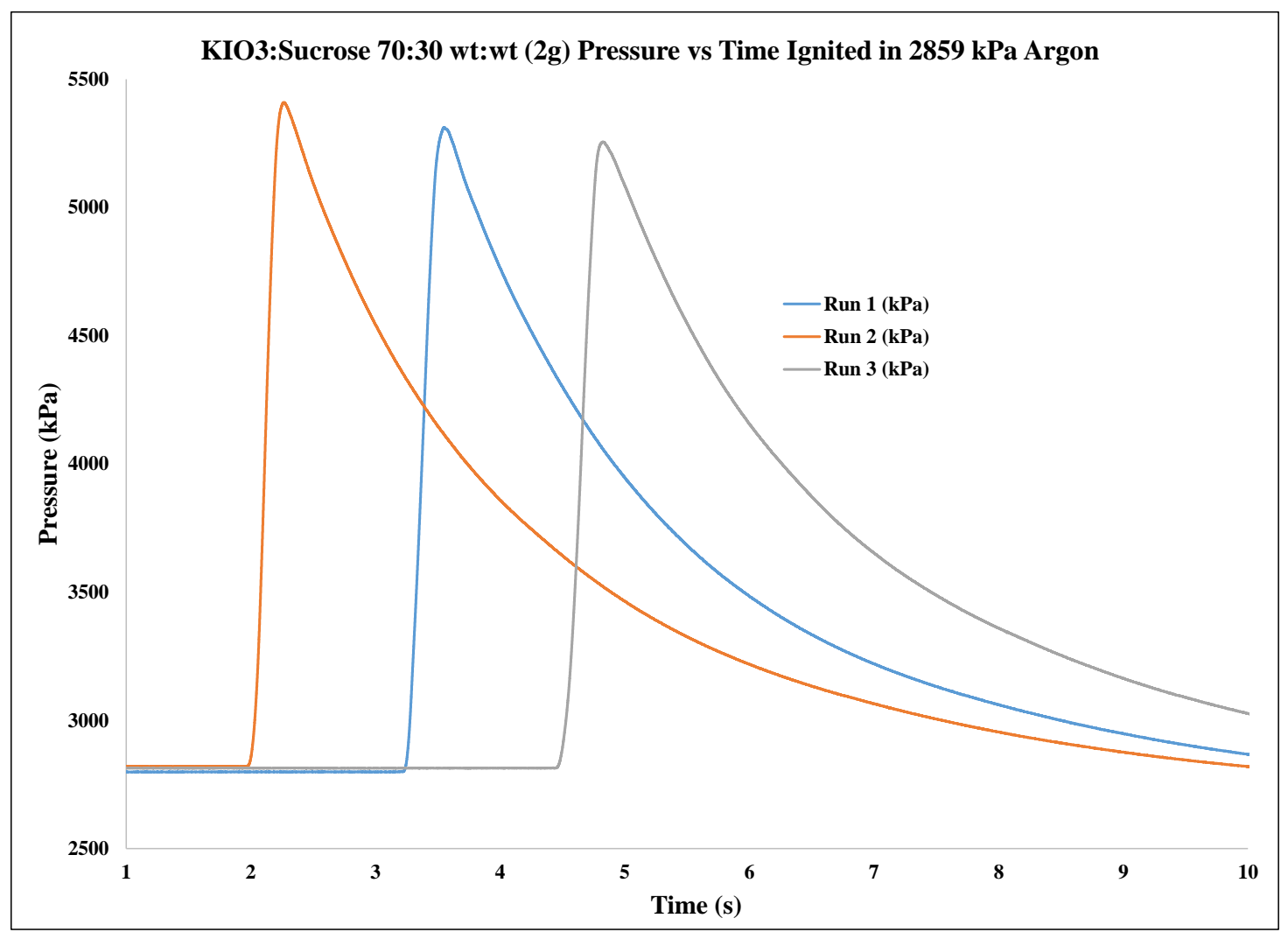

Figure 6.14. Pressure vs. Time curve of $\mathrm{KIO}_{3}:$ Sucrose 70:30 wt:wt (2 $\mathrm{g}$ in $2859 \mathrm{kPa}$ Argon) 


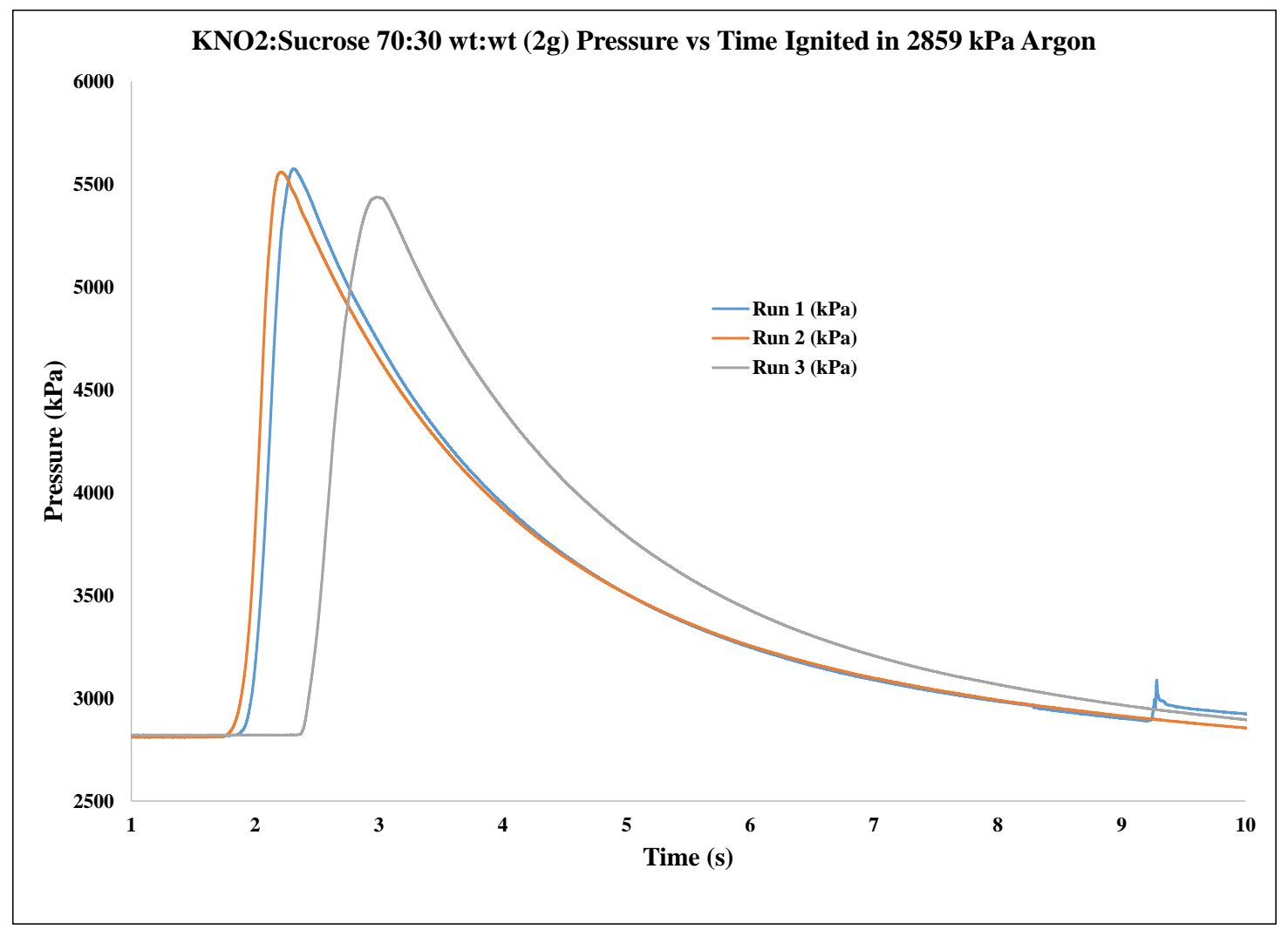

Figure 6.15. Pressure vs. Time curve of $\mathrm{KNO}_{2}$ :Sucrose 70:30 wt:wt

(2 $\mathrm{g}$ in $2859 \mathrm{kPa}$ Argon) 


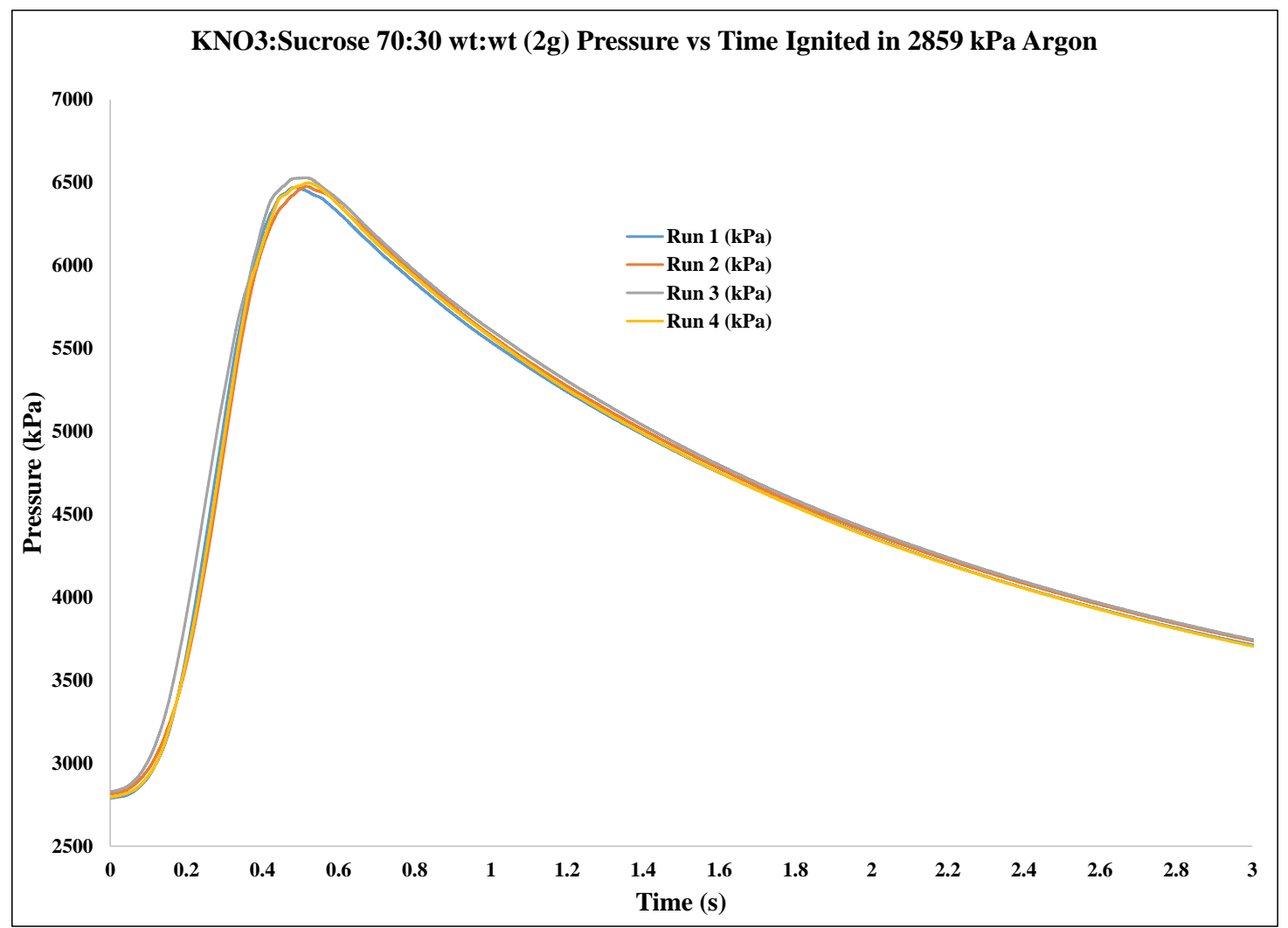

Figure 6.16. Pressure vs. Time curve of $\mathrm{KNO}_{3}$ :Sucrose 70:30 wt:wt (2 $\mathrm{g}$ in $2859 \mathrm{kPa}$ Argon) 


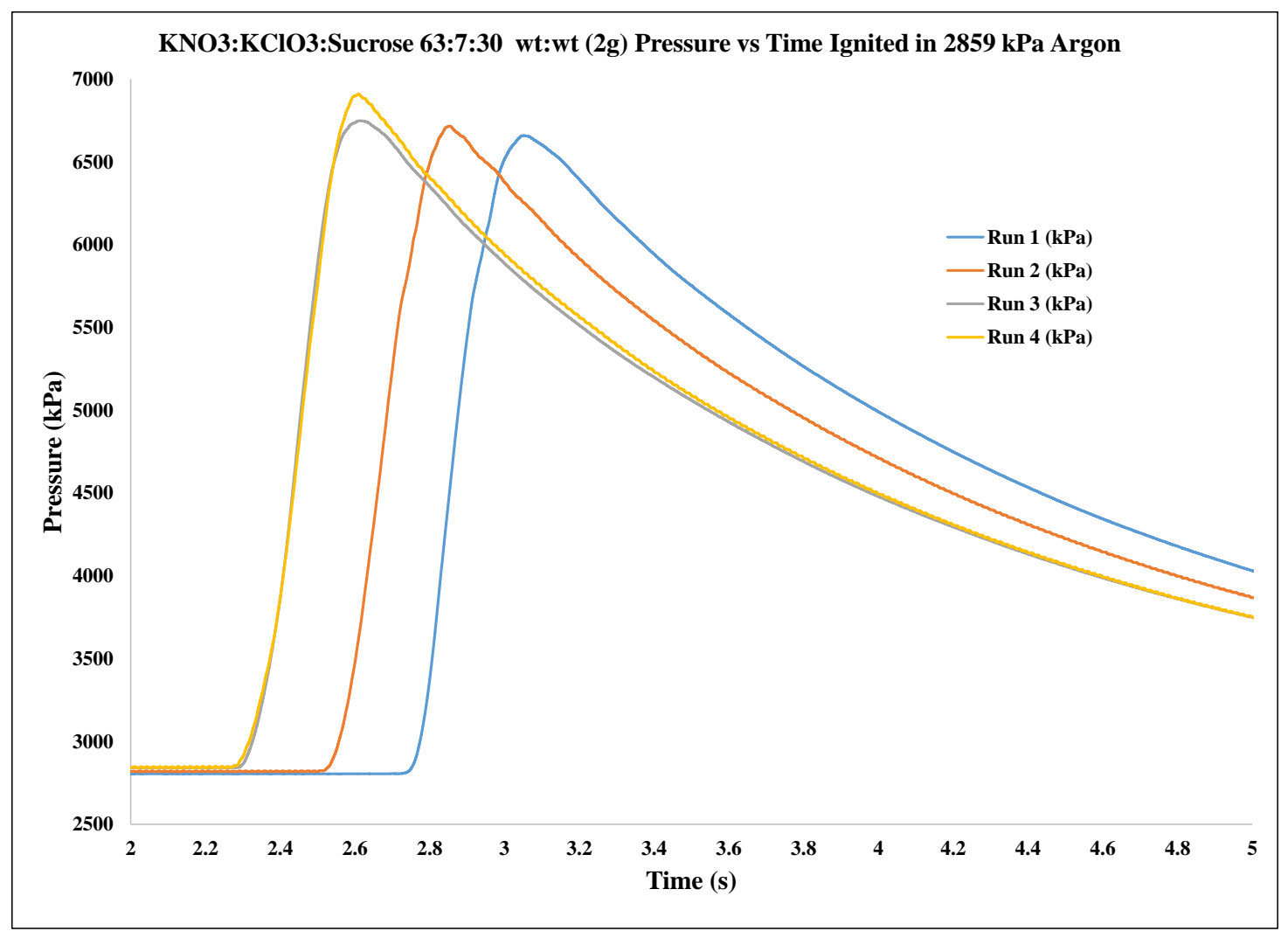

Figure 6.17. Pressure vs. Time curve of $\mathrm{KNO}_{3}: \mathrm{KClO}_{3}:$ Sucrose 63:7:30 wt:wt (2 $\mathrm{g}$ in $2859 \mathrm{kPa}$ Argon) 


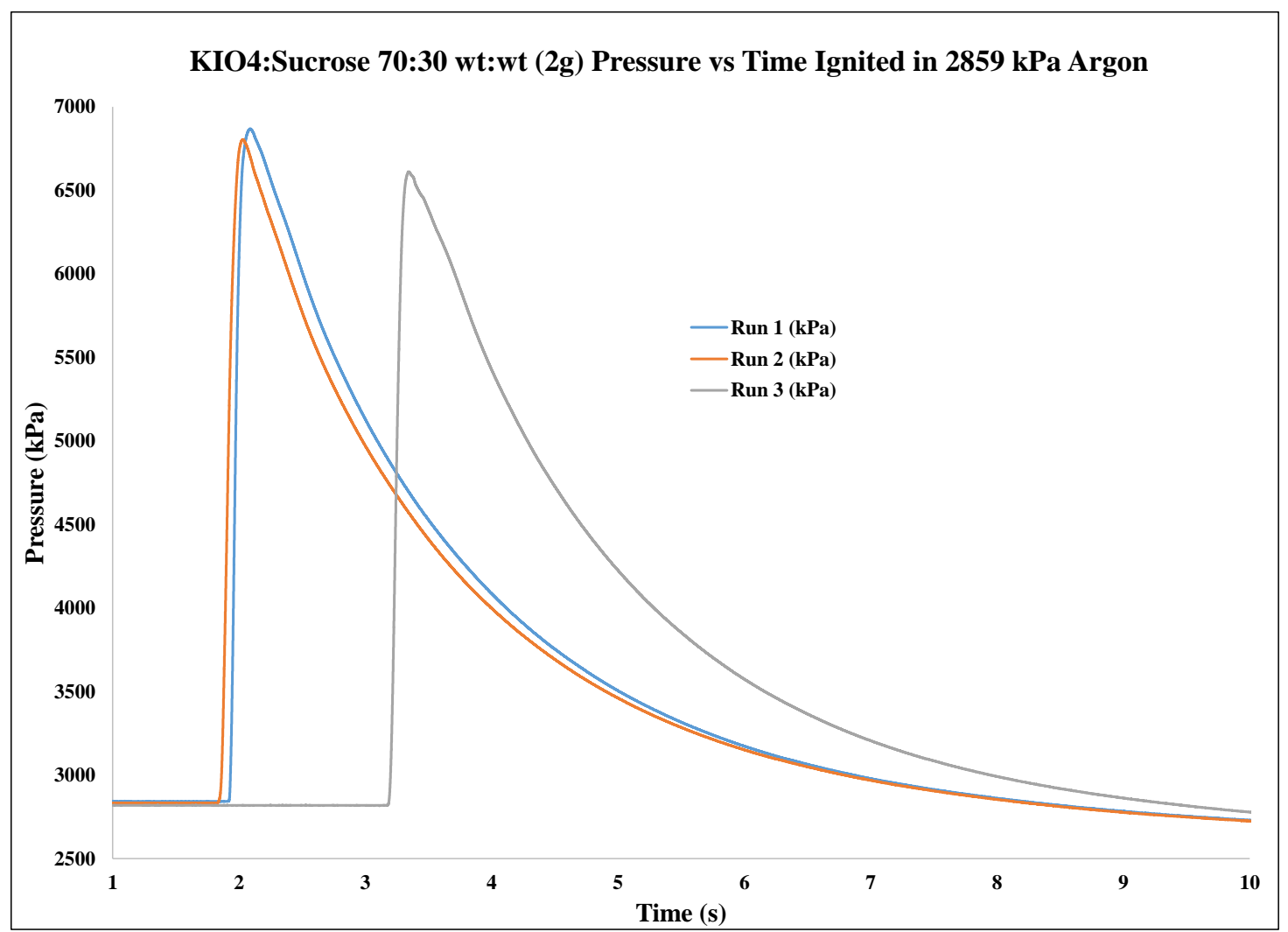

Figure 6.18. Pressure vs. Time curve of $\mathrm{KIO}_{4}$ :Sucrose 70:30 wt:wt (2 $\mathrm{g}$ in $2859 \mathrm{kPa}$ Argon) 


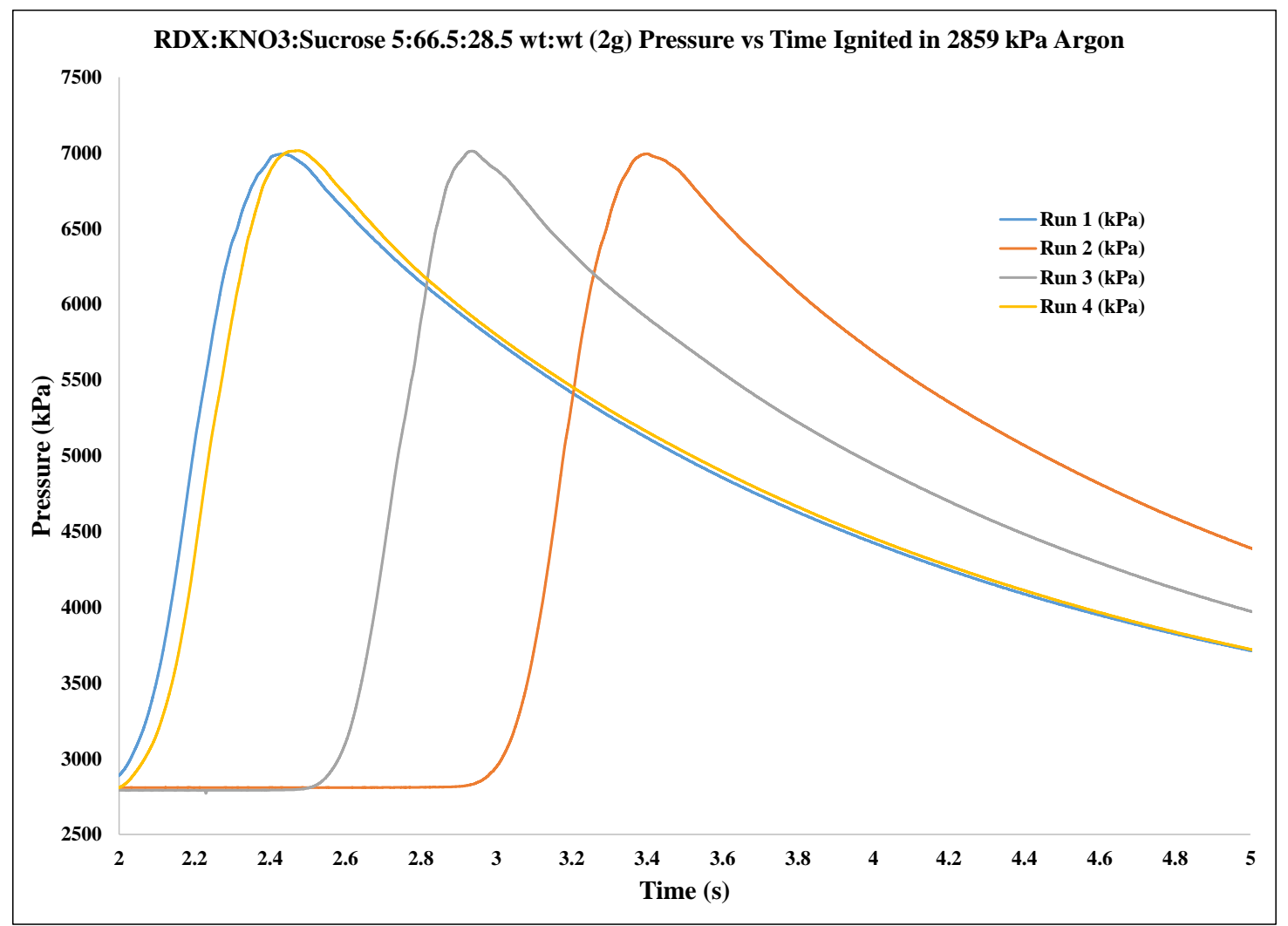

Figure 6.19. Pressure vs. Time curve of RDX:KNO $:$ Sucrose 5:66.5:28.5 wt:wt (2 $\mathrm{g}$ in $2859 \mathrm{kPa}$ Argon) 


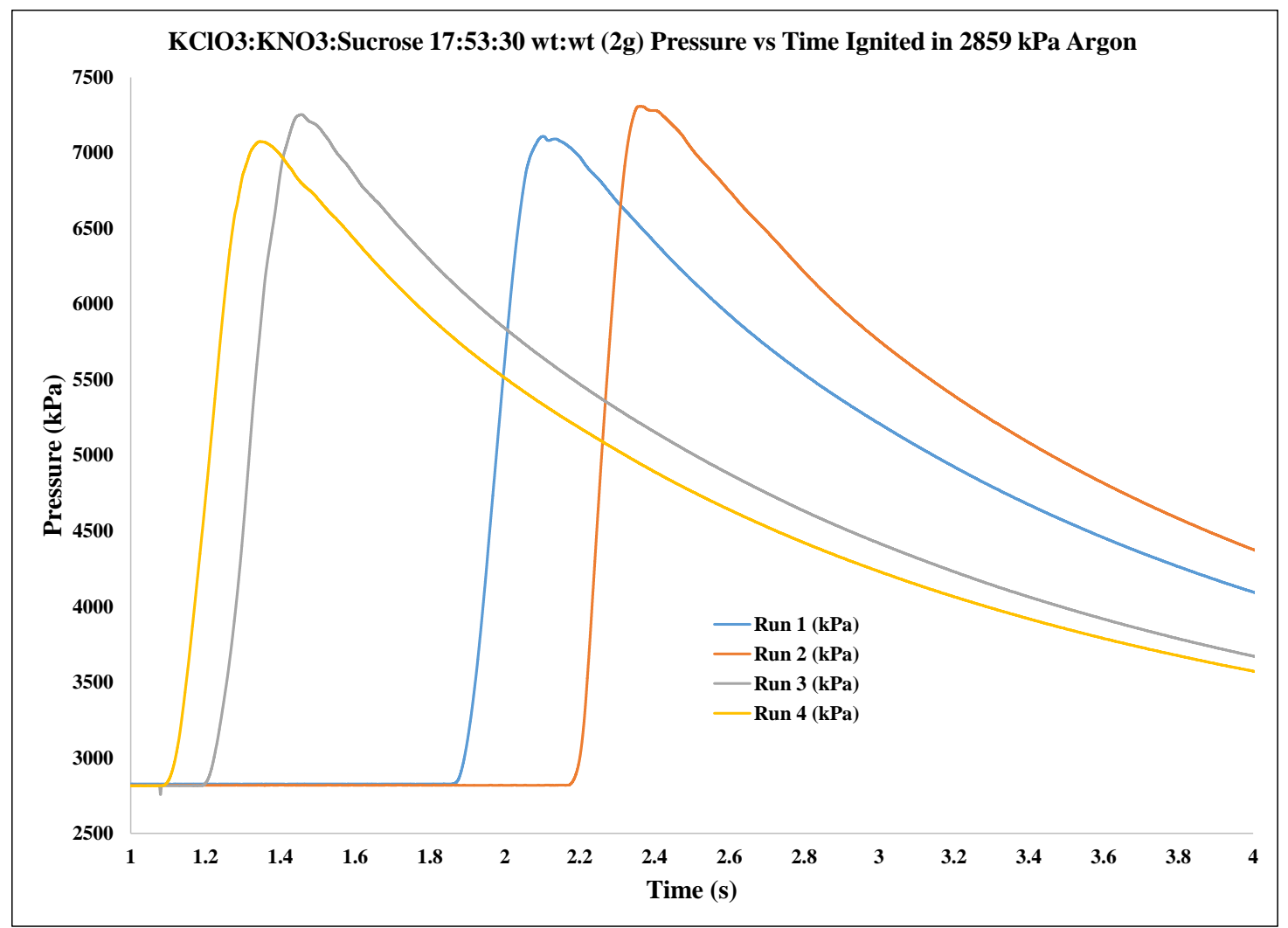

Figure 6.20. Pressure vs. Time curve of $\mathrm{KClO}_{3}: \mathrm{KNO}_{3}$ :Sucrose 17:53:30 wt:wt (2 $\mathrm{g}$ in $2859 \mathrm{kPa}$ Argon) 


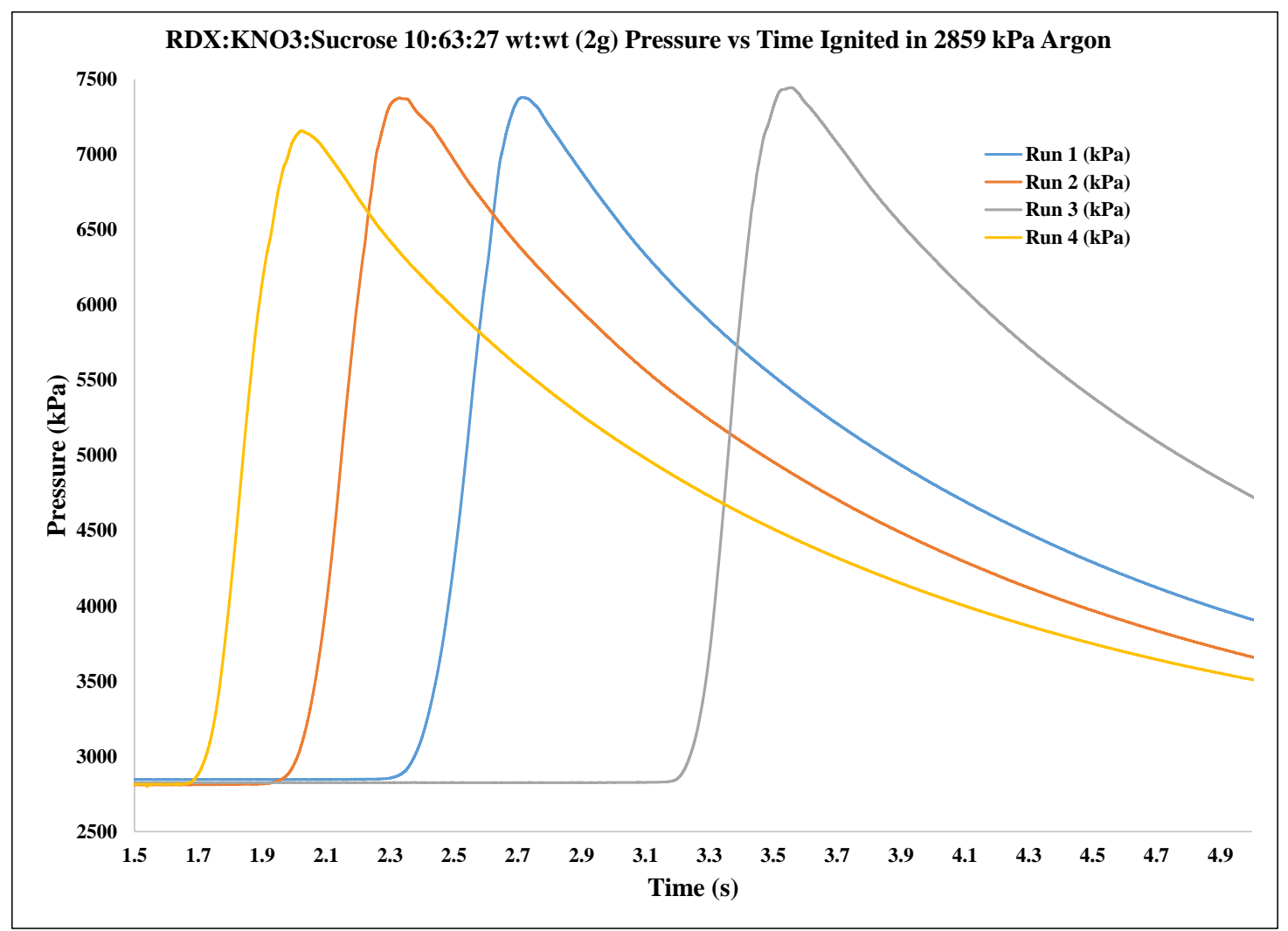

Figure 6.21. Pressure vs. Time curve of RDX:KNO $:$ Sucrose 10:63:27 wt:wt (2 g in $2859 \mathrm{kPa}$ Argon) 


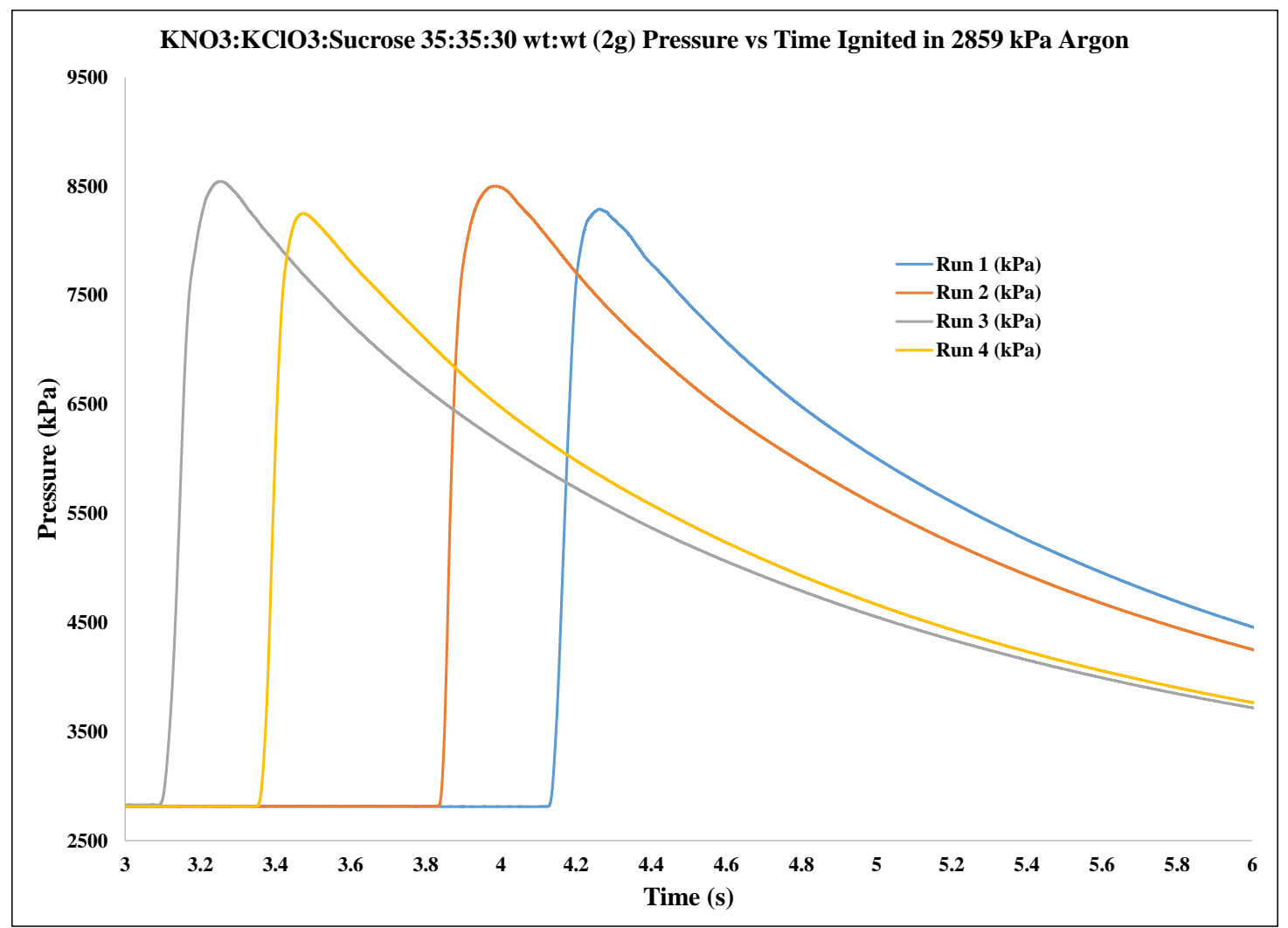

Figure 6.22. Pressure vs. Time curve of $\mathrm{KNO}_{3}: \mathrm{KClO}_{3}:$ Sucrose 35:35:30 wt:wt (2 $\mathrm{g}$ in $2859 \mathrm{kPa}$ Argon) 


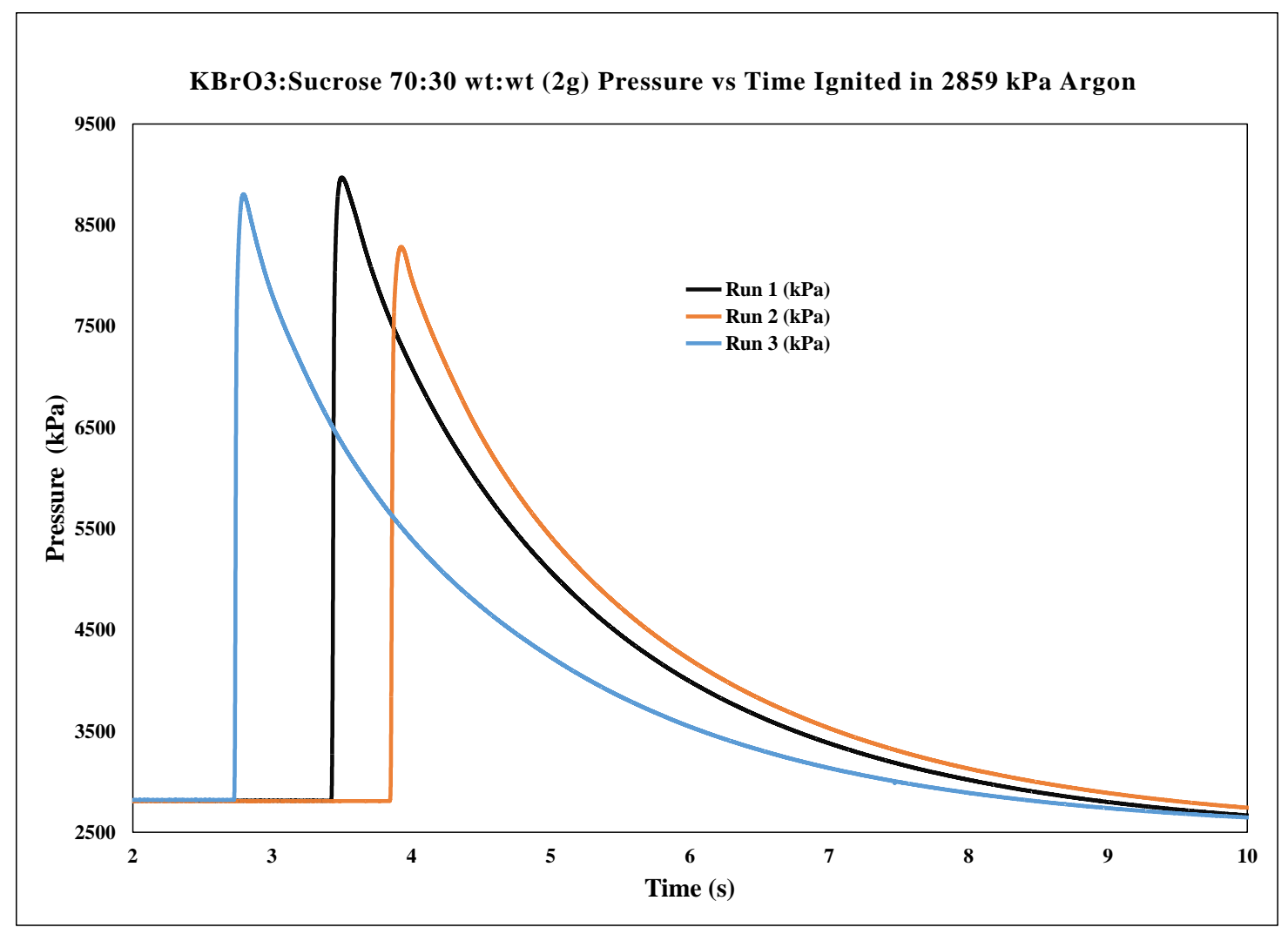

Figure 6.23. Pressure vs. Time curve of $\mathrm{KBrO}_{3}$ :Sucrose 70:30 wt:wt

(2 $\mathrm{g}$ in $2859 \mathrm{kPa}$ Argon) 


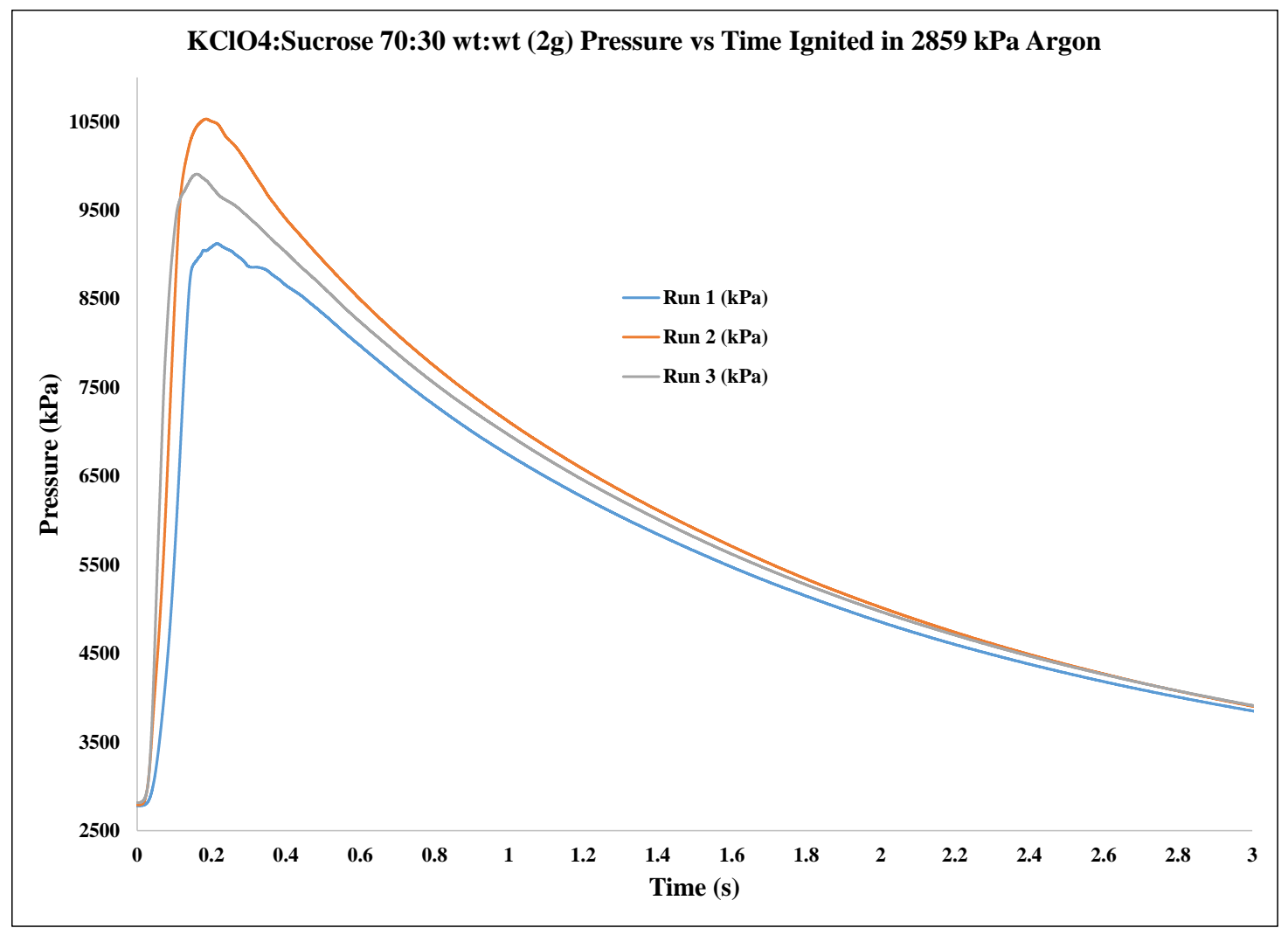

Figure 6.24. Pressure vs. Time curve of $\mathrm{KClO}_{4}$ :Sucrose 70:30 wt:wt (2 g in $2859 \mathrm{kPa}$ Argon) 


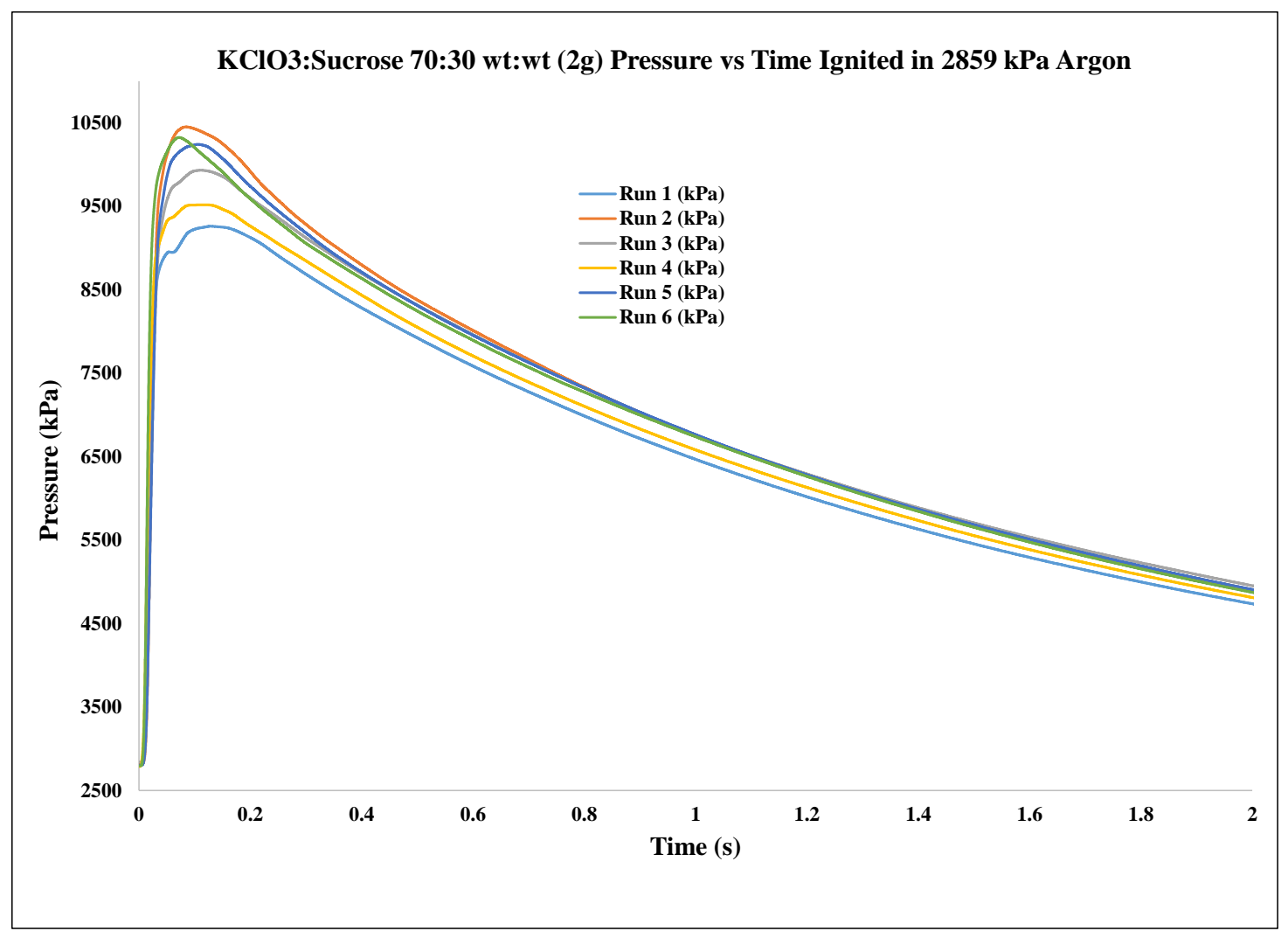

Figure 6.25. Pressure vs. Time curve of $\mathrm{KClO}_{3}:$ Sucrose $70: 30 \mathrm{wt}$ :wt

(2 $\mathrm{g}$ in $2859 \mathrm{kPa}$ Argon) 


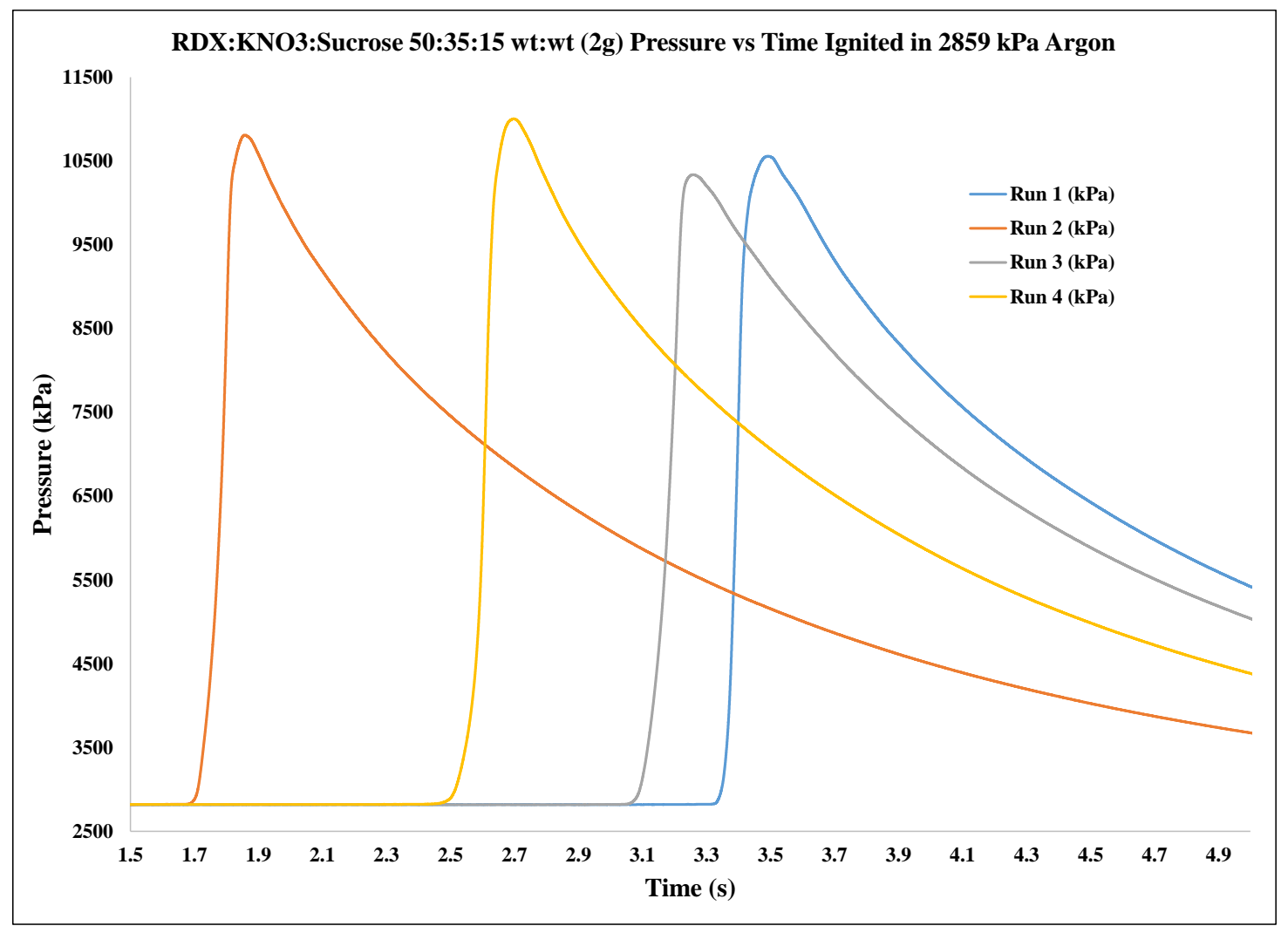

Figure 6.26. Pressure vs. Time curve of RDX:KNO $:$ Sucrose 50:35:15 wt:wt (2 $\mathrm{g}$ in $2859 \mathrm{kPa}$ Argon) 


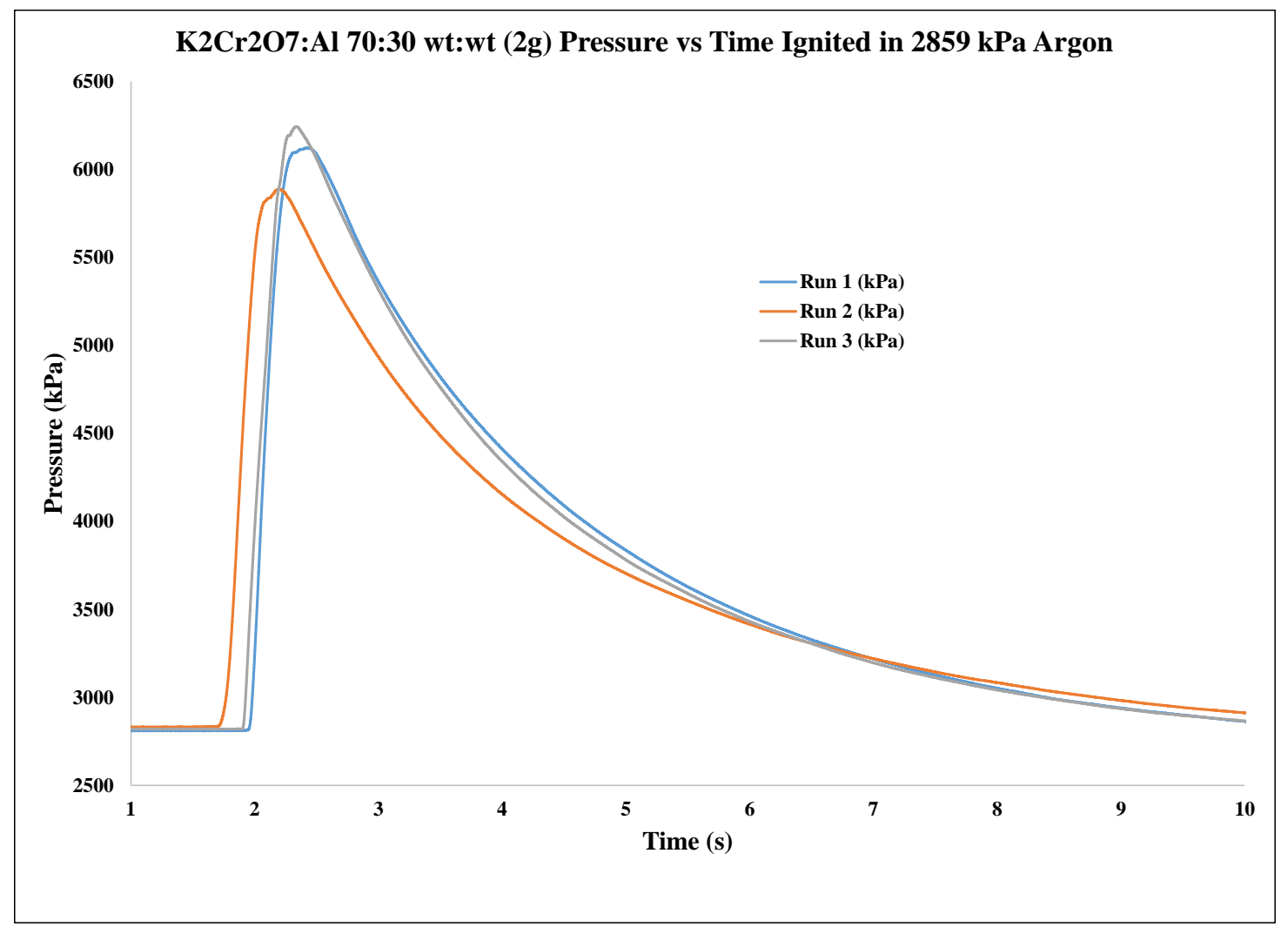

Figure 6.27. Pressure vs. Time curve of $\mathrm{K}_{2} \mathrm{Cr}_{2} \mathrm{O}_{7}$ :Al 70:30 wt:wt (2 $\mathrm{g}$ in $2859 \mathrm{kPa}$ Argon) 


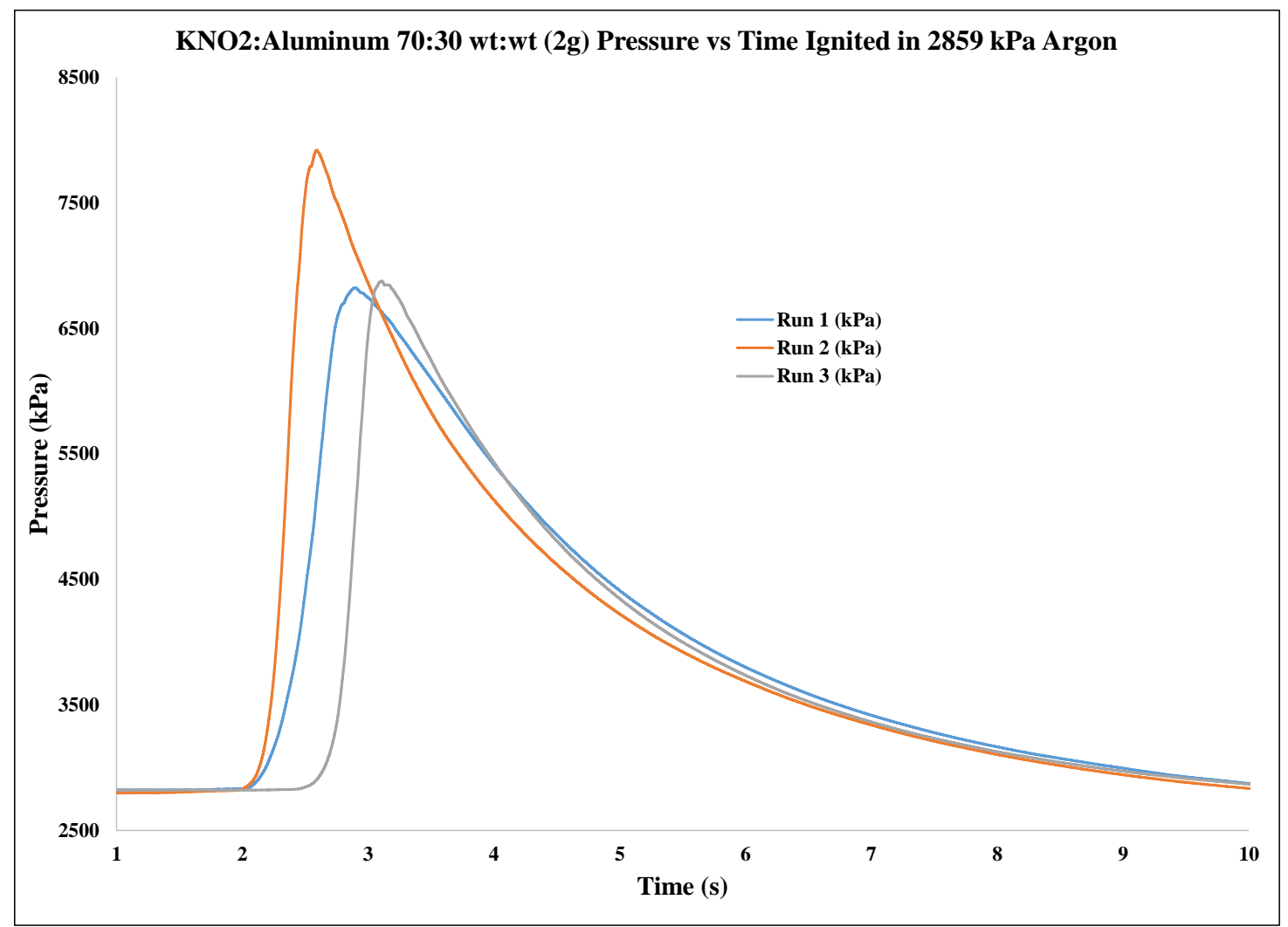

Figure 6.28. Pressure vs. Time curve of $\mathrm{KNO}_{2}: \mathrm{Al} 70: 30$ wt:wt

$\mathrm{g}$ in $2859 \mathrm{kPa}$ Argon) 


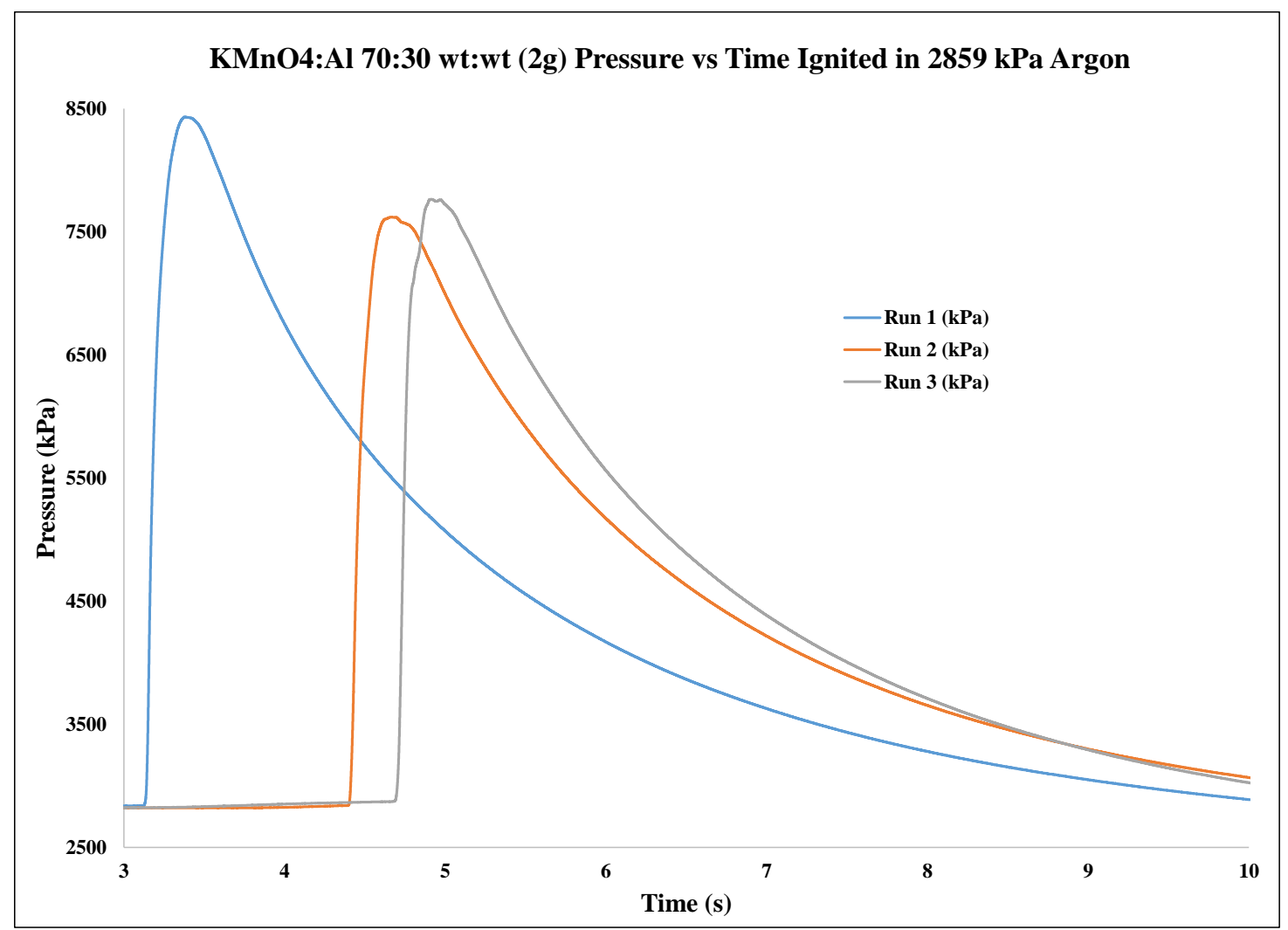

Figure 6.29. Pressure vs. Time curve of $\mathrm{KMnO}_{4}$ :Al 70:30 wt:wt (2 $\mathrm{g}$ in $2859 \mathrm{kPa}$ Argon) 


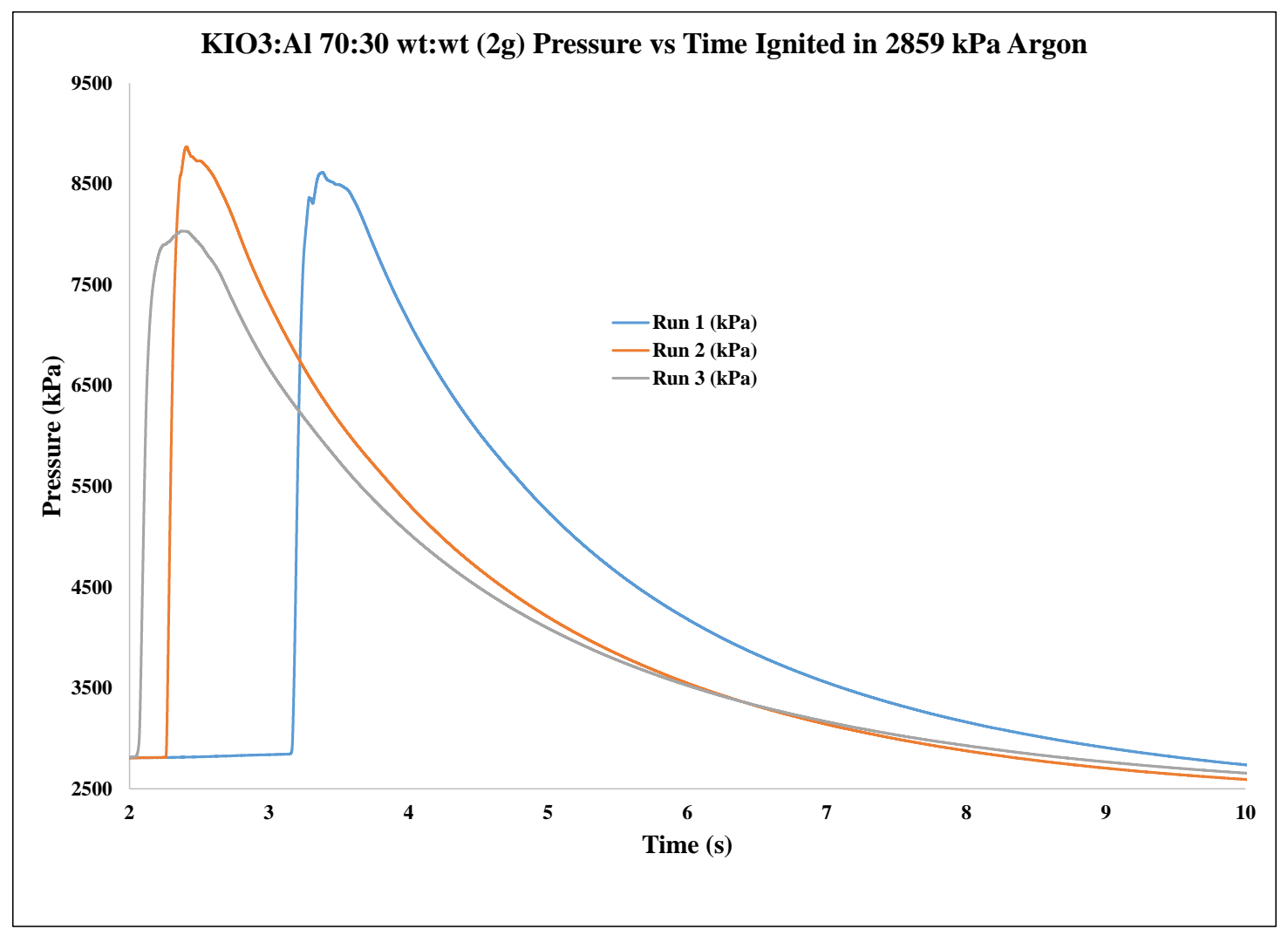

Figure 6.30. Pressure vs. Time curve of $\mathrm{KIO}_{3}: \mathrm{Al} 70: 30 \mathrm{wt}$ :wt

(2 $\mathrm{g}$ in $2859 \mathrm{kPa}$ Argon) 


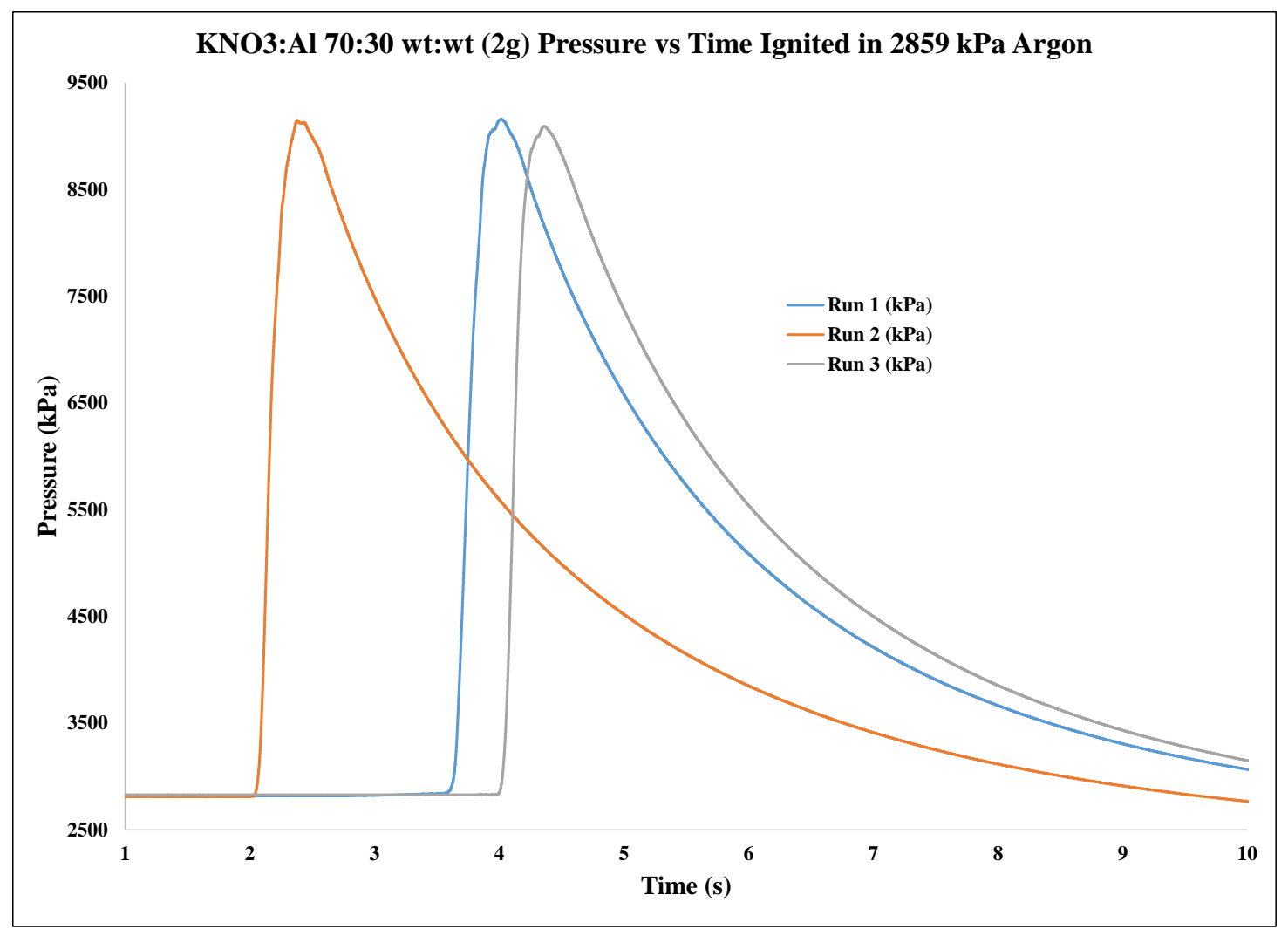

Figure 6.31. Pressure vs. Time curve of $\mathrm{KNO}_{3}: \mathrm{Al}$ 70:30 wt:wt

(2 $\mathrm{g}$ in $2859 \mathrm{kPa}$ Argon) 


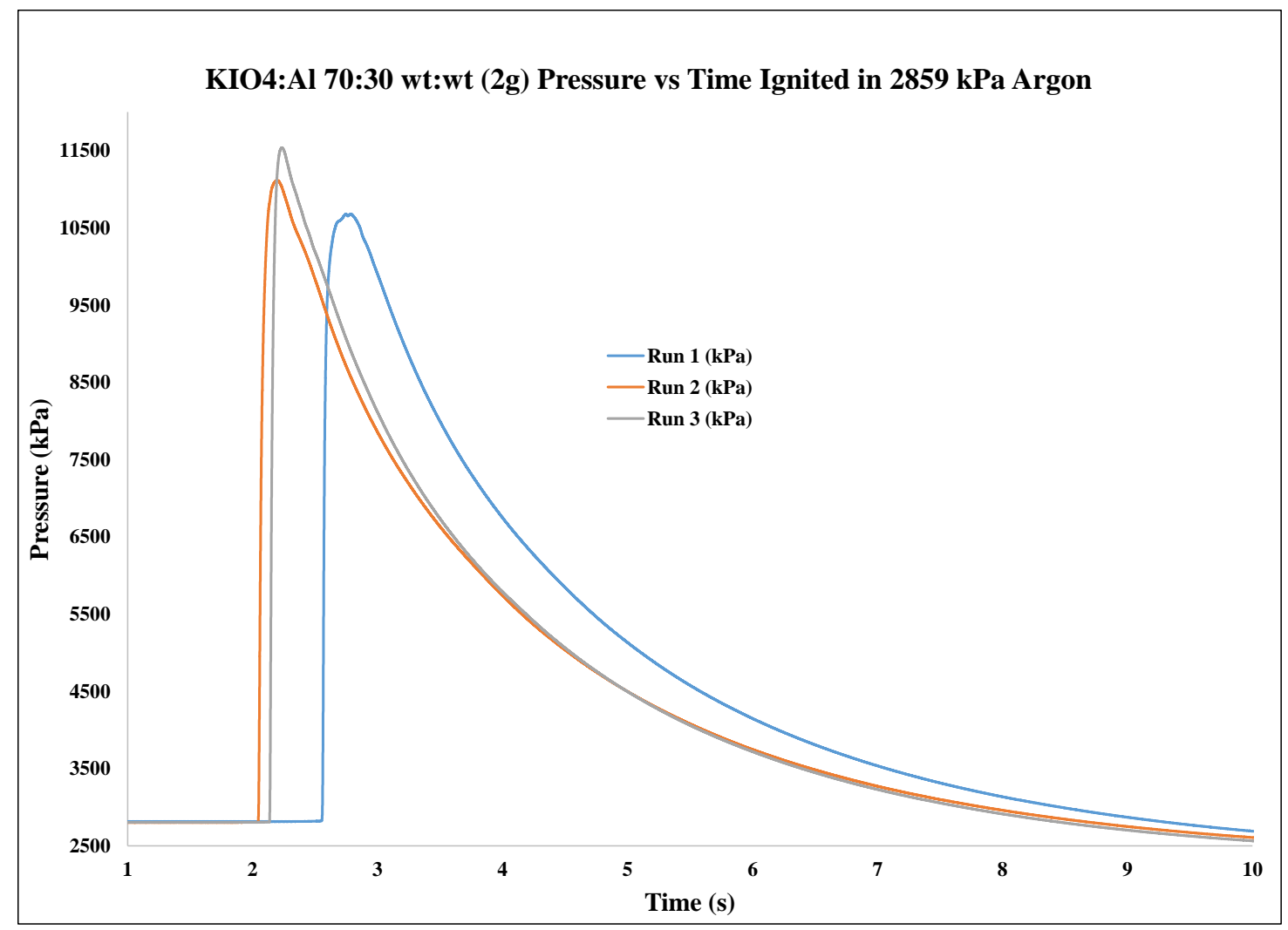

Figure 6.32. Pressure vs. Time curve of $\mathrm{KIO}_{4}: \mathrm{Al}$ 70:30 wt:wt (2 $\mathrm{g}$ in $2859 \mathrm{kPa}$ Argon) 


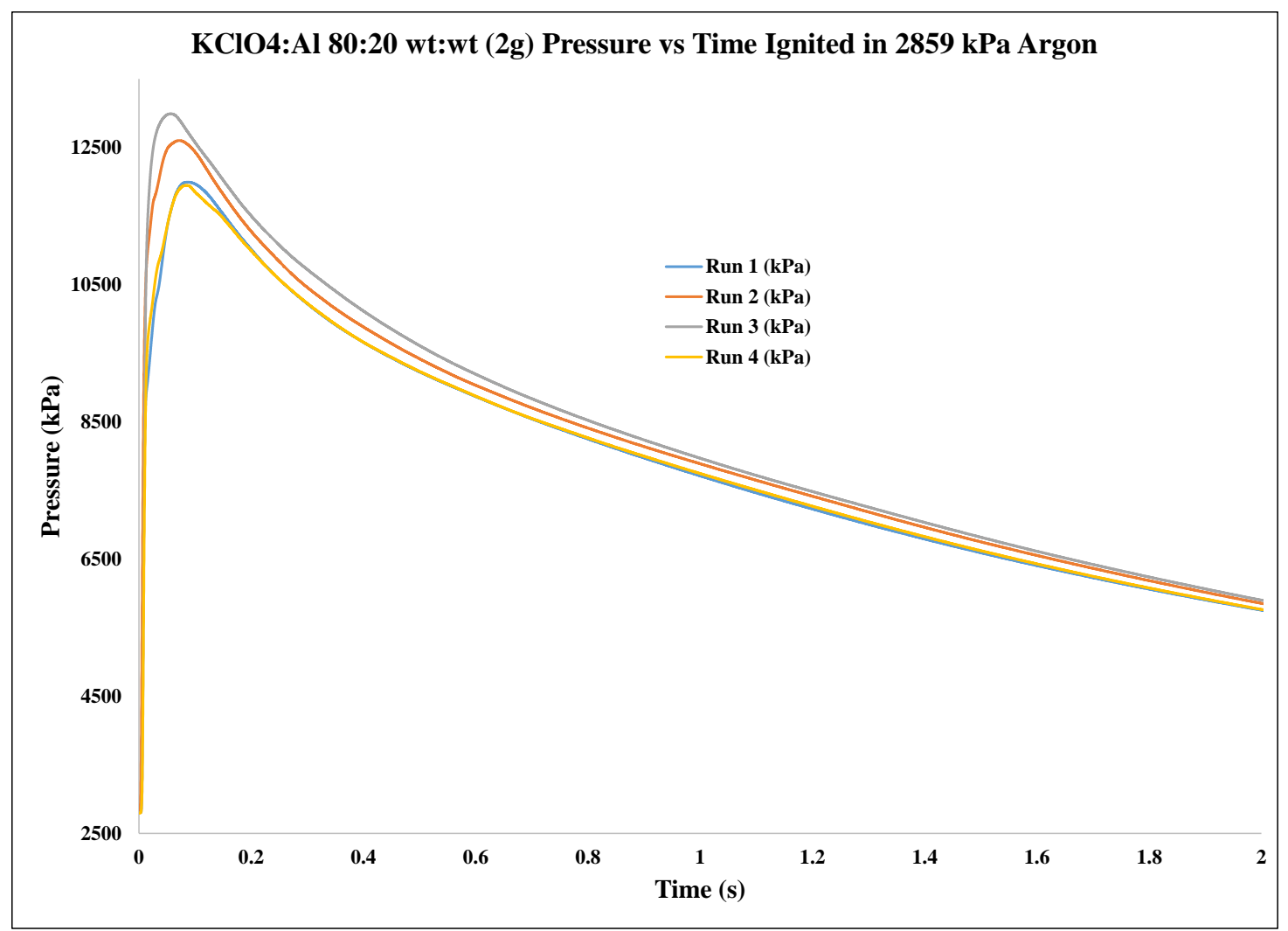

Figure 6.33. Pressure vs. Time curve of $\mathrm{KClO}_{4}$ :Al 80:20 wt:wt

(2 $\mathrm{g}$ in $2859 \mathrm{kPa}$ Argon) 


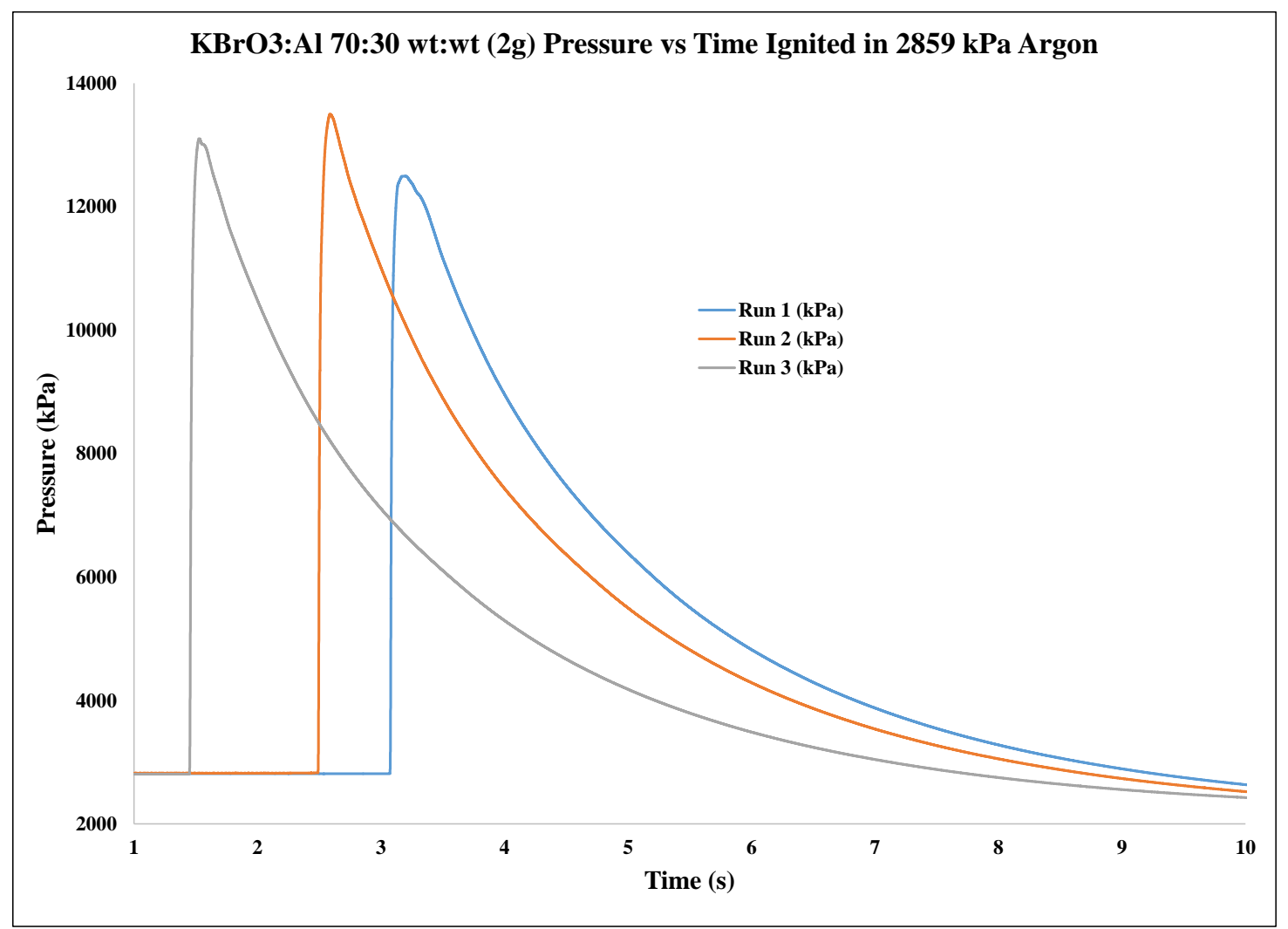

Figure 6.34. Pressure vs. Time curve of $\mathrm{KBrO}_{3}$ :Al 70:30 wt:wt

(2 $\mathrm{g}$ in $2859 \mathrm{kPa}$ Argon) 


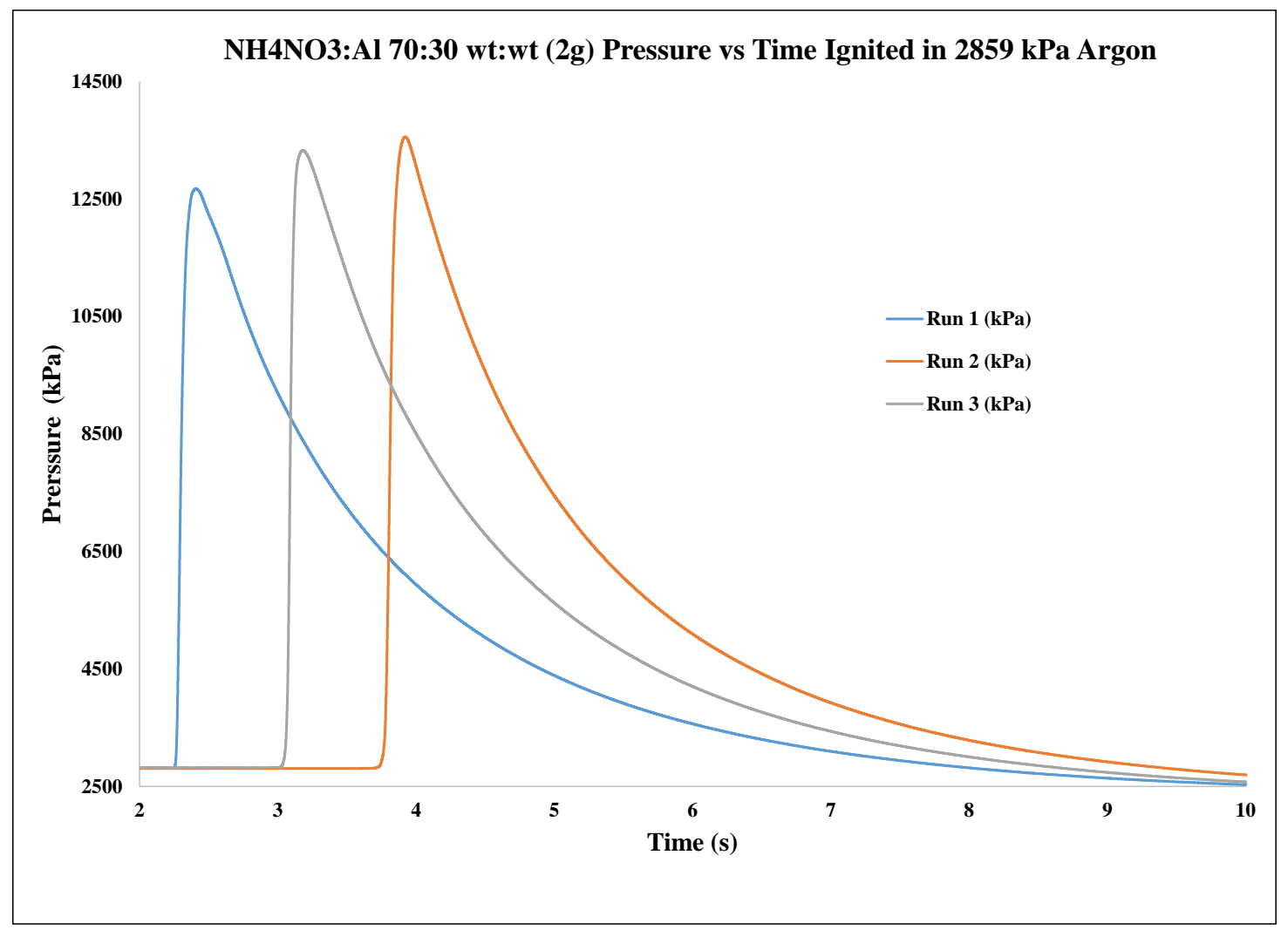

Figure 6.35. Pressure vs. Time curve of $\mathrm{NH}_{4} \mathrm{NO}_{3}$ :Al 70:30 wt:wt

(2 $\mathrm{g}$ in $2859 \mathrm{kPa}$ Argon) 


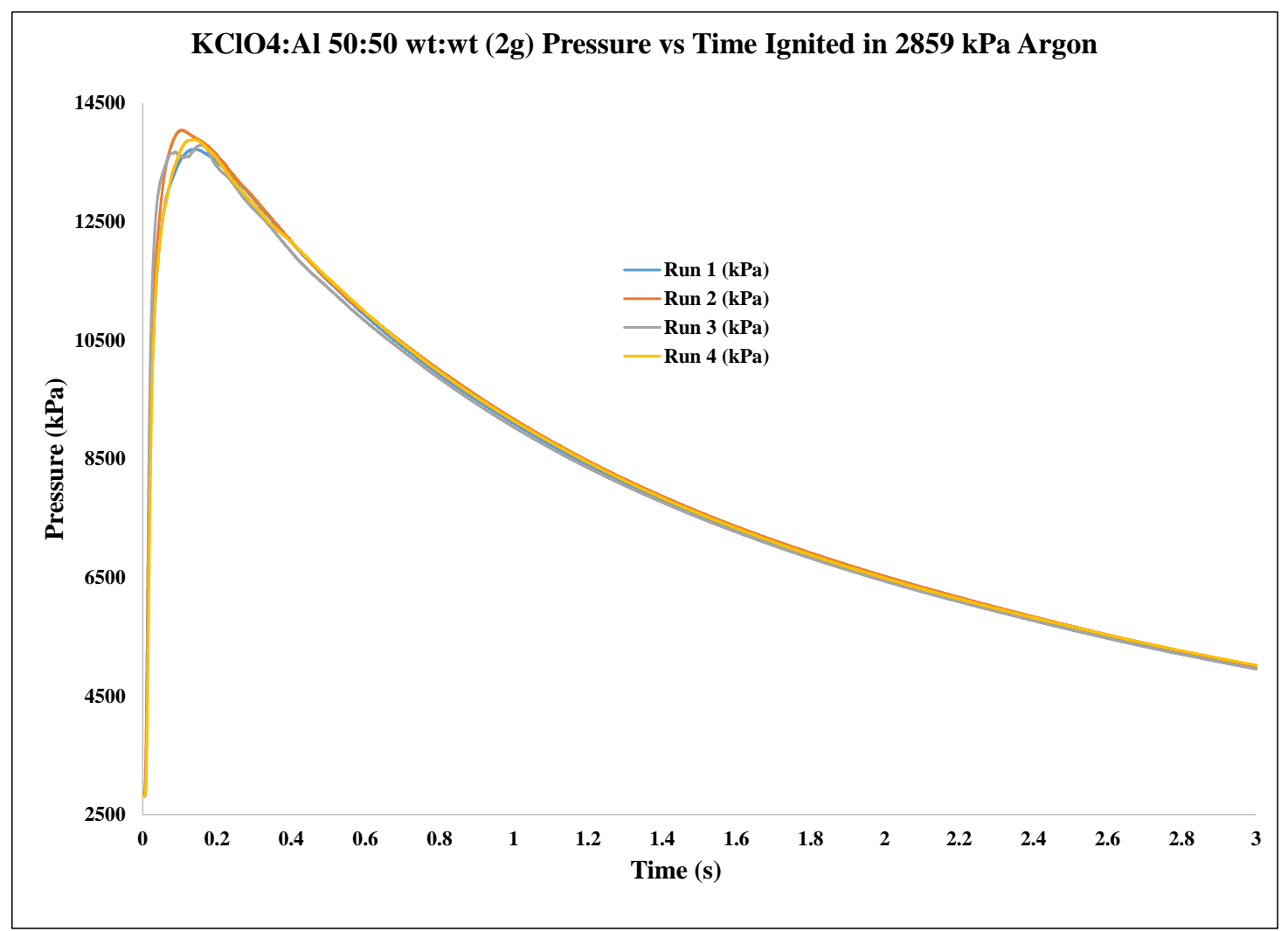

Figure 6.36. Pressure vs. Time curve of $\mathrm{KClO}_{4}$ :Al 50:50 wt:wt

(2 $\mathrm{g}$ in $2859 \mathrm{kPa}$ Argon) 


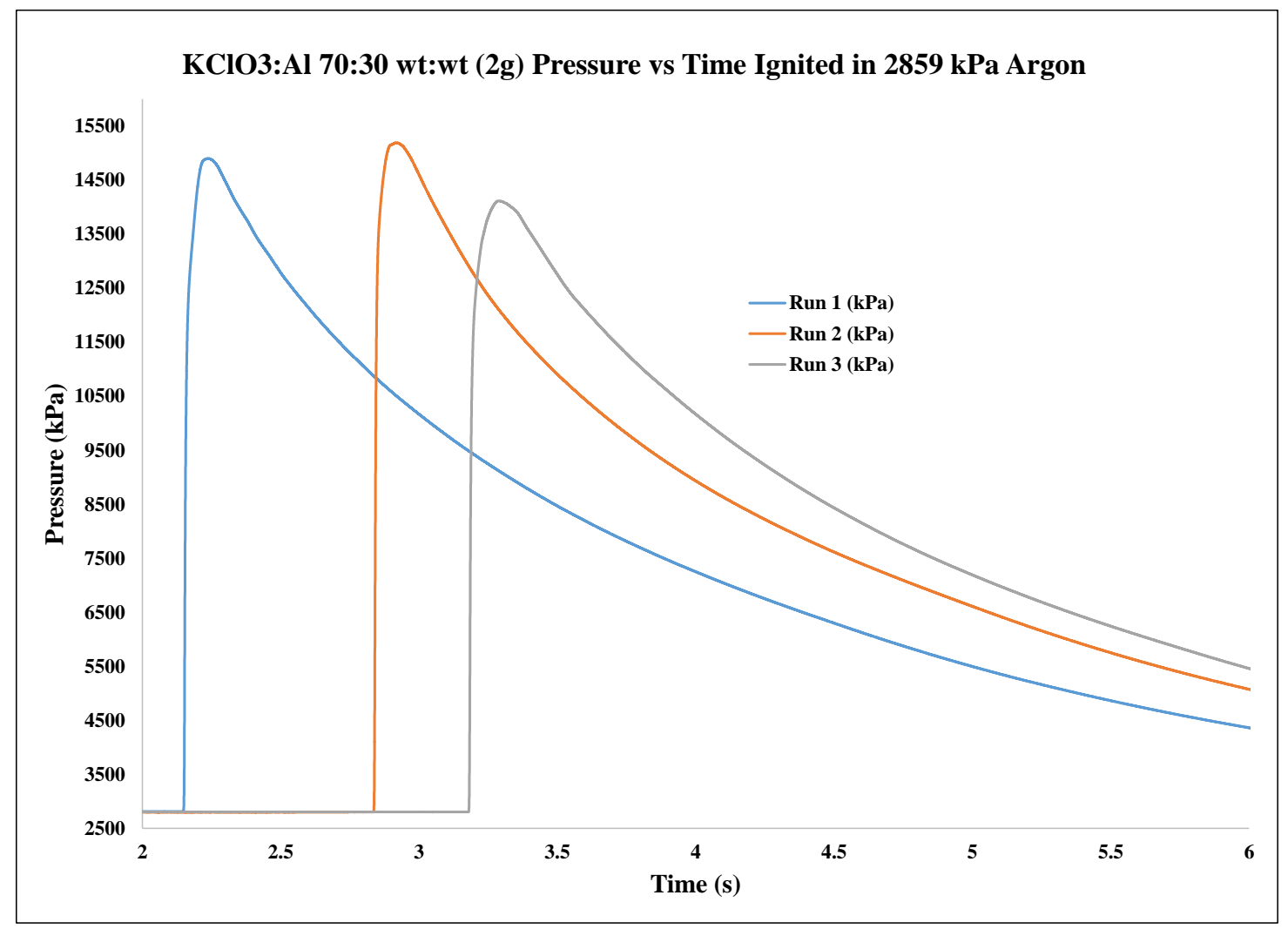

Figure 6.37. Pressure vs. Time curve of $\mathrm{KClO}_{3}: \mathrm{Al} 70: 30 \mathrm{wt}$ :wt

(2 $\mathrm{g}$ in $2859 \mathrm{kPa}$ Argon) 


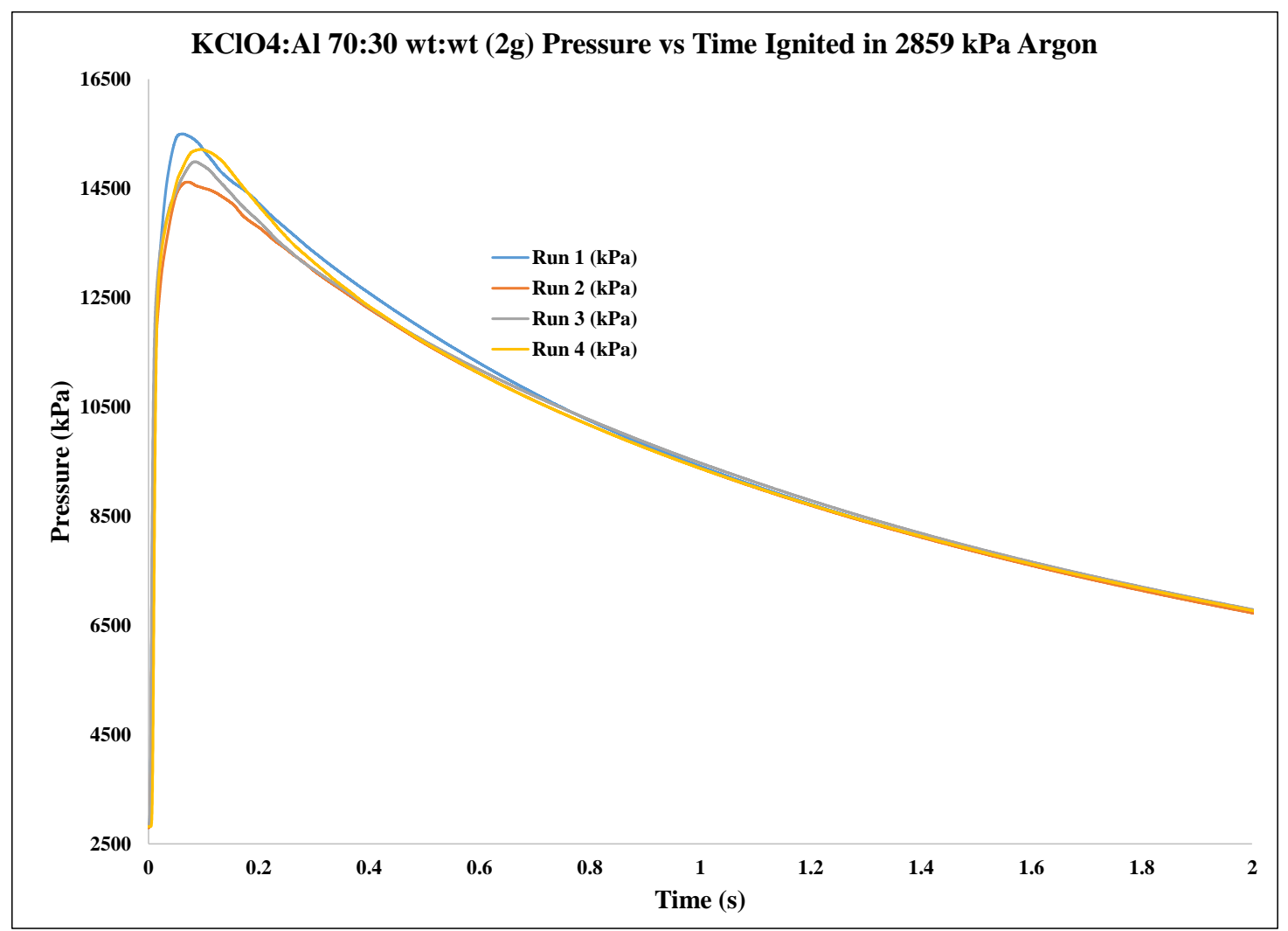

Figure 6.38. Pressure vs. Time curve of $\mathrm{KClO}_{4}$ :Al 70:30 wt:wt

(2 $\mathrm{g}$ in $2859 \mathrm{kPa}$ Argon) 


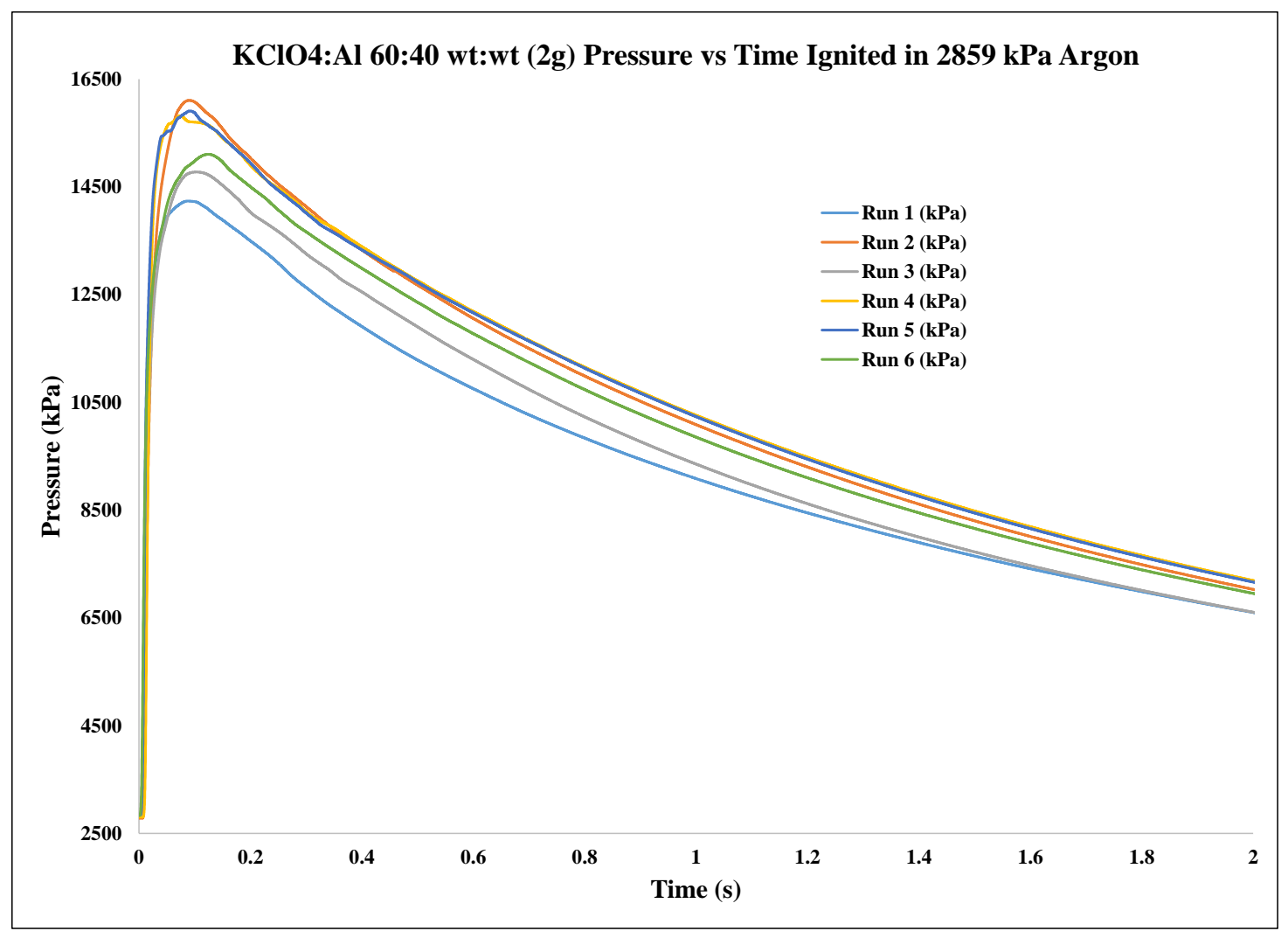

Figure 6.39. Pressure vs. Time curve of $\mathrm{KClO}_{4}: \mathrm{Al}$ 60:40 wt:wt

(2 $\mathrm{g}$ in $2859 \mathrm{kPa}$ Argon) 


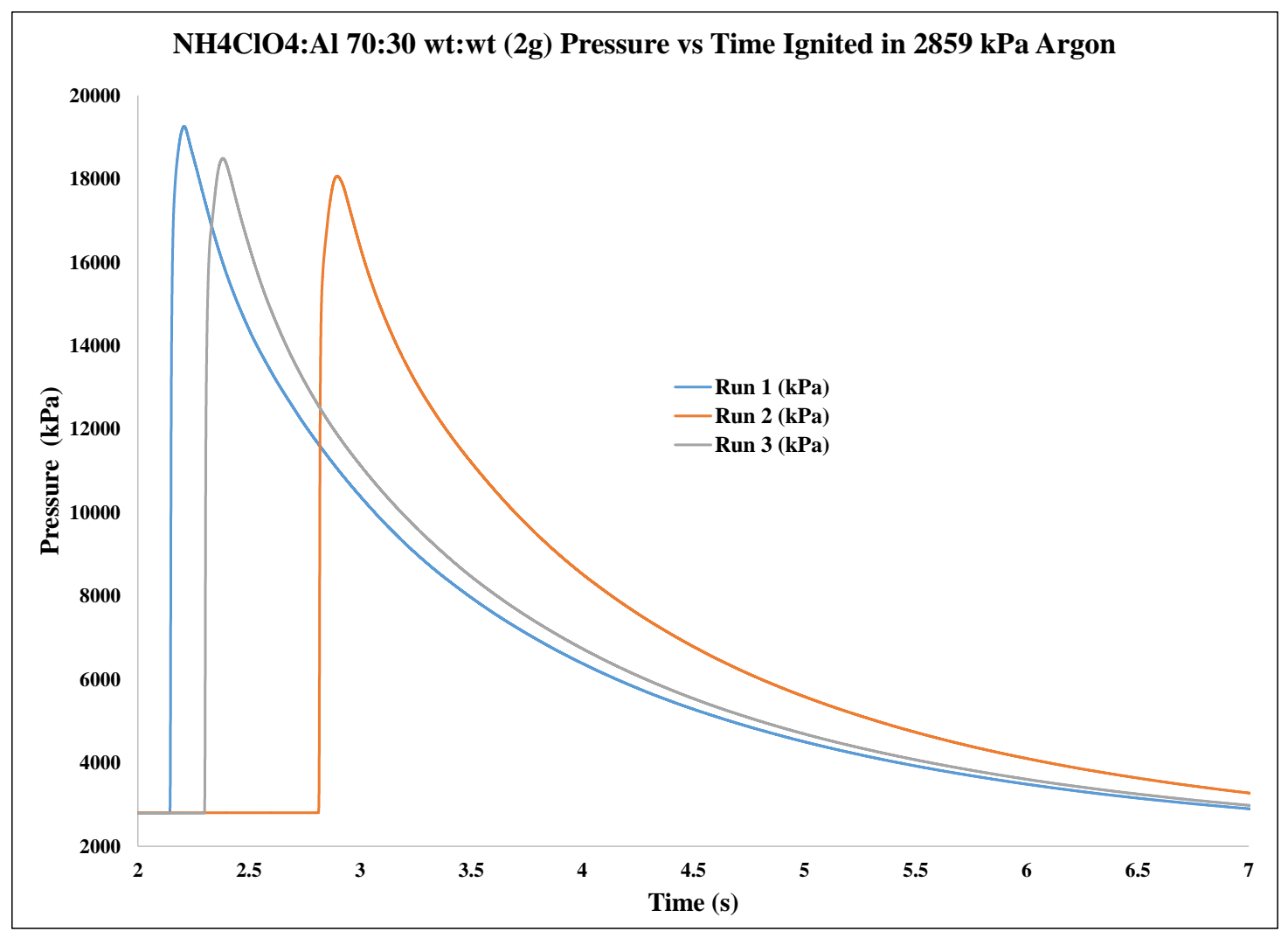

Figure 6.40. Pressure vs. Time curve of $\mathrm{NH}_{4} \mathrm{ClO}_{4}: \mathrm{Al} 70: 30 \mathrm{wt}: \mathrm{wt}$

(2 $\mathrm{g}$ in $2859 \mathrm{kPa}$ Argon) 


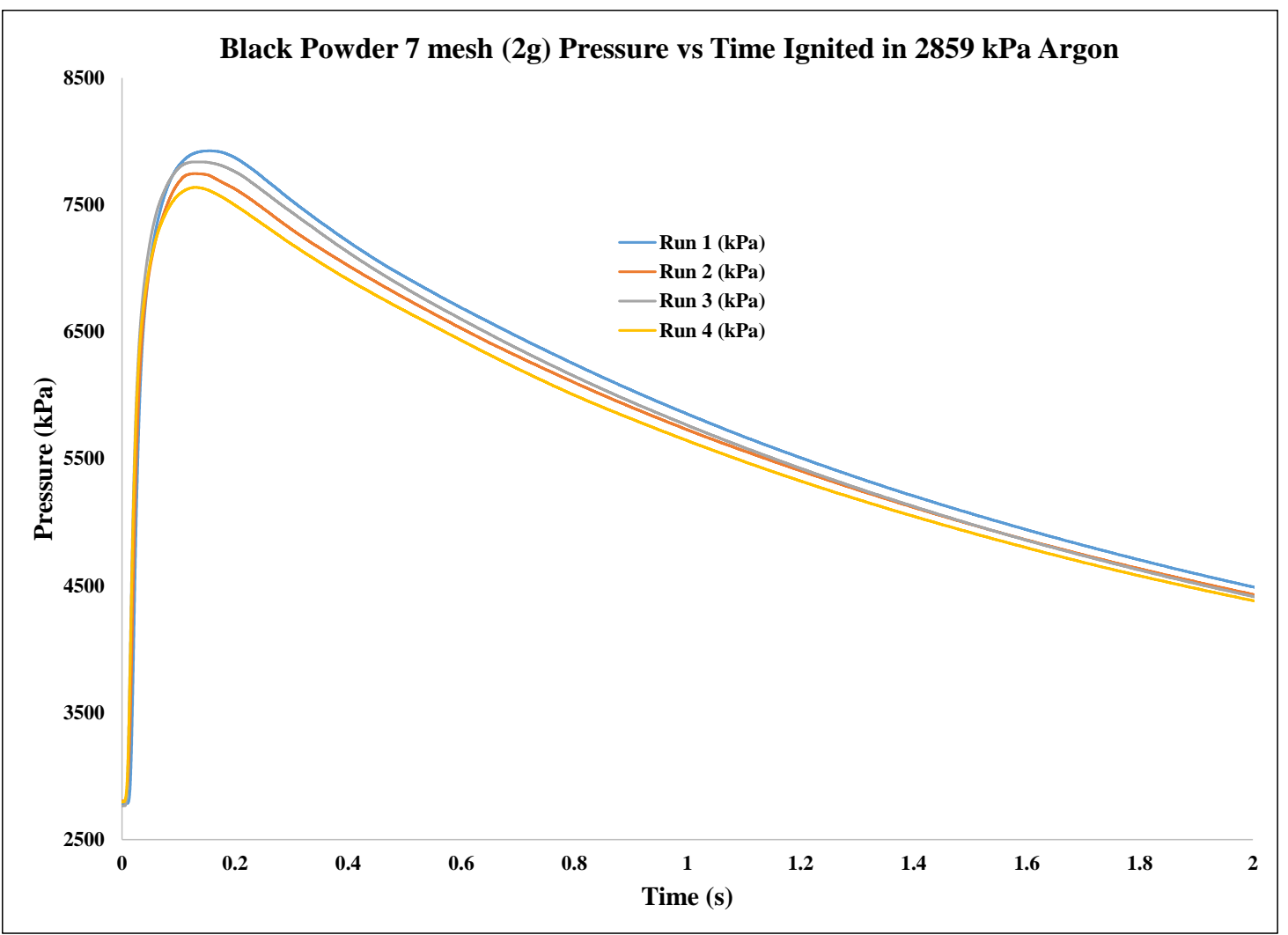

Figure 6.41. Pressure vs. Time curve of 7 mesh granulated Black Powder (2 $\mathrm{g}$ in $2859 \mathrm{kPa}$ Argon) 


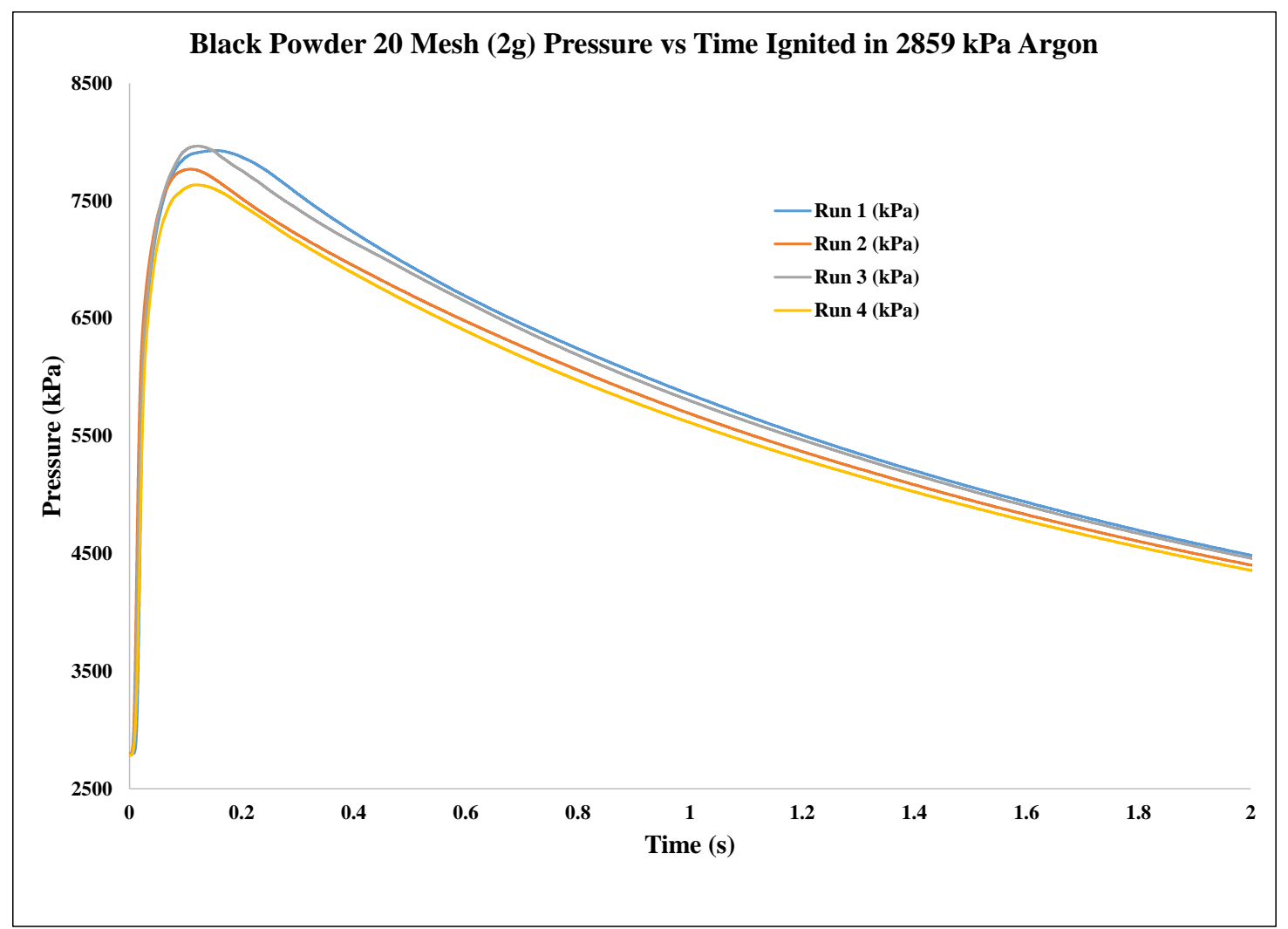

Figure 6.42. Pressure vs. Time curve of 20 mesh granulated Black Powder (2 $\mathrm{g}$ in $2859 \mathrm{kPa}$ Argon) 


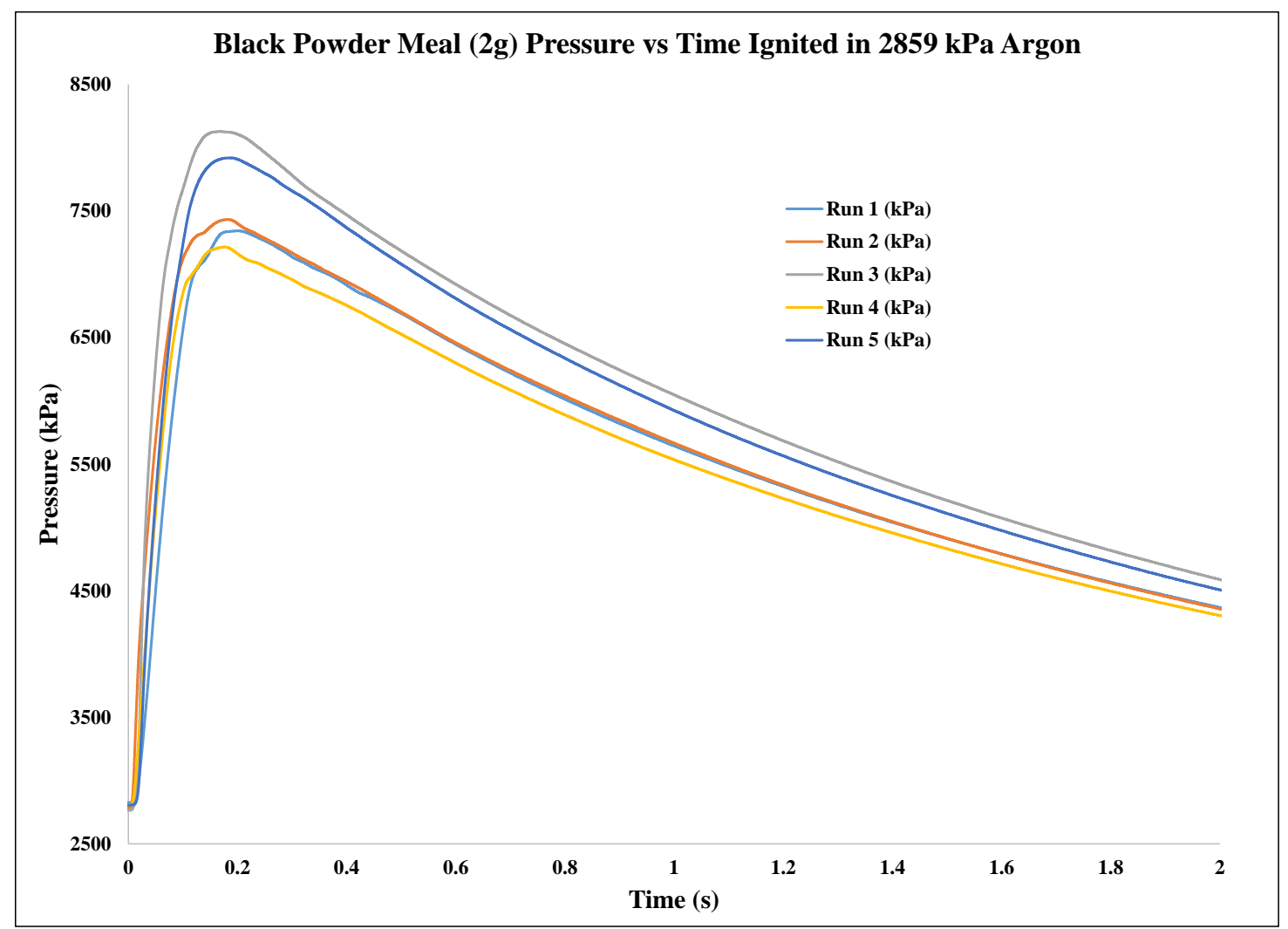

Figure 6.43. Pressure vs. Time curve of Meal Black Powder

(2 $\mathrm{g}$ in $2859 \mathrm{kPa}$ Argon) 


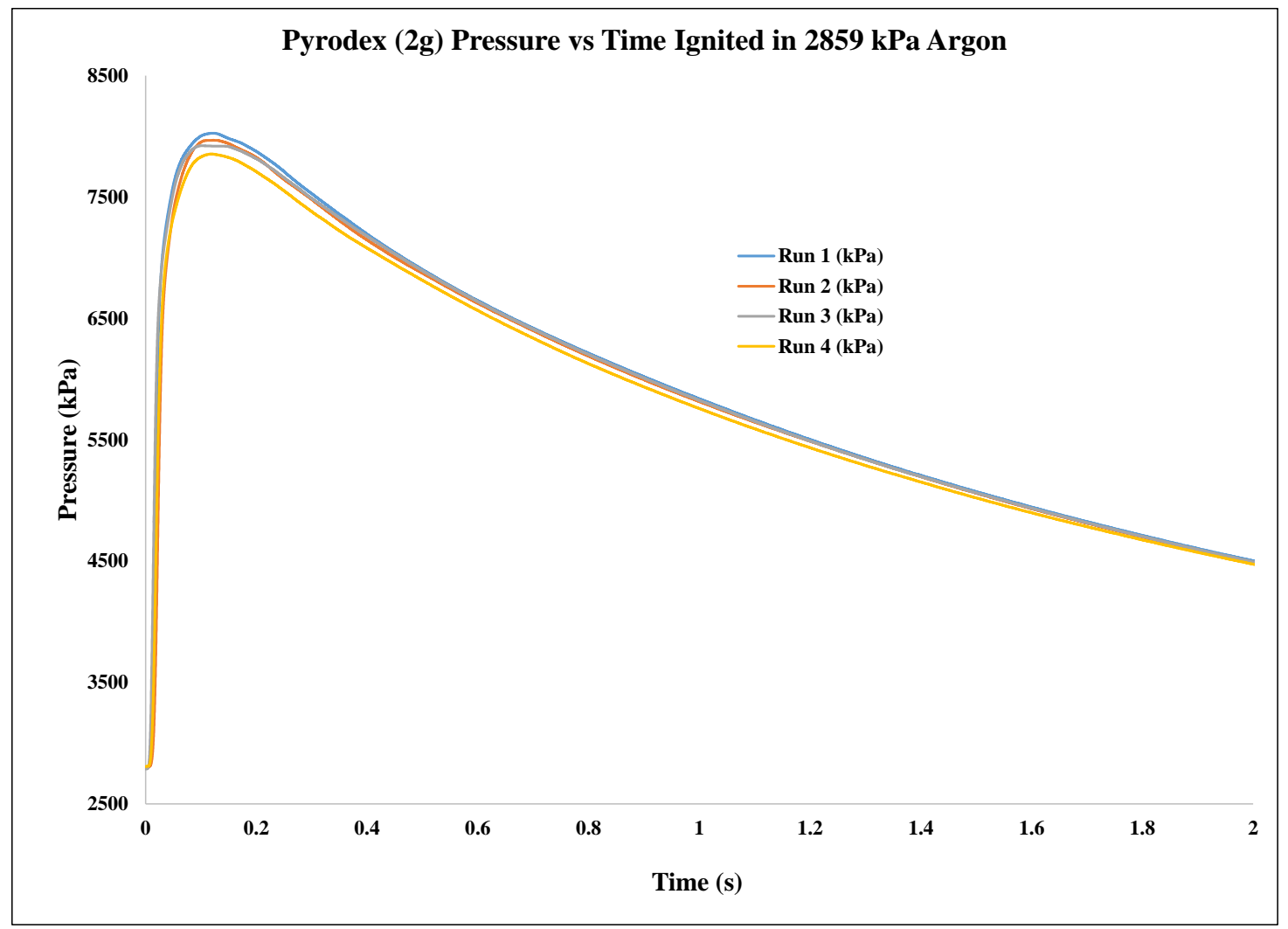

Figure 6.44. Pressure vs. Time curve of Pyrodex (2 g in $2859 \mathrm{kPa}$ Argon) 


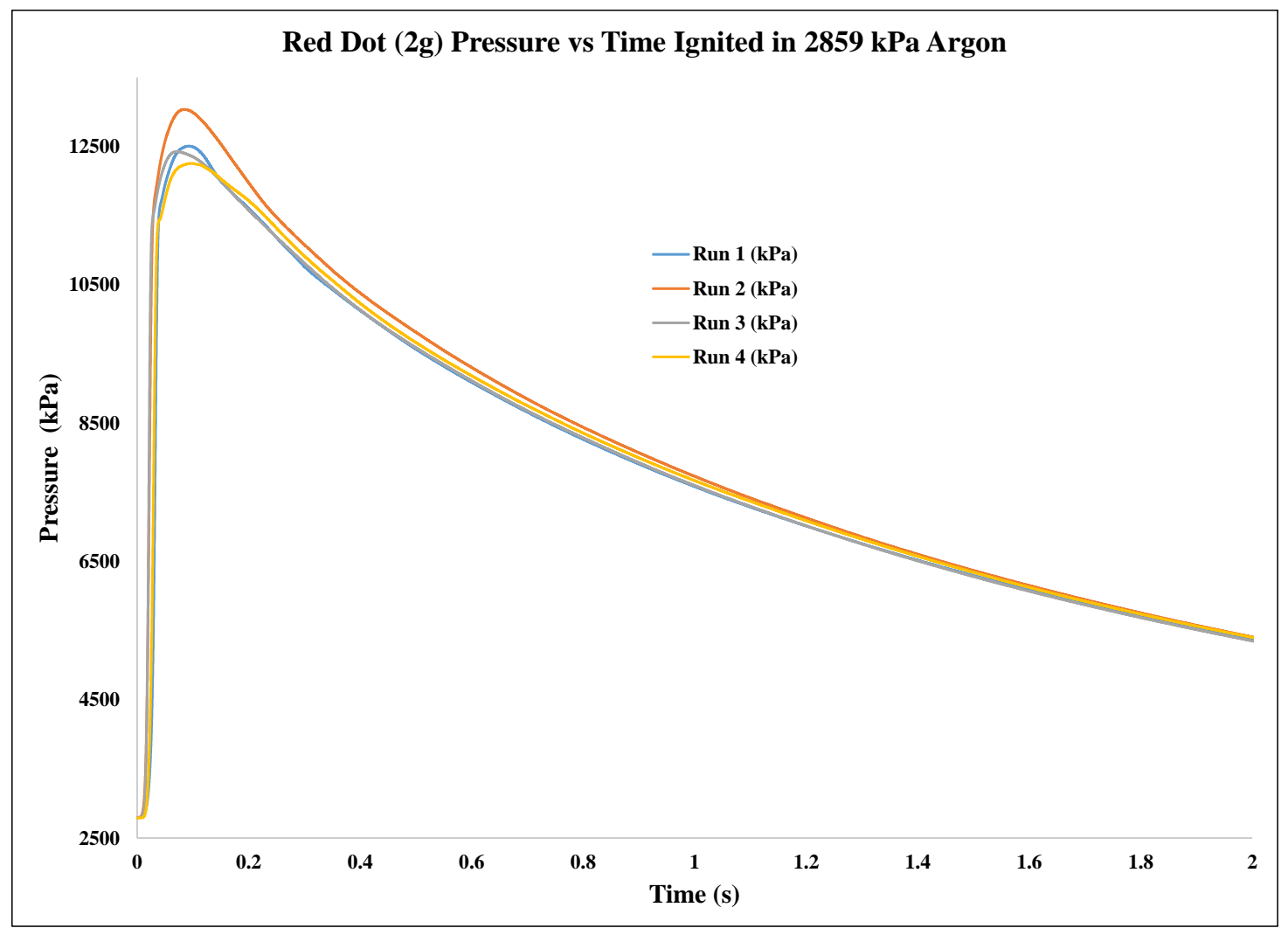

Figure 6.45. Pressure vs. Time curve of Red Dot (2 g in $2859 \mathrm{kPa}$ Argon) 
Airblast Pressure vs. Time Curves 6.096 m (20 ft) from Large Scale Tests

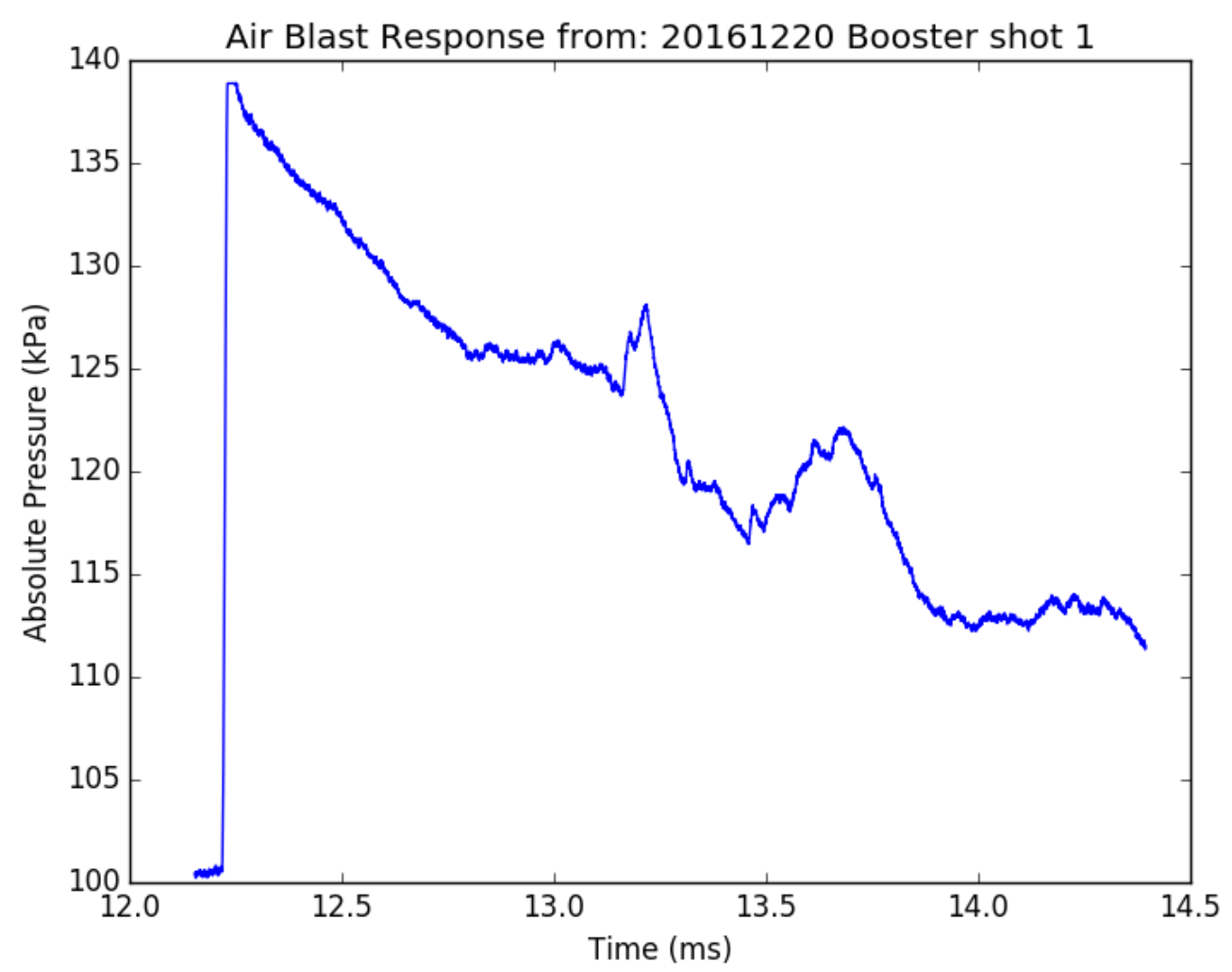

Figure 6.46. Airblast pressure vs. time curve from large scale testing with the booster only (sand as the sample) 


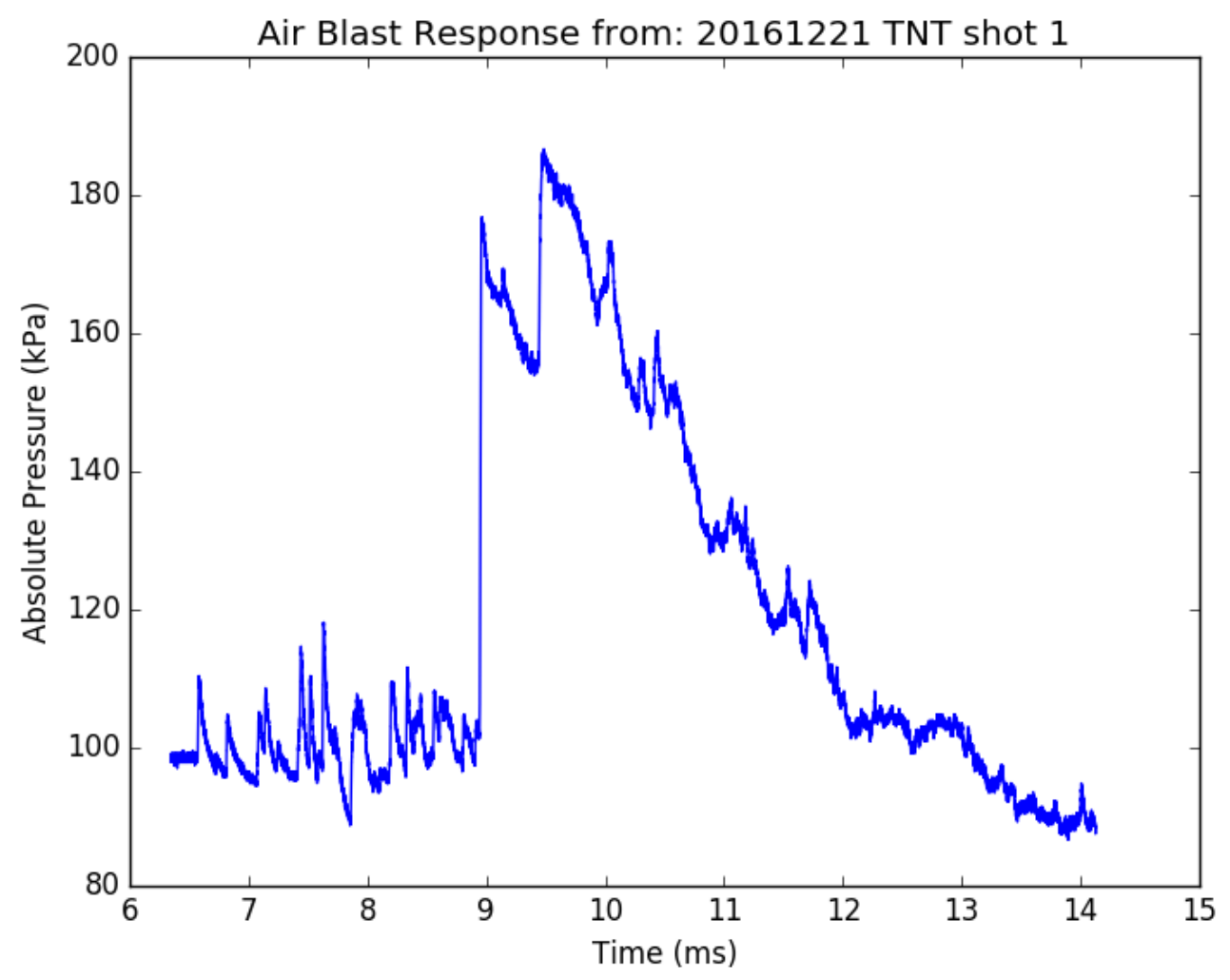

Figure 6.47. Airblast pressure vs. time curve from large scale testing with TNT as the sample. 


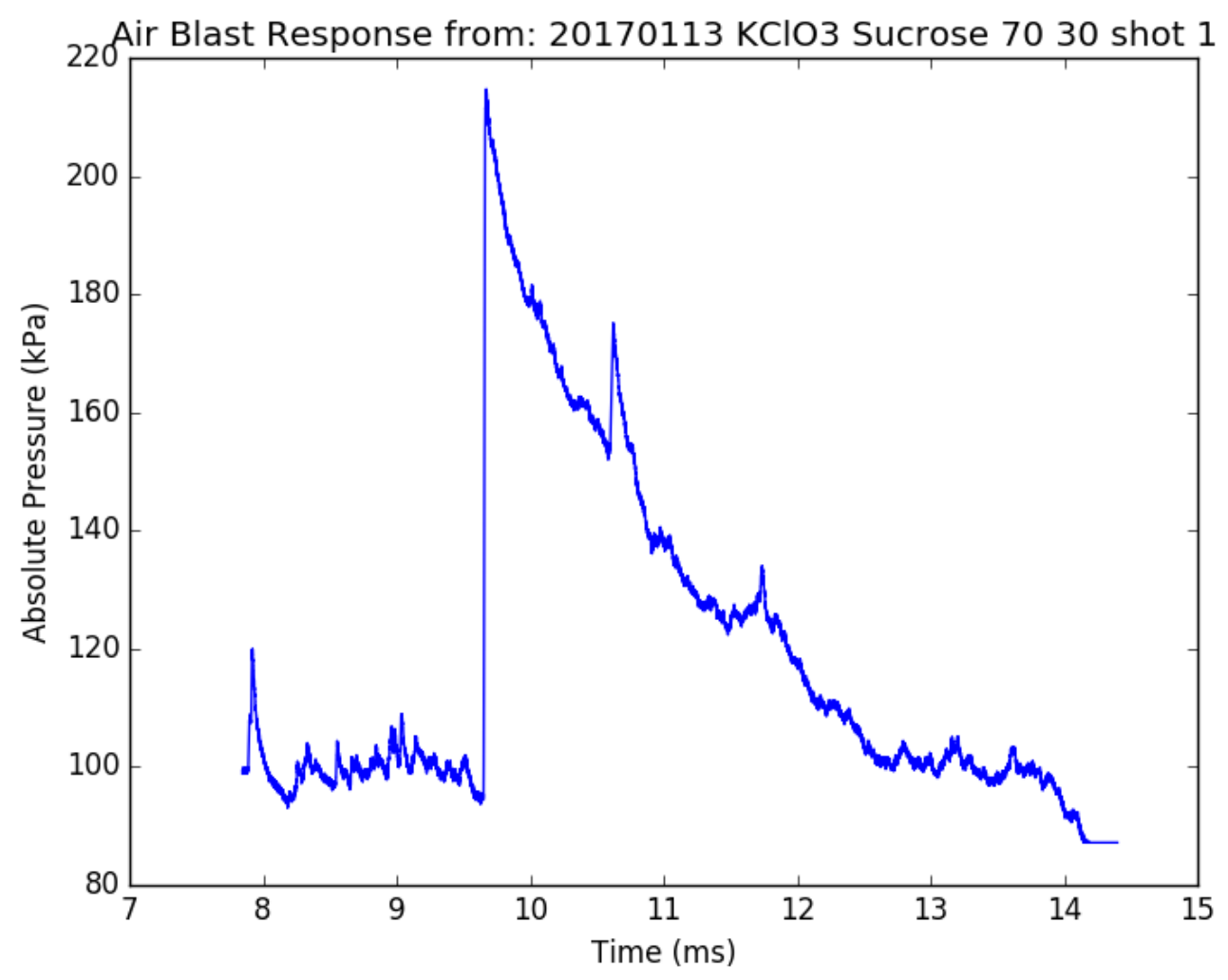

Figure 6.48. Airblast pressure vs. time curve from large scale testing with $\mathrm{KClO}_{3}:$ Sucrose 70:30 wt:wt as the sample 


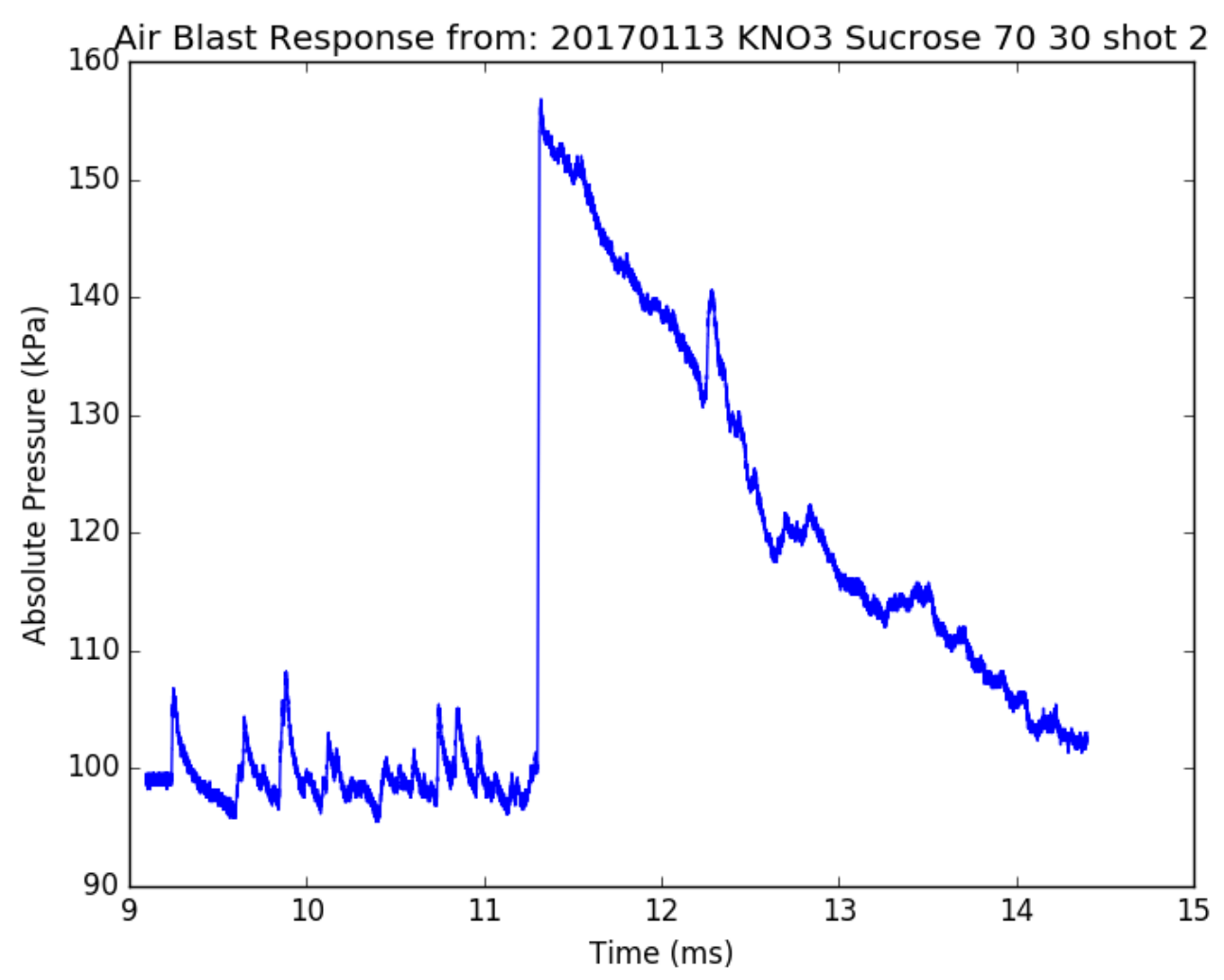

Figure 6.49. Airblast pressure vs. time curve from large scale testing with $\mathrm{KNO}_{3}:$ Sucrose $70: 30 \mathrm{wt}: \mathrm{wt}$ as the sample 


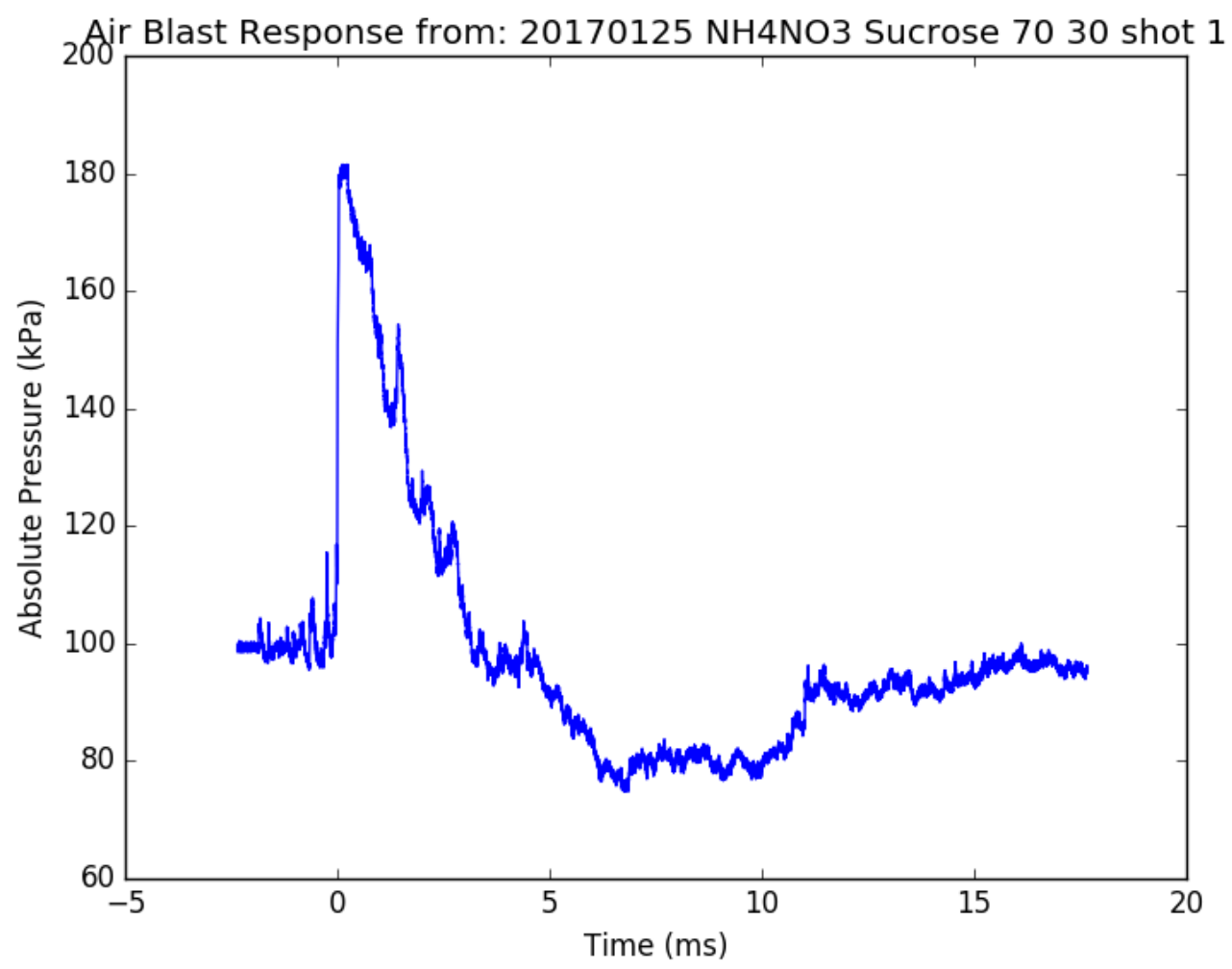

Figure 6.50. Airblast pressure vs. time curve from large scale testing with $\mathrm{NH}_{4} \mathrm{NO}_{3}:$ Sucrose 70:30 wt:wt as the sample 


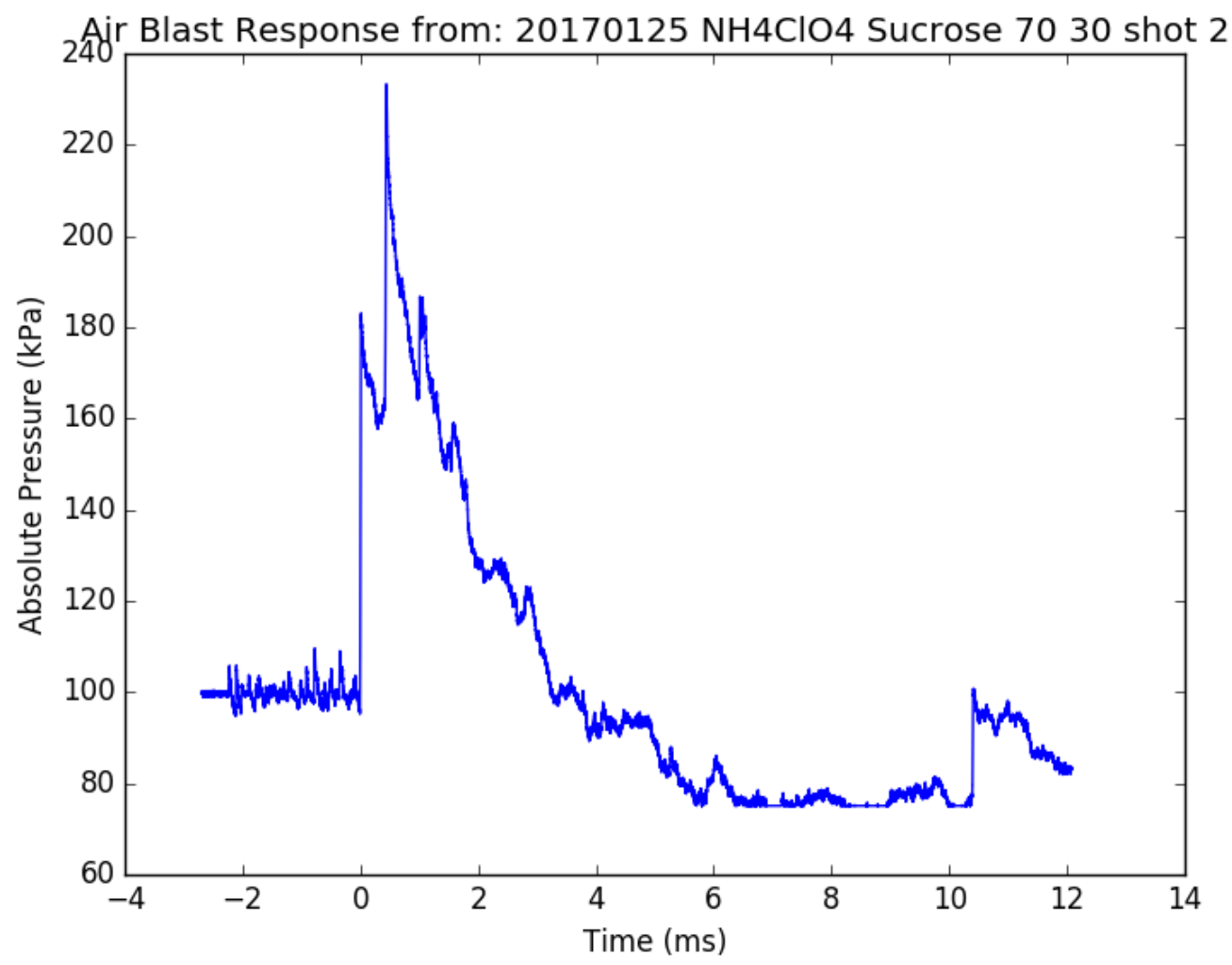

Figure 6.51. Airblast pressure vs. time curve from large scale testing with $\mathrm{NH}_{4} \mathrm{ClO}_{4}$ :Sucrose 70:30 wt:wt as the sample 


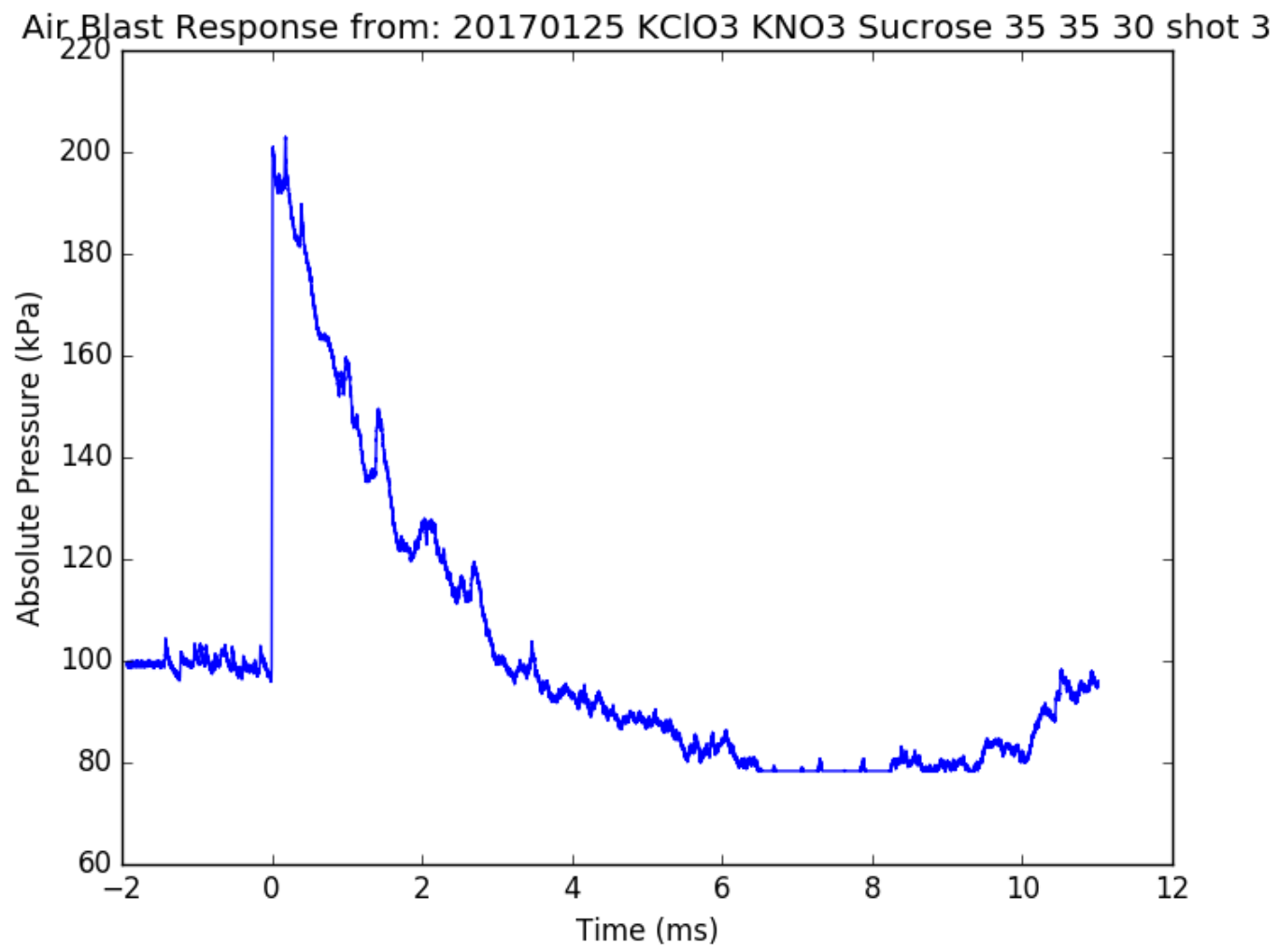

Figure 6.52. Airblast pressure vs. time curve from large scale testing with $\mathrm{KClO}_{3}: \mathrm{KNO}_{3}:$ Sucrose 35:35:30 wt:wt as the sample 


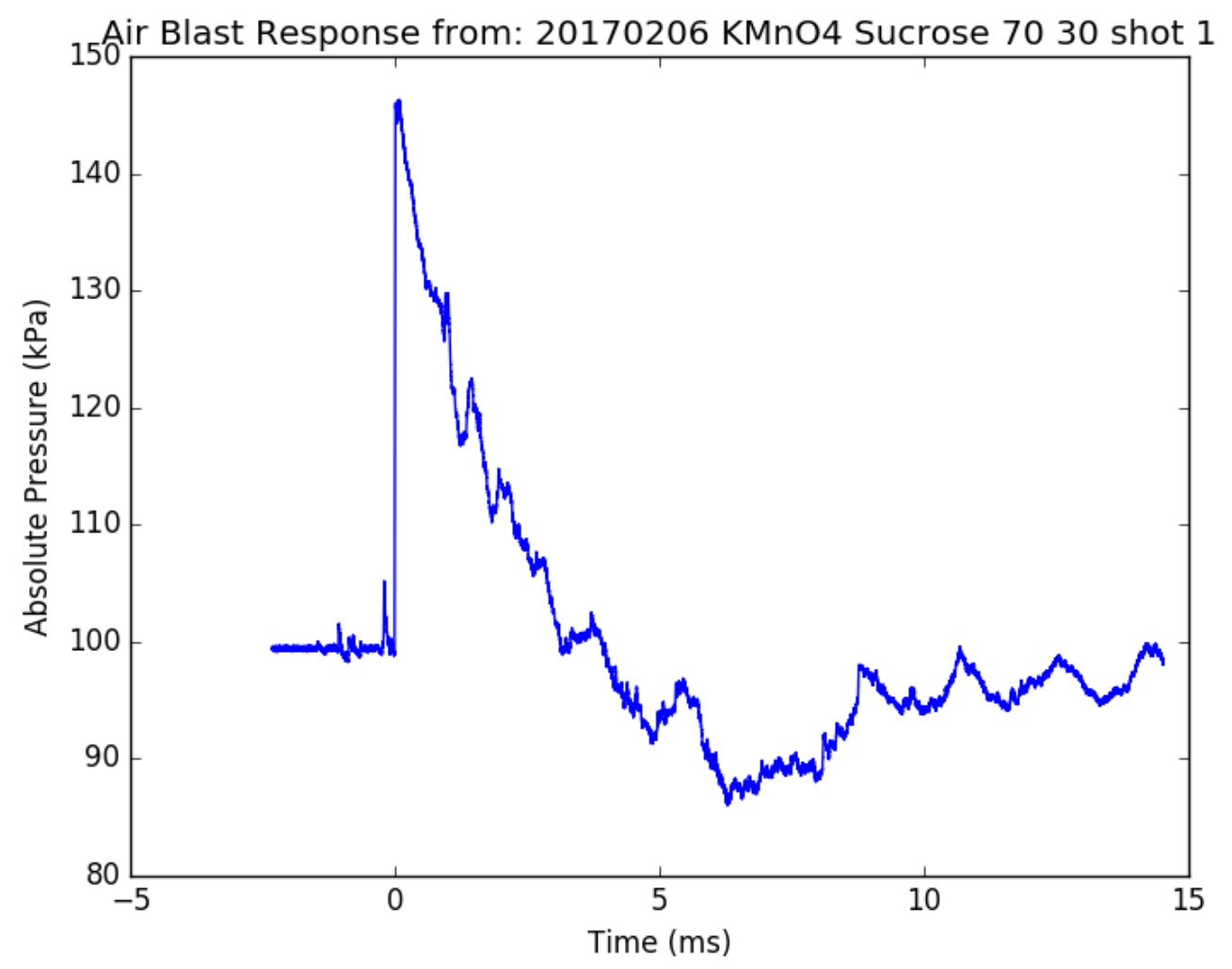

Figure 6.53. Airblast pressure vs. time curve from large scale testing with $\mathrm{KMnO}_{4}:$ Sucrose 70:30 wt:wt as the sample 


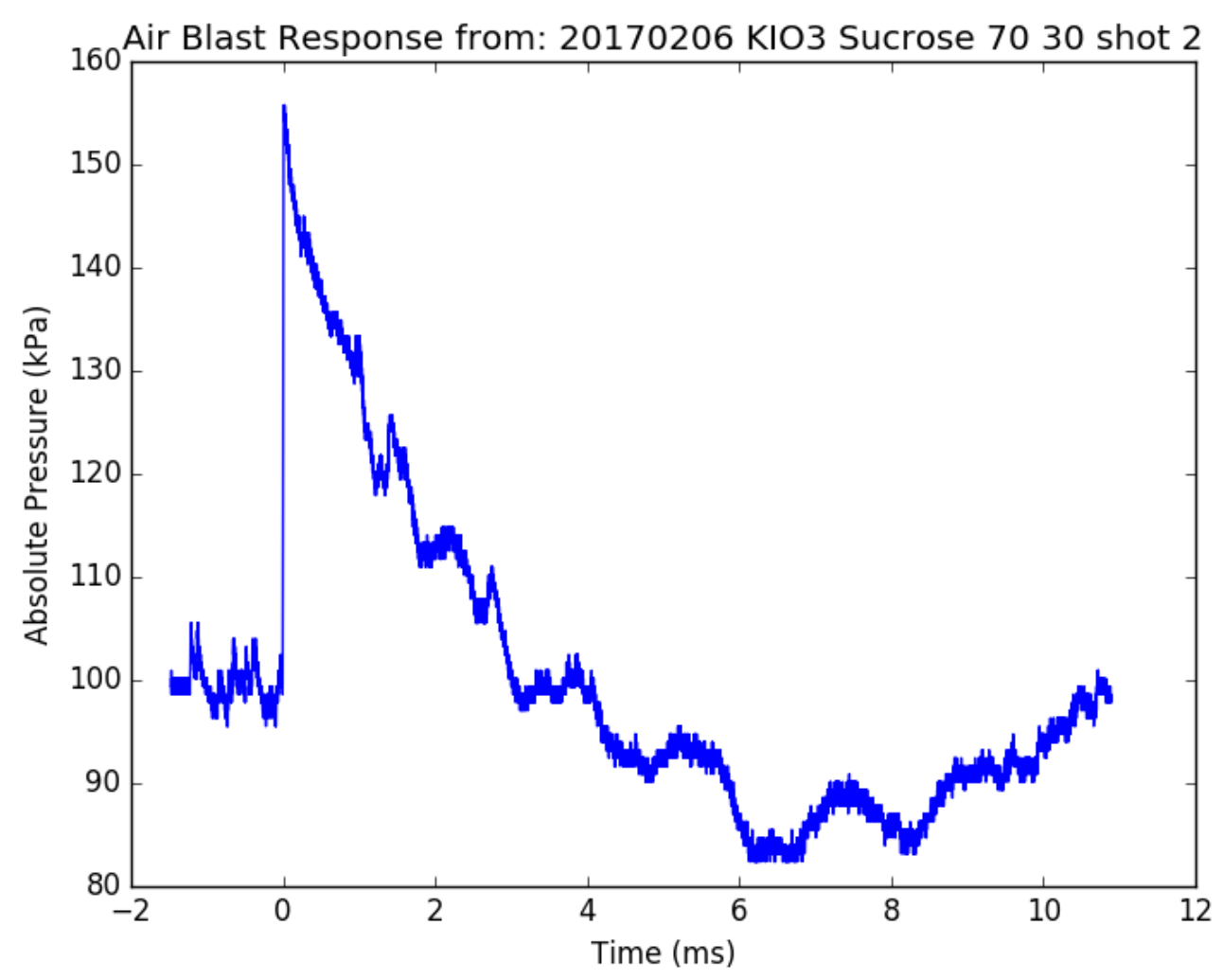

Figure 6.54. Airblast pressure vs. time curve from large scale testing with $\mathrm{KIO}_{3}:$ Sucrose 70:30 wt:wt as the sample 


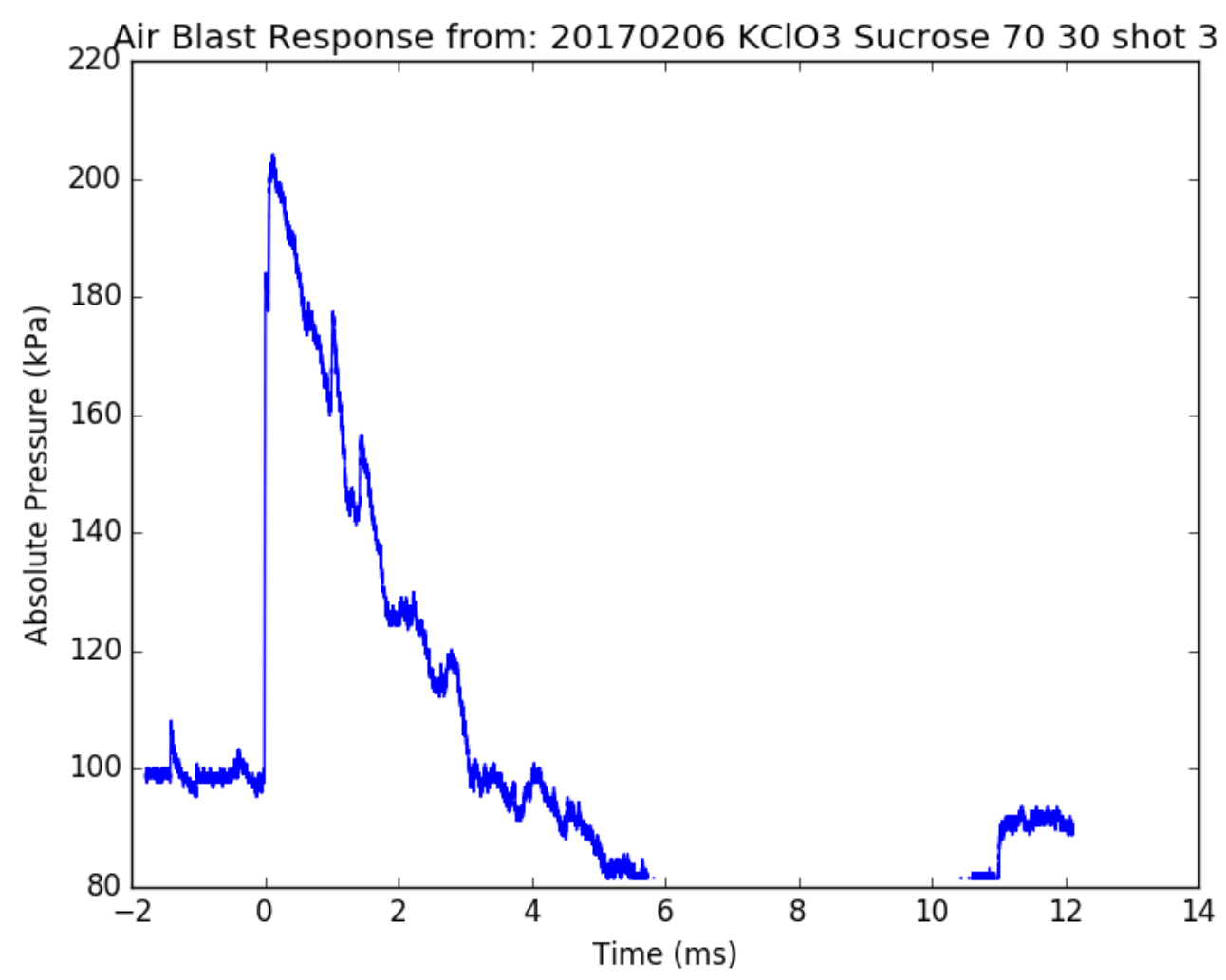

Figure 6.55. Airblast pressure vs. time curve from large scale testing with $\mathrm{KClO}_{3}:$ Sucrose 70:30 wt:wt as the sample 


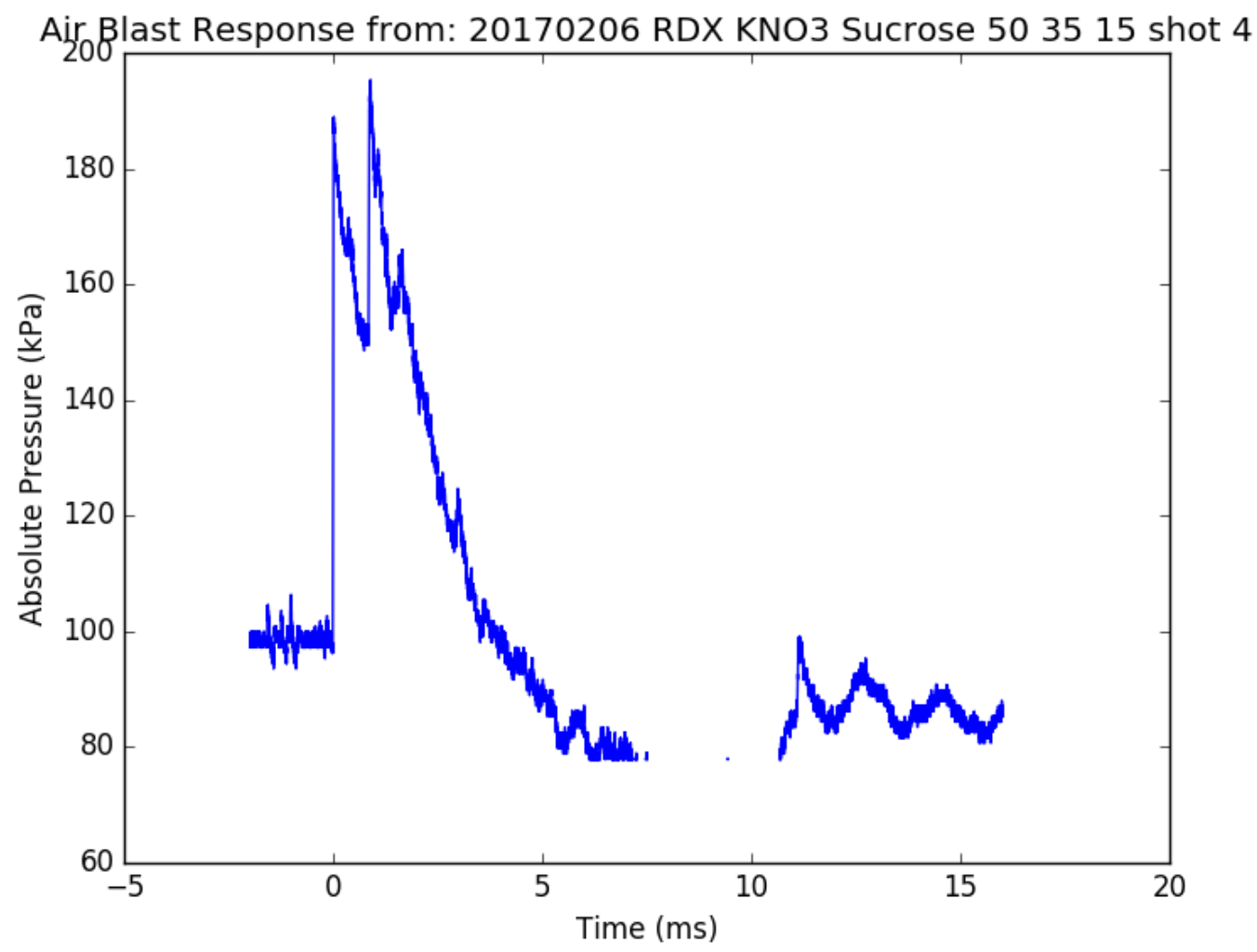

Figure 6.56. Airblast pressure vs. time curve from large scale testing with RDX: $\mathrm{KNO}_{3}:$ Sucrose 50:35:15 wt:wt as the sample 


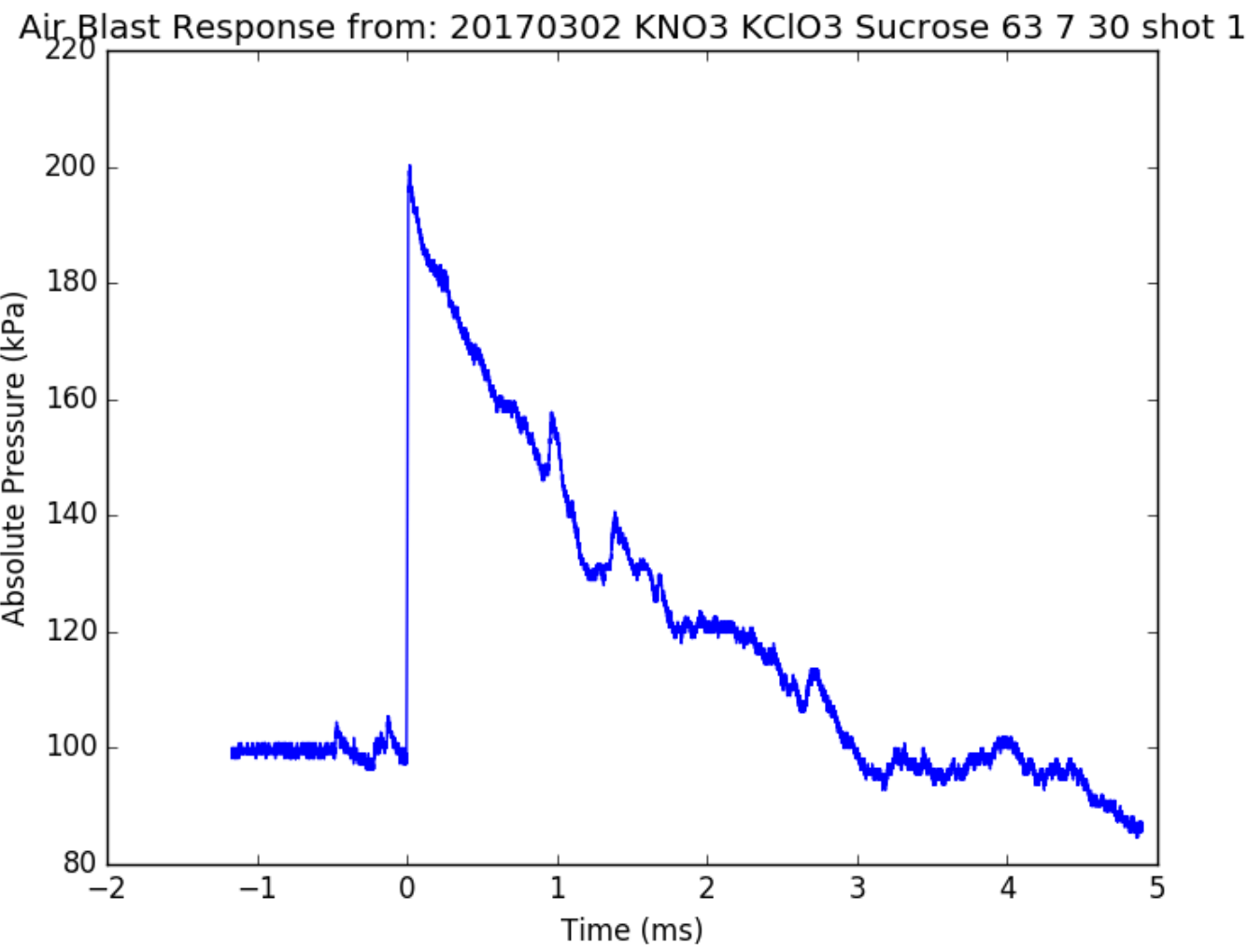

Figure 6.57. Airblast pressure vs. time curve from large scale testing with $\mathrm{KNO}_{3}: \mathrm{KClO}_{3}:$ Sucrose 63:7:30 wt:wt as the sample 
Air Blast Response from: 20170302 KNO3 RDX Sucrose 66.5528 .5 shot 2

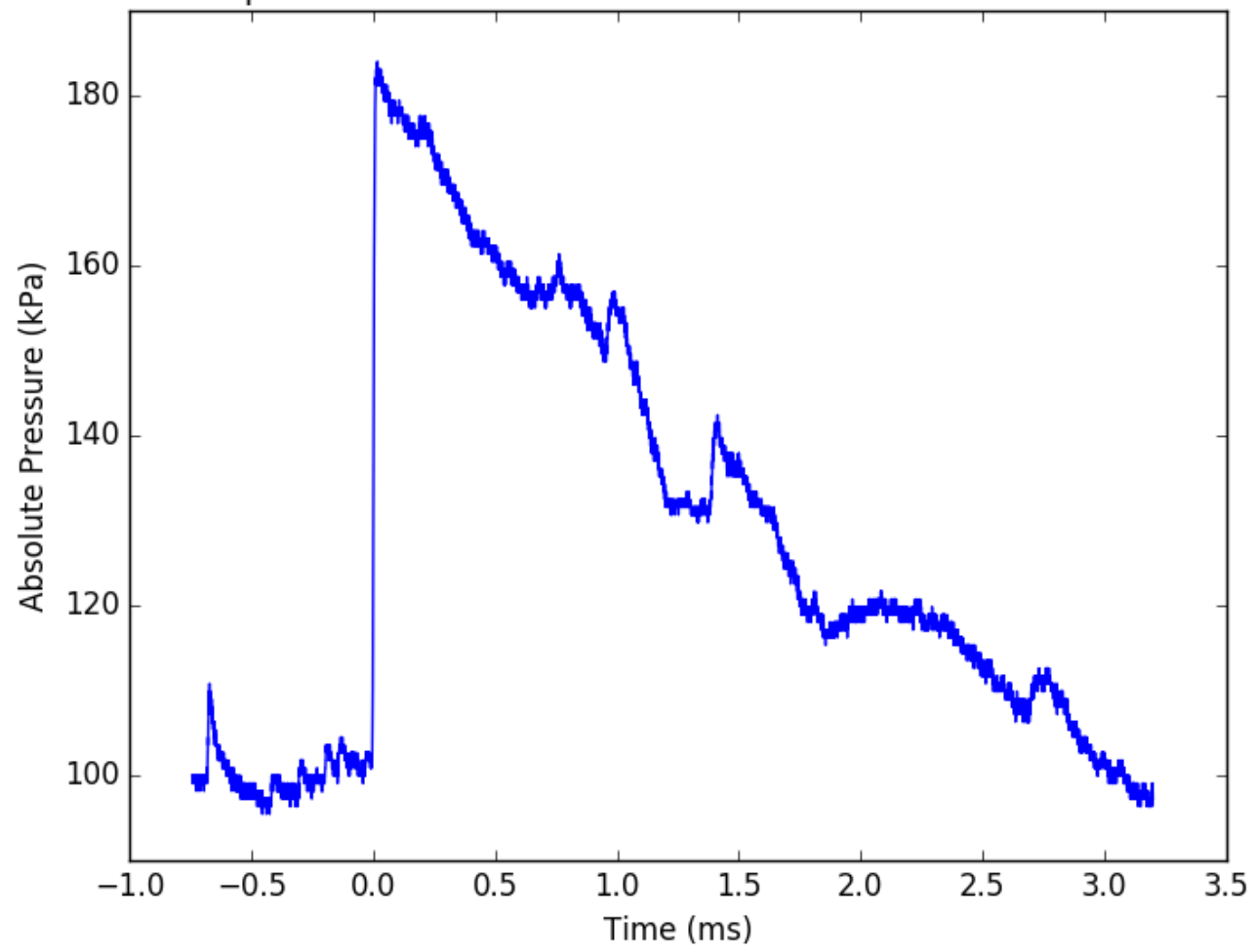

Figure 6.58. Airblast pressure vs. time curve from large scale testing with $\mathrm{KNO}_{3}: \mathrm{RDX}:$ Sucrose 66.5:5:28.5 wt:wt as the sample 


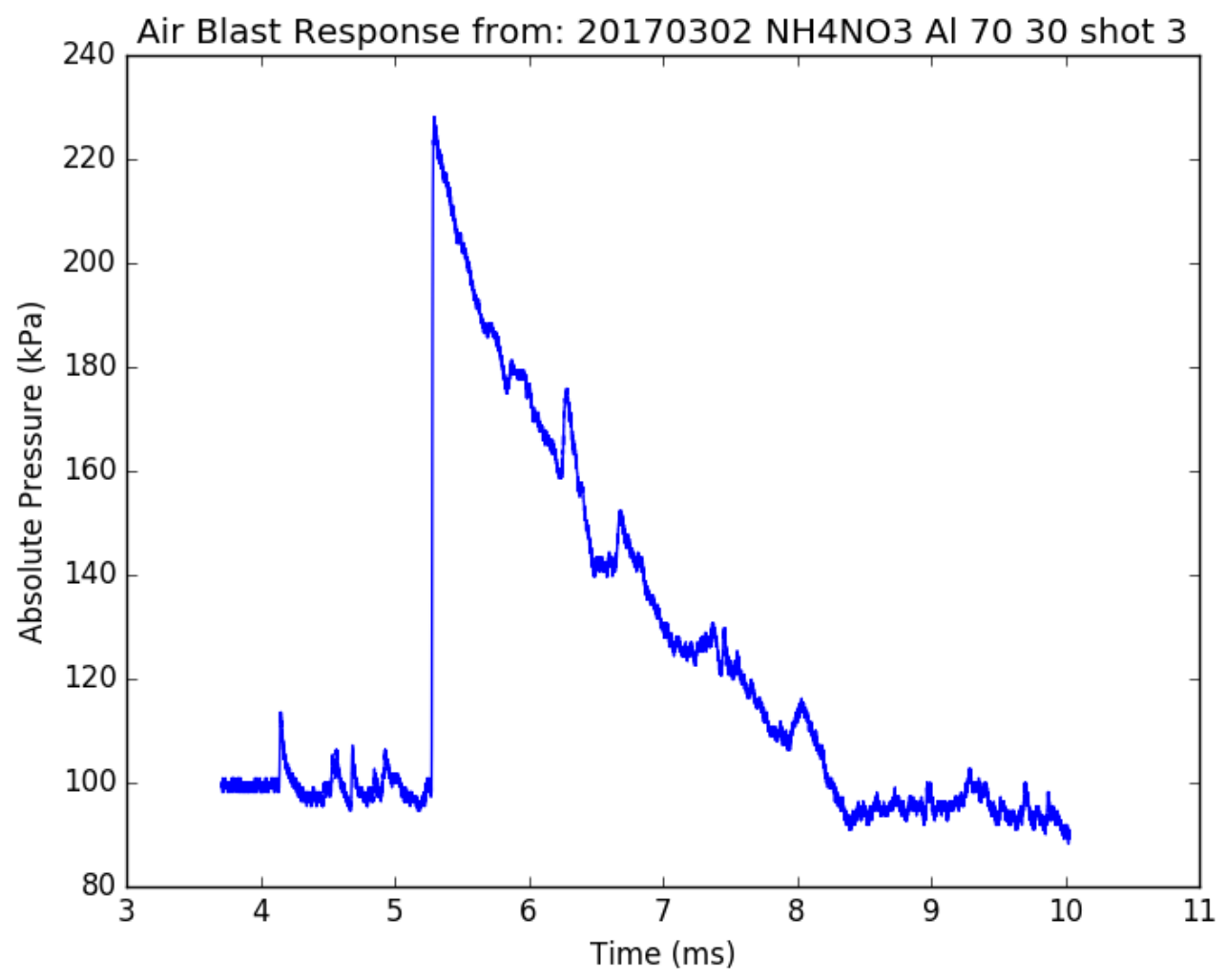

Figure 6.59. Airblast pressure vs. time curve from large scale testing with $\mathrm{NH}_{4} \mathrm{NO}_{3}: \mathrm{Al}$ 70:30 wt:wt as the sample 


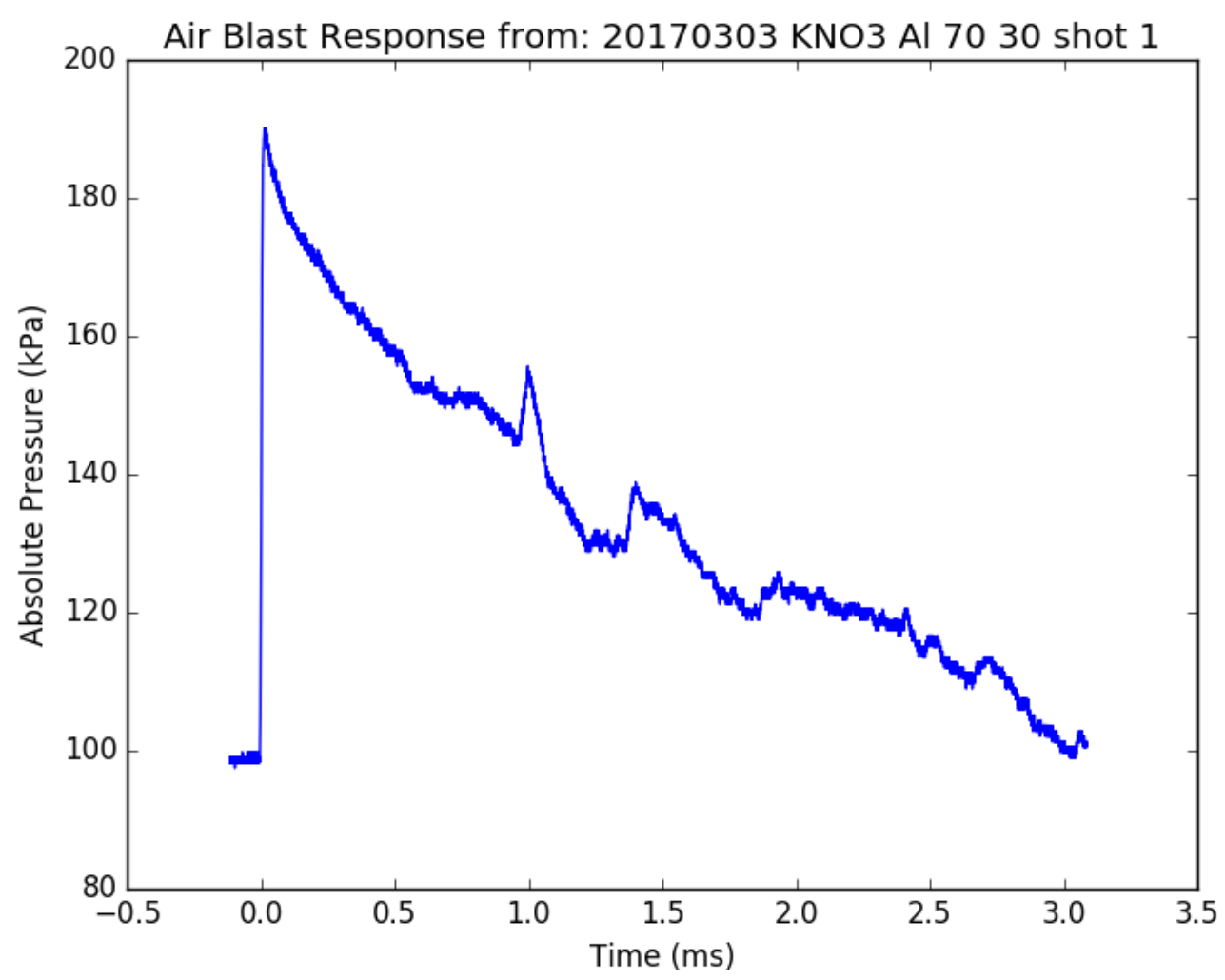

Figure 6.60. Airblast pressure vs. time curve from large scale testing with $\mathrm{KNO}_{3}: \mathrm{Al}$ 70:30 wt:wt as the sample 


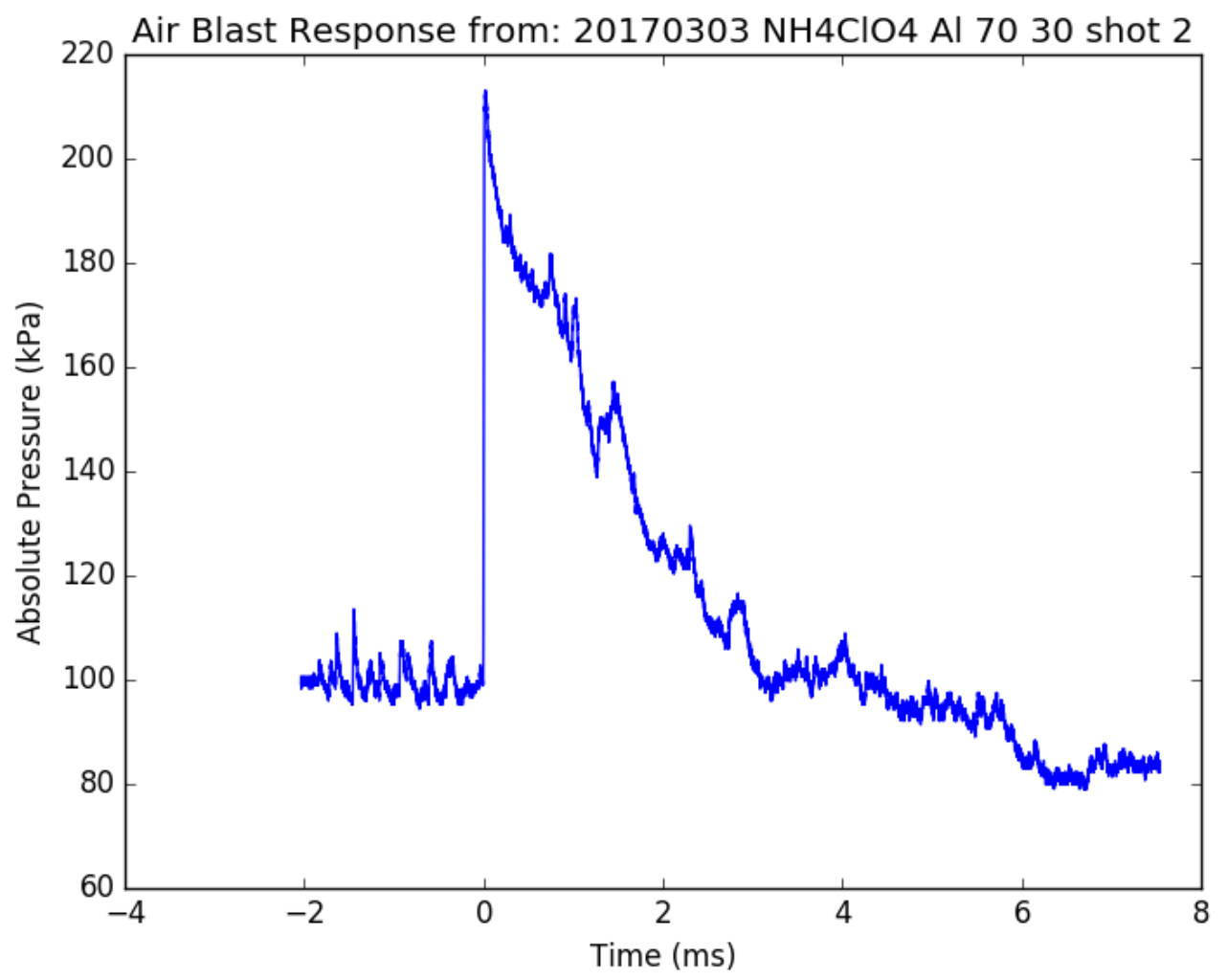

Figure 6.61. Airblast pressure vs. time curve from large scale testing with $\mathrm{NH}_{4} \mathrm{ClO}_{4}: \mathrm{Al}$ 70:30 wt:wt as the sample 
High Speed Camera Records of Large Scale Tests

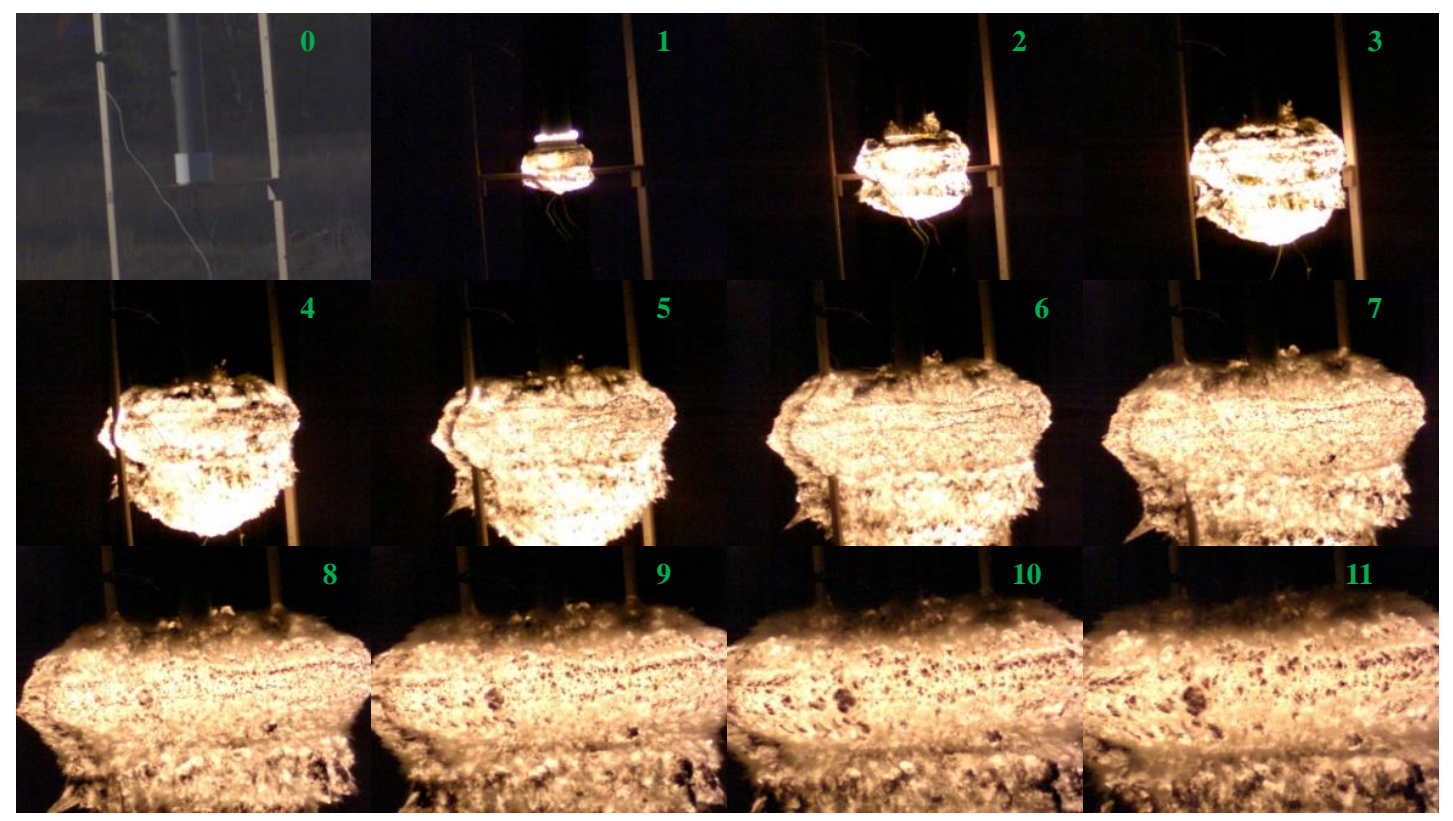

Figure 6.62. High speed camera record from large scale testing with the booster only and sand as the sample (20161220 shot 1$)$

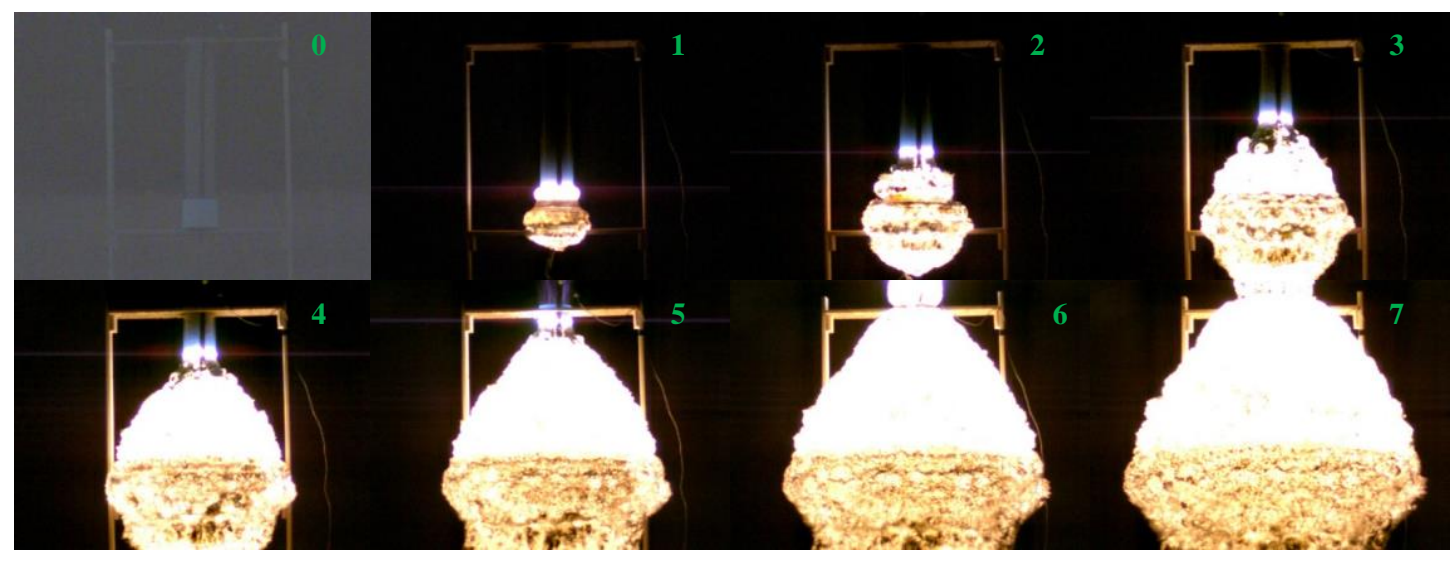

Figure 6.63 High speed camera record from large scale testing with TNT as the sample (20161220 shot 2) 


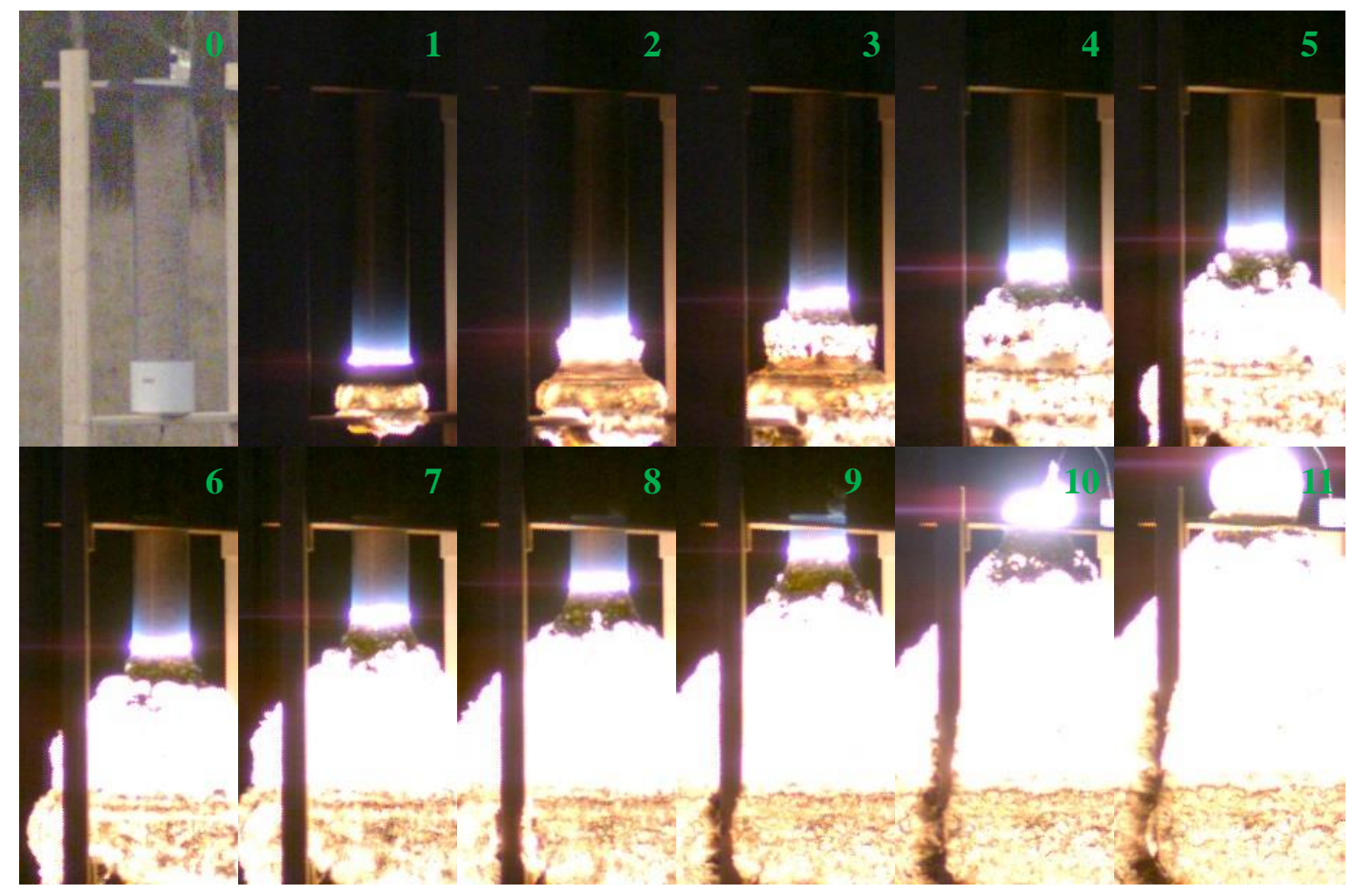

Figure 6.64. High speed camera record from large scale testing with TNT as the sample (20161221 shot 1) 


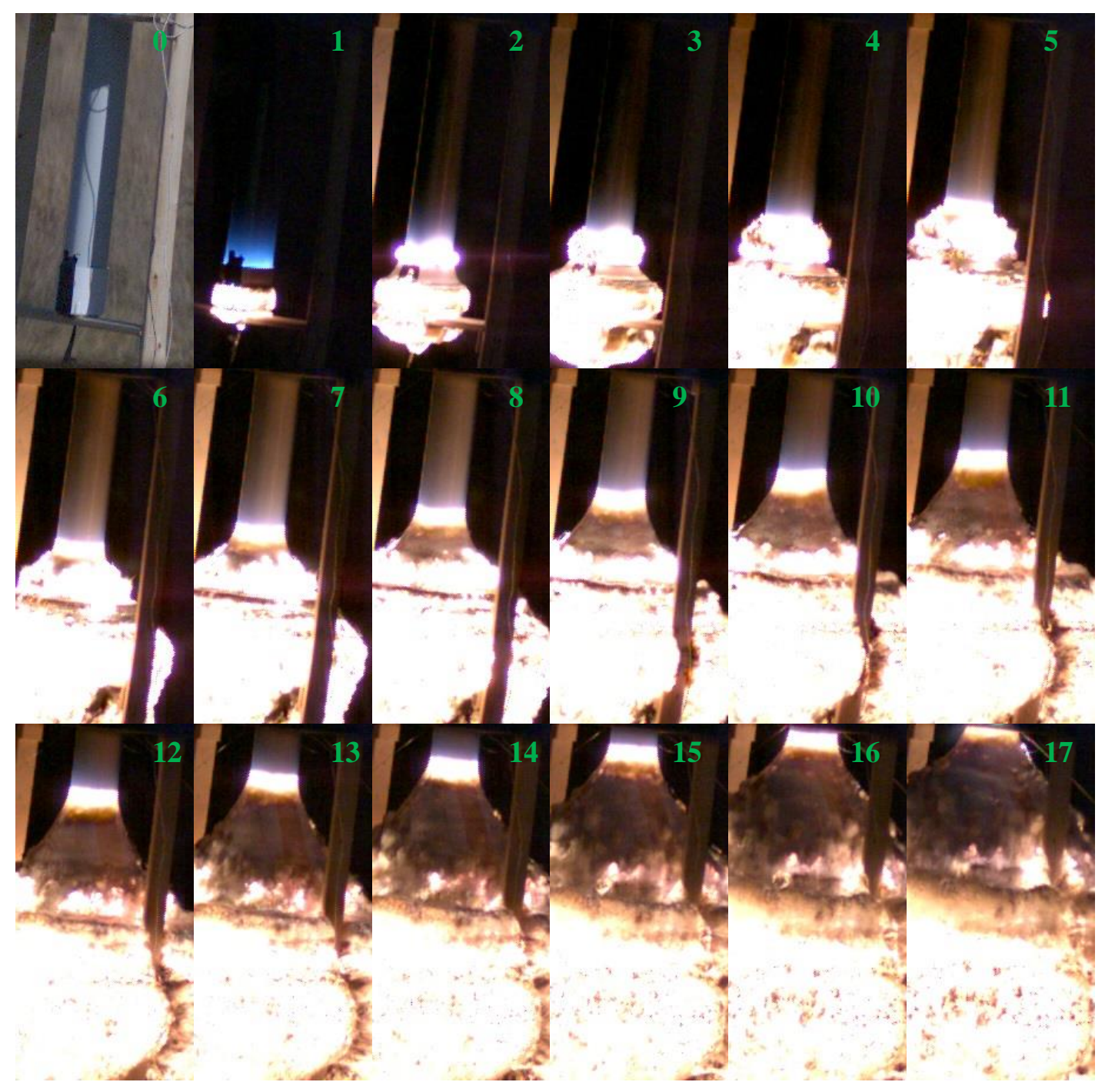

Figure 6.65. High speed camera record from large scale testing with $\mathrm{KClO}_{3}$ :Sucrose 70:30 wt:wt as the sample (20170113 shot 1$)$ 


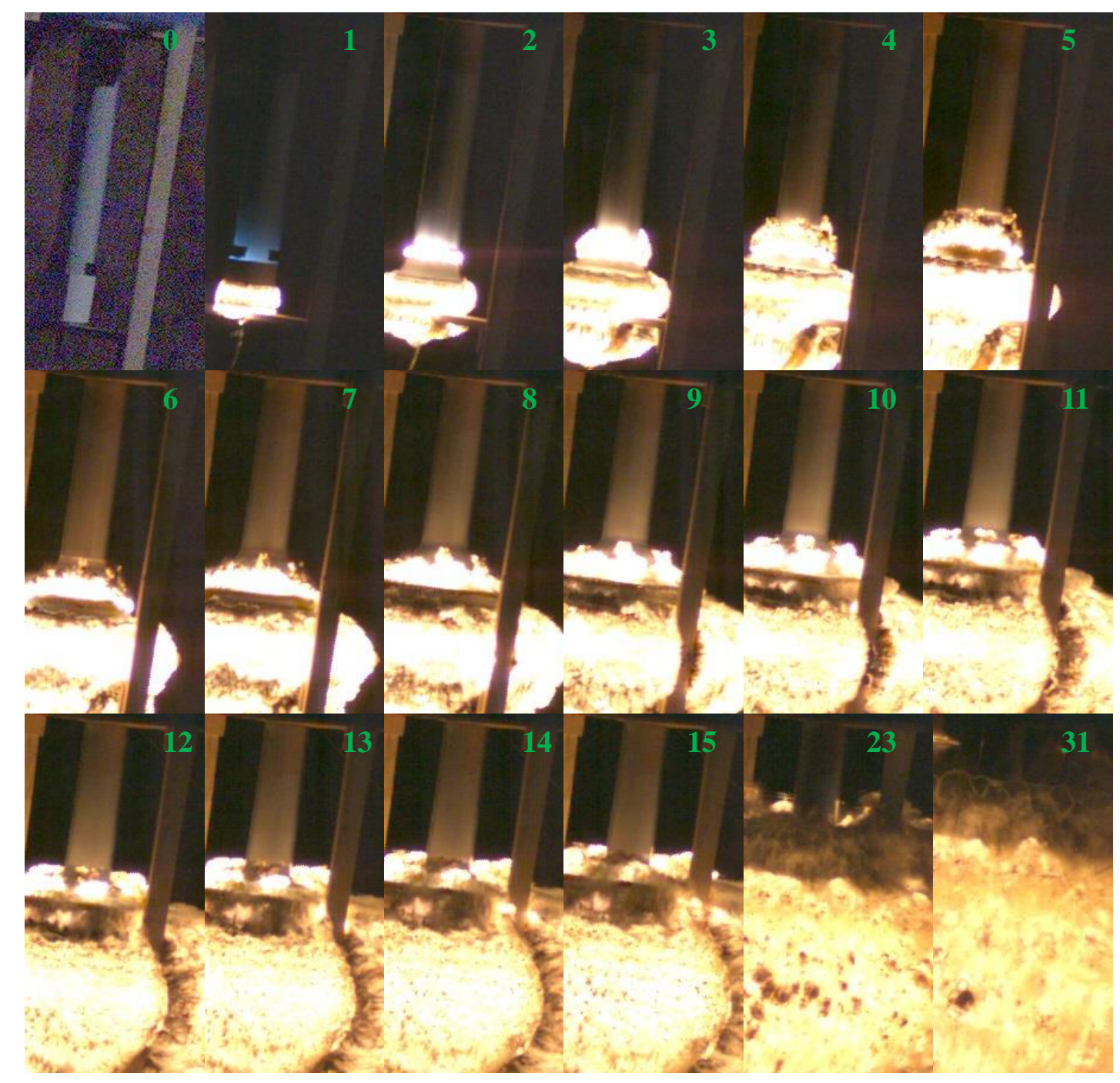

Figure 6.66. High speed camera record from large scale testing with $\mathrm{KNO}_{3}$ :Sucrose 70:30 wt:wt as the sample (20170113 shot 2) 


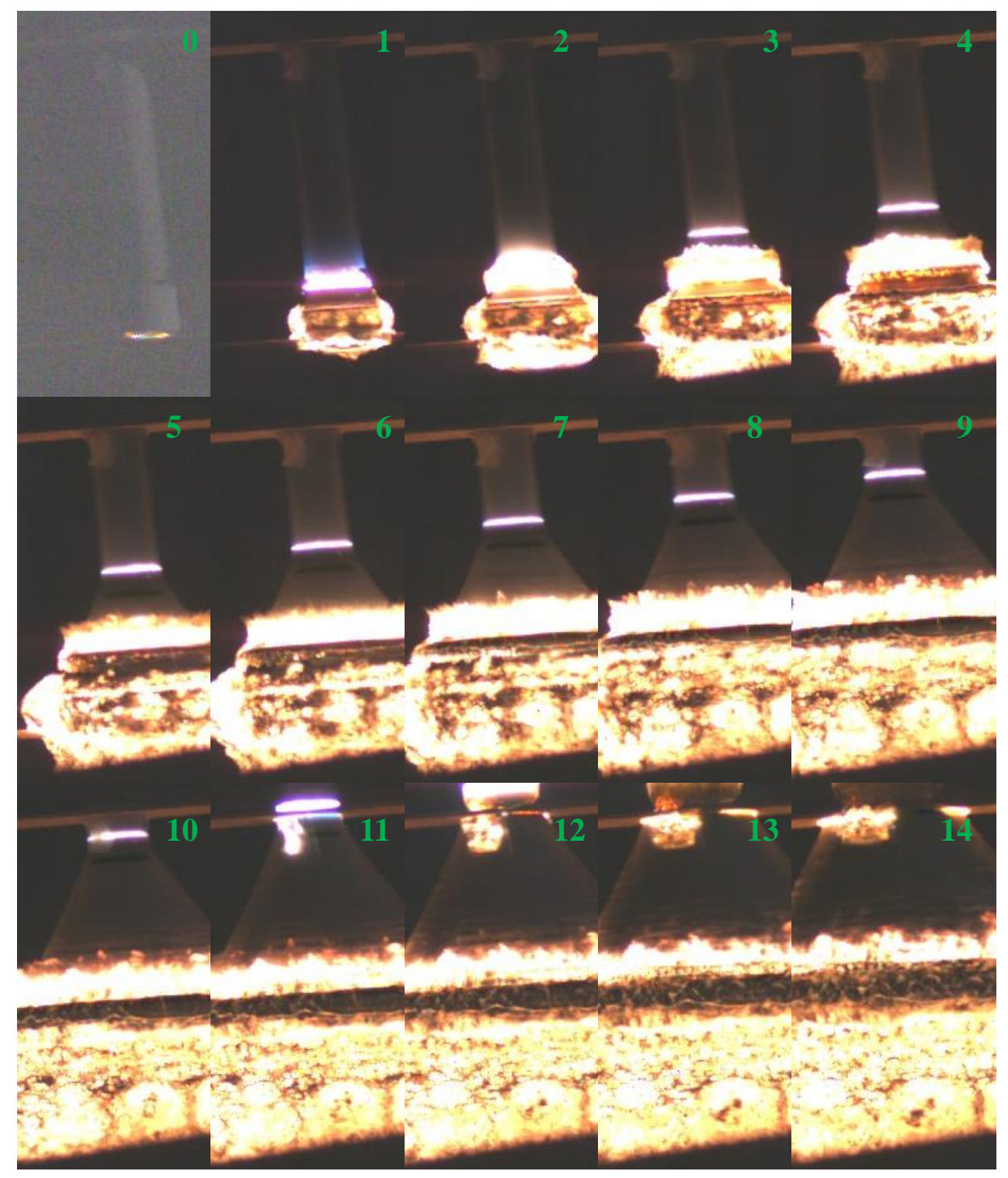

Figure 6.67. High speed camera record from large scale testing with $\mathrm{NH}_{4} \mathrm{NO}_{3}:$ Sucrose 70:30 wt:wt as the sample (20170125 shot 1) 


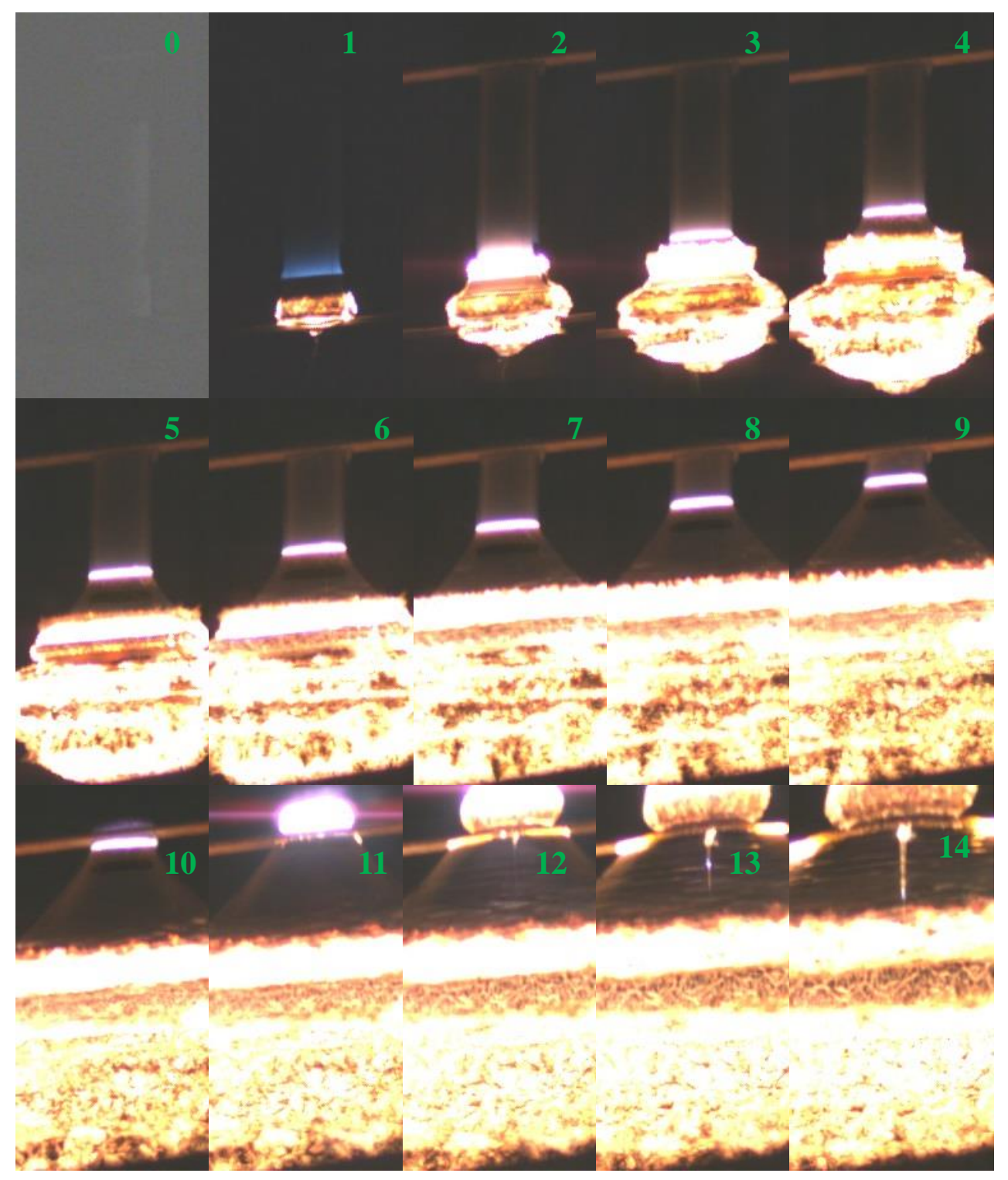

Figure 6.68. High speed camera record from large scale testing with $\mathrm{NH}_{4} \mathrm{ClO}_{4}$ :Sucrose 70:30 wt:wt as the sample (20170125 shot 2) 


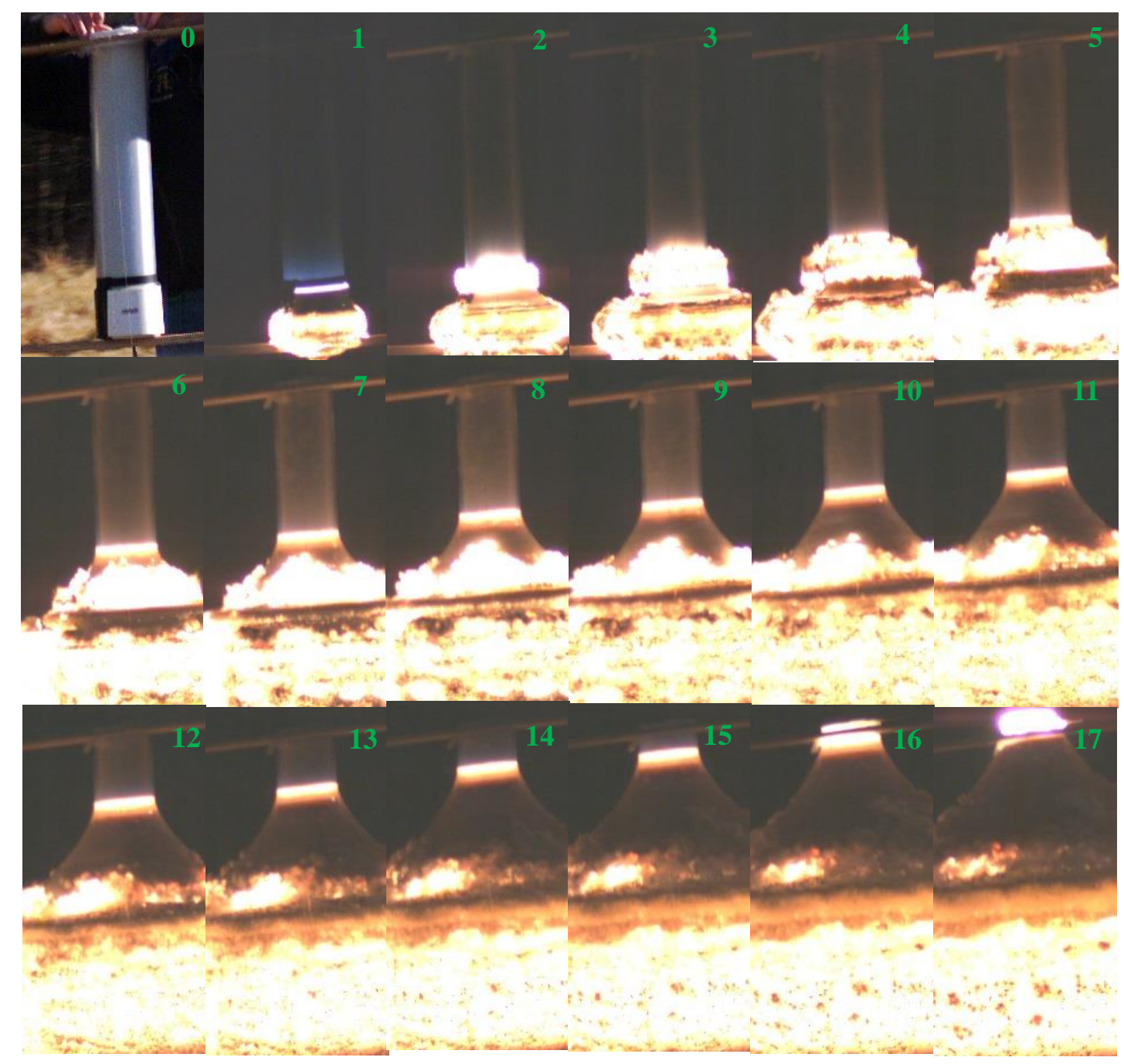

Figure 6.69. High speed camera record from large scale testing with $\mathrm{KNO}_{3}: \mathrm{KClO}_{3}:$ Sucrose 35:35:30 wt:wt as the sample (20170125 shot 3) 


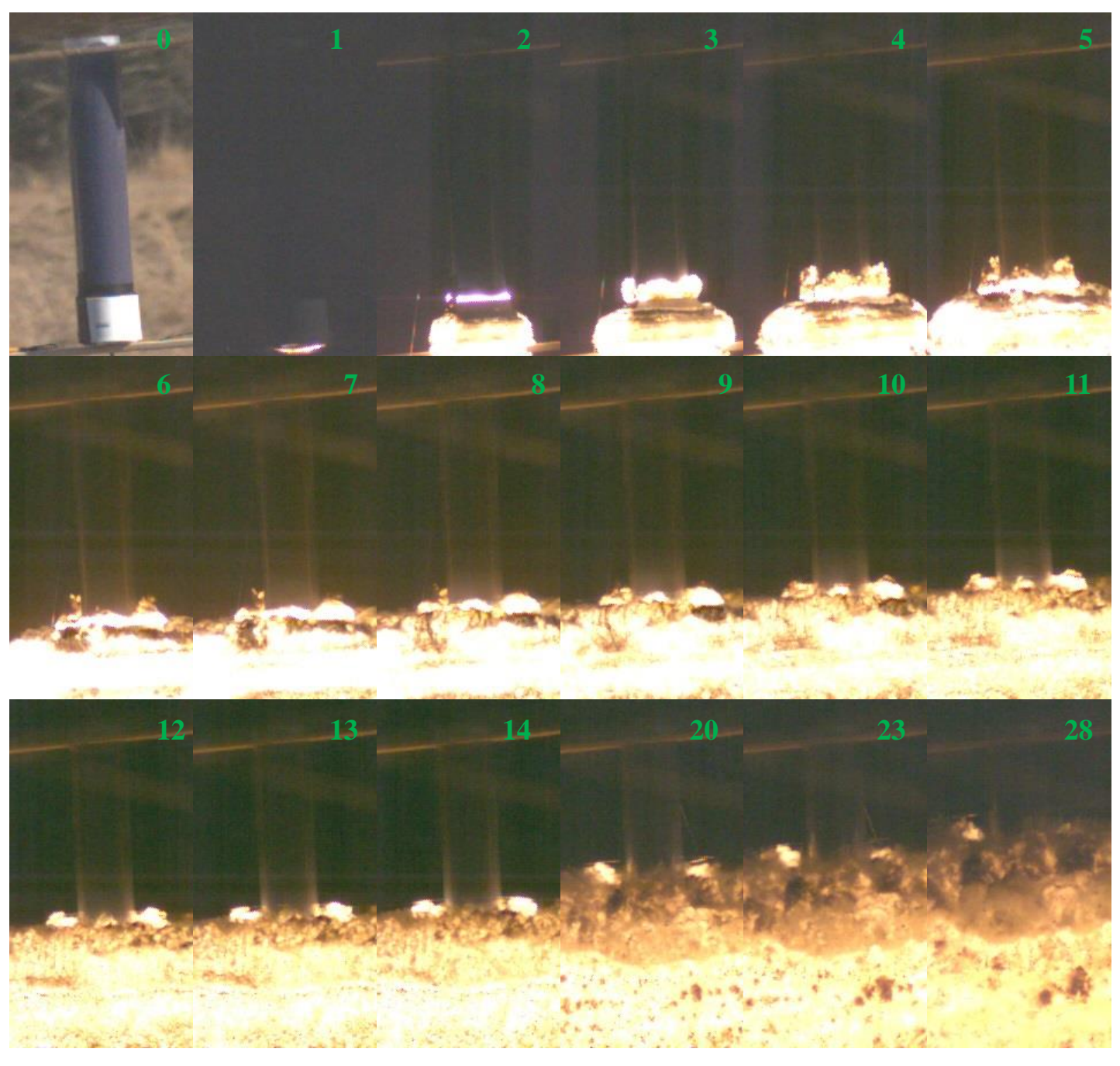

Figure 6.70. High speed camera record from large scale testing with $\mathrm{KMnO}_{4}$ :Sucrose 70:30 wt:wt as the sample (20170206 shot 1$)$ 

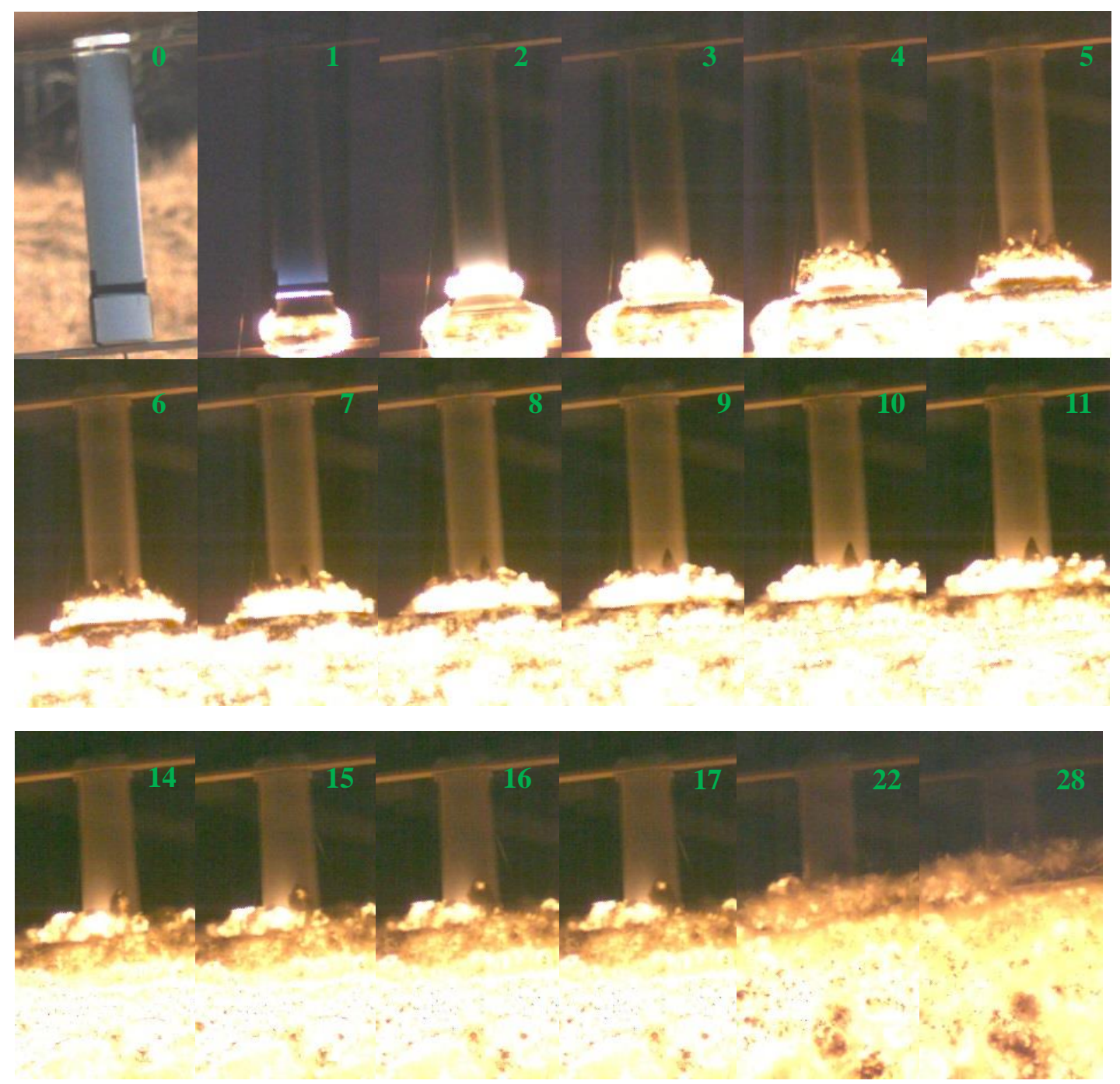

Figure 6.71. High speed camera record from large scale testing with $\mathrm{KIO}_{3}$ :Sucrose 70:30 wt:wt as the sample (20170206 shot 2) 

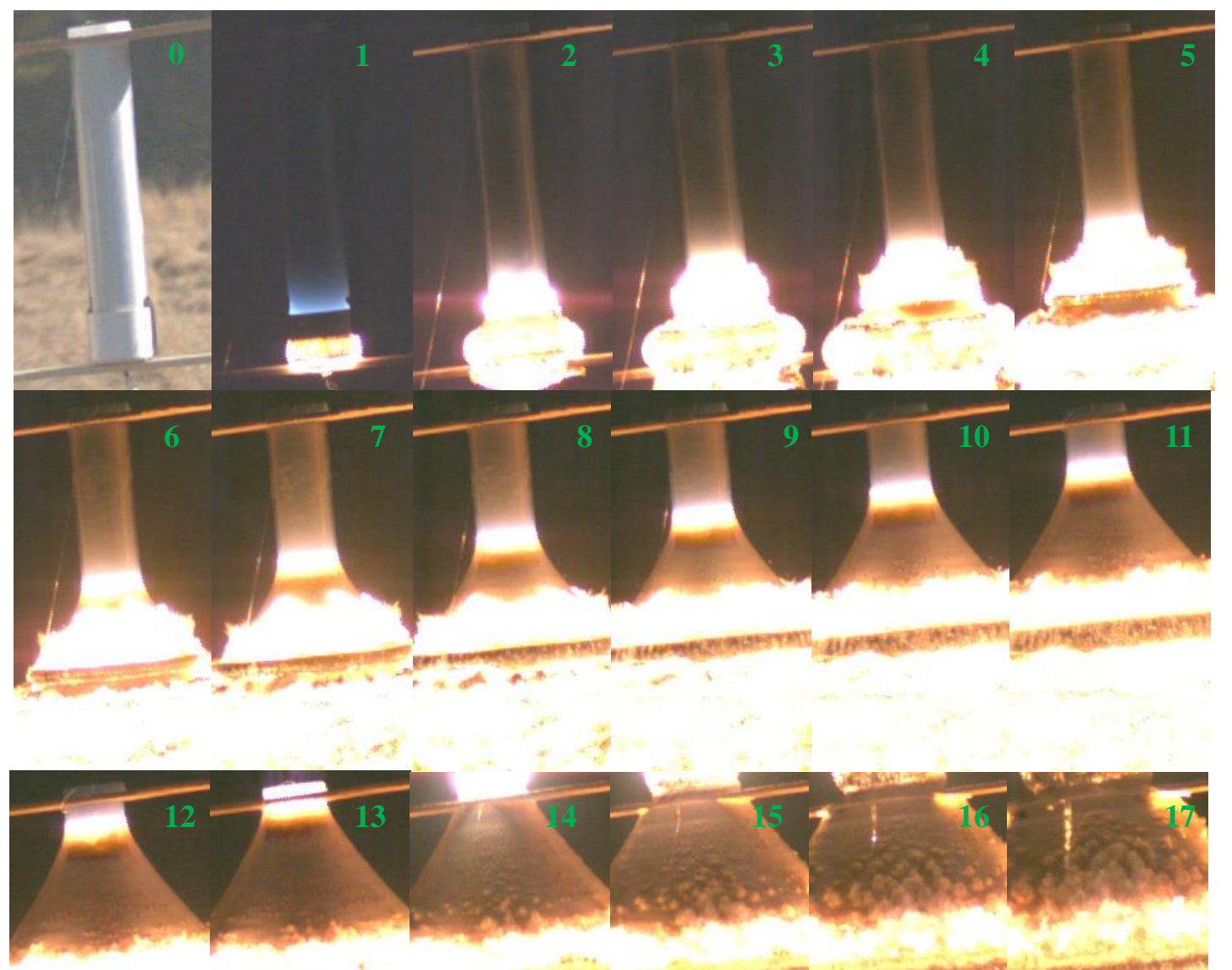

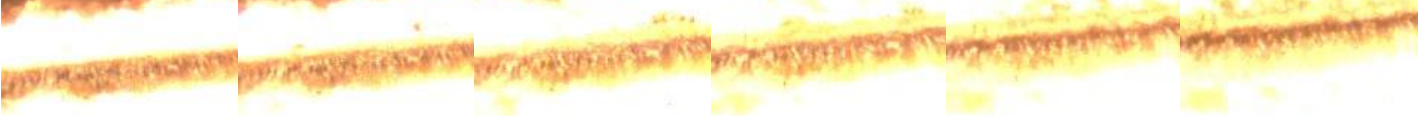

Figure 6.72. High speed camera record from large scale testing with $\mathrm{KClO}_{3}$ :Sucrose 70:30 wt:wt as the sample (20170206 shot 3) 


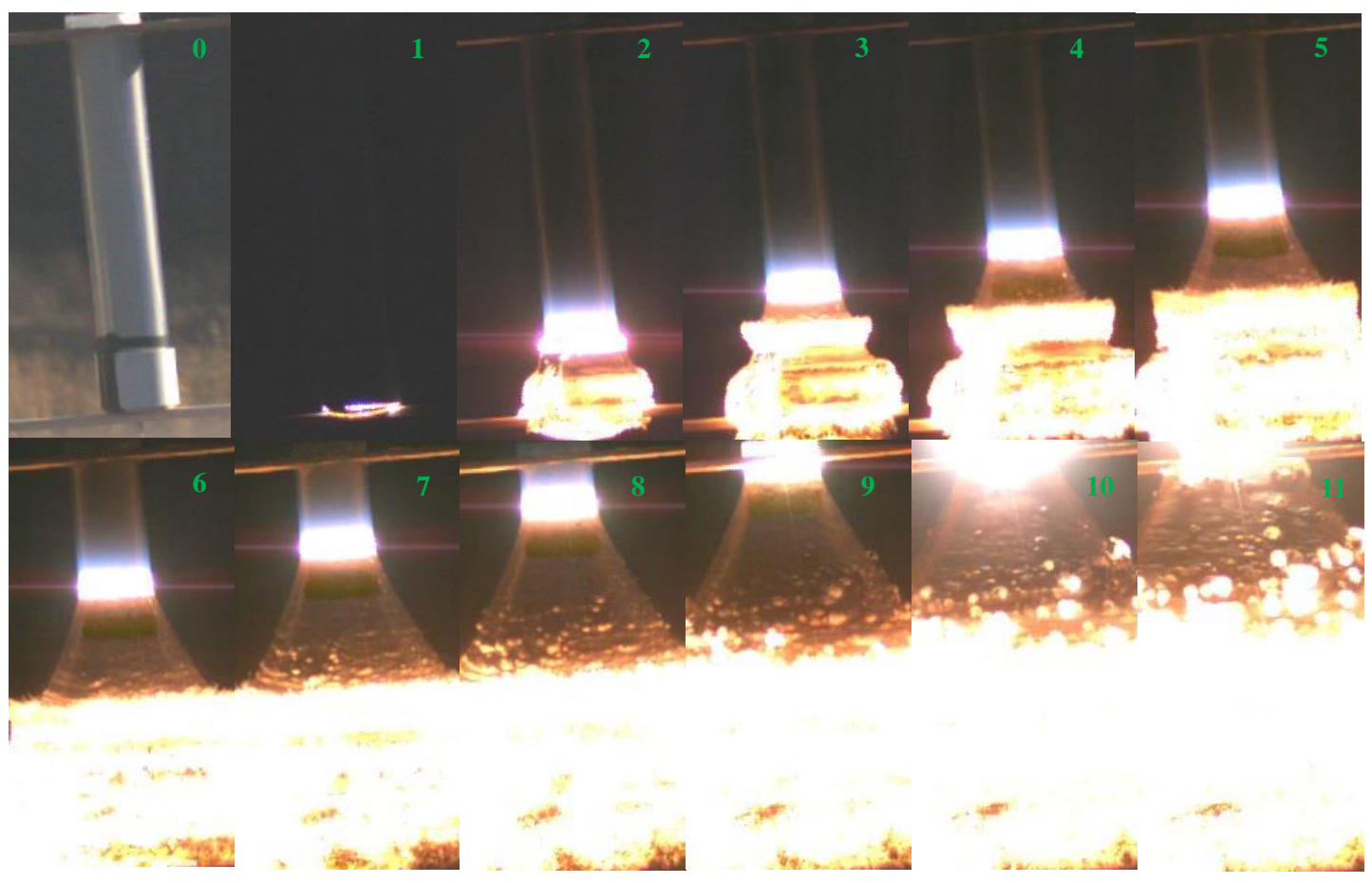

Figure 6.73. High speed camera record from large scale testing with RDX: $\mathrm{KNO}_{3}:$ Sucrose 50:35:15 wt:wt as the sample (20170206 shot 4) 


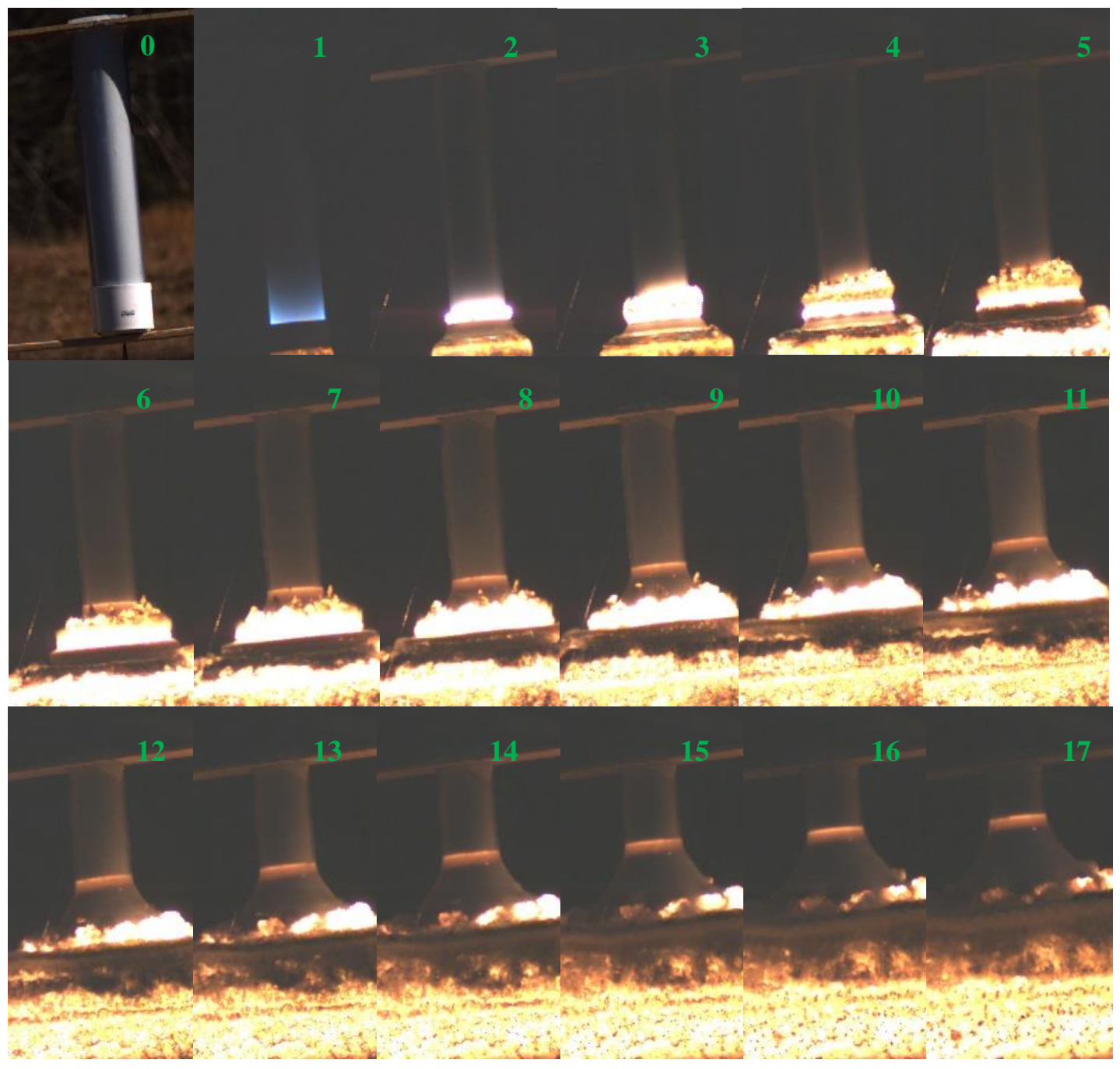

Figure 6.74 High speed camera record from large scale testing with

$\mathrm{KNO}_{3}: \mathrm{KClO}_{3}:$ Sucrose 63:7:30 wt:wt as the sample (20170302 shot 1) 


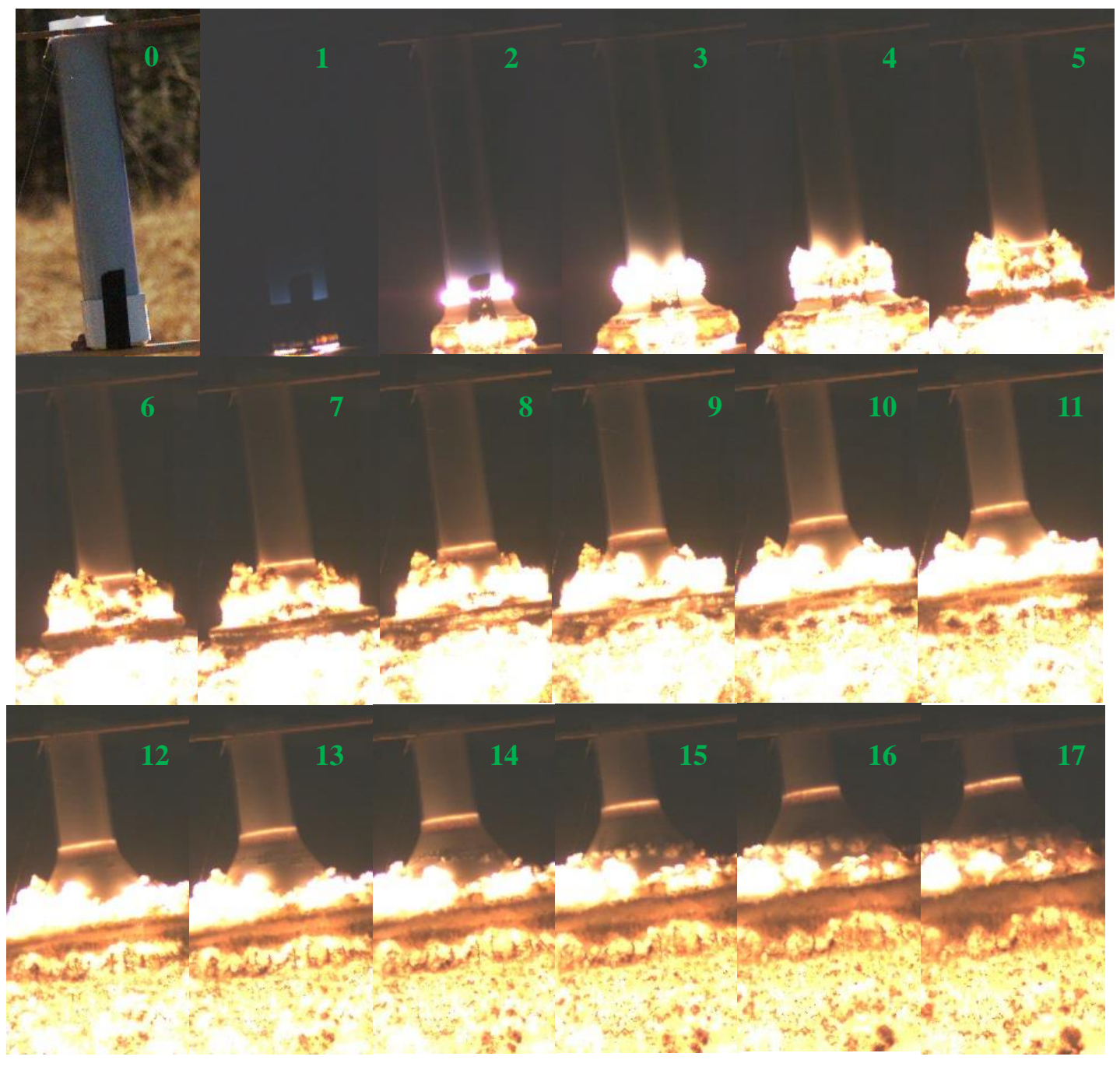

Figure 6.75. High speed camera record from large scale testing with

$\mathrm{KNO}_{3}: \mathrm{RDX}:$ Sucrose 66.5:5:28.5 wt:wt as the sample (20170302 shot 2) 


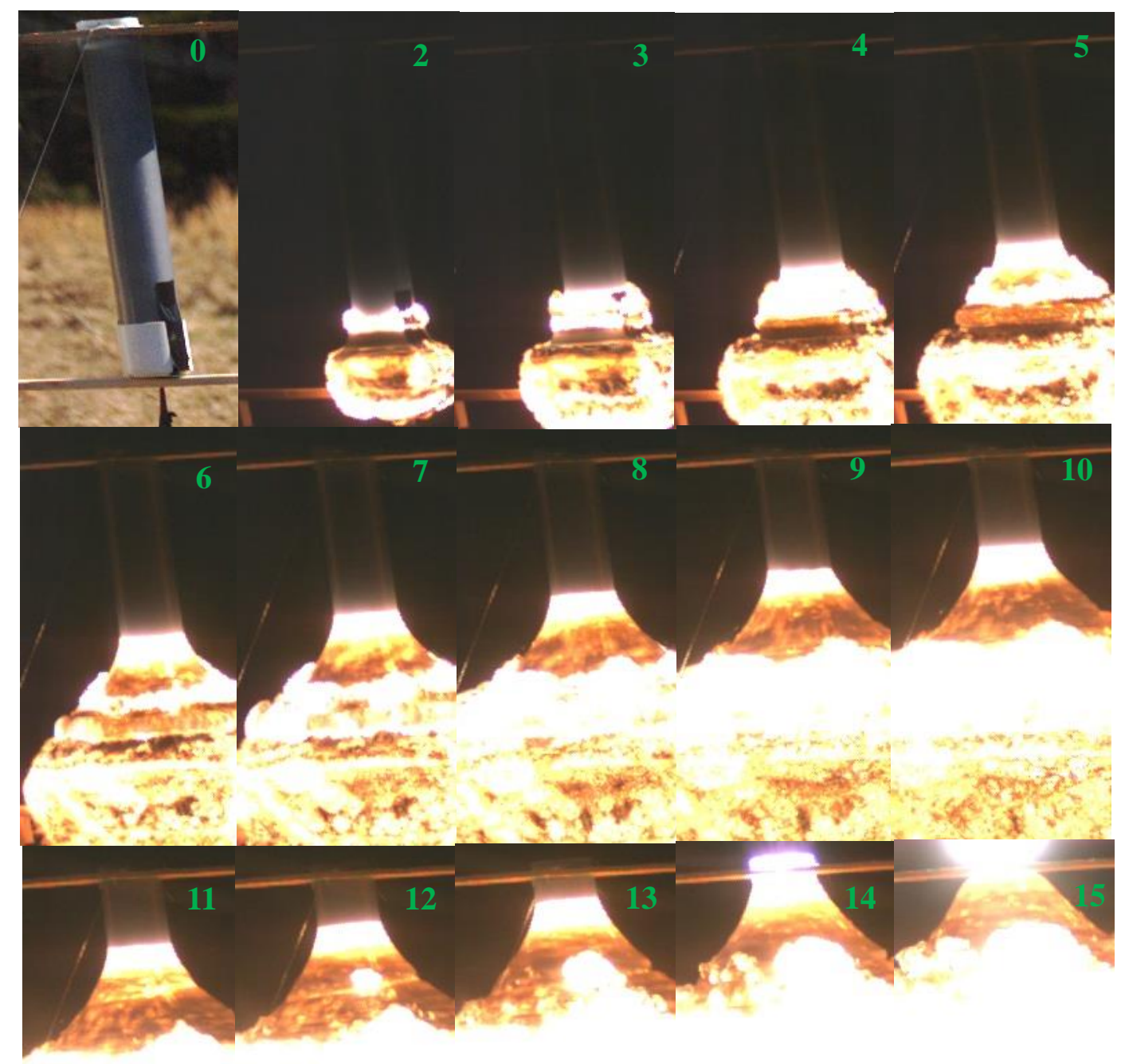

Figure 6.76. High speed camera record from large scale testing with $\mathrm{NH}_{4} \mathrm{NO}_{3}$ : $\mathrm{Al}$ 70:30 wt:wt as the sample (20170302 shot 3) 


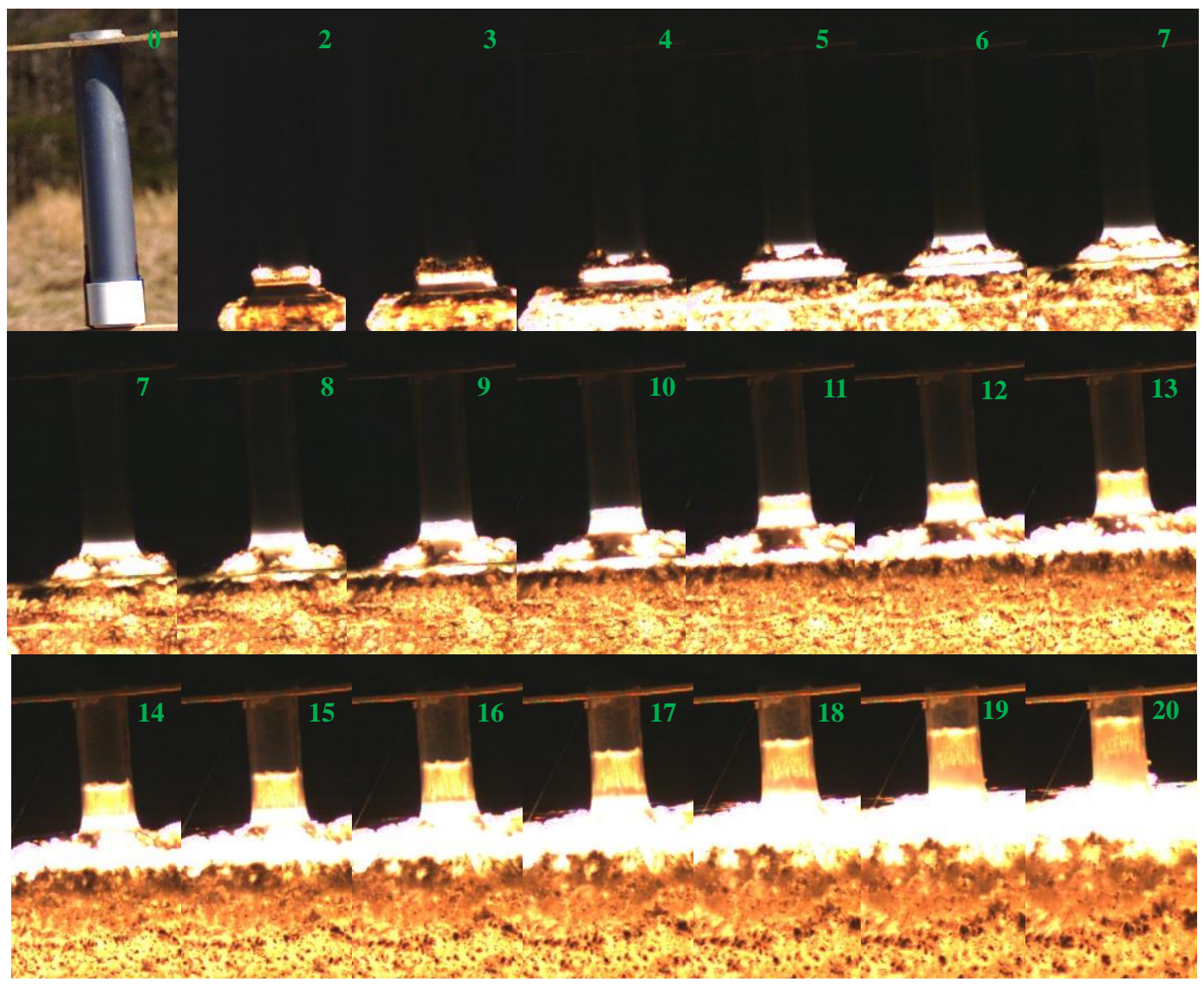

Figure 6.77 High speed camera record from large scale testing with $\mathrm{KNO}_{3}: \mathrm{Al}$ 70:30 wt:wt as the sample (20170303 shot 1$)$ 


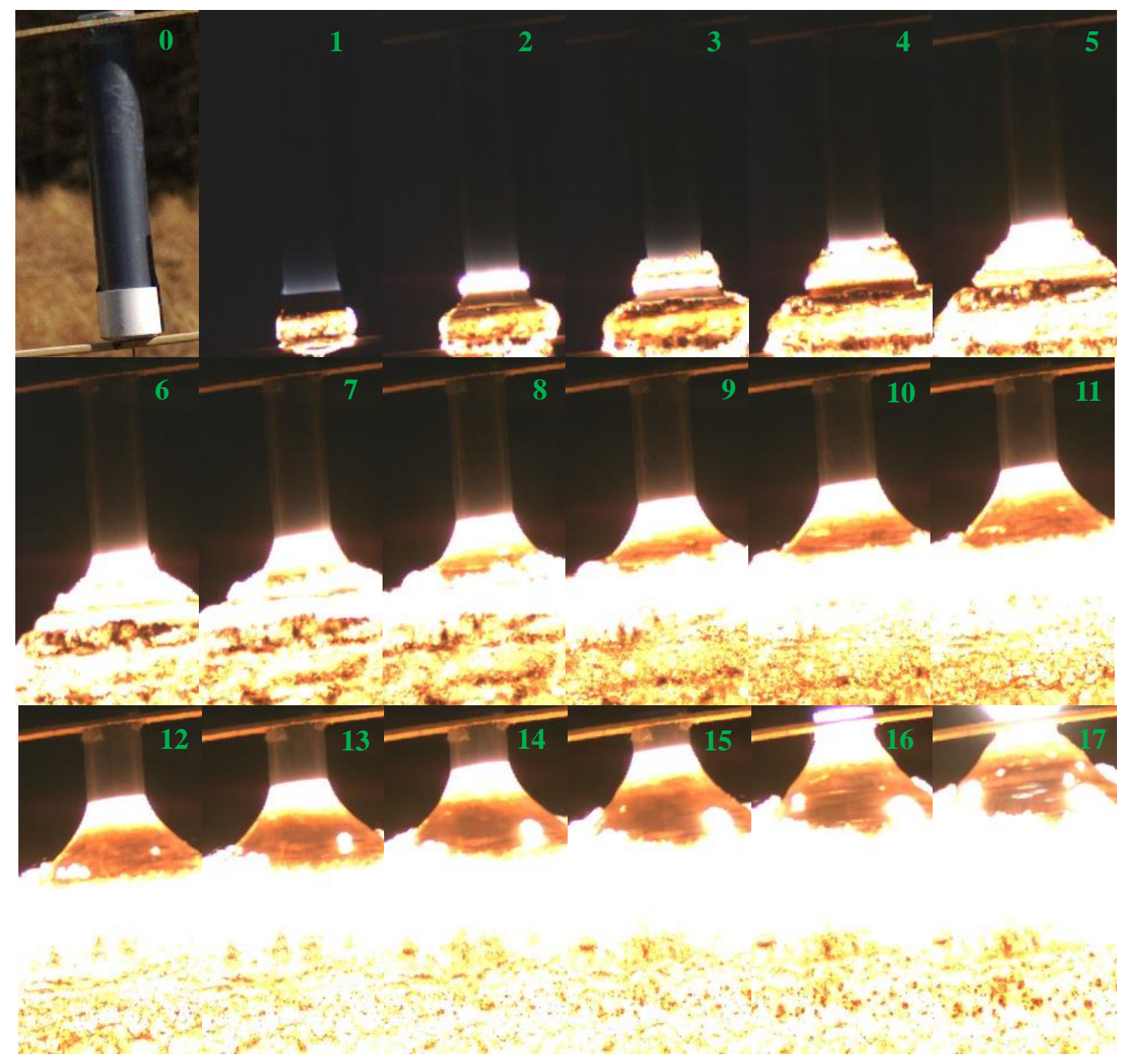

Figure 6.78. High speed camera record from large scale testing with $\mathrm{NH}_{4} \mathrm{ClO}_{4}$ : $\mathrm{Al}$

70:30 wt:wt as the sample (20170303 shot 2) 